\title{
DOWNFLOW DRYOUT IN A HEATED RIBBED VERTICAL ANNULUS WITH A COSINE POWER PROFILE (Results from Test Series ECS-2, WSR, and ECS-2cE)
}

by

T. K. Larson

J. L. Anderson

K. G. Condie

October 1990

Idaho National Engineering Laboratory

EG\&G Idaho, Inc.

P. O. Box 1625

Idaho Falls, ID 83415

Prepared for the

U.S. Department of Energy

Idaho Operations Office

Under DOE Contract No. DE-A C07-76ID01570

and

Westinghouse Savannah River Laboratory

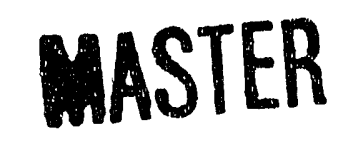
DISTRIBUTION OF THIS DOCUMENT IS UNLIMITED 


\section{ABSTRACT}

Experiments designed to investiéate surface dryout in a heated, ribbed annulus test section simulating one of the annular coolant channels of a Savannah River Plant production reactor Mark 22 fuel assembly have been conducted at the Idaho National Engineering Laboratory. The inner surface of the annulus was constructed of aluminum and was electrically heated to provide an axial cosine power profile and a flat azimuthal power shape. Data presented in this report are from the ECS-2, WSR, and ECS-2cE series of tests. These experiments were conducted to examine the onset of wall thermal excursion for a range of flow, inlet fluid temperature, and annulus outlet pressure. Hydraulic boundary conditions on the test section represent flowrates $(0.1-1.4 \mathrm{l} / \mathrm{s})$, inlet fluid temperatures $(293-345 \mathrm{~K})$, and outlet pressures $(-18-139.7 \mathrm{~cm}$ of water relative to the bottom of the heated length $[61-200 \mathrm{~cm}$ of water relative to the bottom of the lower plenum]) expected to occur during the Emergency Coolant System (ECS) pha'e of a postulated Loss-of-Coolant Accident in a production reactor. The onset of thermal excursion based on the present data is consistent with data gathered in test rigs with flat axial power profiles. The data indicate that wall dryout is primarily a function of liquid superficial velocity. Air entrainment rate was observed to be a strong function of the boundary conditions (primarily flowrate and liquid temperature), but had a minor effect on the power at the onset of thermal excursion for the range of conditions examined. 


\section{SUMMARY}

Experiments have been conducted at the Idaho National Engineering Laboratory to examine the hydraulics and heat transfer associated with downflow in a heated, ribbed aluminum tube surrounded by a polycarbonate shroud. The annular test section designed and constructed to conduct these investigations represents a geometry and axial cosine power shape consistent with the inner-middle coolant channel of a Mark 22 fuel assembly in a Savannah River Production reactor. Experiments conducted represent hydraulic conditions expected during the ECS phase of a large break Loss-of-Coolant Accident. Data gathered during the experiments will be used to gain insight on downflow heat transfer phenomena and for assessment and verification of computer codes used in power limits setting.

Two different general categories of experiments have been conducted to date. The ECS-2, WSR, and ECS-2cE series provided information on the conditions leading to wall dryout (onset of thermal excursion) in the test section. The ECS-2b and ECS-2c series provided information on the heat transfer coefficient in the test section when the heater wall temperature was limited to a value equal to the fluid saturation temperature at the outlet plenum. This report provides results from the thermal excursion experiments. Results for the ECS-2b series were published in July 1990 , with an addendum planned for November 1990 to document the results of the ECS-2c series.

Experiments conducted have provided insight on the influence of air entrainment, inlet fluid temperature, liquid flowrate, and test section back pressure on the power at which wall dryout occurs. Over the range of conditions investigated, the power at wall dryout is primarily a function of liquid superficial velocity. While air entrainment is a strong function of liquid superficial velocity, air entrainment had only a minor effect on the onset of thermal excursion. Test section back pressure had a small effect on the onset, particularly at low liquid flowrates where pooling in the test section occurred.

As expected, results from the experiments conducted show that power limits based on wall $\mathrm{T}_{\text {sat }}$ criteria are more conservative than dryout criteria. $R$ factors (test section power at the criteria under consideration divided by the power required to saturate the test section outlet fluid) 
calculated using wall $\mathrm{T}_{\text {sat }}$ criteria are approximately one-half those calculated using the thermal excursion (dryour) criteria.

Data collected from the INEL experiments are in basic agreement with data reported from test facilities using heaters with flat axial power profiles. For the superficial velocity range of major interest $(0.3$ to 0.8 $\mathrm{m} / \mathrm{s}), \mathrm{R}$ factors obtained from ECS -2 experiments are approximately $15 \%$ lower than those obtained from Westinghouse Savannah River Company (WSRC) experiments. This result was expected since for an equivalent power, the ECS-2 system had higher heat fluxes relative to the WSRC systems and heat flux is an important factor in dryout phenomena. 


\section{ACKNOWLEDGEMENTS}

Many people contributed to the success of the experiments reported in the following pages. B. R. Merkley kept the facility hardware operating. P. $R$. Schwieder and J. R. Boyce solved the electronics mysteries. We are indebted to $H$. N. Romero for operation of the video system. B. R. Merkley, J. R. Boyce, H. N. Romero, and J. M. Hopla helped conduct the experiments. 


\section{CONTENTS}

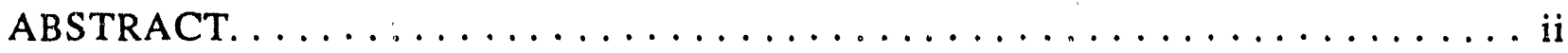

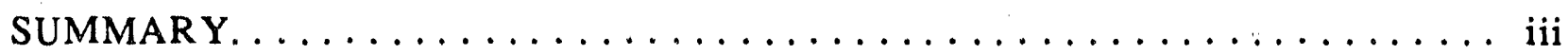

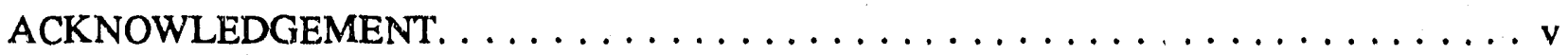

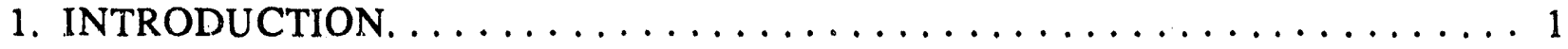

2. FACILITY DESCRIPTION. ...................... 4

2.1 Loop Description. ..................... 4

2.1 .1 Loop Instrumentation................... 6

2.2 Test Section Description..................... 7

2.2.1 Composite Heater.................... 10

2.2 .2 Plena and Shroud................... 15

2.2.3 Test Section Instrumentation............. 15

2.2.4 Data Acquisition System................ 18

3. EXPERIMENT DESCRIPTION. ..................... 21

3.1 Checkout Tests......................... 21

3.1.1 Measurement Verification. ................ 21

3.1.2 System Operational (SO) Test.............. 22

3.1.3 Air Power Pulse and Liquid Full Checkout Tests ...... 22

3.2 Routine Data Integrity Checks................... 23

3.3 Experimental Procedure........................ 24

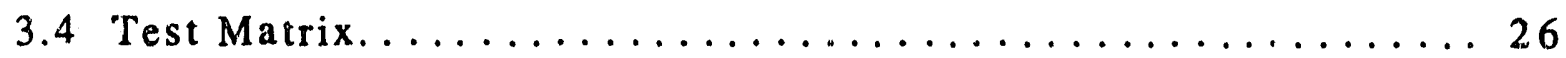

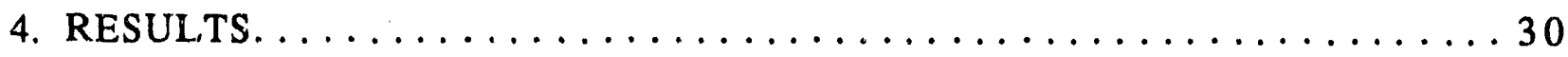

4.1 Typical Test Results...................... 30

4.1 .1 Wall Temperatures........................ 32

4.1.2 Pressures and Differential Pressures............ 35

4.1 .3 Fluid Temperatures.................. 40

4.1 .4 Air Entrainment.................... 43

4.1.5 Azimuthal Wall Temperature Variation.......... 44 


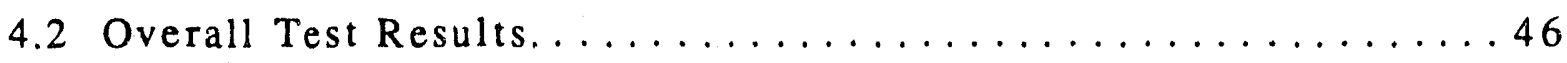

4.2 .1 Inlet Flow Rate.................... 48

4.2.2 Inlet Liquid Temperature................ 55

4.2 .3 Standpipe Setting. .................. 57

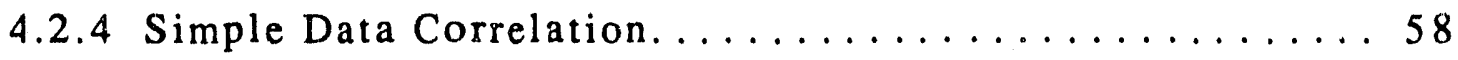

4.2.5 Facility and Operational Influence on

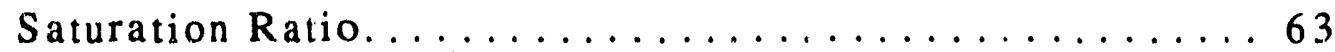

4.3 Comparison of Excursion. Criteria and Wall Saturation

Criteria............................... 66

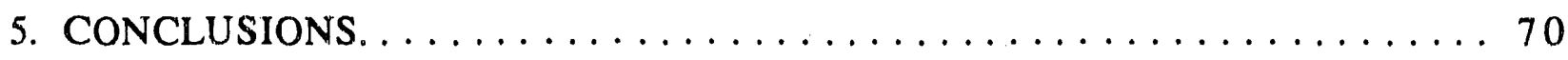

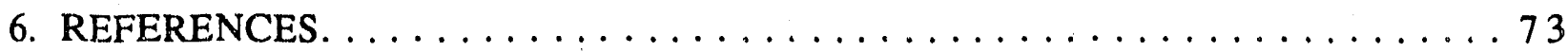

Appendix A: Engineering Drawings for the ECS-2 Test Fixture...... A-1

Appendix B: Measurements Lists for the ECS-2 and ECS-2c

Thermal Excursion Experiments............... 1

Appendix C: Measurement Uncertainty for the ECS-2

Thermal Excursion Tests................... C-1

Appendix D: Calculations Supporting Design/Performance of the ECS-2 Inner Heater. . . . . . . . . . . . . . . 1

Appendix E: Calculated Parameters for the ECS-2 and ECS-2c Thermal Excursion Experiments............... E-1

Appendix F: Data Repeatability for Onset of Thermal Excursion Experiments................... 1

Appendix G: ECS-2 Air Ingress Test Results...............

Appendix H: Video System Used During the ECS-2 Thermal

Excursion Tests. ...................... 
Appendix I: Questionable or Failed Measurements for the

ECS-2 and ECS-2c Thermal Excursion Experiments....... I-1

Appendix J: Experimental Data Summary for INEL Thermal

Excursion Tests (ECS-2, WSR, and ECS-2cE Tests).......J-1

\section{FIGURES}

2.1. ECS-2 loop schematic....................... 5

2.2. ECS-2 test section. ... $\ldots \ldots \ldots \ldots \ldots \ldots \ldots \ldots \ldots \ldots$

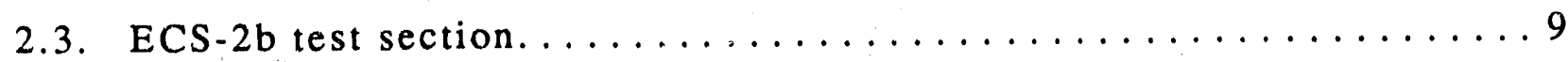

2.4. ECS-2 and ECS-2b test section cross section through heater, viewed from the bottom..................... 10

2.5. Axial power power peaking factors and instrument locations

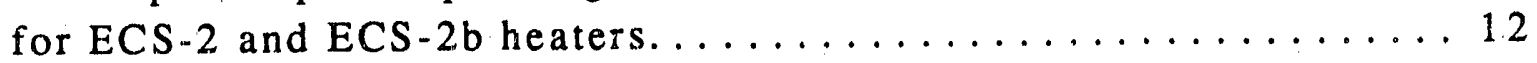

2.6. ECS-2 and ECS-2b aluminum tube cross section ........... 14

4.1. Comparison of electrical and thermal power for ECS-2BL_5..... 31

4.2. Time history of level 7 wall thermocouple and power....... 32

4.3. Full time history of all level 7 thermocouples for ECS-2BL_5 .... 33

4.4. Expanded time scale ccmparison of level 7 thermocouples

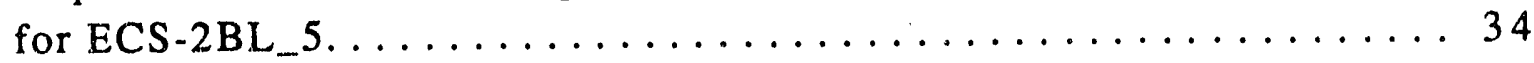

4.5. Wall thermocouple response in B subchannel for ECS-2BL_5.... 35

4.6. Comparison of inlet and ourlet plenum pressures with local atmospheric pressure for Test ECS-2BL_5.......... 36

4.7. Inlet and outlet plenum levels for ECS-2BL_5 $\ldots \ldots \ldots \ldots \ldots$

4.8. Comparison of subchannel pressure measurements at the entrance to the heated length for Test ECS-2BL_5B........ 38 
4.9. Differential pressures in upper half of the heated length for Test ECS-2BL_5........................ 39

4.10. Differential pressures in the lower half of the heated length

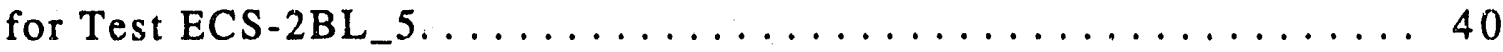

4.11. Plenum and heated length outlet fluid temperatures for Test ECS-2BL_5........................4 4

4.12. Axial fluid temperature distribution for Test ECS-2BL_5...... 42

4.13. Comparison of fluid thermocouples at $257 \mathrm{~cm}$ for Test

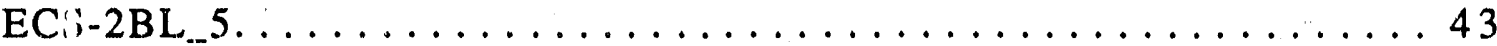

4.14. Expanded time scale comparison of fluid temperatures

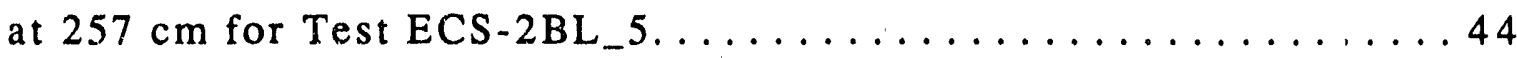

4.15. Air inlet and outlet flowrates for Test ECS-2BL_5 . . . . . . 45

4.16. Azimuthal temperature distribution during power step just prior to excursion power step for Test ECS-2BL_5 . . . . . 46

4.17. Azimuthal wall temperature distribution during power step on which sustained excursion occurred for Test ECS-2BL_5 . . . 47

4.18. Azimuthal fluid temperature distribution during power step just prior to excursion power step for Test ECS-2BL_5 . . . . 48

4.19. INEL thermal excursion data for $295-315 \mathrm{~K}$ inlet temperature and $323-383 \mathrm{~cm}$ standpipe setting..........53

4.20. INEL thermal excursion data for three different inlet temperatures and a standpipe setting of $389 \mathrm{~cm} \ldots \ldots \ldots \ldots 5$

4.21. INEL thermal excursion data for $326 \mathrm{~K}$ inlet temperature with standpipe setting as a parameter.............5

4.22. INEL thermal excursion data with inlet temperature as a paraneter............................. 59 
4.23. INEL thermal excursion data with standpipe setting as a parameter............................ 60

4.24. INEL ECS-2 and ECS-2cE thermal excursion data with

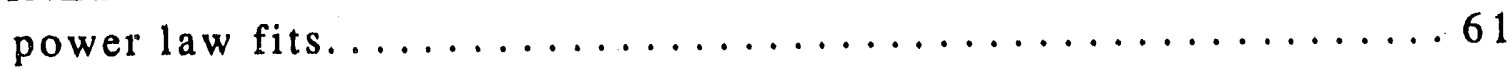

4.25. INEL thermal excursion data compared to Duffey-Hughes model. ..................... 64

4.26. INEL thermal excursion data with test facility as a parameter.........................65

4.27. Thermal excursion data from several sources and INEL wall saturation data. ........................6 68

\section{TABLES}

2.1. Inconel 600 heater information................... 13

2.2. Location of wall thermocouples for ECS-2 heater............ 19

2.3. Location of wall thermocouples for ECS-2b heater.......... 20

3.1. Range of parameters for thermal excursion experiments.......26

3.2. Nominal conditions for excursion tests conducted in the ECS 2 facility.............................. 27

3.3 Nominal conditions for excursion tests conducted in

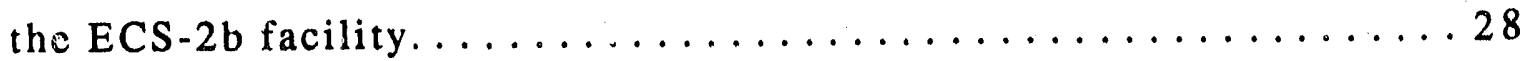

4.1. Statistics for aluminum wall temperatures for pre-excursion power step on Test ECS-2BL_5 (2210-2230s time frame)......49

4.2. Statistics for aluminum wall temperatures on excursion power step on Test ECS-2BL_5 (2340-2360 s time frame)..... 50

4.3. Statistics results for test section fluid temperatures on Test ECS-2BL_5 pre-excursion power step $(2210$ to $2230 \mathrm{~s}) \ldots \ldots \ldots 51$ 
4.4. Summary of results from INEL ECS-2 and WSR thermal excursion experiments...................... 52

4.5. Summary of results from INEL ECS-2cE thermal excursion

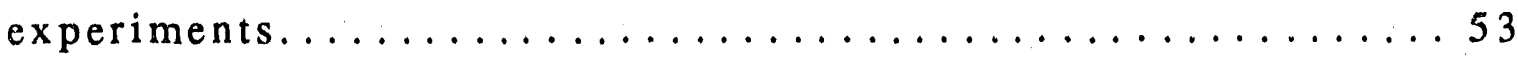

4.6. Power fit constants for Equation 4-1 using inlet temperature data sets.......................6 61

4.7. Influence of $520 \mathrm{~K}$ and $620 \mathrm{~K}$ wall temperature criteria on saturation ratio for INEL thermal excursion data points......667 


\section{INTRODUCTION}

In mid 1987, the U.S. Department of Energy (DOE) initiated a vigorous program to review the safety and operation of the nuclear materials production and nuclear testing facilities under DOE management in the U.S. A major purpose of this ongoing review effort is to ensure that the facilities in the existing research and weapons materials production complex are operated in a safe manner during normal operation and, given a hypothetical design basis accident, the risk to the public is within acceptable limits.

As part of this review effort, Westinghouse Savannah River Company (WSRC) personnel have conducted or contracted research to examine heat transfer in the Savannah River Plant (SRP) reactor fuel assembly during the Emergency Cooling System (ECS) phase of a hypothesized Loss-of-Coolant Accident (LOCA). During the ECS phase of the accident, the reactor fuel assemblies are expected to be filled with a two-phase air-water mixture. Safety requirements dictate that the power levels be low enough during the ECS phase of the accident so that no melting occurs in the fuel assemblies.

Two different criteria, wall saturation temperature and wall dryout, are being considered for use in calculating power limits. Simply stated, wall saturation temperature criterion involves determining the power for a given thermal-hydraulic condition (flowrate, inlet fluid temperature, etc) at which the maximum assembly wall temperature just reaches the local saturation temperature. This criterion would preclude bulk boiling of the liquid in the assemblies. The dryout criterion involves determining the pc ver at which heat transfer from the surface of the heated assembly wall degrades to a point where the surface is basically dry and the wall temperature starts to increase in a nearly adiabatic fashion. Of the two criteria, wall saturation is the considerably more conservative.

Complex geometry and hydraulic interactions involving air entrainment, flooding, and heat transfer to two-phase mixtures necessitate experimental investigation of the processes involved to help determine key factors influencing assembly cooling and hence the power limit criteria. Research results from such investigations will be used in the verification and assessment of models used for establishing acceptable power limits for the reactors. 
Experimental efforts corducted at the Savannah River Site (SRS) Heat Transfer Laboratory to examire ECS power limits are reviewed by Steimke [1]. Prior to 1988, expsriments were conducted in an annulus consisting of a heated stainless steel surface (rather than aluminum as in actual fuel assemblies) and glass or aluminum as the other wall of the annulus $[2 ; 3]$. Stainless steel was used as the heated sirface because of technical difficulties associated with resistively heating aluminum to the power levels requirud for the desired experiments. These facilities did not contain axial spacer ribs in the anculus, a unique feature of the reactor assembly design. Also, these test sections used a flat axial power profile and uniform azimuihal powe1. Facilities shat included spacer ribs and an azimuthal power iilt were constructed in 1988 [4;5;6]. Other facilities were built in 1989 [7] for visuaization studies and to incorporate thermal spray technology for the construction of aluminum heated surfices $[8 ; 9]$. All test sections mentioned above incorporated a flat axial power profile (the FB rig had an azimuthal power tilt) and with the exception of $t$ wo test sections, used stainless steel for the heated surface. Although, both of the thermal sprayed test sections used alumirum for the heated surface, current technology allowed only the outer annulus wall to be heated.

The ECS-1 facility [10] was constructed and operated at the Idaho National Engineering Laboratory (INEL) in 1989 to help address the irfluences of heater surface material properties and conditions on test results. The ECS-1 facility was sponsored by the Department of Energy, Office of Safety Appraisal, Environment Safety and Health and consisted of a ribbed aluminum tube heated from inside with a resiscively heated stain. less steel thbe and surrounded by a Lexan ${ }^{\mathrm{m}}$ shroud to permit visual observation. Nearly 50 experiments were conducted to examine the effects of air entrainment, flow regime transition, flow distribution, and flooding on the heat transfer processes in the annulus.

The suicess of the heater design used in the ECS-1 facility prompted the construction of the ECS-2 facility at the INEL. The ECS-2 program was sponsored by the WSRC and incorporated several improvements relative to the ECS-1 fixture. Foremost was a new inner heater with an axial power profile consistent with the power shape to be used in setting assembly power limits and improvements in the inlet and outlet geometry of the test section to make the plenums nore prototypic. The ECS-2b facility succeeded the ECS-2 racility. With the exception of measurement locations 
and a new heater, the two facilities were essentially the same.

Two different categories of experiments were rus during the course of the INEL ECS-2 program. More than 70 experiments (tne ECS-2b, and ECS$2 c$ series) were conducted to determine the hydralulic conditions that lead to heater wall temperatures that just exceed local fluid saturation temperature. Results from these experiments are discussed by Anderson, et al [11]. Approximately 50 experiments (the ECS-2, WSR, and ECS-2cE series) were conducted to establish and examine the variables and conditions that lead to sustained dryout on the heated surface in the annulus. Tests conducted in these programs were designed to parametrically examine the influence of coolant temperature, coolant flowrate, and back pressure on the heat transfer processes in the ribbed annulus. Data gathered will be used to improve understanding of the physical processes involved and in the assessment and validation of models used in the calculation of power limits criteria.

The remainder of this report details results of the thermal excursion tests conducted at the INEL. Results discussed are from the ECS-2, WSR, and ECS-2cE series of experiments conducted in the ECS- 2 and ECS-2b facilities. Section 2 describes facility design, support systems, measurement capabilities, and the data acquisition system. Experiment conduct and test matrices are addressed in Section 3. Results of the experimental investigations are presented in Section 4. Conclusions and summary statements are given in Section 5. Appendices to this report provide engineering drawings, lists of measurements recorded for the various experiments, measurement uncertainty statements, test fixture design details, and other relevant information. 


\section{FACILITY DESCRIPTION}

This section describes the test facility, support systems, instrumentation, and data acquisition system. As noted above, the experiments described in this report were conducted in the ECS-2 and ECS-2b facilities. In most respects, the ECS-2 and ECS- $2 b$ facilities are similar. In fact, the ECS-2b test section is actually made up from the upper and lower plenums and shroud from the ECS-2 test section and a heater that was intended for the dual heated annulus program. The dual heated inner heater is t..e same design as the ECS-2 heater with slight changes to simplify and improve the fabrication of the heater. Major differences between the ECS- 2 and ECS-2b facilities include the number and location of the test section fluid temperature, absolute pressure, and differential pressure measurements and the location of the heater wall thermocouples. Since the ECS- $2 b$ facility geometry is described by Anderson [11], the description in this report is limited primarily to the ECS-2 hardware.

\subsection{Loop Description}

The ECS-2 loop schematic is shown in Figure 2.1. Water is pumped from the storage tank through the heated make up tank, where it is heated to the desired inlet temperature, and into the upper plenum. The flowrate is controlled remotely from the control room via an air operated flow control valve. For very low flowrates the test section bypass valve was opened to reduce pump outlet pressure. Air is allowed to naturally aspirate into the upper plenum through a $6.7 \mathrm{~cm}$ ( 2.625 in.) ID acrylic tube. The air-water mixture then flows down through the test section annulus into the lower plenum. The test section is described in more detail in Section 2.2. The test section is heated over $381 \mathrm{~cm}$ (150 in.) of its length by a directly heated Inconel tube inside an aluminum outer tube. Power to the heater is supplied by ten $4 / 0$ copper leads from a Transrex DC power supply. Current to the heater is controlled manually from the control room.

The lower plenum serves as a separator, which allows the air to exit from the top of the lower plenum and the liquid from the bottom of the lower plenum. A cooling coil placed in the lower plenum can be used to condense any vapor generated in the test section, which 


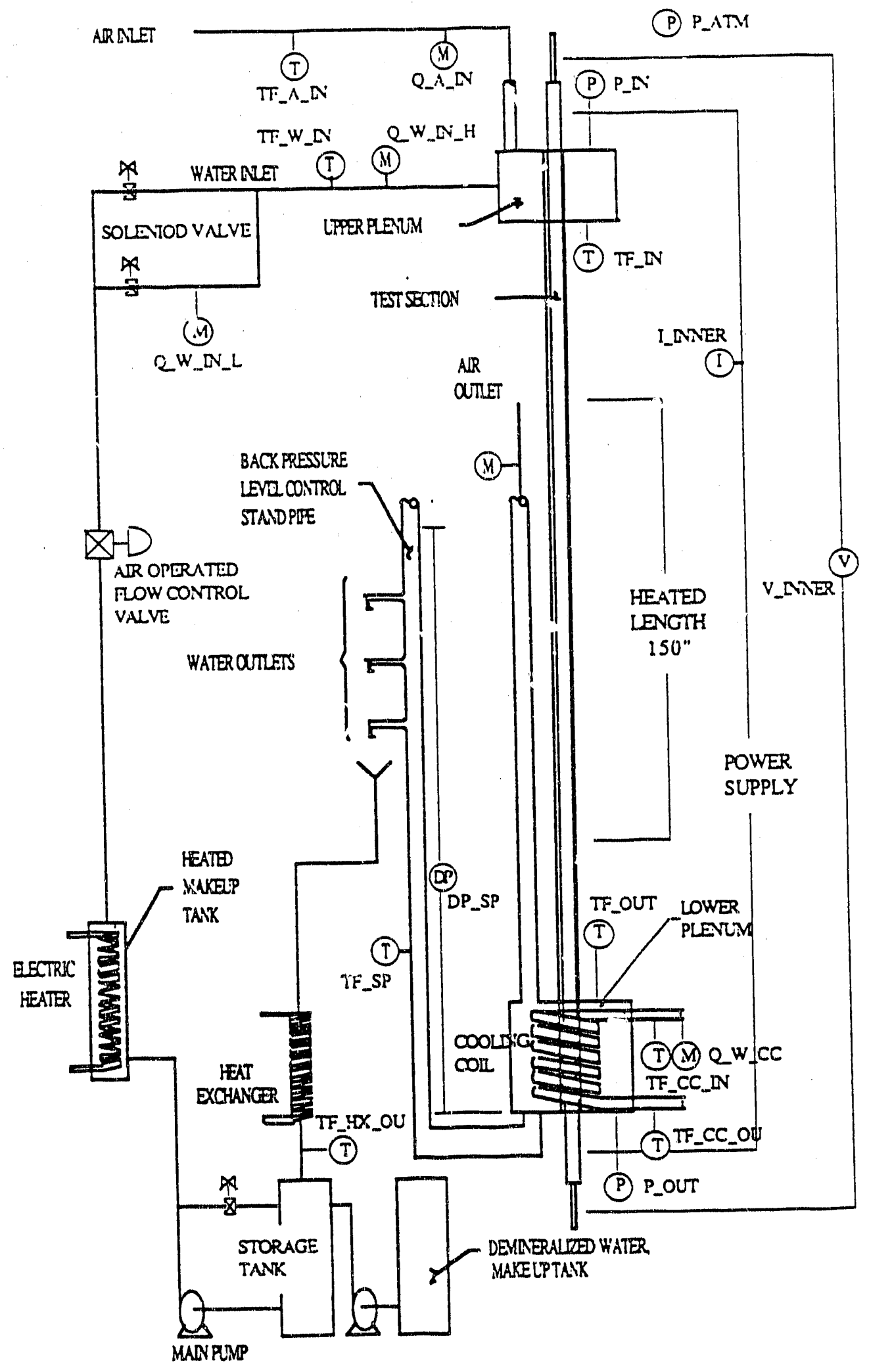

Figure 2.1. ECS-2 loop schematic 
prevents the vapor from exiting through the outlet air measurement station. The water flows from the outlet tap through a heat exchanger and back into the storage tank completing the loop. The loop inventory is supplied by water from the demineralized water tank. The liquid level in the test section is controlied by the height of the water outlet taps located in the back pressure level control standpipe. For the excursion test series, these levels were $-18,0,19,48,51,110$, and 140 $\mathrm{cm}(-7,0,7.5,19,20,43$, and 55 in.) above the bottom of the heated length.

\subsubsection{Loop Instrumentation}

Sufficient loop instrumentation is provided to control and monitor inlet conditions to satisfy program oujectives and to calculate a test section energy balance. (A listing of all instrumentation for the ECS-2 and ECS- $2 b$ test sections is provided in Appendix B). The energy balance is monitored continuously on line to provide an overall integrity check and to determine when the system has reached steady state conditions following a change in power or flowrate. All fluid thermocouples are $1.5-\mathrm{mm}(0.060$-in.) type $\mathrm{K}$ stainless steel sheathed with a grounded junction inserted directly into the fluid stream. They are connected to type $\mathrm{K}$ extension wire which runs to a $339 \mathrm{~K}\left(150^{\circ} \mathrm{F}\right)$ reference oven. Regular copper conductors are used to connect the ovens to the data acquisition system (DAS).

The air inlet and outlet flowrates (Q_A_IN and Q_A_OUT) are measured using Teledyne/Hastings model LU-3M mass flow meters having a measurement range of 0-50 standard liters per minute (SLPM). These are very low pressure drop instruments having an internal diameter of about $6 \mathrm{~cm}(2.5 \mathrm{in}$.). The inlet and outlet air temperatures (TF_A_IN and TF_A_OUT) were measured using fluid thermocouples as described above. Roth a high flow (Q_W_IN_H) and a low flow (Q_W_IN_L) turbine meter were used to measure the inlet liquid flow. Flowrates below $0.30 \mathrm{l} / \mathrm{s}$ were routed through both turbine meters. For flowrates above $0.30 \mathrm{l} / \mathrm{s}$, only the high flow turbine was used. The liquio inlet temperature (TF_W_IN) was measured using a fluid tl $t$ rmocouple and was checked regularly against a calibrated glass thermometer inserted into the inlet liquid stream. The inlet liquid temperature was controlled by adjusting the heat input to the heated makeup tank. No outlet liquid flowrate 
measurements were made and the liquid outlet temperature was measured using a fluid thermocouple (TF_W_OUT for ECS-2 and TF_SP for ECS-2b). The inlet (TF_IN) and outlet (TF_OUT) plenum temperatures were also measured using fluid thermocouples. The inlet (P_IN) and outlet (P_OUT) plenum absolute pressures were measured using Sensotec absolute pressure transducers. The liquid temperature at the outlet of the heat exchanger (TF_HX_OU'T) was measured using a fluid thermocouple. The liquid level in the level control standpipe was measured using a differential pressure cell (DP_SP) connected between the bottom of the lower plenum and a point above the highest outlet tap. During testing, the storage tank temperature was monitored to help determine the necessary secondary heat exchanger flowrate but was not recorded. The water flowrate (Q_W_CC) through the lower plenum cooling coil was measured using a turbine flowmeter and the inlet (TF_CC_IN) and the outlet (TF_CC_OU) temperatures were measured using fluid thermocouples.

The test section voltage (V_INNER) was measured with a volt meter connected directly across the test section. The current through the test section (I_INNER) was determined by measuring the voltage across a current shunt of known resistance.

Local atmospheric pressure (P_ATM) was measured using a Sensotec electronic barometer and was checked daily against the atmospheric pressure recorded at the INEL Standards and Calibration Laboratory.

\subsection{Test Section Description}

For this discussion the test section is defined as the upper and lower plenums, the connecting transparent shroud, and the composite heater. Figure 2.2 shows the ECS-2 test section with pertinent elevations indicated on the right side and instrumentation designations on the left side. A companion figure for the ECS-2b test section is shown in Figure 2.3 and is discussed by Anderson [:1]. Instrumentation on the composite heater is not shown on this figure. A cross section view through the heated portion of the test section for ECS-2b is shown in Figure 2.4. Note that the heater for ECS-2 is essentially the same except that welds on the ECS-2 heater are in the A and C subchannels. 


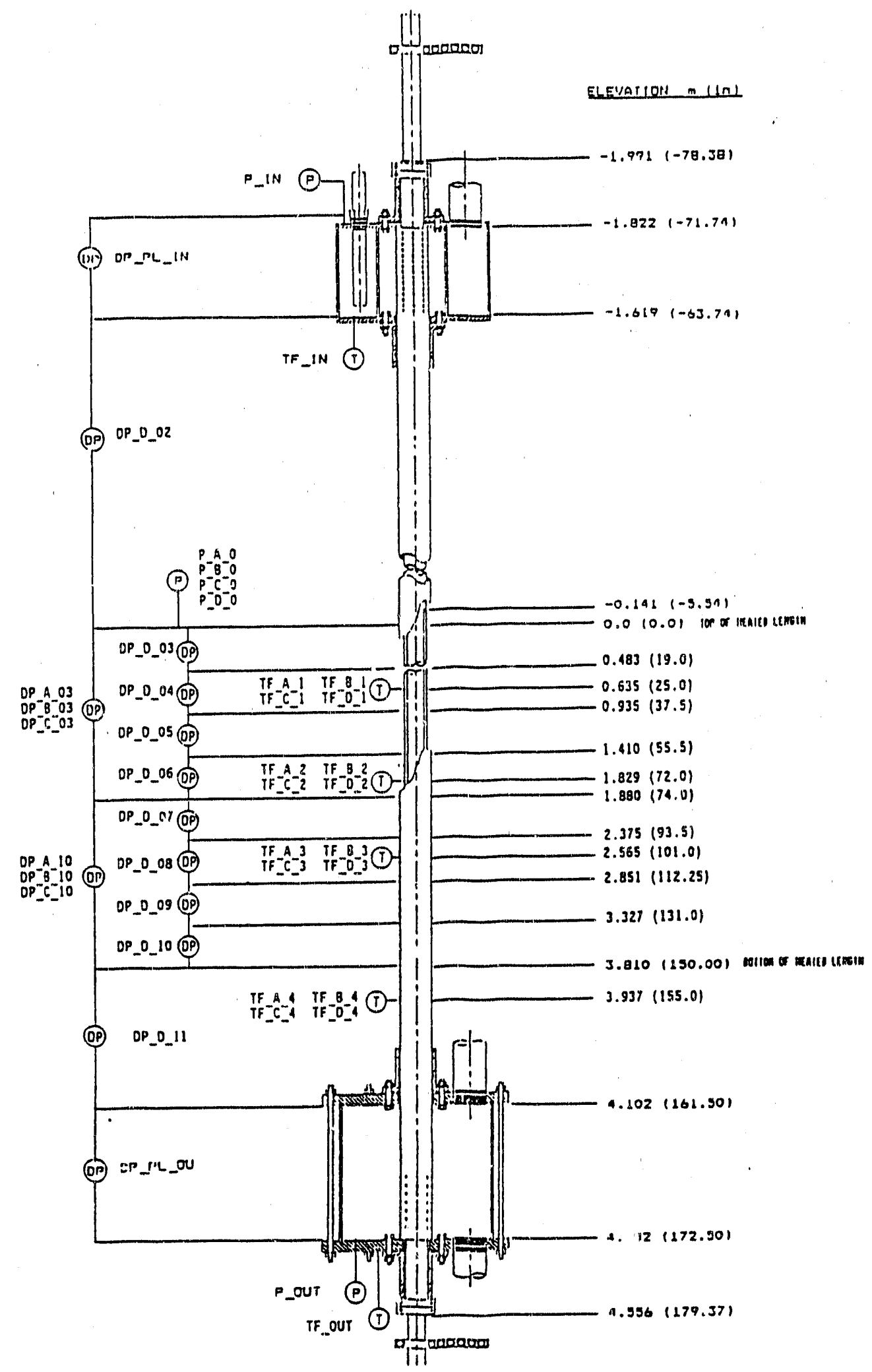

Figure 2.2. ECS-2 test section 


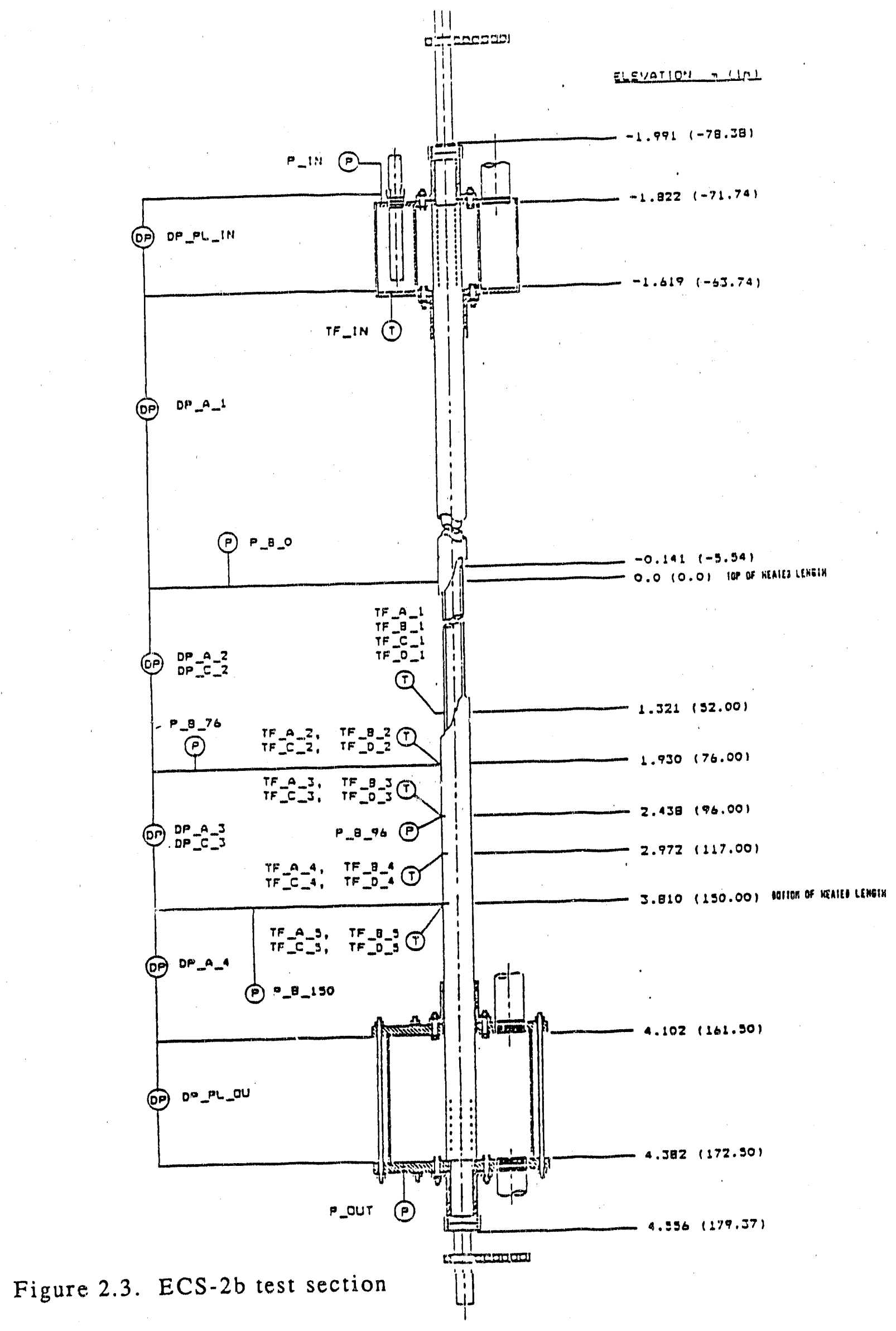




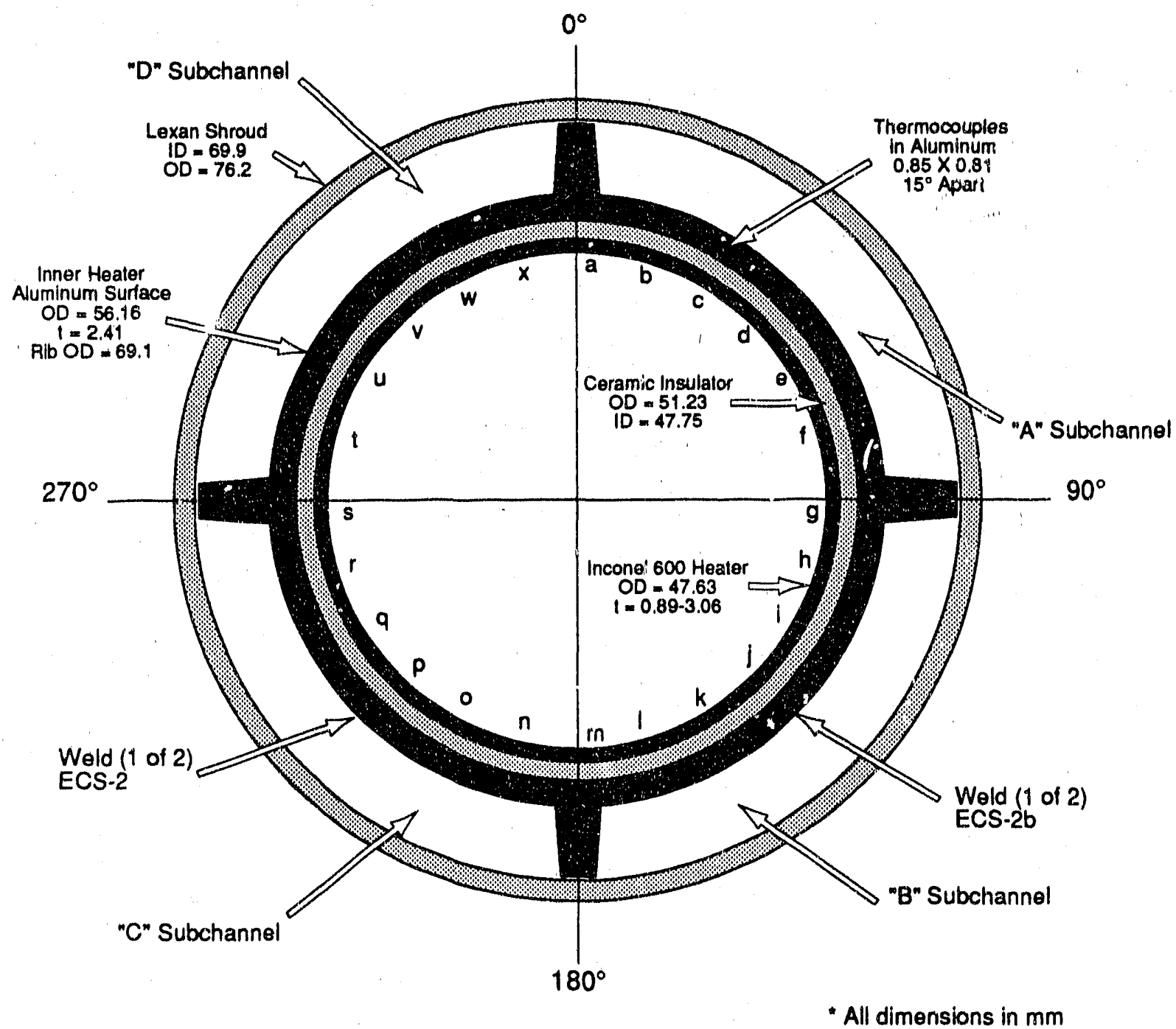

Hydraulic Diameter $=1.197 \mathrm{~cm}$

Flow Area $=13.31 \mathrm{~cm}^{\wedge} 2$

Figure 2.4. ECS-2 and ECS-2b test section cross section through heater, viewed from the bottom

\subsubsection{Composite Heater}

The composite heater, shown in Figure 2.4, consists of a $4.76 \mathrm{~cm}$ ( $1.875 \mathrm{in}$.) OD Inconel 600 resistively heated tube fitted inside a 1.75 $\mathrm{mm}(0.069 \mathrm{in}$.$) thick ceramic insulator, with an aluminum outer tube in$ which the fins have been machined. The aluminum outcr tube was made in two halves and welded onto the assembly in order to facilitate 
fabrication. Power leads through the unheated portion of the heater were made of copper tubing (wall thickness of $8.59 \mathrm{~mm}$ [0.338 in.]) brazed to the ends of the Inconel heater tube. The composite hea er was fabricated by sliding the ceramic insulator over the inconel labe, placing the two aluminum halves over the insulator, and then TIG welding the aluminum halves together longitudinally, with the welds in subchannels $B$ \& D on the ECS-2b heater and in subchannels $A$ \& $C$ on the ECS-2 heater. As the weld cooled, the composite was drawn tightly together. The weld surface was then dressed to the basic tube diameter. The completed assembly for ECS-2 is shown in Drawing 429994 in Appendix A.

The Inconel heater tube was fabricated by welding together eight sections of Inconel 600 tubing of various lengths having five different wall thicknesses in order to produce the axial power profile shown in Figure 2.5. Information for each section is presented in Table 2.1. The sections were welded together using an Astro Arc automatic tube welder. No welding filler material was required with this automatic welder. Several sample pieces for each of the weld joint thickness were made and destructively examined to determine the proper welder settings to ensure a full penetration and uniform weld for each joint. The copper power leads were then brazed to each end of the Inconel tube. The completed assembly is shown in Drawing 430437 in Appendix A. The completed assembly was then hung vertically in air and power leads attached to the copper leads and a thermocouple was attached in the center of each power zone. Power was applied to the heater until the hottest zone reached $800 \mathrm{~K}\left(1000^{\circ} \mathrm{F}\right)$. This maximum temperature was maintained for approximately one-half hour. The temperature profile was similar to the desired power profile indicating the correct sequence of heater sections. Any weld voids would show up as dark spots in the welded zone. None were found. The electrical resistance of the heaters were calculated from the voltage and current measurements to be $0.0206 \mathrm{ohm}$ for both the ECS-2 and ECS-2b heaters. This was within $5 \%$ of the expected resistance calculated from the tube lengths and thicknesses and the published resistivity for Inconel.

The Macor machinable ceramic was purchased as cylinders slightly larger than $5 \mathrm{~cm}$ ( 2 in.) in diameter and approximately $15-\mathrm{cm}$ (6-in.) in length. Each cylinder was machined to an inside diameter of $4.78-\mathrm{cm}$ $(1.880$-in.) and an outside diameter of $5.12 \mathrm{~cm}(2.017-\mathrm{in}$.$) .$ 


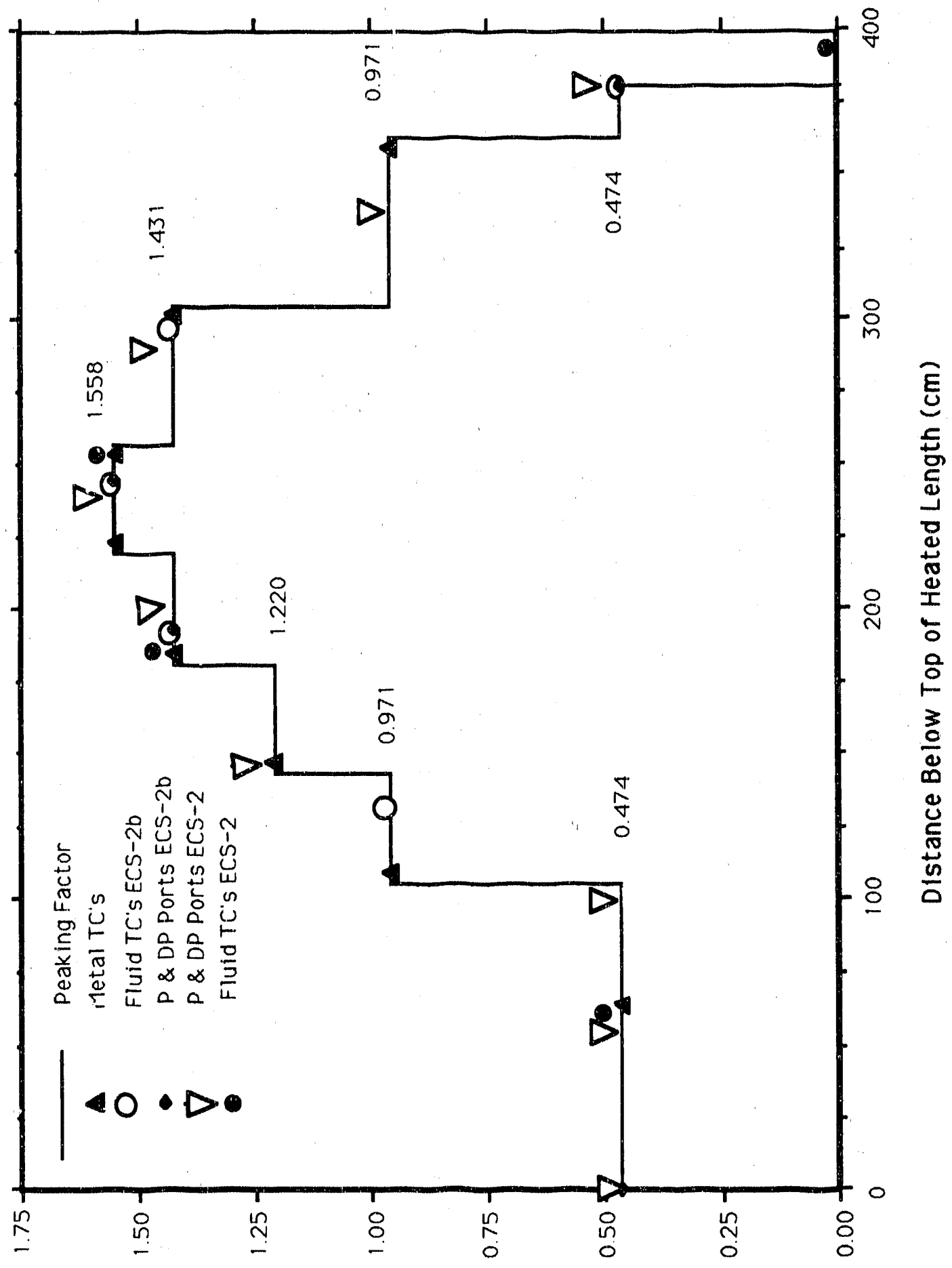

JaMOd OAIJEIOY

Figure 2.5. Axial power peaking factors and instrument locations for ECS -2 and ECS $-2 b$ heaters 
Table 2.1. Inconel 600 heater information

\begin{tabular}{ccccc}
\hline Section & $\begin{array}{c}\text { Power } \\
\text { factor }\end{array}$ & $\begin{array}{c}\text { Distance from } \\
\text { top of heater } \\
(\mathrm{cm})\end{array}$ & $\begin{array}{c}\text { Length } \\
(\mathrm{cm})\end{array}$ & $\begin{array}{c}\text { Wall thickness } \\
(\mathrm{mm})\end{array}$ \\
1 & 0.474 & $000-105$ & 104.8 & \\
2 & 0.971 & $105-143$ & 38.1 & 3.07 \\
3 & 1.220 & $143-181$ & 38.1 & 1.45 \\
4 & 1.431 & $181-219$ & 38.1 & 1.14 \\
5 & 1.558 & $219-257$ & 36.1 & 0.97 \\
6 & 1.431 & $257-306$ & 48.6 & 0.89 \\
7 & 0.971 & $306-363$ & 57.7 & 0.97 \\
8 & 0.474 & $363-381$ & 17.5 & 1.45 \\
& & & & 3.07 \\
\hline
\end{tabular}

A cross section of the aluminum tube in the region of the fins is shown in Figure 2.6. Complete details are given in Drawing 430052 in Appendix A. The tube was made from 6061 Aluminum, instead of 1100 Aluminum as used in a SRS Mark-22 fuel arsembly, because of its good machinability. The fin profile is identical to that used in the SRS Mark22 fuel assembly. The longitudinal groove, placed at $15^{\circ}$ intervals: allow for the placement of thermocouples in the aluminum tube. Location and routing of thermocouples are detailed in Drawing 430386 in Appendix A. Those portions of grooves not used for the actual thermocouples are filled with nonactive thermocouple wire. The thermocouples are $0.81-\mathrm{mm}(0.032$-in.) OD type $\mathrm{K}$ stainless steel sheathed having a grounded junction.

After assembly, welding, and dressing of the heater assembly, a helium leak test was performed to ensure there were no leaks in the weld joints. Holium gas at $350 \mathrm{kPa}(50 \mathrm{psi})$ was applied inside the aluminum tube and leaks were detected by covering the surface, one side at a time, with alcohol and observing any bubbles formed. After any leaks were repaired, the heater assembly was placed inside the flow shroud, connected to the water and power supply and thermally cycled several times to temperatures expected during the test matrix. The heater assembly was removed from the flow shroud and again the 


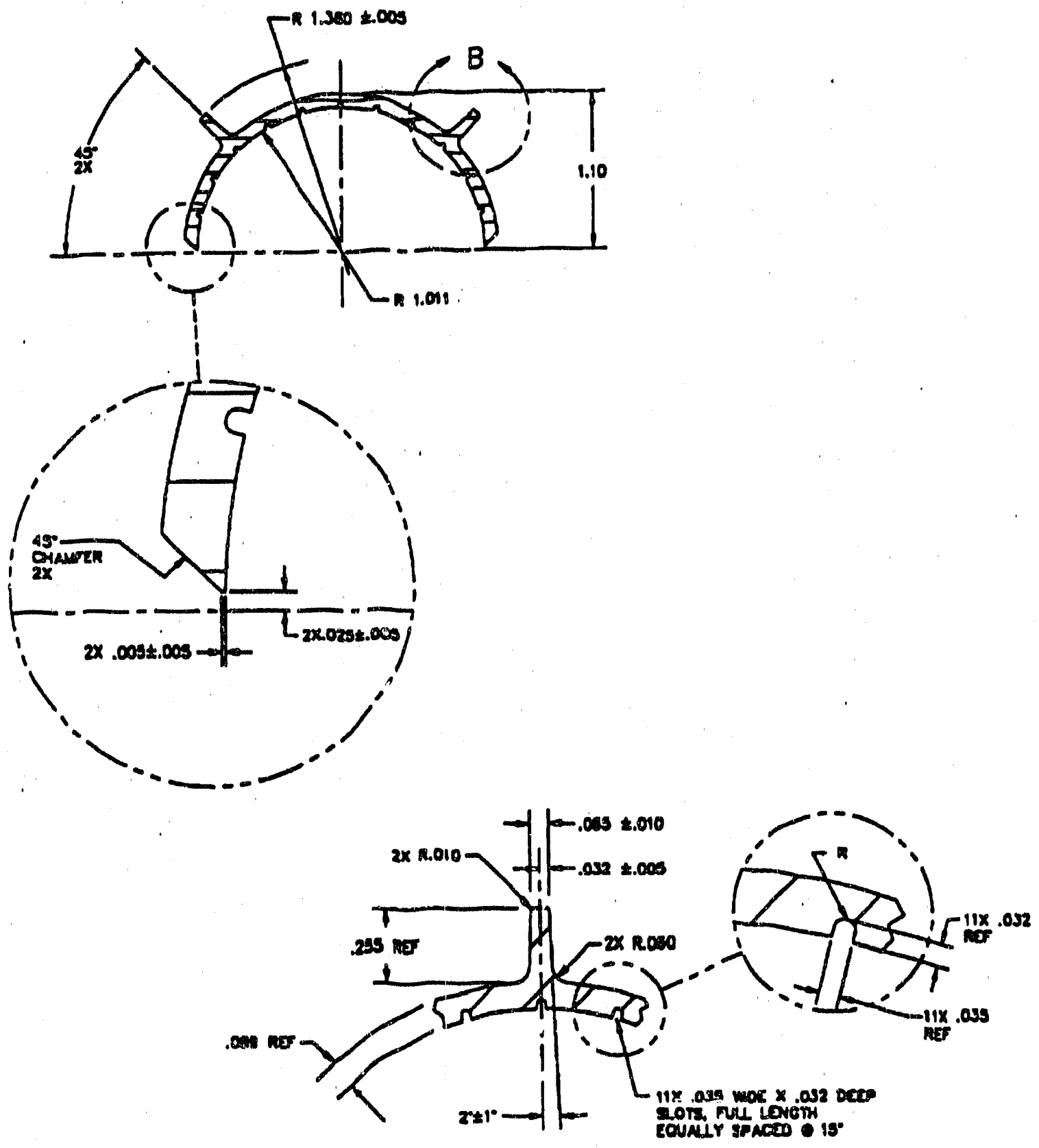

Note: Cross section shown is for the ECS-2b heater. The ECS-2 heater had square-bottomed thermocouple grooves but was the same as the ECS.

$2 b$ heater in other respects.

Figure 2.6 ECS-2 and ECS-2b aluminum tube cross section 
welds were checked for leaks using the same helium leak test procedure. When convinced that no water could leak into the test section internals, the outer surface of the aluminum was treated to make it wettable by immersing the entire heater assembly in a bath of dilute sodium hydroxide for approximately three minutes. Verification of each thermocouple location was made by identifying each junction using a heat gun applied to the heater surface.

As shown on the drawings in Appendix A, the ECS-2 test section design included provisions for a $1.07 \mathrm{~mm}$ ID, $3.66 \mathrm{~m}$ long heater rod that could be positioned off-center inside the composite heater. The internal heater was incorporated to provide an azimuthal power tilt although it was never used.

\subsubsection{Plena and Shroud}

The upper and lower plena were made from acrylic plastic to allow observation of the interior and were designed to provide prototypical elevations and flow resistances. The plenum assembly details are shown in Drawings 430049 and 431747 in Appendix A. The outer flow shroud was made from an $8-\mathrm{cm}$ (3.0-in.) OD polycarbonate tube. Details of the outer shroud are shown in Drawing 430050.

\subsubsection{Test Section Instrumentation}

Fluid measurement locations in the test section are shown in Figure 2.2 and consist of fluid temperature measurements, absolute pressure, and differential pressure measurements.

Test section fluid temperature measurements for the ECS- 2 facility are summarized below:

$\begin{array}{lll}\begin{array}{l}\text { TF_IN } \\ \text { TF_OUT }\end{array} & \begin{array}{l}\text { Upper plenum temperature } \\ \text { Lower plenum temperature }\end{array} \\ \text { TF_A_01 } & \text { Subchannel A } & \begin{array}{l}63.5-\mathrm{cm}(25-\mathrm{in} .) \text { below top of } \\ \text { heated length }\end{array} \\ \text { TF_B_01 } & \text { Subchannel B } & \begin{array}{l}63.5-\mathrm{cm}(25-\mathrm{in} .) \text { below top of } \\ \text { heated length }\end{array}\end{array}$




\begin{tabular}{|c|c|c|}
\hline TF_C_O 1 & Subchannel C & $\begin{array}{l}63.5-\mathrm{cm}\left(25-\mathrm{in} .{ }^{\prime} \text { below top of }\right. \\
\text { heated length }\end{array}$ \\
\hline TF_D_01 & Subchannel D & $\begin{array}{l}63.5-\mathrm{cm}(25-\mathrm{in} .) \text { below top of } \\
\text { heated length }\end{array}$ \\
\hline TF_A_02 & Subchannel A & $\begin{array}{l}183-\mathrm{cm}(72-\mathrm{in} .) \text { below top of } \\
\text { heated length }\end{array}$ \\
\hline TF_B_02 & Subchannel B & $\begin{array}{l}183-\mathrm{cm}(72-\mathrm{in} .) \text { below top of } \\
\text { heated length }\end{array}$ \\
\hline TF_C_O 2 & Subchannel C & $\begin{array}{l}183-\mathrm{cm}(72-\mathrm{in} .) \text { below top of } \\
\text { heated length }\end{array}$ \\
\hline TF_D_02 & Subchannel $D$ & $\begin{array}{l}183-\mathrm{cm}(72-\mathrm{in} .) \text { below top of } \\
\text { heated length }\end{array}$ \\
\hline TF_A_03 & Subchannel A & $\begin{array}{l}257-\mathrm{cm}(101-\mathrm{in} .) \text { below top of } \\
\text { heated length }\end{array}$ \\
\hline TF_B_03 & Subchannel B & $\begin{array}{l}257-\mathrm{cm}(101-\mathrm{in} .) \text { below top of } \\
\text { heated length }\end{array}$ \\
\hline TF_C_03 & Subchannel C & $\begin{array}{l}257-\mathrm{cm}(101-\mathrm{in} .) \text { below top of } \\
\text { heated length }\end{array}$ \\
\hline TF_D_03 & Subchannel D & $\begin{array}{l}257-\mathrm{cm}(101-\mathrm{in} .) \text { below top of } \\
\text { heated length }\end{array}$ \\
\hline TF_A_D4 & Subchannel A & $\begin{array}{l}394-\mathrm{cm}(155-\mathrm{in} .) \text { below top of } \\
\text { heated length }\end{array}$ \\
\hline TF_B_0 4 & Subchannel B & $\begin{array}{l}394-\mathrm{cm}(155-\mathrm{in} .) \text { below top of } \\
\text { heated length }\end{array}$ \\
\hline TF_CO 4 & Subchannel C & $\begin{array}{l}394-\mathrm{cm}(155-\mathrm{in} .) \text { below top of } \\
\text { heated length }\end{array}$ \\
\hline TF_D_0 4 & Subchannel D & $\begin{array}{l}394-\mathrm{cm}(155-\mathrm{in} .) \text { below top of } \\
\text { heated length }\end{array}$ \\
\hline
\end{tabular}

Six absolute pressure measurements are identified below:

$\begin{array}{ll}\text { P_IN } & \text { Upper plenum pressure } \\ \text { P_OUT } & \text { Lower plenum pressure }\end{array}$

P_A_0 Subchannel A at beginning of heated length

P_B_0 Subchannel $B$ at beginning of heated length

P_C_0 Subchannel $C$ at beginning of heated length 
P_D_O Subchannel D at beginning of heated length

The following eighteen differential pressure measurements were present on the ECS-2 facility;

$\begin{array}{ll}\text { DP_PL_IN } & \text { top to bottom of upuer plenum } \\ \text { DP_PL_OU } & \text { top to bottom of lower plenum }\end{array}$

DP_A_03 Subchannel A top of heated length to $188-\mathrm{cm}$ (74in.) below top of heated length

DP_A_10 Subchannel A $188-\mathrm{cm}(74-\mathrm{in}$.) to botiom of heated length $(381-\mathrm{cm}[150-$ in. $])$

DP_B_03 Subchannel B top of heated length to 188-cm (74in.) below top of heated length

DP_B_10 Subchannel B 188-cm (74-in.) to bottom of heated length (381-cm [150-in.])

DP_C_03 Subchannel C top of heated length to $188-\mathrm{cm}$ (74in.) below top of heated length

DP_C_10 Subchannel C $188-\mathrm{cm}(74-\mathrm{in}$.) to bottom of heated length $(381-\mathrm{cm}[150-\mathrm{in}]$.

DP_D_02 Subchannel D $-165-\mathrm{cm}(-65-$ in.) [bottom of inlet plenum] to top of heated length $(0-\mathrm{cm})$

DP_D_03 Subchannel D top of heated length to $48-\mathrm{cm}(19-\mathrm{in}$.) below top of heated length

DP_D_04 Subchannel D 48-cm (19-in.) below top of heated length to $97-\mathrm{cm}(38-\mathrm{in}$.) below top of heated length DP_D_05 Subchannel D 97-cm (38-in.) below top of heated length to $142-\mathrm{cm}(56-\mathrm{in}$.) below top of heated length DP_D_06 Subchannel D $142-\mathrm{cm}(56-\mathrm{in}$.) below top of heated length to $188-\mathrm{cm}(74-\mathrm{in}$.) below top of heated length DP_D_07 Subchannel D 188-cm (74-in.) below top of heated length to $239-\mathrm{cm}(94-\mathrm{in}$.) below top of heated length DP_D_08 Subchannel D 239-cm (94-in.) below top of heated length to $287-\mathrm{cm}(113-\mathrm{in}$.) below top of heated length

DP_D_09 Subrhannel D 287-cm (113-in.) below top of heated length to $333-\mathrm{cm}(131-\mathrm{in}$.) below top of heated 
length

DP_D_10 Subchannel D 333-cm (131-in.) below top of heated length to $381-\mathrm{cm}(150-\mathrm{in}$.) below top of heated length

DP_D_11 Subchannel D 381-cm (131-in.) below top of heated length to $409-\mathrm{cm}(161-\mathrm{in}$.$) top of lower plenum$

For the heater used in the ECS-2 facility, there are 34 thermocouples embedded in the wall of the aluminum tube at the locations indicated in Table 2.2. The heater used in the ECS-2b facility has 44 thermocouples as indicated in Table 2.3.

A master list of ai! instrumentation for ECS-2 experiments is included as Table B-1 in Appendix B. Table B-2 in Appendix B contains the same information for ECS-2b experiments. Uncertainty information for each type of measurement is included as Appendix C. Appendix D provides design calculation information for the heater.

\subsubsection{Data Acquisition System}

A Megadac 2200C interfaced to an IBM System/2 PC made up the data acquisition system (DAS) used for the ECS-2 tests. The Megadac 2200C is a high-speed data acquisition, signal conditioning, and data recording system capable of a continuous sampling rate of up to 20,000 samples per second. Expandable modules allow the Megadac to provide amplification, multiplexing, and analog-to-digital conversion for up to $128 \mathrm{channels}$ of differential input. Signal conditioning included low band pass 4-pole Butterworth filters set for a pass frequency of $2 \mathrm{~Hz}$ for thermocouples and 5 $\mathrm{Hz}$ for other measurements ${ }^{1}$. The IBM PC is used to perform engineering unit conversion and obtain calculated parameters from various measurements.

A high speed video recording system was used on several experiments to record the hydraulic behavior in the test section. Appendix $\mathrm{H}$ contains a detailed description of the video system components and operation.

1. The proper analog filter frequency is less than the Nyquist frequency, which is $1 / 2$ the sample frequency. Thus at a recording frequency of 2 samples per second, the filters should be set at a frequency of less than $1 \mathrm{~Hz}$. Unfortunately, the construction of the Megadac boards precluded installation of a filter circuit with this low of a cutoff frequency. Filters were installed at the lowest attainable frequencies. 
Table 2.2. Location of wall thermocouples for ECS-2 heater

\begin{tabular}{|c|c|c|c|}
\hline DAS Tag ID & $\begin{array}{c}\text { Distance below top } \\
\text { of heated length } \\
(\mathrm{cm})\end{array}$ & Subchannel & $\begin{array}{l}\text { Azimuthal } \\
\text { location } \\
\text { (degrees) }\end{array}$ \\
\hline TI_B_j_1 & 64 & B & 135 \\
\hline TIDD_v_1 & 64 & D & 315 \\
\hline TI $\bar{B}{ }_{2}$ & 107 & B & 135 \\
\hline TIDDV_2 & 107 & $\mathrm{D}$ & 315 \\
\hline TI_Bj3 & 145 & B & 135 \\
\hline TID_v_3 & 145 & $\mathrm{D}$ & 315 \\
\hline TIBj_4 & 183 & B & 135 \\
\hline TI_D_v_4 & 183 & $\mathrm{D}$ & 315 \\
\hline TI_A_a_5 & 221 & $D / A$ & 0 \\
\hline TI_B_g_5 & 221 & $A / B$ & 90 \\
\hline TI_Bj_5 & 221 & B & 135 \\
\hline TI_Cm 5 & 221 & $\mathrm{~B} / \mathrm{C}$ & 180 \\
\hline TI_D_s_5 & 221 & $\mathrm{C} / \mathrm{D}$ & 270 \\
\hline TI_D_v_5 & 221 & D & 315 \\
\hline TI_A_a_6 & 254 & $\mathrm{D} / \mathrm{A}$ & 0 \\
\hline TI_A_C_6 & 254 & A & 30 \\
\hline TI_A_e_6 & 254 & A & 60 \\
\hline TIB_g_6 & 254 & $A / B$ & 90 \\
\hline TI_B_i_6 & 254 & B & 120 \\
\hline TI_B_k_6 & 254 & B & 150 \\
\hline TICIm_6 & 254 & $\mathrm{~B} / \mathrm{C}$ & 180 \\
\hline TI_C_o_6 & 254 & C & 210 \\
\hline TI_Cg_6 & 254 & $\mathrm{C}$ & 240 \\
\hline TIDDs_6 & 254 & $C / D$ & 270 \\
\hline TI_D_u_6 & 254 & D & 300 \\
\hline TIDD_w_6 & 254 & $\mathrm{D}$ & 330 \\
\hline TI A_a_ 7 & 302 & $D / A$ & 0 \\
\hline TI Bg_7 & 302 & $\mathrm{~A} / \mathrm{B}$ & 90 \\
\hline TI $B j_{2} 7$ & 302 & B & 135 \\
\hline TI_C_m 7 & 302 & $\mathrm{~B} / \mathrm{C}$ & 180 \\
\hline TI_D_S_7 & 302 & $\mathrm{C} / \mathrm{D}$ & 270 \\
\hline TIDD_v_7 & 302 & D & 315 \\
\hline TI_B_j8 & 360 & B & 135 \\
\hline TIDDV_8 & 360 & $\mathrm{D}$ & 315 \\
\hline
\end{tabular}

1. See Figure 2.4 for azimuthal angle orientation. 
Table 2.3. Location of wall thermocouples for ECS-2b heater

\begin{tabular}{|c|c|c|c|}
\hline DAS Tag ID & $\begin{array}{c}\text { Distance below top } \\
\text { of heated length } \\
(\mathrm{cm})\end{array}$ & Subchannel & $\begin{array}{c}\text { Azimuthal } 1 \\
\text { location } \\
\text { (degrees) }\end{array}$ \\
\hline TI_A_d_1 & 64 & A & 45 \\
\hline TI_C_p_1 & 64 & C & 225 \\
\hline TIAAd_2 & 109 & A & 45 \\
\hline TI_B_k_2 & 109 & B & 150 \\
\hline TILCD_2 & 109 & C & 225 \\
\hline TI_D_w_2 & 109 & D & 330 \\
\hline TIA_d_3 & 147 & A & 45 \\
\hline TI_B_k_3 & 147 & B & 150 \\
\hline TI_C_p_3 & 147 & $\mathrm{C}$ & 225 \\
\hline TI_D_w3 & 147 & D & 330 \\
\hline TI_A_d_4 & 185 & A & 45 \\
\hline TI_Bi 4 & 185 & B & 120 \\
\hline TI_Cs_4 & 185 & $\mathrm{C}$ & 225 \\
\hline TIDu 4 & 185 & $\mathrm{D}$ & 300 \\
\hline TIA 5 & 223 & $D / A$ & 0 \\
\hline TI_A_d_5 & 223 & A & 45 \\
\hline TIBg_5 & 223 & $\mathrm{~A} / \mathrm{B}$ & 90 \\
\hline T1_B_i5 & 223 & B & 120 \\
\hline TI_Cm5 & 223 & $\mathrm{~B} / \mathrm{C}$ & 180 \\
\hline TI_C_p_5 & 223 & $\mathrm{C}$ & 225 \\
\hline TI_Ds_5 & 223 & $C / D$ & 270 \\
\hline TIDD_u_5 & 223 & D & 300 \\
\hline TIA_a_6 & 253 & $\mathrm{D} / \mathrm{A}$ & 0 \\
\hline TIA_c_6 & 253 & $A$ & 30 \\
\hline TIAA_e_6 & 253 & A & 60 \\
\hline TI_B_g_6 & 253 & $\mathrm{~A} / \mathrm{B}$ & 90 \\
\hline TI_B_i_6 & 253 & B & 120 \\
\hline$T I B \_k 6$ & 253 & B & 150 \\
\hline TI_Cm 6 & 253 & $\mathrm{~B} / \mathrm{C}$ & 180 \\
\hline TI_C_o_6 & 253 & C & 210 \\
\hline TI_C_q_6 & 253 & C & 240 \\
\hline TIDDs_6 & 253 & $C / D$ & 270 \\
\hline TI_D_u_6 & 253 & D & 300 \\
\hline TI_D_W_6 & 253 & D & 330 \\
\hline TI_A_a_7 & 302 & $\mathrm{D} / \mathrm{A}$ & 0 \\
\hline TIAd 7 & 302 & A & 45 \\
\hline TI_B_g_7 & 302 & $A / B$ & 90 \\
\hline TI_B_k_7 & 302 & B & 150 \\
\hline TI_Cm7 & 302 & $\mathrm{~B} / \mathrm{C}$ & 180 \\
\hline TI_C_p_7 & 302 & $C$ & 225 \\
\hline TI_D_s_7 & 302 & $C / D$ & 270 \\
\hline TIDD_w_7 & 302 & D & 330 \\
\hline TI_A_d_8 & 360 & A & 45 \\
\hline TIC C. 8 & 360 & $\mathrm{C}$ & 225 \\
\hline
\end{tabular}

1. See Figure 2.4 for azimuthal angle orientation. 


\section{EXPERIMENT DESCRIPTION}

Procedures used to conduct wall thermal excursion experiments in tie ECS-2 and ECS-2b facilities and to help ensure the validity of the data base generated during the tests are briefly described in this section. System operational checkout and other tests conducted to verify the design, measurement, and support systems are discussed first. Daily procedures used in test setup and measurement calibration are then descrihed. Finally, the procedure used to conduct actual experiments and the test matrices are addressed.

\subsection{Checkout Tests}

Once the facility hardware and measurements system had been completely installed, numerous checkout tests were conducted to insure that the component systems were working properly. These tests included:

(a) measurements verification

(b) system operational (SO)

(c) inner heater design and measurement system verification

(d) power pulse (conducted in air)

(e) power trip test

(f) single-phase liquid full heat transfer.

\subsubsection{Measurement Verification}

After the entire measurement and DAS had been installed, a number of checks were conducted to guarantee proper operation of the instrumentation and data recording system. After the DAS had been set up with necessary calibration constants and transform functions, an er tto-end check on each individual measurement was performed. This involved using known voltage insertion at the sensor location io verify the proper response of the measurement signal at the DAS. Where pessible, all measurements were checked by inserting known voltages that corresponded to the endpoints of the range for which it was calibrated. This procedure also allowed verification of instrument cabling, patch panel setup: and so forth.

Air flow measurement outputs were verified using a technique involving the use of a suction fan and soap bubbles. The system was configured 
with a large intake pipe on the upstream side of the measurement station being checked. An air-soap bubble mixture was drawn through the measurement station to produce a flowrate. With a known cross section area of the piping, the time required for a single soap bubble to travel a known distance alluwed calculation of the volumetric flowrate. This value was checked against the measurement signal output to the DAS (data was not recorded). Although crude, the methodology gave confidence in the measurement.

Turbine meters used to provide liquid flowrate measurement were verified after installation using timed measurements and calibrated collection devices.

Differential pressures, absolute pressures, and fluid and metal thermocouples in the system were verified for location and response while slowly filiing the test section with water. Response of the measurements was correlated with the liquid level in the test section using both hot and cold water bottom fills.

\subsubsection{System Operational (SO) Tests}

The ECS-2 and ECS-2b facilities and all supporting equipment (electrical power, data acquisition, water supply, and so forth) were checked in an integral fashion prior to conducting any planned experiments by conducting System Operational tests. The objective of the SO tests was to ensure that the overall system could function as desired. Included in the SO test were component checks and a "dry run" for a bonafide experiment complete with data archiving and analysis.

\subsubsection{Air Power Pulse (APP) and Liquid Full (LF) Checkout Tests}

Two different tests were run to verify the design details of the inner heater. Three air power pulse tests (APP) and one liquid full (LF) power pulse test were conducted to help verify the axial and azimuthal power profile on the heater. More than $40 \mathrm{LF}$ tests were conducted to examine heat transfer to single-phase liquid.

A. Po tests involved pulsing the test section with a low, constant power for approximately one minute with the test section in a dry air environment. Such a heatup in air was expected to result in a nearly adiabatic 
heatup rate of the test section. Rise rates for each wall thermocouple could then be related to the local power generation rate for comparison to expected values and to investigate evidence of azimuthal variation. Details of the APP tests and conclusions reached are documented in Appendix E of Anderson [11]. APP test results verified that the axial piswer profile was per design specifications and that there were no significant azimuthal power gradients.

One liquid full power pulse test and one air power trip test were conducted to help resolve questions regarding the potential effects of electrical and magnetic fields (induced by the power supply) on the aluminum wall thermocouple readings. Results of these experiments showed that there was no influence of electrical and magnetic fields on the aluminum wall thermocouple readings.

Liquid full tests were run to examine the axial variation in heat transfer to single-phase liquid. These tests were run by setting the standpipe at a level above the top of the heated length to ensure only liquid flow existed in the flow channel. Heat transfer coefficients were then computed from the data and compared with expected values to establish confidence in the data. Details of several of the LF tests and results from the analysis of LF test data are contained in Appendix F of Anderson [11]. Additional information pertaining to the results of the LF tests will be published in an addendum to Anderson's report.

\subsection{Routine Data Integrity Checks}

To ensure the integrity of the data produced in the ECS-2 facility, certain procedures were routinely performed (weekly, daily, or before every test) as required.

DAS balance and calibration were electronically checked daily. Even though the DAS electronics were very stable, electronic balance and two point calibration on the cards in the DAS were performed weekly, or following instrument changeout or measurement channel patch changes.

Differential pressure transducers were checked daily. The cells were valved out of the system, the sense lines were backfilled, and the instruments were checked for any abnormal zero offsets (offsets were corrected if found), and then valved back into the system. 
Pretest and posttest scans of all measurements were conducted for each test. Known, steady-state thermal conditions were established in the test section. Review of this information helped to identify any problems with measurement and electronics consistency. The fluid temperature reading from a calibrated glass thermometer, installed at the inlet to the test section, was compared with the inlet fluid thermocouples to ensure measurement consistency.

Daily, barometric pressure readings, obtained from the INEL Standards and Calibration Laboratory, were recorded in the test operations log book. Water pH measurement results were also recorded daily in the test operations log book (The test operations log book for the ECS-2 experiments consists of three volumes. Copies of these volumes are located in the INEL Technical Library and have identification numbers INEL-NBU-2205, INELNBU-2206, and INEL-NBU-2207).

\subsection{Experimental Procedure}

Most thermal excursior. experiments conducted in the ECS-2 and ECS$2 b$ facilities were conducted using the same procedure. For any given experiment, the sequence of events was as follows:

Before initiation of power to the heater

- Set test section standpipe to desired value

- Initiate iniet flow and set to desired value

- Start the heated water makeup system and adjust the fluid temperature to the desired value

- Start DAS (in monitor mode)

- Verify systems operating.

Test Initiation

- Initiate DAS record 2 minutes prior to application of power

- Set Inconel test section power to approximately $20 \mathrm{~kW}$ and maintain sufficiently long to achieve thermal equilibrium

- Increase test section power by an increment specified by the test engineer followed by a $2-5$ minute soak period

- Record video data per the direction of the test engineer

- Increase test section power by an increment of approximately $20 \mathrm{~kW}$ (discretion of the test engineer) followed by a 2-5 
minute soak period. If thermal excursion does not occur during the power increase, maintain the power setting for approximately 5 minutes to allow system to soak and come to thermal equilibrium

- Continue increasing the test section power in steps followed by a 5 minute soak period until thermal excursion occurs or the test section is at maximum power

- When the test criteria are met (sustained thermal excursion), terminate test section power (normally done automatically by a power trip circuit that monitored specified metal temperatures)

- Terminate DAS record.

\section{Posttest Activities}

- Archive recorded data

- Conduct engineering units calculations and prepare Quick Look plots

- Concuct posttest facility check.

Experiments in the flow coastdown series (ECS-2FC) deviated somewhat from this procedure. For the flow coastdowns, the test section power was held constant while the inlet flow was decreased in discrete steps from the initial value. In the ECS $-2 \mathrm{cE}$ experiments, permanent data recording was not initiated until the test section was near (within approximately $10 \mathrm{~kW}$ ) thermal excursion, power increases were limited to $3 \mathrm{~kW}$, and the soak time at any given power was at least 6 minutes.

The goal for tests in the thermal excursion program was to establish and measure the conditions (test section flowrate, power, inlet fluid temperature, and lower plenum pressure) leading to sustained thermal excursion at any position along the axial length of the heater. The excursion criteria and hence test termination criteria were defined based on maximum aluminum wall temperature. For the majority of the INEL experiments, this maximum temperature was $620 \mathrm{~K}$. On some of the later experiments, the temperature criterion was decreased to $520 \mathrm{~K}$ to be consistent with similar experiments conducted at SRS. Data repeatability and the impact of the different excursion criceria are discussed in Appendix F.

In addition to the maximum wall criteria, an ancillary test section power limit criterion was implemented to provide heater protection during 
the thermal excursion experiments. Equipment design considerations limited the maximum heater power to less than $175 \mathrm{~kW}$. Most experiments, however, were successfully completed at heater powers less than $150 \mathrm{~kW}$.

\subsection{Test Matrix}

Three different groups of wall thermal excursion experiments were conducted in the ECS-2 and ECS-2b facilities. The major goal of these experiments was to determine the test section power required to cause a sustained dryout at some axial location on the heater wall as a function of inlet flow, inlet liquid subcooling, and test section back pressure. Tests conducted encompassed the range of test parameters shown $n$ Table 3.1. In addition to the excursion experiments, a special group of air ingress tests were conducted. A detailed discussion of the air ingress test results is presented in Appendix G. A brief discussion of each test group and associated objectives is given below.

Table 3.2 provides the nominal conditions for the matrix of excursion tests conducted in the ECS-2 facility. As shown, the matrix consisted of 25 baseline (denoted by $B L$ in the test name) experiments, two flow coastdown (denoted by FC in the test name) experiments, and eight experiments (denoted by WSR in the test name) conducted at the special request of WSRC personnel. Table 3.3 lists the nominal conditions for the matrix of excursion test conducted in the ECS-2b facility. Test names in

Table 3.1. Range of parameters for thermal excursion experiments

Parameter

coolani flowrate

inlet plenum pressure

outlet plenum pressure

inlet liquid temperature

heater power
Range

$0 \cdot 1.41 / \mathrm{s}(0-22 \mathrm{gpm})$

$86.2 \mathrm{kPa}$ (local atmospheric)

$-18-139.7 \mathrm{~cm}$ of water $(-7-55$ inches of water) referenced to the bottom of the heated length.

$293-344 \mathrm{~K}(20-71 \mathrm{C})$

$0-175 \mathrm{~kW}$ 
Table 3.2. Nominal conditions for excursion tests conducted in the ECS2 facility

Inlet Inlet ${ }^{1}$ Volumetric Liq. Superficial Standpipe ${ }^{2}$

Test Name Subcooling $(K) \operatorname{Temp}(K)$ Flow $(\mathrm{l} / \mathrm{s})$ Velecily $(\mathrm{m} / \mathrm{s}) \quad(\mathrm{cm})$

\begin{tabular}{|c|c|c|c|c|c|}
\hline ECS-2BL_1 & 75 & 293.5 & 0.1 & 0.075 & 399 \\
\hline ECS-2BL_1B & 75 & 293.5 & 0.1 & 0.075 & 399 \\
\hline ECS-2BL_2 & 75 & 293.5 & 0.3 & 0.225 & 399 \\
\hline ECS-2BL_5 & 45.8 & 322.7 & 0.1 & 0.075 & 399 \\
\hline ECS-2BL_5B & 45.8 & 322.7 & 0.1 & 0.075 & 399 \\
\hline ECS-2BL_5C & 45.8 & 322.7 & 0.1 & 0.075 & 399 \\
\hline ECS-2BL_5D & 45.8 & 322.7 & 0.1 & 0.075 & 399 \\
\hline ECS-2BL_6 & 45.8 & 322.7 & 0.3 & 0.225 & 399 \\
\hline ECS-2BL_7 & 45.8 & 322.7 & 0.5 & 0.376 & 399 \\
\hline ECS-2BL_7B & 45.8 & 322.7 & 0.5 & 0.376 & 399 \\
\hline ECS-2BL-11 & 24.3 & 344.2 & 0.3 & 0.225 & 399 \\
\hline ECS-2BL_11B & 24.3 & 344.2 & 0.3 & 0.225 & 399 \\
\hline ECS-2BL_12 & 24.3 & 344.2 & 0.5 & 0.376 & 399 \\
\hline ECS-2BL_12B & 24.3 & 344.2 & 0.5 & 0.376 & 399 \\
\hline ECS-2BL_13 & 24.3 & 344.2 & 0.7 & 0.526 & 399 \\
\hline ECS-2BL_14 & 24.3 & 344.2 & 0.9 & 0.676 & 399 \\
\hline ECS-2BL_17 & 45.8 & 322.7 & 0.3 & 0.225 & 271 \\
\hline ECS-2BL_18 & 45.8 & 322.7 & 0.5 & 0.376 & 271 \\
\hline ECS-2BL_18B & 45.8 & 322.7 & 0.5 & 0.376 & 271 \\
\hline ECS-2BL_22 & 45.8 & 322.7 & 0.3 & 0.225 & 330 \\
\hline ECS-2BL_23 & 45.8 & 322.7 & 0.5 & 0.376 & 330 \\
\hline$E C S-2 B L \_23 B$ & 45.8 & 322.7 & 0.5 & 0.376 & 330 \\
\hline ECS-2BL_26 & 45.8 & 322.7 & 0.3 & 0.225 & 362 \\
\hline ECS-2BL_26B & 45.8 & 322.7 & 0.3 & 0.225 & 362 \\
\hline ECS-2BL_27 & 45.8 & 322.7 & 0.5 & 0.376 & 362 \\
\hline ECS-2FC_1 & 45.8 & 322.7 & $0.3-0.13^{3}$ & $0.225-0.095$ & 362 \\
\hline ECS-2FC_2 & 45.8 & 322.7 & $0.5-0.27^{3}$ & $0.376-0.203$ & 362 \\
\hline WSR0380 & 55 & 315 & 0.38 & 0.285 & 333 \\
\hline WSR0580 & 55 & 315 & 0.58 & 0.436 & 333 \\
\hline WSR0580C & 55 & 315 & 0.58 & 0.436 & 333 \\
\hline WSR0760 & 55 & 315 & 0.76 & 0.571 & 333 \\
\hline WSR0960 & 55 & 315 & 0.96 & 0.721 & 333 \\
\hline WSR 1040 & 55 & 315 & 1.04 & 0.781 & 333 \\
\hline WSR 1040B & 55 & 315 & 1.04 & 0.781 & 333 \\
\hline WSR 1340 & 55 & 315 & 1.34 & 1.007 & 333 \\
\hline
\end{tabular}

1. Saturation temperature at the inlet is $368.5 \mathrm{~K}$ based on a local atmospheric pressure of $85.6 \mathrm{kPa}$.

2. Elevation referenced to the top of the heated length. To reference to the bottom of the heated length, subtract listed number from $381 \mathrm{~cm}$.

3. Flow coastdown test. 
Table 3.3 contain a "c" and an "E" to denote the fact that the experiments were conducted during the "c" group of runs and were wall excursion tests. ${ }^{2}$

The ECS-2BL experiments were the first excursion tests conducted in the ECS-2 facility. BL tests were initiated in mid-December of 1989 and completed in mid-January of 1990 . The two FC experiments and the air ingress experiments discussed in Appendix $G$ were also conducted during this same time period. WSR tests were conducted during the latter half of January 1990. Attempted conduct of Test WSR1340 resulted in the destruction of the inner heater (as was expected) due to the high flowrates and high inner heater power levels incurred. A new inner heater that was under fabrication for the Dual Heated Annulus program was completed and installed during February 1990. Instrumentation changes were also made to the test section and the facility was then used to conduct the aforementioned ECS-2b and ECS-2c series of tests (wall saturation experiments). ECS-2c excursion tests shown in Table 3.2 were conducted in late June of 1990.

Table 3.3. Nominal conditions for excursion tests conducted in the ECS$2 b$ facility

Inlet inlet Volumetric Liq. Superficial Standpipe Test Name Subcooling (K) Temp (K) Flow (1/s) Velocity $(\mathrm{m} / \mathrm{s})$ (cm)

$\begin{array}{llllll}\text { ECS-2cE11 } & 57 & 311.5 & 0.406 & 0.305 & 333 \\ \text { ECS-2cE12 } & 57 & 311.5 & 0.609 & 0.457 & 333 \\ \text { ECS-2cE13 } & 57 & 311.5 & 0.811 & 0.609 & 333 \\ \text { ECS-2cE } 4 & 57 & 311.5 & 1.014 & 0.762 & 333 \\ \text { ECS-2cE21 } & 42 & 326.5 & 0.406 & 0.305 & 381 \\ \text { ECS-2cE22 } & 42 & 326.5 & 0.406 & 0.305 & 241 \\ \text { ECS-2cE23 } & 75 & 293.5 & 0.406 & 0.305 & 381 \\ \text { ECS-2cE24 } & 75 & 293.5 & 0.406 & 0.305 & 241 \\ \text { ECS-2cE31 } & 42 & 326.5 & 0.811 & 0.609 & 381 \\ \text { ECS-2cE32 } & 42 & 326.5 & 0.811 & 0.609 & 241 \\ \text { ECS-2cE34 } & 75 & 293.5 & 0.811 & 0.609 & 241 \\ & & & & & \\ \text { ECS-2cE42 } & 42 & 326.5 & 1.217 & 0.914 & 241\end{array}$

1. Standpipe referenced to top of the heated length. To reference to the bottom of the heated length, subtract listed number from $381 \mathrm{~cm}$. 
All of the excursion tests conducted were specified with input from WSRC personnel and reflect boundary conditions expected tr represent reactor conditions or those required to duplicate as closely as possible experiments previously conducted at the SRS Heat Transfer Laboratory. For example, the $\mathrm{BL}$ series was designed to provide information on the effects of a range of inlet fluid temperature, inlet flowrate, and facility back pressure. The two FC tests provided information on the effects of transient flow conditions with test section inlet temperature, flowrate, back pressure, and power held constant. Specifications for the WSR tests reflect the desire to duplicate flowrate boundary conditions for experiments that had been conducted at the SRS Heat Transfer Laboratory. Inlet flowrate was the primary variable and neither the inlet fluid temperature or the back pressure were altered during the WSR tests. Objectives of the ECS-2cE experiments were twofold. Fluid temperature and back pressure boundary conditions used are the same values used in the wall saturation tests and reflect the current best estimate values for reactor conditions. ${ }^{3}$ Also, the facility hardware was somewhat different relative to the ECS-2 system since a new inner heater was installed and instrumentation changes were effected. ECS-2cE experimental data therefore offer an opportunity to check for any systematic effects due to system hardware.

2. The majority of the ECS $-2 b$ program centered around investigation of wall saturation criteria. Two different groups of runs, the " $b$ " and "c" series, were conducted to examine conditions satisfying the wall saturation criteria.

3. Improvements in computer code predictions and changes in assumptions about the LBLOCA since the BL tests were conducted led to small changes in the best estimate boundary conditions. 


\section{RESULTS}

Excursion test results are presented in this section. An overview of a typical test will be given first to illustrate test conduct, provide a flavor for the nature of the time series data produced, and explain the data presentation format. Characteristics of the wall temperatures, pressures and differential pressures, fluid temperatures, and air entrainment are discussed. A general description of the factors influencing the wall temperature excursion is then provided. Finally, all the data recorded is summarized and $F$, sented in terms of the $R$ factor (power at the limits criteria of interest divided by the power required to saturate the fluid at the outlet of the test section). Results from both the INEL experiments and the SRS experiments are included. Appendix I contains a list of the measurements that were failed or determined to be questionable for each experiment. Appendix $J$ contains tables of data averages for the power step before excursion and the power step at which excursion occurred for all of the INEL experiments.

\subsection{Typical Test Results}

Data from Tests ECS-2BL_5 are presented to illustrate results from a typical thermal excursion experiment. This particular experiment was conducted on several different occasions and is the basis for the data repeatability discussion in Appendix F. ECS-2BL_.5 was conducted from nominal conditions of $322.7 \mathrm{~K}$ inlet fluid temperature $(45.8 \mathrm{~K}$ subcooling), an inlet flowrate of $0.1 \mathrm{l} / \mathrm{s}$ (superficial velocity of $0.075 \mathrm{~m} / \mathrm{s}$ ), and with an outlet standpipe setting of $43 \mathrm{~cm}$ referenced to the bottom of the lower plenum $(399 \mathrm{~cm}$ relative to the top of the heated length or $-18 \mathrm{~cm}$ relative to the bottom of the heated length). This test was typical of low flow tests with multiple dryout-rewet cycles before a sustained dryout and thermal excursion that occurred at a saturation ratio ( $R$ factor) significantly larger than unity.

ECS-2BL_5 was conducted using the procedure discussed in Section 3.3. After the desired inlet fluid temperature and flowrate were established, data recording was initiated, the heater power was increased to $10 \mathrm{~kW}$ and held for 5 minutes while the system came to thermal equilibrium. Power was then increased by roughly $5 \mathrm{~kW}$ increments with 1-2 minute hold periods over the next 35 minutes until thermal excursion occurred. This exporimont represented one of the more cautious approaches to test conduct 
since ECS-2BL_5 was one of the first excursion experiments conducted and expectations regarding the power at which dryout would occur were not yet clear. Test results indicated that the test section underwent a sustained dryout about 35 minutes after power was initiated at a power of $53.5 \mathrm{~kW}$.

Figure 4.1 shows a comparison of the measured electrical power and the power obtained from a thermal energy balance on the test section heated length. The thermal energy was calculated using a simple heat balance incorporating the measured inlet fluid temperature, flowrate, and fluid temperature at the exit of the heated length. On the ECS-2 facility, a cooling coil located in the lower plenum was used to maintain subcooled fluid conditions in the lower plenum as is expected in the reactor. Plenum temperature measurements were therefore not used for the energy balance. As indicated in F:gure 4.1, thermal equilibrium was achieved on the first two power steps as evidenced by the asymptotic approach of the calculated thermal power to the elecirical power. As the power was increased to $20 \mathrm{~kW}$ and above, the fluid at the outlet of the heated length reached saturation conditions as evidenced by the constant value of the

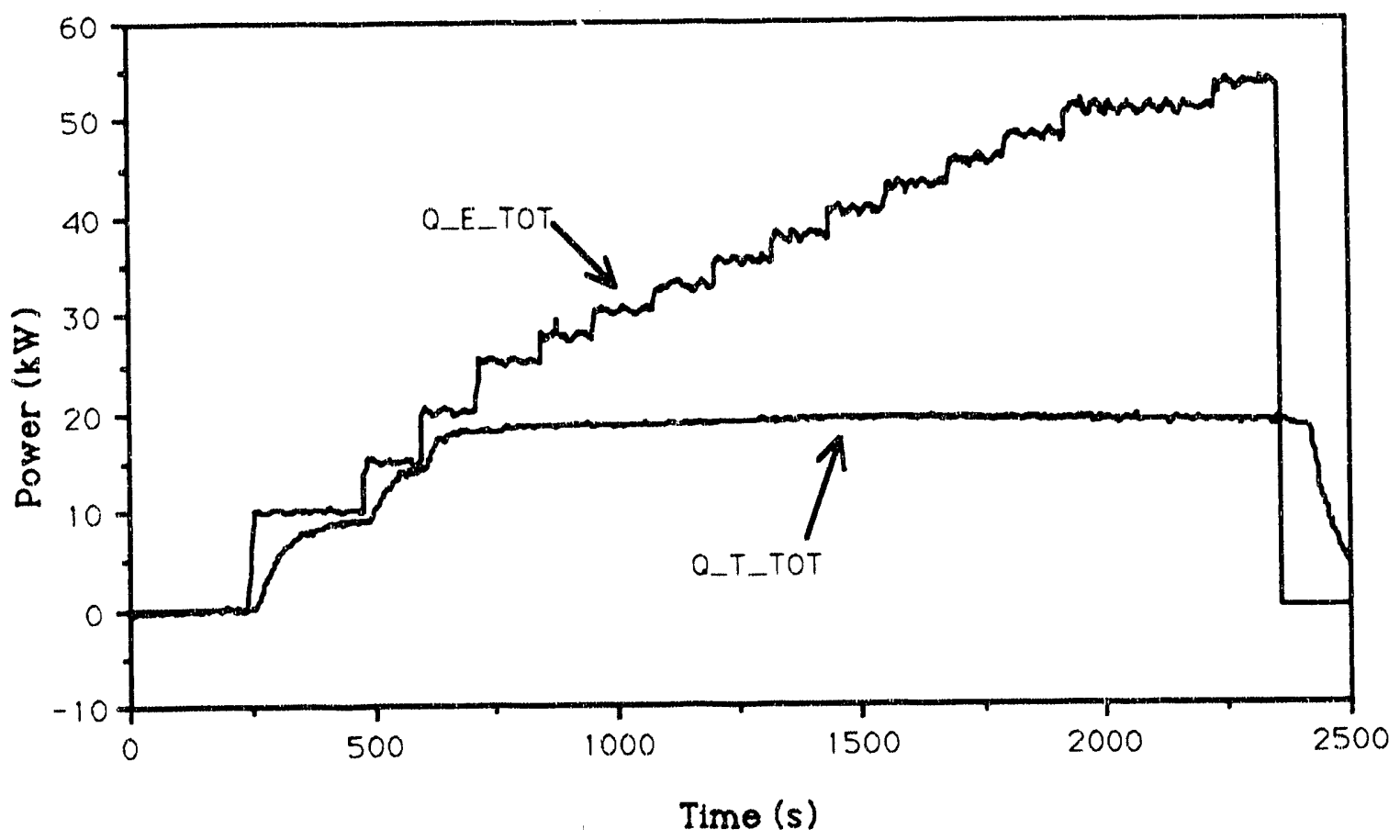

Figure 4.1. Comparison of electrical and thermal power for ECS-2BL_5 
thermal power.

A cursory examination of the data in Figure 4.1 indicates that when the excursion criteria were met, the power input to the test section was nearly three times the amount of power required to saturate the fluid at whe outlet of the heated length $(53.5 \mathrm{~kW}$ relative to $20 \mathrm{~kW}$ required to sat urate the outlet test section).

\subsubsection{Wall Temperatures}

Figure 4.2 shows the time history of an aluminum wall thermocouple at level 7 (302 $\mathrm{cm}$ location ${ }^{4}$ ) and the electrical power. The thermocouple shown is one of several at $302 \mathrm{~cm}$ that underwent sustained thermal excursion at 2360 seconds and ultimately caused the power to trip when the $620 \mathrm{~K}$ maximum temperature criterion was reached. It is interesting to note that the $302 \mathrm{~cm}$ thermocouples are on the power step just below the high power location (level 5 and 6 thermocouples are on the high power

4. Level designations for wall thermocouples do not coincide with power steps on the heater. For example, level 5 and 6 thermocouples are both on the high power zone of the heater. Refer to Figure 2.5 for general information on the wall temperature measurement locations relative to the power steps on the heater.

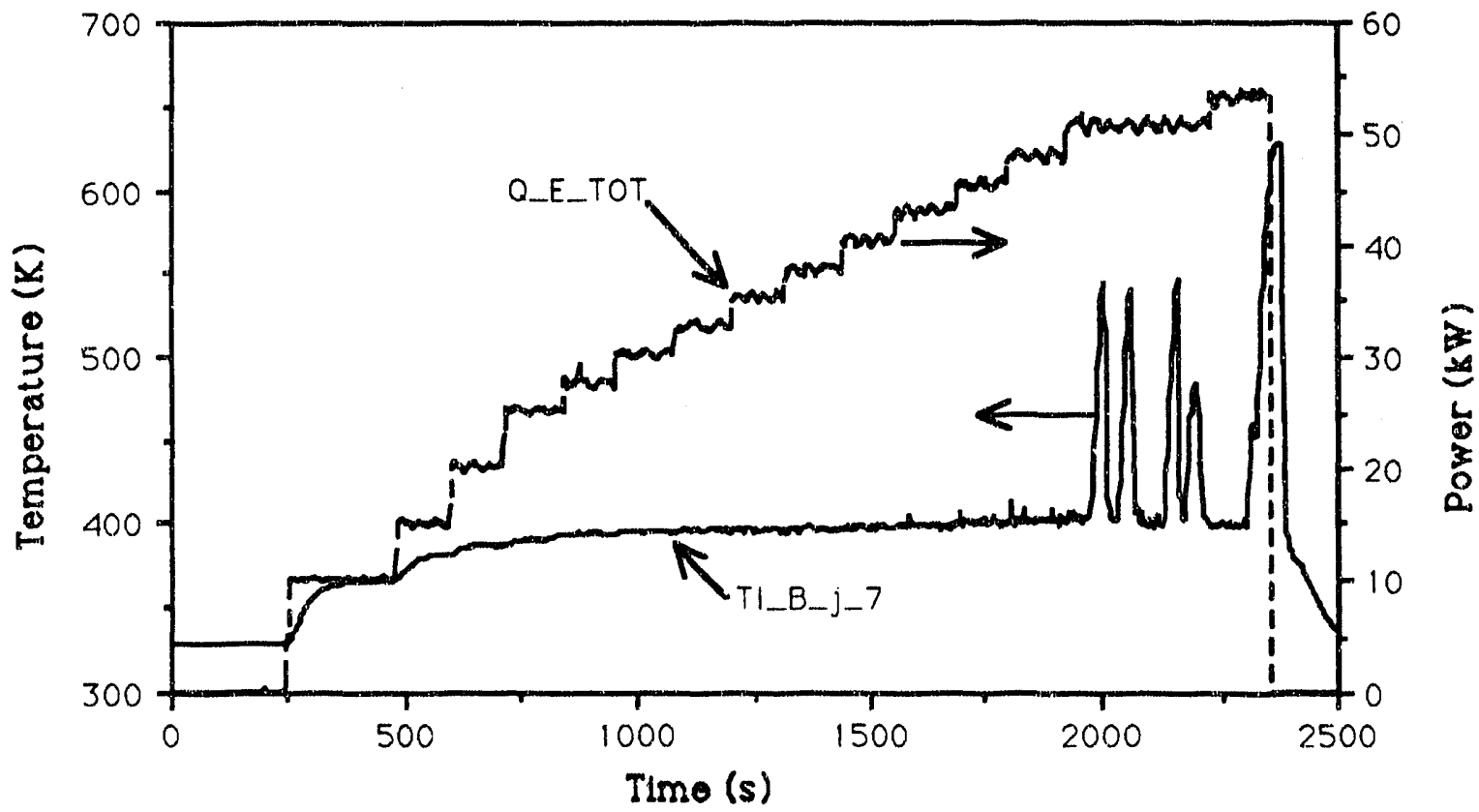

Figure 4.2. Time history of level 7 wall thermocouple and power 
zone). As discussed in Appendix F, sustained dryout did not always occur at level 7 and initiate the trip. Occasionally, level 6 thermocouples met the criteria before those at level 7 (see Figure 2.5).

As mentioned, TI_B_j_7 was one of several measurements that underwent sustained dryout during the ECS-2BL_5 test. Figure $4.3^{5}$ shows the full time history of all of the level 7 thermocouples. This comparison indicates that while there are differences in the individual thermocouple readings before the sustained dryout, the dryout is azimuthally uniform at the $302 \mathrm{~cm}$ location. Further proof of the azimuthal uniformity is shown in Figure 4.4, which is a comparison of the same data as Figure 4.3 on an expanded time scale.

Level 7 thermocouple data shown in Figures $4.2-4.4$, indicate that several temporary dryouts occurred before the final attainment of the trip criteria. Wall temperatures of approximately $550 \mathrm{~K}$ were reached during these excursions before rewetting occurred and cooled the wall back to approximately $400 \mathrm{~K}$. Data shown on the expanded time scale in Figure 4.4 indicates that the dryout-rewet cycles were azimuthally uniform since all the thermocouples show dryout and rewet during the same time periods.

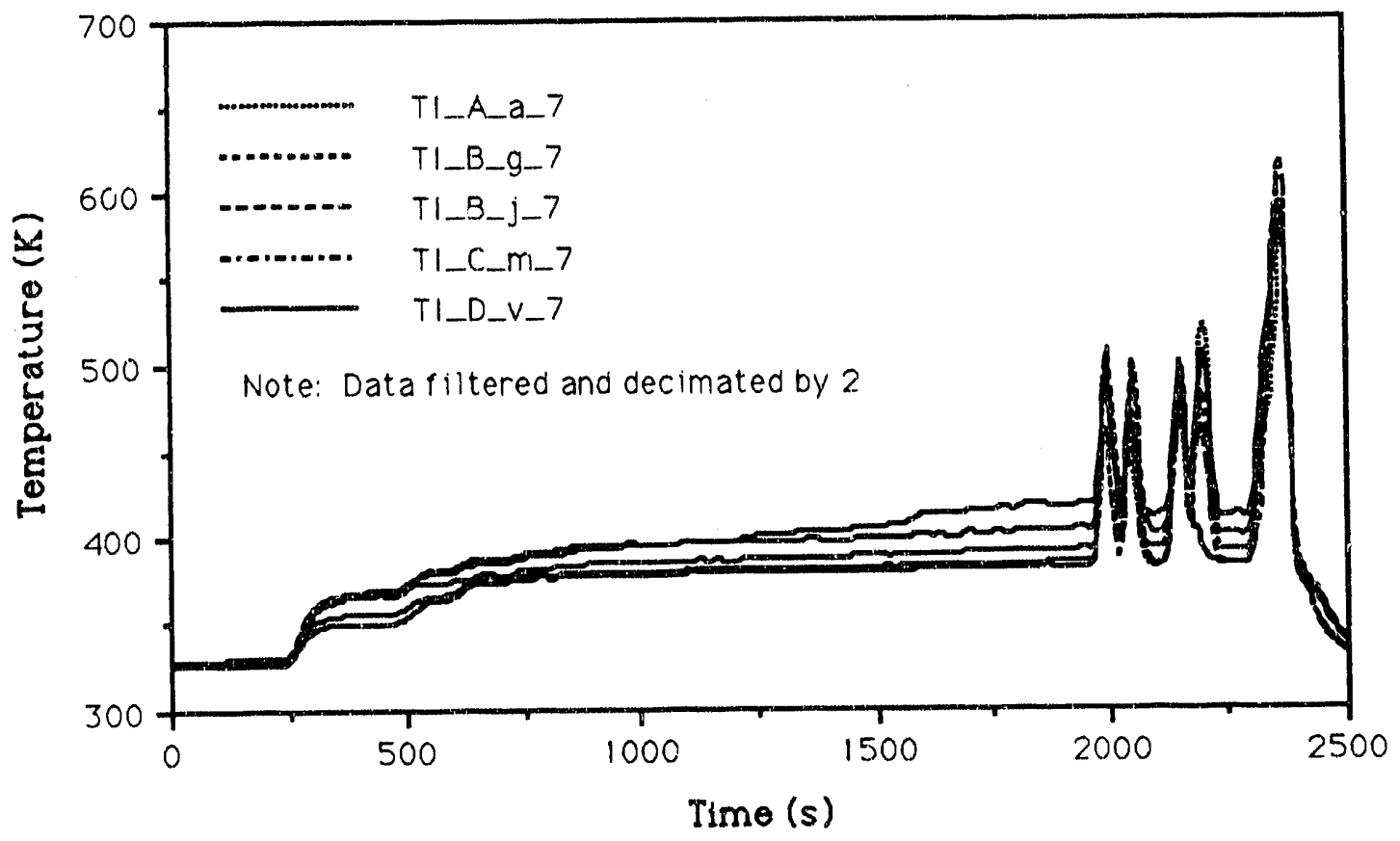

Figure 4.3. Full time history of all level 7 thermocouples for ECS-2BL_5 


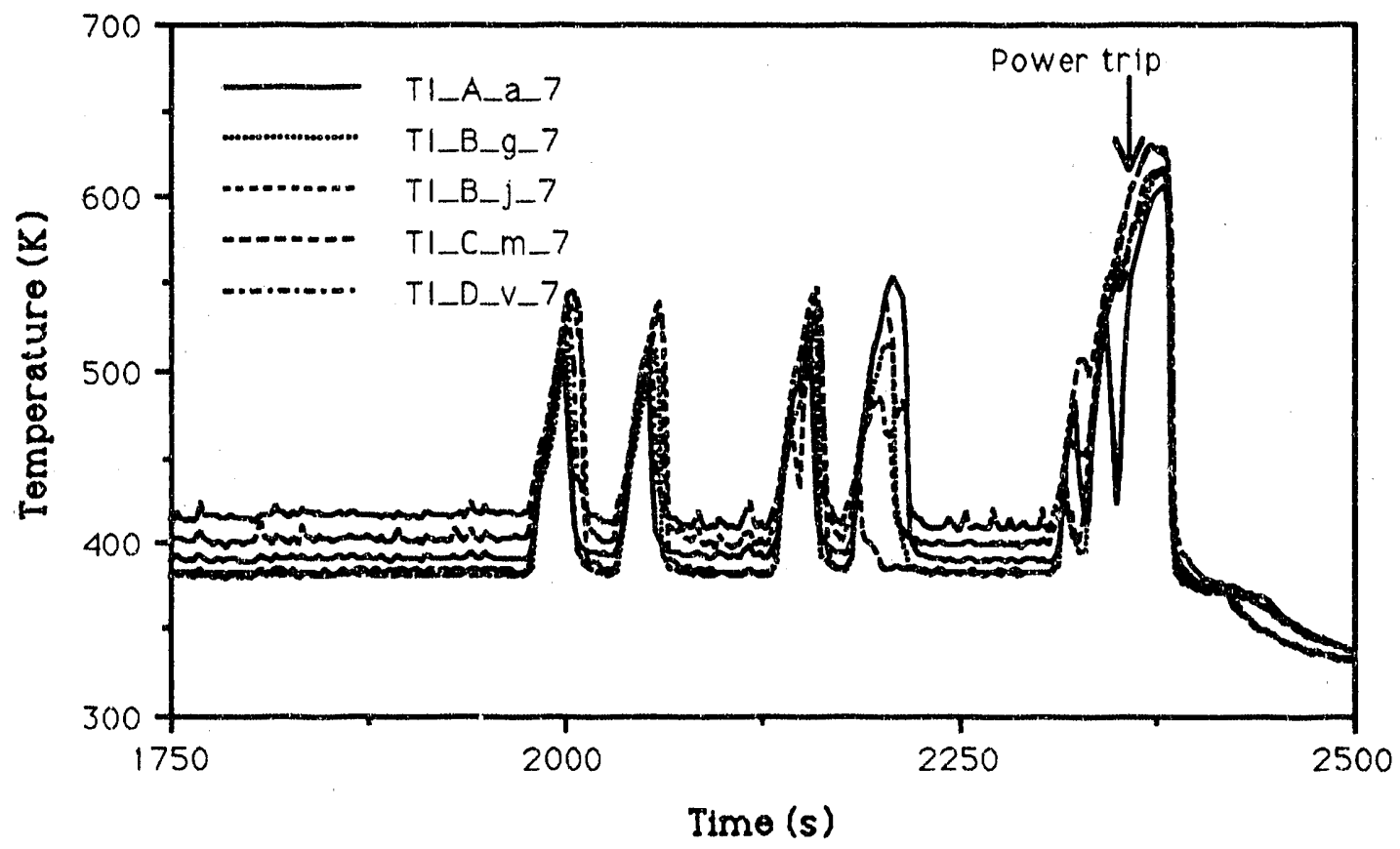

Figure 4.4 Expanded time scale comparison of level 7 thermocouples for ECS-2BL_5

The point at which the power tripped (due to exceeding the temperature criteria) is shown in Figure 4.4. Wall temperatures continued to increase even after the power had tripped because of significant stored energy in the test section.

Thermocouples at level 7 were not unique with respect to the multiple occurrences of the dryout-rewet cycle. Measurements at other levels throughout the heated length showed several cycles of dryout with subsequent rewet. Figure 4.5 demonstrates this feature by showing the axia! distribution of measured wall temperatures at the " $\mathrm{j}$ " azimuthal location $\left(135^{\circ}\right)$ in the $\mathrm{B}$ flow channel for Test ECS-2BL_5. The data are displayed on an expanded time scale encompassing the initiation of the dryout-rewet cycles and the final sustained excursion. Although it is difficult (and not necessary) to discern individual thermocouple traces on this figure, it is obvious that thermocouples at all levels except level 1 , which is on a low

5. Data was filtered using a finite-impulse-response low band pass filter and then decimated (every nth point was kept) to reduce the total volume of data for ease of plotting. 


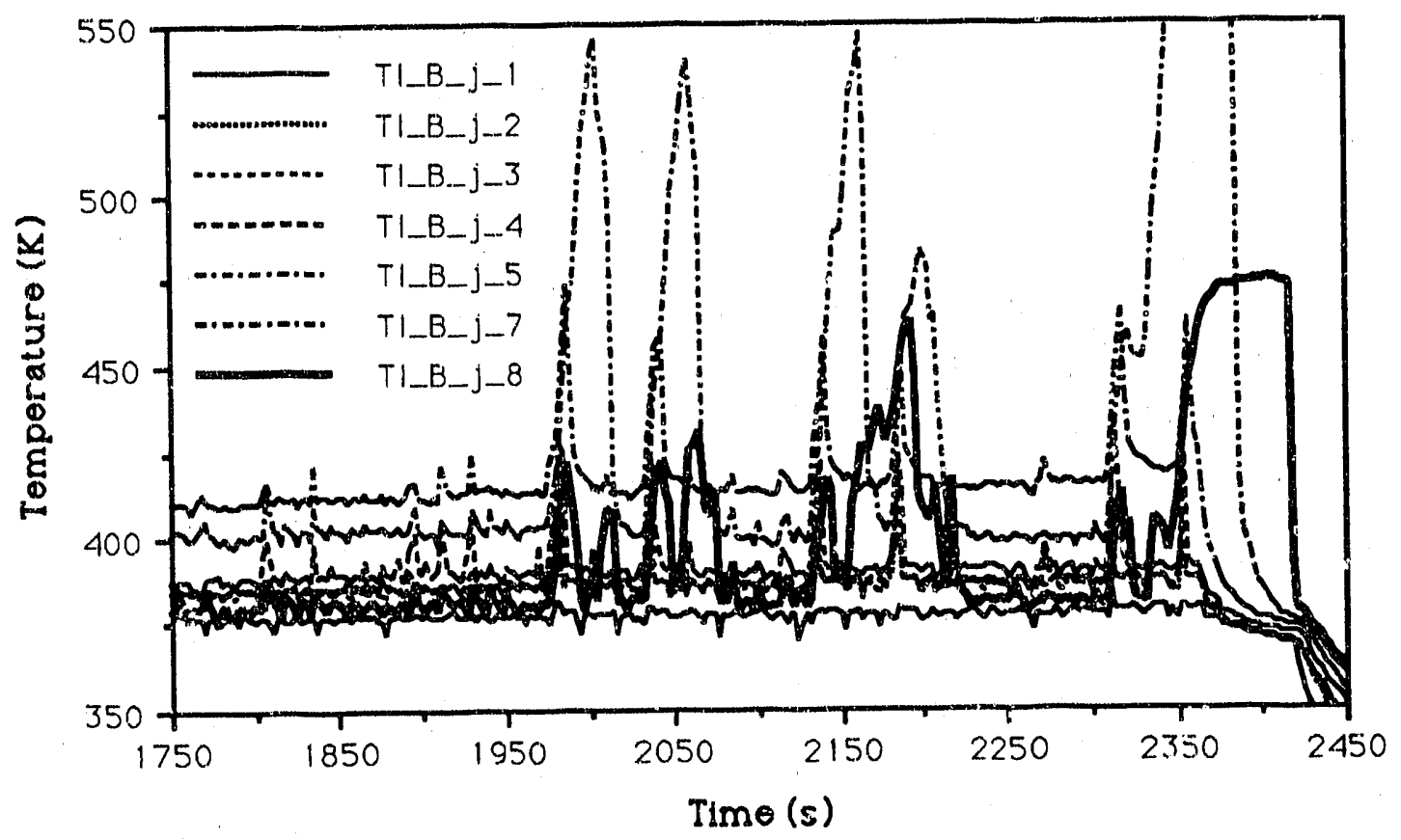

Figure 4.5. Wall thermocouple response in B subchannel for ECS-2BL_5

power step at the top of the heated length, show four or more temporary excursions followed by rewets. Results from the D flow channel, which also had a full axial compliment of wall thermocouples at the same azimuthal location (position "v" or $315^{\circ}$ ), are very similar to those in the B flow channel shown in Figure 4.5.

\subsubsection{Pressures and Differential Pressures}

Figure 4.6 shows the inlet plenum and the outlet plenum absolute pressure measurements compared to the measured local atmospheric pressure. Since the inlet plenum is open to the atmosphere, the pressure measured there is nearly identical to atmospheric pressure. Figure 4.7 shows the inlet and outlet plenum and the standpipe levels computed from the measured differential pressures across these components (Appendix E provides documentation on the calculation procedure). As shown, the inlet plenum head is less than $2 \mathrm{~cm}$ of water whereas the outlet plenum level is $28 \mathrm{~cm}$ indicating that it is basically full. As noted in Section 4.1 , the standpipe was set to provide a back pressure of approximately $43 \mathrm{~cm}$ of water relative to the bottom of the outlet plenum for ECS-2BL_5. The standpipe 


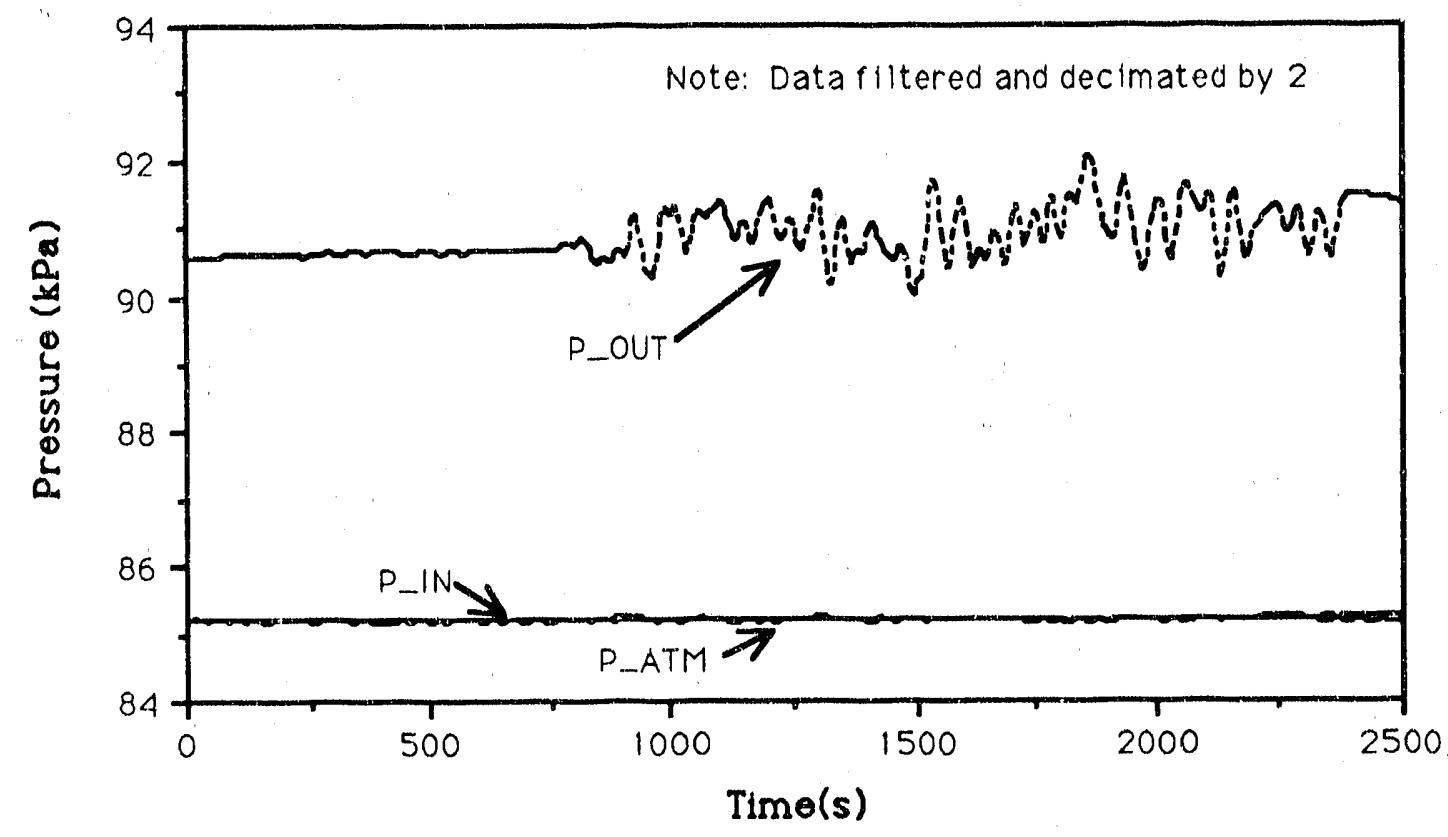

Figure 4.6. Comparison of inlet and outlet plenum pressures with local atmospheric pressure for Test ECS-2BL_5

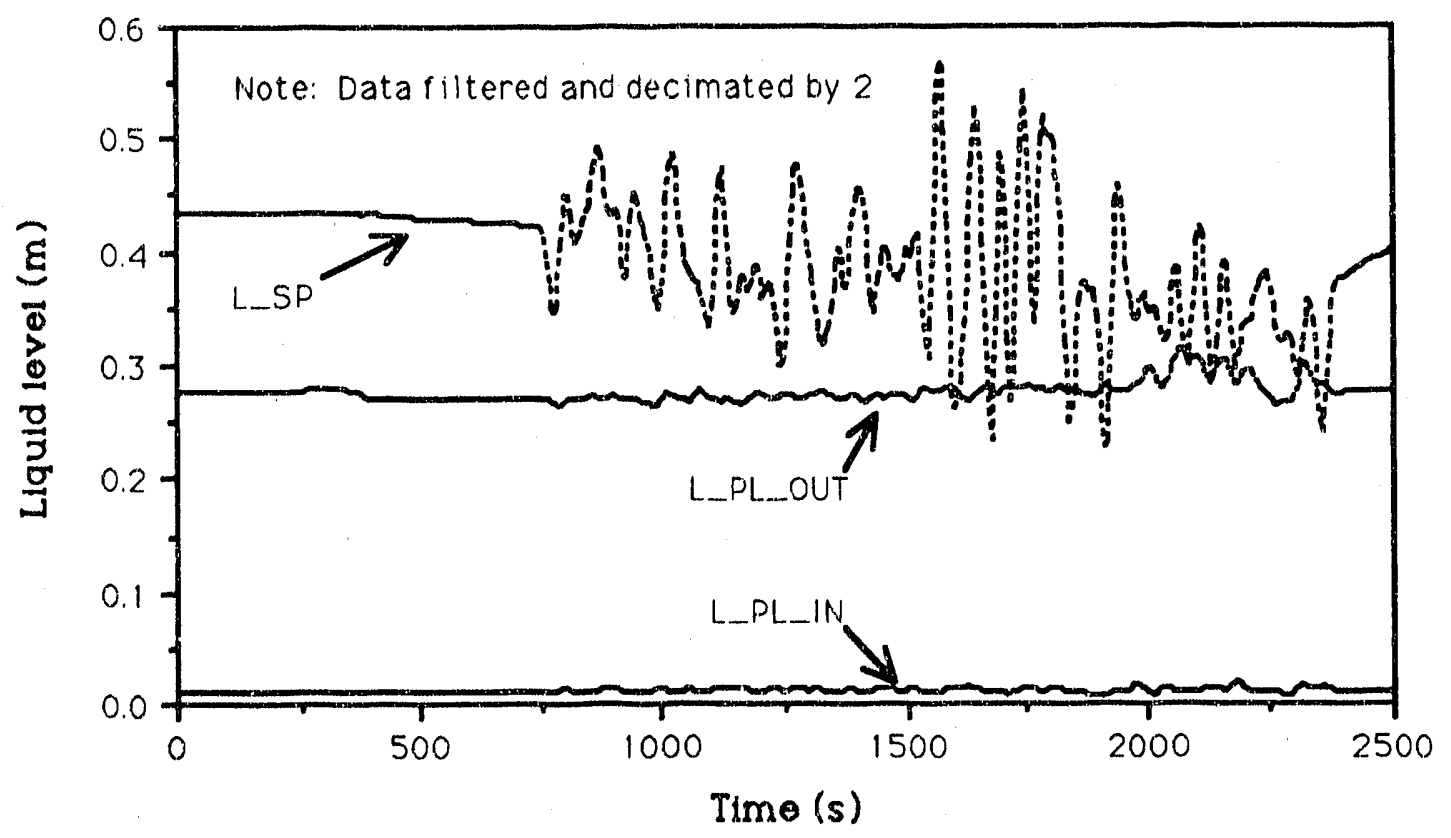

Figure 4.7 Inlet and outlet plenum levels for ECS-2BL_5 
level shown in Figure 4.7 verifies the level setting.

As expected, pressure and differential pressure measurements in the test section showed substantial oscillation during the experiment, particularly after saturation conditions were achieved at the outlet of the heated length. As will be illustrated in the next section, the liquid at the outlet of the heated length reached saturation conditions just after 750 seconds. Substantial vapor generation and holdup ensued resulting in a churn-turbulent flow regime in the test section. The unsteady nature of the local flows caused the fluctuations noted in the measurements. Although not evident on ECS-2BL_5, the holdup in the test section for many experiments was sufficient to cause the iniet plenum level to increase significantly.

For Test ECS-2BL_5, an absolute pressure measurement was located in each subchannel at the beginning of the heated length. These measurements suffered from zero offsets during this test and the data are not presented here. Instead, data from Test ECS-2BL_5B (conditions on BL_5B are identical to those on $\mathrm{BL}_{-} 5$ as discussed in Appendix $F$ ) are presented in Figure 4.8. Data from these two tests are directly comparable until about 1600 seconds. In order to prevent undue clutter on the figure, only the data from the $B$ and $D$ subchannels is shown since the response of each measurement is very similar. The pressure behavior is consistent with the wall temperature measurements presented in Section 4.1 .1 in that there is azimuthal uniformity in the oscillations even though at any given time, there are slight differences in magnitude. It should be noted that the pressure data from Test ECS-2BL_5 showed the same basic response with the exception that due to an electronics problem, the magnitudes were 30 $\mathrm{kPa}$ above atmospheric pressure.

From the data shown in Figure 4.8, at is apparent that the pressure at the inlet to the heated length increased slightly (1-2 $\mathrm{kPa})$ when the test section outlet became saturated at 750 seconds. Although the increase is minor, it is consistent with visual observations during the experiment that suggested water accumulation (void fraction was decreasing slightly) in the unheated part of the test section between the bottom of the inlet plenum and the entrance to the heated length. This observation is consistent with the expected increase in two-phase pressure drop through the test section in light of local flooding noted along the heated length. 


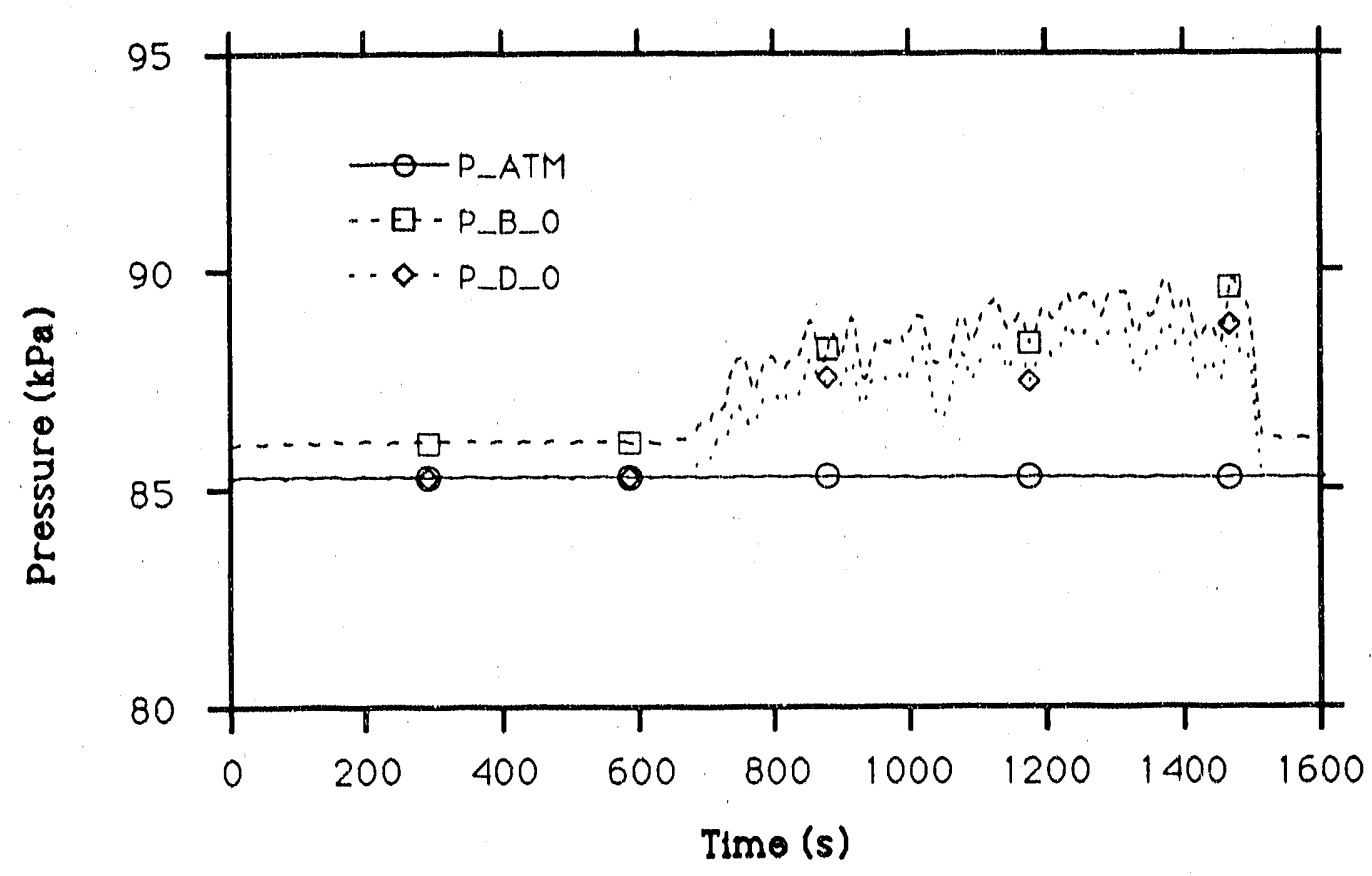

Figure 4.8. Comparison of subchannel pressure measurements at the entrance to the heated length for Test ECS-2BL_5B

Differential pressures measured from the top to the middle of the heated length $(0-$ to $188-\mathrm{cm})$ are shown in Figure 4.9. Data in Figure 4.9 show that the differential pressures in the $A$ and $B$ subchannels are different than the differential pressures in the $C$ and $D^{6}$ subchannels after saturation conditions are reached at the outlet of the heated length. For example, the measured differential pressures in the $C$ and $D$ channels show a slight increasing trend after 750 seconds whereas the differential pressures in the $A$ and $B$ channels indicate a continual decrease until the power was tripped at 2360 seconds. Close scrutiny of Figure 4.9 indicates that at least part of the time, the differential pressure oscillations in the $C$ and $D$ channels are out of phase with the oscillations in the A and B channels. These data are consistent with visual observations that indicated churn-turbulent flow in the test section, channel-to-channel flow variations, channel-to-channel azimuthal flows, and localized flooding.

The data in Figure 4.9 indicate that the upward flow of vapor was preferentially in subchannels $C$ and $D$, resulting in higher void fractions and

6. The D subchannel differential pressure shown is the summation of individual differential pressure measurements from 0 to $188 \mathrm{~cm}$. 


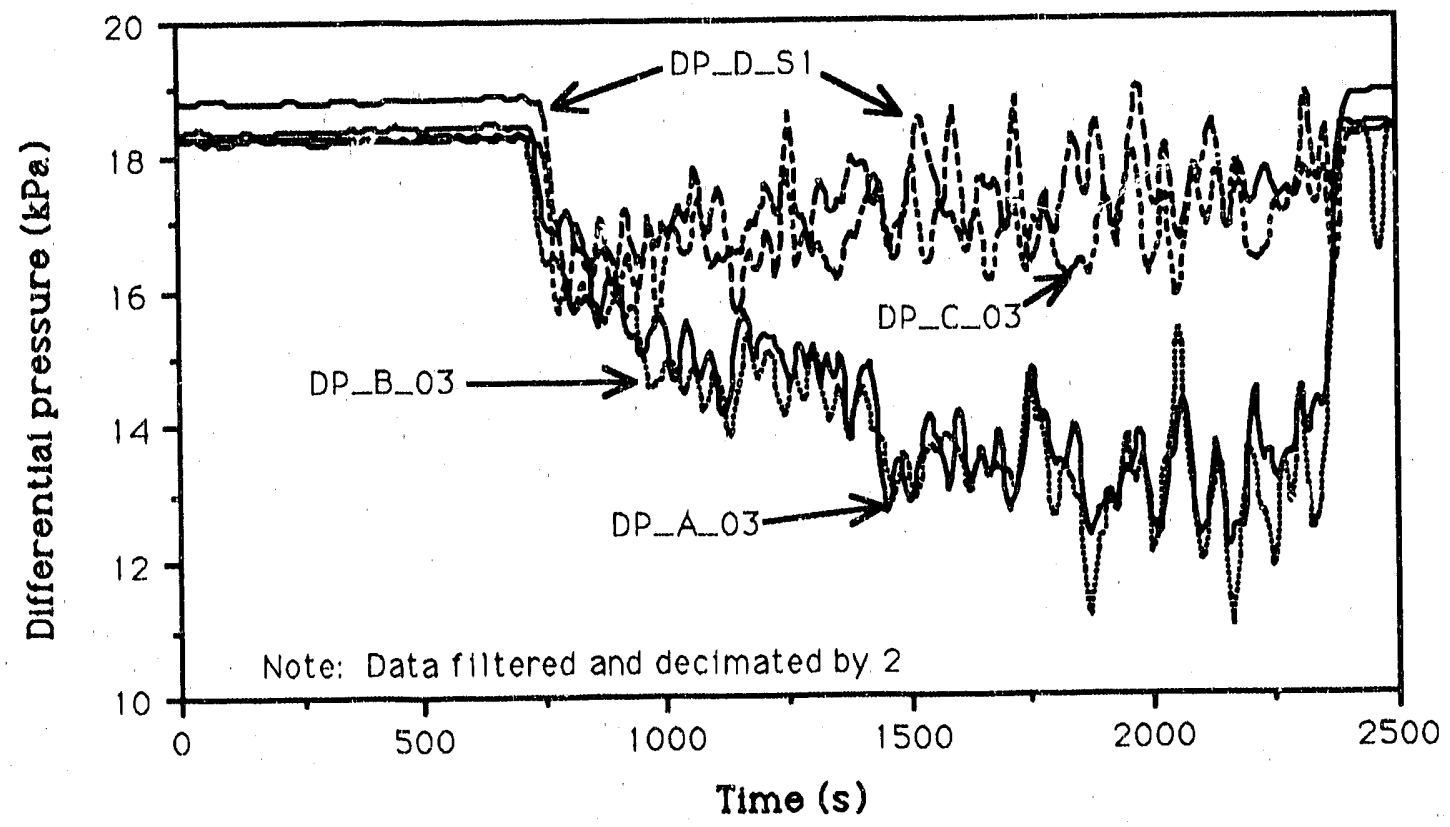

Figure 4.9. Differential pressures in upper half of the heated length for Test ECS-2BL_5

thus higher differential pressures. Differential pressure measurements were zeroed with the reference legs valved out and the legs equalized. Therefore, the measured differential pressure reflects the difference in hydrostatic heads of the reference legs for an empty test section and gives a zero reading for a full test section. Increasing void fraction, therefore, causes increasing differential pressure readings.

Figure 4.10 shows results from differential pressures measured from the middle of the heated length to the bottom of the heated length $(188-\mathrm{cm}$ to $381-\mathrm{cm})$. In the lower half of the heated length, the differential pressures in the $A, B$, and $C$ subchannels are similar while the differential pressure in the $D$ subchannel is different. Again, the response of the differential pressures is consistent with visual indications suggesting somewhat more uniform azimuthal behavior in the lower half of the test section relative to the upper half of the test section. 


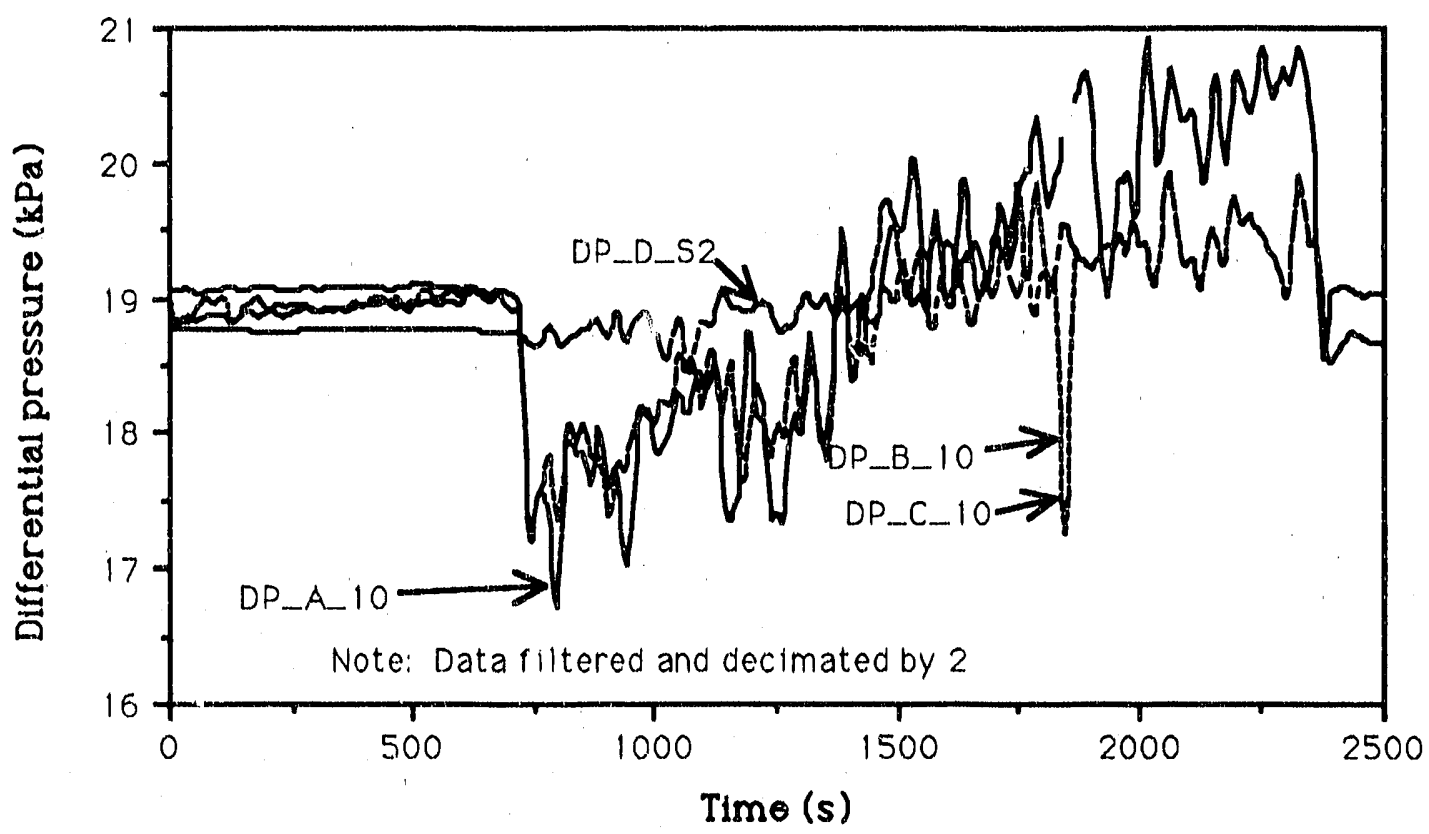

Figure 4.10. Differential pressures in the lower half of the heated length for Test ECS-2BL_5

\subsubsection{Fluid Temperatures}

Fluid temperatures in the inlet plenum, the outlet plenum, and the outlet of the heated length are shown in Figure 4.11 along with the saturation temperature. Saturation temperature is computed using the outlet plenum pressure. The heated length outlet temperature (TF_04_AV) is the average of the four fluid thermocouples located at the $394 \mathrm{~cm}$ elevation (see Appendix E for discussion of the calculated parameters).

Two points are notable with respect to the data shown in Figure 4.11. First, as mentioned in previous sections, the bulk fluid at the outlet of the heated length went saturated at approximately 750 seconds. Bulk satura. tion conditions are evidenced by the asymptotic approach of the data from TF_04_AV to the calculated saturation temperature. Second, the response of TF_OUT indicates that subcooled conditions were maintained in the outlet plenum as desired for the majority of the experiment. As described in Section 2.1, a cooling coil located in the outlet plenum was used to condense steam that entered the plenum in order to prevent steam from compromising the exit air flow measurements. 


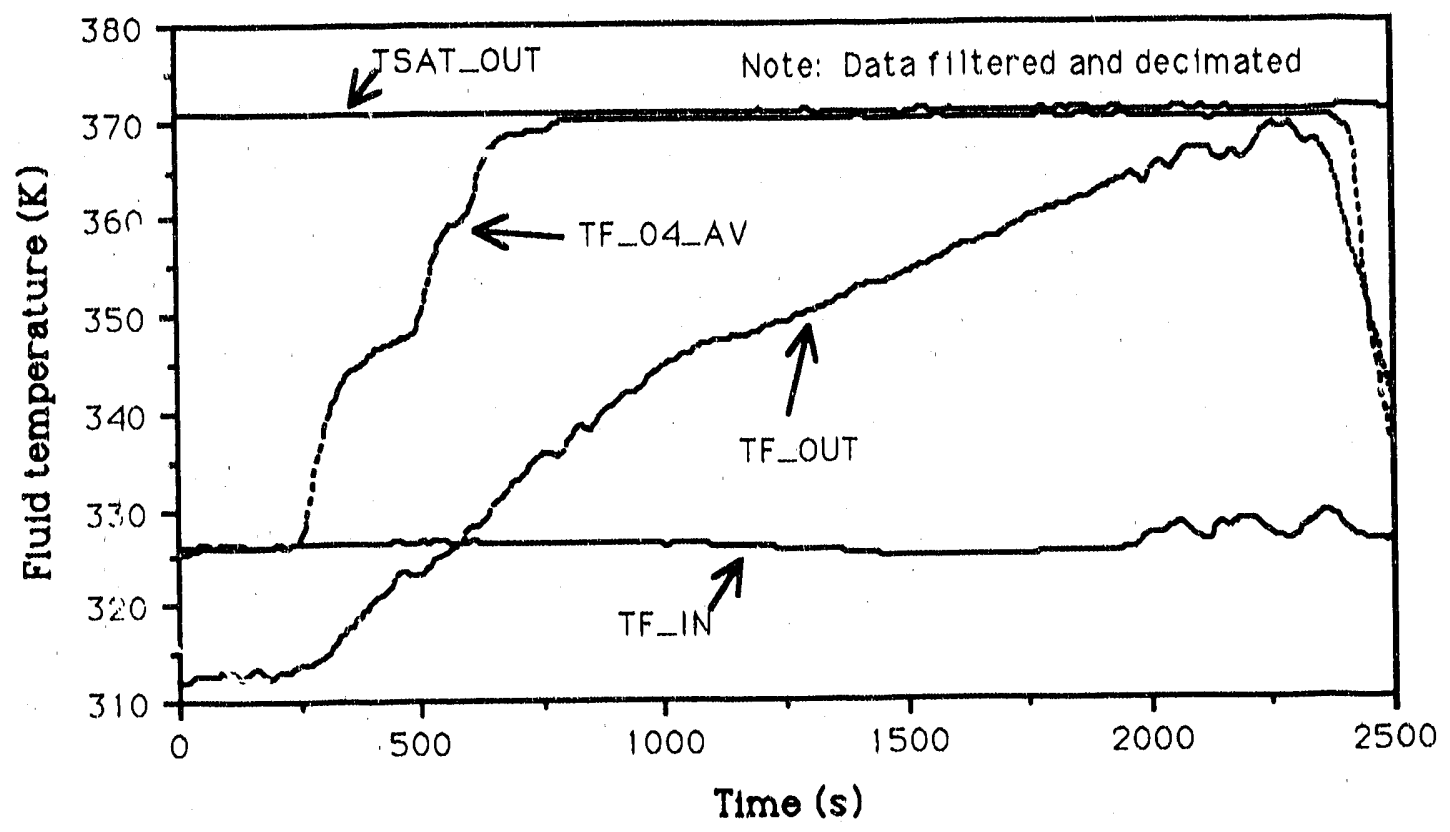

Figure 4.11. Plenum and heated length outlet fluid temperatures for Test ECS-2BL_5

In addition to the fluid temperature measurements at $394 \mathrm{~cm}$ (TF_04_AV in Figure 4.11), fluid thermocouples were located at three other axial positions along the heated length for Test ECS-2BL_5. At each axial location (64-, 183-, 257- and $391 \mathrm{~cm}$ below the top of the heated length), one fluid thermocouple was installed in the center of each flow channel. Figure 4.12 shows a comparison of the averages of all four thermocouple readings at each axial location along with the saturation temperature based on outlet plenum pressure. The data $n$ Figure 4.12 are shown on an expanded time scale to accentuate the axial fluid temperature distribution before saturation conditions were achieved. Consistent with the comparison of electric and calculated thermal power shown in Figura 4.1, it is evident that all the fluid in the test section was saturated by 750 seconds. Before 750 seconds, the axial fluid temperature distribution is interesting in that the average fluid temperature at $257 \mathrm{~cm}$ is somewhat higher than the temperature at $391 \mathrm{~cm}$ although the uncertainty bands $( \pm 3.3 \mathrm{~K})$ on the fluid temperatures overiap. Also one must recall that the test section power is changing in discrete steps over time and true steady-state conditions may not have been achieved at all the power steps. 


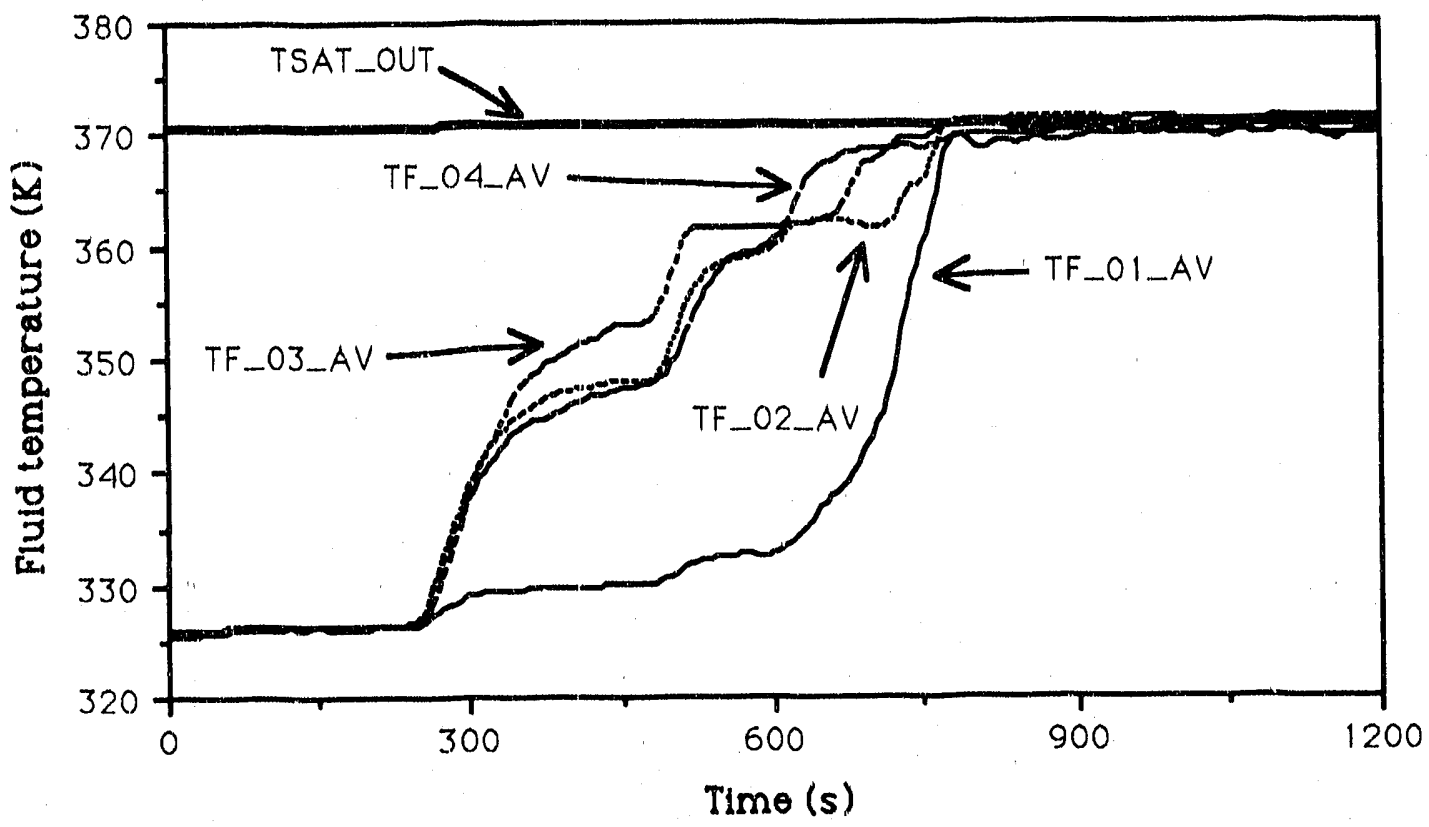

Figure 4.12. Axial fluid temperature distribution for Test ECS-2BL_5

The most significant observation from Figure 4.12 is that all the fluid temperatures indicate saturation conditions beyond 750 seconds. As discussed previously, since the thermal excursion occurred much later in time, long after the fluid in the test section had reached saturation conditions, it is apparent that neither axial or azimuthal fluid temperature distribution had much impact on the occurrence of excursion.

Figure 4.13 compares each fluid temperature at the $257 \mathrm{~cm}$ (level 3 ) location. Data in Figure 4.13 show that before attaining saturation conditions, the $C$ subchannel fluid temperature is higher relative to the other channels. This same relationship was noted at the other three levels where fluid subchannel temperature measurements were made and suggests preferential flow channeling. Such behavior seemed to be more prevalent for the lower flowrate experiments as will be discussed below.

During the time period between 750 and 2500 seconds, all the fluid temperature measurements in the test section showed oscillatory behavior with spikes suggesting superheated vapor conditions. Figure 4.14, which shows the same data as Figure 4.13 on an expanded time scale, illustrates 


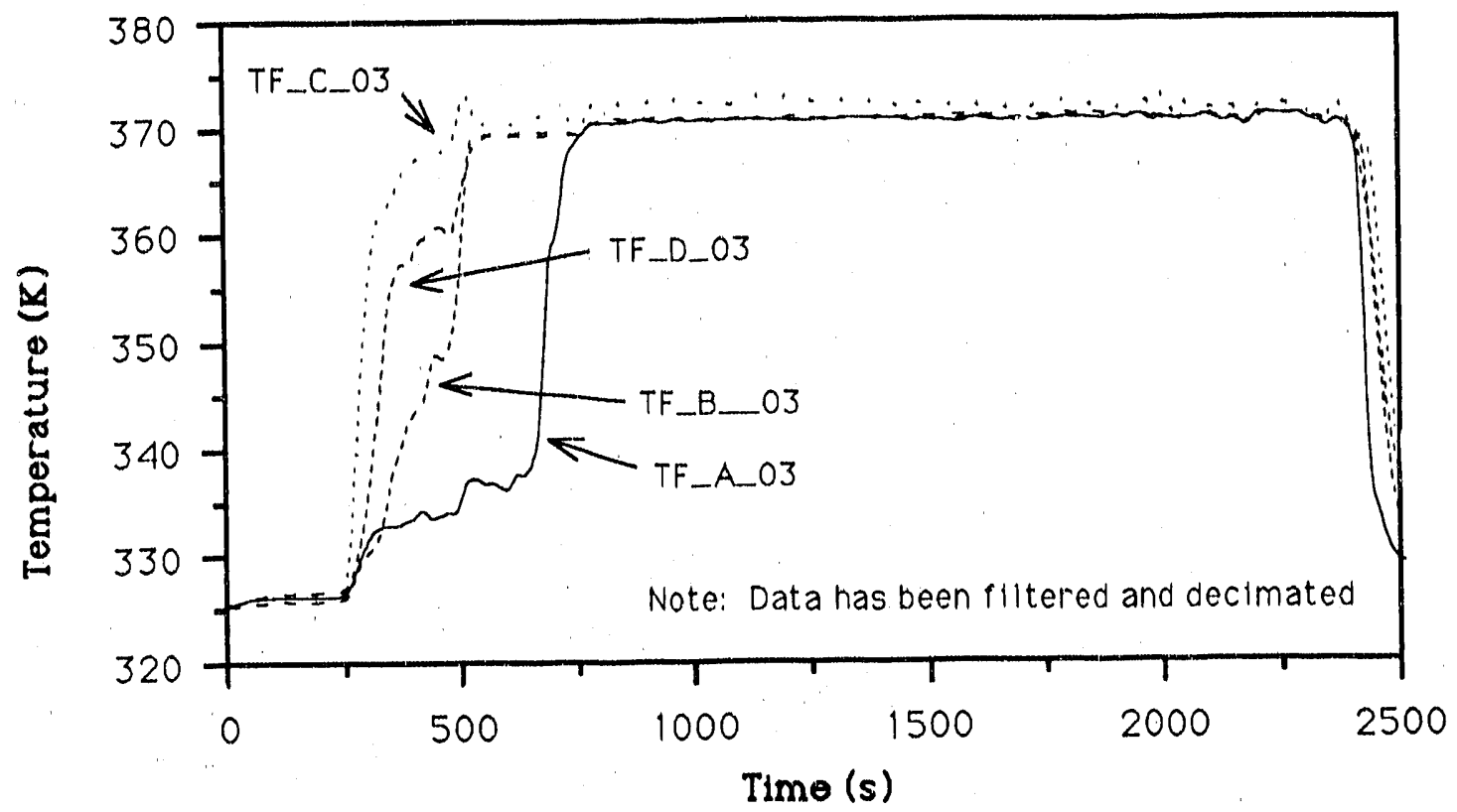

Figure 4.13. Comparison of fluid thermocouples at $257 \mathrm{~cm}$ for Test ECS-2BL_5

the temperature spikes even though the data presented has been filtered and decimated for graphical presentation.

\subsubsection{Air Entrainment}

Air entrainment was noted to be a strong function of the liquid flowrate on the excursion tests as is discussed in detail in Appendix G. For low liquid flows $(<0.51 / \mathrm{s}$ [superficial velocity $<0.38 \mathrm{~m} / \mathrm{s}$ ] $)$, the air entrainment was essentially zero. On Test ECS-2BL_5, the liquid flowrate was $0.1 \mathrm{1} / \mathrm{s}$ (superficial velocity of $0.075 \mathrm{~m} / \mathrm{s}$ ) and, as shown on Figure 4.15 , the air flowrates at the inlet and outlet were near zero until the dryout-rewet cycles started at 2000 seconds. On this particular test, the measured air flowrates are essentially in the noise of the measurement device until significant thermal excursions ensued. Agreement between the inlet and outlet measurement is representative of the response of the air flow measurements observed on other excursion tests.

As is clearly indicated on Figure 4.15 , both the inlet and outlet air measurement response becomes more erratic as saturation conditions were 


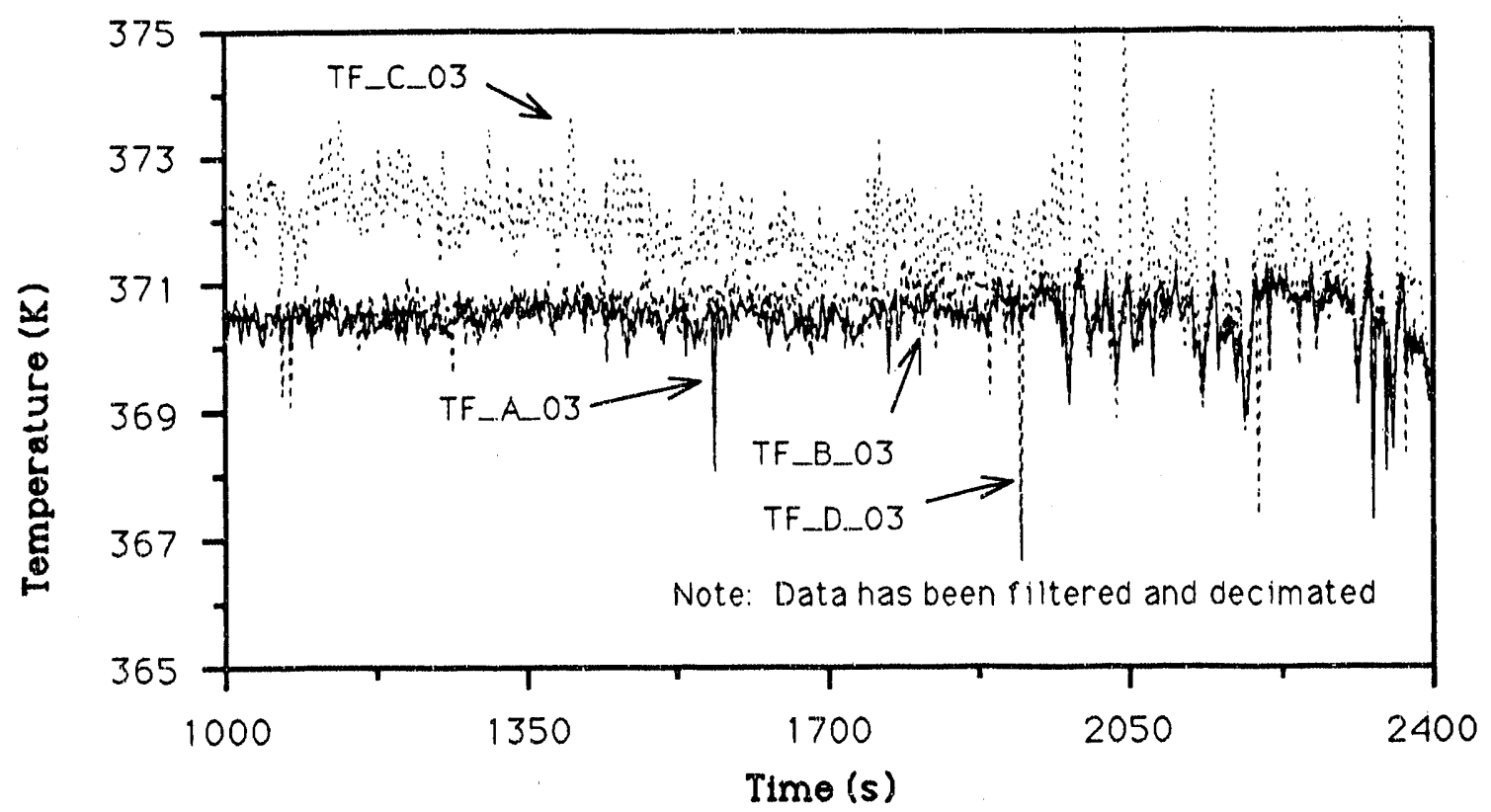

Figure 4.14. Expanded time scale comparison of fluid temperatures at $257 \mathrm{~cm}$ for Test ECS-2BL_5

achieved in the test section and when the dryout-rewet cycles started. This behavior is consistent with the observations of slugging (churn-turbalent flow) and flow reversals resulting from flooding during the dryout/rewet cycles in the test section.

\subsubsection{Azimuthal Wall Temperature Variation}

As was noted in Section 4.1.1, an interesting feature of the aluminum heater wall thermocouple response during the excursion tests conducted at the INEL was the variation among the indicated temperatures at a given axial location. This behavior was addressed in detail in connection with experiments conducted to examine the wall saturation temperature criteria [11] and is currently the subject of analysis for those experiments [12].

As was shown in Figures 4.3 and 4.4 , the spread between the highest and lowest thermocouple readings at the $302 \mathrm{~cm}$ (level 7) was on the order of $30 \mathrm{~K}$. Some spread in the wall temperature readings was noted at all of the axial levels. This spread was maintained up to the time that the sustained excursion occurred. To illustrate this spread, Figure 4.16 shows 


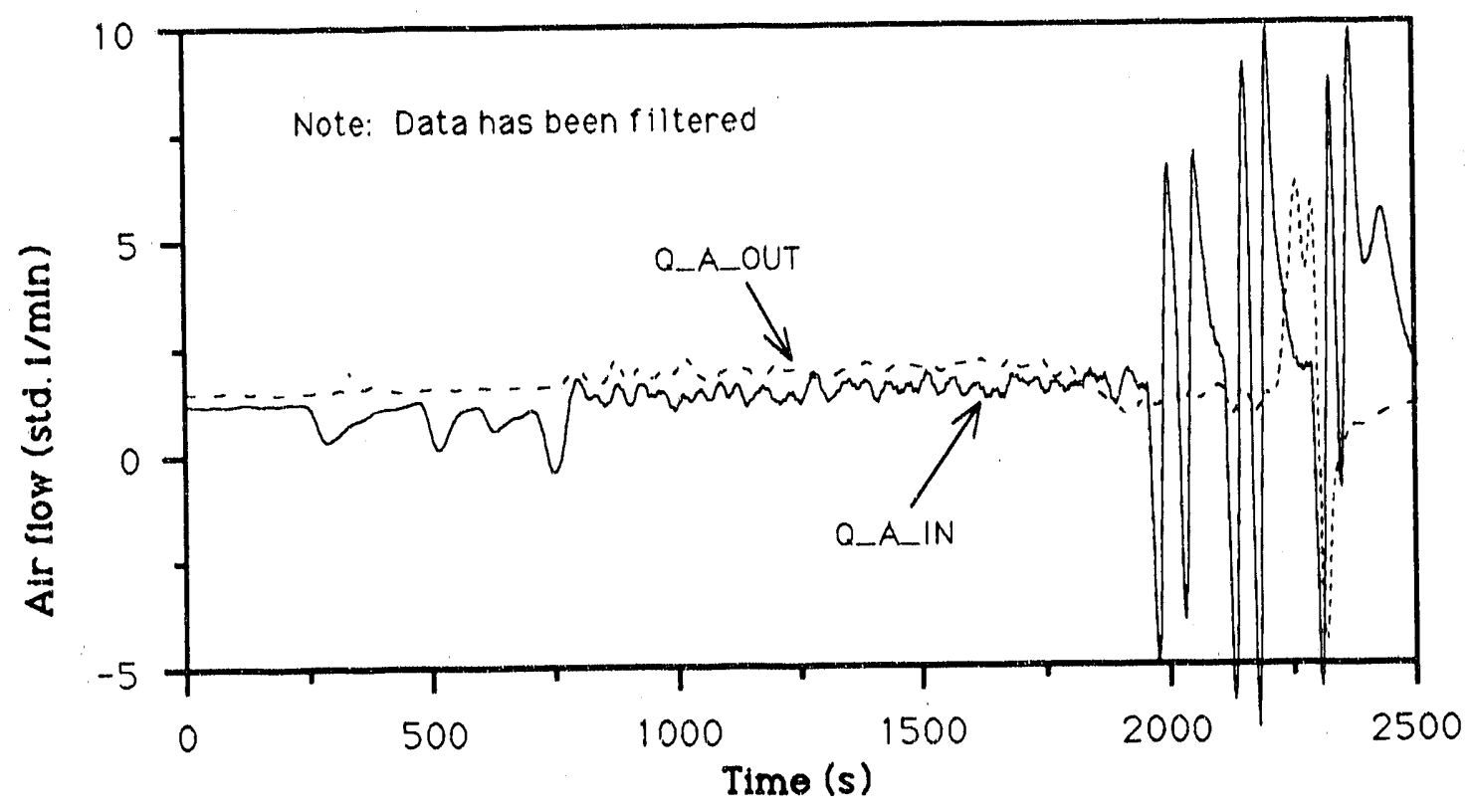

Figure 4.15. Air inlet and outlet flowrates for Test ECS-2BL_5

20 second averages $(2210-2230$ seconds) of all the wall temperature measurements during the power setting $(50.9 \mathrm{~kW})$ just before the setting $(53.4 \mathrm{~kW})$ on which sustained excursion occurred. With the exception of the thermocouples at level 7 , the data shown in Figure 4.16 represents averages computed during a time period when the walls were wetted. Because of the frequency of the dryout-rewet cycles, no time frame could be located wherein all level 7 thermocouples were wetted.

The data in Figure 4.16 show reasonable azimuthal uniformity given the violent oscillatory nature of the hydraulic processes. For example, thermocouples at the high power zone (levels 5 and 6 ) have a spread of approximately $20 \mathrm{~K}$. For reference, the overall average of the level 5 and 6 data shown in Figure 4.16 for the $2210-2230$ second time frame was 405 and $399 \mathrm{~K}$, respectively. Figure 4.17 displays the same type of averaged wall thermocouple information during the power step on which sustained excursion occurred. Note that the level 7 thermocouples underwent a sustained dryout during this time frame. The average of the thermocouple averages at levels 5 and 6 are 416.6 and $417 \mathrm{~K}$, respectively. It is interesting to note from Figures 4.16 and 4.17 that the average wall temperaiúres in the $C$ subchaninel $\left(180^{\circ}\right.$ to $\left.270^{\circ}\right)$ are somewhat higher relative to 


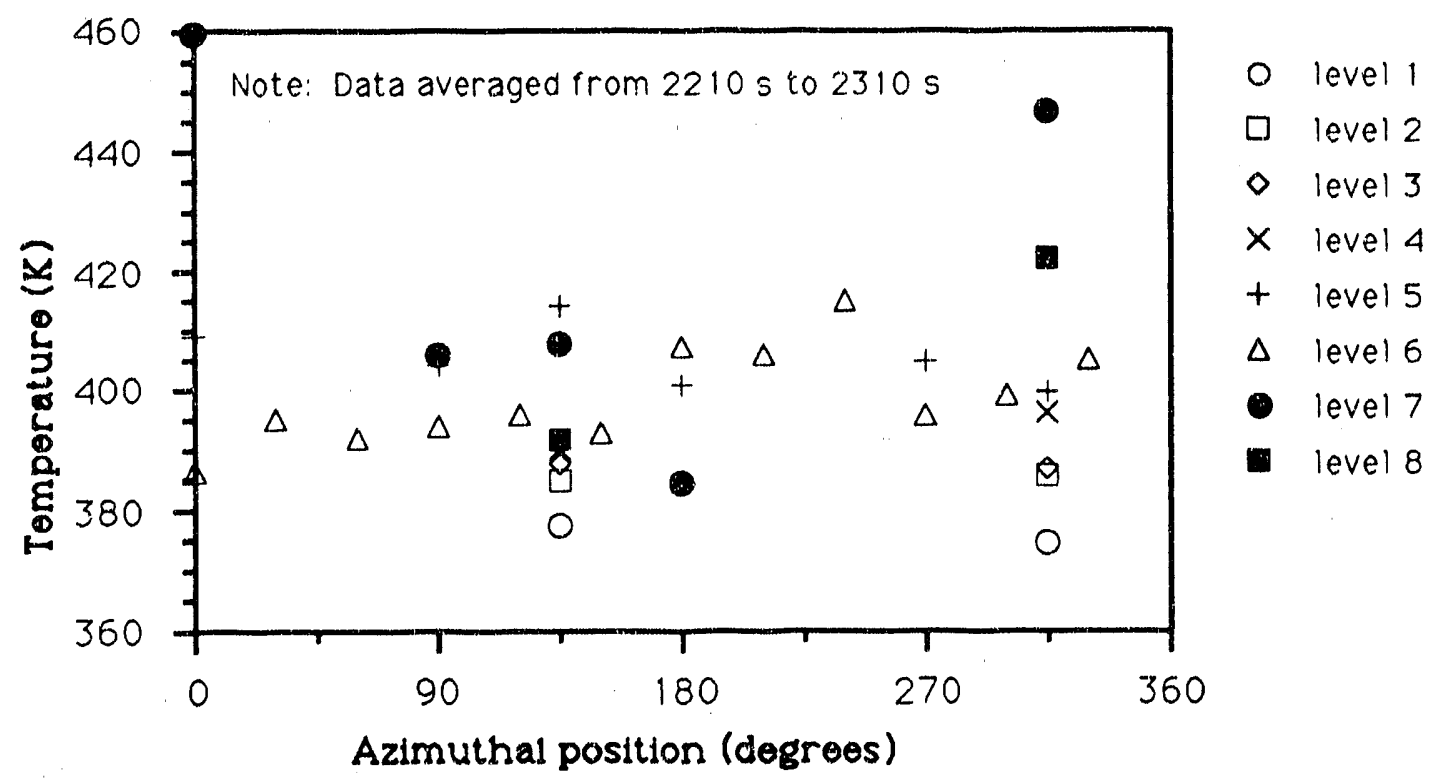

Figure 4.16. Azimuthal temperature distribution during power step just before excursion power step for Test ECS-2BL_5

the other azimuthal positions. This is consistent with the fluid temperature distribution discussed previously. Figure 4.18 shows fluid temperature averages computed for the $2210-2230$ second time frame. Within the uncertainty of the fluid temperature measurements, all of the readings indicate saturation conditions. Tables $4.1,4.2$, and 4.3 list pertinent statistics for all of the aluminum wall and test section fluid thermocouples for the data presented in Figures 4.16, 4.17, and 4.18.

\subsection{Overall Test Results}

A primary objective of the thermal excursion experiments conducted at the INEL was to determine the conditions under which the aluminum wall of the test section underwent a sustained thermal excursion. In this section, the overall results of the excursion tests are presented. Effects of the primary variables (inlet fluid temperature, flowrate, and test section back pressure) and some secondary variables on the excursion are discussed. Finally, results from the INEL experiments including data from the ECS-1 excursion tests [10] and ECS-2b wall saturation tests [11] are compared. 


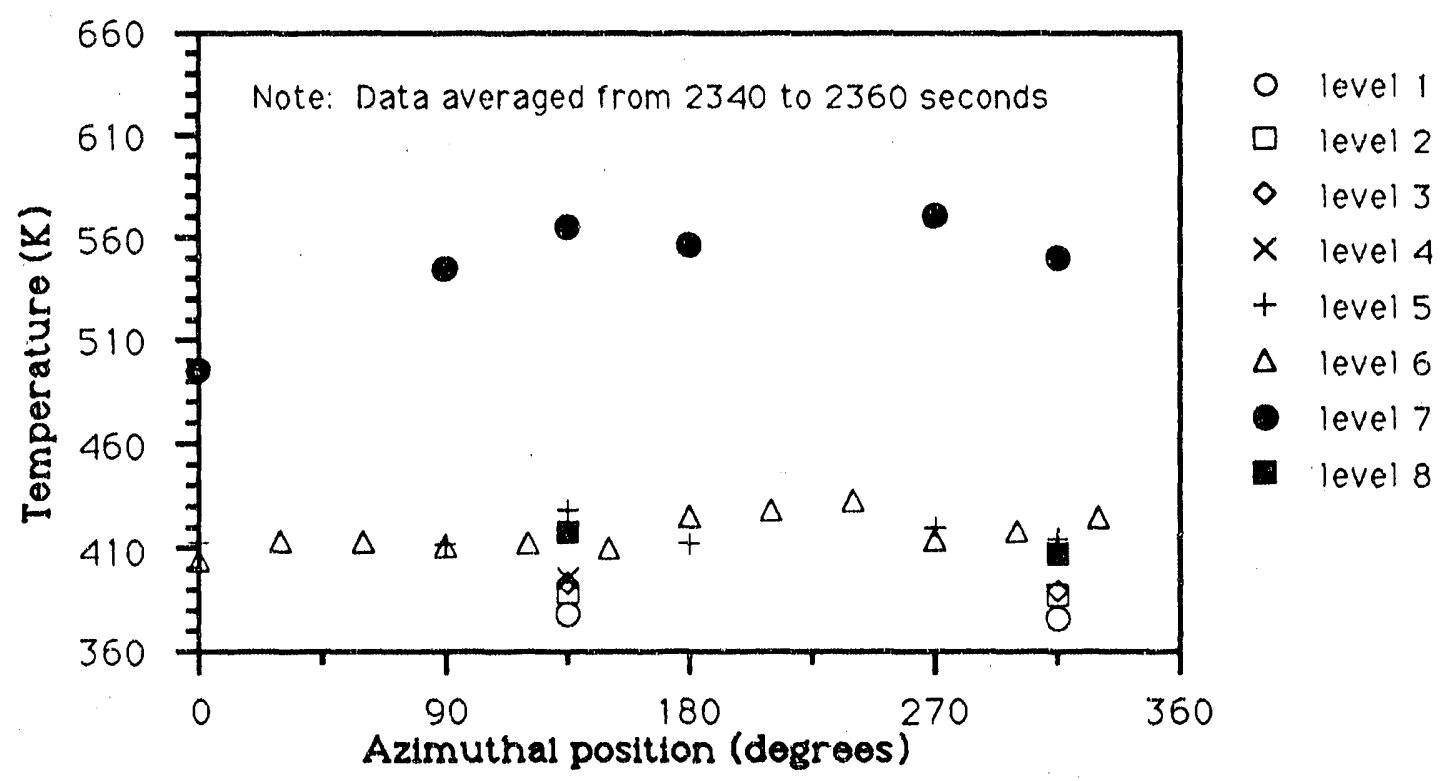

Figure 4.17. Azimuthal wall temperature distribution during power step on which sustained excursion occurred for Test ECS-2BL_5

Common practice used by WSRC researchers is to present results from thermal excursion experiments in terms of the so-called power factor, $R$. The $R$ factor is defined to be the ratio of the power applied to the test section, at the time sustained thermal excursion occurred, divided by the power required to raise the fluid at the outlet of the test section to saturation conditions. Appendix E documents the calculation of the $R$ factor for the wall thermal excursion and wall saturation temperature power limit criteria.

Table 4.4 lists a summary of results from the thermal excursion tests conducted at the INEL. Parameters listed in Table 4.4 for each test include, the test section superficial velocity, the test section inlet water temperature, the test section stand pipe height, the electrical power applied at the instance of excursion, the calculated power to saturate the outlet fluid, and the $R$ factor. Measured data values in this table represent averages taken on the excursion power step. Similar summary tables presented in Appendix $J$ also list data averages on the power step just before the excursion step. Appendix $J$ also presents data averages for all the measurements for the pre-excursion and excursion power steps. 


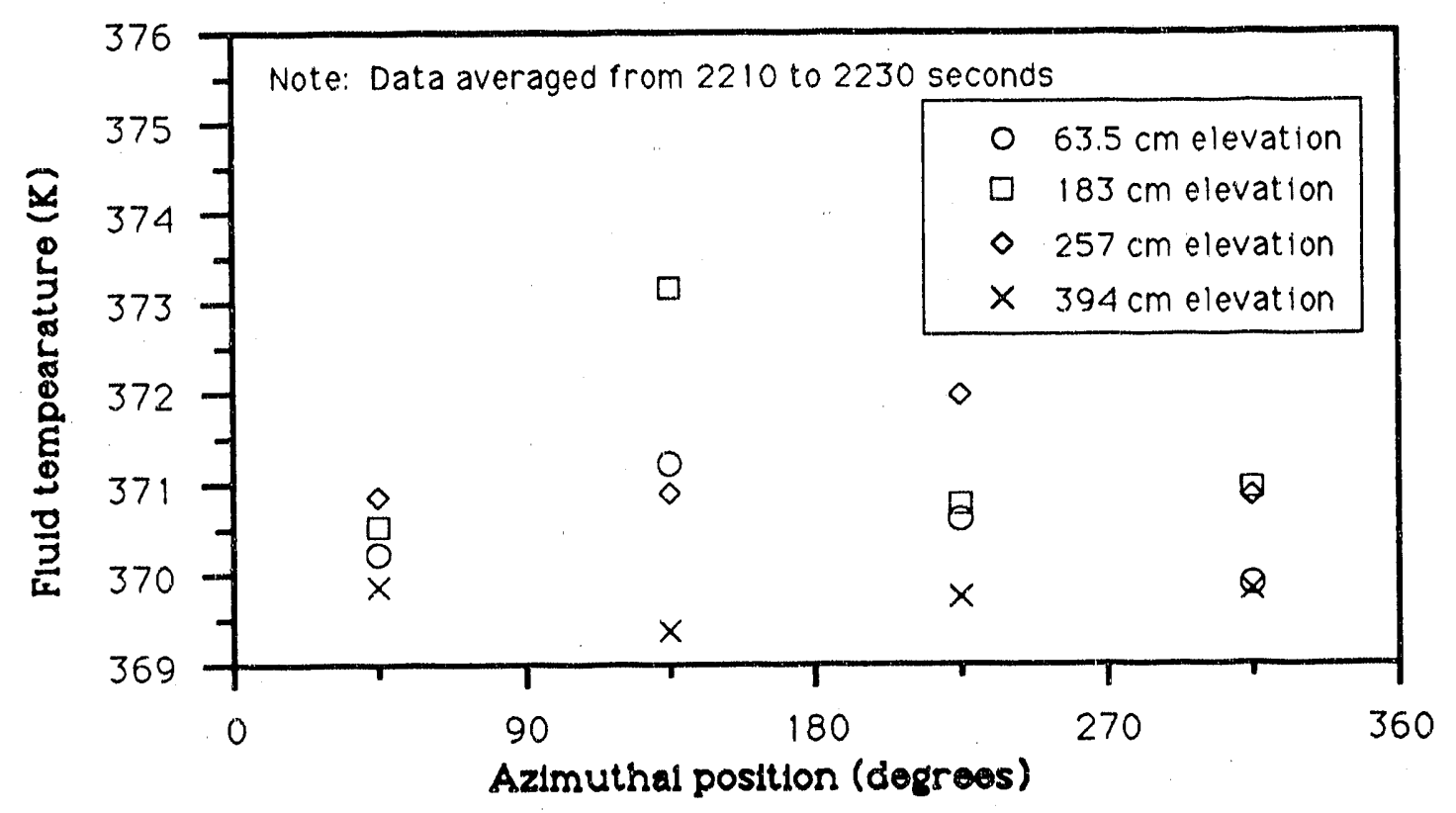

Figure 4.18. Azimuthal fluid temperature distribution during power step just prior to excursion power step for Test ECS-2BL_5

\subsubsection{Effect of Inlet Flowrate}

The data shown in Tables 4.4 and 4.5 can be plotted in various ways to illustrate the effects of boundary conditions. As was observed in the wall saturation experiments discussed by Anderson, et al., liquid flowrate is the major variable influencing the limiting power criteria. Figure 4.19 shows $R$ factors plotted against liquid superficial velocity for all the ECS-2WSR data and subsets of the ECS-2BL and ECS-2cE data. The data points chosen from the three sets are from experiments with reasonably comparable standpipe settings and test section inlet temperatures.

As shown below, the trend of $\mathrm{R}$ factor with superficial velocity in Figure 4-19 is typical when compared to data from other sources. $R$ is seen to decrease from a value of approximately 2.5 at the lowest superficial velocity of $0.075 \mathrm{~m} / \mathrm{s}$ to a value of about 0.6 at $0.78 \mathrm{~m} / \mathrm{s}$, the highest superficial velocity available for these data sets.

$R$ values above unity indicate that the power level at the thermal excursion was higher than the power level required to saturate the fluid at 


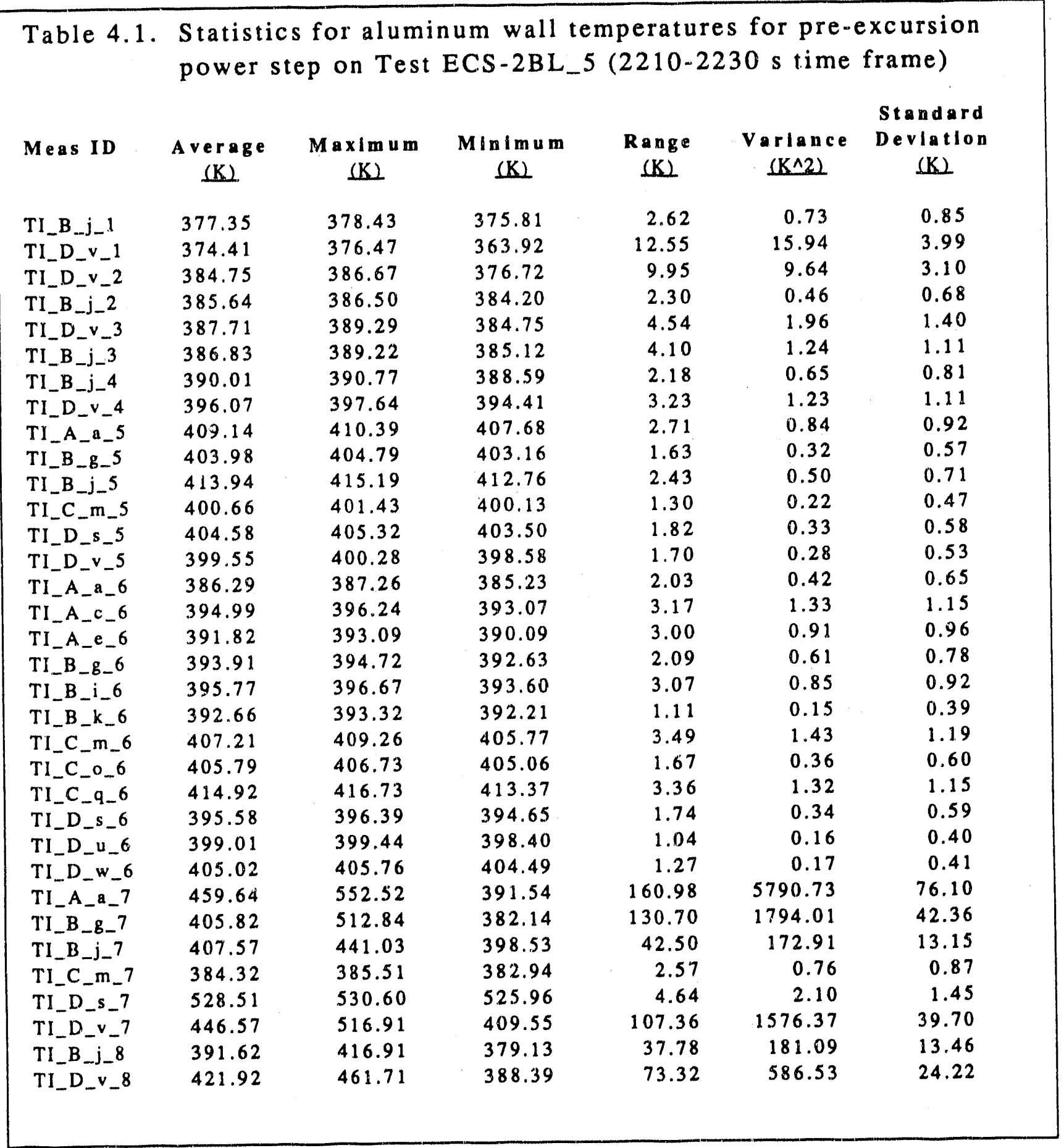

the outlet of the heated length. Hence, steam generated must exit the top and/or bottom of the annulus. R values less than unity imply that saturation conditions were not achieved at the outlet before excursion occurred. However, local saturation and steam production were observed. Although for the test conditions shown in Figure 4.19, there is a scarcity of points in the 0.1 to $0.2 \mathrm{~m} / \mathrm{s}$ superficial velocity range, the trend suggests that $R$ is 


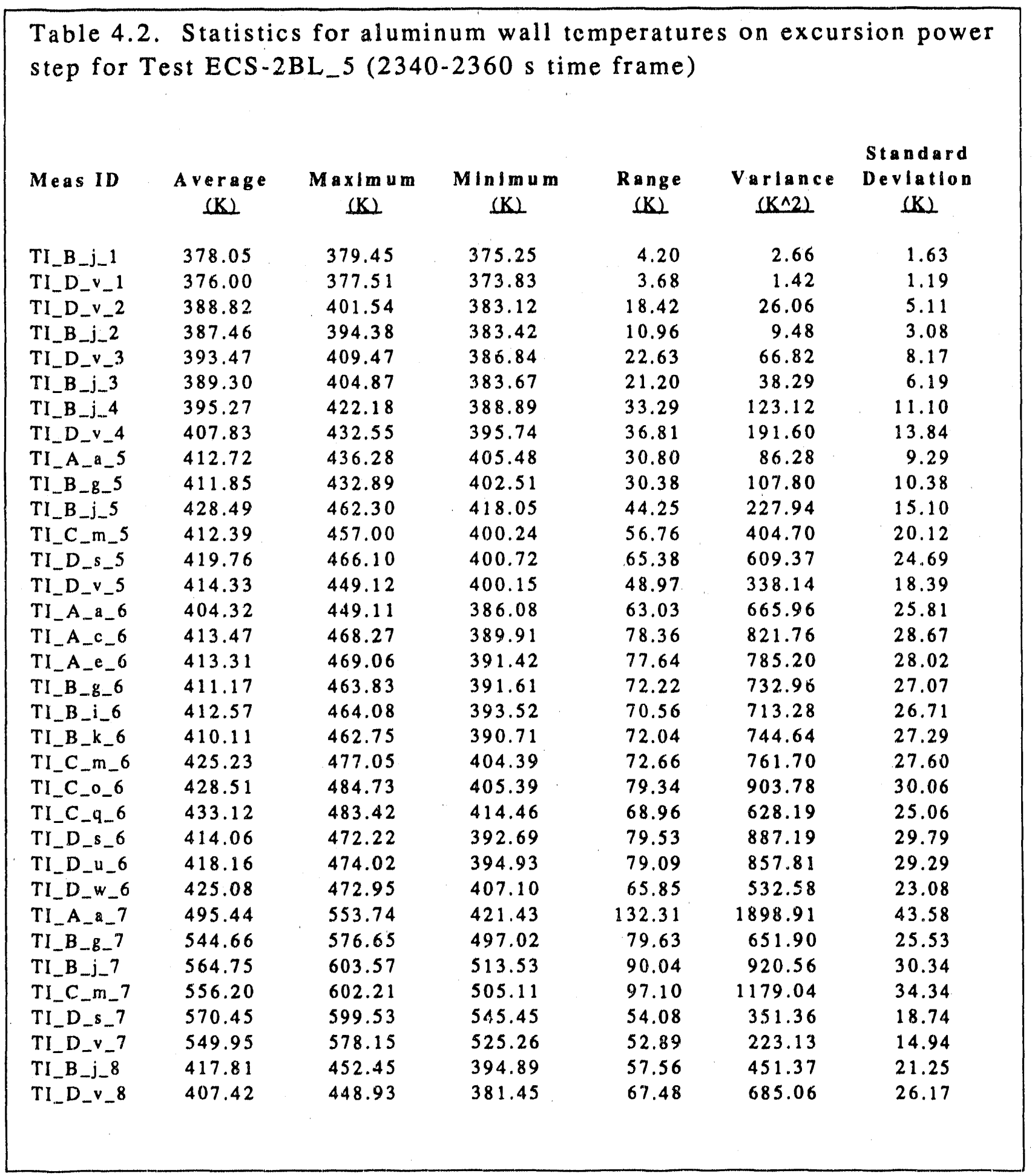

larger than unity for velocities up to about $0.3 \mathrm{~m} / \mathrm{s}$, near unity for the 0.3 $0.45 \mathrm{~m} / \mathrm{s}$ superficial velocity range, and somewhat less than unity for velocities above $0.45 \mathrm{~m} / \mathrm{s}$. With the exception of one high inlet temperature data set discussed below, this trend essentially describes all of the INEL ECS-2 excursion experiments conducted. 


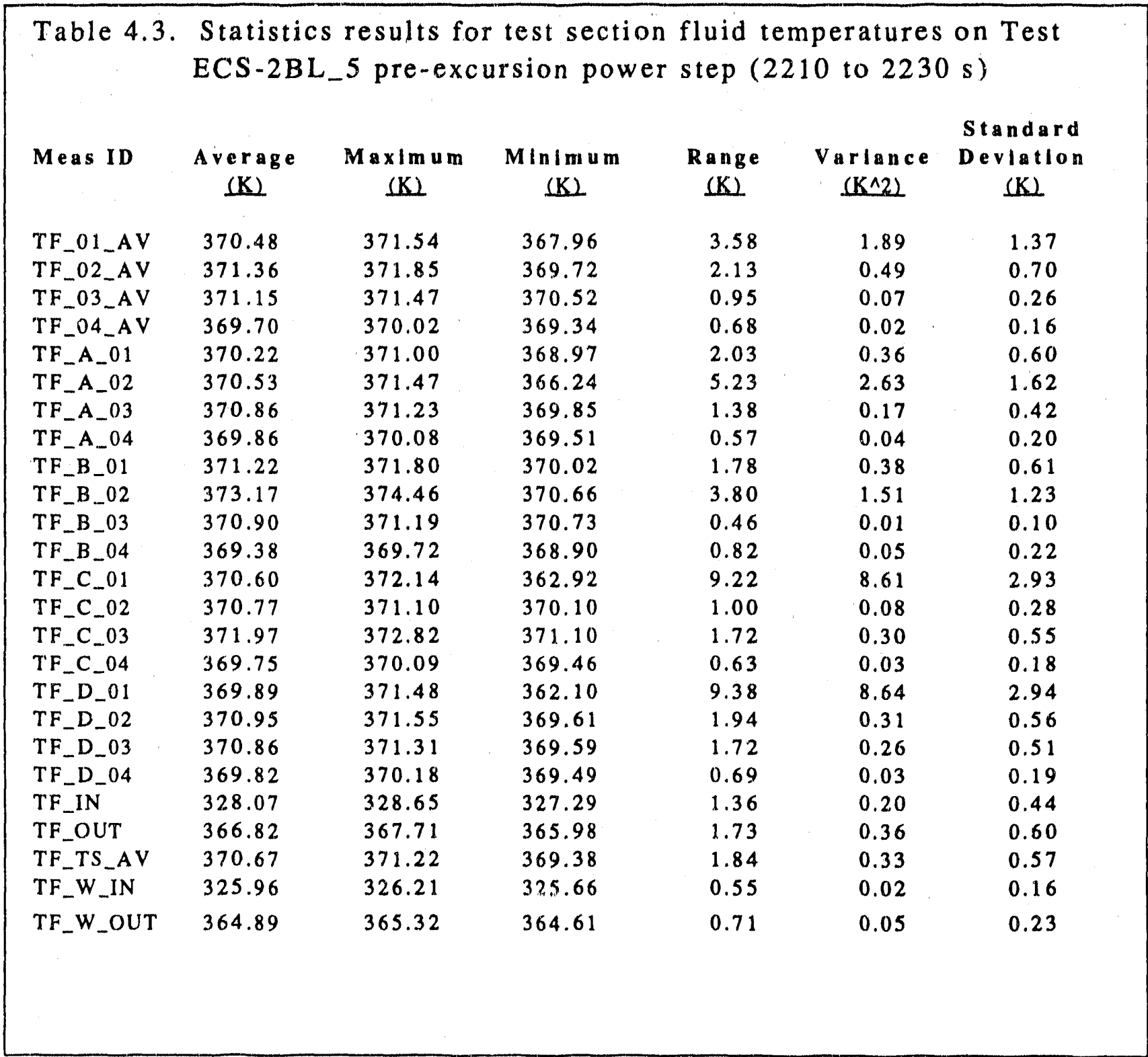

During the excursion experiments, several observations regarding the phenomena occurring in the test section for the various flowrates and the influence this phenomena had on thermal excursion were noted. For the lowest flowrate $\left(j_{\mathrm{f}}<0.2 \mathrm{~m} / \mathrm{s}\right)$ experiments conducted before achievement of saturation conditions in the test section, the flow regime appeared to be primarily rib flow wherein the liquid ran down the wall as a thin film. As the power was increased and saturation conditions were approached, liquid holdup (localized flooding) occurred causing the appearance of a churnturbulent flow regime. In many cases this holdup caused by steam generation along the test section heated length was sufficient to maintain a column of water between the top of the heated length and the bottom of the 


\begin{tabular}{|c|c|c|c|c|c|c|}
\hline \multirow[t]{2}{*}{ TEST ID } & \multirow{2}{*}{$\begin{array}{l}\text { Test Section } \\
\text { Superficial } \\
\text { Velocity } \\
(\mathrm{m} / \mathrm{s})^{2}\end{array}$} & \multirow{2}{*}{$\begin{array}{c}\text { Water } \\
\text { Inlet } \\
\text { Temp. } \\
\text { (K) }\end{array}$} & \multirow{2}{*}{$\begin{array}{c}\text { Stand } \\
\text { Pipe } \\
\text { Height } \\
(\mathrm{cm})^{3}\end{array}$} & \multirow{2}{*}{$\begin{array}{c}\text { Total } \\
\text { Test Section } \\
\text { Power }{ }^{1} \\
(k W)\end{array}$} & \multicolumn{2}{|c|}{$\begin{array}{l}\text { Power to } \\
\text { Saturate R factor } \\
\text { Outlet ( P/Psat) }\end{array}$} \\
\hline & & & & & $(\mathrm{kw})$ & 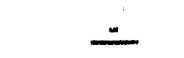 \\
\hline ECS-2BL_1 & 0.072 & 296.7 & 394 & $70.80^{4}$ & 29.54 & 2.34 \\
\hline ECS-2BL_1B & 0.076 & 296.1 & 402 & 78.69 & 31.37 & 2.51 \\
\hline $\mathrm{ECS}-2 \mathrm{BL} \_2$ & 0.223 & 296.4 & 394 & 101.48 & 91.88 & 1.10 \\
\hline $\mathrm{ECS}-2 \mathrm{BL}-5$ & 0.078 & 326.0 & 409 & 53.48 & 19.07 & 2.80 \\
\hline ECS-2BL_5B & 0.074 & 326.1 & 399 & 50.15 & 17.85 & 2.81 \\
\hline ECS-2BL_5C & 0.074 & 324.0 & 401 & 47.96 & 18.78 & 2.55 \\
\hline ECS-2BL_5D & 0.075 & 324.0 & 401 & 50.76 & 19.36 & 2.62 \\
\hline $\mathrm{ECS}-2 \mathrm{BL}_{-} 6$ & 0.225 & 324.7 & 403 & $97.50^{4}$ & 56.77 & 1.72 \\
\hline $\mathrm{ECS}-2 \mathrm{BL}_{-}^{-} 7$ & 0.400 & 324.4 & 393 & 99.80 & 101.28 & 0.99 \\
\hline ECS-2BL_7B & 0.379 & 323.8 & 395 & 99.15 & 97.50 & 1.02 \\
\hline ECS-2BL_11 & 0.225 & 346.5 & 400 & 50.59 & 29.45 & - \\
\hline $\mathrm{ECS}-2 \mathrm{BL}+11 \mathrm{~B}$ & 0.226 & 345.9 & 406 & $70.60^{4}$ & 29.93 & 2.36 \\
\hline ECS-2BL_12 & 0.379 & 342.7 & 399 & 66.41 & 57.63 & -. \\
\hline ECS $-2 B L \_12 B$ & 0.374 & 346.5 & 419 & 96.94 & 48.00 & 2.02 \\
\hline ECS-2BL_13 & 0.526 & 348.6 & 404 & 101.97 & 62.74 & 1.63 \\
\hline ECS-2BL_14 & 0.676 & 345.9 & 395 & 112.43 & 90.85 & 1.24 \\
\hline ECS-2BL_17 & 0.227 & 323.7 & 282 & 63.32 & 61.77 & 1.03 \\
\hline ECS-2BL_18 & 0.377 & 326.0 & 292 & $97.50^{4}$ & 98.76 & 1.00 \\
\hline ECS-2BL_18B & 0.373 & 323.4 & 293 & $98.40^{4}$ & 103.35 & 0.95 \\
\hline ECS-2BL_22 & 0.223 & 325.3 & 312 & 71.13 & 57.74 & 1.23 \\
\hline ECS-2BL_23 & 0.373 & 326.2 & 315 & 103.82 & 95.28 & 1.09 \\
\hline ECS-2BL_23B & 0.373 & 325.1 & 321 & 96.61 & 97.58 & 0.99 \\
\hline ECS-2BL_26 & 0.228 & 325.8 & 365 & 93.72 & 57.01 & 1.64 \\
\hline ECS-2BL_26B & 0.225 & 324.5 & 399 & 89.01 & 57.62 & 1.54 \\
\hline ECS-2BL_27 & 0.350 & 325.2 & 356 & $93.75^{4}$ & 89.18 & 1.05 \\
\hline ECS-2FC_1 & 0.113 & 323.0 & 363 & 40.35 & 30.15 & 1.34 \\
\hline ECS-2FC_2 & 0.225 & 325.9 & 398 & 80.81 & 55.95 & 1.44 \\
\hline ECS-2WSR0380 & 0.286 & 315.8 & 366 & 101.88 & 88.27 & 1.15 \\
\hline ECS-2WSR 0580 & 0.437 & 315.2 & 329 & 121.22 & 137.18 & 0.88 \\
\hline ECS-2WSR0580C & C $\quad 0.434$ & 315.4 & 325 & 110.88 & 136.03 & 0.82 \\
\hline ECS-2WSR 0760 & 0.571 & 314.1 & 330 & 126.82 & 183.01 & 0.69 \\
\hline ECS-2WSR0960 & 0.723 & 314.5 & 340 & $162.50^{4}$ & 230.59 & 0.70 \\
\hline ECS-2WSR 1040 & 0.780 & 313.9 & 323 & 161.39 & 251.70 & 0.64 \\
\hline ECS-2WSR $1040 B$ & В 0.778 & 315.4 & 316 & 161.25 & 244.82 & 0.66 \\
\hline \multicolumn{7}{|c|}{ 1. Power recorded during the excursion. } \\
\hline \multicolumn{7}{|c|}{ 2. Superficial velocity calculated using a test section flow area of $13.31 \mathrm{~cm}^{2}$. } \\
\hline \multicolumn{7}{|c|}{$\begin{array}{l}\text { 3. Measured standpipe level (from differential pressure DP_SP) referenced to the } \\
\text { top of the heated length. }\end{array}$} \\
\hline \multicolumn{7}{|c|}{ 4. Logbook recorded value due to heater voltage offset on DAS channel. } \\
\hline & & & & & & \\
\hline
\end{tabular}




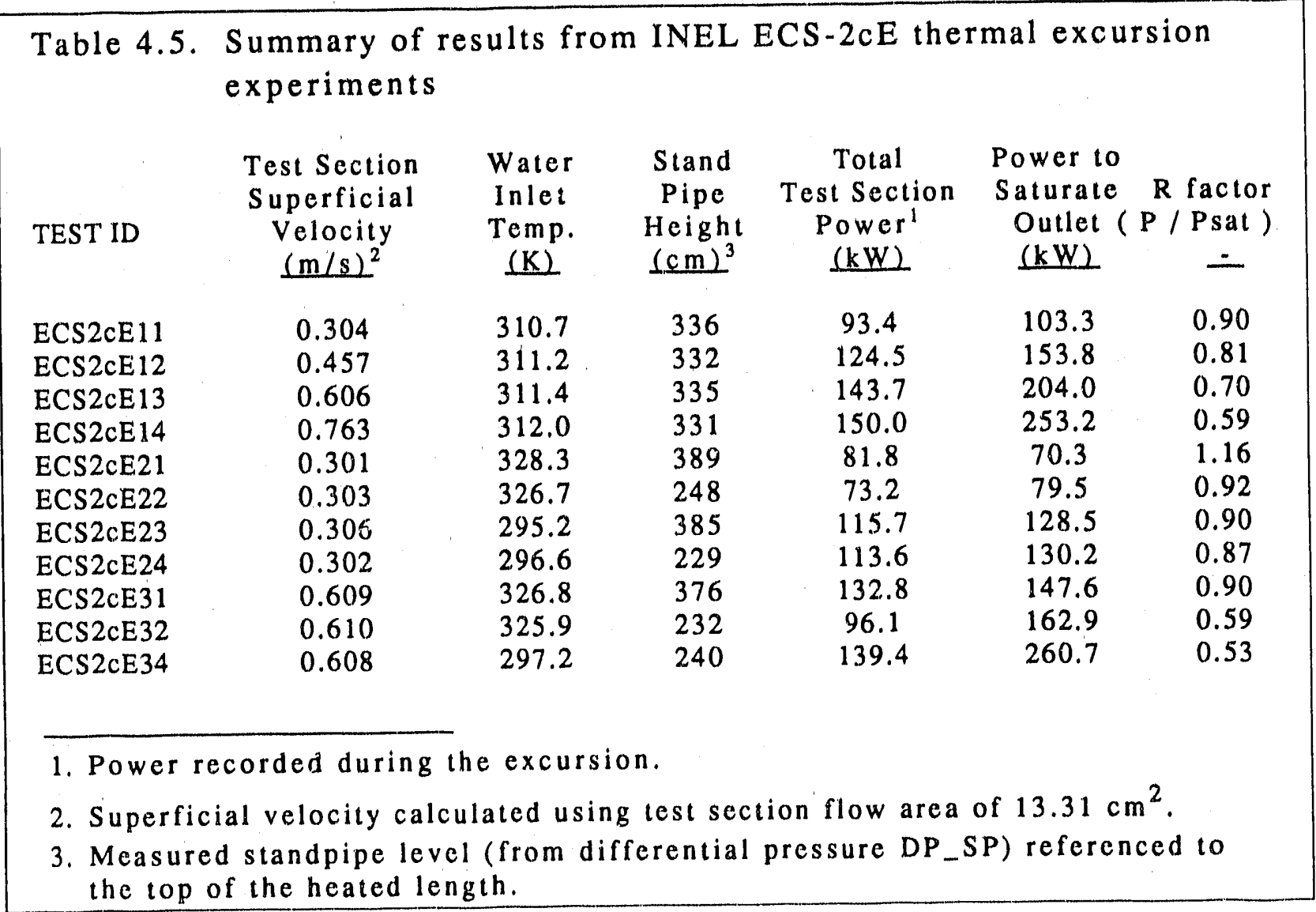

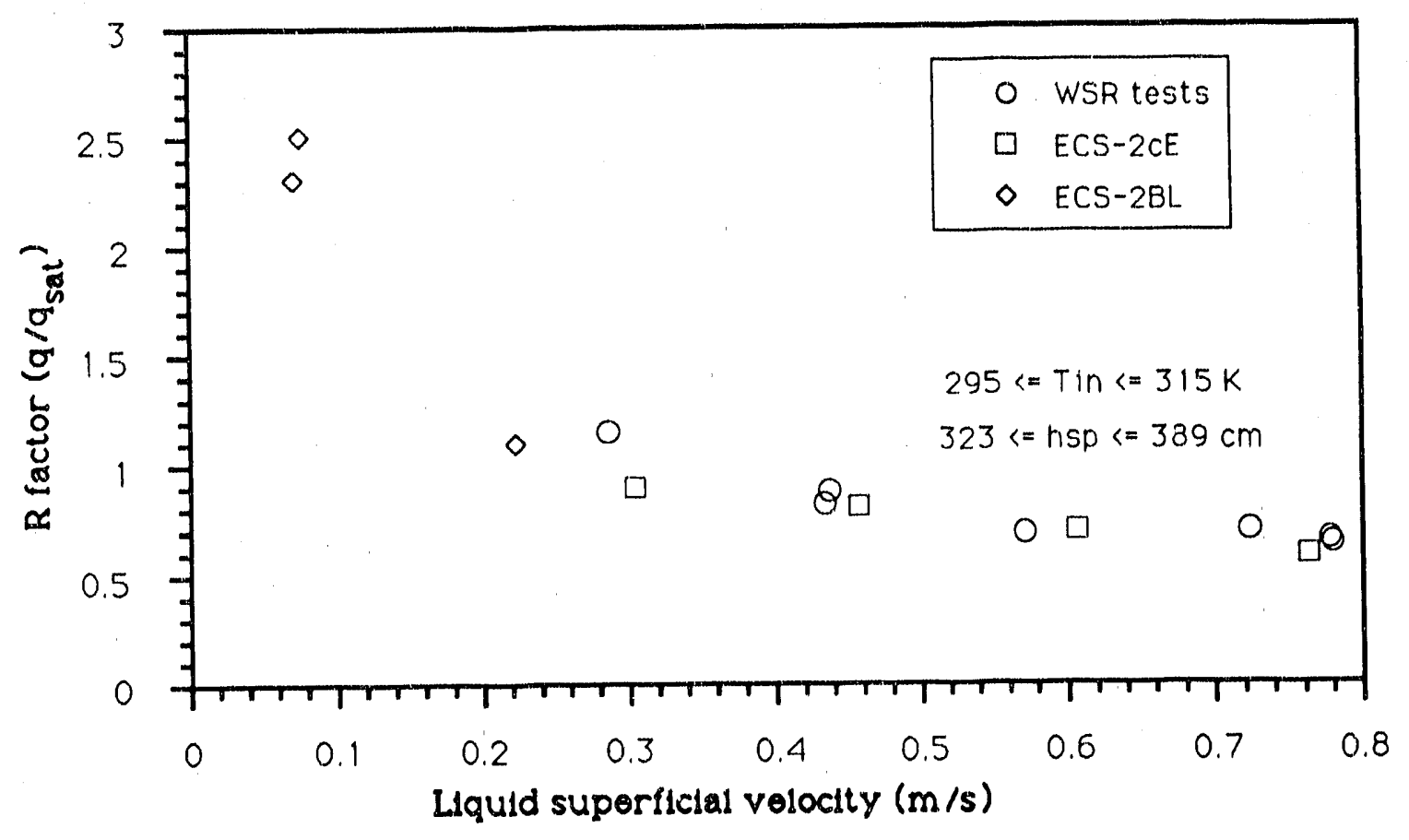

Figure 4.19. INEL thermal excursion data for 295-315 K inlet temperature and $323-383 \mathrm{~cm}$ standpipe setting 
inlet plenum. Steam generated was noted to exit the bottom of the test section to the outlet plenum and also migrate upward through the column of liquid held above the top of the heated length. During this time, intermittent dryout-rewet cycles occurred as described in Section 4.1. Due to the low liquid flowrates, air entrainment was minimal and therefore did not have much impact on the dryout. Wall dryout appeared to be the result of holdup caused by localized flooding preventing sufficient water for cooling from reaching the the higher power zones of the heater. Thermal excursion for these flows tended to occur locally with insufficient steam generation to dryout the entire test section.

At somewhat higher flowrates, approximately $0.2<\mathrm{j}_{\mathrm{f}}<0.5 \mathrm{~m} / \mathrm{s}$, air entrained with the inlet liquid seemed to play a larger role in the processes influencing the onset of wall dryout. Observations of the test section indicated that the water holdup in the section above the heated length was less pronounced than for velocities less than $0.2 \mathrm{~m} / \mathrm{s}$ although considerable holdup still occurred. Air in the test section feasibly contributed to the initiation of the flooding process since it expanded (due to heating) as it flowed down the test section and provided additional pressure drop and degraded the heat transfer. However, visual observations and air flow measurements indicate that once the local flooding and flow reversals started, the air entrainment usually decreased significantly. This result suggests that the enirained air did not have much impact on the dryout process. Wall temperature excursion under these conditions was similar to those observed for the lower flows although there was less water held up in the upper part of the test section.

At the highest flows $\left(j_{\mathrm{f}}>0.5 \mathrm{~m} / \mathrm{s}\right)$ the wall dryout consisted of dry patch formation, rewetting, reformation, and eventually growth. This process was accompanied by considerable vapor generation and if the dry patch was not quickly rewetted, wall heat up occurred. The end result of the wall heatup was expulsion of water from both ends of the heated length due to the rapid expansion of the steam (essentially flooding). The initiating process, however, appeared to be heat flux dominated rather than flooding dominated. The high flow excursions were characterized by very rapid and violent flooding with dryout of the entire test section. The test section remained flooded and dry for many seconds after the power trip because of the significant stored energy (high powers were required for dryout at high flowrates) in the test section. 


\subsubsection{Effect of Inlet Liquid Temperature}

$\mathrm{R}$ factors plotted against liquid superficial velocity with test section inlet temperature as a secondary variable are presented in Figure 4.20. All data from Tables 4.4 and 4.5 with the inlet temperature range indicated and a standpipe setting of $389 \mathrm{~cm}$ are included on this figure. Results shown encompass data gathered with three different inlet fluid temperatures ranging from $74 \mathrm{~K}$ subcooled water $(296 \mathrm{~K}$ inlet temperature) to $24 \mathrm{~K}$ subcooled water ( $346 \mathrm{~K}$ inlet temperature).

Data shown in Figure 4.20 suggest that for a given superficial velocity and standpipe setting, higher inlet fluid temperatures have the effect of increasing the $R$ value. For example, at a superficial velocity of $0.3 \mathrm{~m} / \mathrm{s}$, the $R$ value increased about $40 \%$ between the $296 \mathrm{~K}$ and the $326 \mathrm{~K}$ data. Although there were only a limited number of $296 \mathrm{~K}$ data points taken, the data trends seem to indicate that even larger increases in $R$ may be possible for certain flow ranges. The influence of inlet temperature on $R$ is quite pronounced for higher temperatures as evidenced by significantly

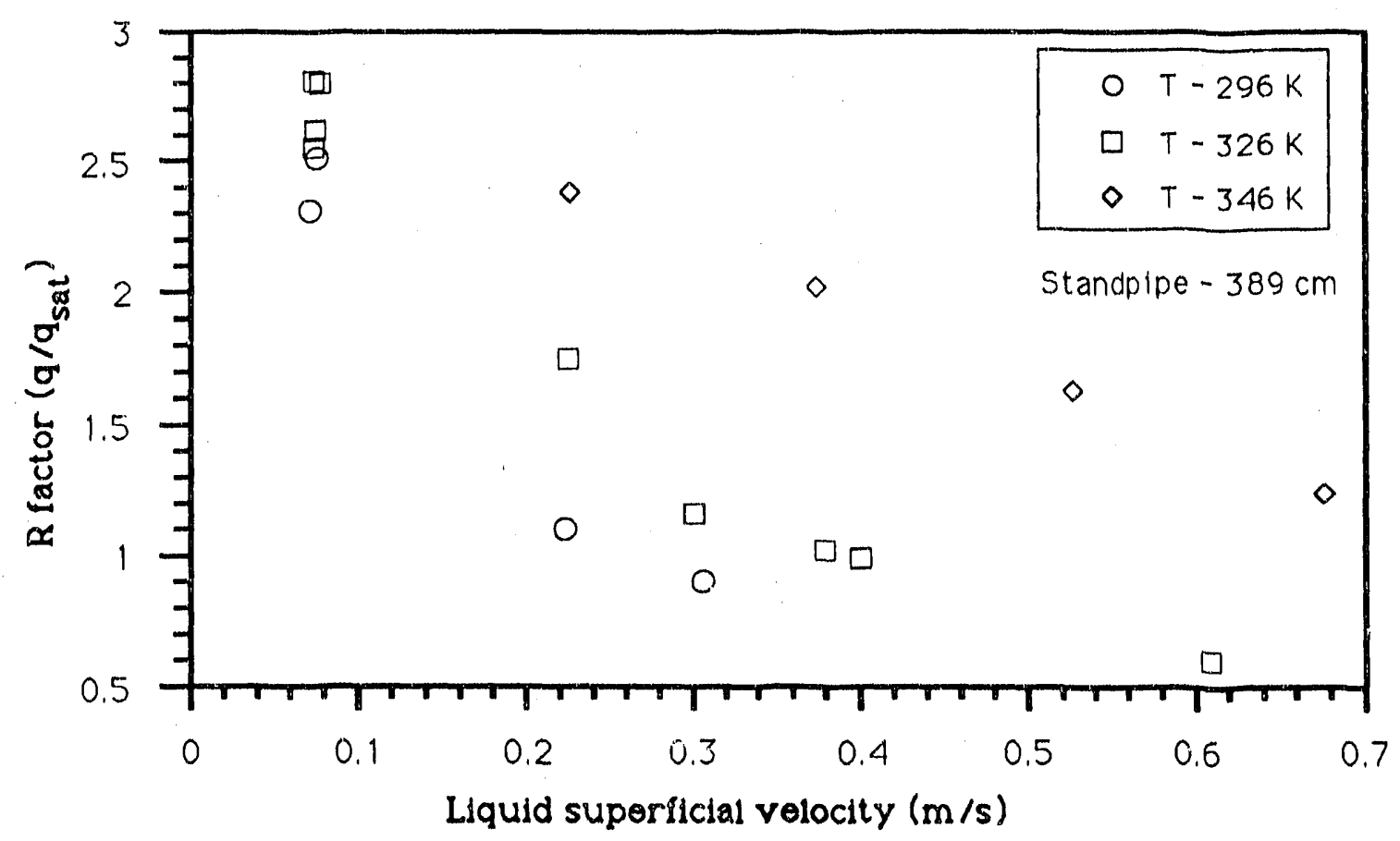

Figure 4.20. INEL thermal excursion data for three different inlet temperatures and a standpipe setting of $389 \mathrm{~cm}$ 
higher $R$ values for the $346 \mathrm{~K}$ data set relative to the remainder of the data shown in Figure 4.20. For the $346 \mathrm{~K}$ data set, the $R$ value did not cross unity although the trend suggests that superficial velocities above $0.8 \mathrm{~m} / \mathrm{s}$ would have resulted in a saturation ratio of one.

Several interesting observations are apparent in Figure 4.20. First, if one extrapolates all of the clata sets to the lowest velocities, $R$ appears to converge to a value somewhere between 2.5 and 3 independent of temperature. That all of the data seem to converge for the lowest flows makes sense in light of the observation that the wall temperature excursion for the lowest flowrates is dominated by local flooding. Second, all the data sets show the tendency for $R$ to cross over unity as the flowrate increases. As inlet temperature increases, the range of velocities where $R$ crosses through unity shifts to higher values. Obviously, as postulated above, the mechanism causing the wall excursion is flowrate dependent and is somewhat inlet temperature sensitive. Third, the data sets for inlet temperatures $326 \mathrm{~K}$ and lower appear to follow a power law, whereas the $346 \mathrm{~K}$ data is nearly linear with superficial velocity.

There are two related explanations for the $346 \mathrm{~K}$ data points. As discussed in Appendix $G$, the air entrainment rate is a strong function of the inlet liquid temperature and a lesser function of standpipe setting. For example, the air ingress data show that the air ingress rate increases by a factor of two with ambient temperature water relative to $346 \mathrm{~K}$ water for a given standpipe setting (see Figures G-5 through G-8). However, for a given inlet temperature, the air ingress only increases by $30 \%$ as the stand pipe setting is decreased from the highest value to the lowest value (see Figure G-3 in Appendix G). While the $346 \mathrm{~K}$ data points were taken with the lowest facility standpipe setting $(389 \mathrm{~cm}$ relative to the top of the heated length or $43 \mathrm{~cm}$ above the bottom of the outlet plenum) which should have allowed the maximum air entrainment, the air ingress rate was minimal primarily because of the temperature effect. Air entrainment rate averages listed in Table J-1 support this observation. Entrained air then had a minimal contribution to the flooding processes that eventually caused sustained dryout. Local vapor generation thus had to be the major contributor. Higher $R$ values could plausibly ensue under these conditions since more power was needed to generate the vapor required to support local flooding relative to cases where there was appreciable entrained air in the flow stream. 


\subsubsection{Effect of Standpipe Setting}

$R$ factor versus liquid superficial velocity with standpipe setting as a parameter for a constant inlet fluid temperature data set is shown in Figure 4.21. In Figure 4.21, the standpipe height has been referenced to the top of the heated length. Therefore, larger standpipe setting numbers actually imply a shorter column of water (and hence lower back pressure) on the outlet plenum. For example, the $389 \mathrm{~cm}$ standpipe height reflects a 43 $\mathrm{cm}$ head of water on the outlet plenum whereas the $241 \mathrm{~cm}$ setting represents a $191 \mathrm{~cm}$ head of water on the outlet plenum. The data are presented in this fashion to avoid potential confusion due to the use of several different reference positions (bottom of the lower plenum, bottom of the heated length, etc.) for test section standpipe setting during the course of the experiments.

The data in Figure 4.21 show the familiar trend of $R$ with superficial velocity evident in Figures 4.19 and 4.20. Although no strong effect of standpipe setting is apparent, one concludes that for a given velocity in the $326 \mathrm{~K}$ data shown, $\mathrm{R}$ tends to increase with a decrease in the back pressure

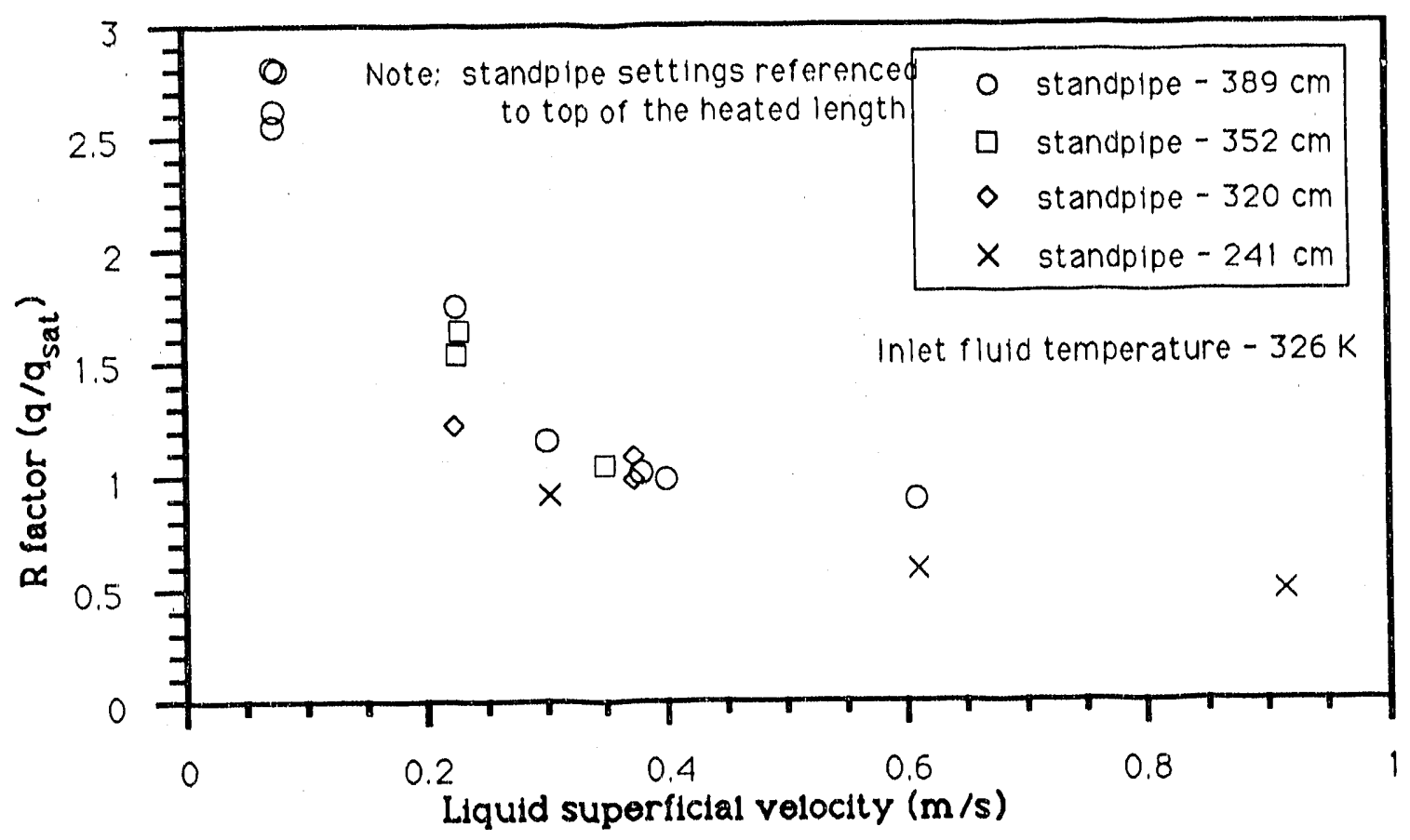

Figure 4.21. INEL thermal excursion data for $326 \mathrm{~K}$ inlet temperature with standpipe setting as a parameter 
(increase in the standpipe setting). For the data at $0.3-$ or $0.6 \mathrm{~m} / \mathrm{s}$ for instance, the $R$ factor increased by about $30 \%$ over the extreme range of standpipe setting displayed. Smaller influences are evident for smaller changes in the standpipe setting (note the points at $0.2 \mathrm{~m} / \mathrm{s}$ or $0.35 \mathrm{~m} / \mathrm{s}$ for instance).

Figure 4.21 does not contain data from the $346 \mathrm{~K}$ inlet temperature tests. As previously discussed, the $346 \mathrm{~K}$ experiments were conducted with the lowest (relative to the bottom of the outlet plenum) standpipe settings.

\subsubsection{Simple Data Correlation}

From the preceding discussion, it is apparent that superficial velocity (or flowrate) is a dominant variable influencing the $\mathrm{R}$ factor. Also, with the exception of the $346 \mathrm{~K}$ data, inlet temperature and standpipe setting were lesser effects than the flowrate. Figures 4.22 and 4.23 present all of the data points contained in Tables 4.4 and 4.5 , with points delineated by inlet temperature and standpipe setting, respectively. Although the overall effect of inlet temperature and standpipe setting are difficult to discern on these plots, the four $346 \mathrm{~K}$ points clearly stand out. As shown in Figure 4.23 , the fact that these four data points appear to be unique can not be attribuied tc back pressure since other data points in Figure 4.23 from the 380-390 $\mathrm{cm}$ standpipe setting are consistent with the majority of the data.

Figure 4.24 presents the $346 \mathrm{~K}$ data points and all the other inlet temperature data points contained in Tables 4.4 and 4.5. It is interesting to note that the two data sets are reasonably well represented with an empirical power law fit, i.e.:

$$
\begin{aligned}
& R=a\left(j_{f}\right)^{b} \\
& \text { where } \\
& a=\text { constant } \\
& j_{f}=\text { liquid superficial velocity }(\mathrm{m} / \mathrm{s}) \\
& \quad b=\text { constant exponent }
\end{aligned}
$$

Values for the a and b constants for the two temperature data sets are shown in Figure 4.24 along with the fitted lines. Table 4.6 lists constants for power law fits develoned using each temperature data set. If all the inlet temperature data sets except the $346 \mathrm{~K}$ data are considered together, 


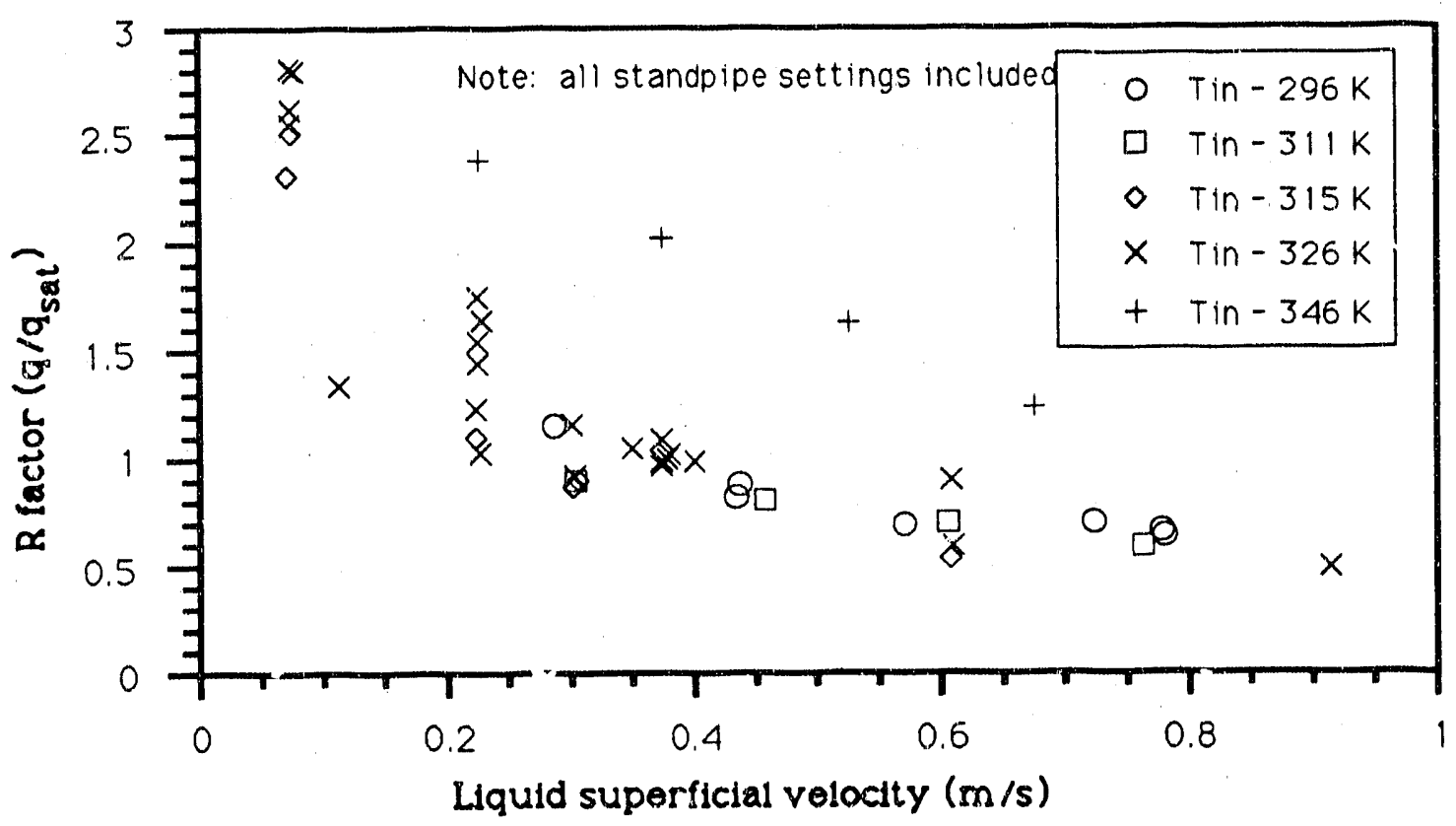

Figure 4.22. INEL thermal excursion data with inlet temperature as a parameter

the values listed in Table 4.6 suggest that a power law with a and b values of 0.5169 and -0.61 , respectively can account for $91 \%$ (the residial squared value) of the variance in the saturation ratio values. This result supports the observation that superficial velocity is the dominant independent variable. Interestingly, the $346 \mathrm{~K}$ data is nearly a perfect fit with a linear equation with an intercept of 2.95 and a slope of -2.537 as shown in Figure 4.24.

Power law fits were calculated in a similar fashion for the data grouped by standpipe setting as shown in Figure 4.23. However, the scatter in the data shown in Figure 4.23 suggests that there should be limited correlation between the constants developed for each individual data set. Indeed, this was the case.

In erder to examine the statistical significance of the influence of the superficial velocity, the inlet temperature, and the standpipe setting on the $\mathrm{R}$ factor, some simple regression analyses in addition to the power law fits discussed above were performed on the data. These analyses included multiple regression, polynomial regression, and stepwise regression. While 


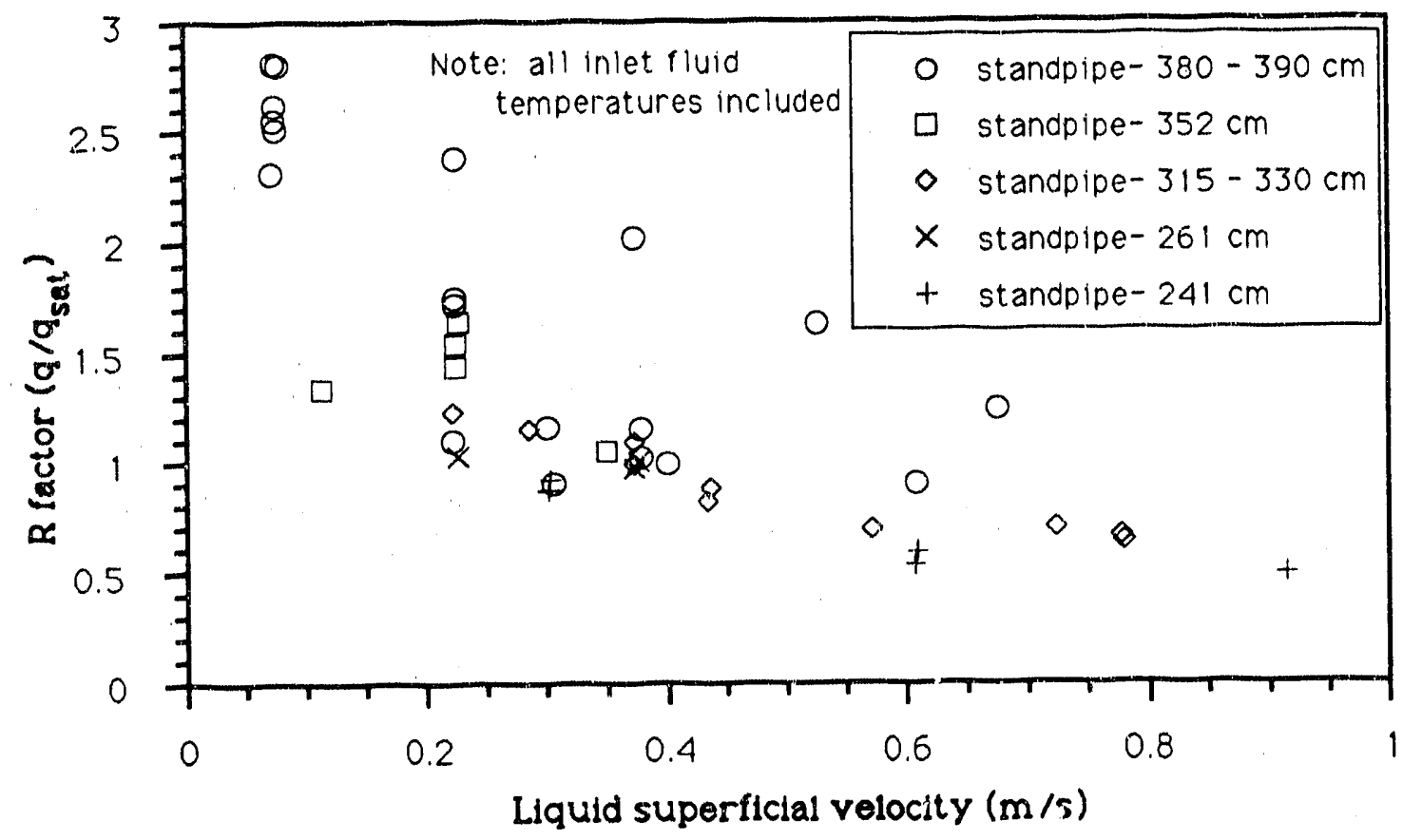

Figure 4.23. INEL thermal excursion data with standpipe setting as a parameter

certainly not an exhaustive investigation of statistical effects, such simple analyses provide insight on the relative importance of the independent variables. Furthermore, it was not expected that any of the additional regression :echniques applied here would necessarily provide a better (or even as good as) fit of the data relative to the simple power law and such was found to be the case.

Multiple regression of the data produced an equation of the form:

$$
R=a_{0}+a_{1} j_{f}+a_{2} T_{i n}+a_{3} h_{s p}
$$

where

$$
\begin{aligned}
& a_{0}=-2.446 \\
& a_{1}=-1.766 \\
& a_{2}=0.009 \\
& a_{3}=0.004
\end{aligned}
$$




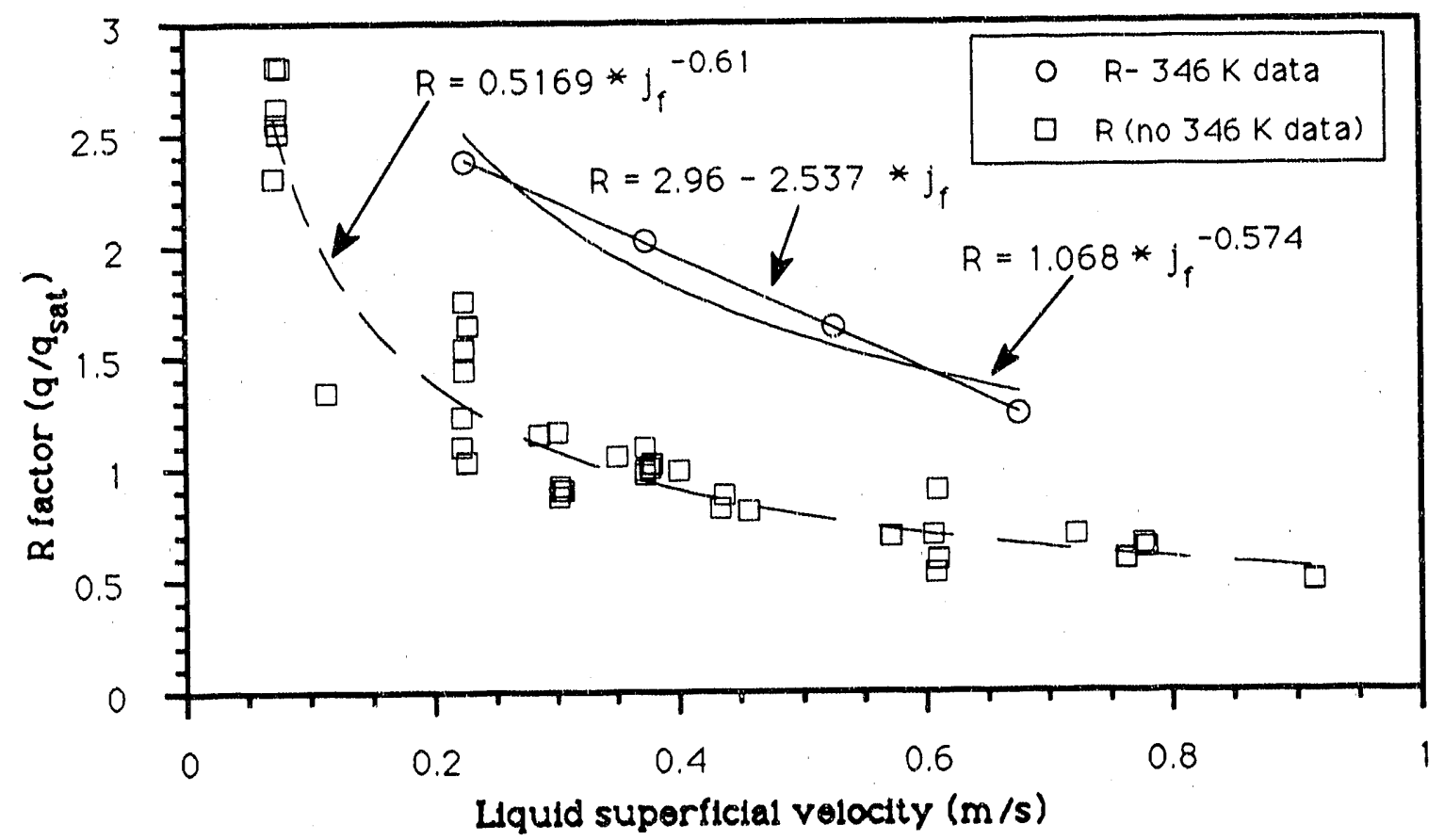

Figure 4.24. INEL ECS-2 and ECS-2cE thermal excursion data with power law fits

Equation 4-2 produced a residual squared value of 0.72 , significantly worse than the power fit. The t-statistic was used to test the hypothesis that the coefficients $a_{1}, a_{2}$, and $a_{3}$ were statistically different than zero. Analysis of the coefficients indicated that the superficial velocity multiplier had a high probability $(>0.9999)$ of being nonzero and there was a high probability that the temperature coefficient was not statistically dif-

Table 4.6 Power fit constants for Equation 4-1 using inlet temperature data sets

\begin{tabular}{|c|c|c|c|c|}
\hline Data Set & $a$ & b & Residual & $\left(\text { Residual }{ }^{1}\right)^{2}$ \\
\hline $296 \mathrm{~K}$ & $0 . \overline{559}$ & $-0 . \overline{533}$ & 0.970 & 0.941 \\
\hline $311 \mathrm{~K}$ & 0.544 & -0.450 & 0.972 & 0.945 \\
\hline $315 \mathrm{~K}$ & 0.376 & -0.714 & 0.994 & 0.988 \\
\hline $326 \mathrm{~K}$ & 0.540 & -0.608 & 0.944 & 0.891 \\
\hline $346 \mathrm{~K}$ & 1.068 & -0.574 & 0.966 & 0.933 \\
\hline all ${ }^{2}$ & 0.517 & -0.610 & 0.955 & 0.912 \\
\hline
\end{tabular}

1. The residual squared is a measure of the ability of the independent variable $\left(j_{f}\right)$ to account for the variance in the dependent variable (saturation ratio).

2. All temperature data sets except the $346 \mathrm{~K}$ data. 
ferent from zero. Results for the standpipe setting coefficient t-test were not conclusive although there was significant probability that the coefficient was not different than zero. A partial F-test suggested that the standpipe setting coefficient was likely not statistically significant, a conclusion consistent with visual observation of the data.

Second and third order polynomial regressions of the $R$ factor with each independent variable (liquid superficial velocity, inlet temperature, and standpipe setting) were calculated. Second and third order regressions of $R$ factor with liquid superficial velocity produced fits (residual squared values of 0.7 and 0.751 , respectively) better than regressions to inlet temperature or standpipe setting. As expected, regression with temperature did not fit the data. Somewhat surprisingly, polynomial regression of $R$ factor with standpipe level provided some fit (albeit poor) to the data (residual squared of 0.58 and 0.63 for second and third order, respectively). However, analysis of the t-test and partial F-test results indicated that the regression coefficients for this case could not be proven to be statistically different from zero. In general and as expected, the polynomial regression results indicated that flowrate was the major significant independent variable.

Based on visual observation of the data (Figures 4-22 and 4-23, for example), the power law fits, and the regression analysis discussed above, the expectation was that flowrate (superficial velocity) was a significant independent variable, standpipe level may be significant (at least for the linear model), and with the exception of the $346 \mathrm{~K}$ data set, inlet temperature was not a significant variable ${ }^{7}$ in terms of predicting the variance in the $R$ factor. A stepwise linear regression was conducted to examine these conclusions. Although the data certainly do not suggest a linear fit, the stepwise regression confirmed that superficial velocity was the best predictor of the variance in $R$ factor with a residual squared of 0.62 . Addition of the standpipe level to the regression improved the residual squared to 0.7 . As expected, the inlet temperature variable did not meet the partial F-test criteria for the stepwise regression and therefore was not included.

The simple statistical tests employed here showed that liquid superficial velocity is the dominant independent variable and that standpipe height may contribute to the prediction of the $R$ factor. These conclusions are

7. The variation of the $346 \mathrm{~K}$ data set relative to the rest of the data is not understood at this time. 
supported by the reasonable empirical fit obtained with a power law equation.

Some theoretical analyses of downflow dryout phenomena has been conducted by Duffey and Hughes [13]. They developed a model for the heat flux required to maintain a stable hot patch on a heated surface cooled by a falling film. Based on an analytical solution of the two-dimensional heat conduction equation and existing heat transfer correlations for the dry patch and the wet regions adjacent to the dry patch, dryout heat flux for turbulent film flow was expressed as a function of the film Reynolds number as:

$$
q_{d}{ }^{*}=0.017 R_{f}^{0.9}
$$

where

$$
\begin{aligned}
& \mathrm{q}_{\mathrm{d}}{ }^{\prime}=\text { dryout heat flux, }\left(\mathrm{kW} / \mathrm{m}^{2}\right) \\
& \operatorname{Re}_{\mathrm{f}}=\text { film Reynolds number, } 4 \Gamma / \mu \\
& \Gamma=\text { film flow rate per unit heated perimeter }[\mathrm{m} /(\pi \mathrm{d})],(\mathrm{kg} / \mathrm{m}-\mathrm{s}) \\
& \mu=\text { liquid viscosity, }(\mathrm{Pa}-\mathrm{s})
\end{aligned}
$$

Film Reynolds numbers were computed for the INEL thermal excursion data in Tables 4.4 and 4.5 using the measured flowrate, viscosity based on the calculated fluid temperatures at level $7(302 \mathrm{~cm})$, and the test section geometry. Dryout heat fluxes were computed for the high power zone using the measured power at dryout and the heater axial peaking factor. These calculations are compared to Equation 4-3 in Figure 4.25 where the measured heat flux at thermal excursion and the flux predicted from the Duffey-Hughes model are plotted against film Reynolds number. As evidenced from Figure 4.25 , the model generally under predicts the dryout flux and the slope of the flux with Reynolds number is higher than the data indicate. The model does predict the power law fit trend in the data suggested in the discussions above.

\subsubsection{Facility and Operational Influence on Saturation Ratio}

To examine the potential for facility hardware or operational considerations influencing excursion test results, test data can be delineated by the facility in which the data were gathered. As discussed in Section 3, two 


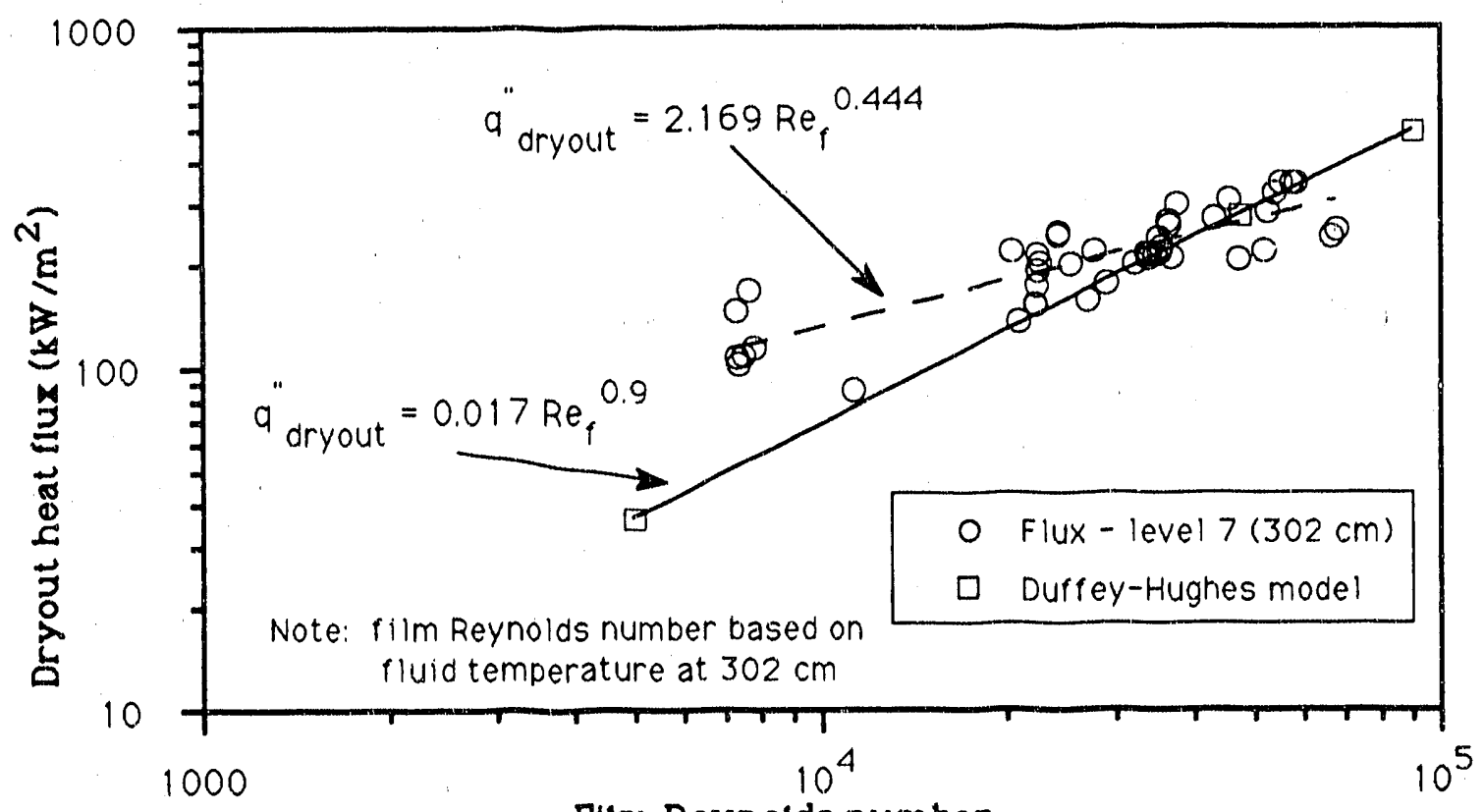

Film Reynolds number

Figure 4.25. INEL thermal excursion data compared to Duffey-Hughes model

different facilities were used to conduct the excursion tests. Furthermore, there were slight intentional differences in test procedure, test completion criteria, and facility boundary conditions for the various experiments.

Noteworthy differences among the various test series included:

- On the ECS-2 and WSR experiments, a cooling coil in the outlet plenum was used to maintain subcooled liquid conditions in the outlet plenum (the objective was to improve the air flow measurements by condensing the steam entrained into the outlet plenum). This cooling coil was not used in the ECS-2cE experiments.

- Sustained excursion criteria for the ECS-2 and WSR experiments were defined to be any wall temperature above approximately 620 $\mathrm{K}(350 \mathrm{C})$ whereas on the ECS $-2 \mathrm{cE}$ experiments, a lower limit of 520 $\mathrm{K}(250 \mathrm{C})$ was used.

- On the two ECS-2FC experiments, the power was held constant while the flow was decreased in steps until excursion was achieved. On all other experiments, the flow was held constant and the power was 
increased until excursion was attained.

- The test procedure used to conduct the ECS-2cE experiments differed somewhat relative to the other experiments. Details of the differences are discussed in Section 3.

Figure 4.26 presents the excursion test results in the usual fashion with $R$ factor plotted against liquid superficial velocity with test facility as a parameter. Cursory review of the data as presented in Figure 4.26 does not suggest any clear dependencies that might be attributed to facility hardware or test procedure with the possible exception of the flow coastdown experiment ECS-2FC_ 1 . As indicated, the $R$ value obtained from this experiment was 1.34 and occurred when the superficial velocity was $0.11 \mathrm{~m} / \mathrm{s}$. This $R$ value is lower than the $R$ values obtained on the ECS-2BL experiments conducted with superficial velocities of $0.07 \mathrm{~m} / \mathrm{s}$ yet consistent with $R$ values that were obtained from experiments conducted at approximately $0.2 \mathrm{~m} / \mathrm{s}$ including ECS-2FC_2, the only other flow coastdown experiment. Unfortunately, since only two flow coastdown tests were run, it is not possible to determine whether ECS-2FC_ 1 is an outlier or represents behavior

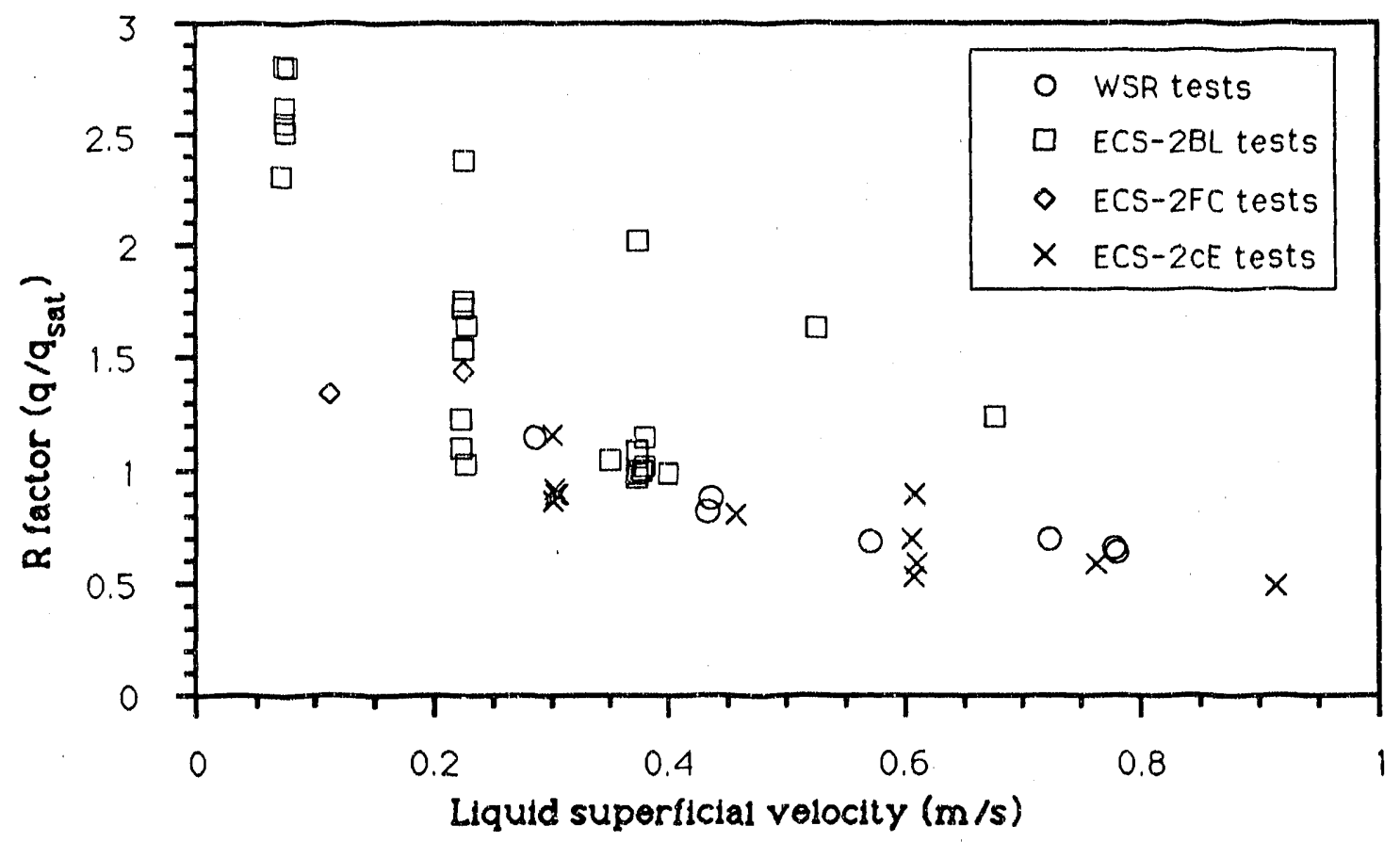

Figure 4.26. INEL thermal excursion data with test facility as a parameter 
unique to flow coast down.

Review of the information in Figure 4.26 does not suggest any bias in the data due to the lower plenum cooling coil operation or the different wall temperature criteria used to define onset of excursion. However, on several of the ECS-2BL experiments, if the $520 \mathrm{~K}$ (rather than the $620 \mathrm{~K}$ ) wall temperature criteria would have been used, the experiments would have been terminated sooner (thus at lower power level) due to the dryout-rewet cycles discussed in Section 4.1. The ECS-2BL and WSR dat. points were reviewed to determine which data points could be affected by the wall temperature criteria. Table $4.7 \mathrm{summarizes}$ the influence of the trip criteria on the $R$ factor for the ECS-2BL and ECS-2WSR data sets. Results in Table 4.7 indicate that the saturation ratio for ten experiments was affected. Minor changes in $\mathrm{R}$ factor $(<6 \%)$ resulted in six of those cases. For four experiments, the change in the trip criterion resulted in a change in the $\mathrm{R}$ value by more than $10 \%$ (10\% is the test repeatabiliity as shown in Appendix F).

\subsection{Comparison of Excursion Criteria and Wall Saturation Criteria}

One of the uses of the INEL excursion data is to provide a basis for comparison to excursion data obtained from other facilities and also to provide a relative base for data gathered using wall saturation temperature rather than excursion criteria. A comparison of data from several different sources is shown in Figure 4.27. Data on this figure include those in Figure 4.26 in addition to data from the INEL ECS-1 thermal excursion tests [10]. the INEL ECS-2b wall saturation tests [11], and WSRL excursion data from rigs $F A$ and $F B$ [14].

Figure 4.27 indicates that there is reasonable agreement among the data from the different facilities. This comparison shows the much more conservative nature of the wall saturation criteria relative to the excursion criteria. $R$ factors for the wall saturation criteria are generally about half of those for the excursion criteria for a given superficial velocity.

Figure 4.27 contains data gathered from test sections with flat axial power profiles and from facilities with axial cosine power profiles. With respect to the excursion data, it appears that the range in results from any given facility is as large as or larger than the data spread between any two given facilities. From this observation, one can conclude that for the global 


\begin{tabular}{|c|c|c|c|c|c|c|}
\hline TEST ID & $\begin{array}{c}\text { Power to } \\
\text { Saturate } \\
\text { Outlet } \\
(\mathrm{kW}) \\
\end{array}$ & $\begin{array}{c}520 \mathrm{~K} \text { trip } \\
\text { Total } \\
\text { Test Section } \\
\text { Power } \\
(\mathrm{kW})\end{array}$ & $\begin{array}{l}\text { criteria } \\
\text { R factor } \\
\text { (P/Psat) } \\
\end{array}$ & $\begin{array}{l}\frac{620 \mathrm{~K} \text { trip }}{\text { Total }} \\
\text { Test Section } \\
\text { Power } \\
(\mathrm{kW})\end{array}$ & $\begin{array}{l}\text { R factor } \\
\text { (P/Psat) } \\
\end{array}$ & $\begin{array}{r}\text { Percen } \\
\text { change } \\
\text { R factor } \\
\end{array}$ \\
\hline ECS-2BL_1 & 29.54 & 70.80 & 2.34 & $70.80^{2}$ & 2.34 & 0.0 \\
\hline ECS-2BL_1B & 31.37 & 68.00 & 2.17 & 78.69 & 2.51 & 13.6 \\
\hline ECS-2BL_2 & 91.88 & 90.00 & 0.98 & 101.48 & 1.10 & 11.3 \\
\hline ECS-2BL_5 & 19.07 & 50.00 & 2.62 & 53.48 & 2.80 & 6.5 \\
\hline ECS-2BL_5B & 17.85 & 50.15 & 2.81 & 50.15 & 2.81 & 0.0 \\
\hline ECS-2BL_5C & 18.78 & 47.96 & 2.55 & 47.96 & 2.55 & 0.0 \\
\hline ECS-2BL_5D & 19.36 & 50.76 & 2.62 & 50.76 & 2.62 & 0.0 \\
\hline ECS-2BL_6 & 56.77 & 97.50 & 1.72 & $97.50^{2}$ & 1.72 & 0.0 \\
\hline ECS-2BL_7 & 101.28 & 99.80 & 0.99 & 99.80 & 0.99 & 0.0 \\
\hline ECS-2BL_7B & 97.50 & 96.00 & 0.98 & 99.15 & 1.02 & 3.2 \\
\hline ECS-2BL_1 $11^{3}$ & 29.45 & 50.59 & - & 50.59 & - & - \\
\hline ECS-2BL_11B & 29.93 & 70.60 & 2.36 & $70.60^{2}$ & 2.36 & 0.0 \\
\hline ECS-2BL_12 & 57.63 & 66.41 & 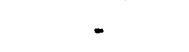 & 66.41 & - & - \\
\hline ECS-2BL_12B & 48.00 & 96.94 & 2.02 & 96.94 & 2.02 & 0.0 \\
\hline ECS-2BL_13 & 62.74 & 101.97 & 1.63 & 101.97 & 1.63 & 0.0 \\
\hline ECS-2BL_14 & 90.85 & 112.43 & 1.24 & 112.43 & 1.24 & 0.0 \\
\hline ECS-2BL_17 & 61.77 & 63.32 & 1.03 & 63.32 & 1.03 & 0.0 \\
\hline ECS-2BL_18 & 98.76 & 96.00 & 0.97 & $97.50^{2}$ & 0.99 & 2.0 \\
\hline ECS-2BL_18B & 103.35 & 98.40 & 0.95 & $98.40^{2}$ & 0.95 & 0.0 \\
\hline ECS-2BL_22 & 57.74 & 71.13 & 1.23 & 71.13 & 1.23 & 0.0 \\
\hline ECS-2BL_23 & 95.28 & 101.50 & 1.07 & 103.82 & 1.09 & 2.2 \\
\hline ECS-2BL_23B & 97.58 & 94.00 & 0.96 & 96.61 & 0.99 & 2.7 \\
\hline ECS-2BL_26 & 57.01 & 93.72 & 1.64 & 93.72 & 1.64 & 0.0 \\
\hline ECS-2BL_26B & 57.62 & 89.01 & 1.54 & 89.01 & 1.54 & 0.0 \\
\hline ECS-2BL_27 & 89.18 & 91.00 & 1.02 & $93.75^{2}$ & 1.05 & 2.6 \\
\hline ECS.2FC 1 & 30.15 & 40.35 & 1.34 & 40. & 1.34 & 0.0 \\
\hline ECS-2FC_2 & 55.95 & 80.81 & 1.44 & 80.81 & 1.44 & 0.0 \\
\hline ECS-2WSR0380 & 88.27 & 91.00 & 1.03 & 101.88 & 1.15 & 10.7 \\
\hline ECS-2WSR0580 & 137.18 & 121.22 & 0.88 & 121.22 & 0.88 & 0.0 \\
\hline ECS-2WSR0580C & 136.03 & 110.88 & 0.82 & 110.88 & 0.82 & 0.0 \\
\hline ECS-2WSR0760 & 183.01 & 126.82 & 0.69 & 126.82 & 0.69 & 0.0 \\
\hline ECS -2 WSR 0960 & 230.59 & 162.50 & 0.70 & $162.50^{2}$ & 0.70 & 0.0 \\
\hline ECS-2WSR 1040 & 251.70 & 121.00 & 0.48 & 161.39 & 0.64 & 25.0 \\
\hline ECS-2WSR 1040B & 244.82 & 161.25 & 0.66 & 161.25 & 0.66 & 0.0 \\
\hline
\end{tabular}

1. Defined as the $R$ factor calculated using the $620 \mathrm{~K}$ criteria minus the $R$ factor calculated using the 520 criteria times 100 divided by the $620 \mathrm{~K} R$ factor.

2. Logbook recorded value due to heater voltage offset on DAS channel.

3. Dryout did not occur on this test. 


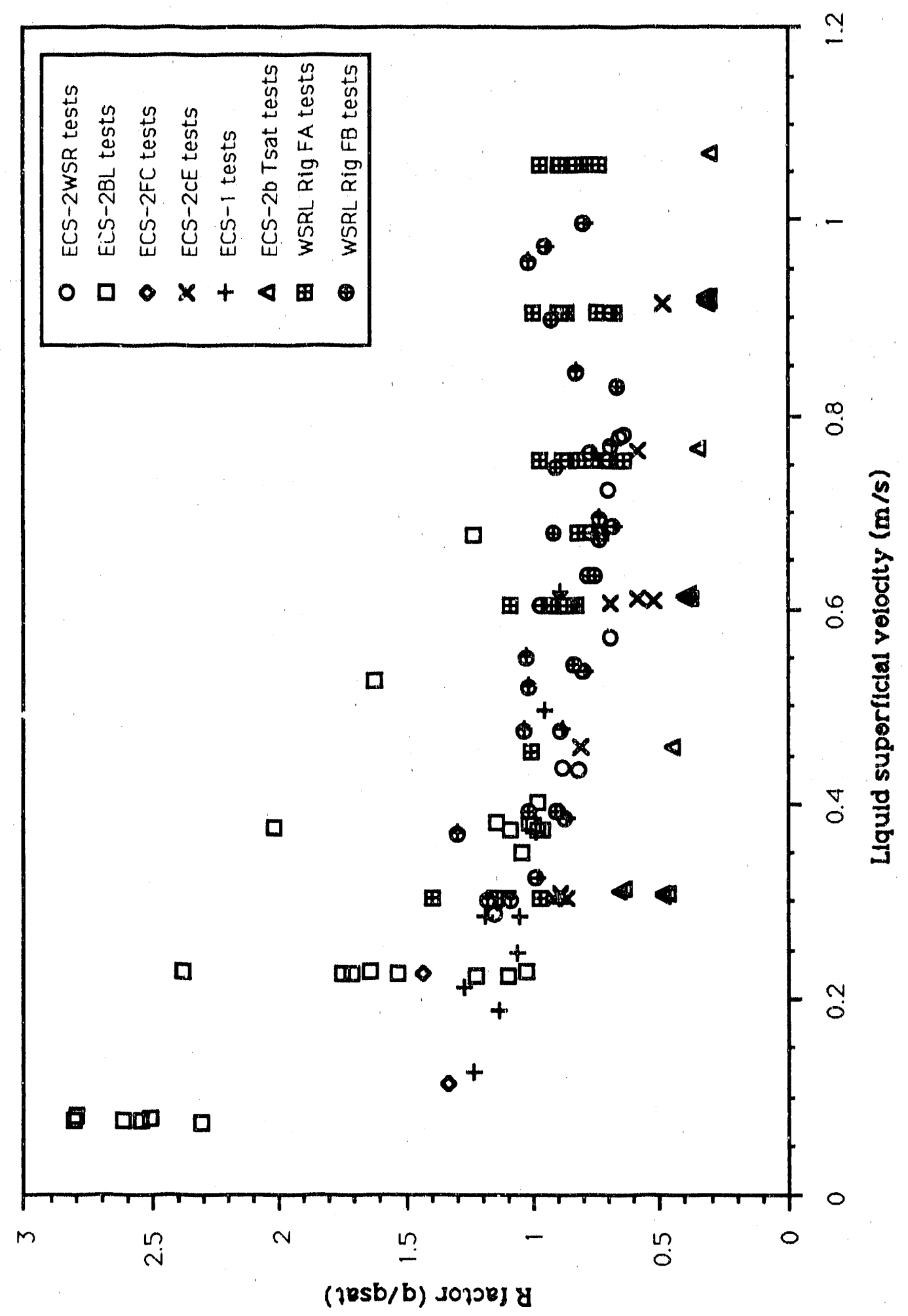

Figure 4.27. Thermal excursion data from several sources and INEL wall saturation data 
saturation ratio, there does not appear to be a significant difference between the cosine profile and the flat axial power profile results. However, as argued by Duffey and Hughes, the dryout process is governed by heat flux, energy (local fluid temperature effect), and flow. Thus, for a given set of conditions, the axial power profile will influence the physical location and the total power at which dryout occurs. Close examination of the data in Figure 4.27 supports this argument. Note that the $R$ values for the INEL ECS -2 experiments (cosine axial power profile) are approximately $10-15 \%$ lower than $R$ values for comparable SRS Rig FA experiments (flat axial power profile). This result stems from the fact that for a given total power, the ECS-2 facility had higher heat fluxes than did the FA system. 


\section{CONCLUSIONS}

More than 40 experiments covering a range of thermal-hydraulic conditions expected to occur during a hypothesized large break loss-of-coolant accident (LOCA) in a Savannah River Production reactor were successfully conducted at the INEL to support SRS investigation of downflow dryout in a heated annulus. These data are described and documented in this report, which will serve as a reference for use of the data in production reacior power limits setting calculations and computer code evaluations. Specific conclusions derived from evaluation of the INEL thermal excursion data include:

- Thermal excursion data represented in terms of the saturation ratio, $R$ (power at excursion divided by power required to saturate the bulk flow) show that $R$ varies from a maximum of $2.5-3$ to a minimum of about 0.5 for the superficial velocity range from 0.07 to about $1 \mathrm{~m} / \mathrm{s}$, respectively.

- The saturation ratio is primarily a function of test section flow (liquid flowrate, liquid superficial velocity, or film Reynolds number). Inlet liquid temperature and facility back pressure have a weaker influence on the $R$ value than does flow.

- Depending to some extent on inlet fluid temperature, the $\mathbf{R}$ factor crosses unity for a superficial velocity between 0.3 and $0.45 \mathrm{~m} / \mathrm{s}$. This observation indicates that different phenomena are causing wall thermal excursion depending on the flowrate. R factors larger than unity imply that the bulk fluid is at saturation when excursion occurs while $R$ factors less than one indicate that excursion occurs before the bulk flow is saturated.

- Wall dryout is caused by local flooding and/or dry patch spreading depending on the flow and heat flux conditions. Flowrate plays a major role in determining which dryout conditions predominate.

- Air entrainment is a strong function of the liquid flowrate and the liquid temperature and a weaker function of the test section back pressure. Air entrainment increases with increasing flowrate and decreases with increasing inlet fluid temperature and increasing back pressure on the test section. Air entrainment rate decreases 
substantially at the onset of thermal excursion.

- INEL data showed that the aluminum wall of the heated test section could rewet even after temperatures in excess of $550 \mathrm{~K}$ had been achieved. Many experiments showed prolonged operation consisting of intermittent dryout-rewet cycles followed by a sustained thermal excursion after power increases had been effected.

- Although the processes leading to thermal excursion were quite chaotic and usually consisted of churn-turbulent types of flow regimes, the test results are very repeatable. On experiments conducted to examine repeatability, a spread of less than $10 \%$ in $R$ value was noted.

- Hardware and test conduct differences between the various facilities used to conduct the experiments had little effect on test results.

- The present data are in general agreement with data gathered at the SRS Heat Transfer Laboratory. With respect to saturation ratio results, it appears that facilities with axial cosine power shapes produce data generally consistent with data from facilities with flat axial power profiles although there is considerable data scatter for all facilities. For comparable conditions, $R$ values obtained with a axial cosine power profile are $10-15 \%$ lower than $R$ values obtained with a flat axial power profile.

- Preliminary statistical examination of the excursion data suggests that flow is the dominant variable. Excursion data represented as $R$ factor as a function of flow can be reasonably correlated with an empirical power law.

- A mechanistic approach such as that proposed by Duffey and Hughes essentially results in a power law ropresentation of the data. Their correlation with recommended constants underpredicts the dryout heat flux.

- Two flow coastdown experiments were conducted to examine the influence of flow controlled (at constant power) experiment results relative to power controlled (at constant flow) experiment results. Although the flow coastdown results suggest the $R$ values are lower 
than those obtained under constant flow-increasing power conditions, insufficient data are available to derive concrete conclusions. It appears that one of the flow coastdown points may be an outlier.

- For the INEL excursion tests, data gathered at $347 \mathrm{~K}$ inlet temperature shows saturation ratios nearly a factor of two larger than the saturation ratio for data from inlet liquid temperatures less than or equal to $326 \mathrm{~K}$. No explanation for this difference currently exists.

- Large scatter in the saturation ratio versus liquid superficial velocity plots and the unique behavior of the $346 \mathrm{~K}$ data set relative to other data sets, implies our incomplete understanding of the mechanisms governing the downflow dryout process. Clearly, further work is necessary to more fully understand the dryout process and the mechanistic representation of the data trends. 


\section{REFERENCES}

[1] J. L. Steimke, "Status of Heat Transfer Rig FA," WSRC-TKp0-44, Draft Report, January 26,:990.

[2] J. R. Taylor, "Melting in Mark 16 Assemblies During a Loss of Coolant Accident," DPST-79-445, December 7, 1979.

[3] J. L. Steimke, "Emergency Cooling System Power Limits for Reactor Assemblies," SPST-86-815, December 1, 1986.

[4] J. L. Steimke, "Status of Heat Transfer Experiment," SPT-88-854, October 12,1988 .

[5] J. L. Steimke, "Heated Annulus Test, Rig A," Experimental Task Plan, Task 88-059-1, Rev. 0, February 8, 1989.

[6] H. N. Guerrero, "Heated Annulus Test, Rig B," Task Plan 88-064-1, March 3, 1989.

[7] A. L. Kielpinski, "Heated Channel Experiment," Task Plan 88-061-2, May 1, 1989.

[8] B. L. Johnston, "Thermal Excursions Under ECS Conditions in a Single Annulus with Azimuthal Tilt," WSRC-TR-90-45, February 1990.

[9] J. L. Steimke and C. M. Hart, "Non-Boiling Heat Transfer in Rig FA," NED-ECS-890173, November 1989.

[10] V. T. Berta, K. G. Condie, and J. A. Shroeder, "Phenomenological Scoping Studies of Downflow in a Uniformly Heated Ribbed Vertical Annulus," EGG-ES\&H-8464, ES\&H-SRP-3-89, August 1989.

[11] J. L. Anderson, K. G. Condie, and T. K. Larson, "Downflow Heat Transfer in a Heated Ribbed Vertical Annulus with a Cosine Power Profile (Results from Test Series ECS-2b)," Idaho National Engineering Laboratory Report, EGG-EAST-9144, July, 1990.

[12] J. L. Anderson, K. G. Condie, ad T. K. Larson, "Justification and Methodology for Metal Thermocouple Corrections (ECS-2c and ECS-2b Test Series)," draft Idaho National Engineering Laboratory Report, ir ansmitted by letter from J. L. Ande. ion (INEL) to J. L. Steinke (WSRC), PROPOSED ECS-2c THERMOCOUPLE CORRECTIONS, JLA-11-90, September 28, 1990.

[13] R. B. Duffey and E. D. Hughes, "Dryout Stability and Inception at Low Flowrates," Idaho National Engineering Laboratory Report, EGG-EAST. 8491 , November 1989.

[14] J. L. Anderson (INEL) personal communication with J. L. Steimke (WSRC), May 21, 1990. 


\section{Appendix A}

Engineering Drawings for the ECS-2 Test Fixture 


\section{Appendix A}

\section{Engineering Drawings for the ECS-2 Test Fixture}

Engineering drawings that document the design and construction of the ECS-2 test facility hardware are presented on the following pages. Additional information and drawings for the ECS-2c test fixture can be found in Appendix A of Anderson, et al. [Anderson, et al 1990].

\section{Reference}

Anderson, et al 1990 J. L. Anderson, K. G. Condie, and T. K. Larson,

"Downflow Heat Transfer in a Heated Ribbed Vertical Annulus with a Cosine Power Profile (Results for Test Series ECS-2b)," Idaho National Engineering Laboratory Report, EGG-EAST-9144, July, 1990. 


\section{NOTES.}

1. PRESERVE AND PROTECT PER STO 7020. CASS II

2. CLEANUNESS PER STO 7022. LEVEL $C$

3. MARK PER STO 7006-21 WTH 429993-1 ASSEMBLY

4. BRAZE PER CP DI 12.0. USUALLY WEPECT PRAR CP 9.6, APPENOXX I.

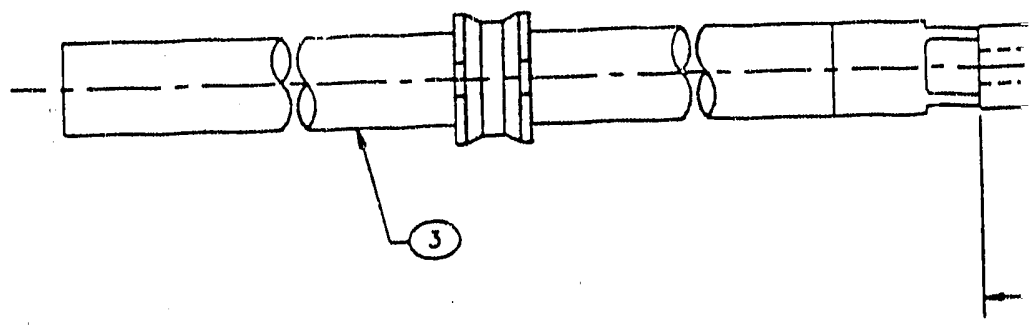

C
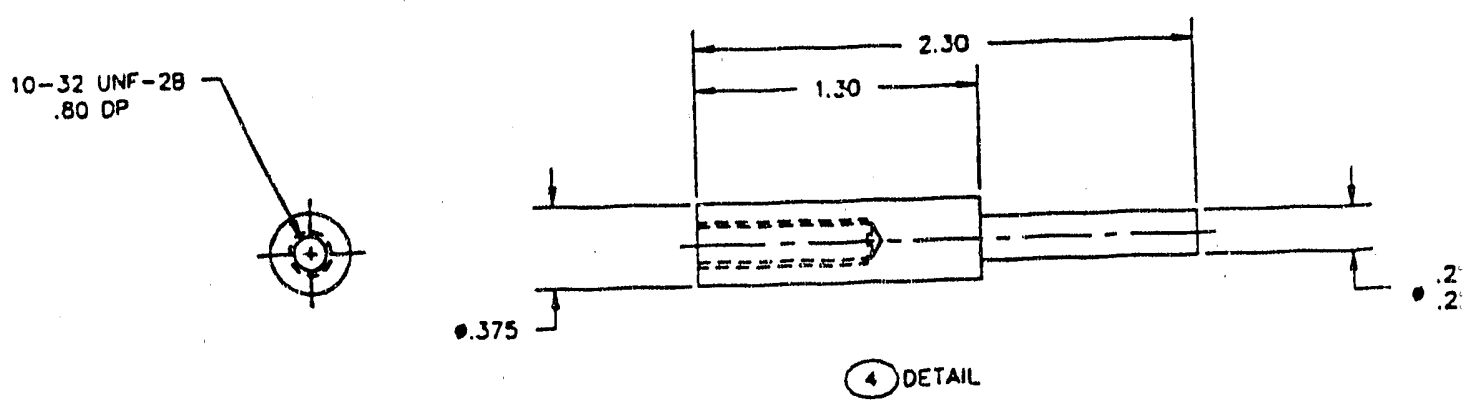

$B$
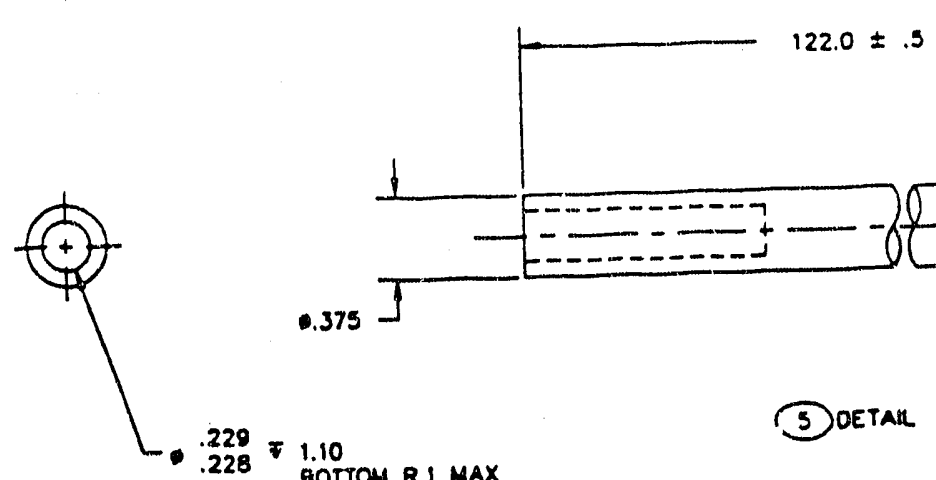

(5) Detak

A

OOTIOA R.I maX

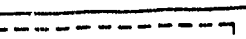

$---1-5+-$

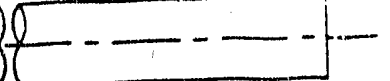

.228 


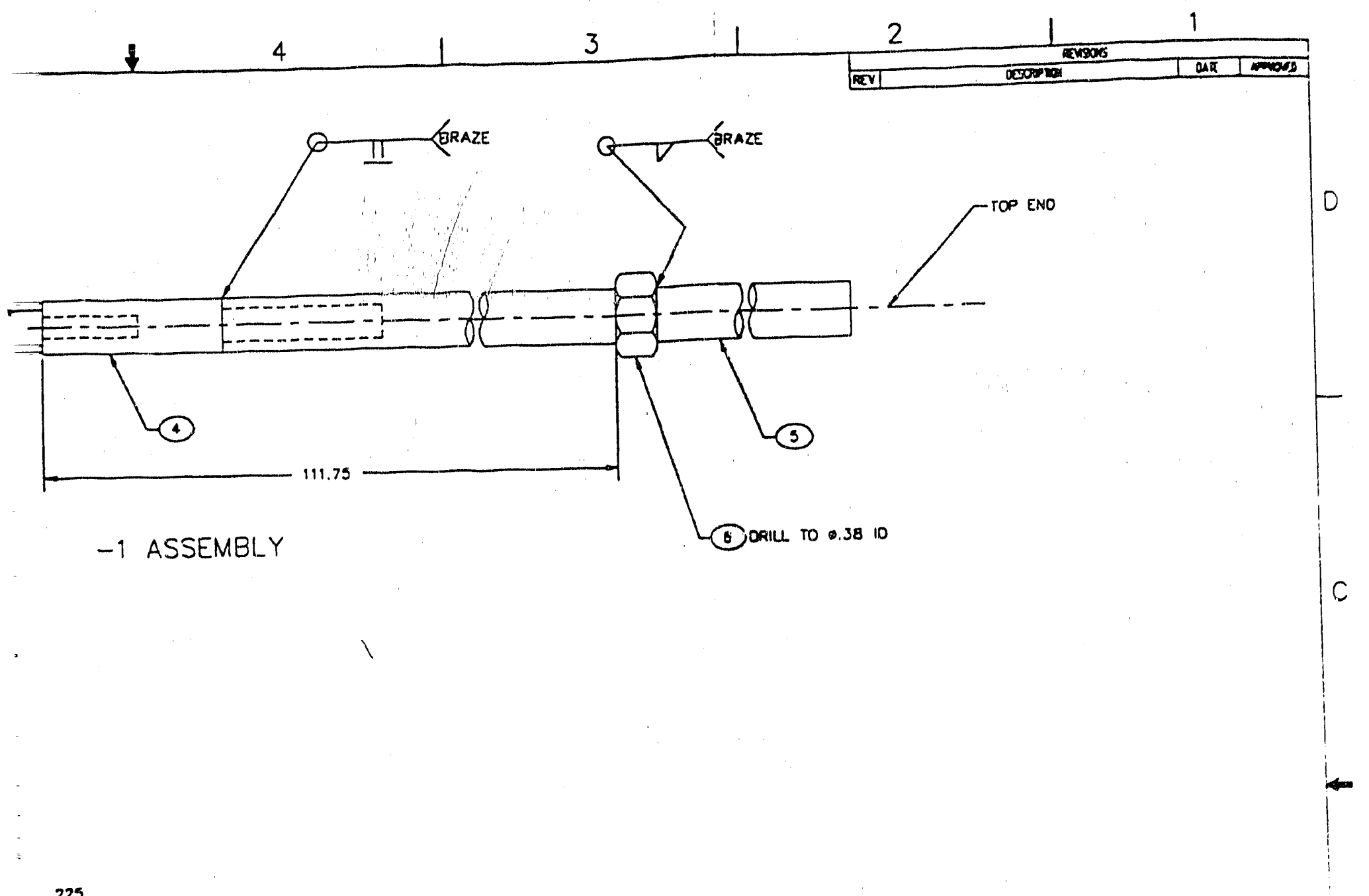

.225
.224

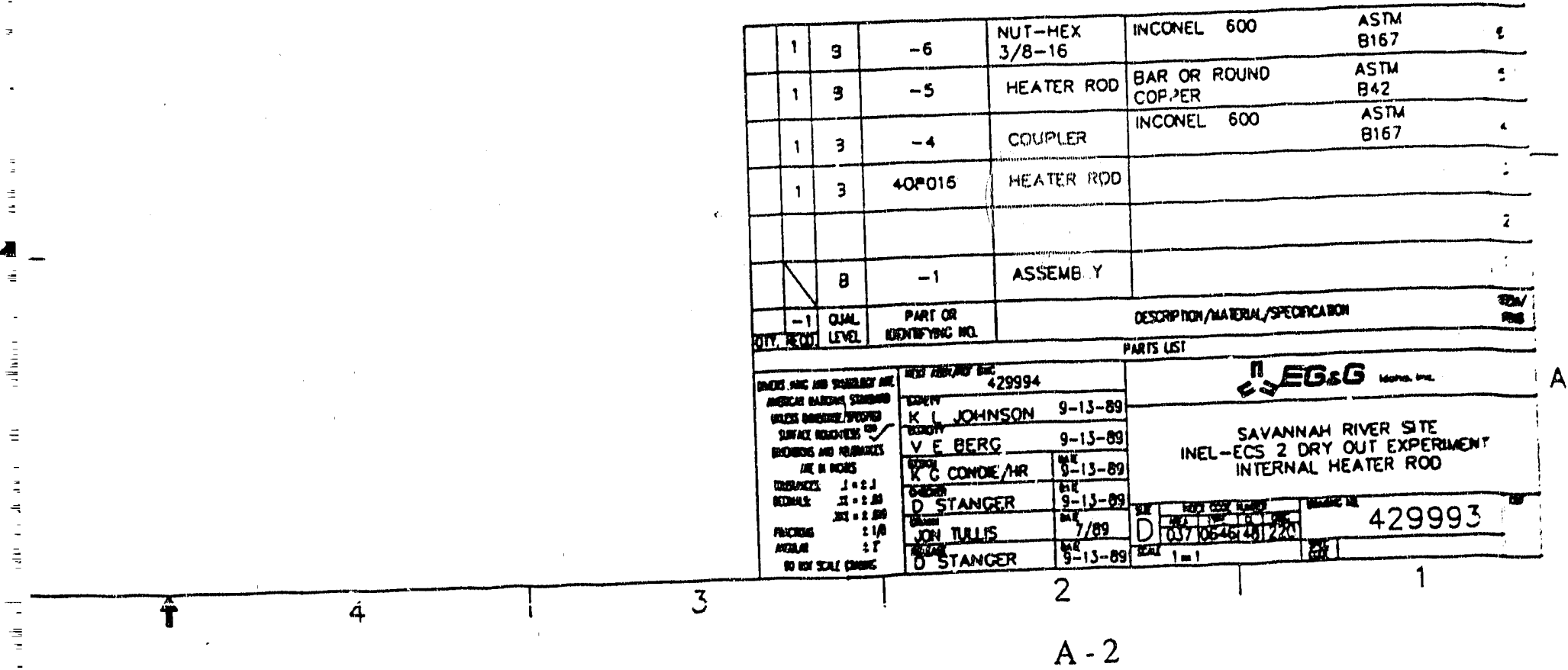




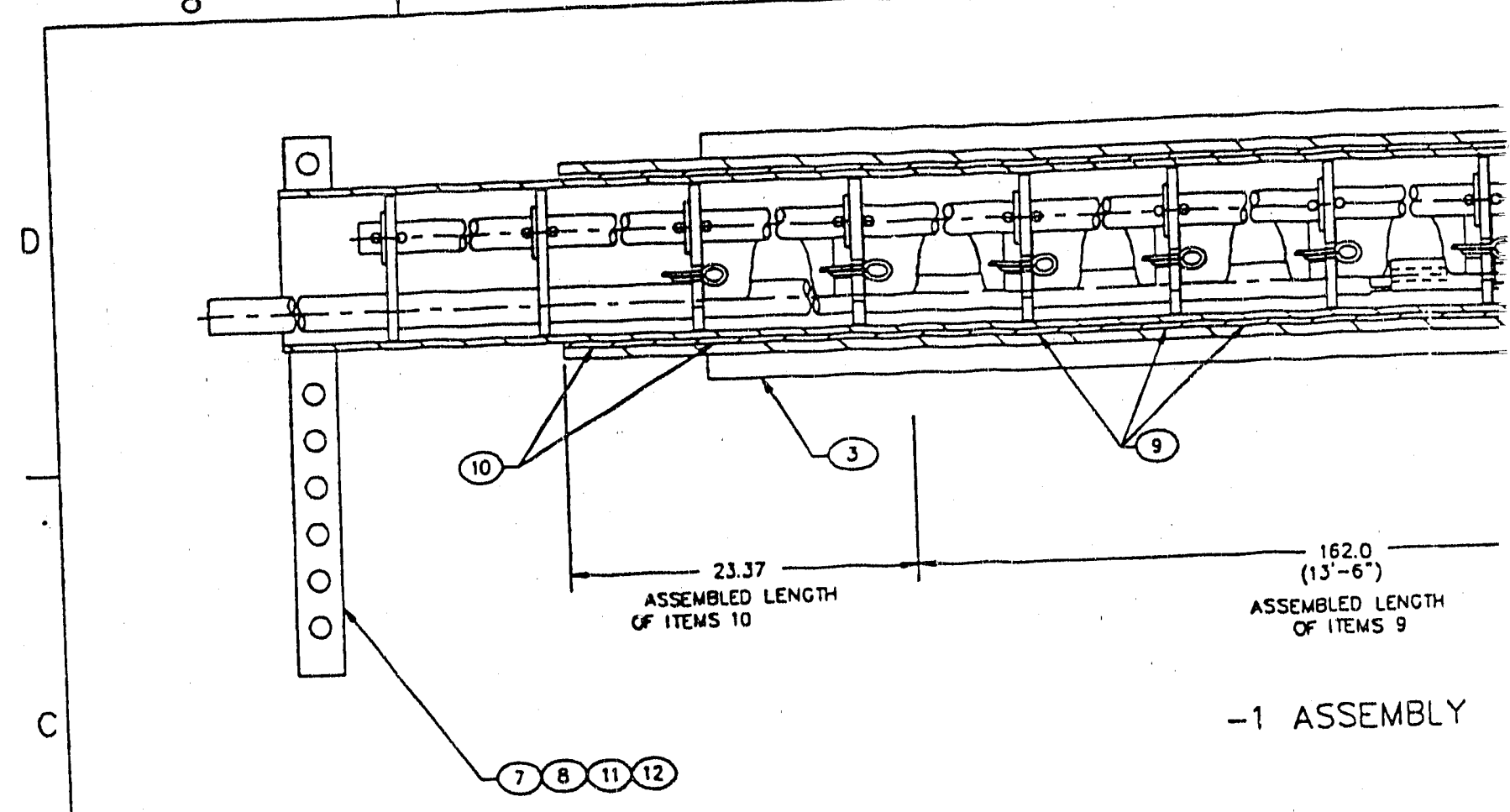

NOTES.

1. PRESERVE ANO PROTECT PER STO 7020. QASS II

2. CLEANLINESS PER STO 7022. LEVEL C

1. MARK PER STO 7006-202 MTH 429994-1 ASSY ON INOICATED SURFACE

A. MARK PER STO 7006-21 WTH 129994 ANO APPROPRIATE DASH MUMBER

5. WELD PER CP AZ.O USUALLY INSPECT PER CP 9.6. APPENDIX 1 UL DROCEDURE $B-3$. CRITERIA APPENOIX NN. $C-1$.

- $2.017 \pm .001$

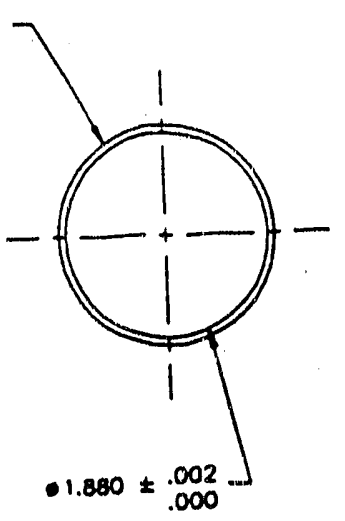

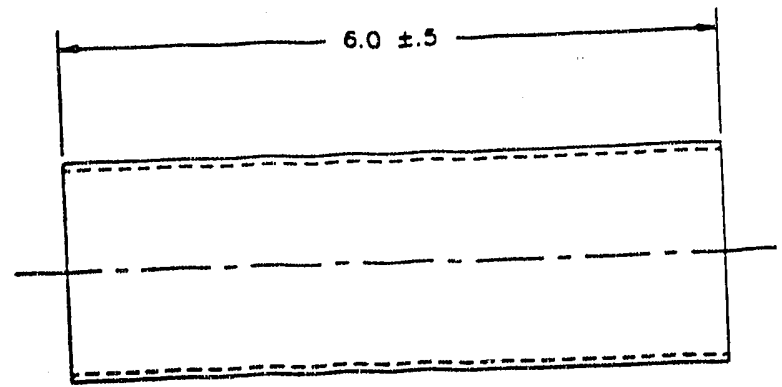

(8)(10)DETAIL A
2X ENTRE LENCTH AFTER ASSEMBLY 

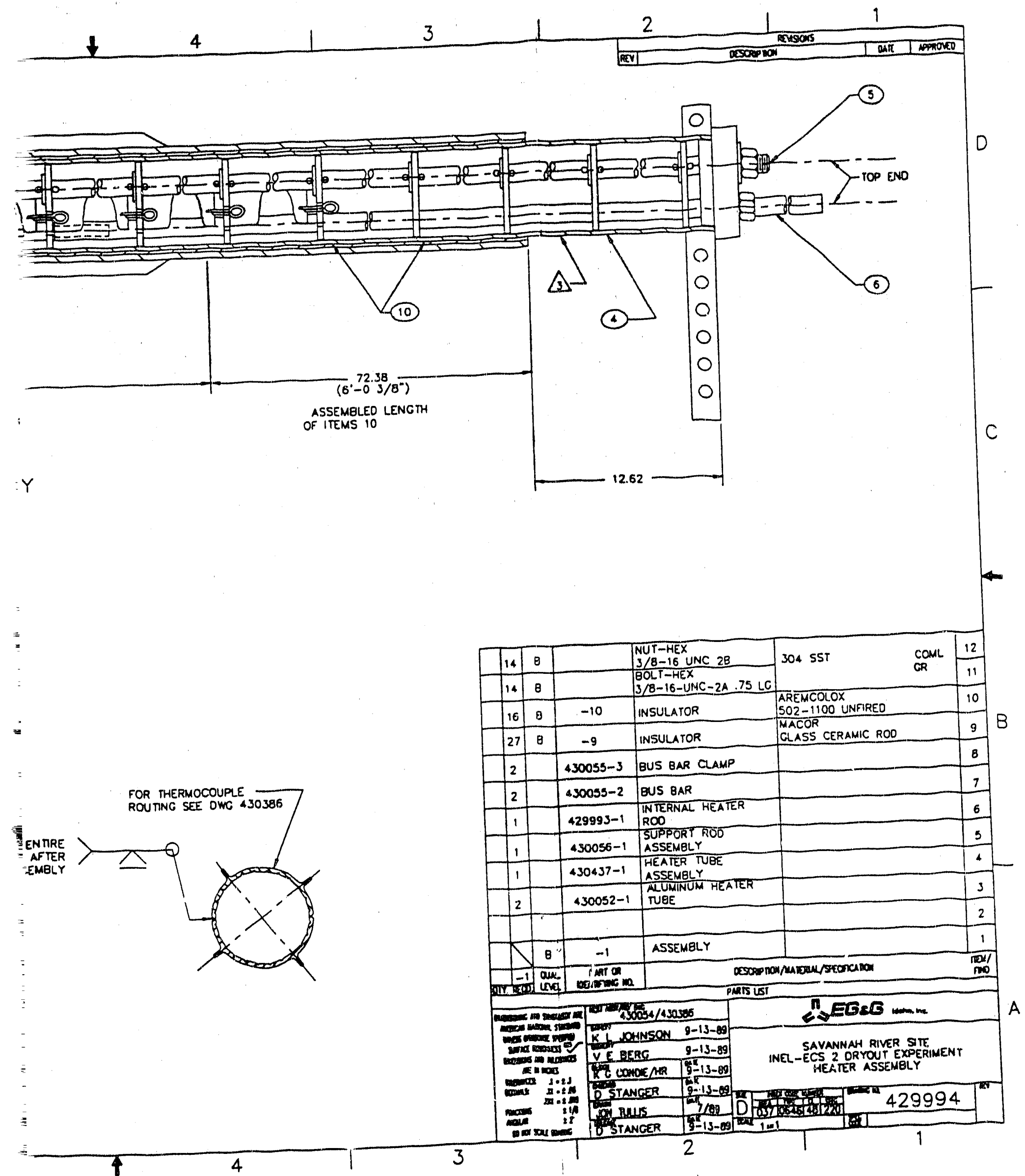

A - 3 


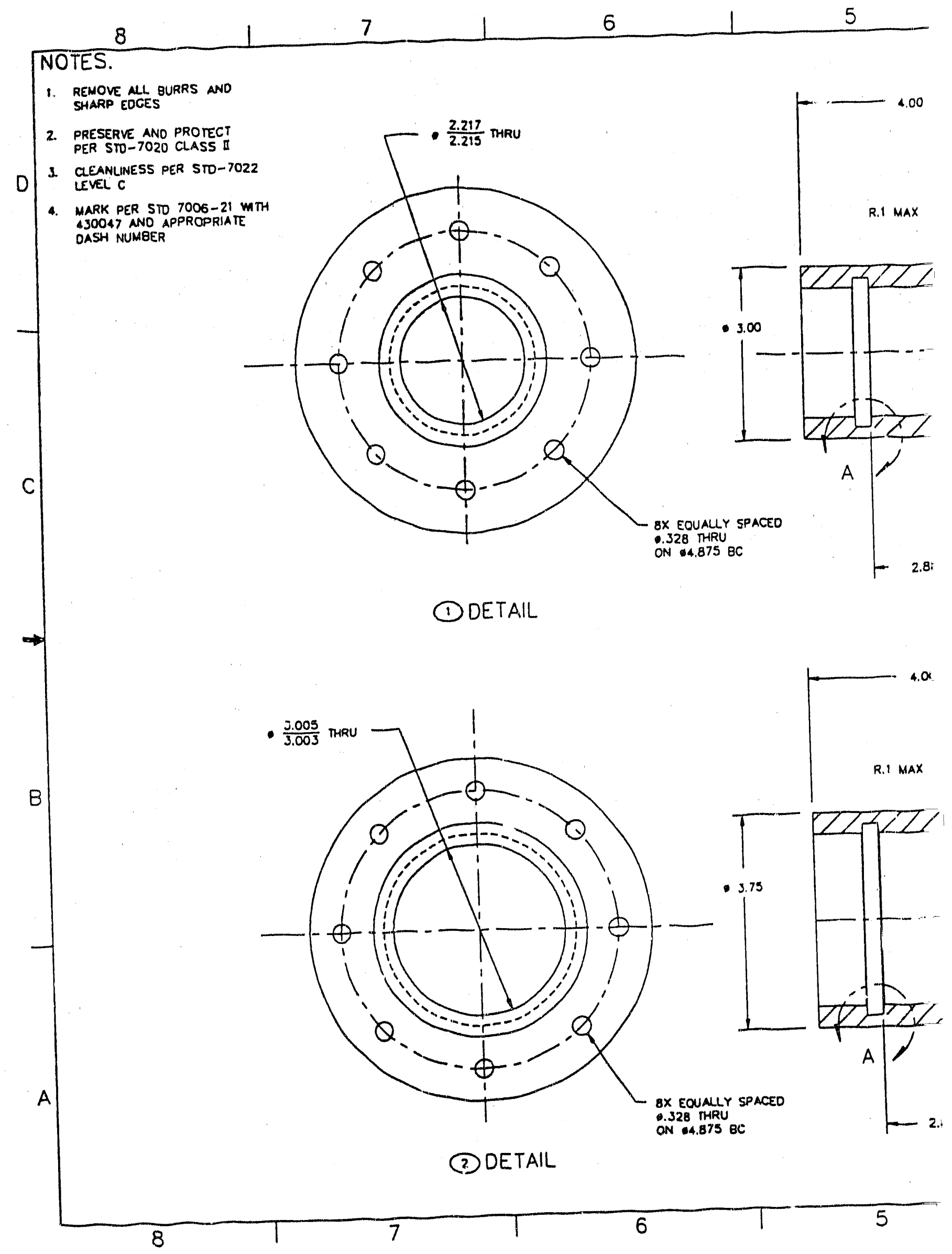




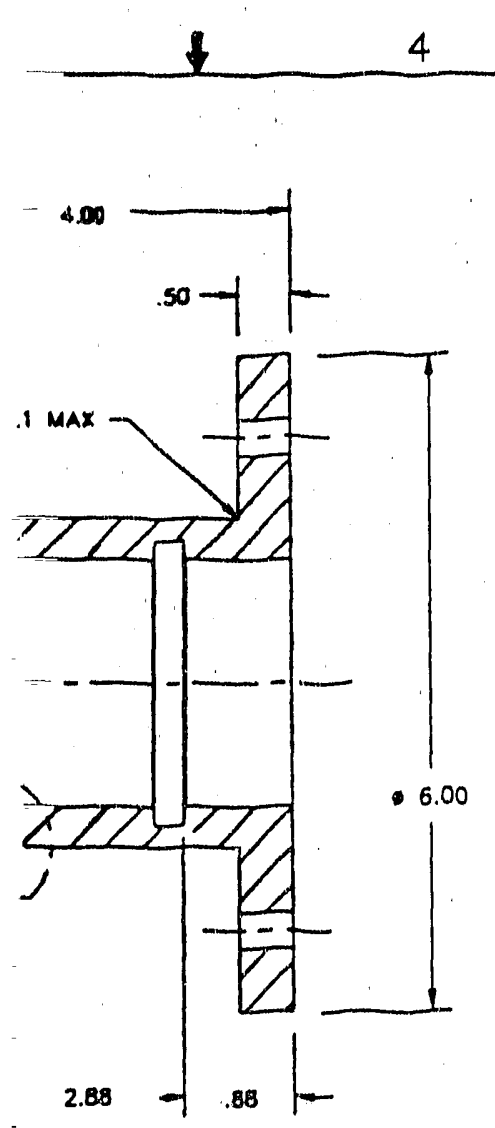

$3 \quad 1$

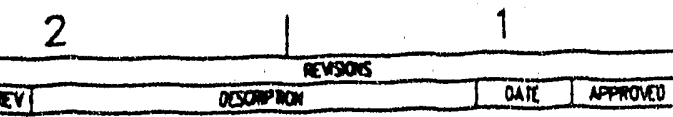

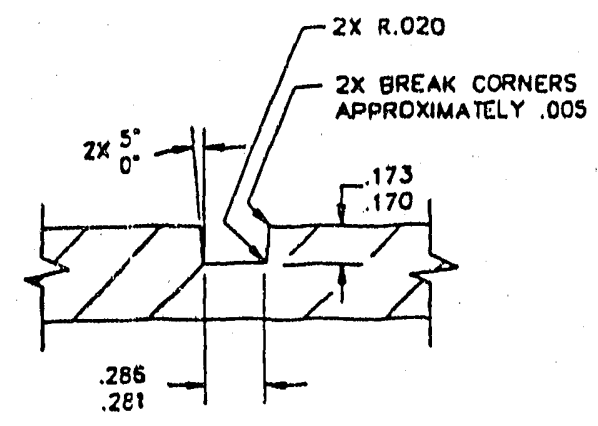

$$
\begin{aligned}
& \text { VIEW A } \\
& 2 \times \text { ITEN } \\
& 2 \times \text { ITEM } 2 \\
& \text { SCALE NONE }
\end{aligned}
$$
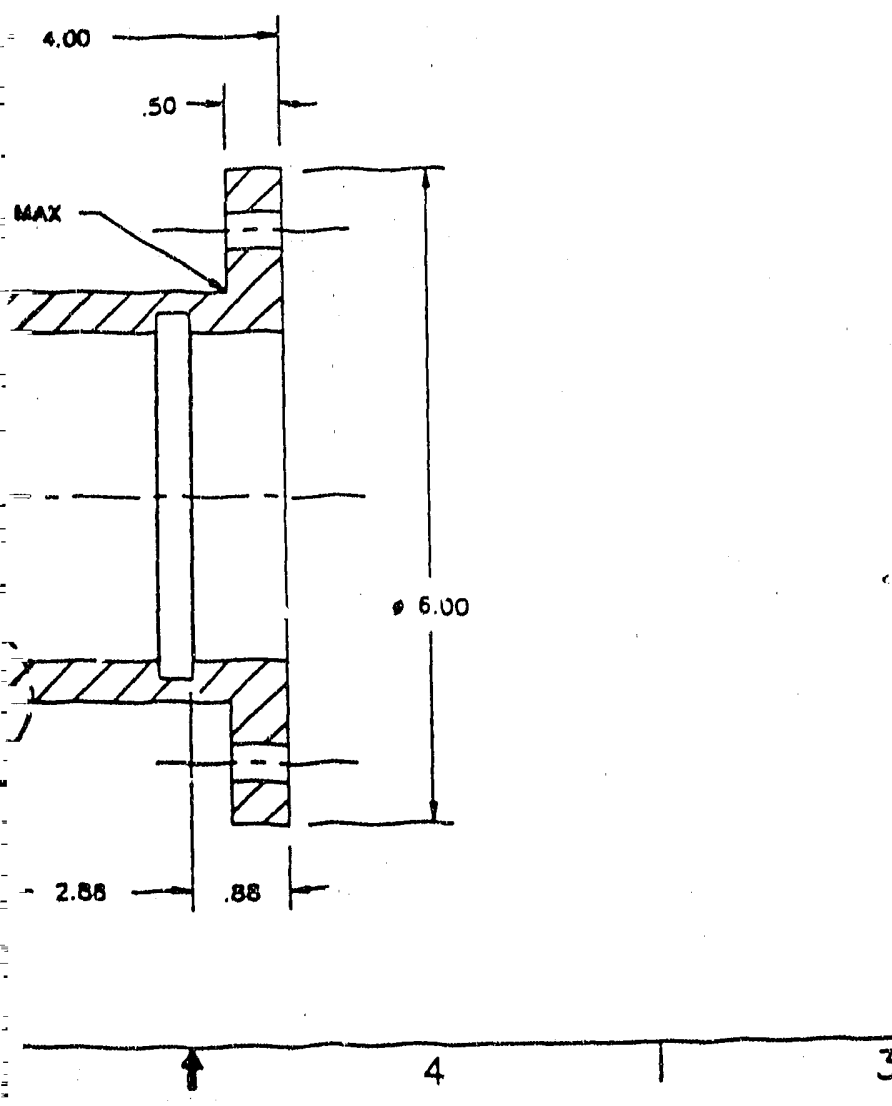

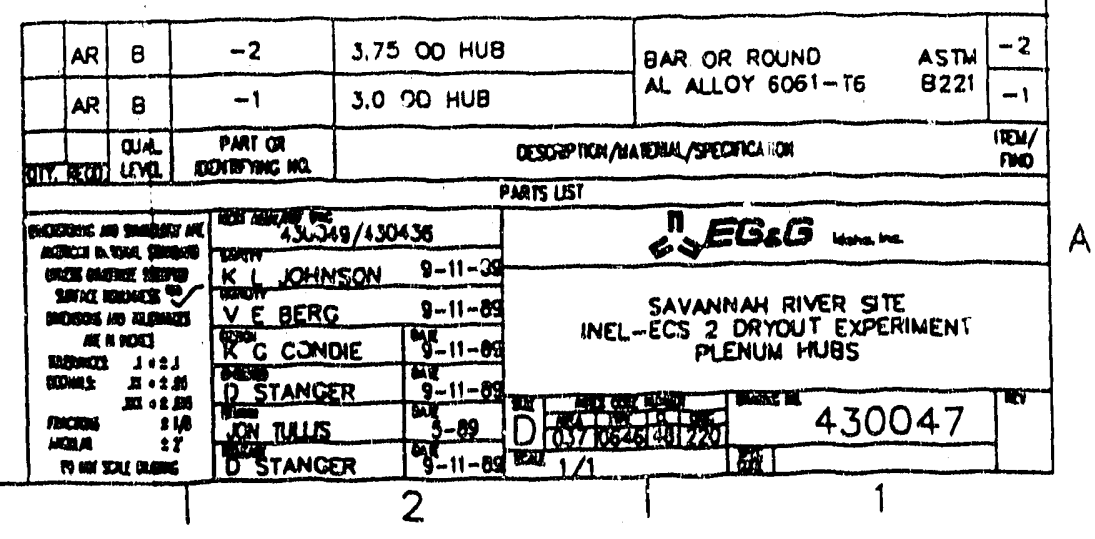

$$
\text { A }-4
$$


8

NOTES.

1. REMOVE ALL BURRS MNO SHARP EDGES

2. CLEANLINESS PER STO-7022 LEVEL C

3. PRESERVE AND PROTECT PER STO 7020 CLASS II

4. MARK PER STO 7006-21 WTH 430048 AND APPROPRIATE DASH NUMBER.
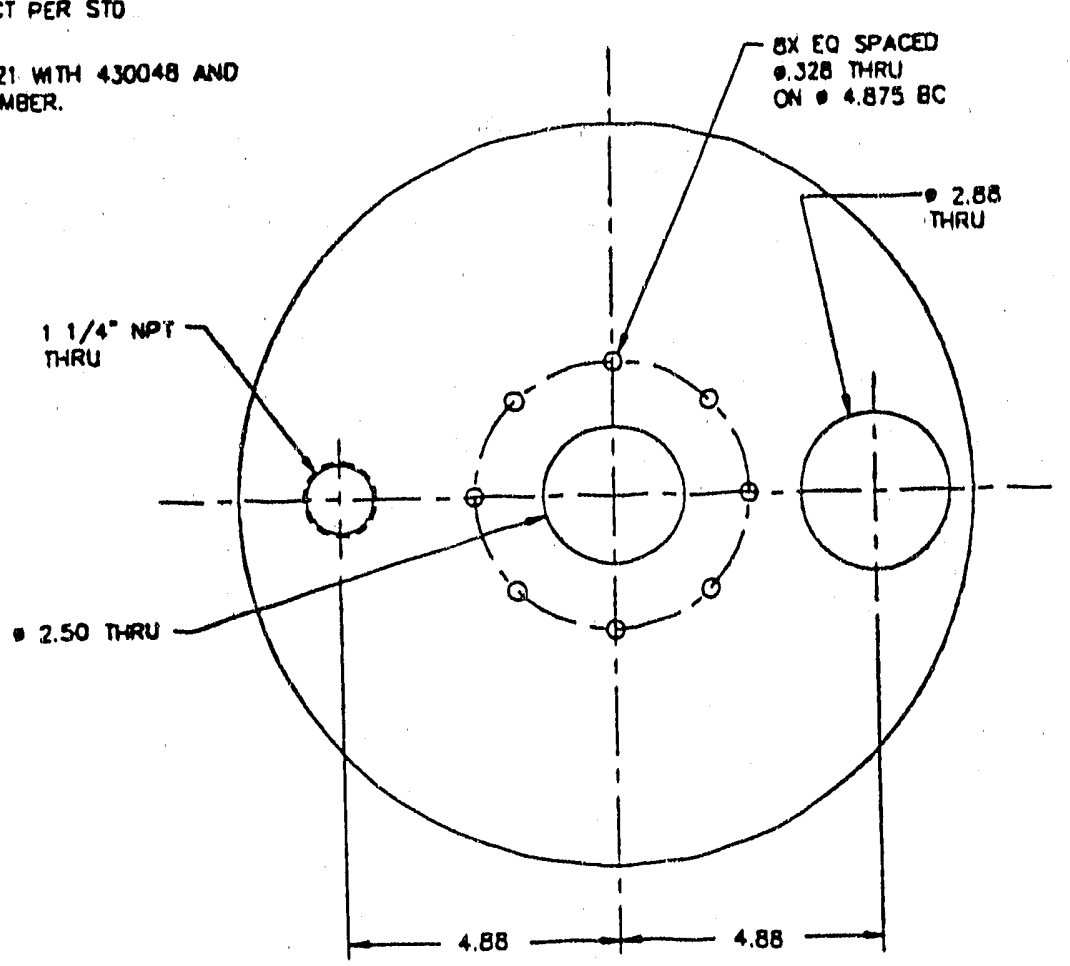

(1) DETAIL

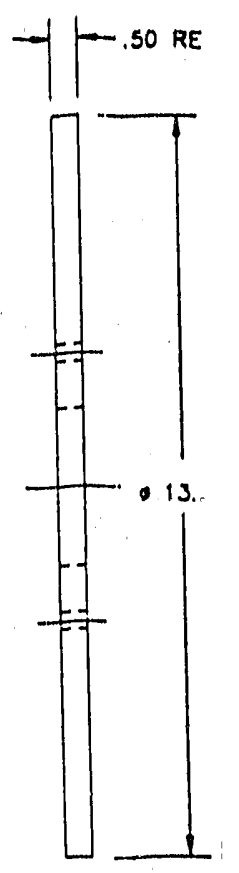

C

B

A
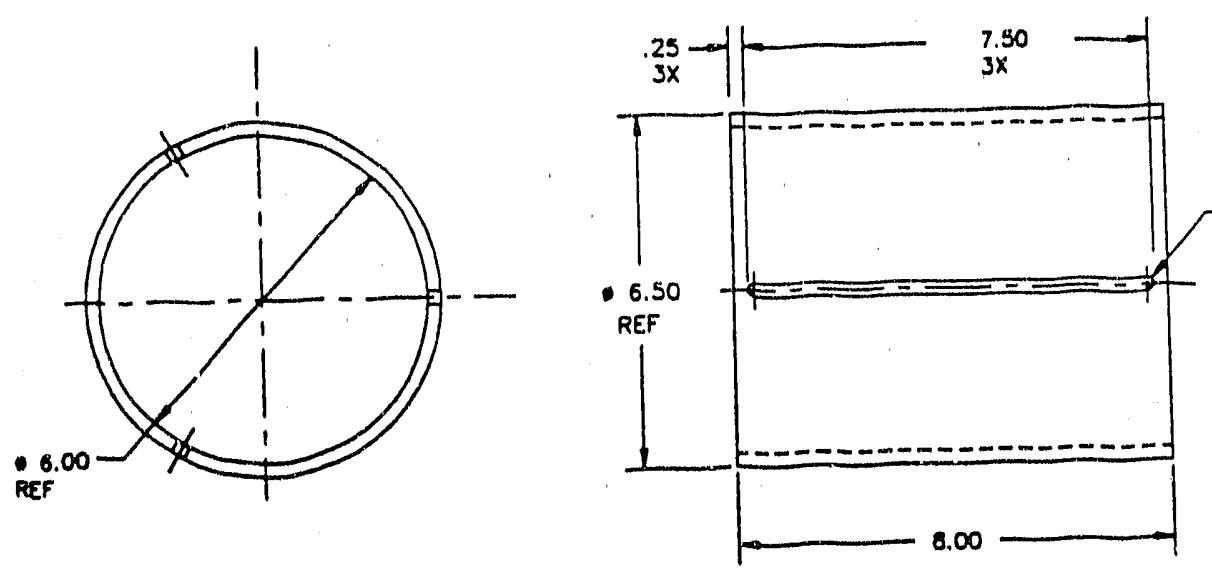

.31 slots

SO SPACEO

- 120

(3) DETAIL 


\begin{tabular}{lllllll}
1 & 4 & 3 & 2 & 1 & 1 \\
\hline
\end{tabular}

.50 REF

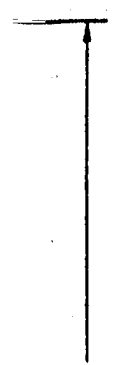

- 13.50

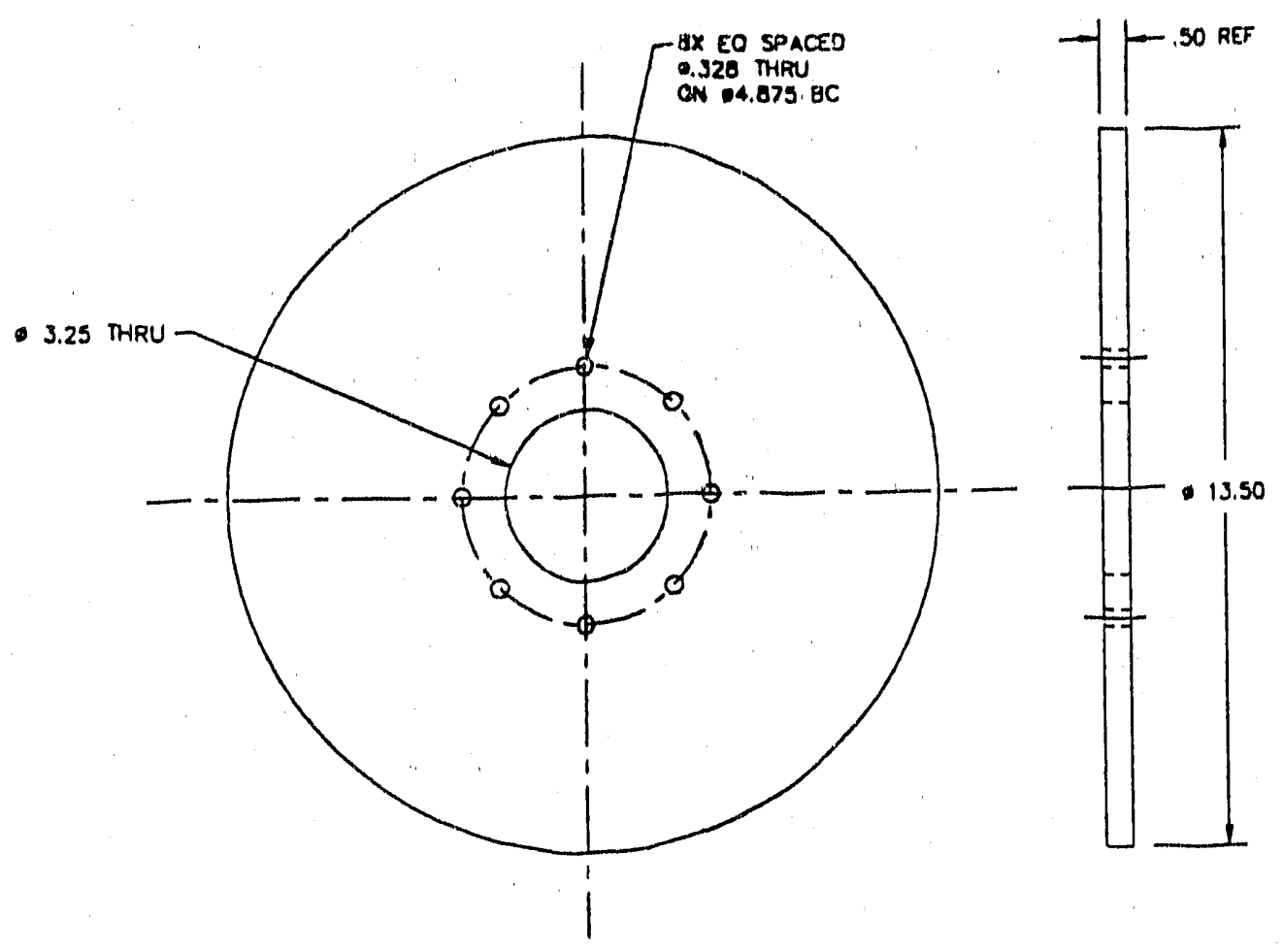

(2) DETAIL

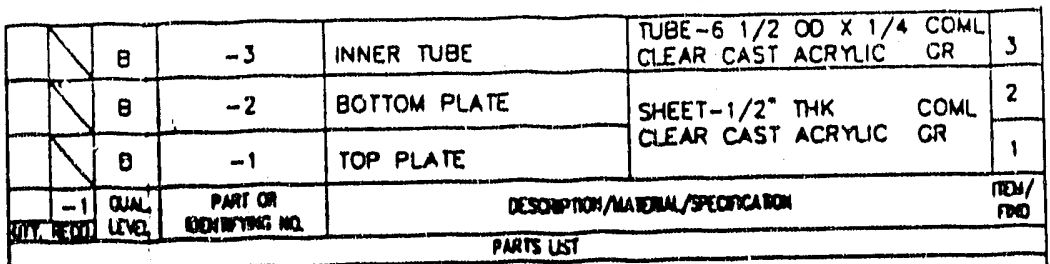

\begin{tabular}{|c|c|c|c|}
\hline 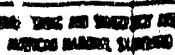 & Fienting & & $e^{n}=\mathrm{E}$. 15 \\
\hline & $\begin{array}{l}\text { Y E BERG } \\
\text { C CONOIE }\end{array}$ & $\frac{9-11-00}{\mid-11-00}$ & $\begin{array}{l}\text { SAVANMNH RIVER STE } \\
\text { INEL-ECS } 2 \text { ORYOUT EXPERIMENT } \\
\text { UPPER PLENUM PARTS }\end{array}$ \\
\hline & YCER & & 430048 \\
\hline
\end{tabular}


NOTES:

A SOVENT WELO JONT USING ITEM 19 OR APPROVEO EQUAL PER MANUFACTUREHS INSTRUCTONS

A MARK PER 5TO 7006-202 WTH 450049-1 ASSEMBLY ON INDICATED SURFACE

3. PRESERVE AND PROTECT PER STO-7020 CLASS II

4. CLEANUINESS PER STD-7022, LEVEL C

(5) ITEM 12 SUPPLIED GY OTHERS

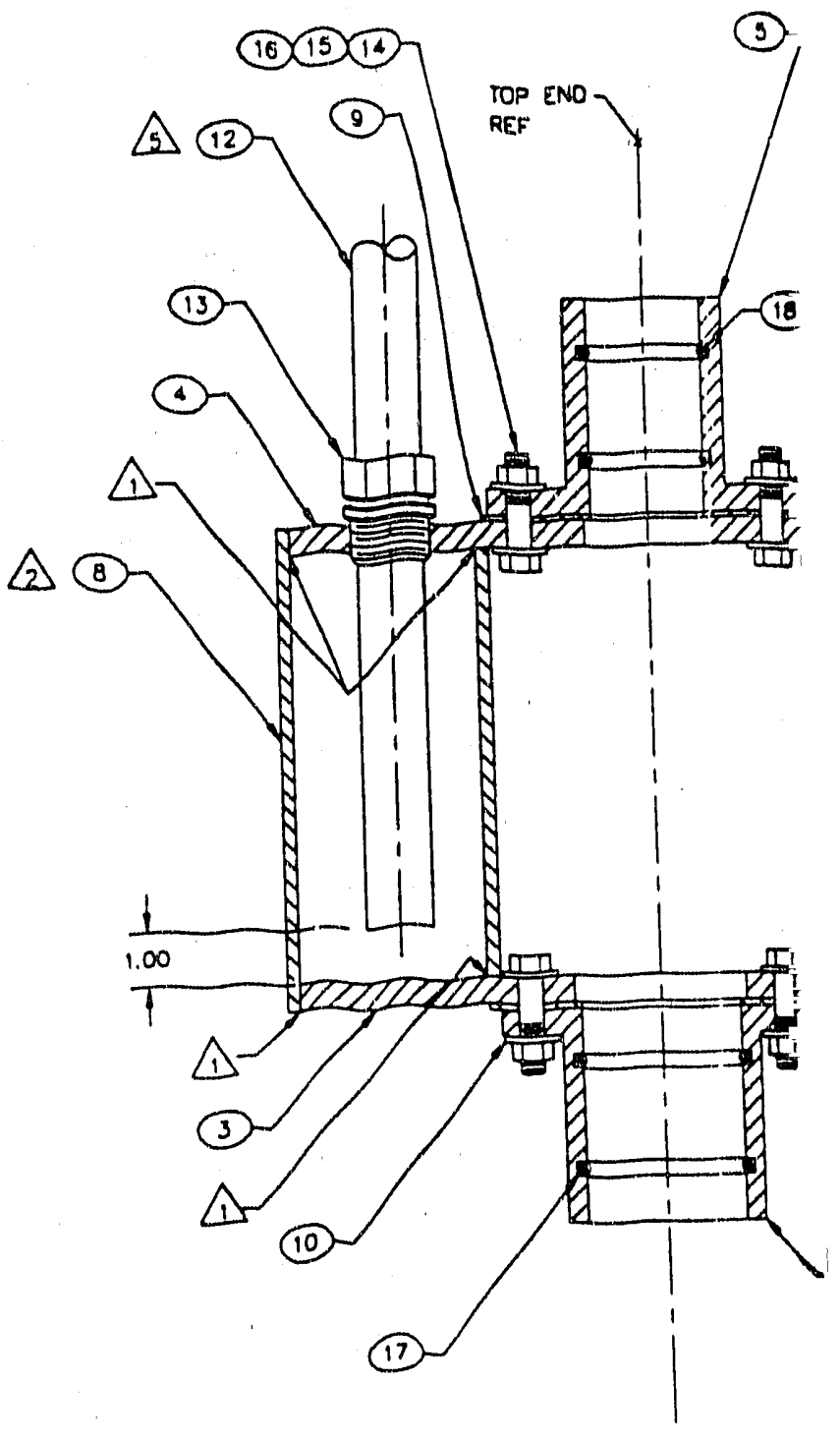

- 1 ASSEMBLY 


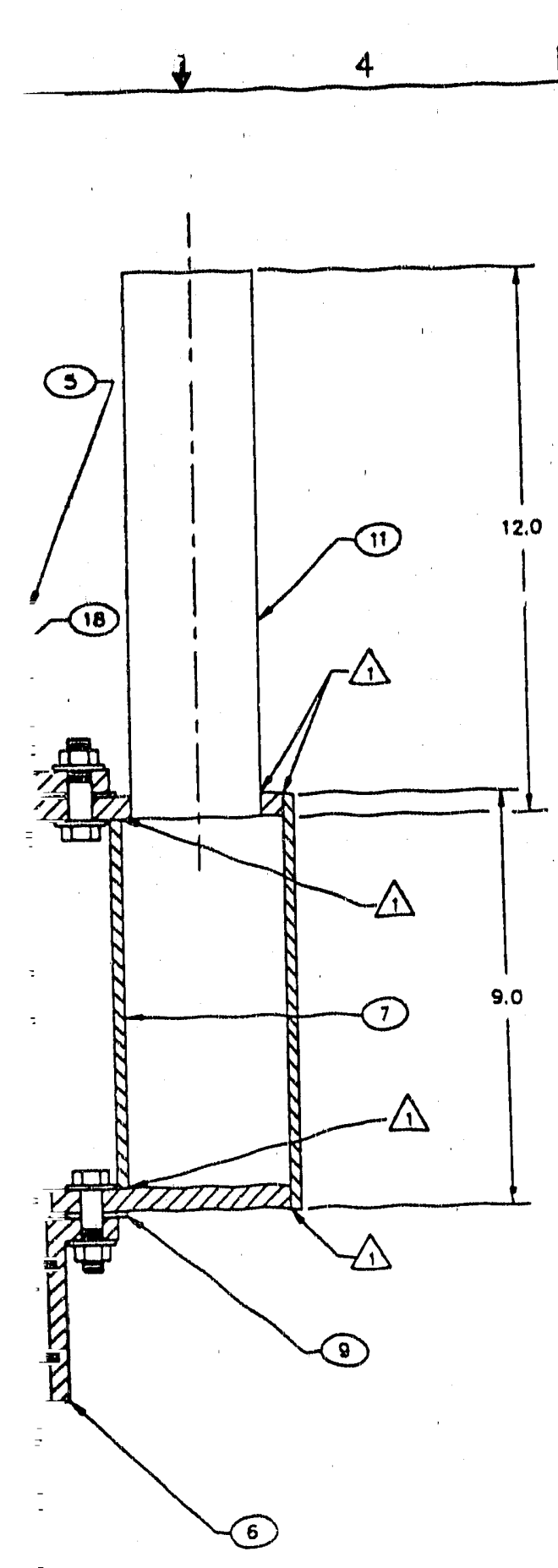

3

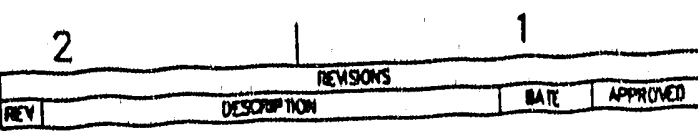

C

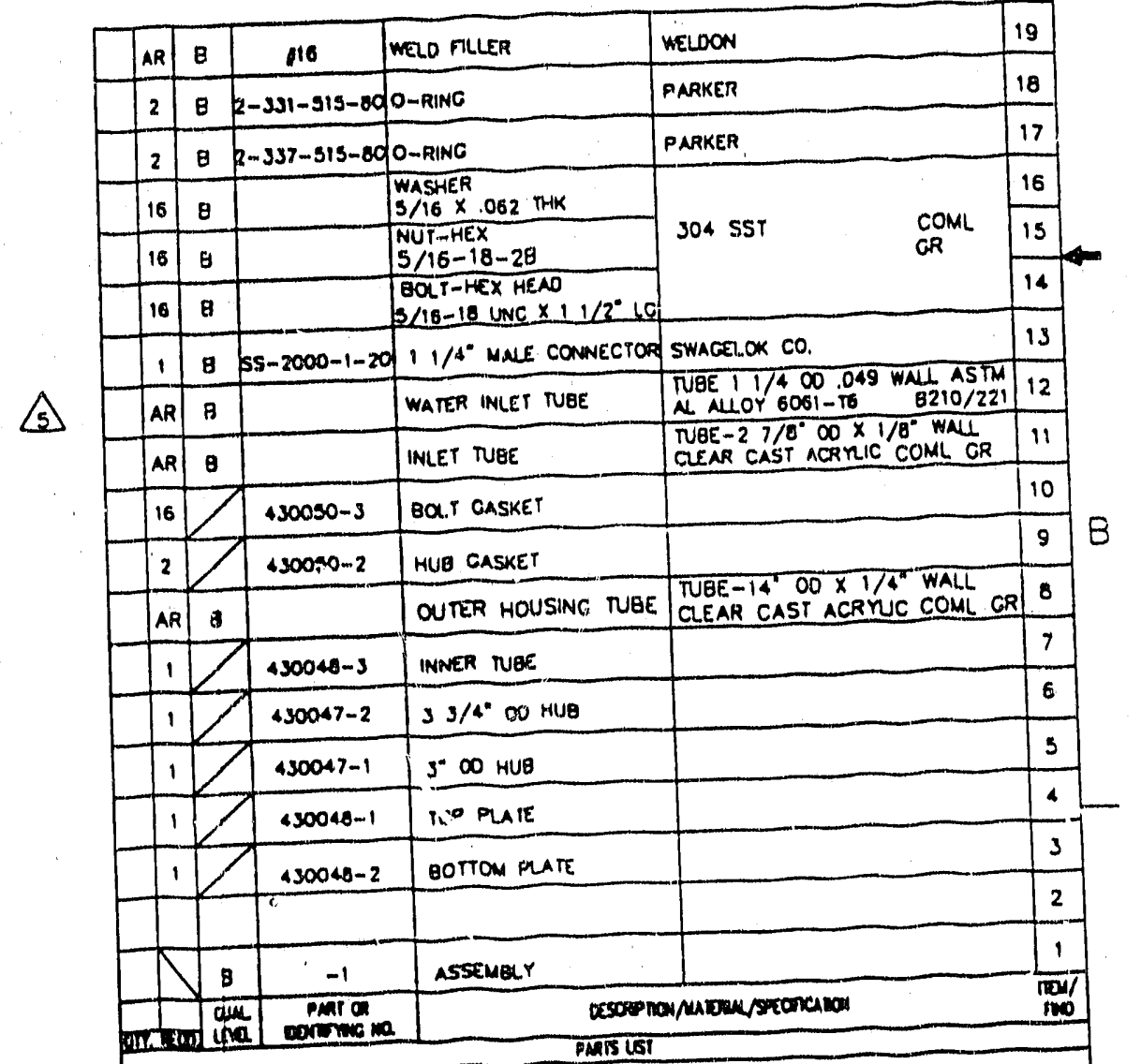

ABLY

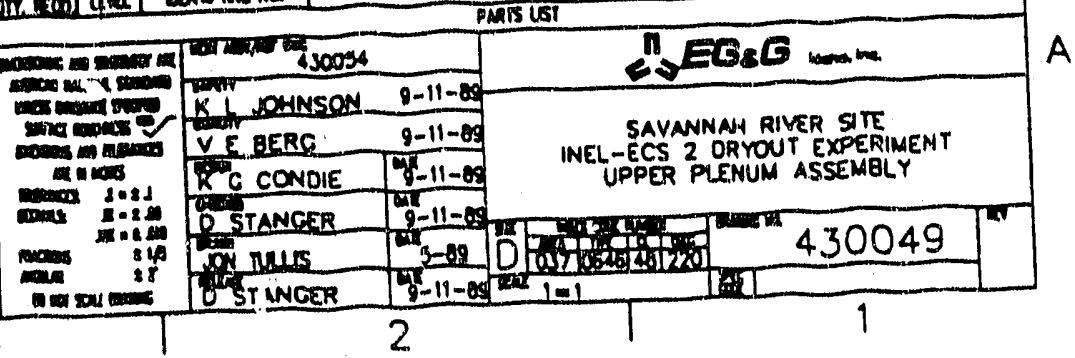

A -6 
NOTES.

A. PERMISSEUL TO OBTANA REOUIFEO LENCTH OF ITEM I BY USINC 2 OR MORE PIECES

(1) MNRK PER STT-7006-21 WITH 430050 ANO APPROPRIATE OASH NUMBER

3. PRESERVE AND PROTECT PER STO-7020 CASS II

4. GeANUINESS PER STO-7022. LeVEL C.

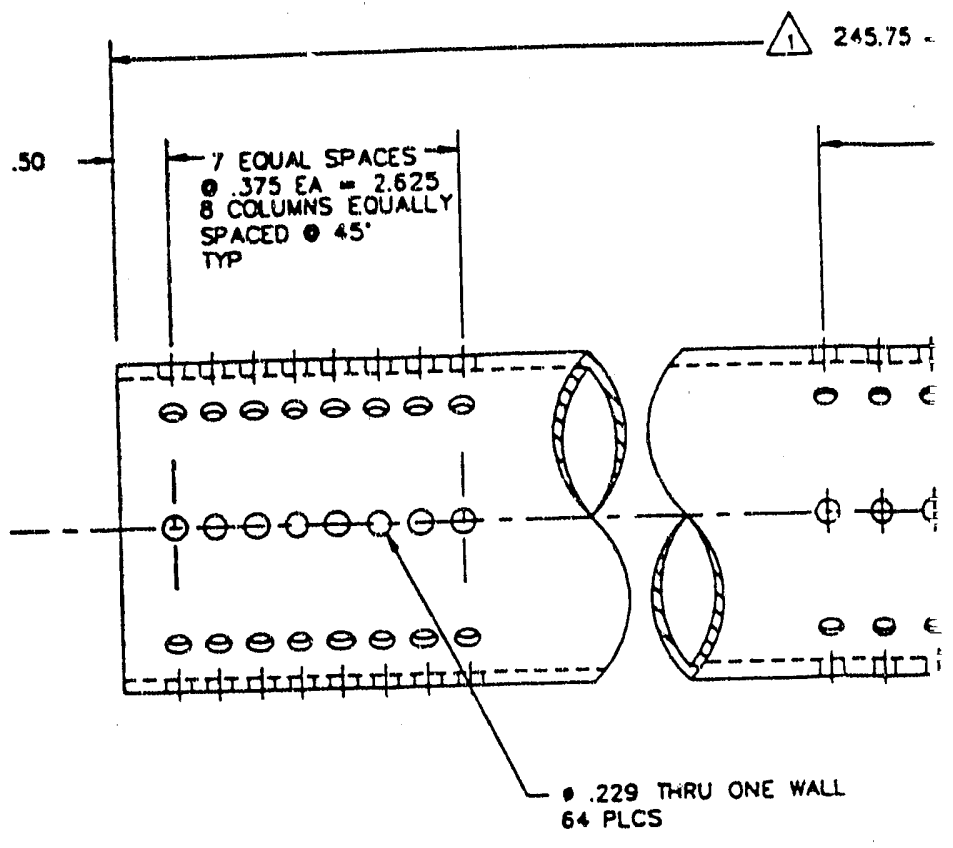

(1)

SCALE
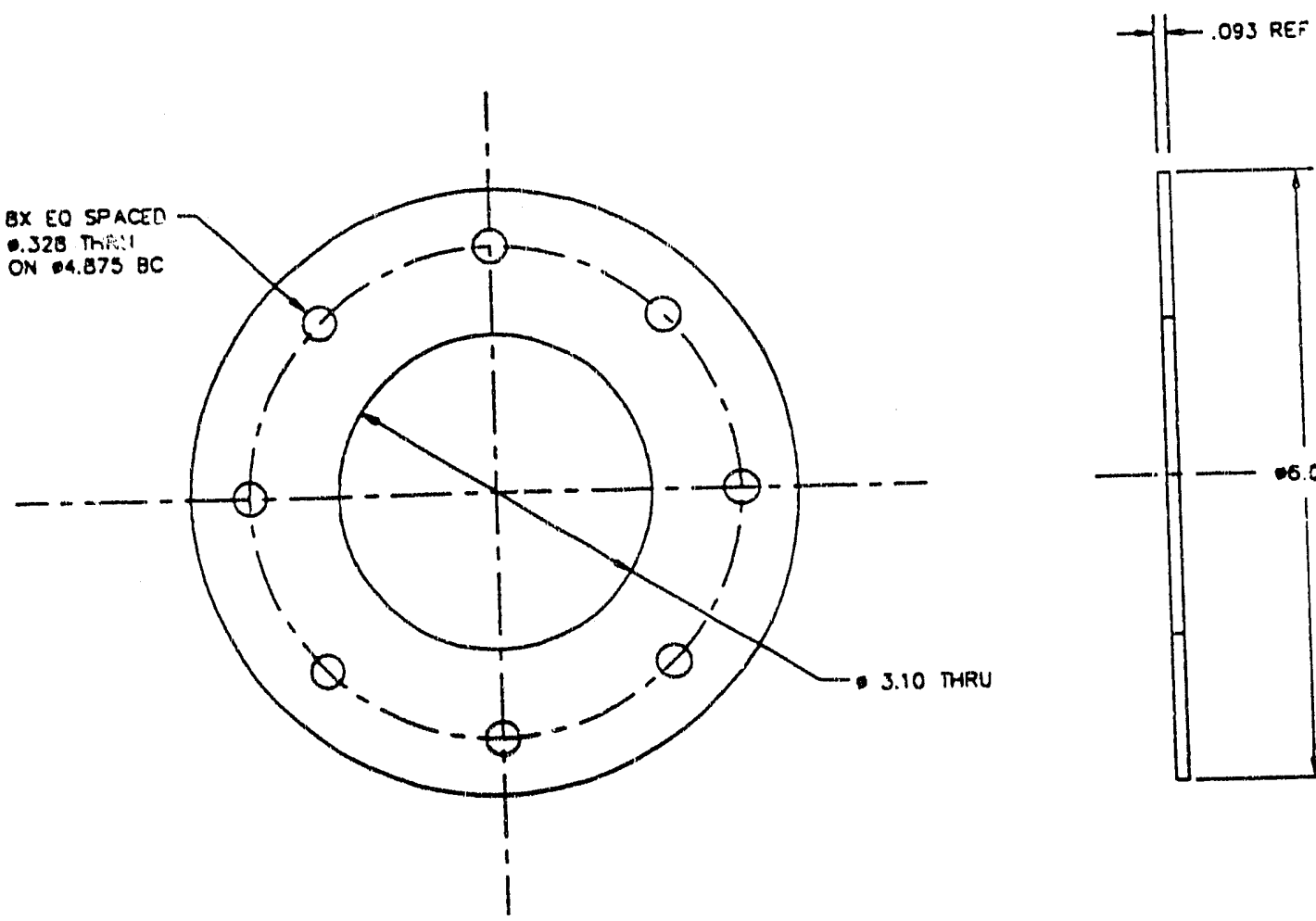

A

(2) DETAIL $\triangle$

SCALE $1-1$ 


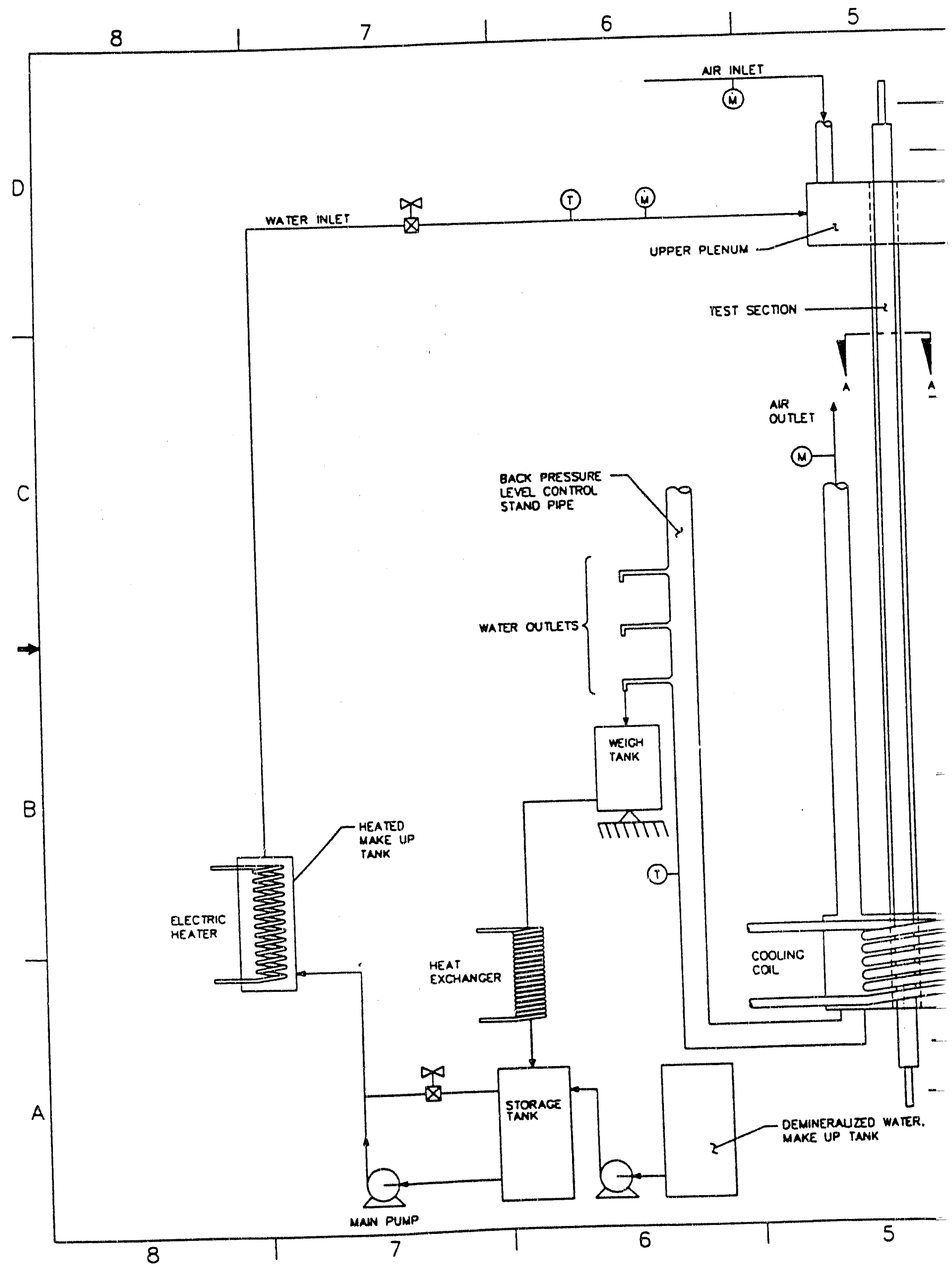




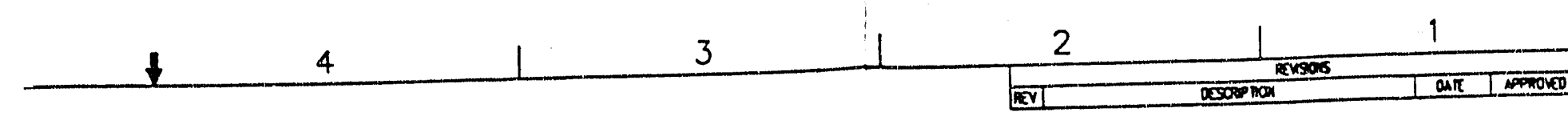

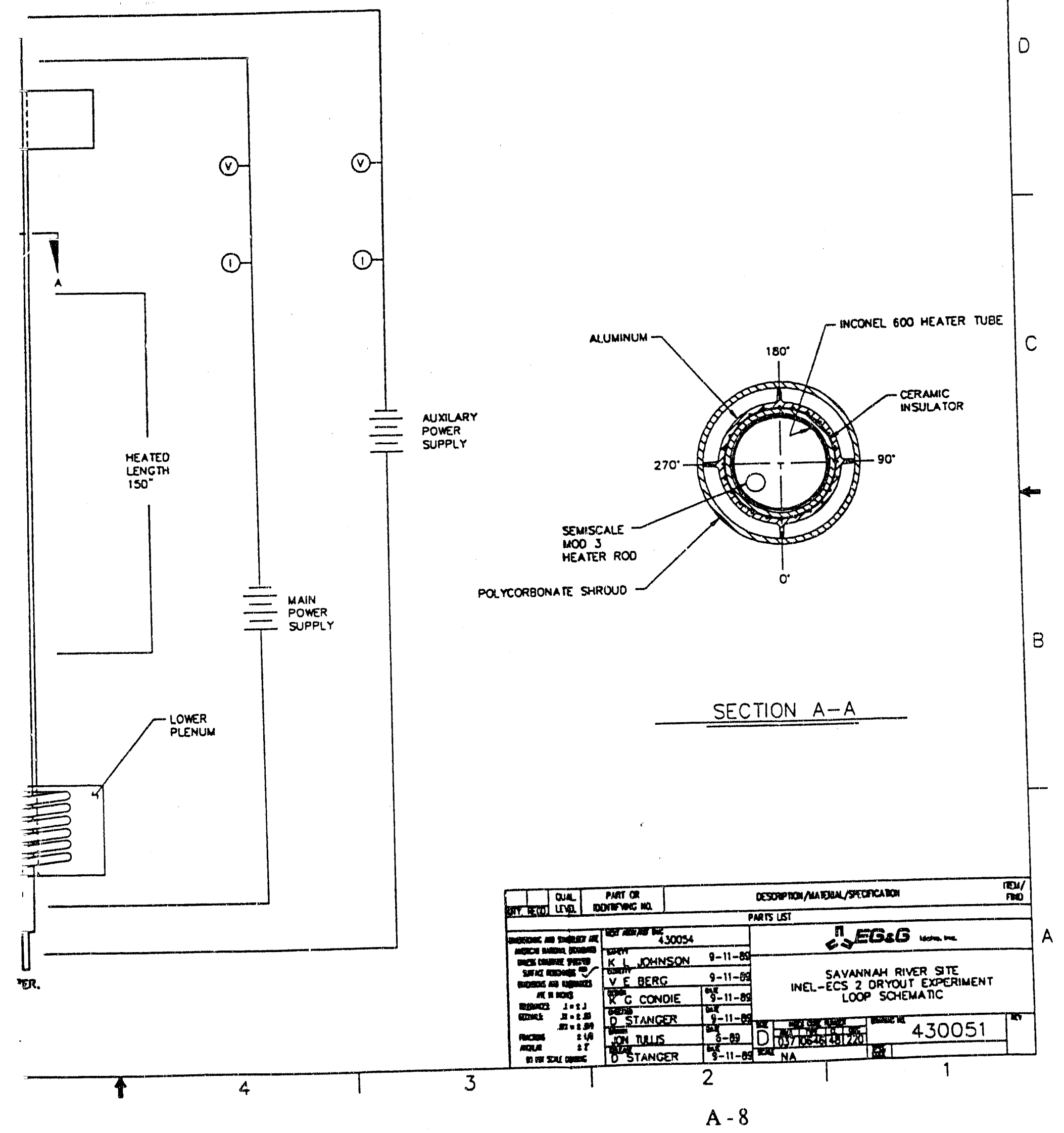


NOTES.

1. REMOVE all bURRS AND SHARP EDCES

2. PRESERVE ANO PROTECT PER STO-7020 CASS II

3. MARK PER 5TO 7006-21 WTH 430052-1

4. cleanliness per sto-7022. level $C$
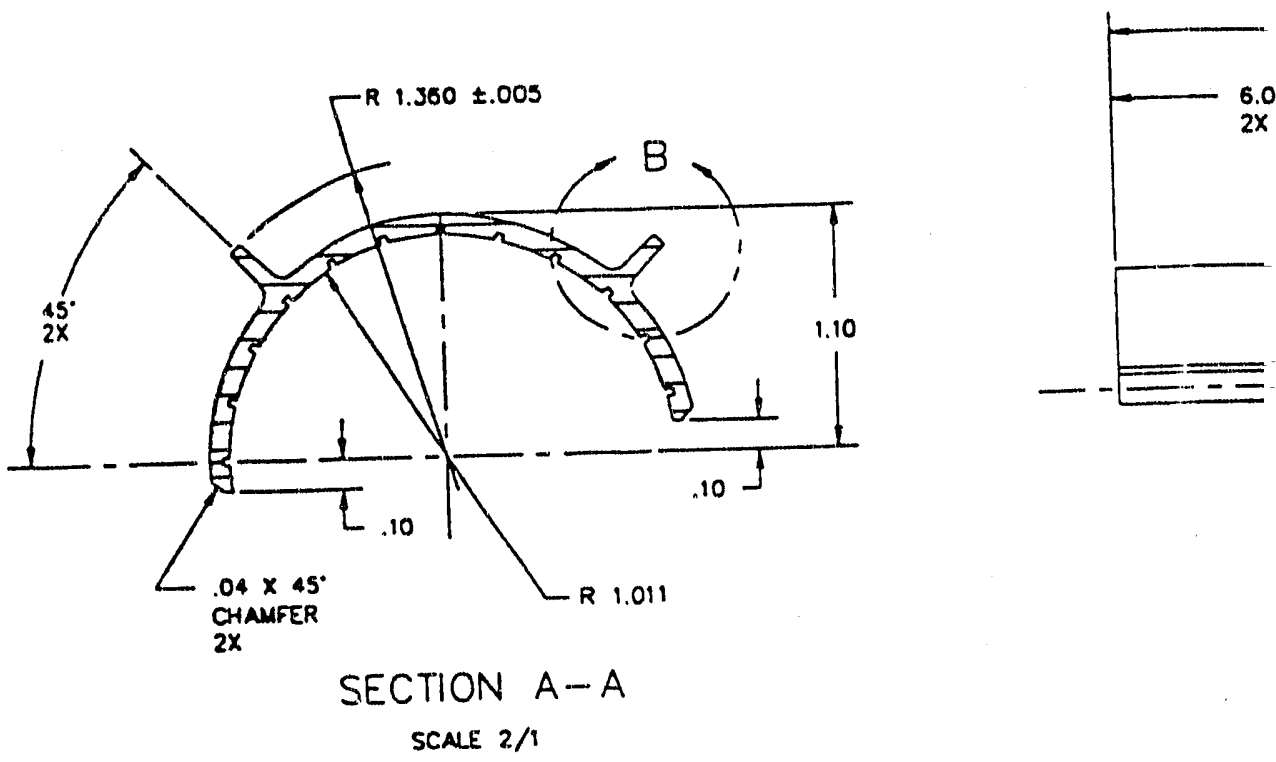

B

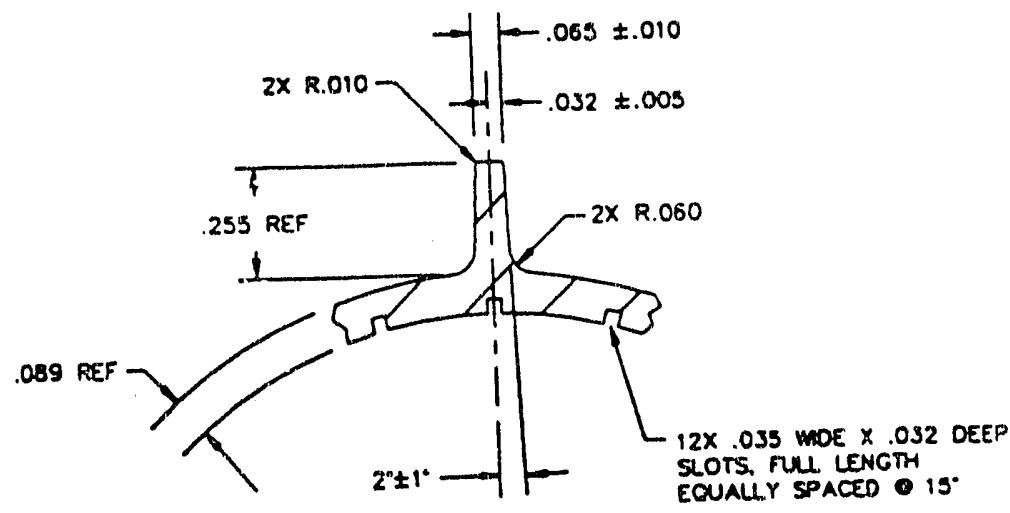

DETAIL B

SCALE $4 / \pi$ 


\begin{tabular}{llllll}
4 & 3 & 2 & 2 & 1 & 1 \\
\hline
\end{tabular}

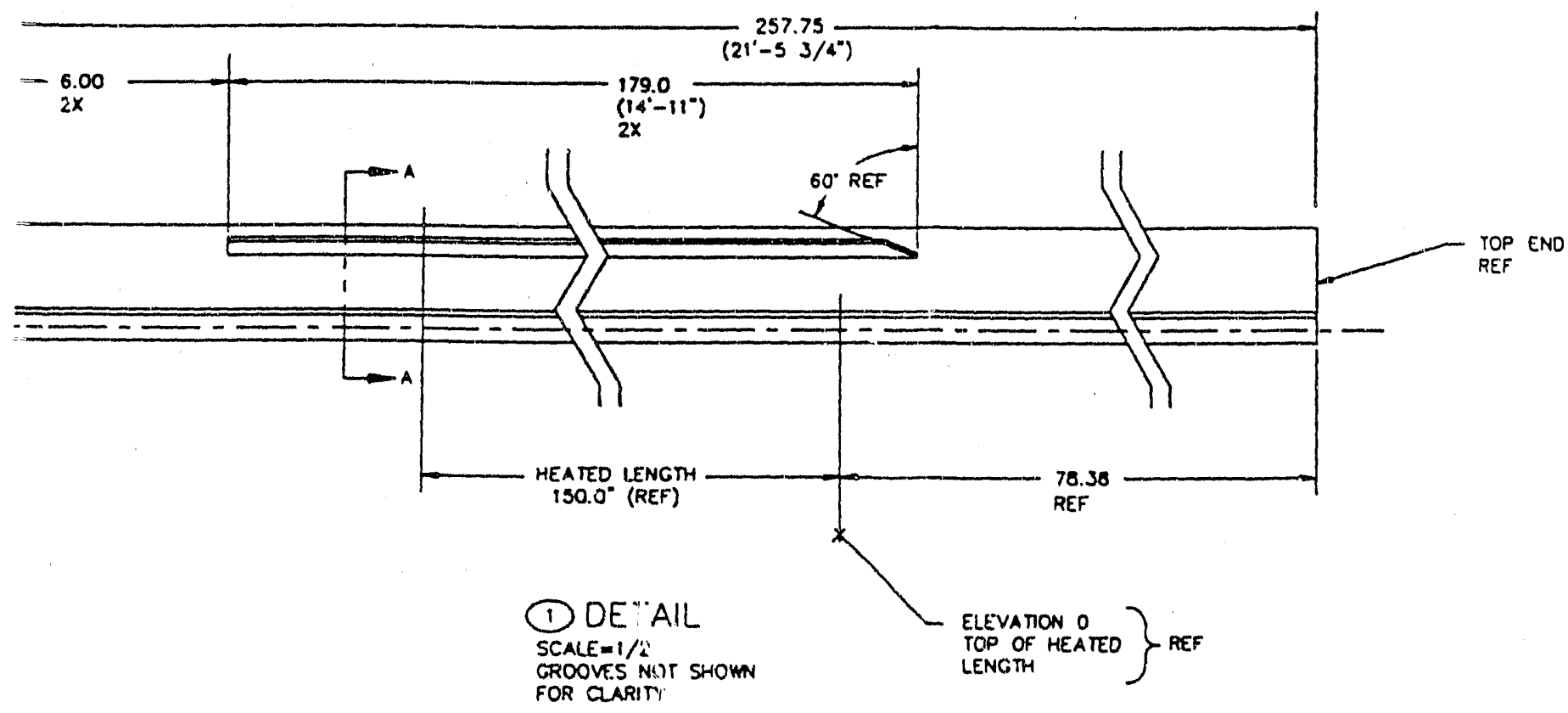

3

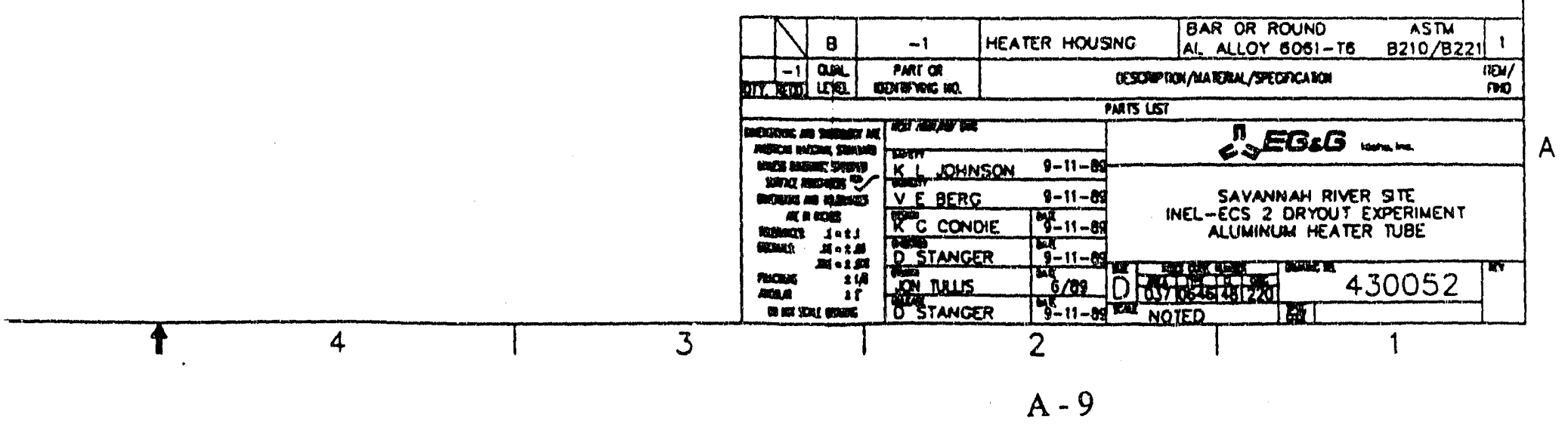


1. PREsERVE ANO PROTECT PER STO-7020 CLASS II

2. CLEANUNESS PER STO-7022, LeVEL. C.

13. WARK PER STO 7006-21 WTH 430053 ANO NPPROPRIATE DASH NUMBER.

0

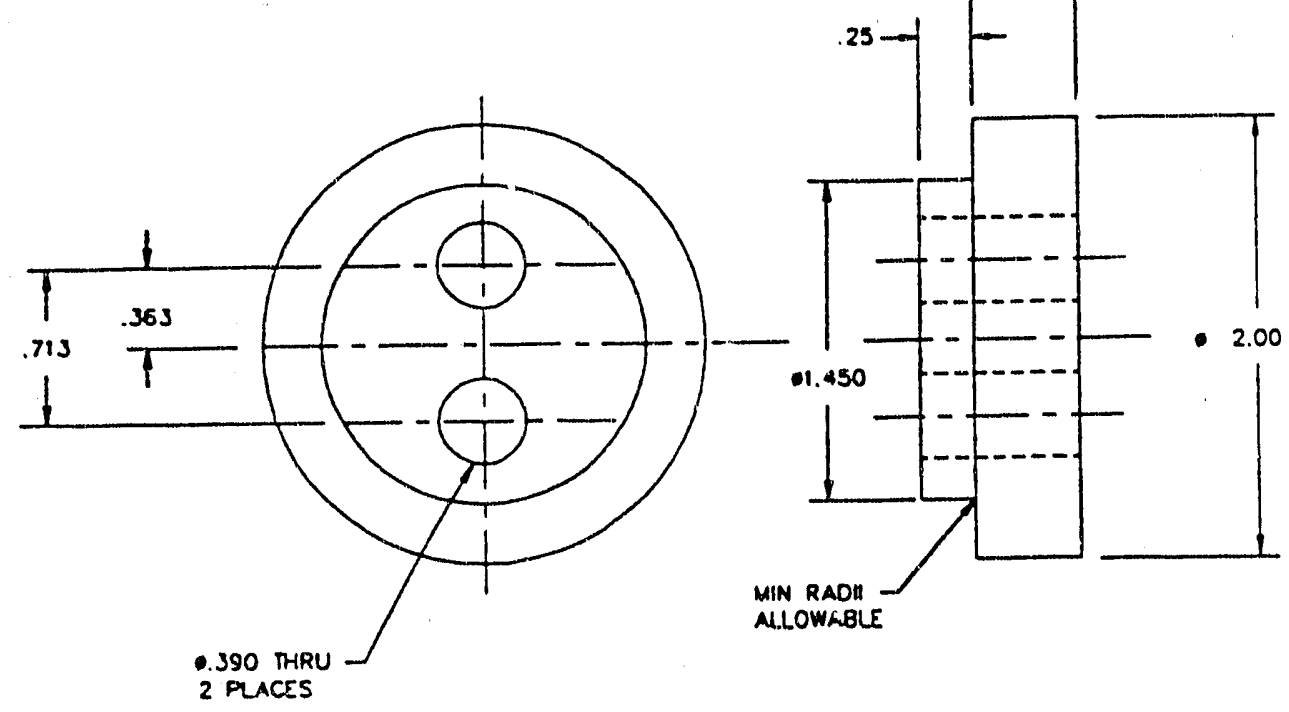

(1)DETAIL $\widehat{3}$

SCNE $2 / 1$

B
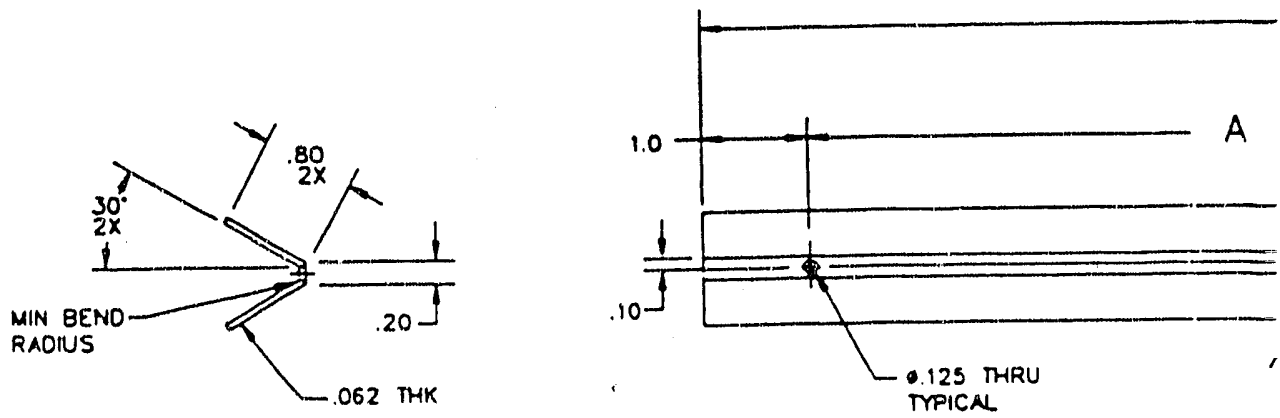

A

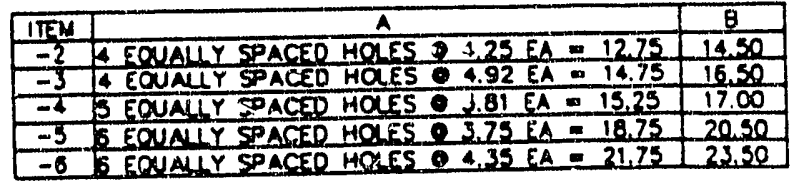

(2) THRU (6 


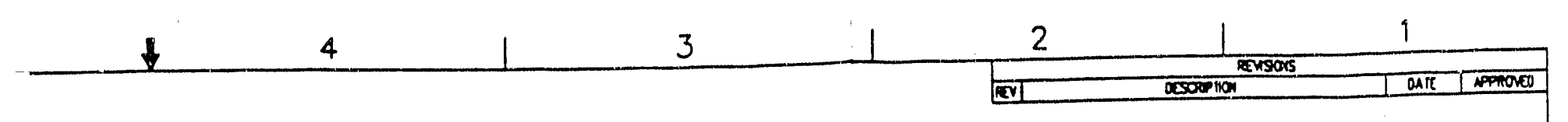

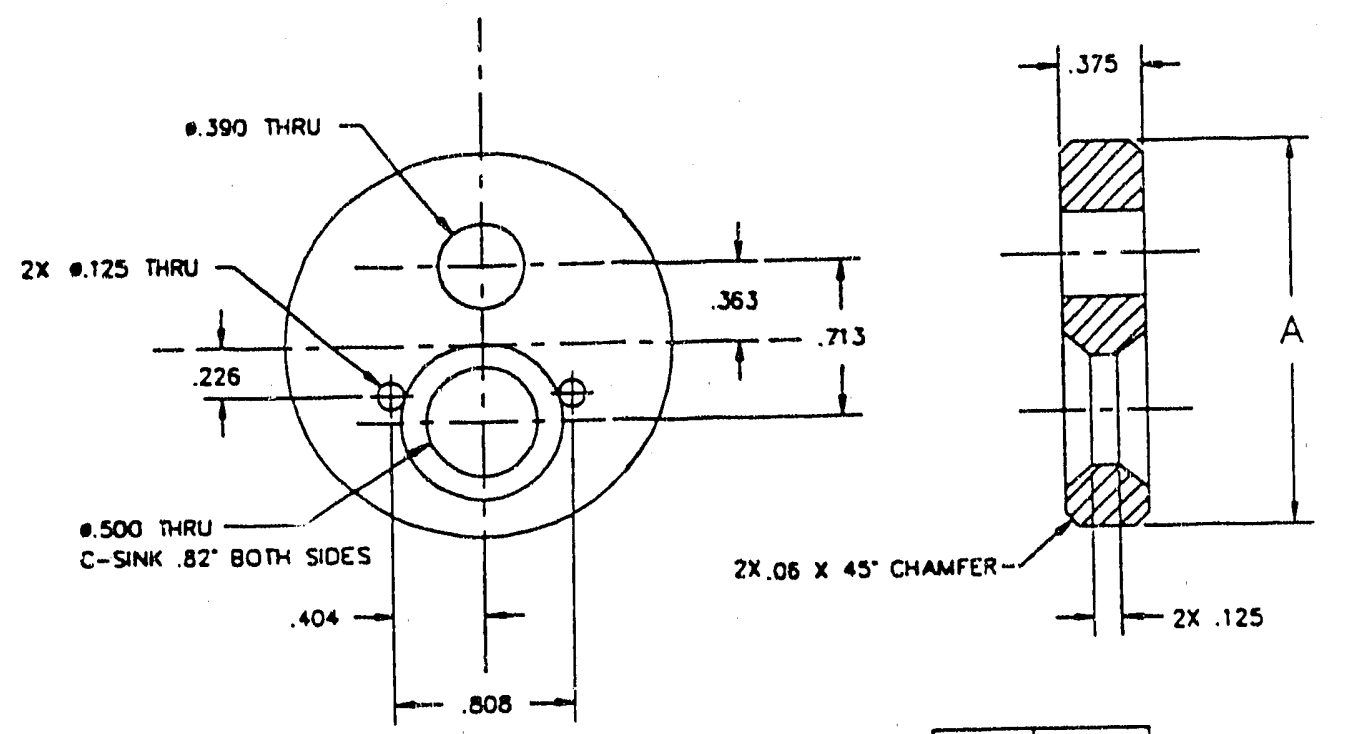

(7) THRU (12) DETAIL SA

SCALE: NONE

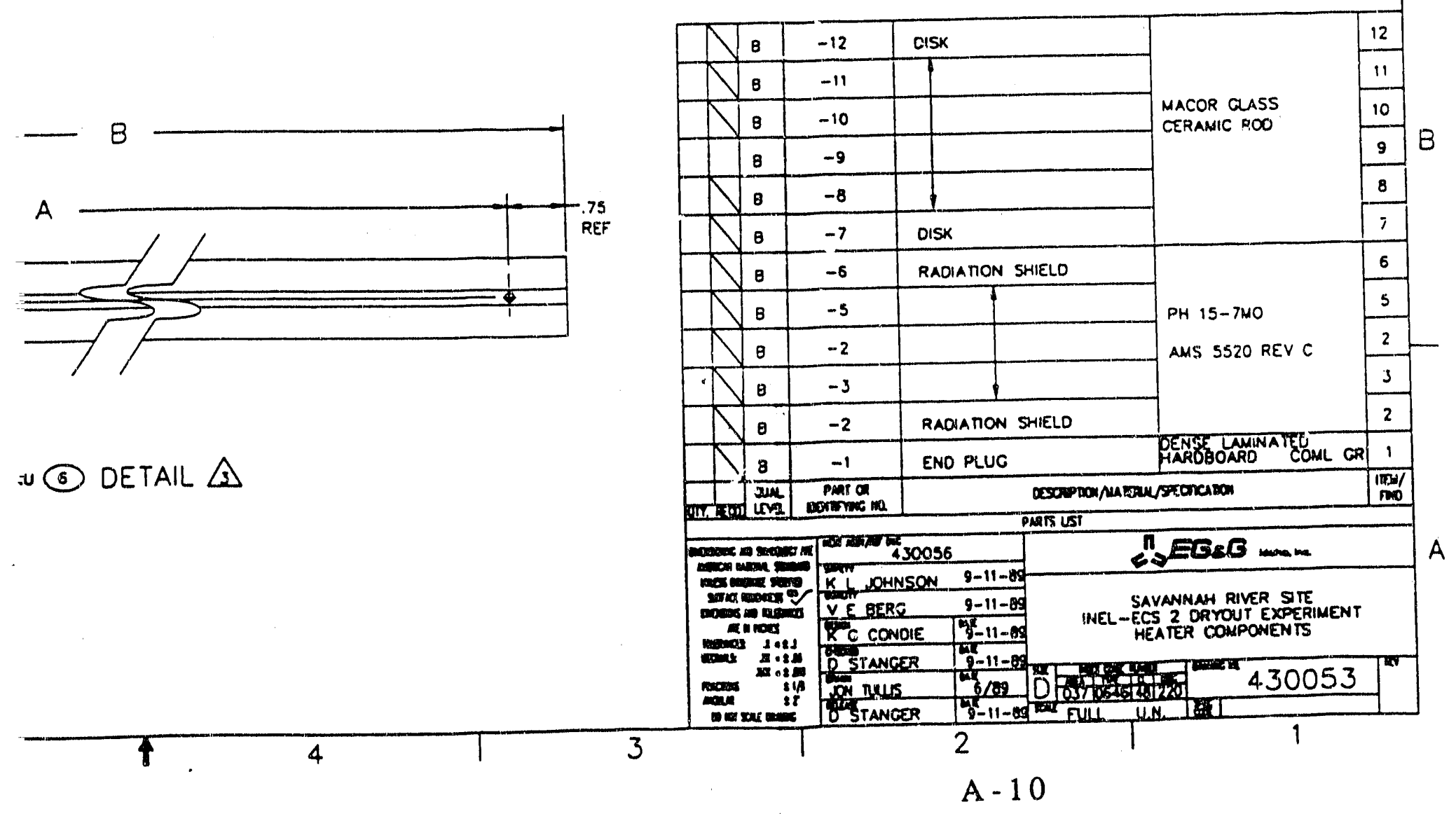

$\because$ (5) DETAIL AS

\begin{tabular}{|c|c|}
\hline ITEM & DIM A \\
\hline-7 & 1.450 \\
\hline-8 & 1.583 \\
\hline-9 & 1.711 \\
\hline-10 & 1.735 \\
\hline-11 & 1.748 \\
\hline-12 & 1.755 \\
\hline
\end{tabular}


NOTES.

1. CLEANUMESS PER STO 7022. LEVEL C

2. PRESERVE ANO PROTECT PER STO 7020. CUASS II

A. WARK PER STO-7006-202 WTH 430054-1 ASS'Y

D 4. HOOK UP GY OTHERS SEE DWG 430051

C

B

A

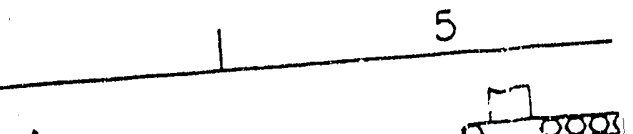

$\triangle$ MATER INLET

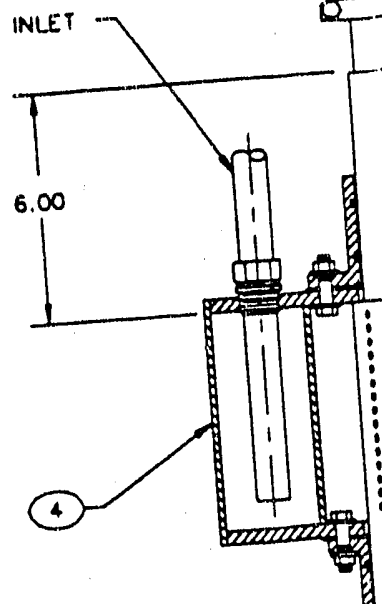

(6)

(6)

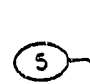

-1 ASSEMBLY 


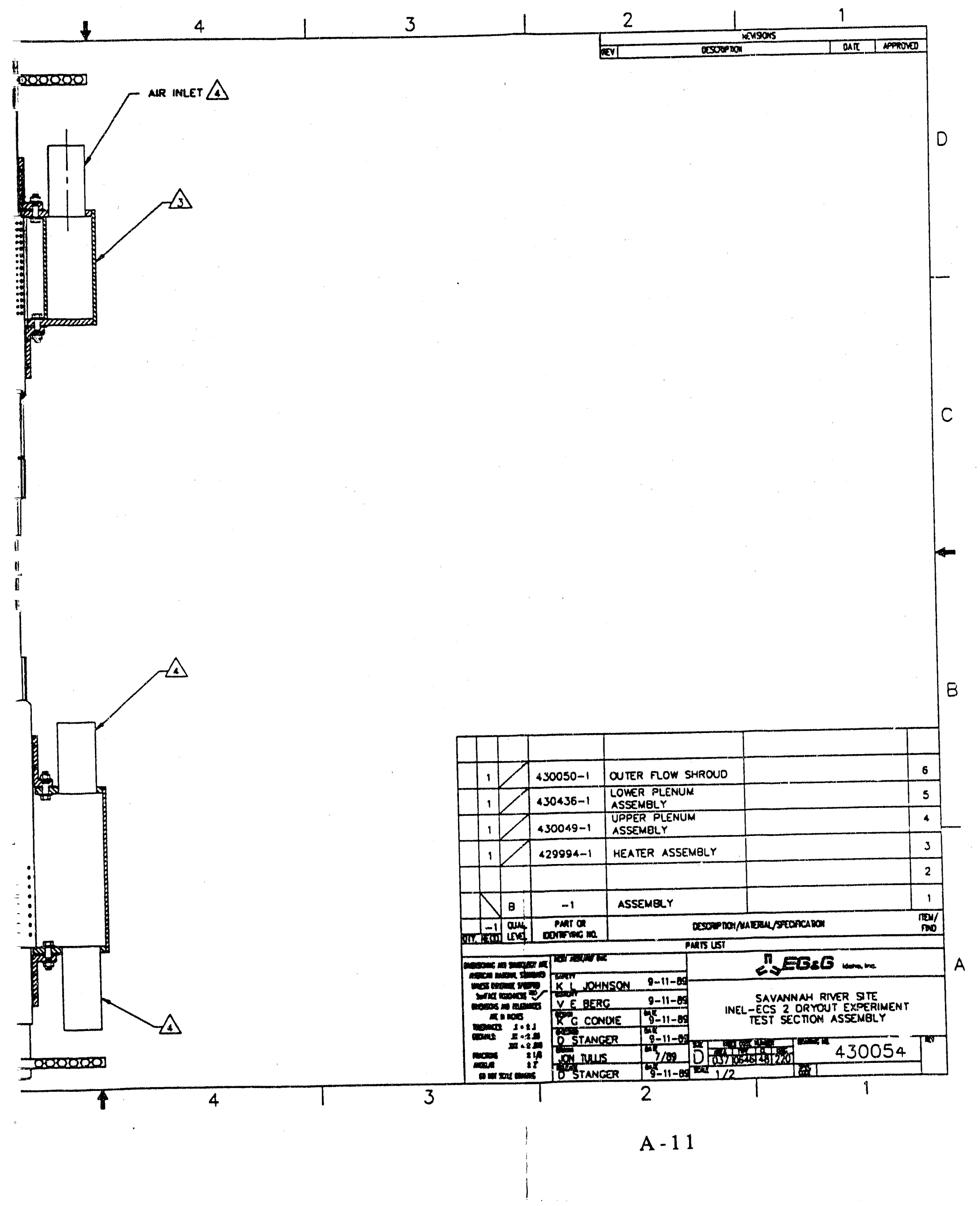


8

7

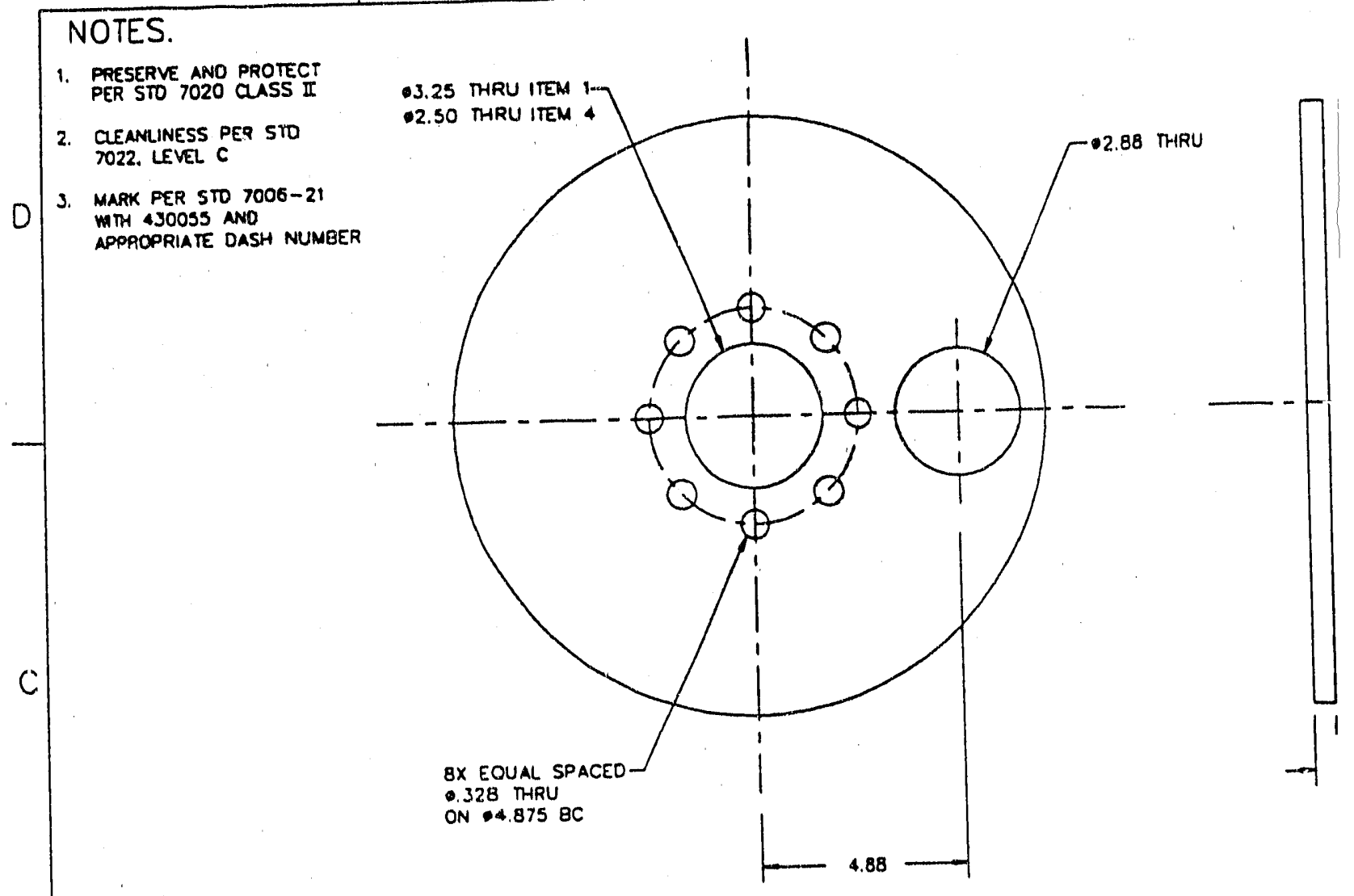

B

(1) DETAIL (SHOMN)

(4) DETAIL

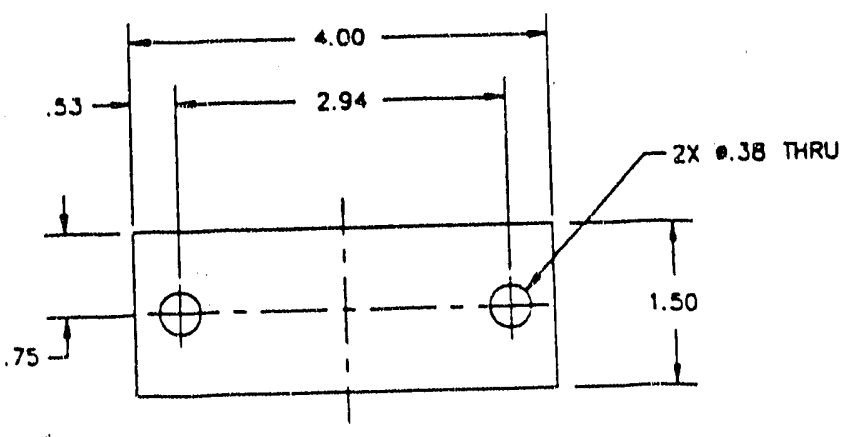

A

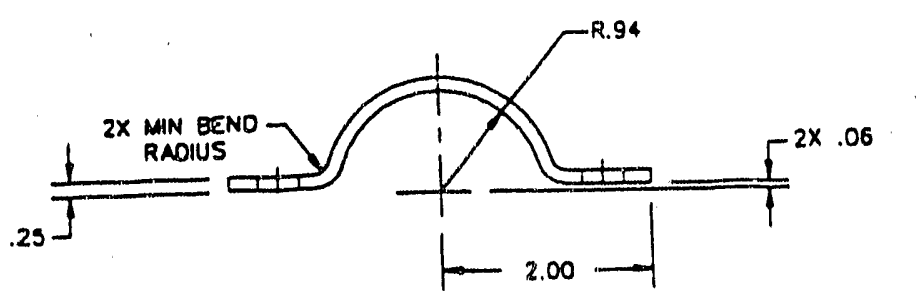

(3) DETAIL 


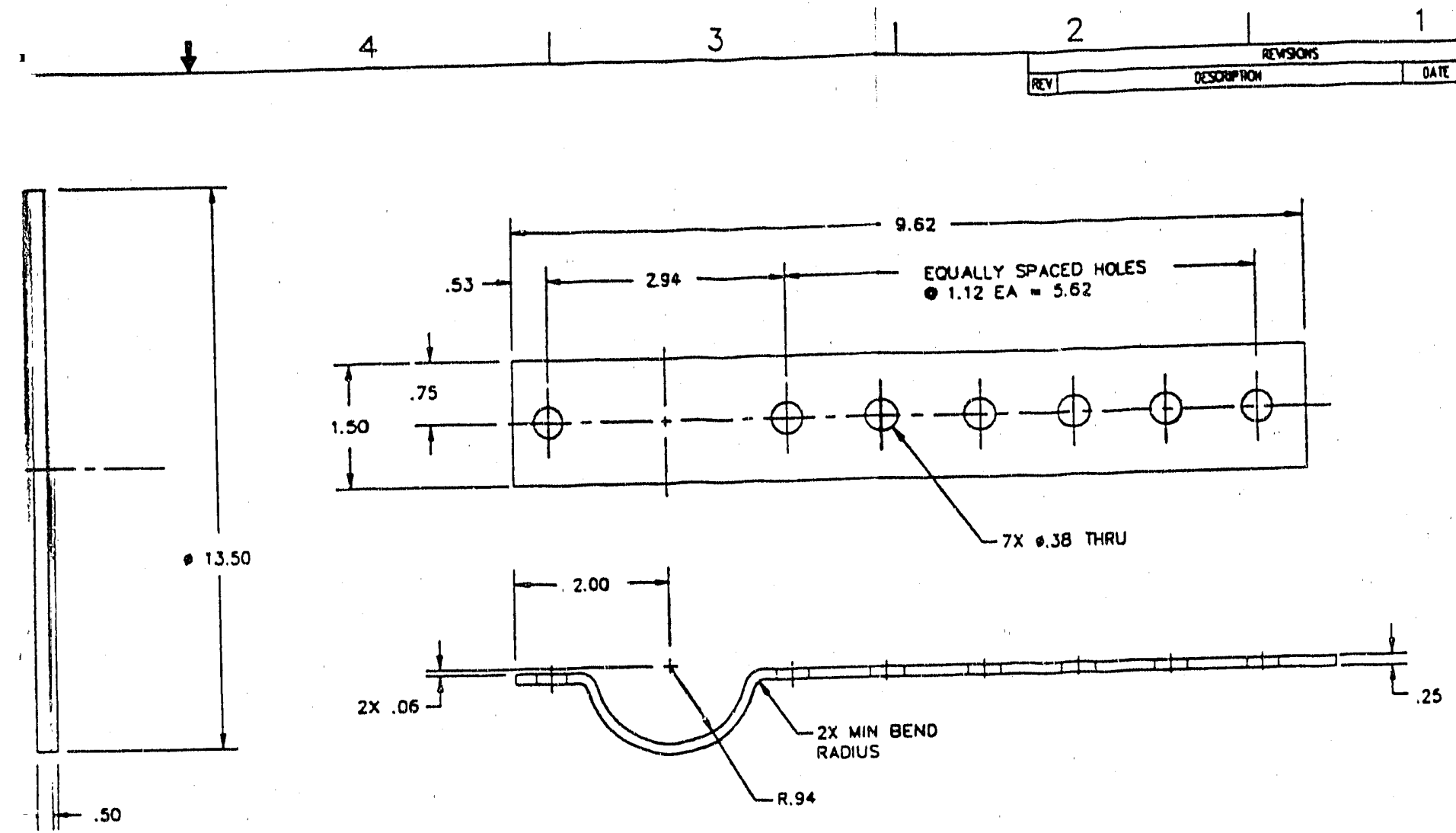

(2) DETAIL

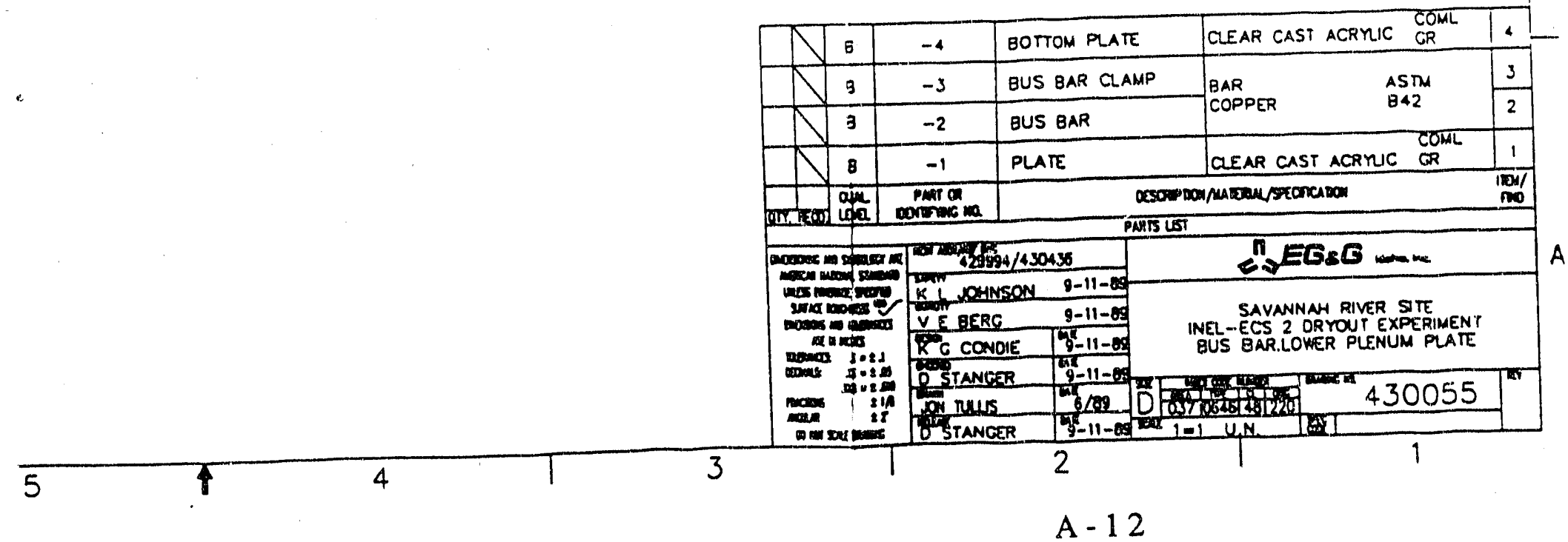




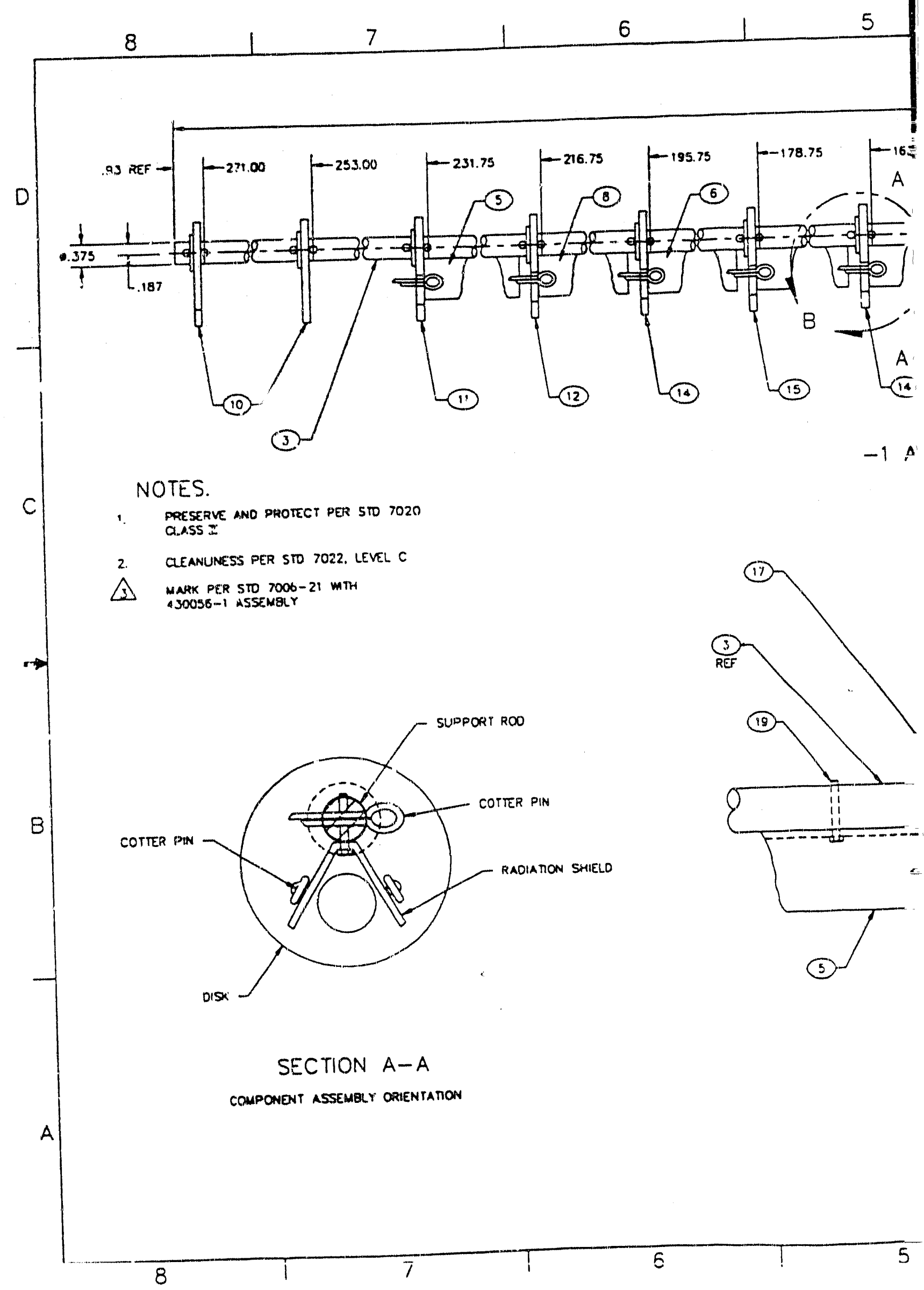




\begin{tabular}{lllllll}
+ & 4 & 3 & 1 & 2 & 1 & 1 \\
\hline
\end{tabular}

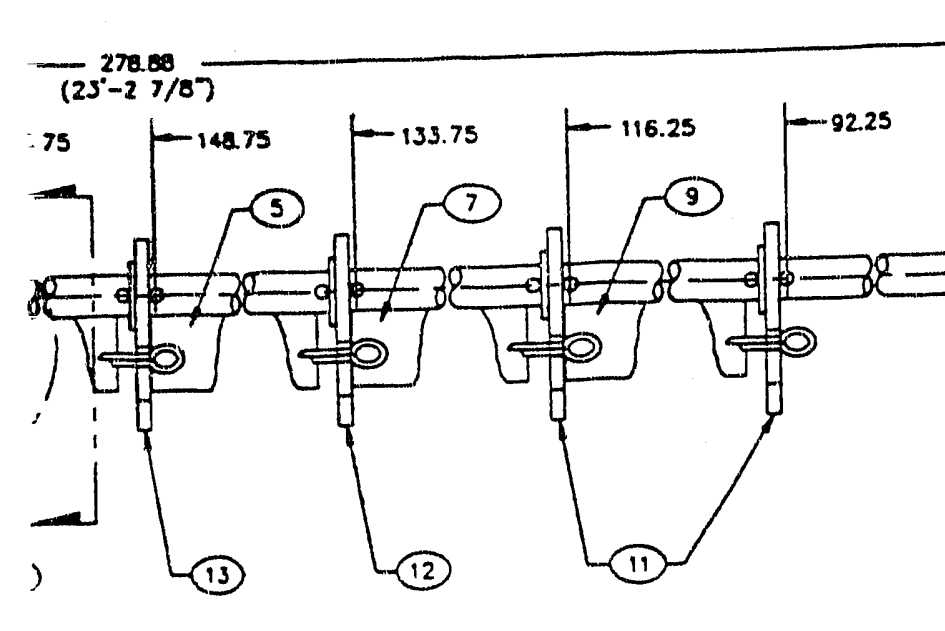

.SSEMBLY A $A$
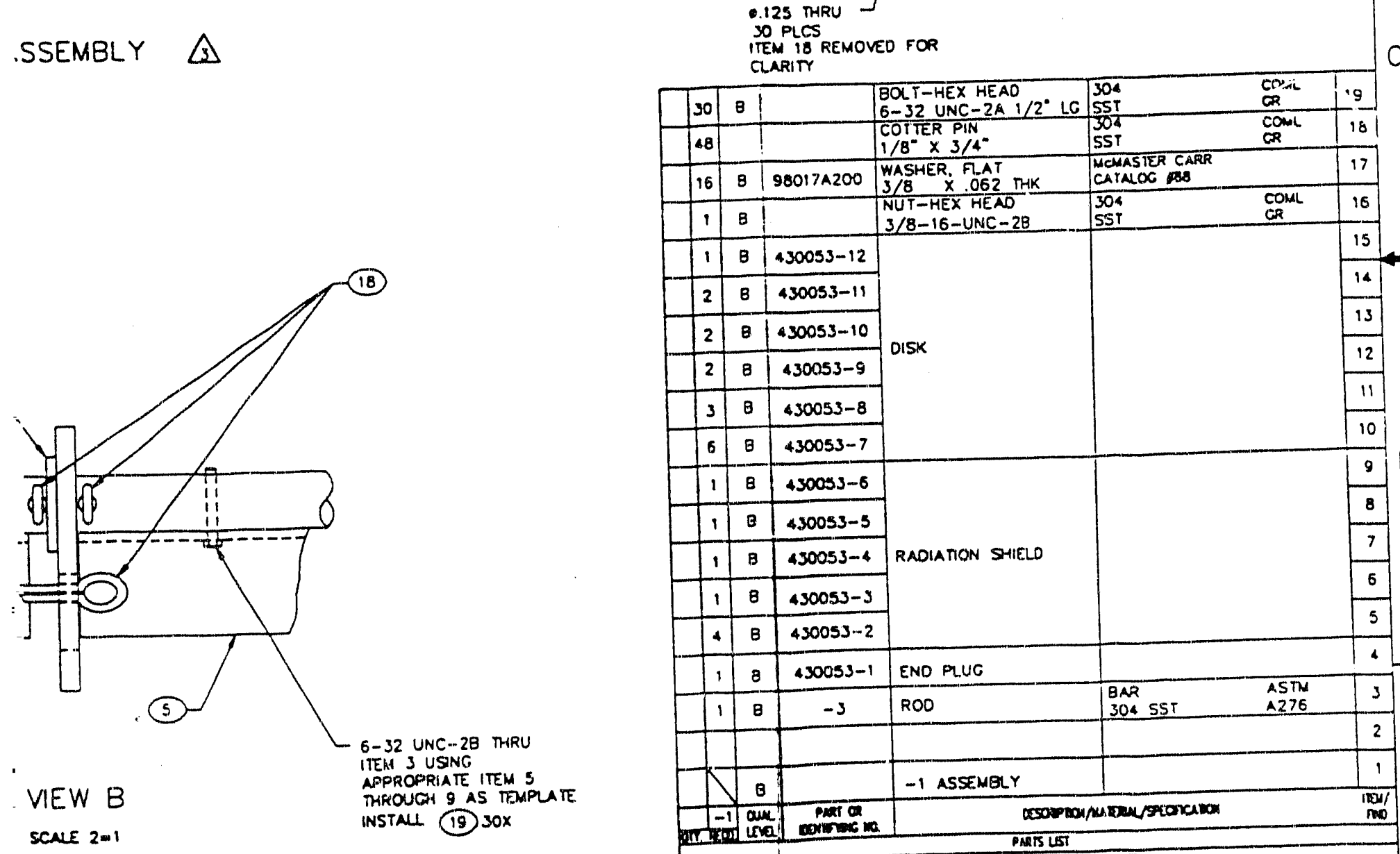

4

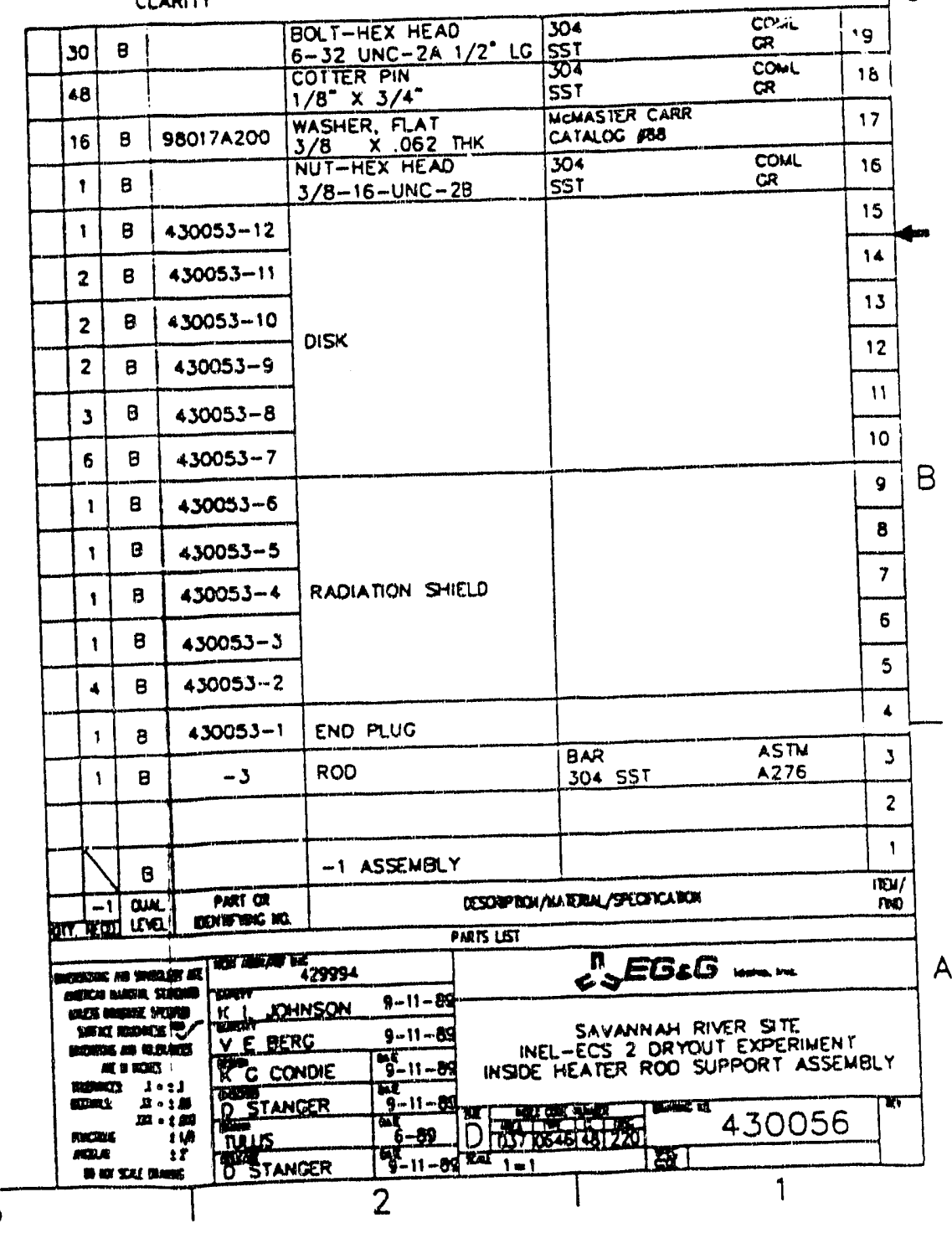

A -13 


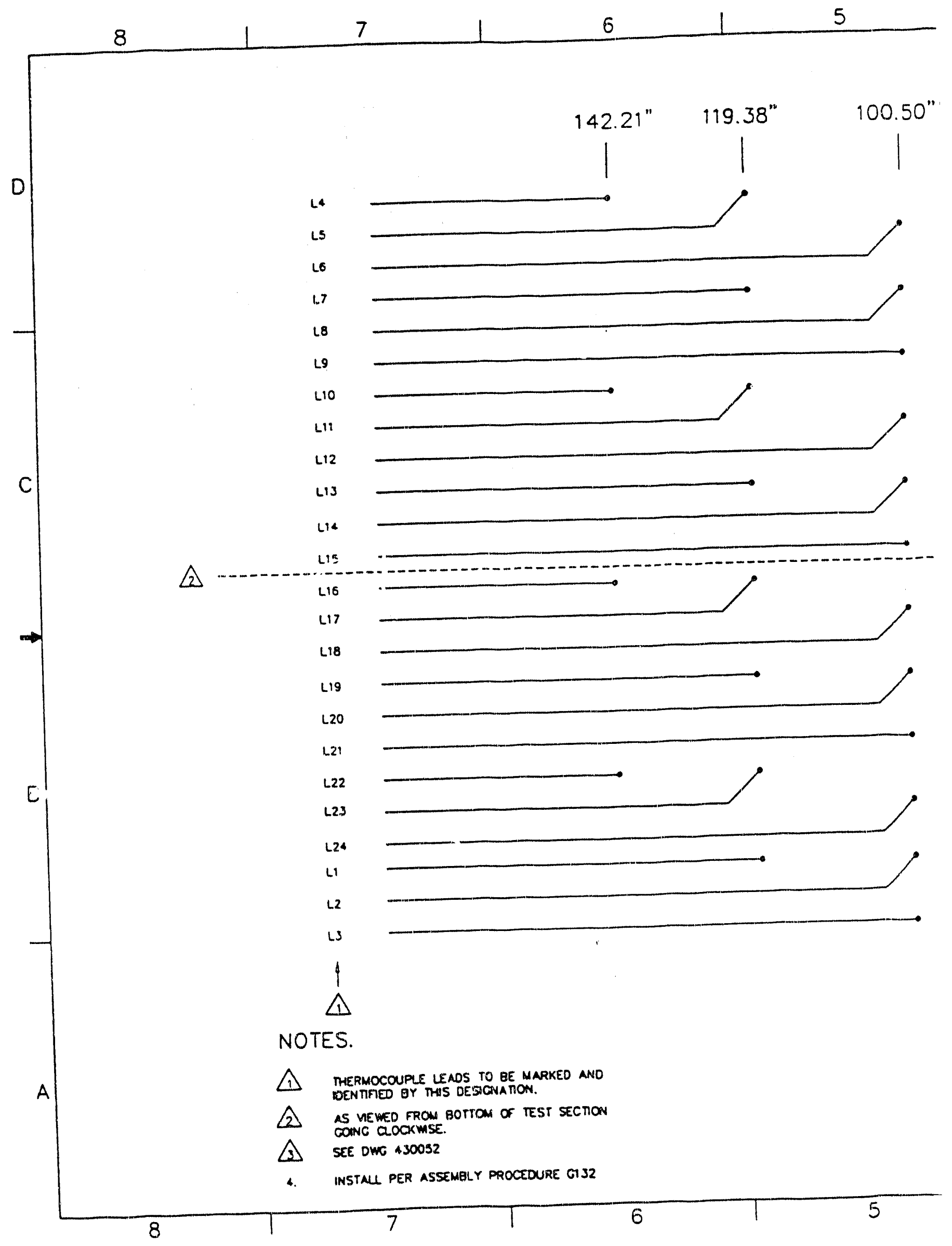




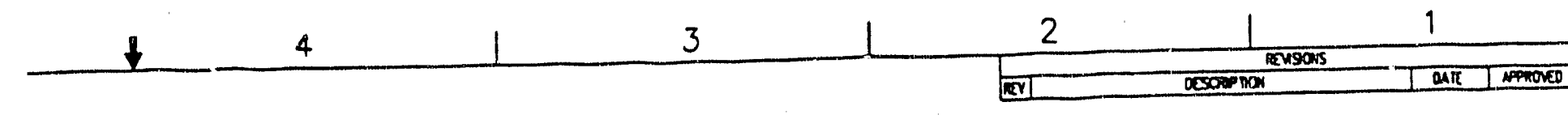

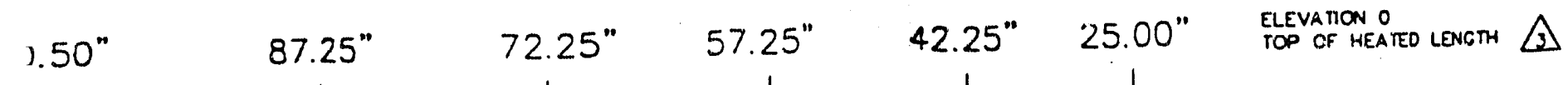
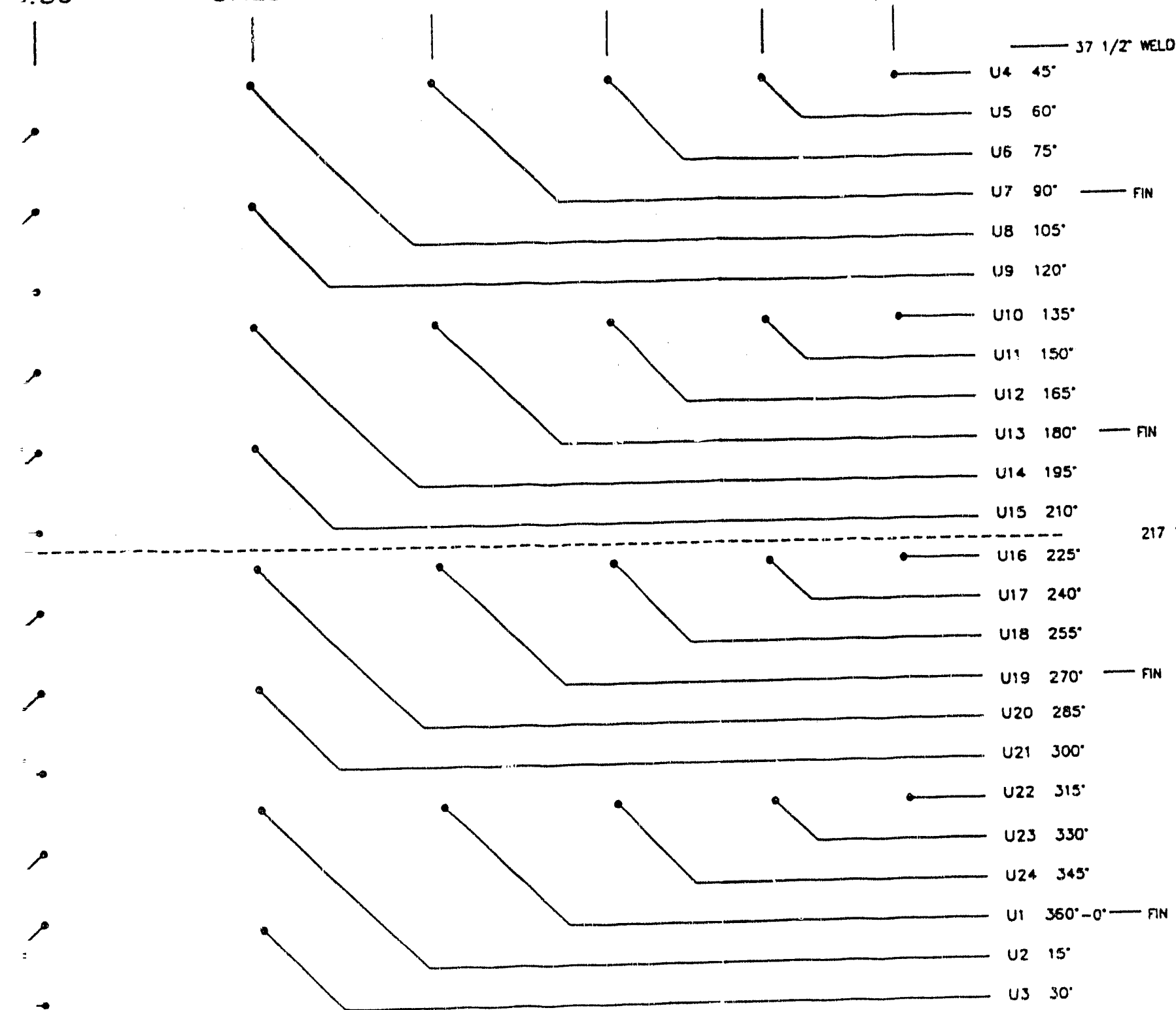

U10 $135^{\circ}$

UII $150^{\circ}$

U12 $165^{\circ}$

U13 $180^{\circ}-$ FN

U14 $195^{\circ}$

U15 $210^{\circ}$

$116 \quad 225$

$2171 / 2^{\circ}$ WELD

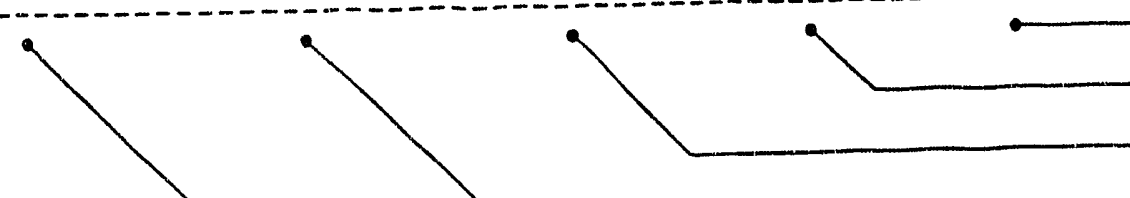

U17 $240^{\circ}$

U18 255"

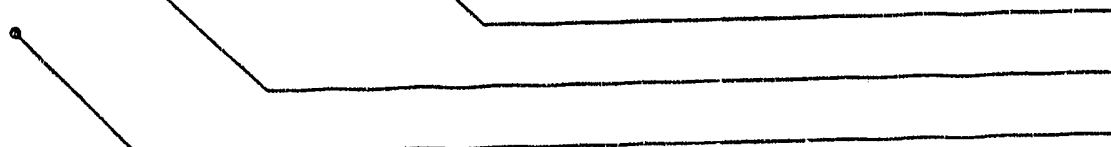

U19 $270^{\circ}-$ FIN

U20 $285^{\circ}$

U21 $300^{\circ}$

$422315^{\circ}$

U23 $330^{\circ}$

U24 $345^{\circ}$

Ui $360^{\circ}-0^{\circ}-$ FIN

U2 $15^{\circ}$

U. $30^{\circ}$

A

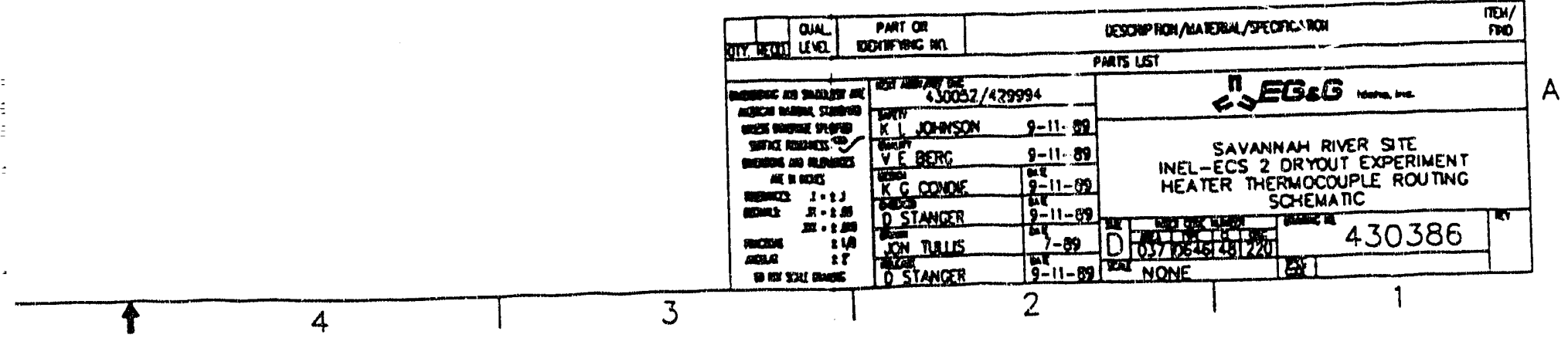

A -11 


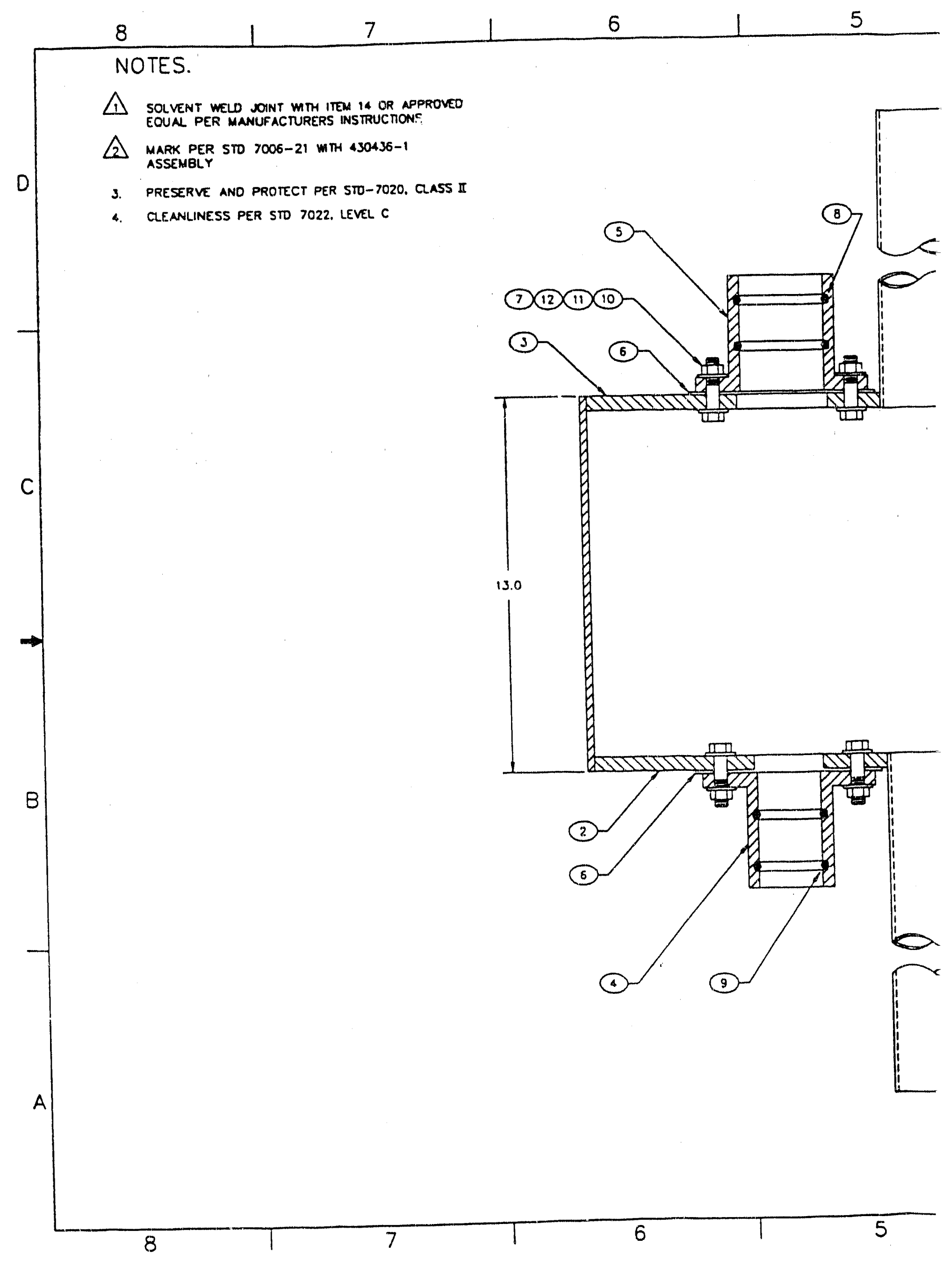




\begin{tabular}{llllll}
1 & 4 & 3 & 2 & 1 & 1 \\
\hline
\end{tabular}
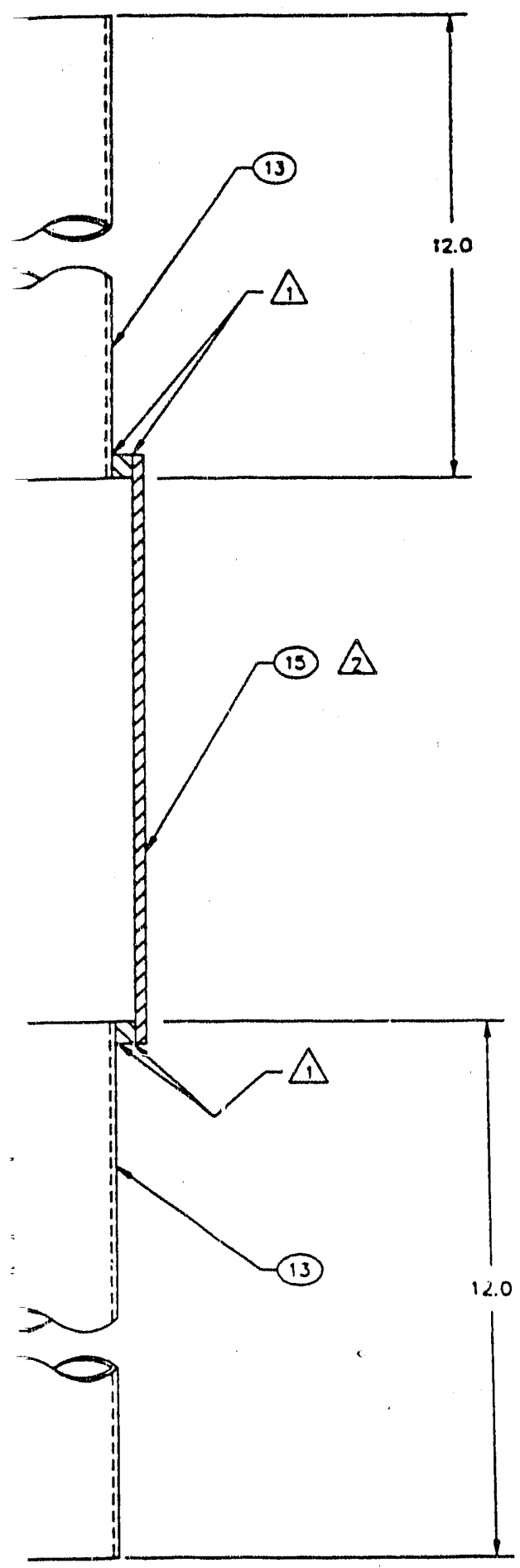

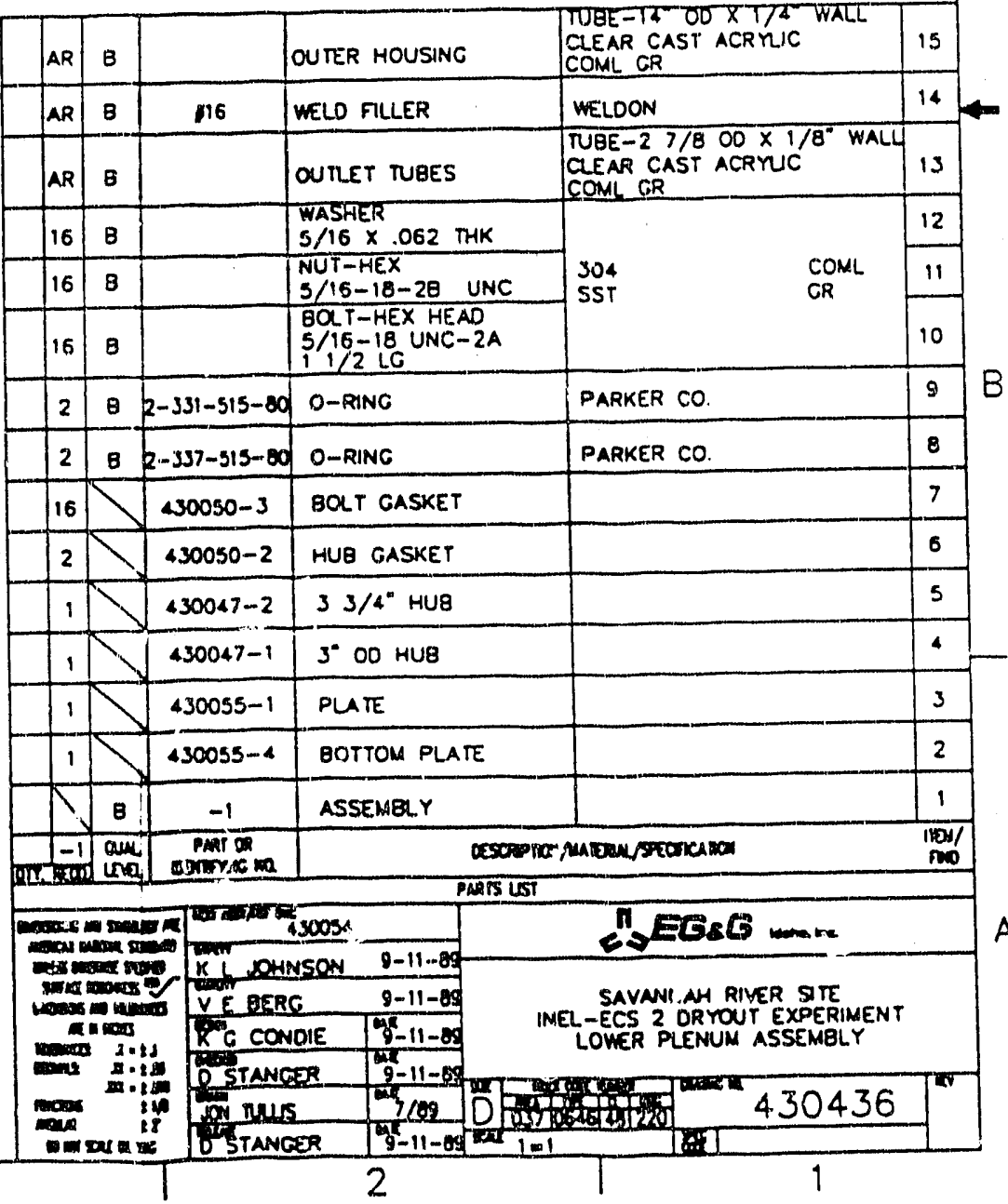




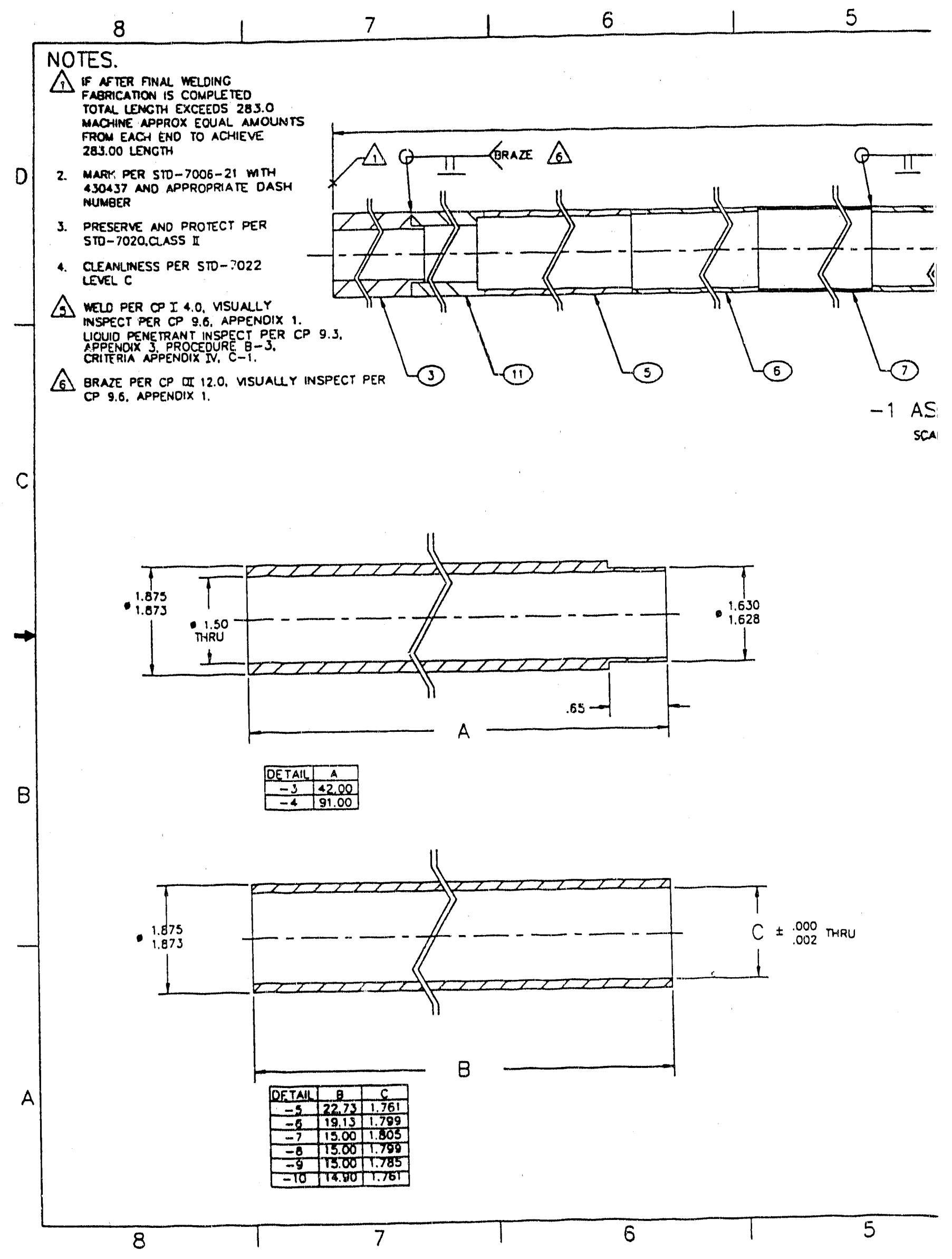




\begin{tabular}{llll|l}
4 & 1 & 3 & 2 & 1 \\
\hline
\end{tabular}

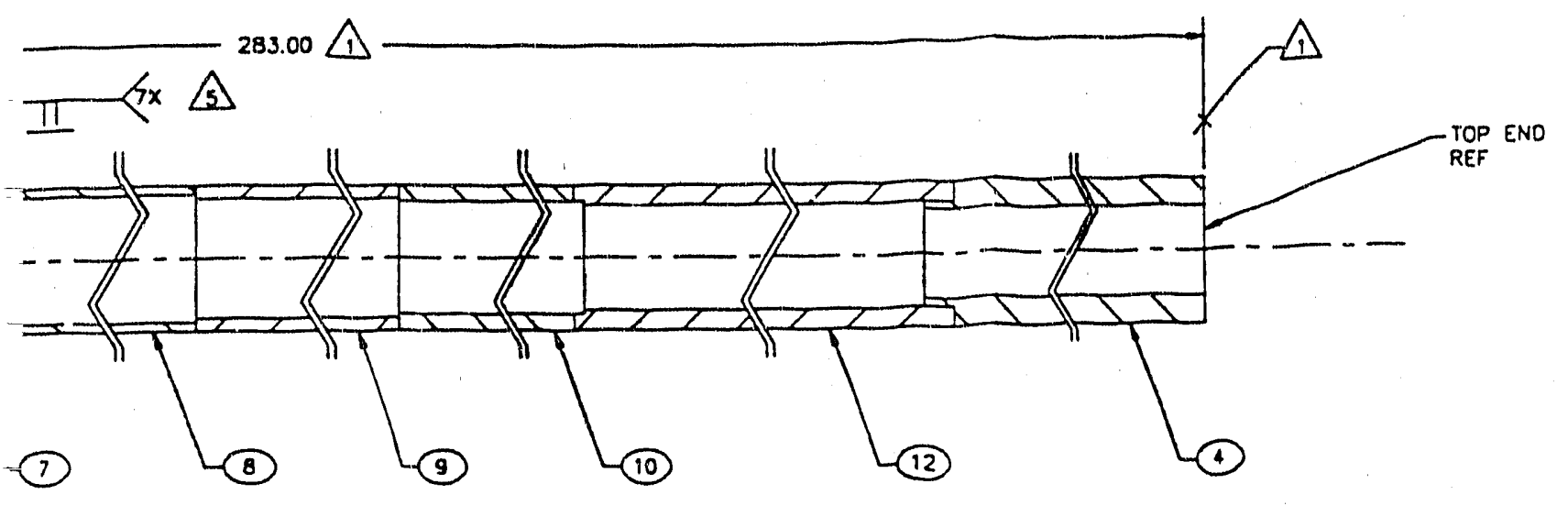

1 ASSEMBLY

SCALE $=1 / 2$

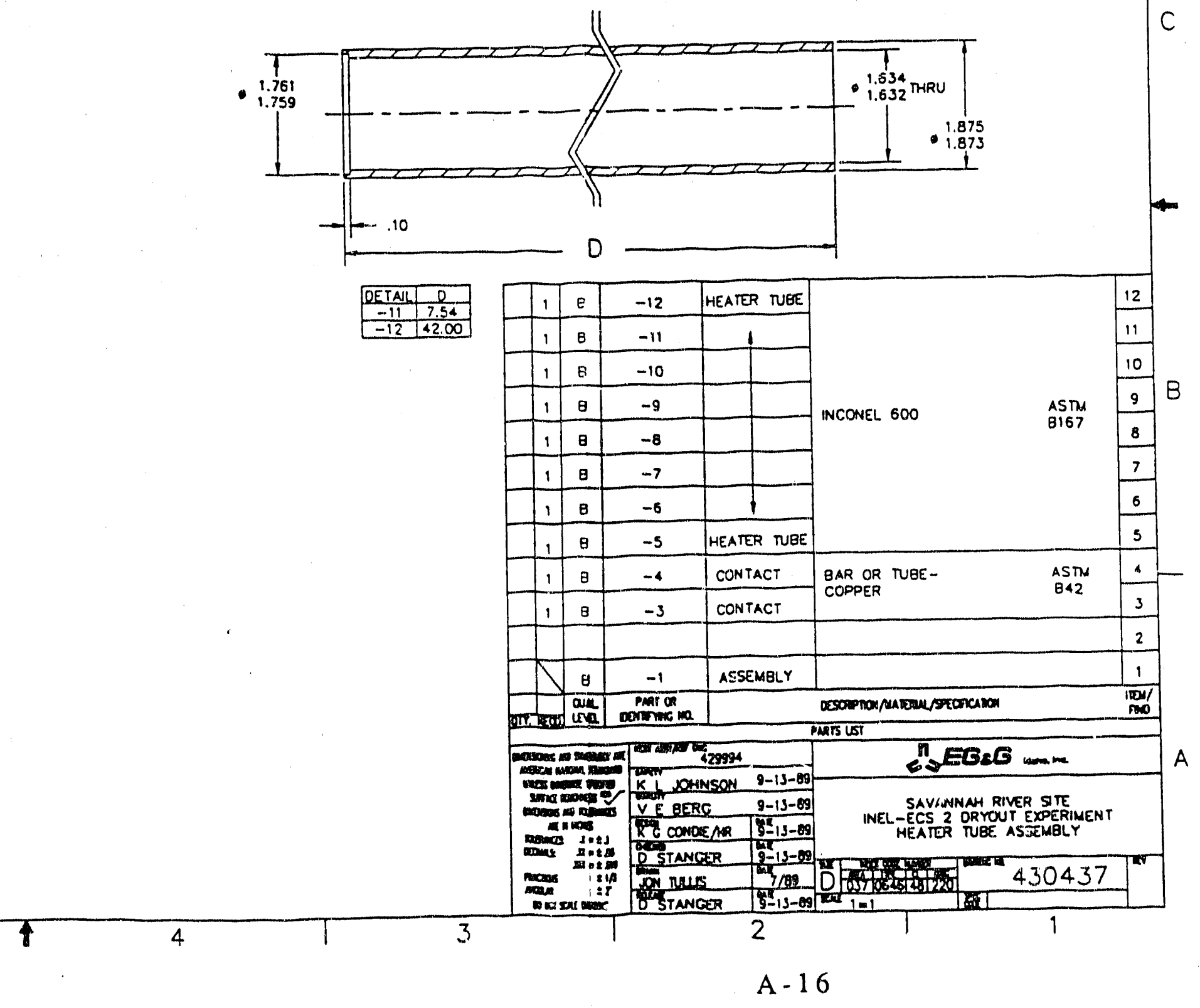




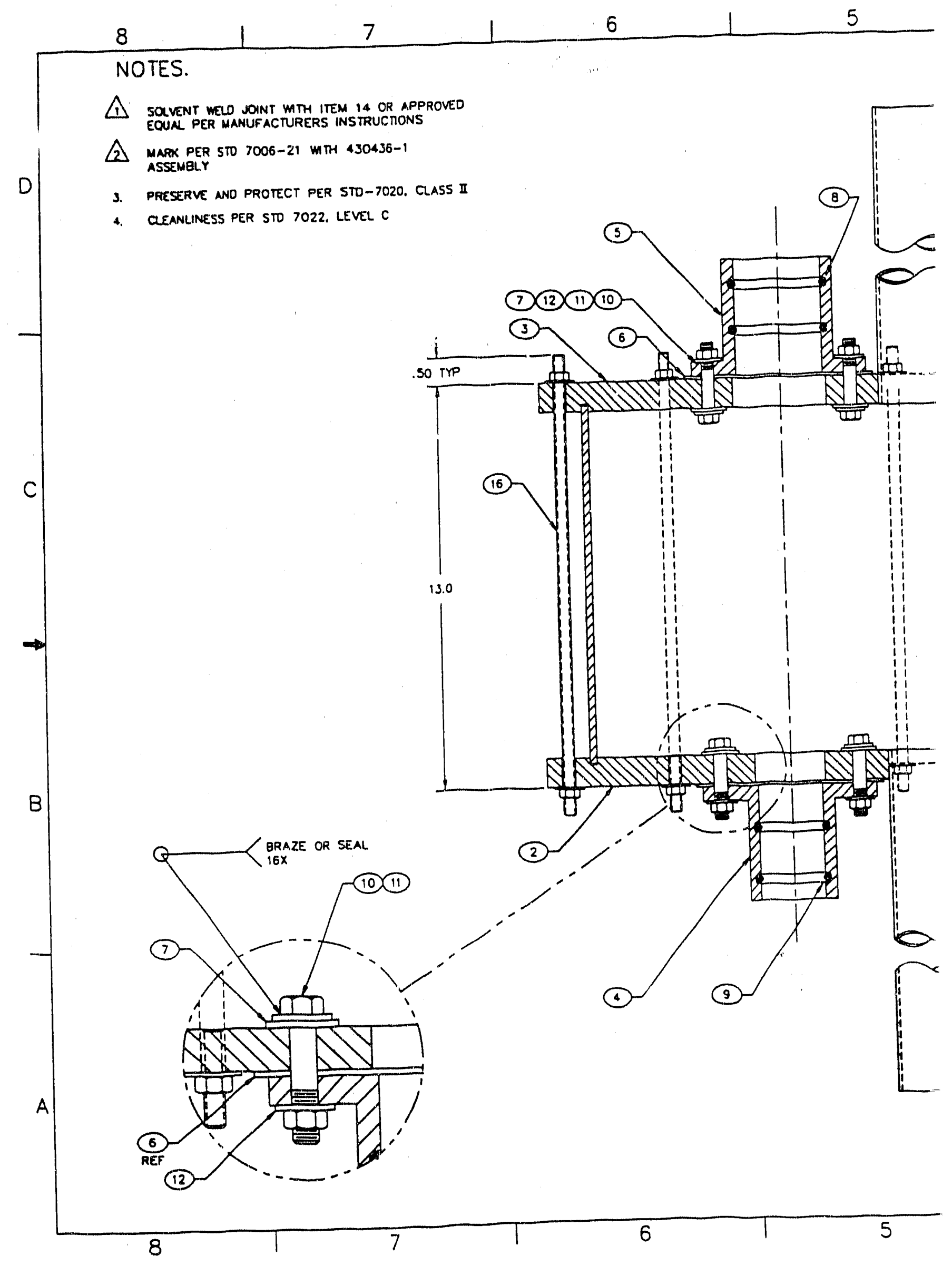



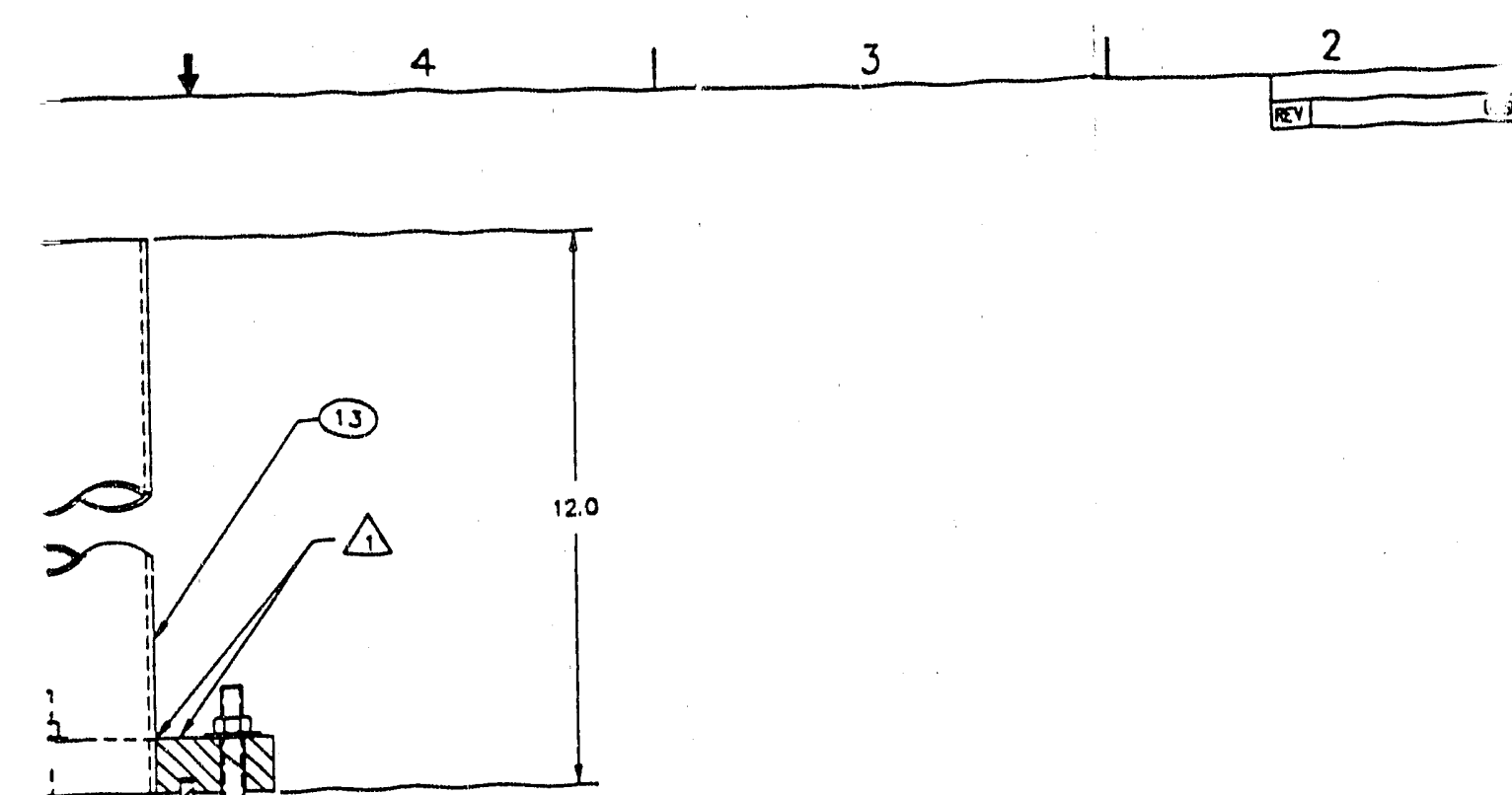

RELEASED

FOR RECORD ONLY

DO NOT FABRICATE

CHECKER J.P.BUSHMAN

DATE

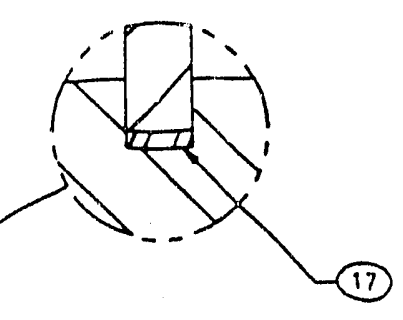

\begin{tabular}{|c|c|c|c|}
\hline$A R$ & $B$ & \\
\hline$A R$ & $B$ & \\
\hline$A R$ & $B$ & \\
\hline$A R$ & $B$ & \\
\hline$A R$ & $B$ & \\
\hline$A 6$ & \\
\hline & & \\
\hline & &
\end{tabular}

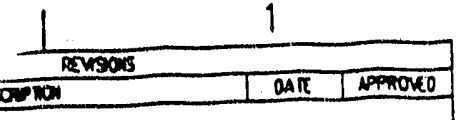

C

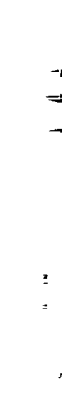




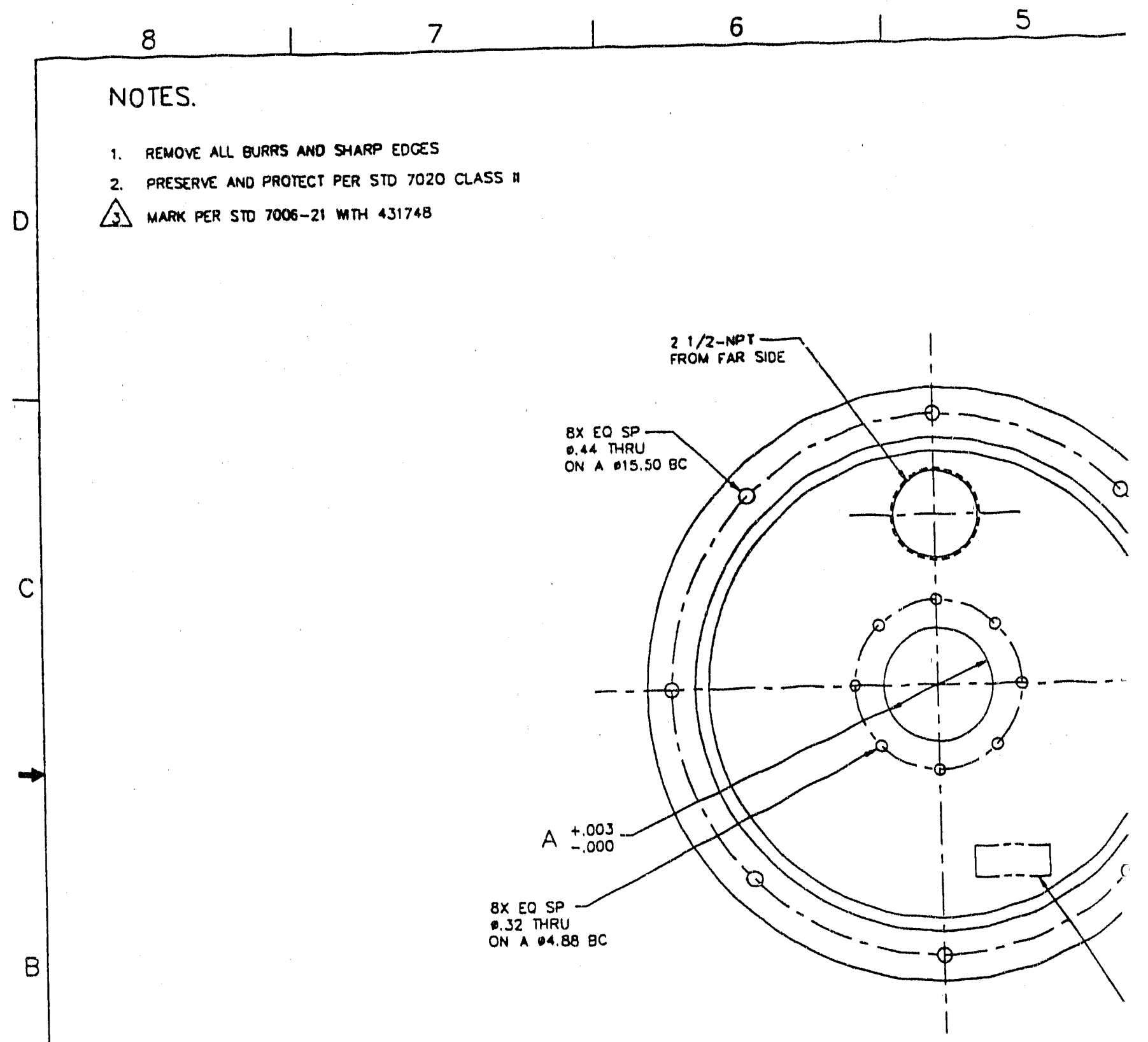

(1) oetall

A 


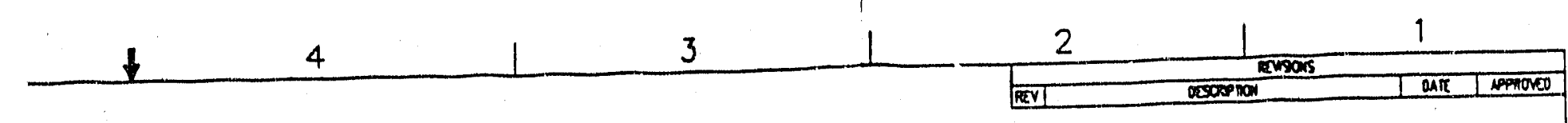

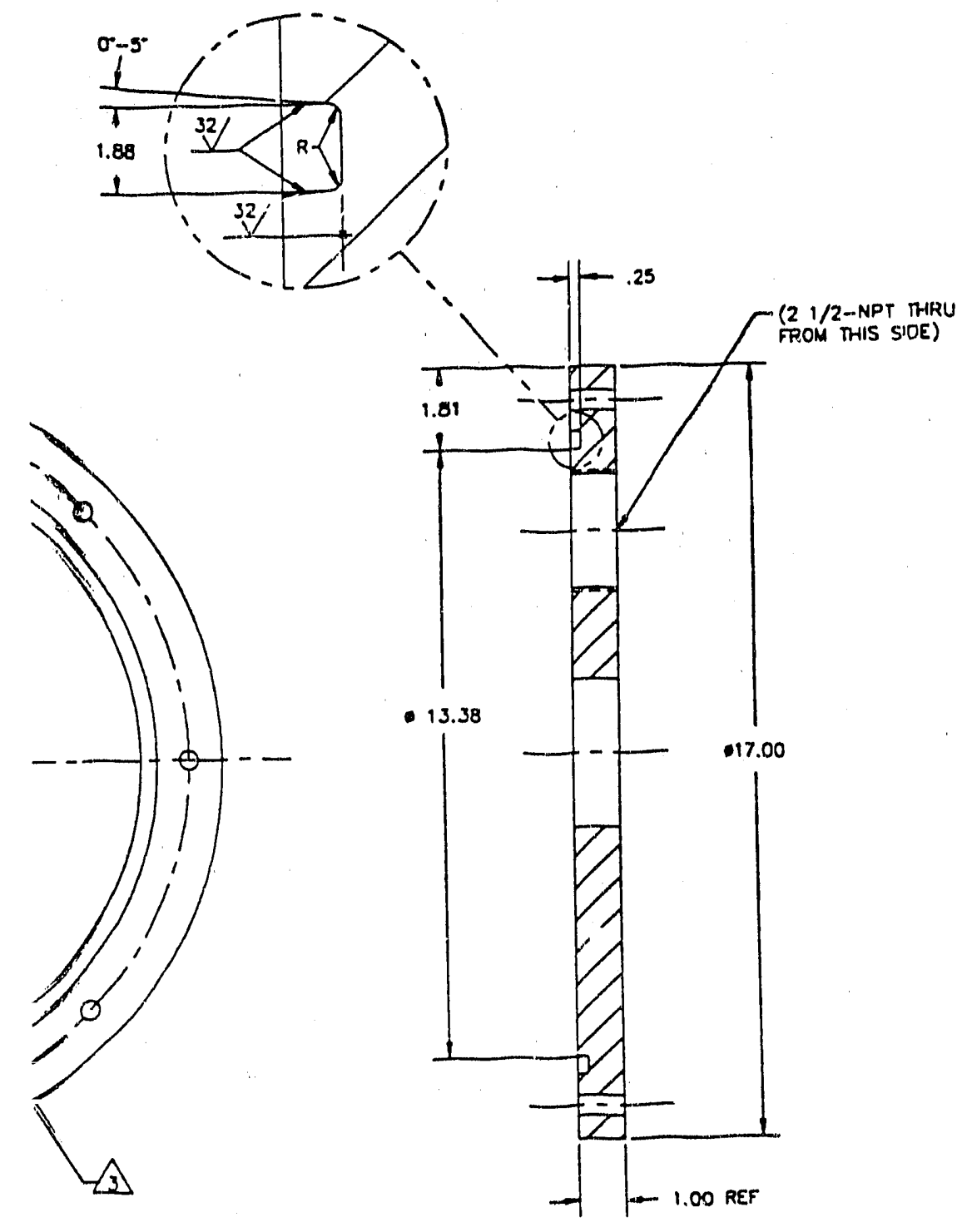

\begin{tabular}{|c|c|c|c|c|c|c|}
\hline AR & $B$ & & PLATE & $\begin{array}{l}\text { PLATE- I THK } \\
\text { CIFAR CAST ACRMIC }\end{array}$ & $\begin{array}{l}\text { CrML } \\
\text { CR }\end{array}$ & 1 \\
\hline & $\begin{array}{l}\text { ase } \\
\text { ind }\end{array}$ & DaPr on & & 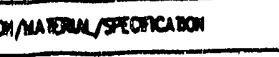 & & $\begin{array}{l}\text { now/ } \\
\text { non }\end{array}$ \\
\hline
\end{tabular}

RELEASED

FOR RECORD ONLY DO NOT FABRICATE CHECKER J.P.BUSHMAN DATE 6-13-90

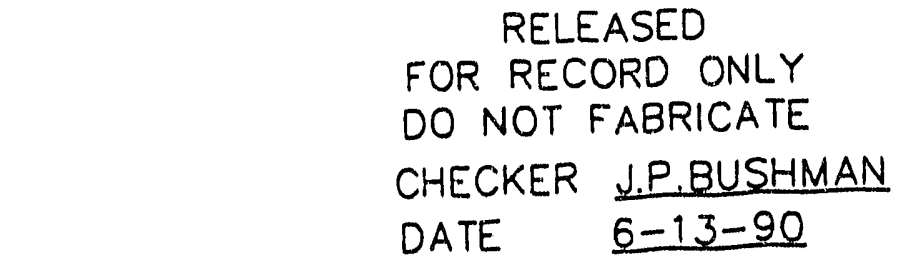

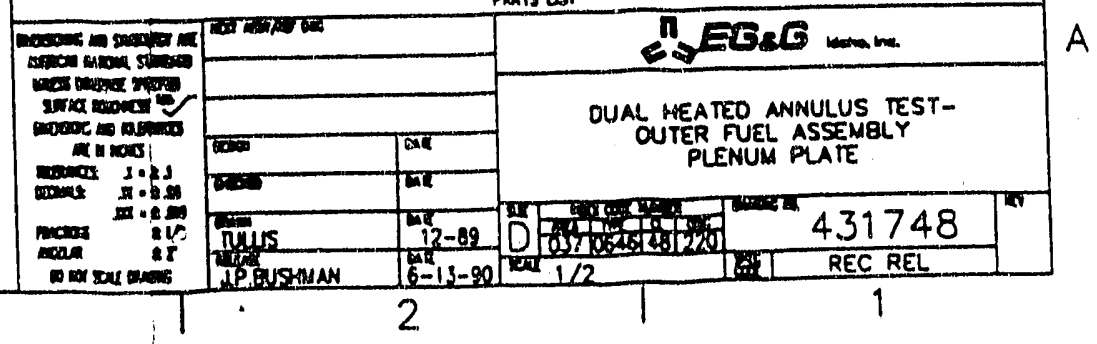

$$
\text { A }-18
$$


Appendix B

Measurements Lists for the ECS-2 and ECS-2c Thermal Excursion Experiments 


\section{Appendix B}

\section{Measurements Lists for the ECS-2 and ECS-2c Thermal Excursion Experiments}

Common practice established during the INEL thermal excursion experiments was to use a shorthand notation called the "DAS tag ID" when referring to a particular measurement. Since this practice was used throughout the body of this report, reference information regarding the relationship between the measuremeni ID, measurement location, and so forth, is provided in this appendix.

Since excursion experiments were conducted in two different facilities with different inner heaters and instrumentation, two instrument tables are provided. Tables B-1 and B-2 apply to experiments conducted in the ECS-2 and ECS-2b facilities, respectively. Columns in these measurements lists contain the name used for measurement identification, the tag name used in the data acquisition system that is associated with the measurement identification, the type of measurement being made, the physical location of the measurement in the test section (or on the facility), the test section fluid subchannel where the measurement is located (if applicable), and the range over which the measurement was specified to operate. Note that due to instrument failures or electronics problems, not all of the measurements listed on the attached tables may be available for a particular experiment. Appendix I provides a list of known problematic instruments for the excursion tests. 


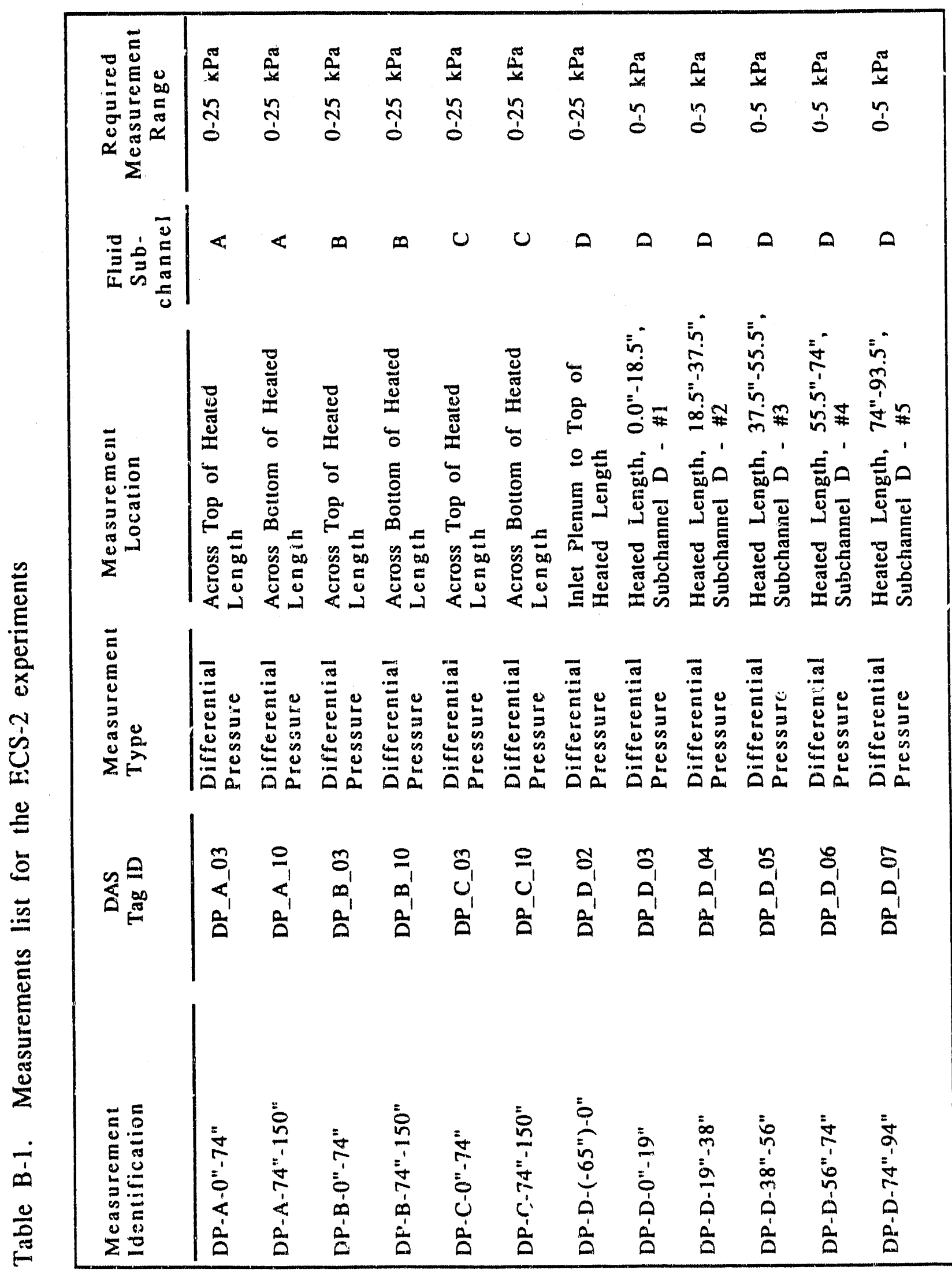




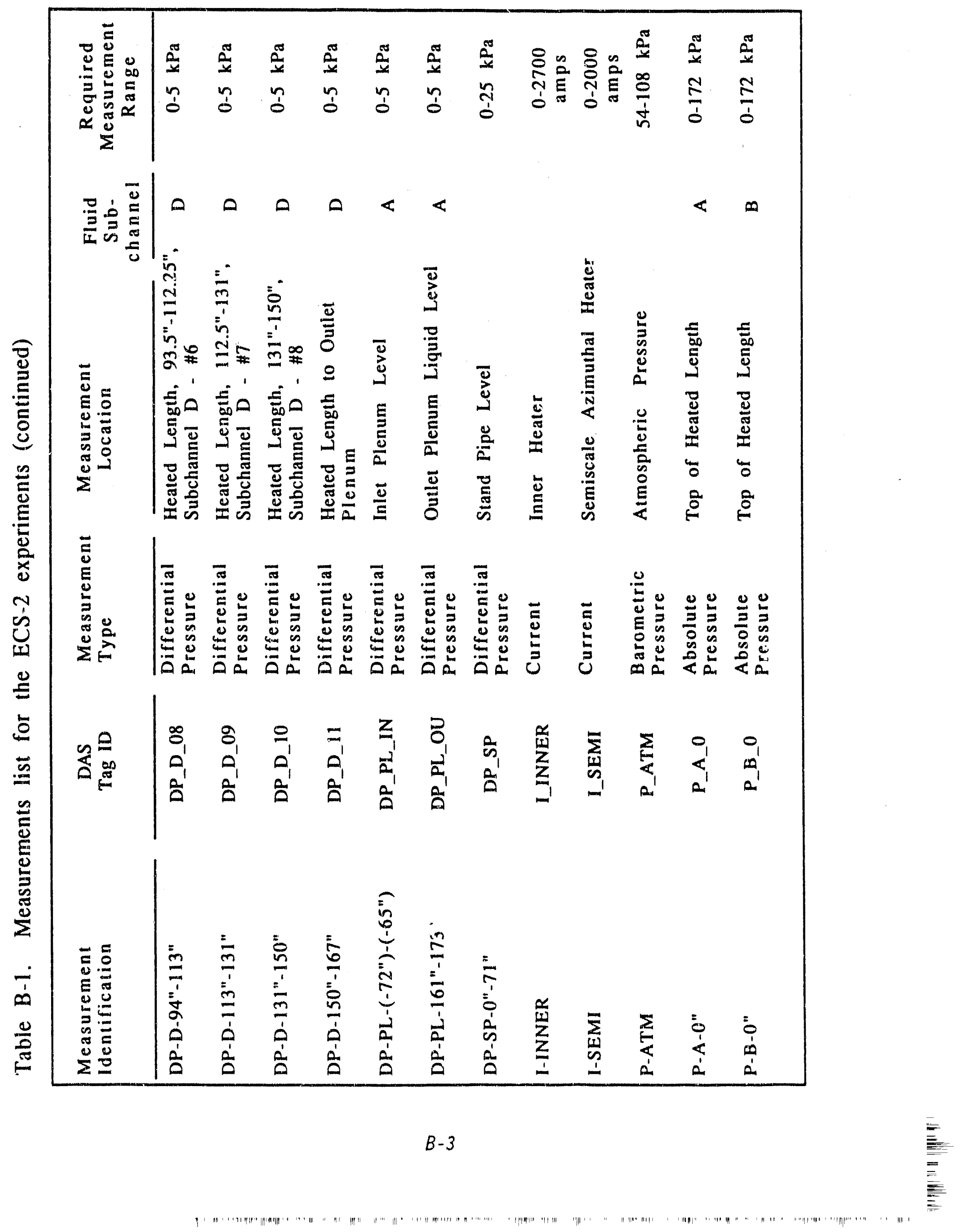




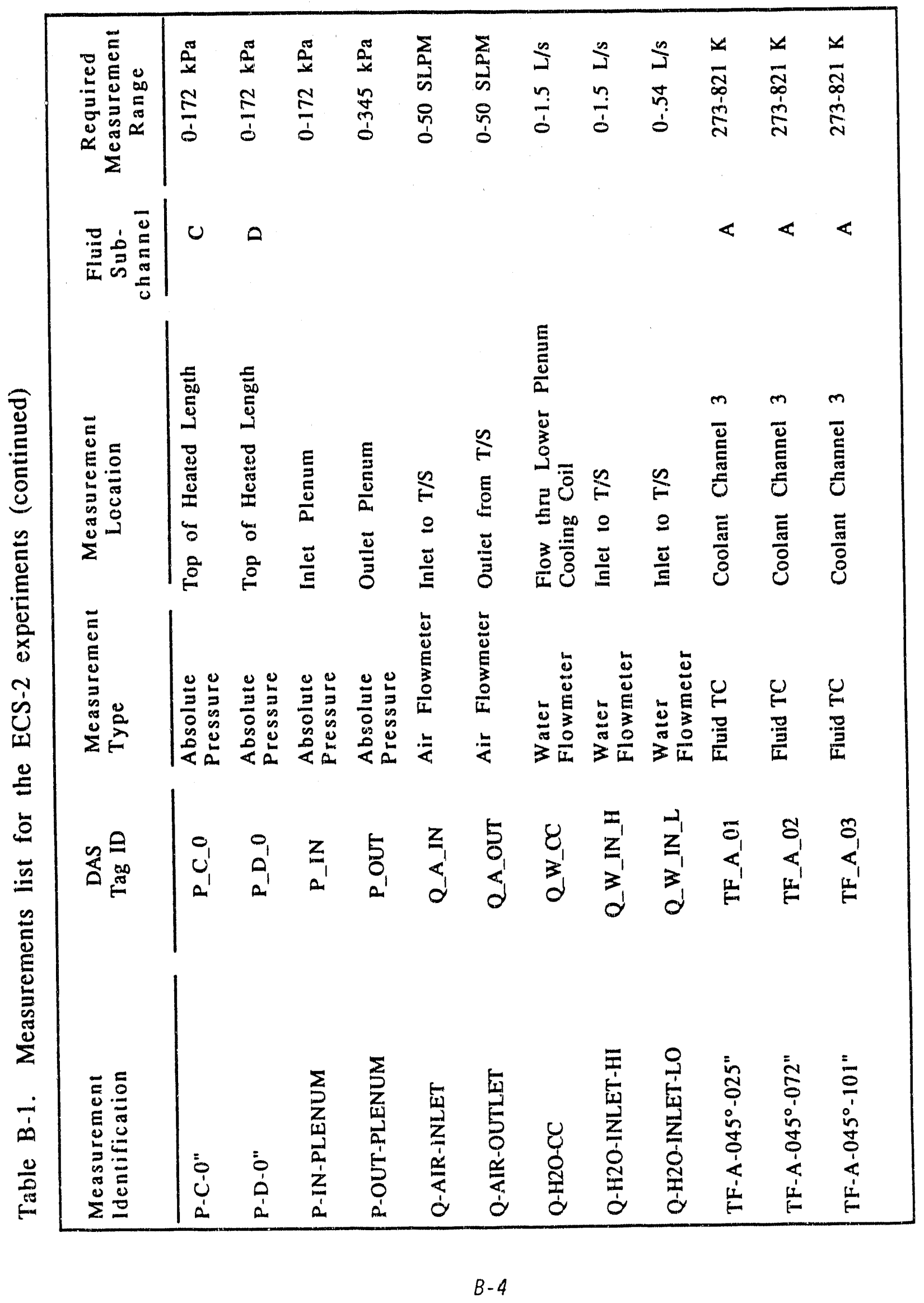




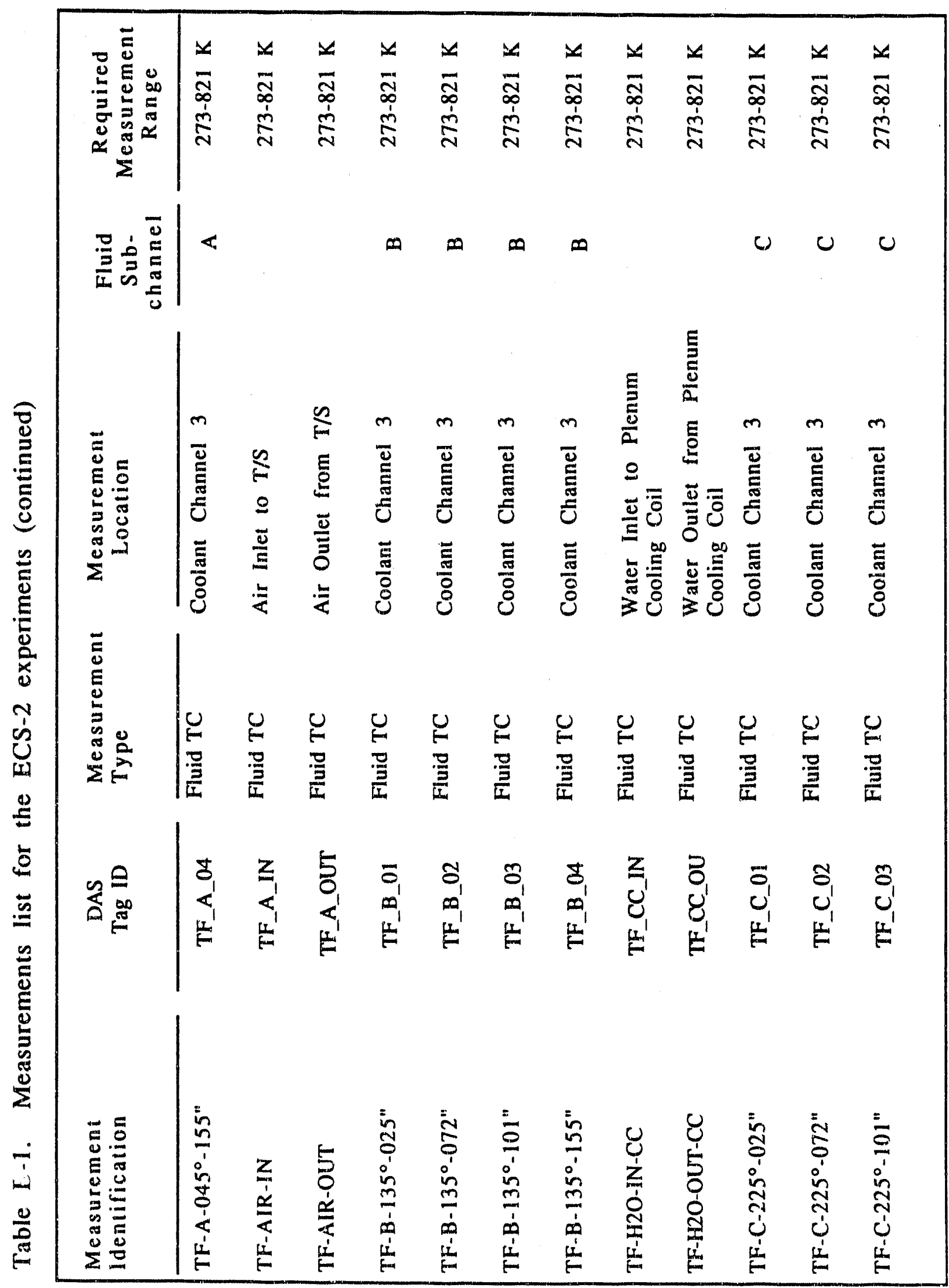




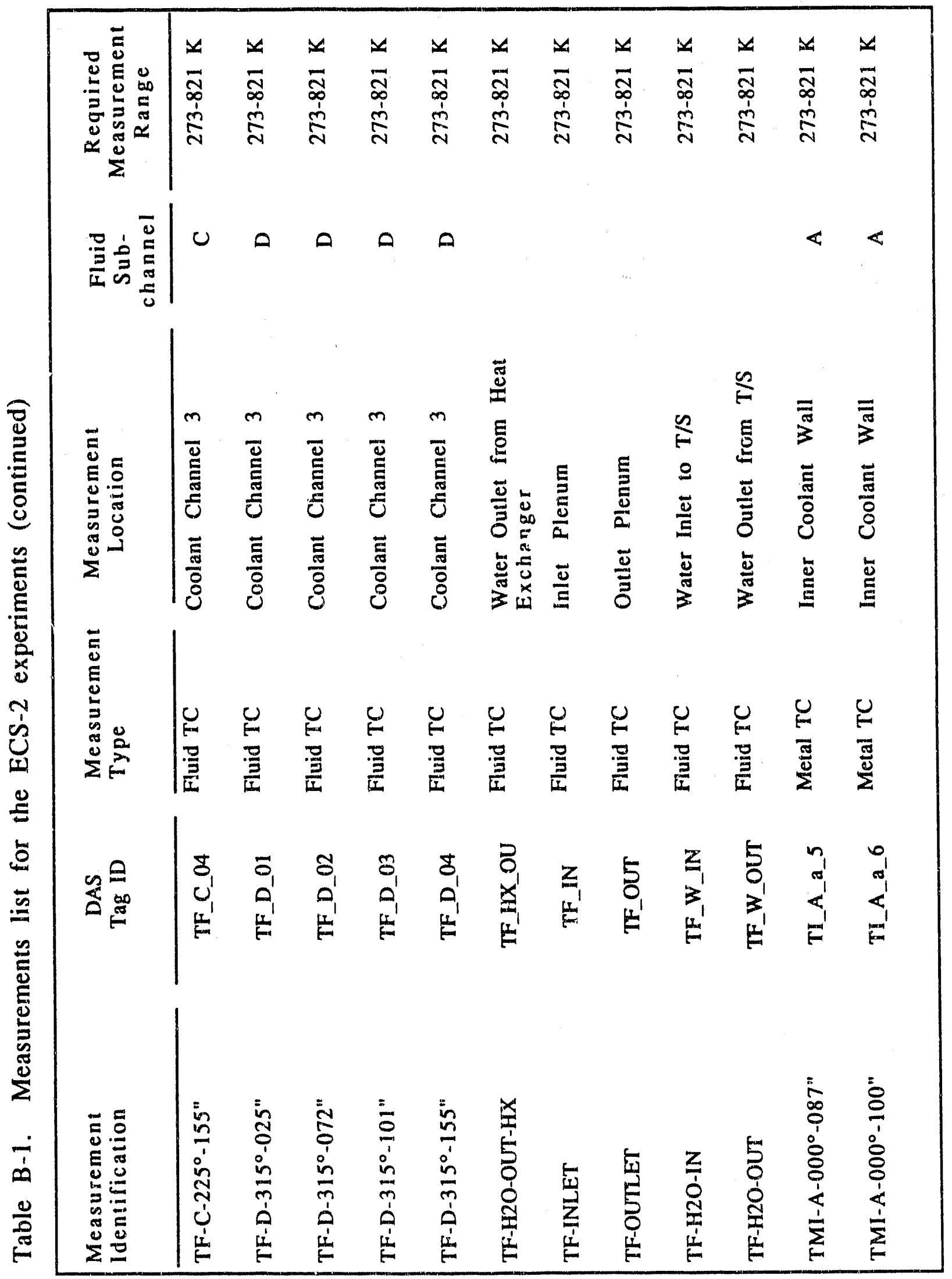




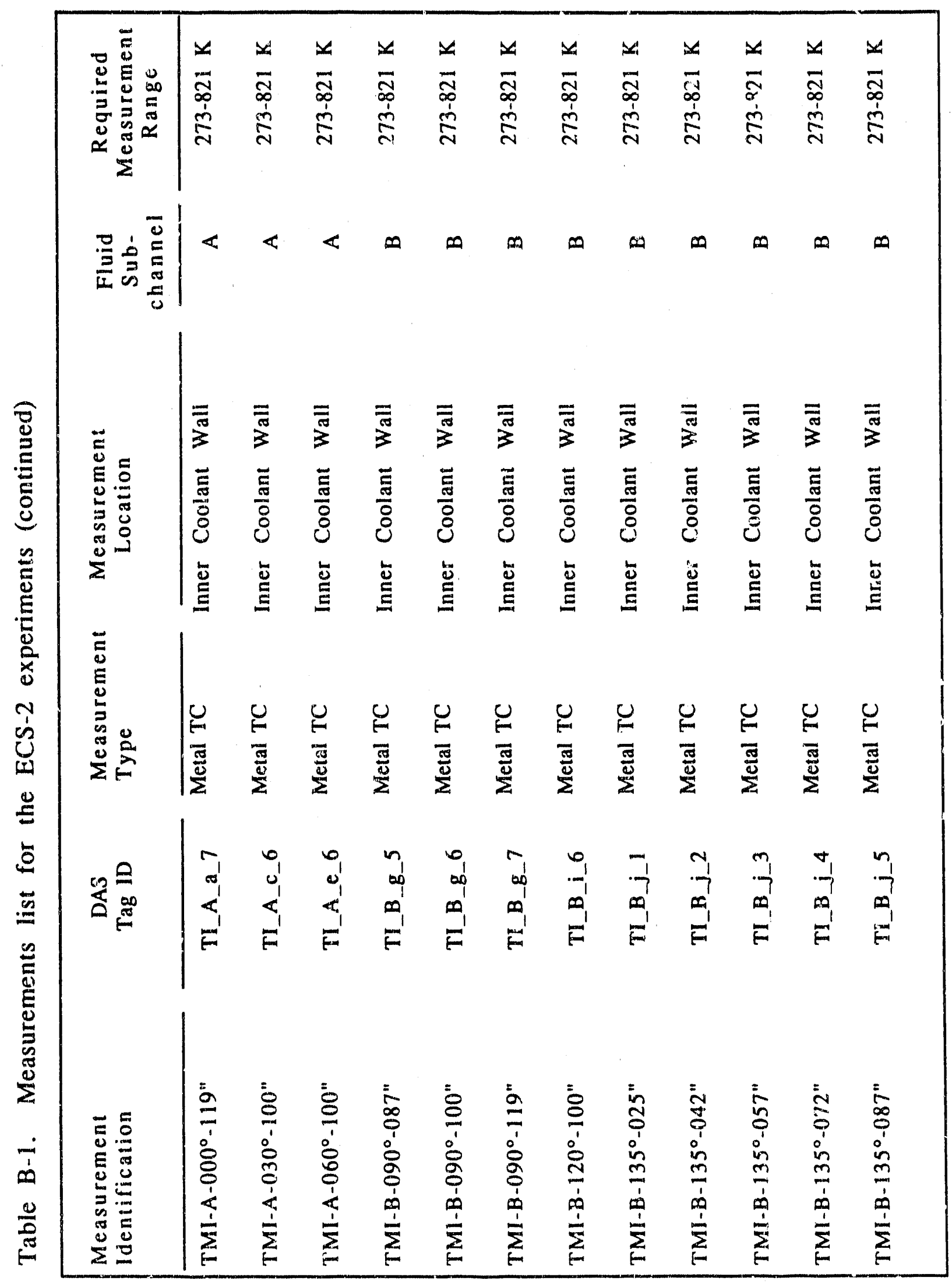

$B-7$ 


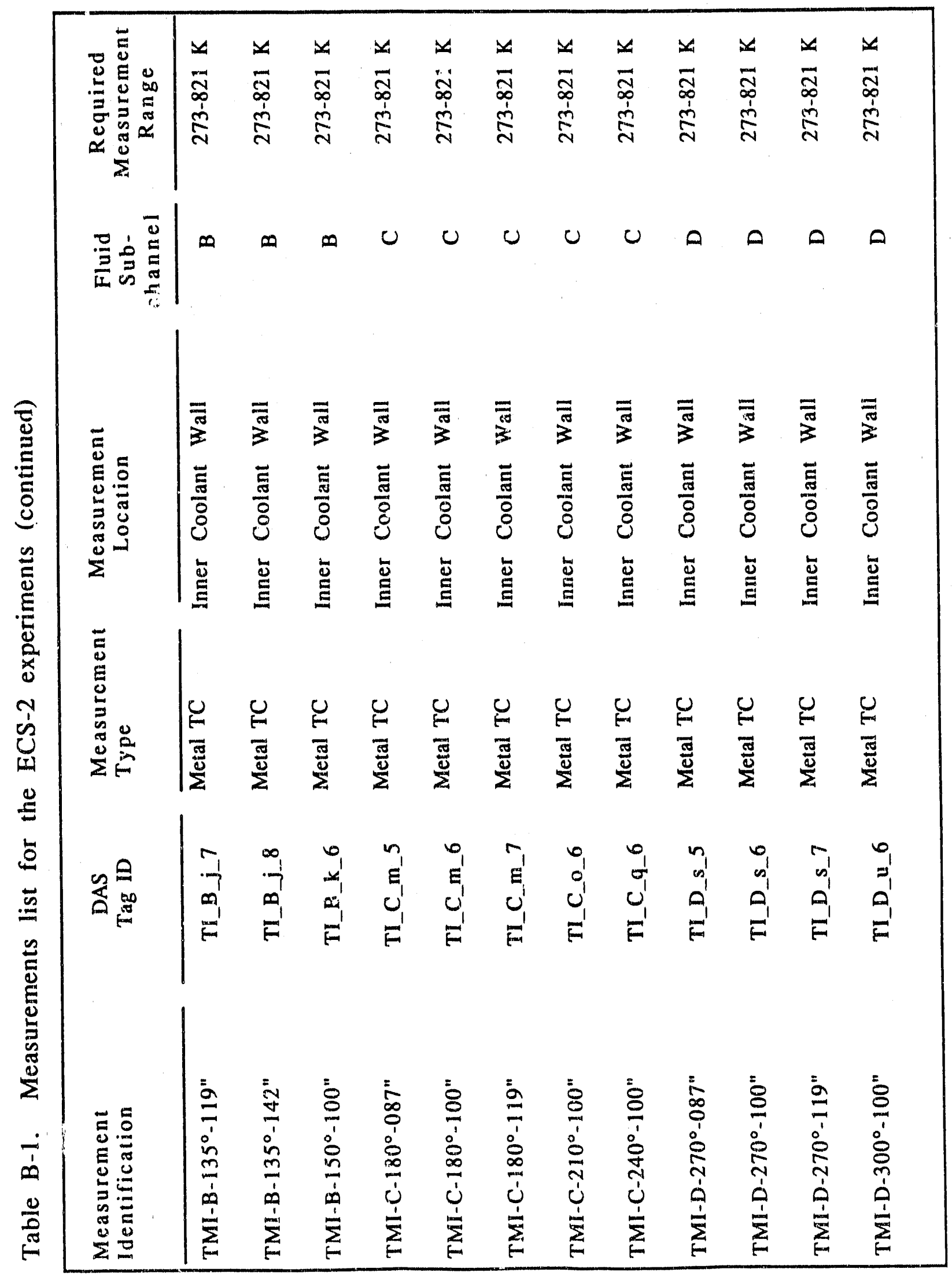




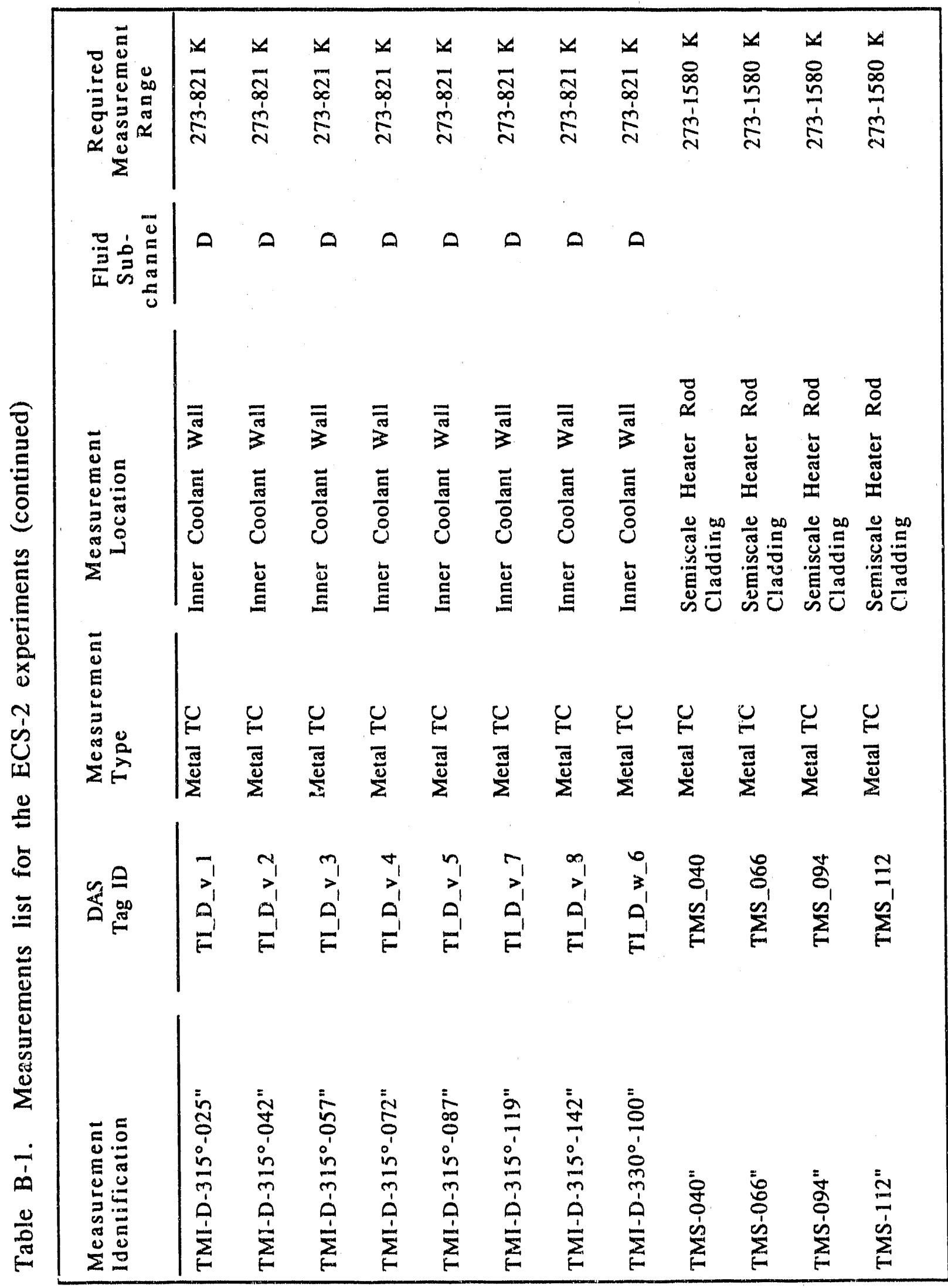




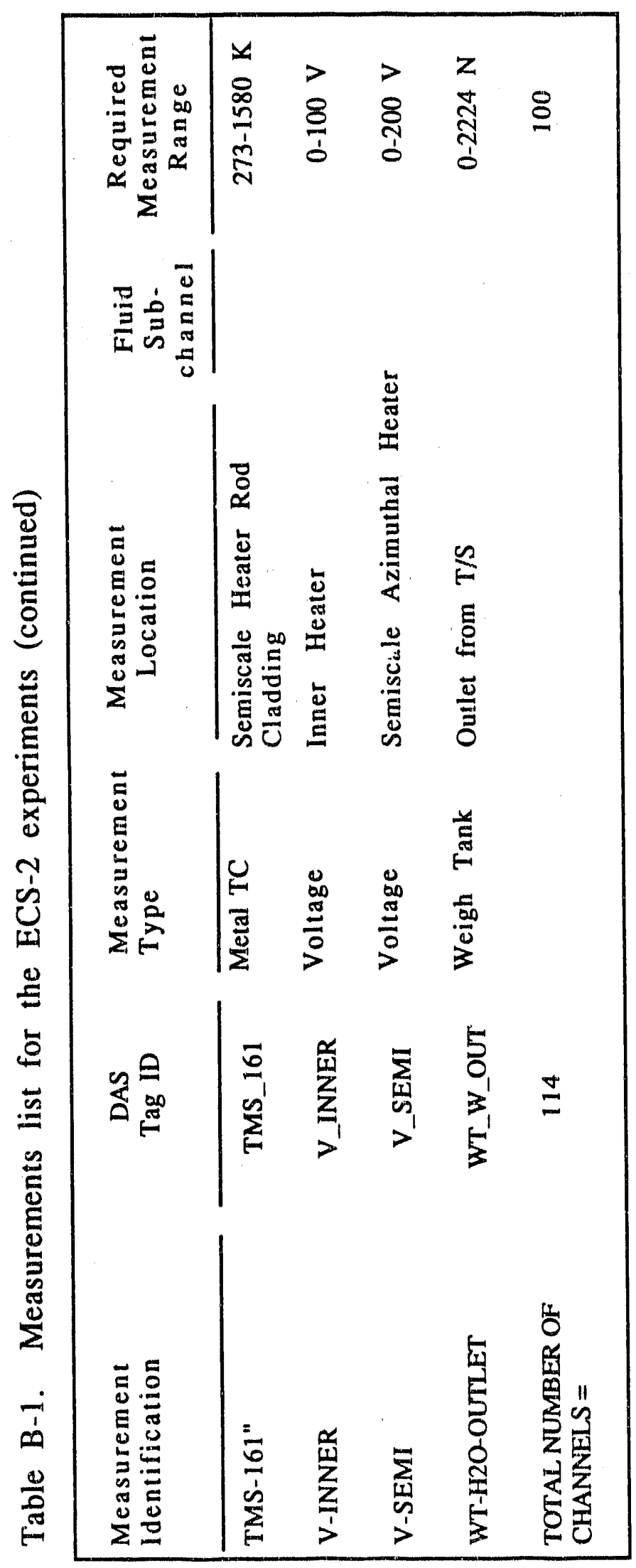

B- 10 


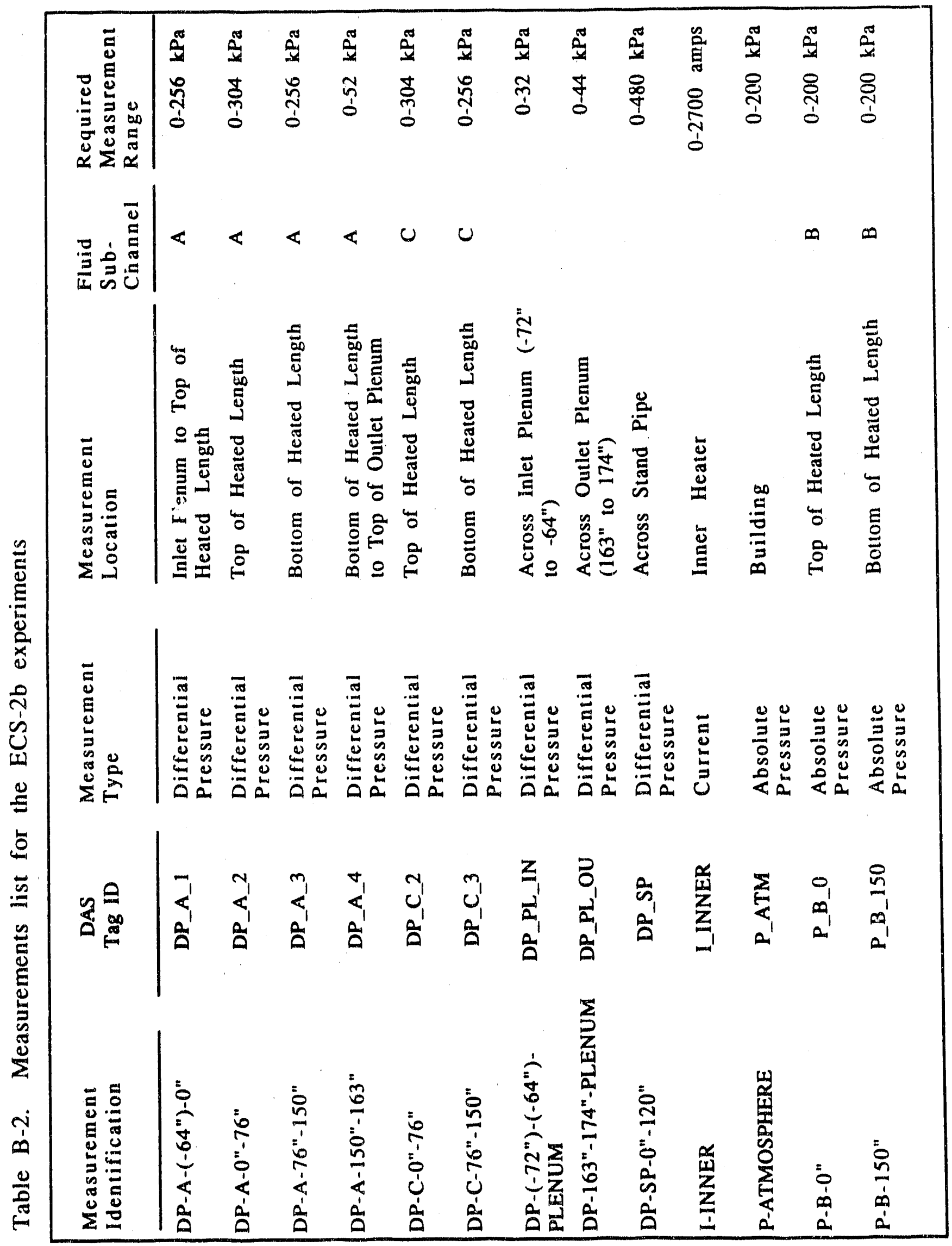




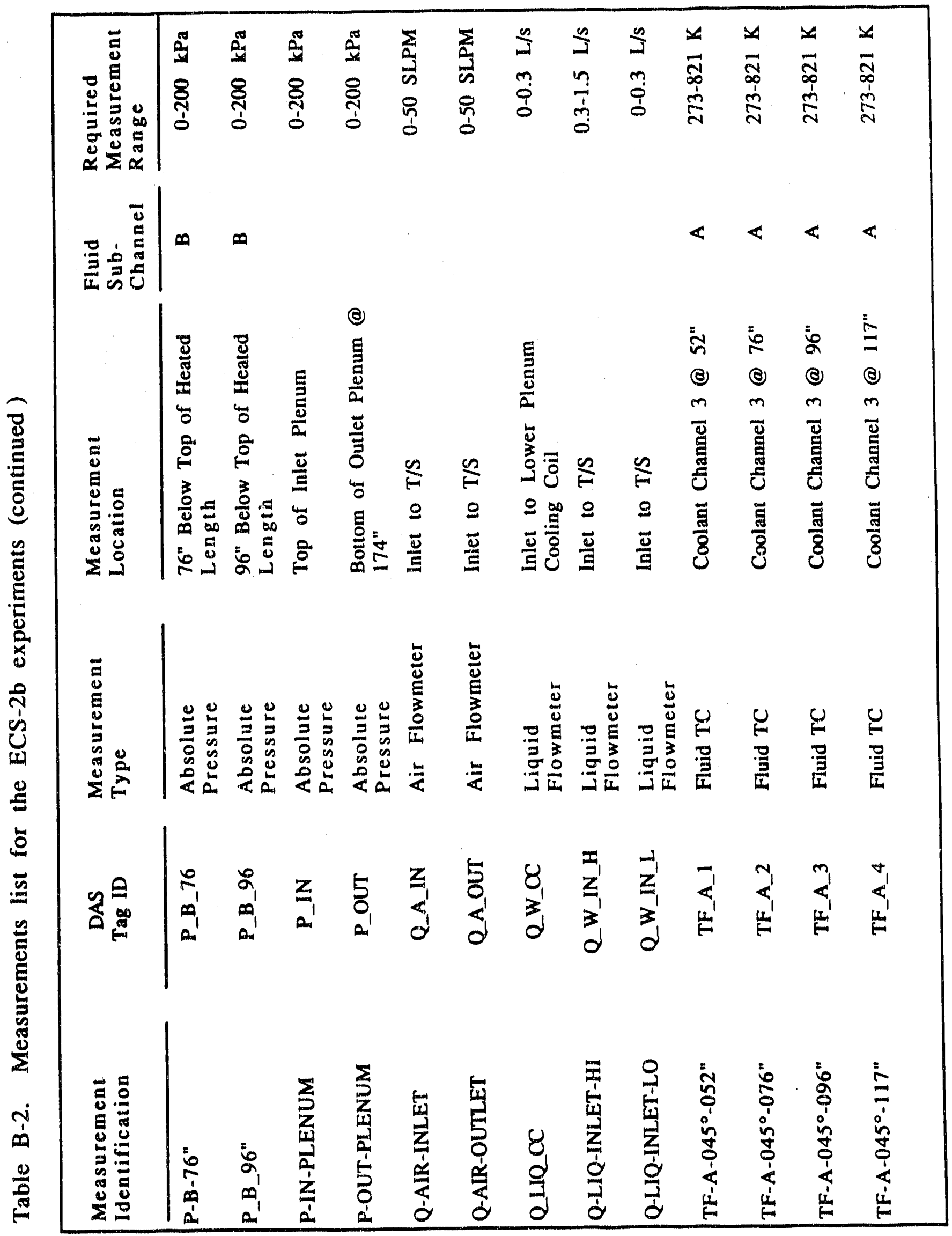




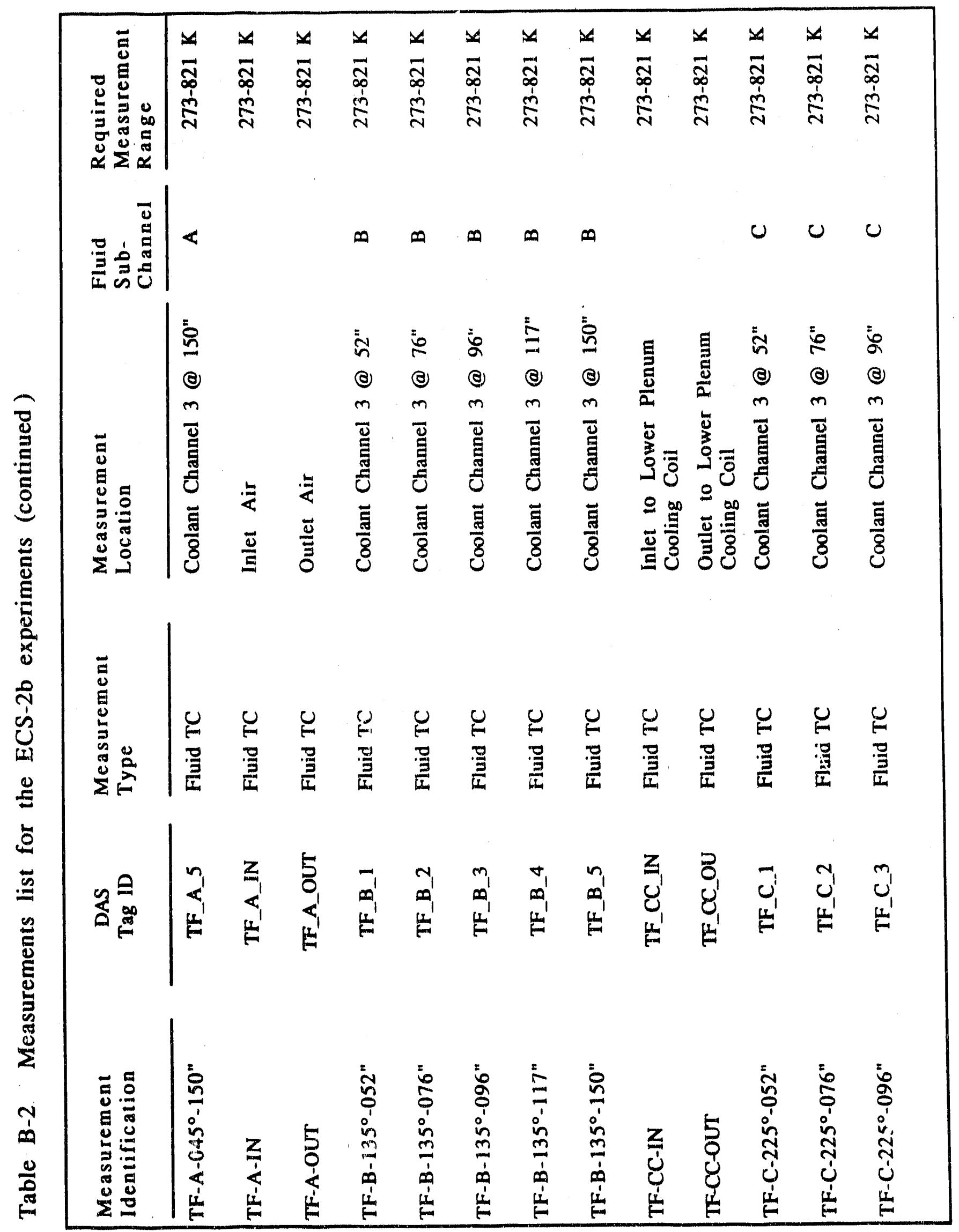




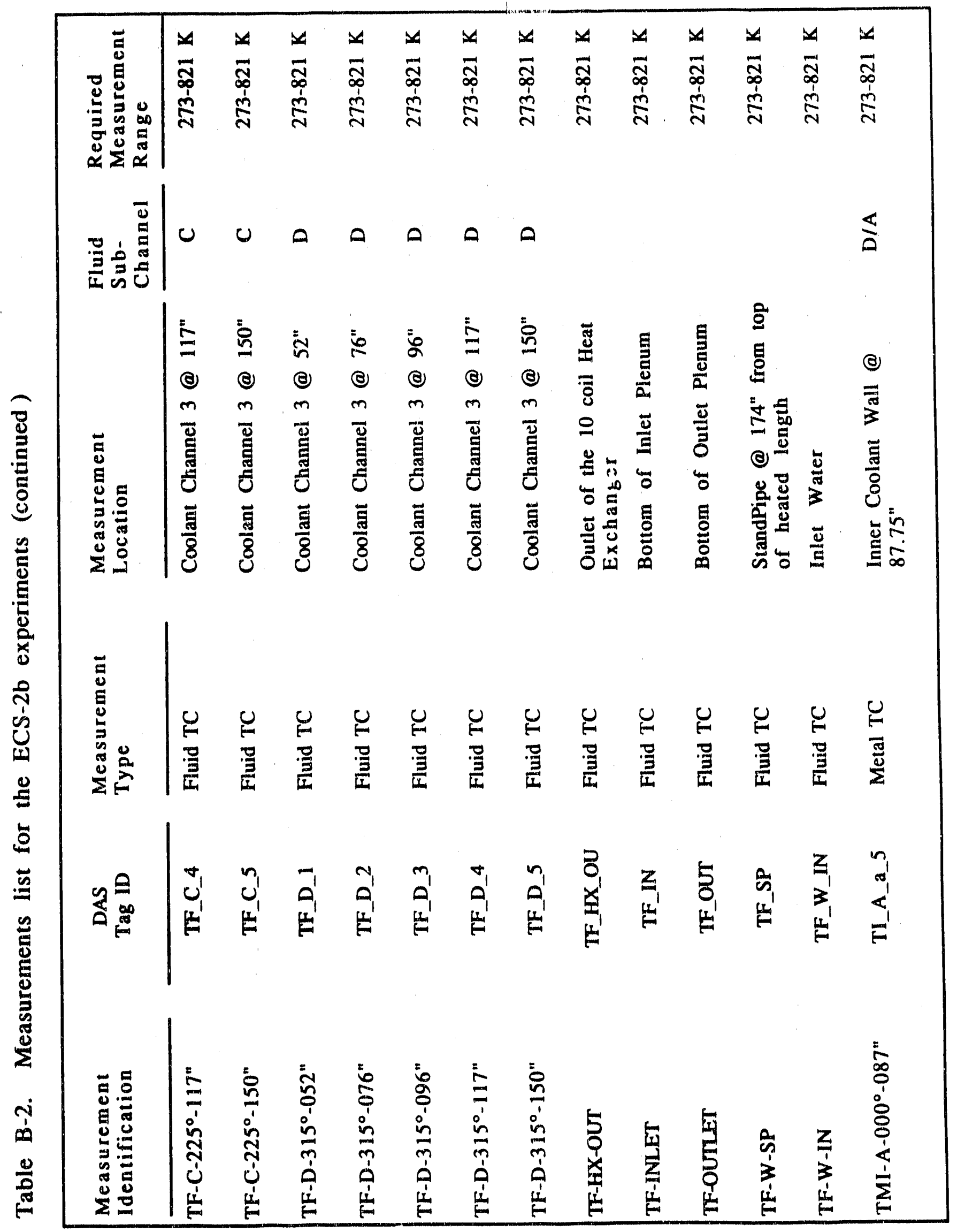




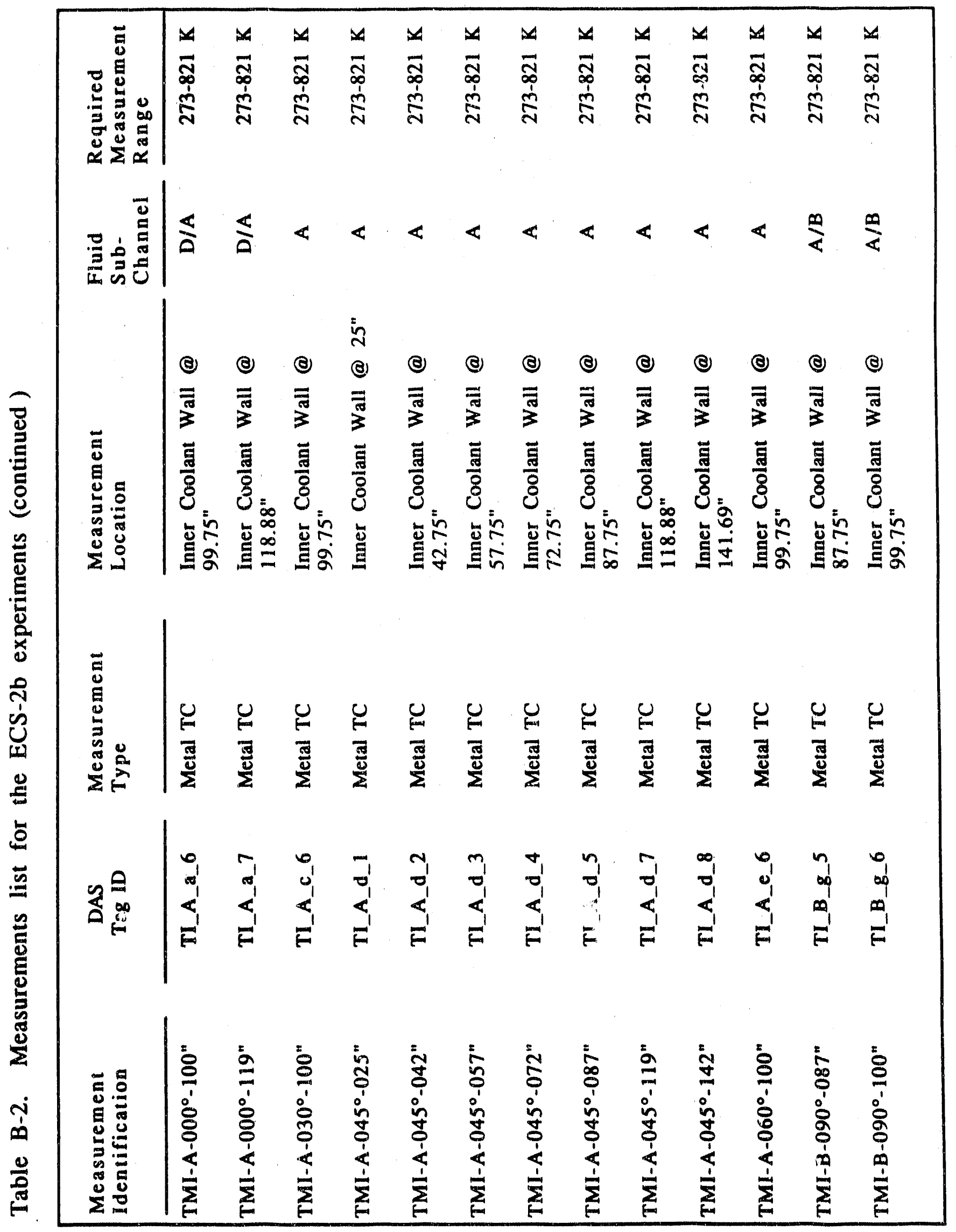




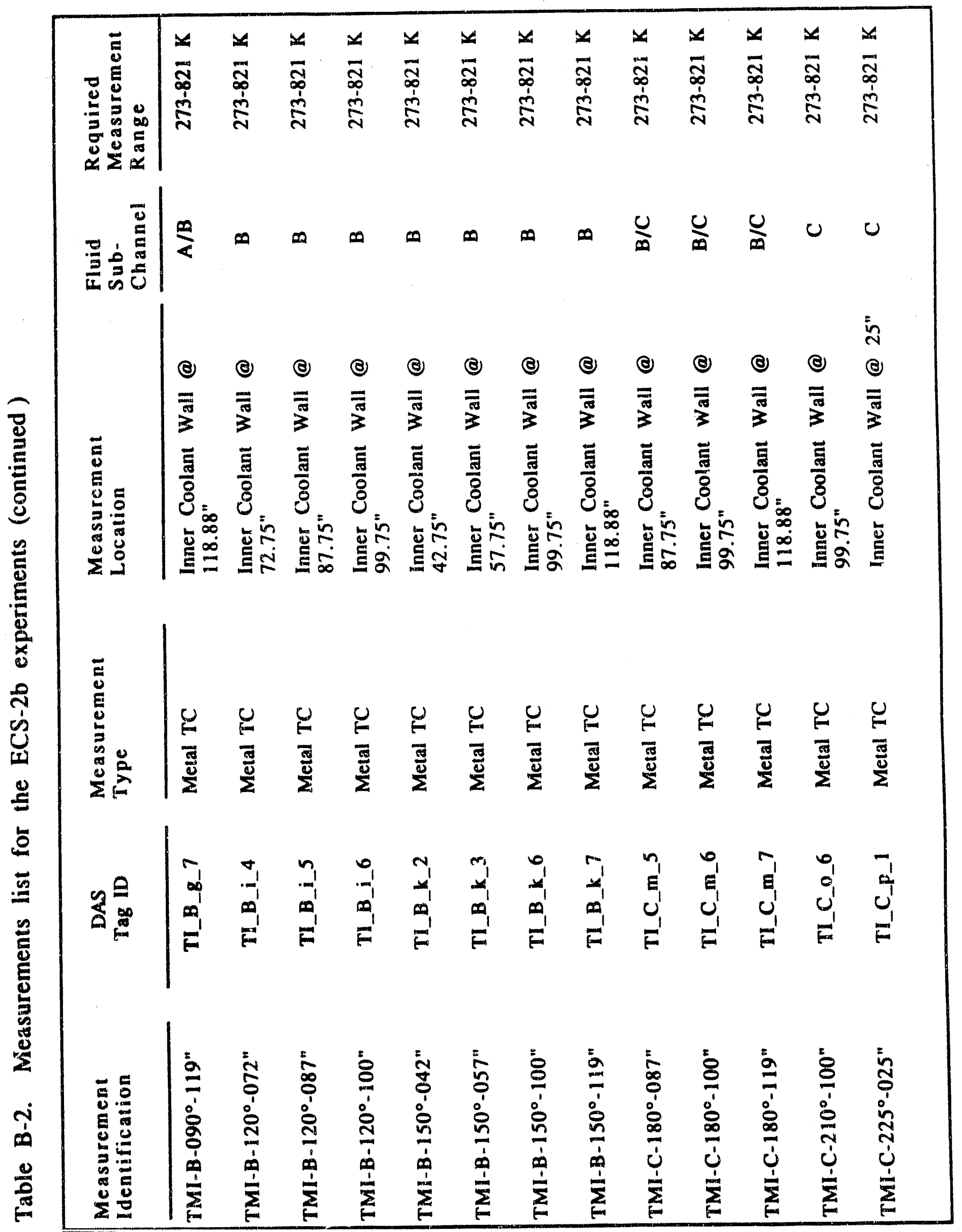




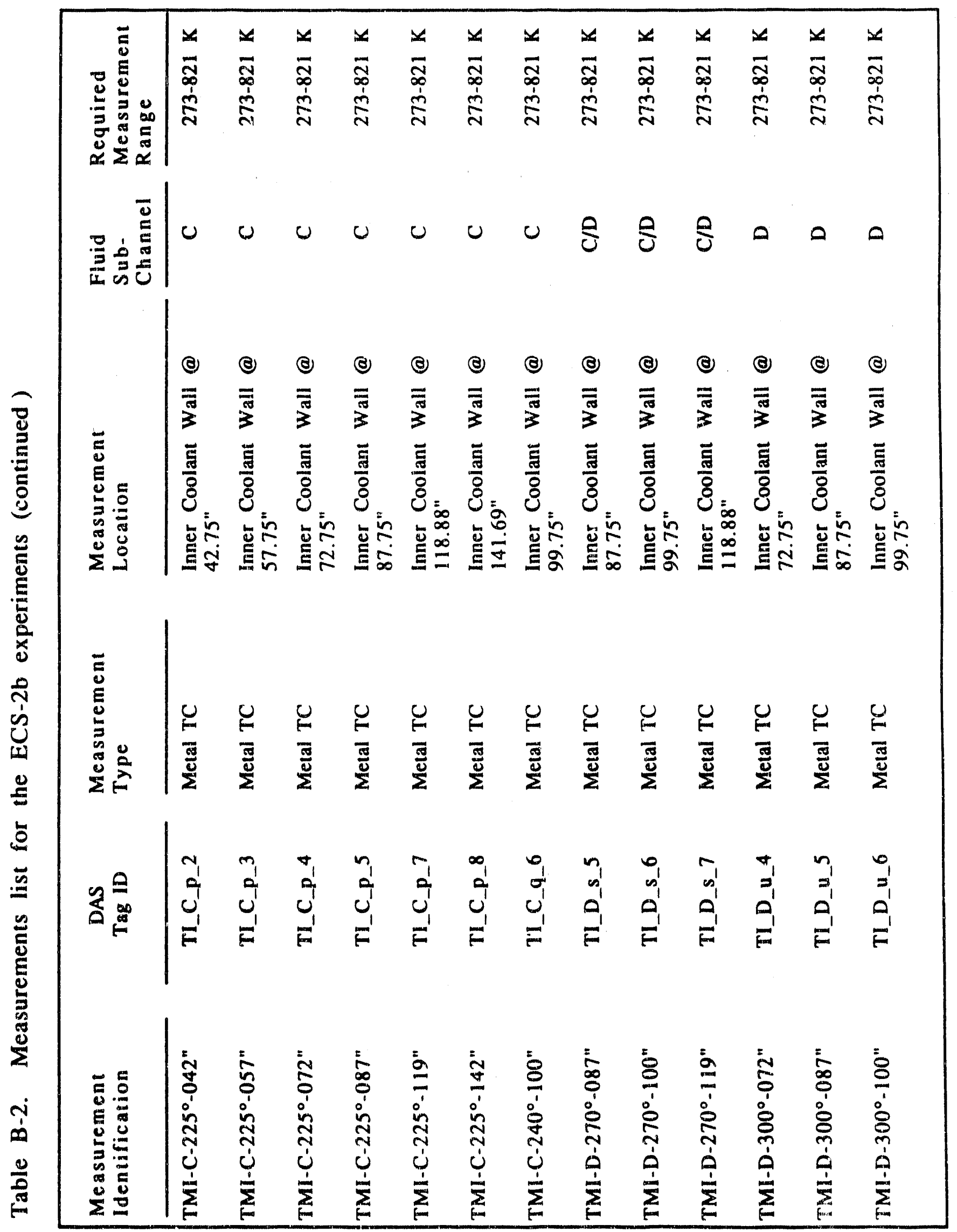




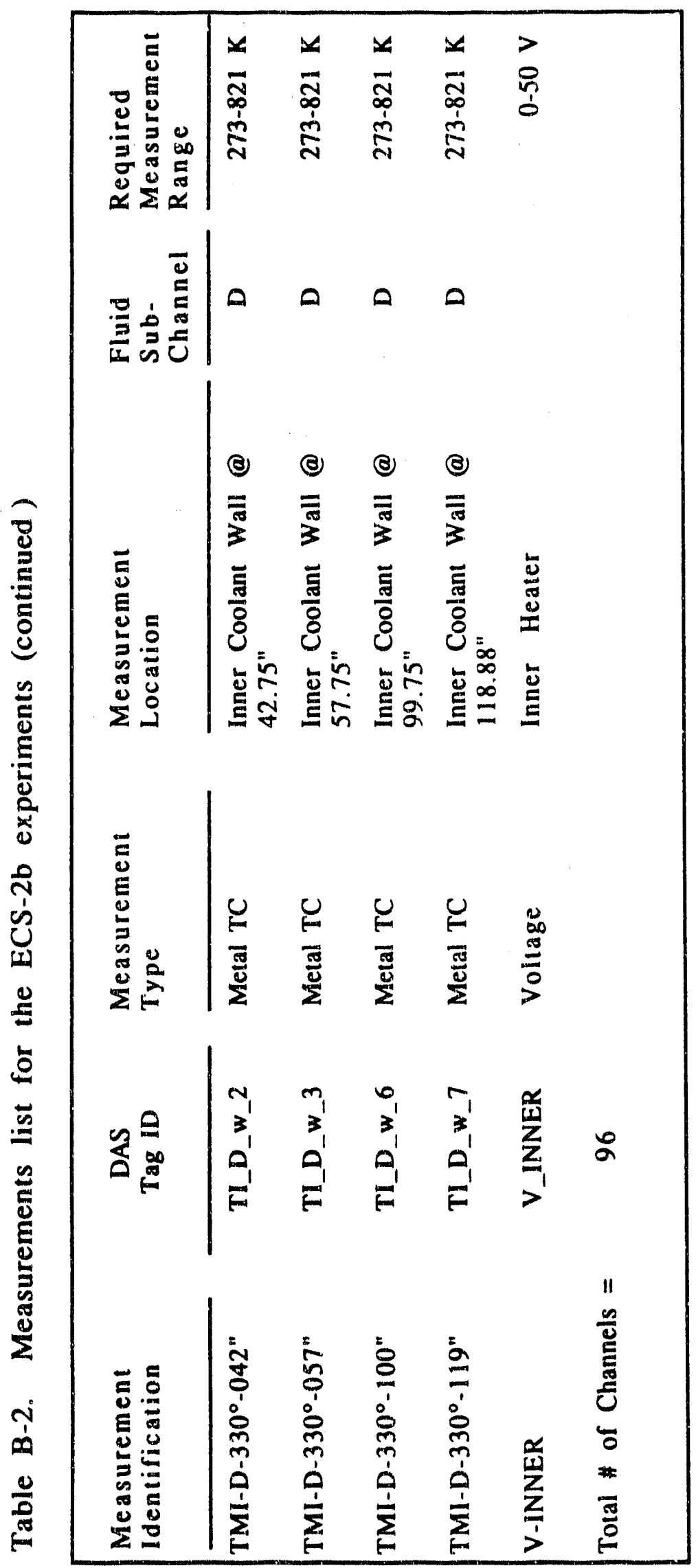


Appendix $\mathbf{C}$

Measurement Uncertainty for the ECS-2 Thermal Excursion Tests 


\section{Appendix C \\ Measurement Uncertainty for the ECS-2 Thermal Excursion Tests}

An extensive measurement uncertainty analysis was conducted for the measurements and instrumentation used in the test fixture for the thermal excursion experiments. Details of this analysis are documented in Wilkins [Wilkins 1990]. Results of Wilkin's uncertainty analysis for tests conducted in the ECS-2 test fixture are equally applicable for experiments conducted in the ECS-2b fixture since the instrumentation used in the two facilities is essentially the same. A brief summary of the uncertainty analysis results is given here to provide a measure of the uncertainty associated with the data presented in this report.

Wilkins describes the potential error sources and the quantitative contribution of each to the overall uncertainty in various key measurements made during the ECS-2 test series. Those measurements include:

(a) voltage and current to the test section (used to determine the input power to the test)

(b) air and water mass flows

(c) fluid and metal temperatures in the test section

(d) mass-energy balance

(e) absolute and differential pressures at selected points in the test section

(d) contribution of the data acquisition system uncertainty to each of those measurements.

Possible error sources for the measurements were combined by the root-sum-square (RSS) method of summing bias and precision errors, and are given at the $95 \%(2 \sigma)$ confidence level. The single exception to this is the metal thermocouple uncertainties, where bias errors were summed algebraically in order to preserve the sign of the dominant bias term. Equations appropriate for computing specific measurement uncertainties (U) are given below. Table C-1 lists low-and high-range uncertainty values for the measured parameters. 


\section{Data acquisition system:}

$\mathrm{U}_{\mathrm{DAS}}= \pm 0.11 \%$ of range

\section{Power:}

$\mathrm{U}_{\mathrm{POW}}= \pm\left[\left(\mathrm{IU}_{\mathrm{E}}\right)^{2}+\left(\mathrm{E} \mathrm{U}_{\mathrm{I}}\right)^{2}\right]^{1 / 2}$

where

$\mathrm{U}_{\mathrm{E}}= \pm\left[(0.11 \text { volt })^{2}+(0.2 \% \mathrm{E})^{2}\right]^{1 / 2}$

$\mathrm{U}_{\mathrm{I}}= \pm\left[(5.16 \mathrm{amps})^{2}+(1.02 \% \mathrm{I})^{2}\right]^{1 / 2}$

Since $E=R^{*} I$ and $R$ is approximately a constant $(0.0206$ ohms), the approximate total uncertainty in the power is

$\mathrm{U}_{\mathrm{POW}}= \pm\left[2.34 \%+\left(4.50 \times 10^{-8} \mathrm{I}^{2}\right)\right]^{1 / 2} \mathrm{I}$

resulting in a power uncertainty of $1.5 \%$ at $100 \mathrm{~kW}$.

Flow:

Inlet air: $\quad \mathrm{U}_{\mathrm{q}}= \pm\left[(0.586 \text { SLPM })^{2}+(0.95 \% \mathrm{q})^{2}\right]^{1 / 2}$

Outlet air: $\quad U_{q}= \pm\left[(0.677 \text { SLPM })^{2}+(1.50 \% q)^{2}\right]^{1 / 2}$

Water: $\quad \mathrm{U}_{\mathrm{q}}= \pm\left[(0.0045 \mathrm{1/s})^{2}+(0.37 \% \mathrm{q})^{2}\right]^{1 / 2}$

where

$q=$ volumetric flow reading (SLPM for air, $1 / \mathrm{s}$ for water)

Fluid Temperature:

$\mathrm{T} \leq 560 \mathrm{~K}$

$$
\mathrm{U}_{\mathrm{T}}= \pm\left((3.33 \mathrm{~K})^{2}+[0.1 \%(\mathrm{~T}-273) \mathrm{K}]^{2}\right\}^{1 / 2}
$$


$\mathrm{T}>560 \mathrm{~K}$

$$
\mathrm{U}_{\mathrm{T}}= \pm\left((2.50 \mathrm{~K})^{2}+[0.76 \%(\mathrm{~T}-273) \mathrm{K}]^{2}\right\}^{1 / 2}
$$

Metal Temperature: ${ }^{1}$

$\mathrm{T} \leq 560 \mathrm{~K} \quad$ Upper TCs: $\quad \mathrm{U}_{\mathrm{T}}= \pm\left\{(3.33 \mathrm{~K})^{2}+[6 \%(\mathrm{~T}-273) \mathrm{K}]^{2}\right\}^{1 / 2}$

$$
-[2.102 \mathrm{~K}+10.1 \%(\mathrm{~T}-273 \mathrm{~K})]
$$

Lower TCs: $\quad \mathrm{U}_{\mathrm{T}}= \pm\left\{(3.33 \mathrm{~K})^{2}+[6 \%(\mathrm{~T}-273 \mathrm{~K})]^{2}\right\}^{1 / 2}$

$$
-[-1.898 \mathrm{~K}+10.1 \%(\mathrm{~T}-273 \mathrm{~K})]
$$

$\mathrm{T}>560 \mathrm{~K} \quad$ All TCs: $\quad \mathrm{U}_{\mathrm{T}}= \pm\left\{(2.50 \mathrm{~K})^{2}+[6.05 \%(\mathrm{~T}-273) \mathrm{K}]^{2}\right\}^{1 / 2}$

$$
-[0.102 \mathrm{~K}+10.1 \%(\mathrm{~T}-273 \mathrm{~K})]
$$

Mass-energy balance:

$\mathrm{U}_{\mathrm{Q}}= \pm\left[\left(\mathrm{c}_{\mathrm{p}} \Delta \mathrm{T} \mathrm{U}_{\mathrm{m}}\right)^{2}+\left(\mathrm{mc}_{\mathrm{p}} \mathrm{U}_{\Delta \mathrm{T}}\right)^{2}\right]^{1 / 2}$

where

$\mathrm{U}_{\mathrm{m}}= \pm\left[\left(\mathrm{q} \mathrm{U}_{\mathrm{q}}\right)^{2}+\left(\mathrm{q} \mathrm{U}_{\mathrm{q}}\right)^{2}\right]^{1 / 2}$

$\mathrm{U}_{\Delta T}= \pm\left[\left(\mathrm{U}_{\mathrm{Tin}}\right)^{2}+\left(\mathrm{U}_{\mathrm{Tout}}\right)^{2}\right]^{1 / 2}$

Absolute Pressure:

$(0-172 \mathrm{kPa}): \quad \mathrm{U}_{\mathrm{P}}= \pm 0.40 \mathrm{kPa}$

$(0-345 \mathrm{kPa}): \quad \mathrm{U}_{\mathrm{P}}= \pm 0.80 \mathrm{kPa}$

$(54-108 \mathrm{kPa}): \quad \mathrm{U}_{\mathrm{P}}= \pm 0.126 \mathrm{kPa}$ (electronic barometer)

Differential Pressure:

1. Bias terms in the metal temperature uncertainty can result in negative uncertainties, indicating the measured temperature reads high.

C-3 
BLH Transducer: $\quad U_{d P}= \pm\left[(0.808 \% R G)^{2}+(0.125 \mathrm{kPa})^{2}\right]^{1 / 2}$

CEC/Genisco Transducer: $U_{d P}= \pm\left[(0.917 \% \mathrm{RG})^{2}+(0.125 \mathrm{kPa})^{2}\right]^{1 / 2}$

where

$R G=$ differential pressure reading

\section{References}

Wilkins 1990 S. C. Wilkins and R. A. Larson, "Savannah River Site ECS-2

Tests Uncertainty Report," Idaho National Engineering Laboratory Report, EGG-EE-9066, July 1990. 
Table C-1. Summary of low-to high-range uncertainty for ECS-2 and ECS-2b measurements

Parameter

Power

Instantaneous inlet air flow

Average inlet air flow

Instantaneous outlet air flow

Average outlet air flow

Water flow

Fluid temperature

Metal temperature

Mass-energy balance

Differential pressure

$$
\begin{array}{lll}
\text { BLH transducers } & \pm 0.125 \mathrm{kPa} & \pm 0.238 \mathrm{kPa} \\
\text { CEC transducers } & \pm 0.125 \mathrm{kPa} & \pm 0.332 \mathrm{kPa}
\end{array}
$$

High Range

$$
\pm 1.7 \mathrm{~kW}
$$

\pm 2.32 SLPM

$\pm 0.99 \mathrm{~g} \mathrm{~m} / \mathrm{min}$

\pm 3.42 SLPM

\pm 2.61 SLPM

$\pm 0.00451 / \mathrm{s}$

$\pm 0.011 \mathrm{l} / \mathrm{s}$

$\pm 3.37 \mathrm{~K}$

$\because 4.85 \mathrm{~K}$

$\pm 3.33 \mathrm{~K}$

$+33.1-89 \mathrm{~K}$

$\pm 8.18 \mathrm{~kW}( \pm 10.2 \%) \quad \pm 23.6 \mathrm{~kW}( \pm 30.3 \%)$
Uniformly $\pm 0.40 \mathrm{kPa}$
Uniformly $\pm 0.80 \mathrm{kPa}$
$54-108 \mathrm{kPa}$ range Uniformly $\pm 0.126 \mathrm{kPa}$
$0-172 \mathrm{kPa}$ range
$0-345 \mathrm{kPa}$ range
Uniformly $\pm 0.126 \mathrm{kPa}$

C-5 


\section{Appendix D}

Calculations Supporting Design/Performance of the ECS-2 Inner Heater 


\section{Appendix D}

\section{Calculations Supporting Design/Performance of the ECS-2 Inner Hearer}

Numerical models were used to examine the performance characteristics of the proposed inner heater design before the physical heater was built. This appendix summarizes the models constructed, discusses the performance of the inner heater relative to a production reactor fuel assembly, and presents conclusions of the conduction analysis conducted with these models. Additional analyses of the inner heater design are discussed in Appendix D of Reference [1].

\section{Reference}

[1] J. L. Anderson, K. G. Condie, and T. K. Larson, "Downflow Heat Transfer in a Heated Ribbed Vertical Annulus with a Cosine Power Profile (Results from Test Series ECS-2b)," Idaho National Engineering Laboratory Report, EGG-EAST-9144, July, 1990. 
A test apparatus is being designed at INEL that will simulate thermal transient behavior of a Mark 22 assembly with fuel decay heat and low coolant flow conditions. The apparatus design consists of two concentric heated tubes which model the inner and outer Mark 22 fuel rings; downward coolant flow will be introduced in the annulus between the tubes. The purpose is to obtain thermal excursion data for the range of conditions expected in the Mark 22 assemblies during the ECS addition phase of a hypothetical large-break Loss of Coolant Accident. Thermal characterization studies were performed to:

(a) compare the transient response behavior of the test apparatus heated tubes to the Mark 22 fuel rings,

(b) compare maximum temperatures of each test apparatus tube to its corresponding Mark 22 fuel ring, assuming steady-state dryout of one $\left(90^{\circ}\right)$ azimuthal sector and 1 iquid film cooling of the remaining sectors, and

(c) determine adiabatic heatup rates for the test apparatus tubes.

The thermal response characteristics of the outer tube design were determined to be nearly identical to those of the Mark 22 outer fuel ring. The test apparatus response time constant was about 10\% 1onger, and the maximum temperature rise during sector dryout was $2 \% 10$ wer than for its Mark 22 counterpart. The dimensions of the outer tube design and outer fuel ring are nearly the same, and the outer tube electrical heater adds an insignificant amount of thermal mass to the system.

For the inner tube design the response cime constant was about 2.4 times as long, and the maximum temperature rise about $14 \%$ higher than for the Mark 22 inner fuel ring. The slower response was attributed to the additional thermal mass required for inner tube heater design. The tube thickness design value is considered a reasonable compromise between thermal time constant and maximum temperature rise response characteristics. Increased inner tube thickness would have increased the system thermal mass, thus slowing the response time even further, while decreased thickness would have increased the maximum temperature rise 
value. Thus, the selected tube thickness value represents the best match of thermal response characteristics within the constraints of the heater design requirements.

The adiabatic heatup rates represent the maximum rates obtainable with complete apparatus dryout. No credit is taken for azimuthal thermai conduction; hence, the calculated rates are significantly higher than anything expected during the thermal excursion experiments. The values were $37.4 \mathrm{k} / \mathrm{s}$ for the inner tube with a heater power of $18.7 \mathrm{~kW} / \mathrm{ft}$ $(44.6 \mathrm{~K} / \mathrm{s}$ with heater power of $22.4 \mathrm{~kW} / \mathrm{ft})$, and $31.5 \mathrm{~K} / \mathrm{s}$ for the outer tube with a heater power value of $17 \mathrm{~kW} / \mathrm{ft}$. 


\section{CONTENTS}

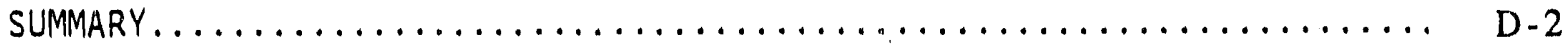

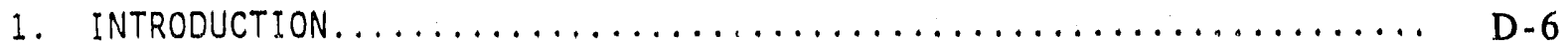

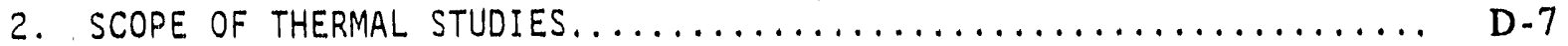

3. TWO-OIMENSIONAL THERMAL CALCULATIONS $\ldots \ldots \ldots \ldots \ldots \ldots \ldots \ldots \ldots \ldots \ldots \ldots \ldots$

3.1 Computer Codes............................. D -8

3.1.1 ABAQUS Finite Element Code...................... D-8

3.1.2 PATRAN Computer-Aided Engineering System.............. D 8

3.1.3 Calculational Sequence........................ D

3.2 Test Apparatus Heated Tube and Mark 22 Fuel Ring Models...... D-10

3.2 .1 Outer Tube Mode1s............................... D 11

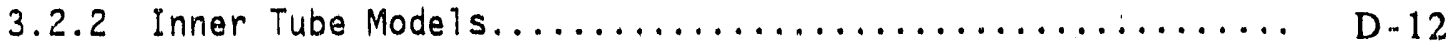

3.2.3 Initial and Boundary Conditions.................. D. 12

3.3 Results of Outer Tube Comparison................... D 13

3.4 Results of Inner Tube Comparison................... D-15

4. TEST APPARATUS AdIABATIC HEATUf RATES ................. D-16

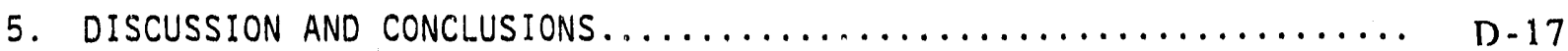

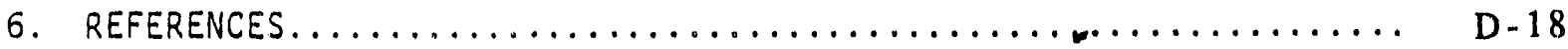

APPENDIX A-Listings of FORTRAN Programs that Transform PATRAN Model Boundary Conditions into ABAQUS Input Cards................... D-27

APPENDIX B-Supporting Calculations for SRL Test Apparatus and Mark

22 Fuel Assembiy Thermal Models............................. D-31

APPENDIX C-PATRAN "Session" Files for Generating Inner and Outer

Tube Finite Difference Models........................... D 45 


\section{FIGURES}

1. Cross section of a Mark-22 assembly....................... D. 19

2. Proposed configuration for the dual heated dryout heat transfer

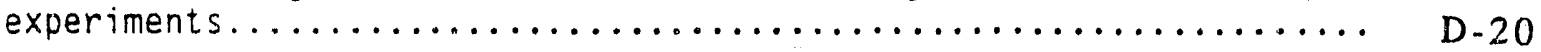

3. PATRAN / ABAQUS Calculation Flowchart..........................

4. Test apparatus and Mark 22 finite difference mesh models........ D-22

5. Test apparatus and Mark 22 outer tube thermal transient responses... D-23

6. Test apparatus and Mark 22 outer tube thermal time constants....... D-24

7. Test apparatus and Mark 22 inner tube thermal transient responses... D-25

8. Test apparatus and Mark 22 inner tube thermal time constants...... D-26 


\section{INTRODUCTION}

Heat transfer experiments are to be performed at INEL to support the safe operation of the Savannah River Site production reactors. One safety concern is the thermal response of the Mark 22 fuel assemblies during the ECS aditition phase of a hypothetical large-break Loss of Coolant Accident (LOCA). The: * assemblies consist of a series of concentric target and fuel rings that are separated by annular coolant channels, each divided by ribs into four azimuthal sectors, as shown in Figure 1. The phenomenon of interest involves the dryout of one or more $\left(90^{\circ}\right)$ sectors. Uncertainties exist in the prediction of dryout incipience and the requirements for successful rewet of a dry surface, given the assembly boundary conditions of inlet coolant flow and fuel decay heat. Experimental studies are desired to obtain thermal excursion data for the range of conditions expected in the Mark 22 assemblies during the ECS addition phase of the hypothetical LOCA.

A test apparatus is being designed at INEL that will simulate the thermal transient behavior of the inner and outer fuel rings and the enclosed coolant annulus (designated as Channel 3 of Figure 1). 1 It will have the capability to heat both the inner and outer walls of the coolant annulus. Additionally, it is to be constructed of reactor "typical" materials, i.e., aluminum. It will use an existing design for the inner heated tube that simulates a Mark 22 inner fuel; an outer heated tube is being added to simulate the outer fuel. Figure 2 shows the proposed configuration of the test apparatus.

Calculations were performed to characterize the expected thermal behavior of the test apparatus heated tubes, and to compare the transient response characteristics to those of Mark 22 assembly fuel rings. The purposes of the analyses were: (a) to ensure that the test apparatus inner and outer fuel rings will exhibit prototypical transient thermal behavior during thermal excursion tests, and (b) to provide maximum heatup rate and temperature information to be used as guidance for termination criteria for the thermal excursion experiments. Details of the studies are described in the following paragraphs. 
The thermal calculations included in the present document are outlined below:

1. Transient thermal time constants were estimated for two-dimensional $(r-\theta)$ finite difference models of the test apparatus outer heated tube and the Mark 22 outer fuel ring. These models will be collectively designated "outer tube models." The calculations were performed using the ABAQUS computer code. The results ${ }^{2}$ indicated the ciesirability for a thinner-walled outer tube than was provided in the initial design. Following the incorporation of this modification into the design, the calculation was repeated. Results of the final calculations are presented.

2. Similar calculations were also performed for $r-\theta$ models of the test apparatus inner tube and the Mark 22 inner fuel, collectively'designated as "inner tube models." This characterization was for information only, because an existing inner heated tube design will be used for the experiments.

3. Steady-state temperatures were calculated for the inner and outer tube models, with heat source values representative of maximum test apparatus power and coolant convection boundary conditions representing dryout of one $\left(90^{\circ}\right)$ sector.

4. Adiabatic heatup rates were estimated for the test apparatus heated tubes.

Items 1, 2, and 3 were accomplished using the ABAQUS three-dimensional, finite element computer code, with a two-dimensional thermai mesh created using PATRAN. Item 4 used simple hand calculations. The details of the thermal calculations, the results, and the conclusions of the effort are contained in the following sections.

D-7 
3. TWO-DIMENSIONAL THERMAL CALCULATIONS

\subsection{Computer Codes}

\subsubsection{ABAQUS Finite Element Code}

The two-dimensional transient thermal response calculations were performed using the ABAQUS ${ }^{3}$ computer code, using a finite element mesh generated using PATRAN PIUS. ${ }^{4}$ ABAQUS is a general purpose, production oriented, finite element code. It is simple to use and has capabilities for a wide range of nonlinear applications, one of which is the solution of three-dimensional, transient heat conduction, or thermal diffusion, problems. Steady-state solutions are obtained by direct integration of the spatial partial differential equation. Transient solutions are obtained by integrating the temporal/spatial equation with the backward difference operator (modified (rank-Nicholson method).

\subsubsection{PATRAN Computer-Aided Engineering System}

PATRAN Plus is an open-ended, general purpose, three-dimensional computer aided engineering software system. It includes the capabilities for generating finite element meshes in cartesian, cylindrical, or spherical coordinate systems, using automated command sequences. Element material properties, volumetric heat generation rates for elements, and surface heat fluy values and convection heat transfer coefficients for edges can all be specified. Translation of files from PATRAN to ABAQUS and back are done with PATABA and ABAPAT, respectively, which are supplied with the PATRAN Plus software. The ABAQUS and PATRAN Plus software packages used for the calculations comply with EG\&G Quality Manual Section QP-21, Computer Software Configuration Management. 5 In addition, Hawkes performed verification and benchmark calculations using these software packages. ${ }^{6}$ Results showed that ABAQUS and PATRAN produced the correct solutions to heat transfer problems when installed on INEL computers. 


\subsubsection{Calculational Sequence}

The sequence of calculational steps is shown in figure 3 . PATRAN was used to generate the model finite difference mesh, using input values for major dimensional values (i.e. radii of inner and outer surfaces and rib corner coordinates). The command sequence used to create the desired model is stored in the ().ses file; the ().dat file contains the binary representation of the current model plus a number of flags which contrul various display options. The completed model was written to a "neutral," or interface, file, the format of which is described in Chapter 29 of the PATRAN Plus User Manual. ${ }^{3}$ The neutral file was input to a translator (PATABA) that converted the model into the format required for ABAQUS. Present translator capabilities are limited to conversion of node coordinates, making node/element associations, and assigning material/property information to element groups. This information forms the dimensional structure of the ABAQUS input deck.

Model boundary conditions, material property tables, and transient control information were entered manually into the ABAQUS [( ).inp] deck, as shown in Figure 3. The boundary conditions (film heat transfer coefficients and heat sources) are specified by: (a) input cards specifying the boundary location and type, and (b) subroutines assigning the vaiue. The input cards were generated by the simple Fortran programs CONTRAN2, SHEAT, AND VHEAT. CONTRAN2 is used for surfaces with film heat transfer coefficient boundary conditions, and is maintained as a controlled document in the E\&ST Software Index per E\&ST Group Standard Practice 4.0. SHEAT and VHEAT are versions of CONTRAN2 slightiy modified to generate appropriate cards that specify distributed heat sources for element surfaces or volumes. Listings for SHEAT and VHEAT are contained in Appendix $A$; these two programs are not controlled versions, but were shown to produce the correct boundary conditions via spot checks and card-to-card consistency checks. The subroutines which assign values to the boundaries are named FILM and DFLUX, and specify convection and heat source values, respectively, as a function of azimuthal angle and transient time. These values are applied to the model elements as specified by the input cards described above. Material property tables and time step control parameters were added to the ABAQUS input deck. The final step was to change the element 
designations from the type supplied by PATRAN (S4R5) to diffusion-continuum, 2-dimensional, 4-node (DC2D4), which is recognized by ABAQUS as a heat transfer element. The ABAQUS finite element code was then used to obtain the transient thermal solutions.

As shown in Figure 3, three methods are available for obtaining plots. The mesh representation can be plotted directly, as can any variable written to ( ).fil. For the present application, the most useful directly-plotted information was the temperature response.

The method for obtaining color fringe plots required translating the ( ). Fil information back to PATRAN-compatible form. Again, the translation between the two major software items is not complete, and manual steps were required to supplement the translation. The ABAQUS results file is written using internal data management routines in order to minimize computer $1 / 0$ cost and disk storage requirements. The ABAQUS documentation offers sample coding, the purpose of which is to convert the results file into ASCII format: i.e., to the ( ).fin file. The implementation of this coding is the CONVERT program. The ABAPAT transiator was then used to obtain a PATRAN-compatible file containing the nodal temperature information required for the color fringe plots.

The third plotting method used the Lotus 1-2-3 PC software package, which is capable of performing mathematical manipulations (e.g., logarithms and least-squares linear fitting) of nodal temperature history data. The translation was performed using TREAD, another implementation of ABAQUS sample coding. The data were then downloaded to the $P C$ and input to the $1-2-3$ spreadsheet program. The thermal time constants were obtained using this procedure.

\subsection{Test Apparatus Heated Tube and Mark 22 Fuel Ring Models}

Two-dimensional $(r-\theta)$ transient thermal response calculations were made to compare the thermal responses of the test apparatus outer heated tubes and the Mark 22 assembly fuel rings. For each calculation, models of the test apparatus tube and the corresponding Mark $22^{\circ}$ fuel ring were included on the 
same input deck so the results of the calculation could easily be compared. Figure 4 shows the finite difference mesh models used for the calculation; the top $90^{\circ}$ section represents the test apparatus inner and outer tubes, and the bottom $90^{\circ}$ section represents the fuel rings of Mark 22 assembly. Note there is no thermal connection between the two model sections.

\subsubsection{Quter Tube Models}

The Test Apparatus outer tube is T6061 aluminum tubing with vertical thermocouple grooves every $15^{\circ}$ around the outer circumference. A heat flux boundary condition is applied to the outer surface using etched foil heaters, which consist of a thin (0.005-in.) Inconel strip sandwiched between two 0.010-in.-thick mica sheets. An aluminum sheet, surrounding the tube, forms a bridge across the thermocouple grooves to prevent local overheating of the Inconel. The original design specified a 1.375 -inch tube inside radius, a wall thickness of $0.125 \mathrm{in.}$, and a 0.032 -in. aluminum sheet. This design was modified based on results of a preliminary thermal response calculation that indicated the need for a thinner tube. The final dimensions, based on the $1.375-i n$. inside radius, were a wall thickness of $0.074 \mathrm{in}$. and an aluminum sheet thickness of $0.016 \mathrm{in}$. The foil heaters were assumed to contribute a negligible amount to the thermal mass of the outer tube, and were omitted from the model. The Mark 22 outer fuel model was based on the dimensions in the Hydraulics Manual, 7 and consists of the fuel tube portion from the log mean radius inward.

The derivations of dimensional values for nodalization, heat flux boundary conditions, etc., required to support the PATRAN and ABAQUS input values are in Appendix B. The PATRAN "session" files to create the inner tube models are in Appendix $C$. Heat addition rate for the test apparatus outer tube was $240 \mathrm{~kW} / \mathrm{m}^{2}$, based on maximum heater power of $22.4 \mathrm{~kW}$. This was an early design value; the present maximum heater power is $18.7 \mathrm{~kW} .1$ The Mark 22 model had a symmetry boundary at the $\log$ mean radius and included a uniformly distributed heat source value of $225.2 \mathrm{MW} / \mathrm{m}^{3}$; this produces the same steady-state heat flux at the inside surface as the $240 \mathrm{~kW} / \mathrm{m}^{2}$ heat flux value; thus, the two heat sources were equivalent.

\section{D - 11}




\subsubsection{Inner Tube Models}

The test apparatus inner tube design is the same one to be used for the ECS-2 thermal excursion experiment. It has a heated T6061 aluminum tube with a 2.211-in. outside diameter and a 0.095-in. wall thickness. Four ribs are affixed to the outer surface (at $90^{\circ}$ intervals) and vertical thermocouple grooves are machined into the inner circumference, spaced $15^{\circ}$ apart. The cross-section drawing, which shows the above details, is in the EOS.1 Details of the rib dimensions and arrangement are in drawing 430052.8 Inside the tube is a MACOR ceramic insulator surrounding an Inconel tube heater, which has an axially-varying wall thickness to simulate a non-uniform axial flux profile. The Inconel heater dimensions are taken from drawing $430437^{9}$ and correspond to axial location 5 , the location of maximum heat flux. The corresponding Mark 22 inner fuel model was again based on the dimensions in the Hydraulics Manual, and consists of the portion from the $\log$ mean radius outward.

As with the outer tube models, the derivation of the values used to generate the inner tube models is in Appendix B, and the PATRAN "session" files that create the outer tube models are in Appendix $C$. The heat generation rate for the test apparatus inner tube was $427.3 \mathrm{MW} / \mathrm{m}^{3}$, based on a maximum linear heat generation rate of $17 \mathrm{~kW} / \mathrm{ft}$. The corresponding value for the Mark 22 inner fuel ring was $207.8 \mathrm{MW} / \mathrm{m}^{3}$.

\subsubsection{Initial and Boundary Conditions}

The initial condition for the coolant channel surface of each model was a heat transfer coefficient representative of forced convection to a liquid falling film at $10 \mathrm{gpm}$ flowrate (assumed typical of annulus low-flow ECS conditions), and $311 \mathrm{~K}$. The calculation of this heat transfer coefficient is in Appendix $B$ of Reference 2; the value was $8800 \mathrm{~W} / \mathrm{m}^{2}-K$. A steady-state solution was obtained for this "wetted" condition. A transient condition was then initiated by setting the convection heat transfer coefficient on half $\left(45^{\circ}\right)$ of each section to a low value $\left(7.6 \mathrm{~W} / \mathrm{m}^{2}\right)$ to represent dryout of one annular sector. The calculations were continued until a new steady-state condition was achieved. 


\subsection{Results of Outer Tube Comparisen}

The thermal transient behavior of the test apparatus outer and inner tube models were compared to the corresponding models for the Mark 22 fuel rings for conditions simulating dryout of one annular sector. Because of the dryout boundary condition, the behavior of the two models is dominated by azimuthal heat conduction. The one-dimensional, transient heat conduction equation provides an approximate description of the response:

$$
\frac{\partial^{2} T}{\partial x^{2}}=\frac{1}{\alpha} \frac{\partial T}{\partial t}
$$

where

$$
\begin{aligned}
& T \text { is temperature. } \\
& x \text { is location along the azimuthal direction. } \\
& t \quad \text { is time, and } \\
& \alpha \quad \text { is the thermal diffusivity of the material. }
\end{aligned}
$$

Assume a solution of the form:

$$
T=f(t) \cdot g(x)
$$

Substituting (2) into (1) gives:

$$
f(t) \cdot g^{\mu}(x)=\frac{1}{\alpha} f^{\prime}(t) \cdot g(x)
$$

or

$$
\frac{g^{\prime \prime}(x)}{g(x)}=\frac{1}{\alpha} \frac{f^{\prime}(t)}{f(t)}
$$

If $x$ and $t$ are independent, the only way to satisfy the equation is for each function to be constant:

$$
\frac{f^{\prime}(t)}{f(t)}=\alpha \cdot \frac{g^{\prime \prime}(x)}{g(x)}=\alpha \cdot \beta^{2} .
$$

D- 13 
where the form of Eqn. (3) suggests that the constant is some multiple of $\alpha$. For any fixed location on the models, the thermal response is approximately described by:

$$
f=C_{1} e^{\alpha \beta^{2} t}
$$

Using the initial and final conditions of the problem gives:

$$
\frac{T_{f}-T(t)}{T_{f}-T_{f}}=e^{-t / \tau}
$$

where

$$
\begin{aligned}
& T(t) \text { is the transient thermal response. } \\
& T_{i} \text { is the initial temperature. } \\
& T_{f} \text { is the final temperature, and } \\
& \tau \quad \text { is the thermal time constant. }
\end{aligned}
$$

The linear form of this equation is

$$
\ln \left[T_{f}-T(t)\right]=t / \tau+\ln \left[T_{f}-T_{f}\right]
$$

Figures 5 and 6 show the thermal responses of the outer tube models for the location at the center of the dryout patch (the symmetry boundary at the $0^{\circ}$ azimuthal position). Figure 5 is temperature versus time, and figure 6 shows in $\left(T_{f}-T\right)$ versus time and the corresponding least-squares fitted lines for calculated temperatures at the center of the dryout patch $\left(0^{\circ}\right)$.

The regression results were, at the center of the dryout region:

$$
\begin{array}{ll}
\text { Test Apparatus : } & \ln (722.51-T)-t / 7.69+\ln (416.98) \\
\text { Mark 22: } & \ln (731.07-T)--t / 7.02+\ln (414.45)
\end{array}
$$

Hence, the thermal time constants were:

Test Apparatus

Mark 22

$$
\begin{aligned}
& 7.7 \mathrm{~s} \\
& 7.0 \mathrm{~s}
\end{aligned}
$$


The resulis of the calculation for steady-state maximum temperature with dryout conditions were:

$\begin{array}{ll}\text { Test Apparatus } & 722 \mathrm{~K} \\ \text { Mark } 22 & 731 \mathrm{~K}\end{array}$

The steady-state temperatures of the test apparatus with the dryout boundary condition were nearly identical to those calculated for the Mark 22 outer fuel ring; the temperature rise of the test apparatus model was $98 \%$ of that calculated for the Mark 22 model. The thermal time constants also agreed closely; the test apparatus response was slower because of the larger thermal mass and lower thermal conductivity of the T6061 test apparatus tube compared to U-AT (fuel) and aluminum (cladding) used in the Mark 22 model.

\subsection{Results of Inner Tube Comparison}

Figures 7 and 8 show the thermal responses of the inner tube models for the location at the center of the dryout patch (the symmetry boundary at the $0^{*}$ azimuthal position). Figure 7 shows temperature versus time, and Figure 8 shcws in $\left(T_{f}-T\right)$ versus time. The corresponding linear least-squaris fitted equations are:

Test Apparatus: $\ln (517.74-T)=-t / 10.04+\ln (141.25)$

Mark 22: $\ln (497.22-T)=-t / 4.14+\ln (155.19)$

Hence, the thermal time constants were:

Test Apparatus

Mark 22
$10.0 \mathrm{~s}$

$4.1 \mathrm{~s}$

The results of the calculation for steady-state maximum temperature with dryout conditions were:

Test Apparatus

Mark 22
$594 K$

$566 \mathrm{~K}$

D- 15 
The steady-state temperatures of the test apparatus with the dryout boundary condition are slightly higher than for the Mark 22 inner fuel ring. (Tota) transient temperature rise is about 14\% higher for the test apparatus.) However, the thermal response of the test apparatus is significantly slower. The difference in temperature rise is due to the difference in thermal conductivity of T6061 aluminum and that of the Mark 22 fuel and clad materials. The slower response is because of the mass of the Inconel heater and the MACOR insulating tube; wall thicknesses of the test apparatus tube itself and the Mark 22 fuel ring are comparable.

\section{TEST APPARATUS ADIABATIC HEATUP RATES}

Adiabatic heatup rates were determined for the inner and outer tubes of. the test apparatus. These are the heatup rates for the theoretical case of complete dryout of the apparatus. The calculation provides an estimate of the maximum heatup rates attainable, for use in design of test apparatus protection systems. Details of the calculations are in Appendix $B$. Outer tube calculations were done for maximum heater power values of $22.4 \mathrm{~kW}$ and $18.7 \mathrm{~kW}$. The results were heatup rates of 44.6 and $37.4 \mathrm{~K} / \mathrm{s}$, respectively. For the inner tube, a maximum heater power value of $17 \mathrm{~kW} / \mathrm{ft}$ was used; the calculated heatup rate was $31.5 \mathrm{~K} / \mathrm{s}$.

D -16 


\section{DISCUSSION AND CONCLUSIONS}

The calculated thermal response characteristics of the test apparatus outer tube were nearly identical to those of the Mark 22 outer fuel tube mode1. Transient temperature rise was 2\% lower than for the Mark 22 model and the estimated thermal time constant was about $10 \%$ slower. Based on the similarity of response of the thermal models, the test apparatus outer tube should be nearly indistinguishable from a Mark 22 outer fuel ring for equal sets of boundary conditions. Calculations for the inner tube thermal models also showed responses very similar to the Mark 22 inner fuel ring. The differences are due to the lower value of test apparatus azimuthal conduction and the heater, which adds a significant amount of thermal mass to the system. The original thermal studies, performed by Schroeder, 10 were done to provide response similarity for transient times of up to about 30 seconds. The tube thickness final design value was a reasonable compromise between overall transient response temperature rise and the thermal time constant. A thicker tube would increase the thermal mass, thus slowing the response time even further. A thinner tube would have further reduced the azimuthal conduction of the system. Thus, the selected value for tube thickness represented the best compromise between heater design requirements and fidelity to prototypical thermal behavior. These results, i.e. the demonstration of closely matched thermal characteristics for both test apparatus tubes, indicates that the thermal behavior of the entire apparatus, including the enclosed coolant annulus, should provide the best prototypical behavior attainable for the given design constraints.

The adiabatic heatup rates represent the maximum rates attainable for the given heat input values. The calculated rates are significantly higher than the results of the transient calculations (Figures 5 and 7 ), which indicate average heatup rate values of $-25 \mathrm{~K} / \mathrm{s}$. The azimuthal conduction characteristics of the system, and the assumption of one $\left(90^{\circ}\right)$ dry sector, significantly reduces the rate to far below the adiabatic rate. 


\section{REFERENCES}

1. J.L. Anderson, T.K. Larson, H.N. Romero, Experimental Operating Specifications, Dual Heated ECS Heat Transfer Experiments (draft), July 5, 1989.

2. J.E. Fisher 1 tr to J.R. Wolf, "Results of Thermal Response Calculations for SRL Dual Heated ECS Heat Transfer Experiment Outer Tube, "EG\&G Interoffice Correspondence JEF-03-89, August 7, 1989.

3. ABAQUS Users Manual, Version 4.7, Hibbitt, Karlsson \& Sorensen, Inc., 1988.

4. PATRAN Plus User Manual Volumes I and II, Release 2.3, PDA Engineering, Costa Mesa, California, July 1988.

5. EG\&G Idaho, Inc. Quality Manual, Issue 14, March 17, 1989, Document No. QP-21.

6. G.L. Hawkes, Verification and Benchmarking of ABAOUS and PATRAN for Heat Transfer Applications, EGG-EAST-8680, to be published.

7. Hydraulics and Heat Transfer of Mark 22 Fuel Assemblies, DPSTM-22(H), Revised November 1974.

8. Savannah River Site INEL-ECS 2 Dryout Experiment Aluminum Heater Tube, EG\&G Idaho Dwg. 430052, June 1989.

9. Savannah River Site INEL-ECS 2 Dryout Experiment Heater Tube Assembly, EG\&G Idaho Dwg. 430437, July 1989.

10. J.A. Schroeder, private communication, 9-21-1989. 


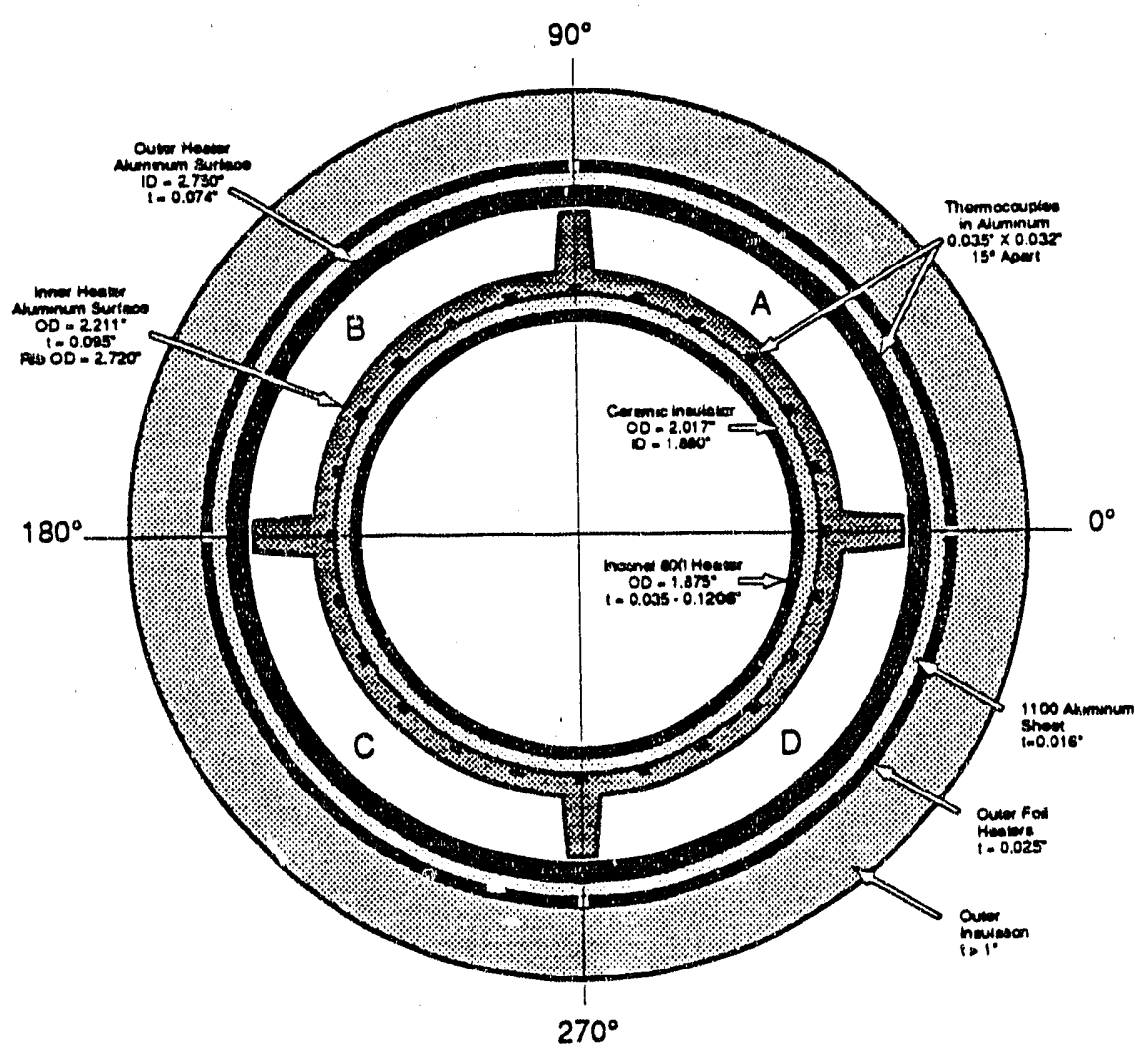

Figure 2. Proposed configuration for the dual heated dryout heat transfer experiments.

D -20 


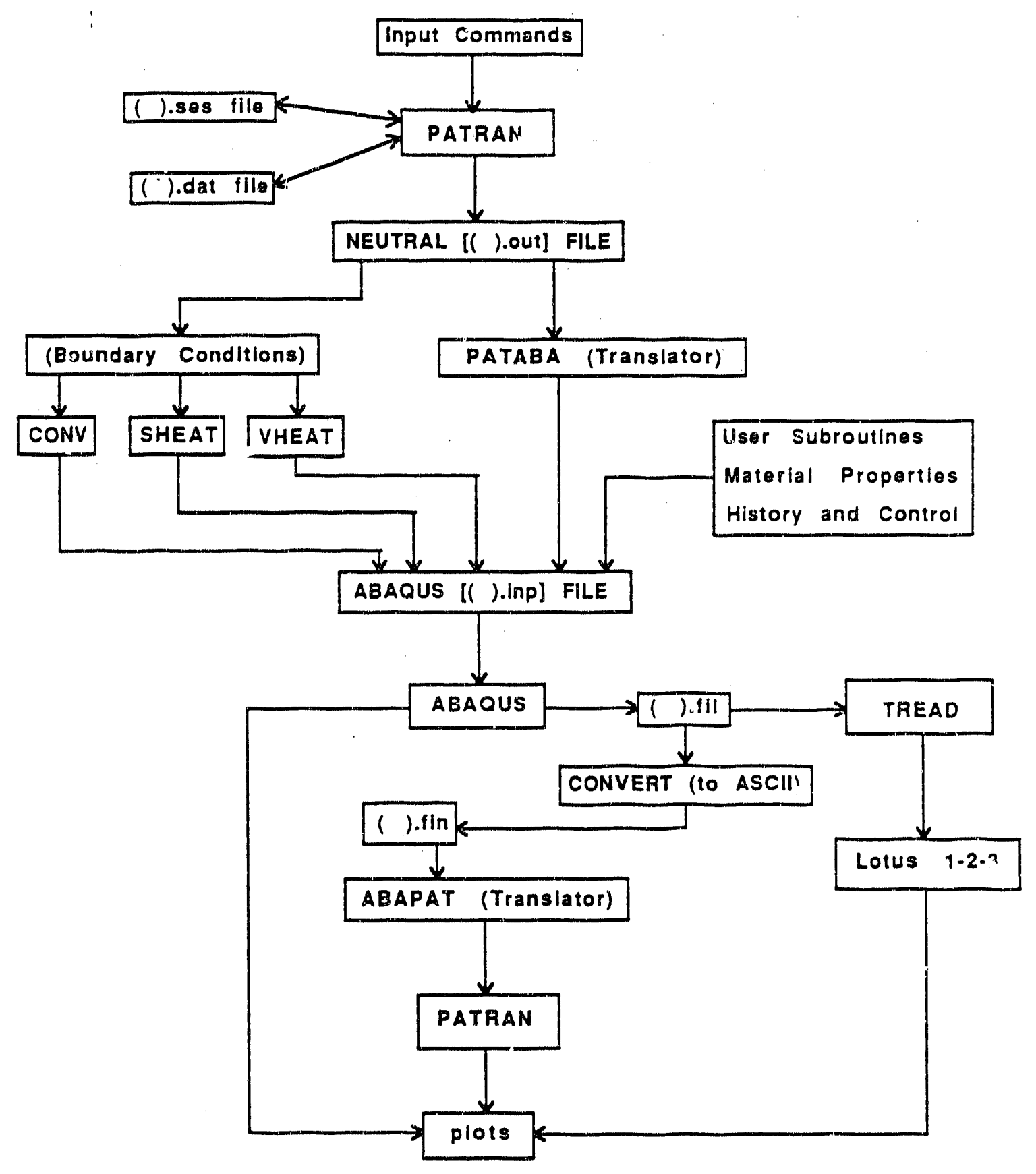

Figure 3. PATRAN / ABAQUS Calculation Flowchart

D-21 


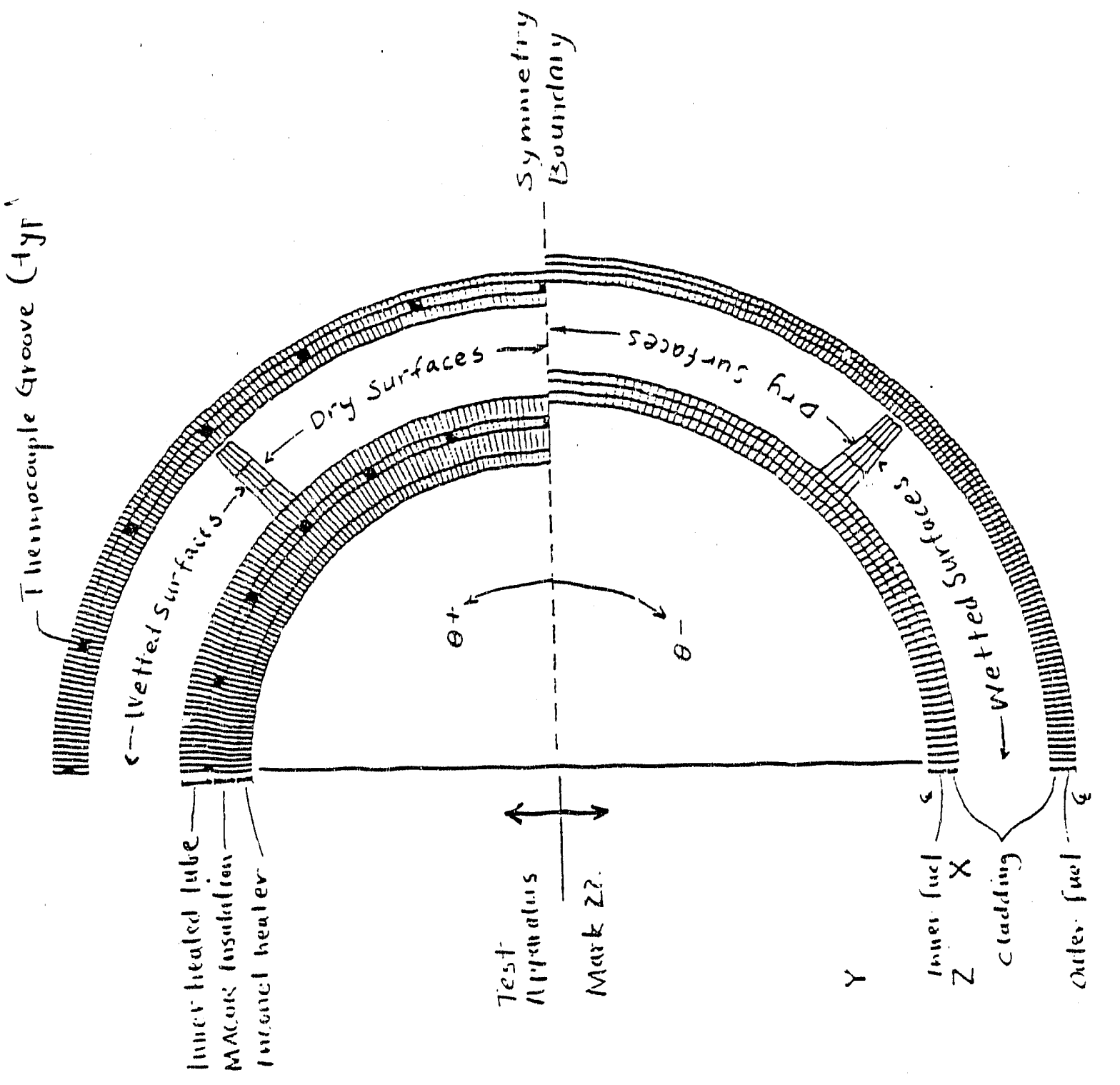

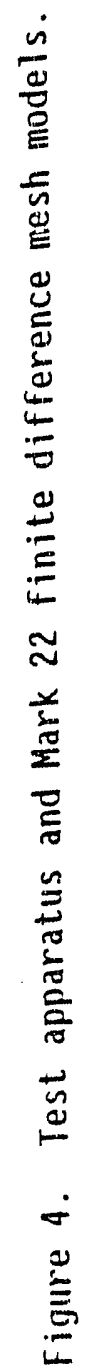

D 22 


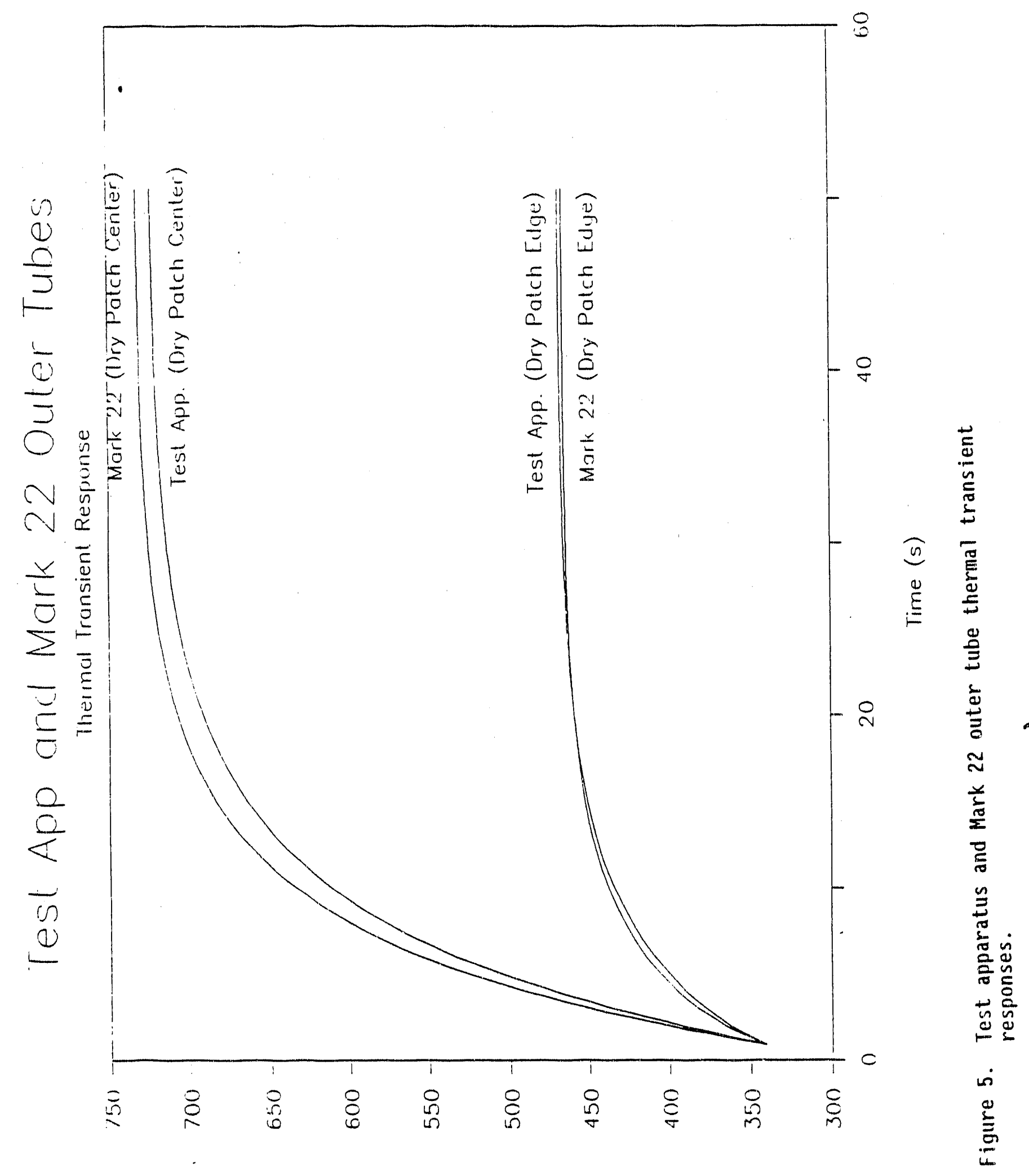

(i) oมก:0dodur

D- 23 


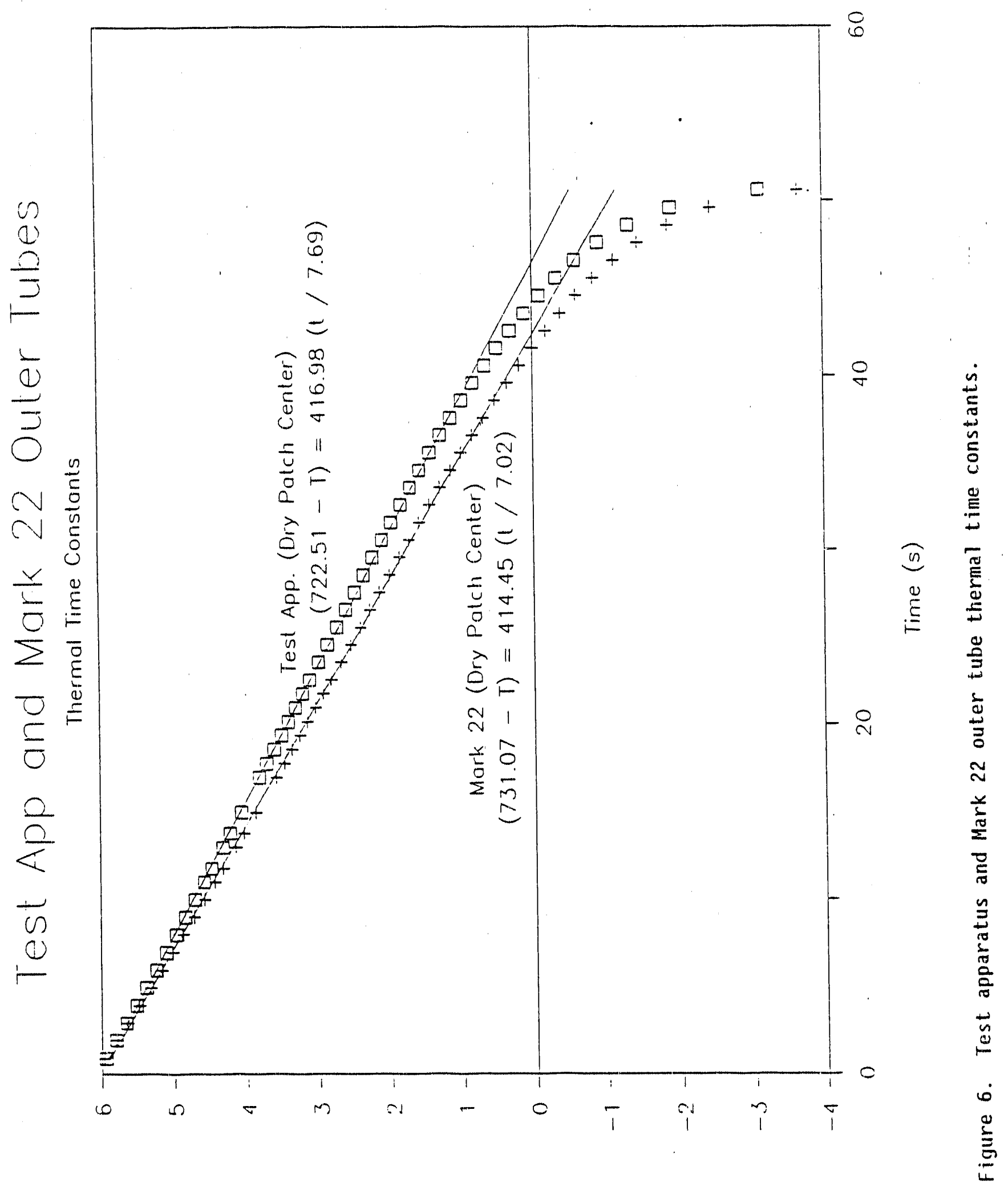

$$
(1-10 U ! ! \perp) \text { U }
$$




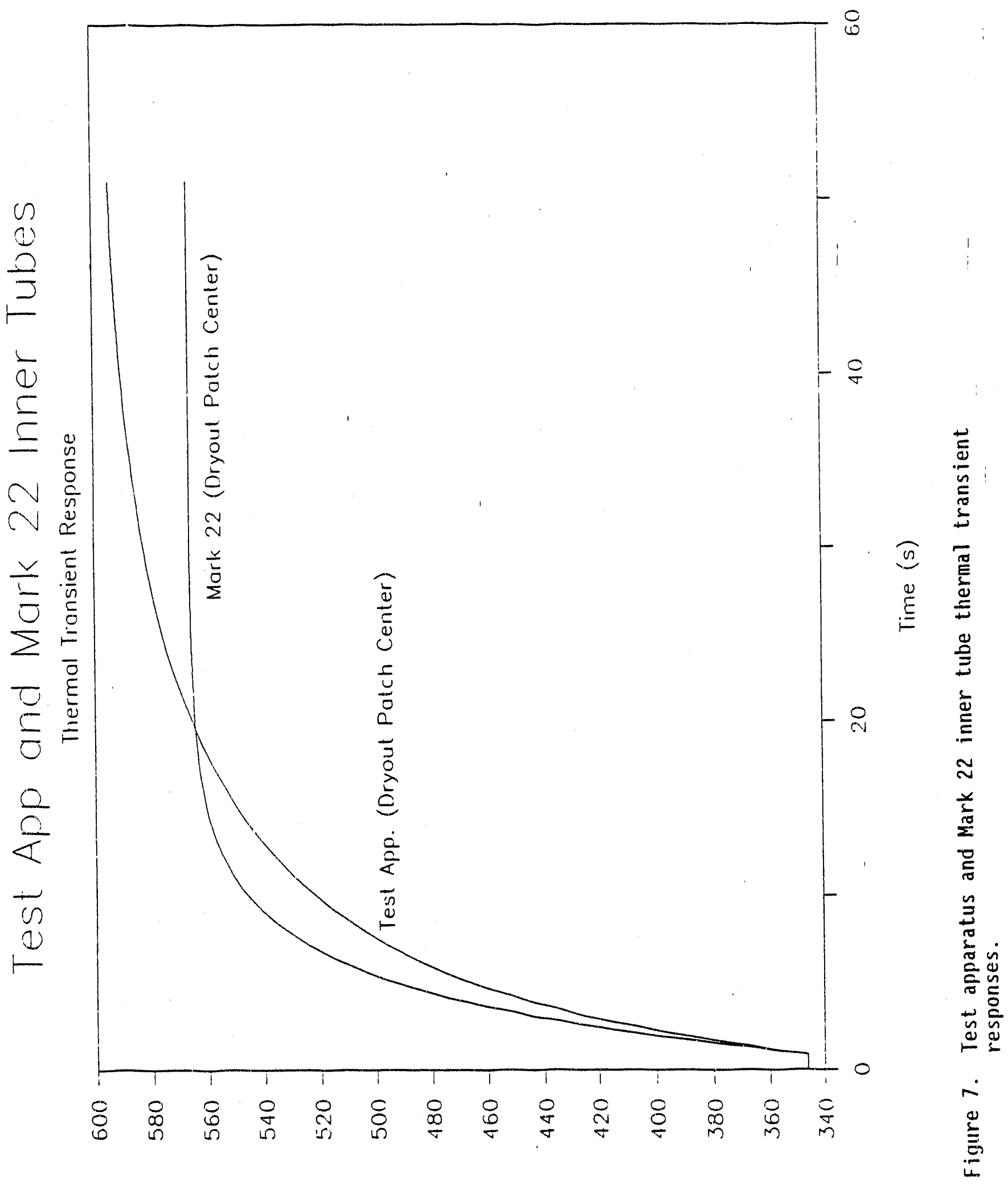

(ii) aגmiodacua! 


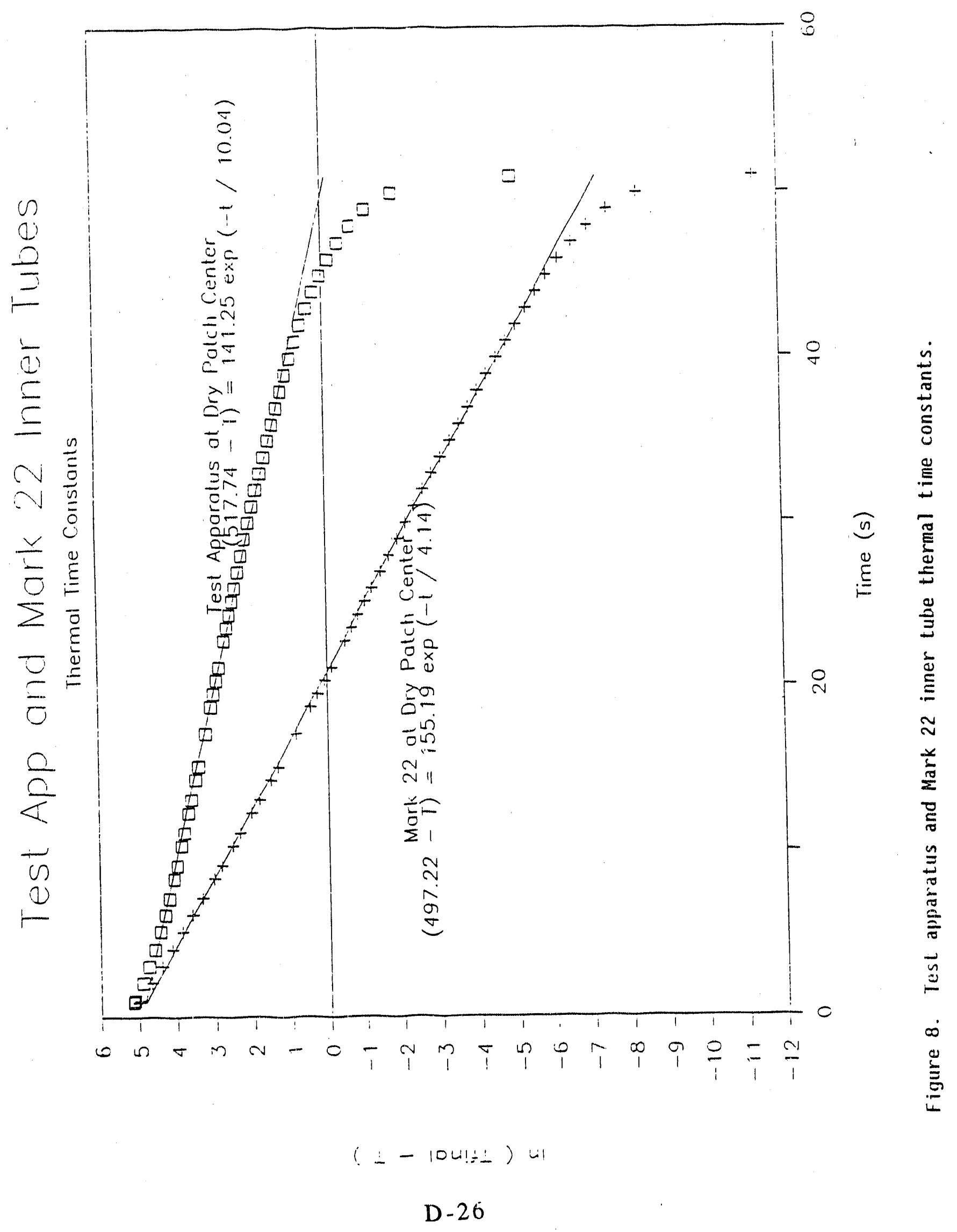


APPENDIX A

Listings of FORTRAN Programs that Transform PATRAN Model Boundary Conditions into ABAQUS Input Cards 
program sheat

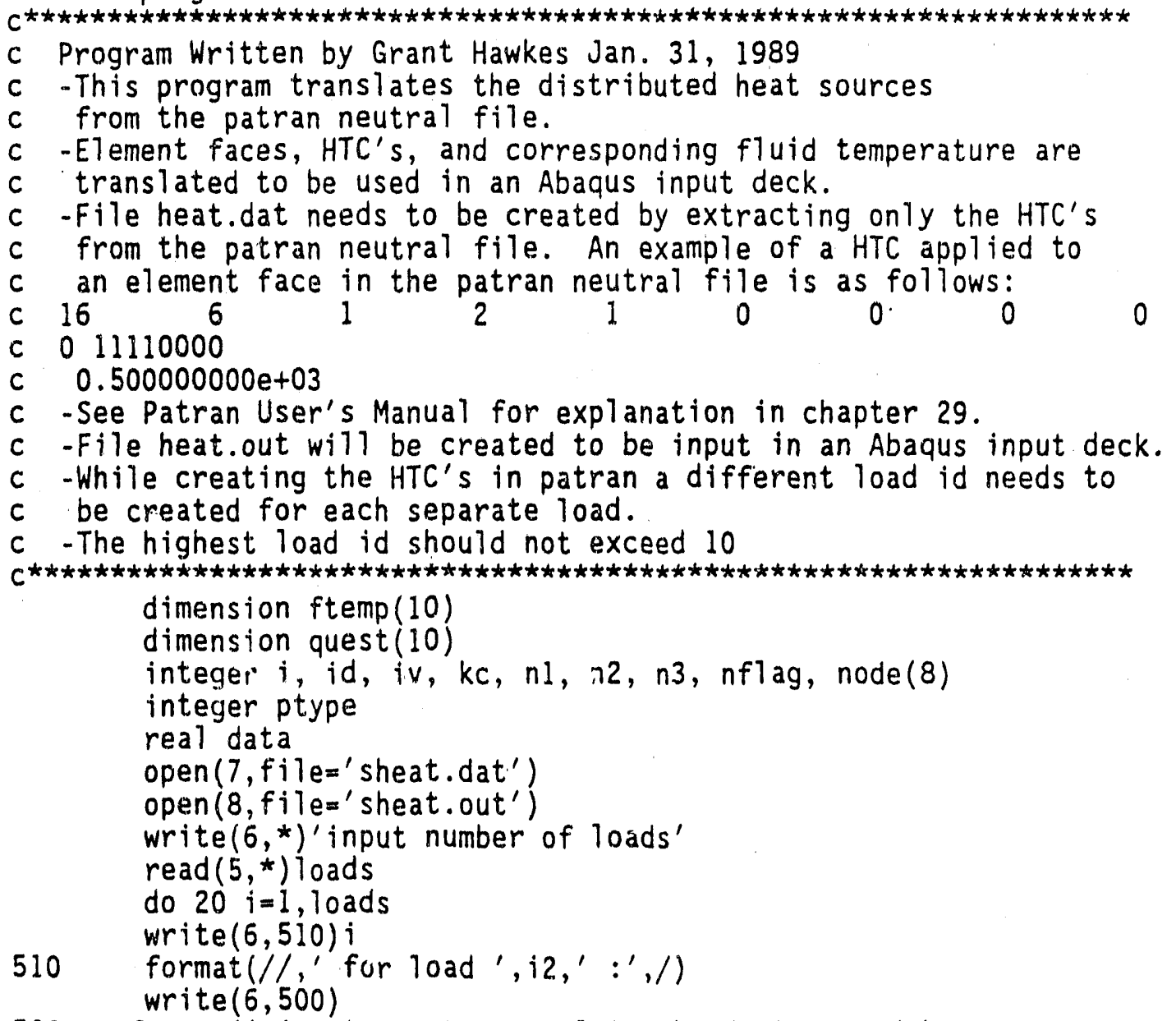

500 format(' input 1 to translate the distributed heat sources from \& patran as constant', $/,{ }^{\prime}$ input 2 to calculate the heat source va \& lues with a user subroutine') $\operatorname{read}\left(5,{ }^{*}\right)$ quest $(i)$

20 continue

10 continue write $(8, *)^{\prime * D F L U X '}$

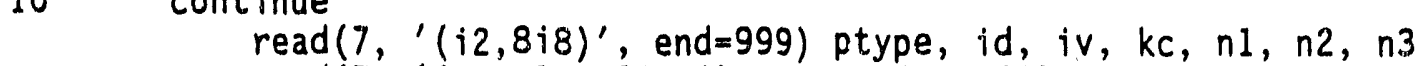
$\operatorname{read}\left(7, '(i 1,1 x, 8 i 1)^{\prime}\right)$ nflag, (node $\left.(i), i=1,8\right)$ $\operatorname{read}(7$, ' (5e16.9)') data

if (quest(iv).eq.1.0) then if ( (node (1) .eq. 1) and. (node (2) .eq. 1)) then write $(8, '(i 4, a 4$, el2.4)' $)$ id, , 'S1,', data else if ((node (2) .eq. 1) . and. (node(3) .eq. 1)) then write $(8, '(i 4$, a 4, e12.4)') id,', S2,', data el se if ((node (3) .eq. 1) .and. (node (4) .eq. 1)) then

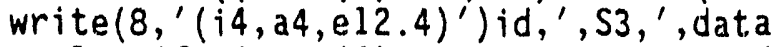
else if ((node (4) .eq. 1) .and. (node (1) .eq. 1)) then write $\left(8, '(i 4, a 4, e 12.4)^{\prime}\right)$ id,', 54, , , data endif

elseif (quest(iv).eq.2.0) then if $((\operatorname{node}(1)$.eq. 1) . and. (node (2) .eq. 1)) then write $\left(8, '(i 4, a 5)^{\prime}\right)$ id, ', SINU'

$$
\text { D }-28
$$


else if ((node (2) .eq. 1) .and. (node(3) .eq. 1)) then write $\left(8, '(14,25)^{\prime}\right)$ id, , , S2NU'

else if ((node (3) .eq. 1) . and. (node (4) .eq. 1)) then write $\left(8,{ }^{\prime}(i 4, a 5)^{\prime}\right)$ id, , ,S3NU'

else if ((node (4) .eq. 1) . and. (node(1) .eq. 1)) then write $\left(8,,^{\prime}(i 4,25)^{\prime}\right)$ id, ', S4NU' endif

endif

999

go to 10

continue

close (7)

c. ose (8)

stop

end 
program vheat

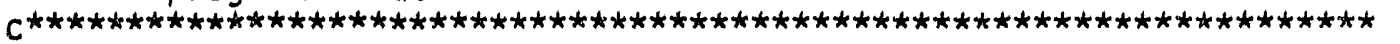

Program Written by Grant Hawkes Jan. 31, 1989

Modified by J. E. Fisher July 1989

- This program translates the distributed heat sources

from the patran neutral file.

-Element faces, HTC's, and corresponding fluid temperature are translated to be used in an Abaqus input deck.

- File heat.dat needs to be created by extracting only the HTC's from the patran neutral file. An example of a HTC applied to an element face in the patran neutral file is as follows:

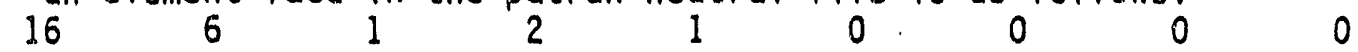

011110000

$0.500000000 \mathrm{e}+03$

- See Patran User's Manual for explanation in chapter 29.

-File heat.out will be created to be input in an Abaqus innut deck.

- While creating the HTC's in patran a different load id needs to

be created for each separate load.

-The highest load id should not exceed 10

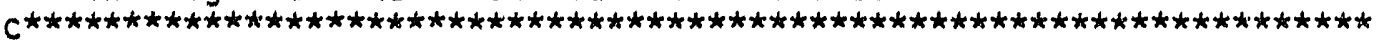

dimension ftemp (10)

dimension quest(10)

integer $i, i d, i v, k c, n 1, n 2, n f l a g, n o d e(8)$

integer ptype

real data

open $\left(7, f i l e={ }^{\prime}\right.$ vheat.dat')

open $\left(8, f i 1 e={ }^{\prime}\right.$ vheat.out')

write $\left(6,{ }^{*}\right)^{\prime}$ input number of 10 ads'

$\operatorname{read}(5, *)$ loads

do $20 j=1$, loads

510 format $\left(/ /,,^{\prime}\right.$ for load ', $\left.12,,^{\prime}:{ }^{\prime}, /\right)$

write $(6,500)$

500 format (' input 1 to translate the distributed heat sources from

\& patran as constant', $/$, input 2 to calculate the heat source va

\& lues with a user subroutine') $\operatorname{read}\left(5,{ }^{*}\right)$ quest $(i)$

20

continue

10

write $(8, *)^{\prime} *$ DFLUX'

continue

read (7, '(i2,8i8)', end=999) ptype, id, iv, kc, n1, n2

$\operatorname{read}\left(7, '(i 1,1 \times, 8 i 1)^{\prime}\right)$ nfiag, (node $\left.(i), i=1,8\right)$

if $\operatorname{read}\left(7\right.$, ' $\left.(5 \mathrm{e} 16.9)^{\prime}\right)$ data

(quest(iv).eq.1.0) then

write $\left(8,{ }^{\prime}(\right.$ i 4, a 4, el2.4, al, e12.4)' $)$ id, ', BF, ', data

e]se

write $\left(8,,^{\prime}(i 4,25)^{\prime}\right)$ id, ', BFNU'

endif

go to 10

999 continue

close (7)

close (8)

stop

end

D -30 
APPENDIX B

Supporting Calculations for SRL. Test Apparatus and Mark 22 Fuel Assembly Thermal Models 
$\sum_{S} E E_{\Sigma} E$ Idaho, Inc.

FOAM EO\&Q.1592

(Rev. 5.77)

CALCULATION WORK SHEET

Page 1

Pages

Subject SRLTe:t Apparatus Cuter Tube Model Date 25 sept 89 Prepared By Fisher

Checked GL H Work Request

The outer nested tube dincusions are $2.75^{\prime \prime}=0 \times 0.074$ "wall thickness.

Axial thermocouple grooves will be machined ito the outer surface, $0.035^{\prime \prime}$ wide $x 0.035^{\prime \prime}$ deere, spaced at $15^{\circ}$ intervals.

An Aluminum sheet, $0.016 "$ thick, surrounds the tube and forms a thermal bridge across the tharmocouple grooves. A heat flux boundary condition will be in posed at the outer surface, equivalent to $22.4 \mathrm{~kW}$ per 15 -inch axial section (maximum value).

Input values for reference radial pouts 1,2,3, and 4 are:

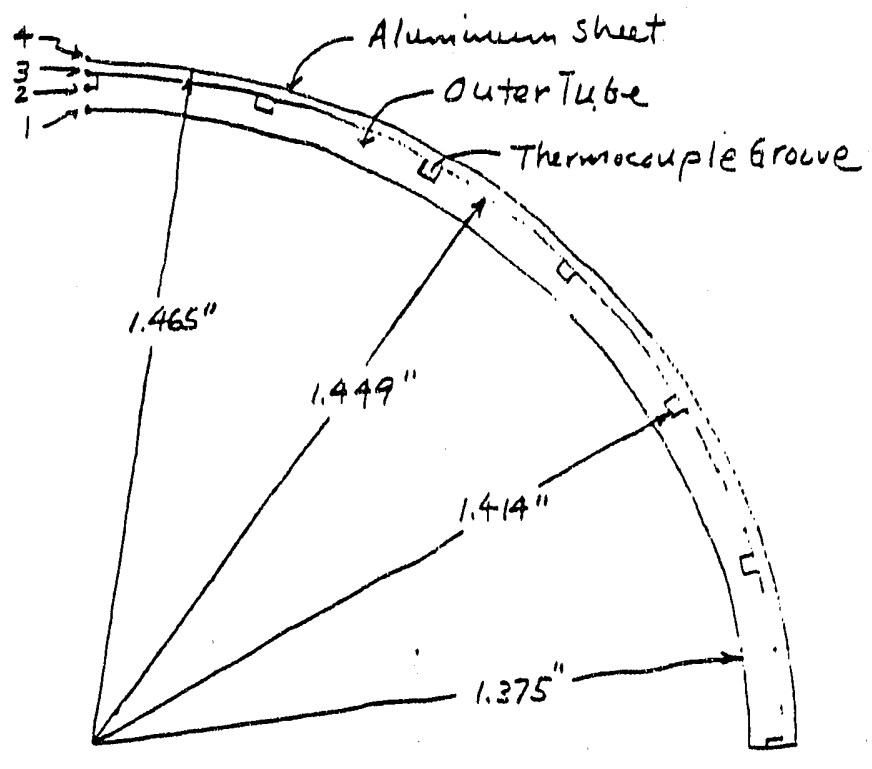

$\begin{array}{lll}\text { point } & \operatorname{rad}(\mathrm{in}) & \frac{\operatorname{rad}(\mathrm{m})}{1} \\ 1 & 1.375 & 0.0349250 \\ 3 & 1.414 & 0.0359156 \\ 4 & 1.449 & 0.0368046\end{array}$

For model simplicity, the computational mesh should approxicuactiby over lan the tharmaciuple grooves. Assume 20 hicks par $15^{\circ}$ sector. Ti hermocoupli groove 132 nodes wide:

$$
d s=r d \theta=(1.449)(2)\left(\frac{15}{20}\right) \frac{\pi}{180}=0.0379^{\prime \prime}
$$

Heat flux:

$$
\begin{aligned}
\frac{22.4 \times 1 c^{2} w}{(2 \pi)(1.465)(15) \dot{m}^{2}} \frac{i^{2}}{(.1254)^{2} m^{2}} & =251450 \cdot \mathrm{w} / \mathrm{m}^{2} \\
D-32 & \sim 25 \mathrm{~km} / \mathrm{m}^{2}
\end{aligned}
$$




\section{$\prod_{D} E \boldsymbol{E} \Xi$ idaho, Inc.}

FUAM EQSO. 1592

(Aev 5.it)

\section{CALCULATION WORK SHEET}

Subject SRL Tastf pearatus Inner Heated Tu!n. Model Date 11 sept 89

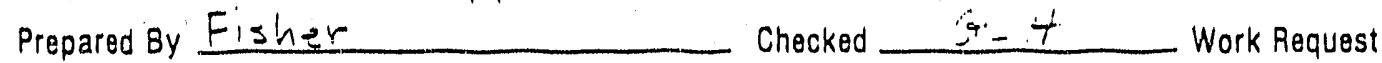

The test apparatus inner tube is 2.211 " od $x$ 0.09:" wall thickers. Thernucouple wells in the inner surface are $0.034^{\prime \prime}$ wide $x 0.032^{\prime \prime}$ deep, and are spaced at $15^{\circ}$ Intervals. The gecinetry is complicated by the presence of rifs on the

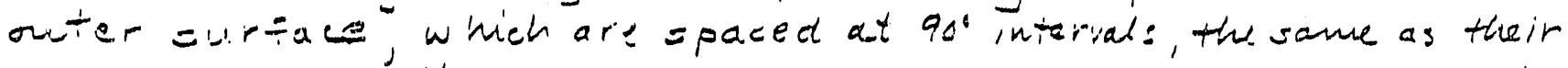
counterparts on the Marle 22 inner Fuel ping. An Inconel heater imposes a Geat $f$ lux boundary condition on the inside tubs surface $F$ MAcor tulse separate: tike inner heat2d tube and the heater.

The computatima? mesh for the turo-dimensional ABAQUS calccilation was gemeratad using PATRAN. The fisllming calculations are the derivation of ilu retzrence pount: for the PATKAN mash. These points (11 throughzí) - aro indrcated on the sketch.

Details are presented for points 17 and 14. Remaniing points can be readily ofterned from the given dimenswous.

Point $\$ 17$ :

1. $\Delta y=(0.255+\Delta x) \tan \left(\theta_{2}\right)+0.0325$

2. $\Delta y=r \sin (\theta$,

3. $\Delta x=r-r \cos \left(\theta_{1}\right)$
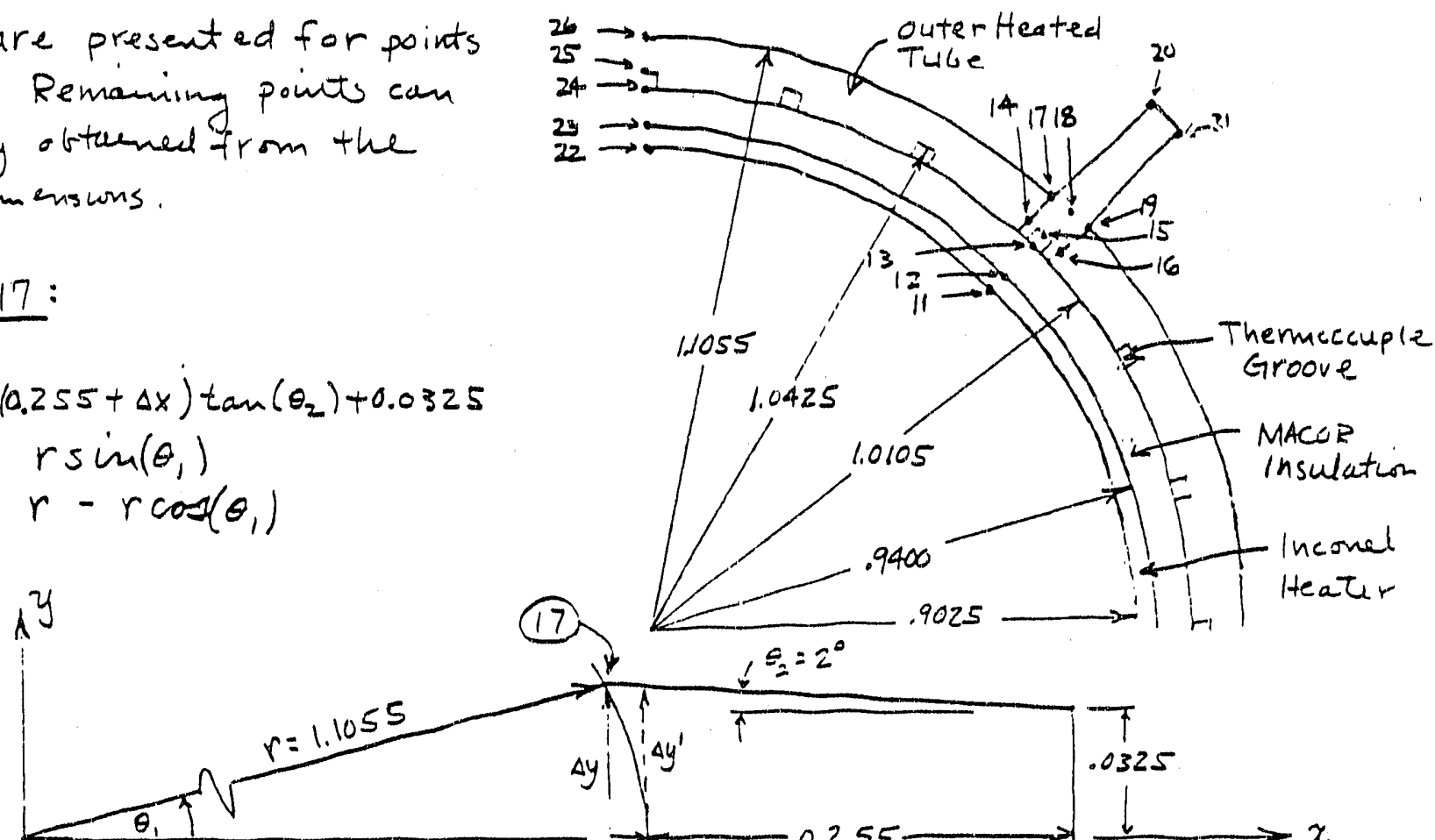

$\subseteq=2^{\circ}$ 
NEE\&G Idaho, inc.

FOAM EG \&G.1592

(Fer. 5-77)

CALCULATION WORK SHEET

Page 5 of 13 Pages

Subject SRL Test Apparatus Inner Heat ea Tube Model Date $11 S_{-12} \leq T$

Prepared By $I$ i: les Checked

Work Request

$\Delta y \simeq \Delta v^{\prime}=0.255 \tan \left(2^{\circ}\right)+0.0325=0.0414048$

$$
\theta_{1}=\sin ^{-1}\left(\frac{\Delta y}{r}\right)=\sin \left(\frac{.0414048}{1.1055}\right)=2.1464^{\circ}
$$$$
\Delta x=r\left[1-\cos \left(\theta_{1}\right)\right]=1.1055[1-\cos (2.1464)]=0.00077565
$$

$\Delta y=(0.255+0.00077565) \tan \left(2^{\circ}\right)+c . c 325=0.0414312 \varepsilon$

$\theta_{1}=\sin ^{-1}\left(\frac{0.04143188}{1.1055}\right)=2.1478$

$$
\begin{aligned}
& \Delta x=0.0077666 \\
& \Delta_{y}=0.04143192 \\
& \theta_{1}=2.1478
\end{aligned}
$$

$\operatorname{Point}=17(r, \theta)=\left(1.1055,2.1478^{\circ}\right), \quad(x, y)=(1.104723,0.041431)$

Point $\$ 14:$

$$
\begin{aligned}
d \theta=\frac{d s}{r}=\frac{.034}{1.0425}= & 0.032614 . \\
& \times \frac{186}{\pi}=1.87^{\circ}
\end{aligned}
$$

$x=1.0425 \div 14$

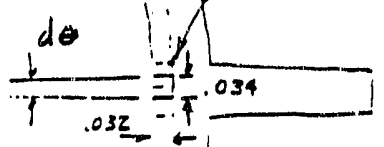

$r=1.0105$

$\Rightarrow$ use azimuthal node spacing of $1^{\circ}$, Each thermocouple escupies tui element widths.

$$
\begin{aligned}
& x=r \cos \theta=(1.0425) \cos (2)=1.04186 \\
& y=r \sin \theta=(1.0425) \sin (2)=0.03038
\end{aligned}
$$

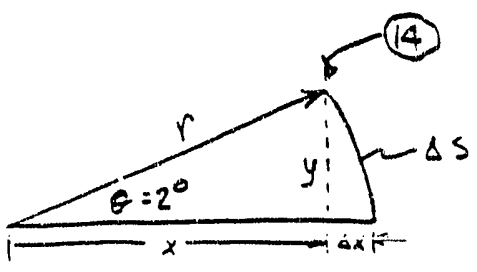

D -36 
CALCULATION WORK SHEET!

Subject SRL Test Apparatus Inner Heated Tube Modal Page $-\frac{6}{11 \quad 5-\frac{13}{89}-\text { Pages }}$ Prepared By Fisher Checked . GL H

The actual coordinates s used for points 14 (and 16) were clightiy different from the $\sigma$ up.. The original calculation used the more obscure approximations:

$$
\begin{aligned}
x & =r-\Delta s \sin (\theta) \\
& =r-r \theta \sin (\theta)
\end{aligned} \quad y=r \in \cos (\theta)
$$

and the calculations contained a mistake:

$$
\begin{aligned}
& x=1.0425-\frac{(1.0405)(2) \pi}{18 c} \sin \left(2^{\circ}\right)=1.041232 \\
& y=\frac{(1.0405)(2) \pi}{180} \cos \left(2^{\circ}\right)=0.036298
\end{aligned}
$$

However, these results differ only slightly from the correct values, i.

$$
\frac{1.041232}{1.04186}=0.9994 \text { and } \frac{0.036298}{0.03638}=0.9977 \text {. Also, point }
$$

14 and 16 only affect the position of the thermocouple wall within the model. There fore, the calculation was not repeated with the corrected values.

The remaining points required ne ealeubation. Points 11 through 21 were rotated to the correct orientation. The value : were transformed t polar coordinates, rotated $-45^{\circ}$, then transformed back to rectangular coordinates. The attached table shows the results of a. Le te $1-2-3$ spread sect ut ale performs the reference point calculation and converts the result: ti metric unit is.

D -37 
Test Apparatus Inner Heated Tube Reference Points

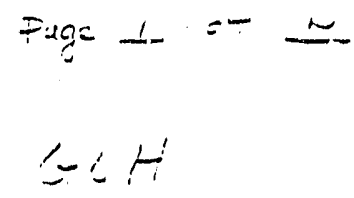
21 August 89 with Einal Numbering system

\begin{tabular}{|c|c|c|c|c|c|}
\hline rid & $x$ & $Y$ & $\mathbf{R}$ & Theta (rel) & Theta \\
\hline $\begin{array}{l}11 \\
12 \\
13 \\
14 \\
15 \\
16 \\
17 \\
18 \\
19 \\
20 \\
21 \\
22 \\
23 \\
24 \\
25 \\
26\end{array}$ & $\begin{array}{l}1.36050000 \\
1.36050000 \\
0.00000000 \\
0.00000000 \\
0.00000000 \\
0.00000000 \\
0.00000000\end{array}$ & $\begin{array}{r}0.00000000 \\
0.00000000 \\
0.00000000 \\
0.03629818 \\
0.00000000 \\
-0.03629818 \\
1 \\
0.03250000 \\
-0.03250000 \\
0.90250000 \\
0.94000000 \\
1.01050000 \\
1.04250000 \\
1.10550000\end{array}$ & $\begin{array}{l}0.90250000 \\
0.94000000 \\
1.01050000 \\
1.04186494 \\
1.04250000 \\
1.04186494 \\
1.10550000 \\
1.10550000 \\
1.10550000 \\
1.36088813 \\
1.36088813\end{array}$ & $\begin{array}{r}0.00000000 \\
0.00000000 \\
0.00000000 \\
1.99656711 \\
0.00000000 \\
-1.99656711 \\
2.14780000 \\
0.00000000 \\
-2.14780000 \\
1.36843716 \\
-1.36843716\end{array}$ & $\begin{array}{l}45.00000000 \\
45.00000000 \\
45.00000000 \\
46.99656711 \\
45.00000000 \\
43.00343289 \\
47.14780000 \\
45.00000000 \\
42.85220000 \\
46.36843716 \\
43.63156284\end{array}$ \\
\hline
\end{tabular}

DS $(14,16) \quad 0.03632030$

Points Rotated +45 Degrees

\begin{tabular}{|c|c|c|c|c|}
\hline Grid & $x($ in. $)$ & $Y$ (in.) & $\mathrm{x} \quad(\mathrm{m})$ & $Y(m)$ \\
\hline $\begin{array}{l}11 \\
12 \\
13 \\
14 \\
15 \\
16 \\
17 \\
18 \\
19 \\
20 \\
29 \\
22 \\
23 \\
24 \\
25 \\
26\end{array}$ & $\begin{array}{l}0.83816387 \\
0.66458037 \\
0.71453140 \\
0.71059583 \\
0.73715882 \\
0.76192921 \\
0.75186105 \\
0.78170655 \\
0.81045371 \\
0.93903781 \\
0.98499975\end{array}$ & $\begin{array}{l}0.63816387 \\
0.66468037 \\
0.71453140 \\
0.76192921 \\
0.73715882 \\
0.71059583 \\
0.81045371 \\
0.78170655 \\
0.75186105 \\
0.98499975 \\
0.93903781\end{array}$ & $\begin{array}{l}0.01620936 \\
0.01688288 \\
0.018149110 \\
0.01804913 \\
0.01872383 \\
0.01935300 \\
0.01909727 \\
0.01985535 \\
0.02058552 \\
0.02385156 \\
0.02501899 \\
0.00000000 \\
0.00000000 \\
0.00000000 \\
0.00000000 \\
0.00000000\end{array}$ & $\begin{array}{l}0.01620936 \\
0.01688288 \\
0.01814910 \\
0.011935300 \\
0.011872383 \\
0.01804913 \\
0.02058552 \\
0.01985535 \\
0.01909727 \\
0.02501899 \\
0.02385156 \\
0.02292350 \\
0.02387600 \\
0.02566670 \\
0.02647950 \\
0.02807970\end{array}$ \\
\hline
\end{tabular}


$\therefore S E$ ERE

Idaho, Inc.

FORM EG\&G-1592

CALCULATION WORK SHEET

Page 12 oi 13

Pages

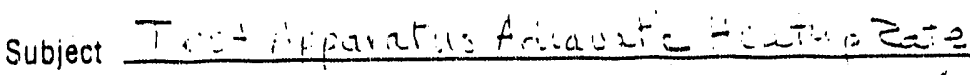

Date $\because \Xi \Xi \Sigma=-\Sigma=$

Prepared By $=i: 110 r$

Checked

Work Request

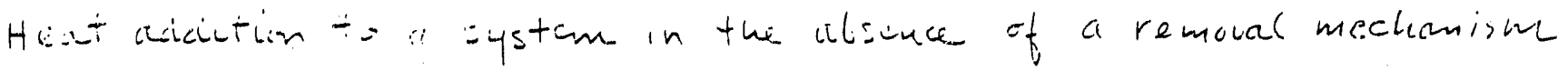
results in.

$$
q=\rho c_{p}+\frac{d T}{d T}
$$

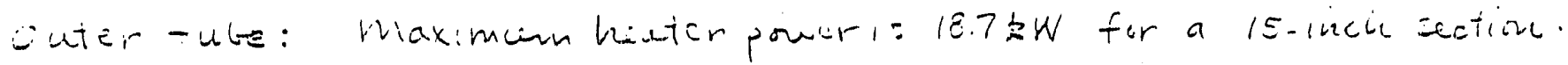

$$
\begin{aligned}
& \frac{q}{A}=\frac{18.7 \times 10^{3} \mathrm{~W}}{(2 \pi)(1.465)(15) \mathrm{in}^{2}} \frac{\mathrm{in}^{2}}{(.0254)^{2} \mathrm{~m}^{2}}=209926 \mathrm{~W} / \mathrm{m}^{2} \\
& H_{\Delta c_{0} 1}=\pi\left[(1.449)^{2}-(1.375)^{2}\right](.0254)^{2} h=4.2356 \times 10^{-4} \mathrm{~h} \mathrm{~m}^{3} \\
& H_{100}=\pi\left[(1.465)^{2} \cdot(1.445)^{2}\right](.0254)^{2} \mathrm{~h}=9.4499 \times 10^{-5} \mathrm{~h} \mathrm{~m} \\
& P_{6 c t)} \sim=700 \mathrm{eg} / \mathrm{m}^{3} \\
& c_{b=61}-9<2.1+J / k g . K \\
& P_{\text {lice }} \sim 270.8 .53 \mathrm{tg} / \mathrm{m}^{3} \\
& C_{P_{1100}} \sim 913.57 \mathrm{~T} / \mathrm{kg}-\mathrm{K}
\end{aligned}
$$

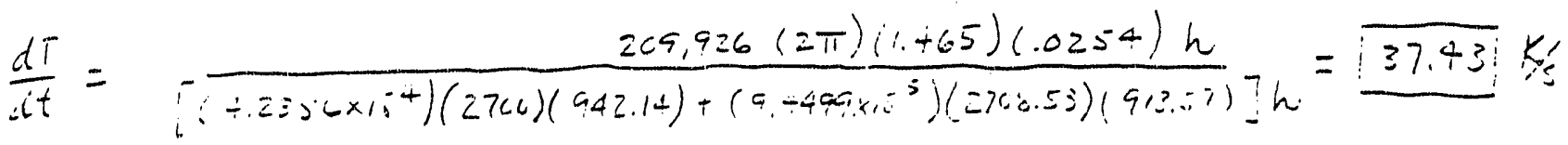

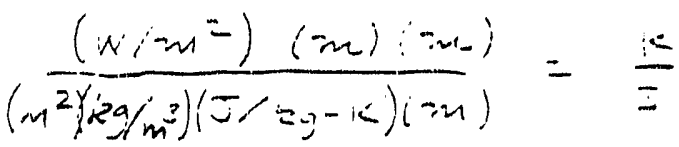

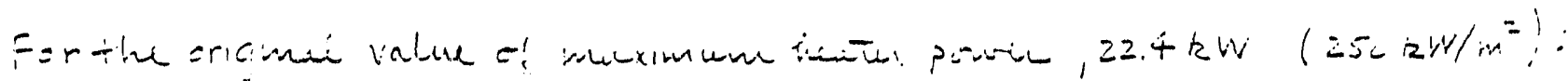

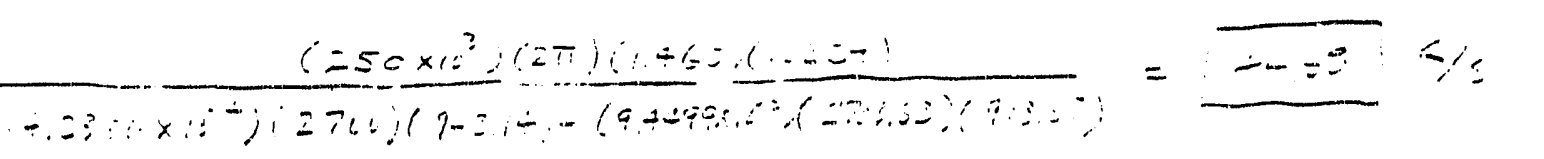

$$
\begin{aligned}
& 41-D-43
\end{aligned}
$$




\section{CALCULATION WORK SHEET}

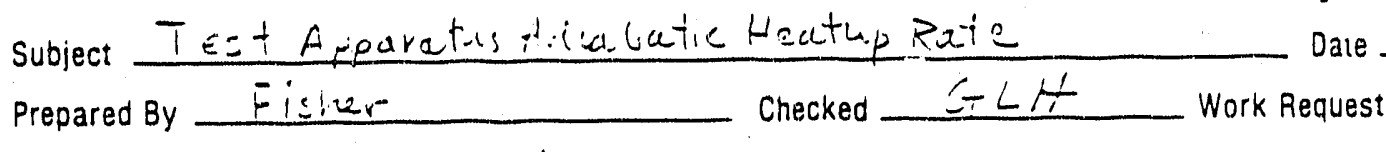

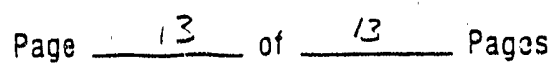

Inner Tube: Maxinum heates powes is $17 \mathrm{~kW} / \mathrm{ft}$

$\psi_{6061}=\pi\left[(1.1055)^{2}-(1.0105)^{2}\right](.0254)^{2} h+\frac{2}{2}(.0325+.04 \times 4)(.0255)(.0254)^{2}(4) h$
$=4.1230 \times 10^{-4} h$

$\left.F_{\text {iAaCOR }}:-\left[(1.0105)^{2}-6.7460\right)=\right]\left(62541^{2} h=8.8216 \times 10^{-5} h\right.$

$\psi_{\text {inconet }}=\pi\left[(i . \dot{x} \omega)^{2}-(.9025)^{2}\right](.0251)^{2} h=1.4004 \times 10^{-4} h$

$P_{\text {macon }}=2514.9 \mathrm{tg} / \mathrm{m}^{3}$

$C_{\text {macor }}=E 36 . \overline{\mathrm{J}} \mathrm{J} / \mathrm{kg}-\mathrm{K}$

$P_{\text {incoual }}=E 331.41 \mathrm{mg} / \mathrm{m}^{3}$

$C_{p \text { inconet }}=+60.46 \mathrm{~J} / \mathrm{kg}-\mathrm{K}$

$\frac{d i}{\text { ait }}=\frac{(17000) / .30+8}{\left(4.1230 \times 10^{-4}\right)(2760)(942.14)+\left(8.8716 \times 10^{-5}\right)(2514.9)(836.5)+\left(1.4004 \times 10^{-4}\right)(8331.41)(460.46)}$ 1048.80 186.7

$\frac{w / m}{\left(\mathrm{~m}^{2}\right)\left(\mathrm{kg} / \mathrm{m}^{3}\right)(J \log -\mathrm{k})}$

537.23 $=31.46 \frac{k}{5}$ 


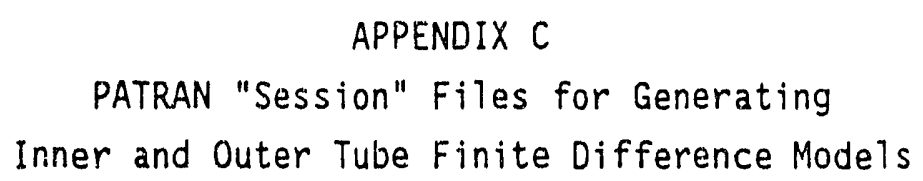

D -45 
Outer Tube Models

D-46-78 
Inner Tube Models D- $49 / 50$ 
Appendix E

Calculated Parameters for the ECS-2 and ECS-2c Thermal Excursion Experiments 


\section{Appendix E}

\section{Calculated Parameters for the ECS-2 and ECS-2c Thermal Excursion Experiments}

Throughout the main body of this report and in the data tabulations contained in Appendix $J$, reference is made to calculated parameters. Information in this appendix documents the calculation of the computed parameters.

\section{Saturation Temperature Calculation}

Saturation temperature was calculated from local pressure measurements using an Antoine equation curve fit for water. This equation as used for the ECS-2 and ECS-2c experiments was

$$
T=\left[\frac{a}{b-\log _{10}(P / c)}\right] \frac{1}{1.8}
$$

where

$$
\begin{aligned}
& \mathrm{T}=\text { fluid saturation temperature in } \mathrm{K} \\
& \mathrm{P}=\text { pressure in } \mathrm{kPa} \\
& \mathrm{a}=4044.17692 \\
& \mathrm{~b}=7.186012 \\
& \mathrm{c}=6.894
\end{aligned}
$$

This equation is valid for pressures between 1.76 and $124 \mathrm{kPa}$.

\section{Liquid Level Calculation}

Liquid levels were computed from select differential pressure measurements. All of the differential pressure cells were connected se that the high side of the cell was attached to the standing leg (filled with cold water) of the sense line connected to the test section and the low side of the cell was connected to the test section. The differential pressure is 


$$
\Delta \mathrm{P}_{\text {meas }}=\mathrm{P}_{H}-\mathrm{P}_{\mathrm{L}}
$$

where

$$
\begin{aligned}
& \Delta P_{\text {meas }}=\text { measured differential pressure } \\
& P_{H}=\text { hydrostatic pressure on the high side of the cell } \\
& P_{L}=\text { hydrostatic pressure on the low side of the cell }
\end{aligned}
$$

Each hydrostatic pressure can be represented as

$$
P_{1}=\rho_{i} g h_{i}+P_{\text {ref }}
$$

where

$$
\begin{aligned}
& P_{i}=\text { hydrostatic pressure in leg } i \\
& P_{r e f}=\text { pressure at the reference tap location } \\
& P_{i}=\text { density in leg } i \\
& g=\text { acceleration due to gravity } \\
& h_{i}=\text { vertical height of leg } i
\end{aligned}
$$

With the measured differential pressure and known sense line vertical distances and pressure tap locations, the effective level can be calculated as

$$
\begin{aligned}
& \mathrm{h}=\mathrm{h}_{\mathrm{c}}-\frac{\Delta \mathrm{P}_{\text {meas }}}{\rho_{\text {meas }}}+\mathrm{h}_{\text {ref }} \\
& \text { where } \\
& \mathrm{h}_{\mathrm{c}}=\text { reference component height } \\
& \Delta \mathrm{P}_{\text {meas }}=\text { measured differential pressure } \\
& \rho_{\text {meas }}=\text { fluid density in the test section } \\
& \mathrm{g} \quad=\text { acceleration due to gravity } \\
& \mathrm{h}_{\text {ref }}=\text { reference height for the level measurement }
\end{aligned}
$$

Tablc E-1 lists the relevant parameters used in the calculation of levels for the thermal excursion tests. 
Table E-1. Parameters used for level calculations for the thermal excursion experiments ${ }^{1}$

For ECS-2 experiments

\begin{tabular}{lcllc} 
Level ID & \multicolumn{1}{c}{$\underline{h}_{c}$} & \multicolumn{1}{c}{$\Delta \mathrm{P}_{\text {meas }}$} & \multicolumn{1}{c}{$\ell_{\text {meas }}$} & $h_{\text {ref }}$ \\
L_SP & 1.803 & DP_SP & RHOW_SP & 0 \\
L_PL_OUT & 0.279 & DP_PL_OUT & RHOW_OUT & 0 \\
L_PL_IN & 0.213 & DP_PL_IN & RHOW_IN & 0 \\
L_TS_TOT & 5.74 & DP_D_ALL & RHOW_TS & L_PL_OUT
\end{tabular}

For ECS-2cE experiments

Level ID

L_SP

$\underline{h}_{\mathrm{c}}$

$\Delta P_{\text {meas }}$

DP_SP

Pmeas

$h_{\text {tef }}$

L_PL_OUT

2.064

DP_PL_OUT

RHOW_SP

0

L_PL_IN

0.279

DP_PL_IN

RHOW_OUT 0

L_TS_TOT

0.208

DP_D_ALL

RHOW_IN

0

RHOW_TS L_PL_OUT

1. The physical geometry was different for the ECS-2 and ECS-2c facilities. Therefore, the component heights used in the level calculations are slightly different.

\section{Superficial Velocity Calculation}

Liquid and vapor superficial velocities were calculated on line in the DAS and are listed in the data tabulations for the ECS-2cE experiments.

Superficial velocities were computed in British units and are presented in the data tabulations in $\mathrm{ft} / \mathrm{s}$. Superficial velocity was calculated as

$$
f_{1}=\frac{Q_{i}}{A_{t s}}
$$

where

$$
\begin{aligned}
& \mathrm{j}_{\mathrm{i}}=\text { superficial velocity of component } \mathrm{i} \\
& \mathrm{Q}_{\mathrm{i}}=\text { volumetric flowrate of component } \mathrm{i} \\
& \mathrm{A}_{\mathrm{ts}}=\text { test section flow area }\left(13.31 \mathrm{~cm}^{2}\right)
\end{aligned}
$$

and the appropriate units conversions were made to obtain British units. 


\section{Liquid Density}

Liquid density as a function of temperature was computed using a second order fit to water properties from the 1967 ASME Steam Tables. The following equation

$$
\begin{aligned}
& \rho_{1}=a+b T+c T^{2} \\
& \text { where } \\
& \qquad \begin{aligned}
a & =760.48 \\
b & =1.837 \\
c & =-3.503 \times 10^{-3} \\
T & =\text { measured liquid temperature in } \mathrm{K}
\end{aligned}
\end{aligned}
$$

produces a maximum error of $0.9 \mathrm{~kg} / \mathrm{m}^{3}(0.1 \%)$ at the low end $(273 \mathrm{~K})$ of the temperature range. Over the temperature and pressure range of interest for the ECS-2 experiments $(85.6 \mathrm{kPa}$ and $292 \mathrm{~K}<\mathrm{T}<373 \mathrm{~K})$, the maximum error is $0.56 \mathrm{~kg} / \mathrm{m}^{3}$ or $0.06 \%$.

\section{Local Heat Flux}

The local power generation rate at an axial location on the heater can be defined as

$$
\begin{aligned}
& \mathrm{q}_{\mathrm{i}}=\frac{\mathrm{q}_{T}}{\mathrm{~L}} \mathrm{p}_{\mathrm{f}} \mathrm{l}_{\mathrm{I}} \\
& \text { where } \\
& \mathrm{q}_{\mathrm{T}}=\text { heater total power } \\
& \mathrm{L}=\text { heater total length } \\
& \mathrm{p}_{\mathrm{f}}=\text { peaking factor for the zone } \mathrm{i} \\
& \mathrm{l}_{\mathrm{i}}=\text { length of the zone } \mathrm{i}
\end{aligned}
$$

The local heat flux can be calculated from knowledge of the local power and the surface area for heat transfer. In conjunction with Equation E-7, the local flux for power step i is 
$q_{1}^{\prime \prime}=\frac{q_{T}}{L} \frac{p_{1} l_{1}}{A_{1}}=\frac{q_{T}}{L} \frac{p_{1}}{\pi d_{i}}$

where

$\mathrm{A} i=$ heat transfer area for power zone $\mathrm{i}$

$\mathrm{di}=$ diameter of zone $\mathrm{i}$

Table E-2 lists relevant dimensions and power factors for the inner heater. Note that the denominator of Equation E- 8 is a constant equal to $0.669 \mathrm{~m}^{2}$ for the ECS-2 and ECS-2c heaters.

Table E-2. Geometric parameters for inner heater

\begin{tabular}{|c|c|c|c|c|c|c|c|c|}
\hline \multirow[b]{2}{*}{$\begin{array}{c}\text { Heater } \\
\text { zone }\end{array}$} & \multirow[b]{2}{*}{$\begin{array}{c}\text { Length } \\
(\mathrm{cm})\end{array}$} & \multicolumn{2}{|c|}{ Incenel } & \multicolumn{2}{|c|}{ Macor } & \multicolumn{2}{|c|}{ Aluminum } & \multirow[b]{2}{*}{$\begin{array}{l}\text { Power } \\
\text { Factor }\end{array}$} \\
\hline & & $\begin{array}{c}\text { ID } \\
(\mathrm{cm}) \\
\end{array}$ & $\begin{array}{c}O D \\
(\mathrm{~cm})\end{array}$ & $\begin{array}{c}\text { ID } \\
(\mathrm{cm})\end{array}$ & $\begin{array}{c}\mathrm{OD} \\
(\mathrm{cm}) \\
\end{array}$ & $\begin{array}{c}\text { ID } \\
(\mathrm{cm}) \\
\end{array}$ & $\begin{array}{r}\mathrm{OD} \\
(\mathrm{cm}) \\
\end{array}$ & \\
\hline 1 & 104.775 & 4.1478 & 4.7600 & 4.7600 & 5.1359 & 5.1359 & 5.5880 & 0.47 \\
\hline 2 & 38.100 & 4.4729 & 4.7600 & 4.7600 & 5.1359 & 5.1359 & 5.5880 & 0.97 \\
\hline 3 & 38.100 & 4.5339 & 4.7600 & 4.7600 & 5.1359 & 5.1359 & 5.5880 & 1.22 \\
\hline 4 & 38.100 & 4.5695 & 4.7600 & 4.7600 & 5.1359 & 5.1359 & 5.5880 & 1.43 \\
\hline 5 & 38.100 & 4.5847 & 4.7600 & 4.7600 & 5.1359 & 5.1359 & 5.5880 & 1.56 \\
\hline 6 & 48.590 & 4.5695 & 4.7600 & 4.7600 & 51359 & 5.1359 & 5.5880 & 1.43 \\
\hline 7 & 57.912 & 4.4729 & 4.7600 & 4.7600 & 5.1359 & 5.1359 & 5.5880 & 0.97 \\
\hline 8 & 17.247 & 4.1478 & 4.7600 & 4.7600 & 5.1359 & 5.1359 & 5.5880 & 0.47 \\
\hline
\end{tabular}

Saturation Ratio Calculation (R Factor)

Researchers at WSRL commonly use the so-called $R$ factor or saturation power ratio for the presentation of power limits data. The $R$ factor is defined simply as the ratio of the power at the defined limiting criteria (for example, electrical power applied to the test section when a sustained thermal excursion occurred) divided by the power required to saturate the fluid at the outlet of the heated length. For the thermal excursion experiments, this definition of the $R$ factor is 


$$
R=\frac{q_{t s}}{\dot{m} C_{p}\left(T_{\text {sat }}-T_{\text {in }}\right)}
$$

where

$$
\begin{aligned}
& \mathrm{q}_{\mathrm{ts}}=\text { power applied at the limiting criteria } \\
& \mathrm{m}=\text { test section inlet mass flowrate } \\
& \mathrm{C}_{\mathrm{p}}=\text { test section inlet liquid specific heat } \\
& \mathrm{T}_{\mathrm{sat}}=\text { saturation temperature at outlet plenum } \\
& \mathrm{T}_{\mathrm{in}}=\text { test section inlet liquid temperature }
\end{aligned}
$$

An $\mathrm{R}$ factor can be computed in a similar fashion for experiments conducted using wall saturation temperature as the power limiting criteria. For the INEL ECS-2b experiments described in Anderson [Anderson, et al 1990], the $R$ factor was defined as

$$
R=\frac{h\left(T_{\text {sat }}-T_{f}\right) A_{\text {surface }} / P}{\dot{m} C_{p}\left(T_{\text {sat }}-T_{\text {in }}\right)}
$$

where

$\mathrm{h}=$ heat $\operatorname{transfer}$ coefficient

$\mathrm{T}_{\text {sat }}=$ saturation temperature

$\mathrm{T}_{\mathrm{f}}=$ local bulk fluid temperature

$A_{\text {surface }}=$ surface area of the heater

$P=$ axial peaking factor

$\mathrm{m}=$ test section inlet liquid mass flowrate

$\mathrm{C}_{\mathrm{p}}=$ liquid specific heat

$\mathrm{T}_{\mathrm{in}}=$ test section inlet fluid temperature

The numerator of Equation E-10 was defined in terms of the computed heat transfer coefficient to account for variations in the wall temperature from the saturation temperature.

\section{Integrated Thermal and Electrical Powers}

To compare thermal and electrical powers, the integrated power from the inlet to the axial locations of the fluid thermocouples was computed and $i: i$ 
presented in the tables in Appendix J. The total thermal power was calculated as

$$
\begin{aligned}
& \mathrm{q}_{\mathrm{t}}=\dot{\mathrm{m}} \mathrm{C}_{\mathrm{p}}\left(\mathrm{T}_{\text {out }}-\mathrm{T}_{\mathrm{in}}\right) \\
& \text { where } \\
& \mathrm{T}_{\text {out }}=\text { test section outlet fluid temperature } \\
& \mathrm{T}_{\text {in }}=\text { test section inlet fluid temperature } \\
& \mathrm{m}=\text { mass flowrate } \\
& C_{\mathrm{p}}=\text { specific heat }
\end{aligned}
$$

The integrated thermal power up to each fluid thermocouple location was computed using Equation E-11 with $T_{\text {out }}$ replaced by the average fluid temperature at that location. Note that Equation E-11 is accurate only until saturation conditions are reached.

Total electrical power was calculated as the product of the measured total voltage and current in the heater. Knowledge of the axial positions of the fluid thermocouples and the axial power profile for the heater allowed computation of the electrical power integrated from the inlet up to the fluid thermoccuple location. For each facility, the location of the fluid thermocouples was constant as was the axial power profile. Therefore, the integrated electrical power is simply a constant that is a function of axial position times the total electrical power. Table E-3 lists the constants used for the ECS-2 and ECS-2c programs.

\section{Average Fluid and Wall Temperatures}

Average fluid temperature was computed as the arithmetic average of all the fluid temperatures at a given location. For example, the average fluid temperature at the $253 \mathrm{~cm}$ elevation for the ECS -2 facility experiments (TF_03_AV) was computed as

TF_03_AV $=\left(T F \_A \_03+T F \_B \_03+T F \_C \_03+T F . . D \_03\right) / 4$

Average wall temperatures were computed in a like fashion using an equation similar to Equation E-12 with fluid temperature replaced with wall thermocouple measurements at a specific axial location and on a specific power step. 
Table E-3. Integrated electrical power constants for thermal excursion tests.

ECS-2 and ECS-2WSR tests

axial position $(\mathrm{cm})$ constant

63.5

183.0

257.0

381.0
0.079

0.357

0.646

1.0
ECS-2CE tests

axial position $(\mathrm{cm})$ constant

132

0.2

193

0.4

244

0.6

297

0.8

381

1.0

In the data tables, the computed average fluid and wall temperatures all have an "AV" suffix in their measurement identification. The average of the wall thermocouples at the $253 \mathrm{~cm}$ elevation, for example, would be labeled TI_6_AV. The test section average fluid temperature was computed as the average of the average fluid temperatures at each fluid temperature measurement location.

\section{Heater Electrical Resistance}

For some of the experimenis, the electrical resistance of the inner heater was computed and stored in the data tables. The resistance was computed using the measured heater voltage and current, ie.,

R_INNER $=$ V_INNER / I_INNER

\section{Reference}

Anderson, et al 1990 J. L. Anderson, K. G. Condie, and T. K. Larson, "Downflow Heat Transfer in a heated Ribbed Vertical Annulus with a Cosine Power Profile (Results from Test Series ECS-2b)," Idaho National Engineering Laboratory Report, EGG-EAST-9144, July 1990. 


\section{Appendix F}

\section{Data Repeatability for Onset of}

Thermal Excursion Experiments 


\section{Appendix F}

\section{Data Repeatability for Onset of Thermal Excursion Experiments}

Data repeatability was investigated during the course of the thermal excursion test program conducted in the ECS- 2 and ECS-2b facilities by performing essentially the same experiment multiple times. By design, the same experiment was conducted on numerous occasions ro support facility checkout procedures, investigate changes in the facility hardware, and provide experiment/facility demonstratious for the customer, visiting dignitaries, and other interested personnel. A comparison of the data from the experiments is presented in this appendix to demonstrate the high degree of repeatability observed in the test results.

Thermal excursion experiment ECS-2BL_5 was conducted on four different occasions for the reasons cired above. This test was conducted with nominal conditions of $324 \mathrm{~K}$ inlet temperature, an inlet flowrate of $0.1 \mathrm{l} / \mathrm{s}$, and with a standpipe level of $43 \mathrm{~cm}$ relative to the bottom of the lower plenum. In addition to the base case test, the experiment was also conducted as ECS-2BL_5B, ECS-2BL_5C, and ECS-2BL_5D with the actual conditions and on the dates shown in Tab!: F-1.

Conduct dates for the repeatability tests are shown in the second column of Table F-1. It is noteworthy that these experiments were not all conducted on the same date and that the elapsed time between performance of the individual tests was nearly a calendar week in all cases. Also, between the conduct of the base case test and ECS-2BL_5B, the bottom $1.8 \mathrm{~m}$ of the Lexan ${ }^{\mathrm{TM}}$ shroud ${ }^{1}$ was replaced with $1.8 \mathrm{~m}$ of aluminum shroud of the same inner diameter.

Examination of the values in Table F-1 shows that the variation in flowrate and inlet temperature between the tests was less than $6 \%$ and $1 \%$, respectively. Such small differences influence the energy balance so that the power required to saturate the fluid in the lower plenum (the eighth

1. During testing, the heater and shroud came in contact resulting in deformation and partial melting of the lower part of the shroud. To preclude further prublems, the decision was made to replace the lower part of the shroud with aluminum. 
Table F-1. Conduct dates and actual conditions for repeatability tests.

\begin{tabular}{|c|c|c|c|c|c|c|c|c|}
\hline $\mathrm{EST}^{1}$ & $\begin{array}{c}\text { Test } \\
\text { Conduct } \\
\text { Date } \\
\end{array}$ & $\begin{array}{c}\text { Test Section } \\
\text { Superficial } \\
\text { Velocity } \\
(\mathrm{m} / \mathrm{s})^{2}\end{array}$ & $\begin{array}{l}\text { Water } \\
\text { Inlet } \\
\text { Temp. } \\
(\mathrm{K})\end{array}$ & $\begin{array}{c}\text { Air } \\
\text { Ent. } \\
\text { Rate } \\
\text { (SLPM) }\end{array}$ & $\begin{array}{l}\text { Stand } \\
\text { Pipe } \\
\text { Height } \\
(\mathrm{cm})^{3}\end{array}$ & $\begin{array}{l}\text { Test } \\
\text { Section } \\
\text { Power } \\
(\mathrm{kW})\end{array}$ & $\begin{array}{c}\text { Power to } \\
\text { Saturate } \\
\text { Outlet } \\
(\mathrm{kW})\end{array}$ & $\begin{array}{c}\mathbf{R} \\
(\text { P/Psat }) \\
- \\
\end{array}$ \\
\hline 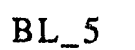 & $12 / 15 / 89$ & 0.078 & 325.96 & 0.01 & 408.70 & 53.48 & 19.07 & 2.80 \\
\hline $\mathrm{BL}_{-} 5 \mathrm{~B}$ & $12 / 19 / 89$ & 0.074 & 326.08 & 10.01 & 399.37 & 50.15 & 17.85 & 2.81 \\
\hline $\mathrm{BL}, 5 \mathrm{C}$ & $12 / 29 / 89$ & 0.074 & 324.04 & see 4 & 400.76 & 47.96 & 18.78 & 2.55 \\
\hline $\mathrm{BL}_{-} \div \mathrm{D}$ & $1 / 10 / 90$ & 0.075 & 323.96 & 8.01 & 401.40 & 50.76 & 19.36 & 2.62 \\
\hline
\end{tabular}

1. ior clarity, the ECS-2 prefix on the test names has been dropped.

2. Superficial velocity based on test section flow area of $13.31 \mathrm{~cm}^{\wedge} 2$.

3. Reference is top of heated length, increasing downward.

4. Air meters not functioning properly.

column) varies between the tests by as much as $1.5 \mathrm{~kW}$.

The $R$ factor, which is the power at the occurrence of thermal excursion (the seventh column) divided by the power required to saturate the fluid in the lower plenum (calculated by the test section energy balance) for each test is shown in the last column of Table F-1. The spread in the $R$ values is approximately $9 \%$.

The rather small spread in the $R$ factors for the repeatability tests is quite interesting in light of the random nature of the hydraulic and heat transfer processes leading to the thermal excursion. Furthermore, these four tests were not conducted in exactly the same fashion. For instance, Test BL_5 was one of the first excursion experiments conducted and the excursion condition was conservatively approached with a series of many small increases in total test section power over the course of about $2400 \mathrm{~s}$. As experience was gained with the operation of the system and the phenomena under investigation, the conduct of the test was accelerated by using larger power steps. These differences in test conduct are demonstrated in Figure F-1, a comparison of the test section electrical power for the four experiments. As shown, Tests $\mathrm{BL}_{-} 5 \mathrm{~B}, \mathrm{BL} \_5 \mathrm{C}$, and $\mathrm{BL}$-5D were conducted in approximately 1500 s by using somewhat larger power steps relative to the base case experiment. As evidenced from the comparisons in Table F-1, difference in test conduct or test section hardware apparently had little effect on the power at which thermal excursion occurred. 


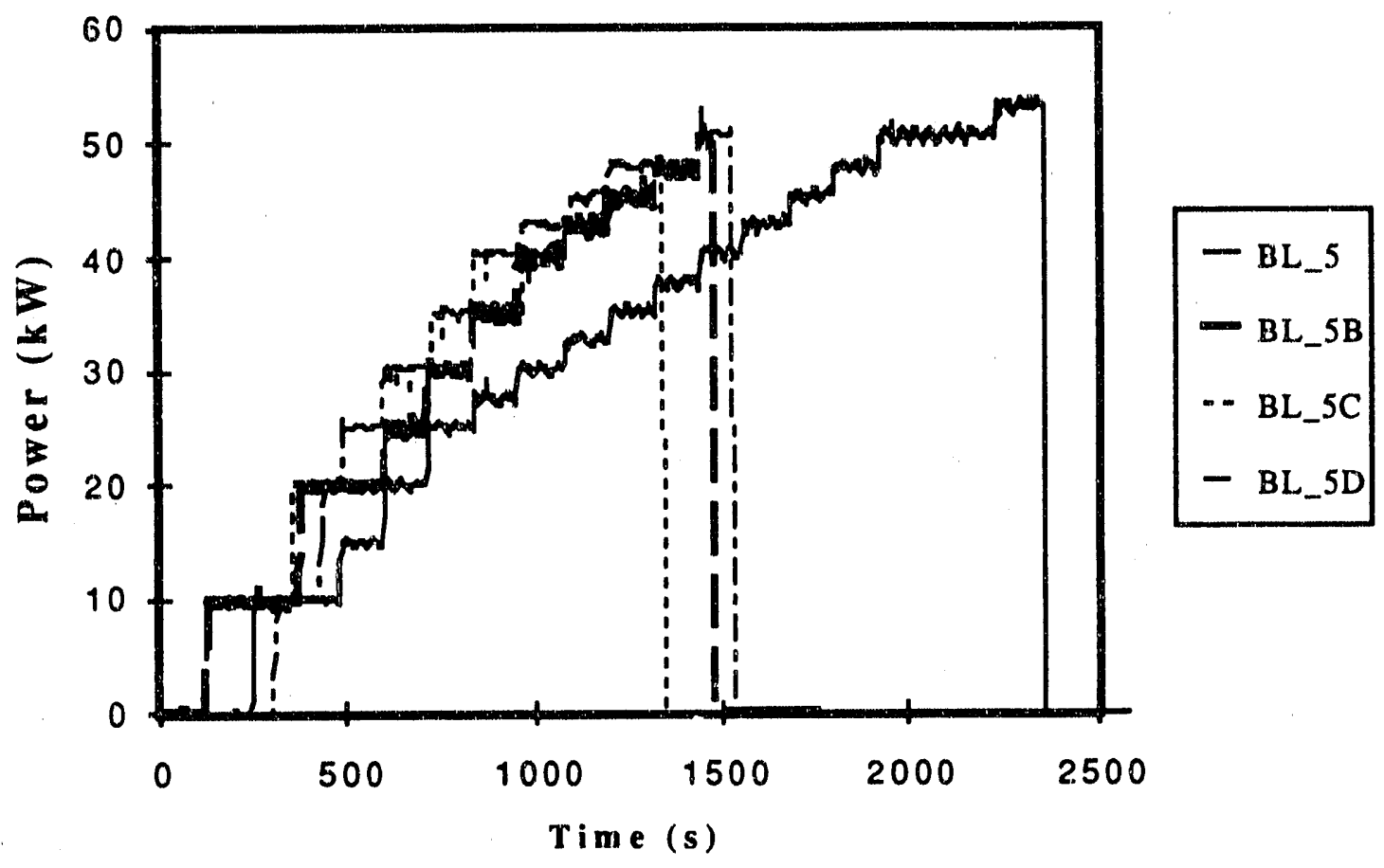

Figure F-1. Comparison of electrical power for repeatability tests.

As was discussed previously, in the excursion tests the power to the test section was terminated when any wall thermocouples attained a temperature of $600 \mathrm{~K}$. Table F-2 lists for each of the repeatability tests, the wall thermocouples that initiated the power trip, the time at which the trip occurred, and the peak temperature and ime that the peak temperature was recorded after the power was tripped.

From the data in Table F-2, it is obvious that the location of the dryout was not always the same in the repeatability tests. For example, in three of the tests, the thermocouples at level 7 were the first to dry out and reach the $600 \mathrm{~K}$ trip criterion, whereas on Test BL_5C, the level 6 thermocouples dried out first. It is note worthy that the thermocouples initiating the trip on the $\mathrm{BL}_{-} 5 \mathrm{x}$ repeatability tests were generally at $302 \mathrm{~cm}$ (level 7 ) below the top of the heated length rather than at the high power zone. One may have expected that the highest power location would dryout first. 
Table F-2. Thermocouples initiating power trip for repeatability tests

\begin{tabular}{|c|c|c|c|c|c|}
\hline $\begin{array}{c}\text { Test ID } \\
\ldots \\
\end{array}$ & $\begin{array}{c}\text { Time of } \\
\text { Trip } \\
\text { (s) }\end{array}$ & $\begin{array}{c}\text { TC Initiating } \\
\text { Trip } \\
- \\
\end{array}$ & $\begin{array}{c}\text { TC Reading } \\
\text { at Trip } \\
(\mathrm{K})\end{array}$ & $\begin{array}{c}\text { Peak } \\
\text { TC Reading } \\
\text { (K) }\end{array}$ & $\begin{array}{c}\text { Time of } \\
\text { Peak Reading } \\
\text { (s) }\end{array}$ \\
\hline $\mathrm{BL}_{-} 5$ & $\begin{array}{l}2360 \\
2360 \\
2360\end{array}$ & $\begin{array}{l}\text { TI_B_j_7 } \\
\text { TI_D_s_7 } \\
\text { TI_C_m_7 }\end{array}$ & $\begin{array}{l}603.6 \\
599.5 \\
602.2\end{array}$ & $\begin{array}{l}627.76 \\
631.85 \\
629.56\end{array}$ & $\begin{array}{c}2373 \\
2373 \\
2372.5\end{array}$ \\
\hline BL_5B & $\begin{array}{l}1482 \\
1482 \\
1482\end{array}$ & $\begin{array}{l}\text { TI_A_a_7 } \\
\text { TI_B_g_7 } \\
\text { TI_B_j_7 }\end{array}$ & $\begin{array}{c}566 \\
563.8 \\
565.2\end{array}$ & $\begin{array}{c}588 \\
587.8 \\
593.74\end{array}$ & $\begin{array}{l}1490 \\
1490 \\
1492\end{array}$ \\
\hline$B L \_5 C$ & $\begin{array}{l}1344 \\
1344\end{array}$ & $\begin{array}{l}\text { TI_C_q_6 } \\
\text { TI_D_W_6 }\end{array}$ & $\begin{array}{c}566 \\
593.3\end{array}$ & $\begin{array}{l}609 \\
629\end{array}$ & $\begin{array}{l}1358 \\
1356\end{array}$ \\
\hline$B L \_5 D$ & $\begin{array}{l}1529 \\
1529 \\
1529 \\
1529\end{array}$ & $\begin{array}{l}\text { TI_C_C_q_6 } \\
\text { TI_D_w_6 } \\
\text { TI_B_j_7 } \\
\text { TI_D_v_7 }\end{array}$ & $\begin{array}{c}468 \\
425 \\
601.7 \\
613.74\end{array}$ & $\begin{array}{l}603.7 \\
588.7 \\
647.1 \\
640.2\end{array}$ & $\begin{array}{c}1512 \\
1512 \\
1552.4 \\
1550\end{array}$ \\
\hline
\end{tabular}

1. For clarity, the ECS-2 prefix on the test names has been dropped.

2. The thermocouples continue to heatup after power trip due to stored energy in the heater. 
Appendix G

ECS-2 Air Ingress Test Results 


\section{Appendix $\mathbf{G}$}

\section{ECS-2 Air Ingress Test Results}

\section{INTRODUCTION}

Twelve experiments were conducted in the ECS-2 facility to examine the functional relationship between the rate at which air was entrained into the test section and other test section boundary conditions. These experiments were termed the air ingress (AI) tests. Inlet liquid temperature and flowrate and back pressure on the lower plenum (the standpipe setting) were the major variables in the AI tests.

The procedure used to conduct the AI tests was somewhat different than the procedure used to conduct the excursion tests. Since the major objective of the AI tests was to determine the parameters influencing entrainment of air into the test section, the heater was not energized. For a given standpipe setting and inlet fluid temperature, experiment conduct entailed injecting water into the upper plenum in the normal manner, allowing the test section to stabilize, printing a data scan (an average of approximately 25 seconds of data) on the DAS, and then changing the inlet liquid flowrate and repeating the data scan. For the AI tests, the inlet liquid flowrate was increased in $0.2 \mathrm{l} / \mathrm{s}$ increments between 0.1 and $1.5 \mathrm{l} / \mathrm{s}$. After a change in inlet flowrate, the test section was allowed to stabilize for at least 2 minutes before taking a data scan.

Tests were conducted with three different inlet temperatures and four different standpipe settings. Table G-1 is the test matrix for the AI test group.

\section{RESULTS}

Data collected during the AI test series shows that, for a given standpipe level ${ }^{1}$ and inlet liquid temperature, the rate at which air is entrained into the top of the test section increases with increasing liquid flowrate. Figures G-1, G-2, and G-3 graphically present the data collected during the

1. For the purposes of this discussion, the standpipe level is referenced to the bottom of the lower plenum. 


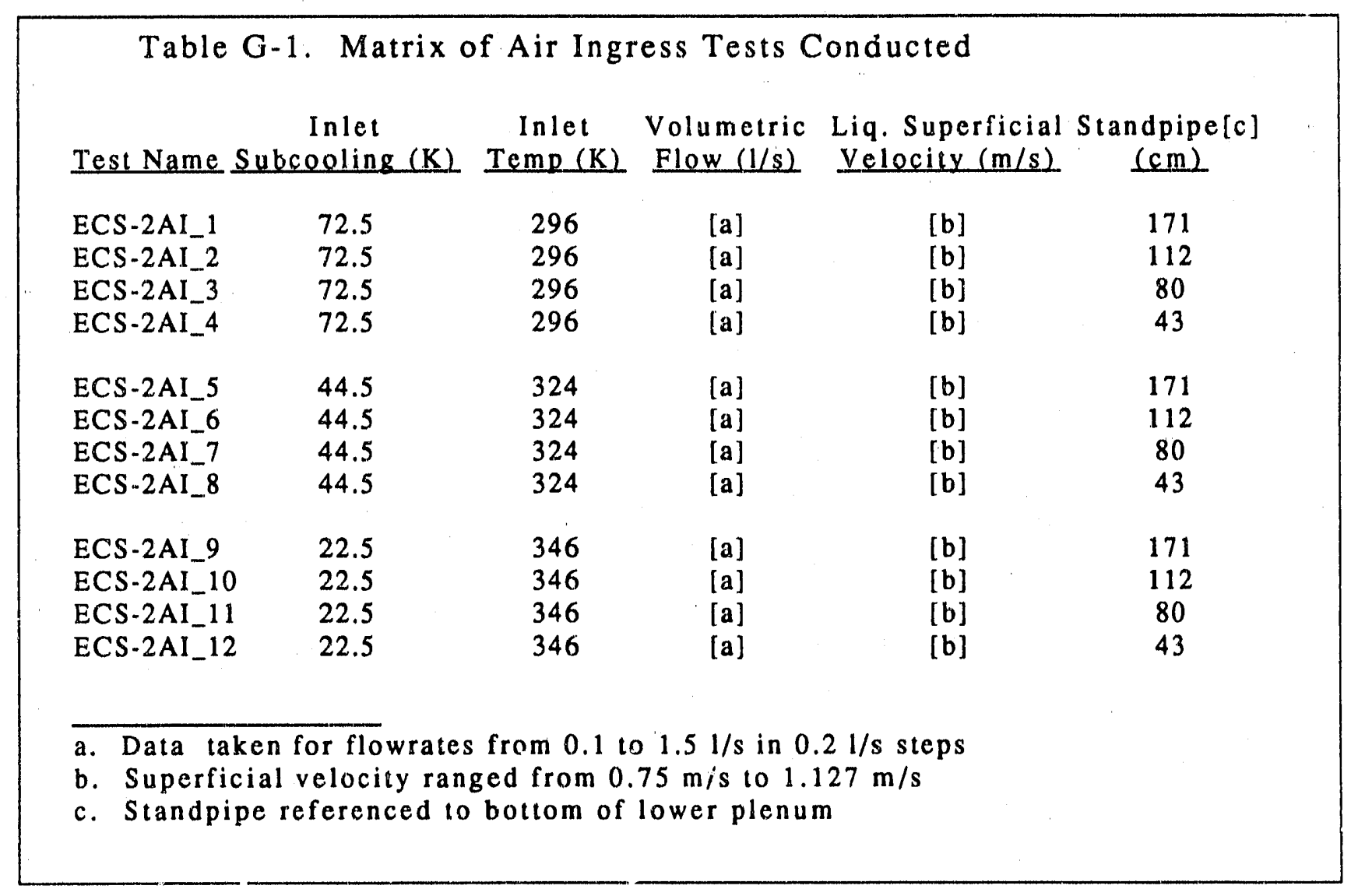

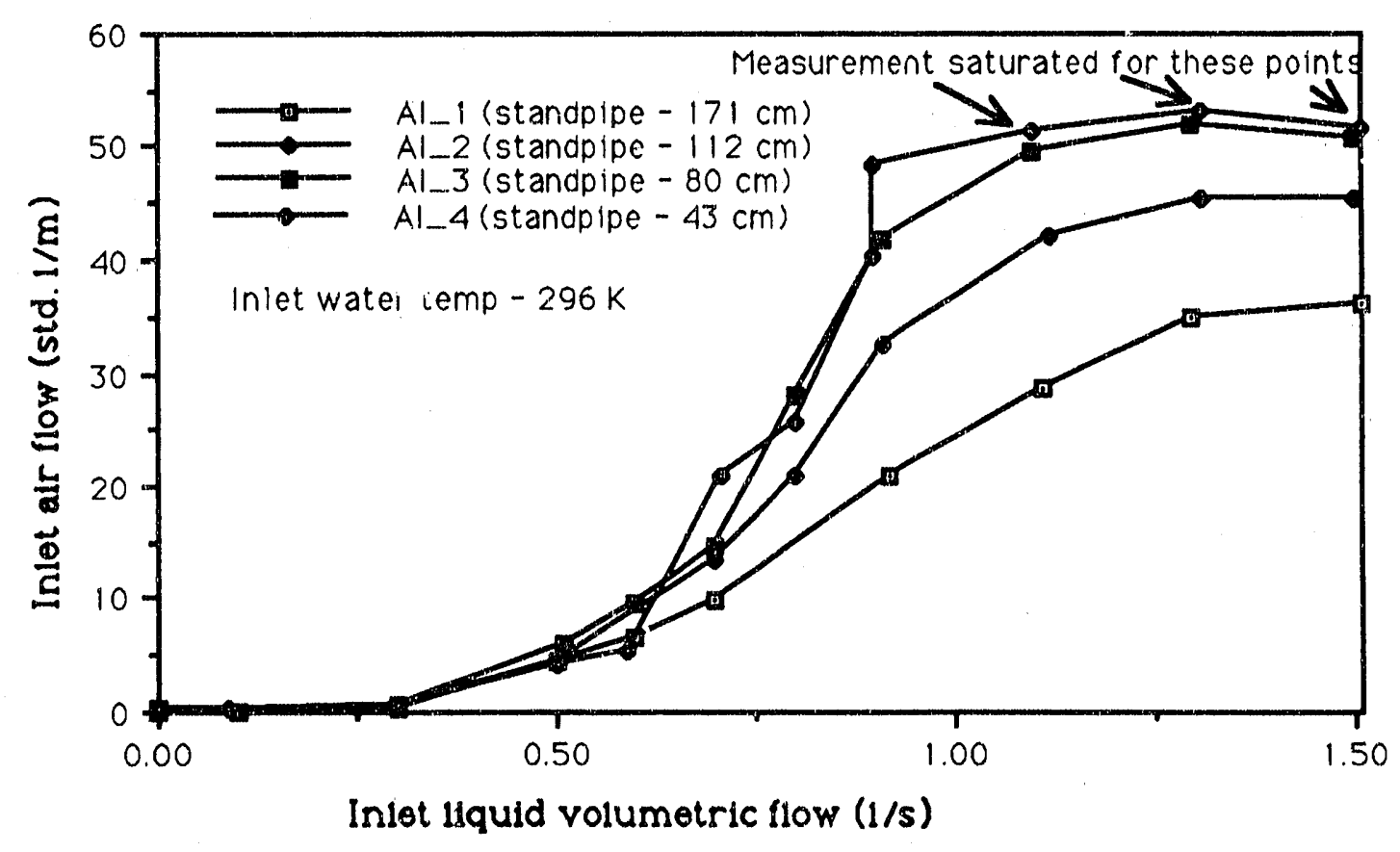

Figure G-1. Air ingress rate for $296 \mathrm{~K}$ inlet liquid temperature. 


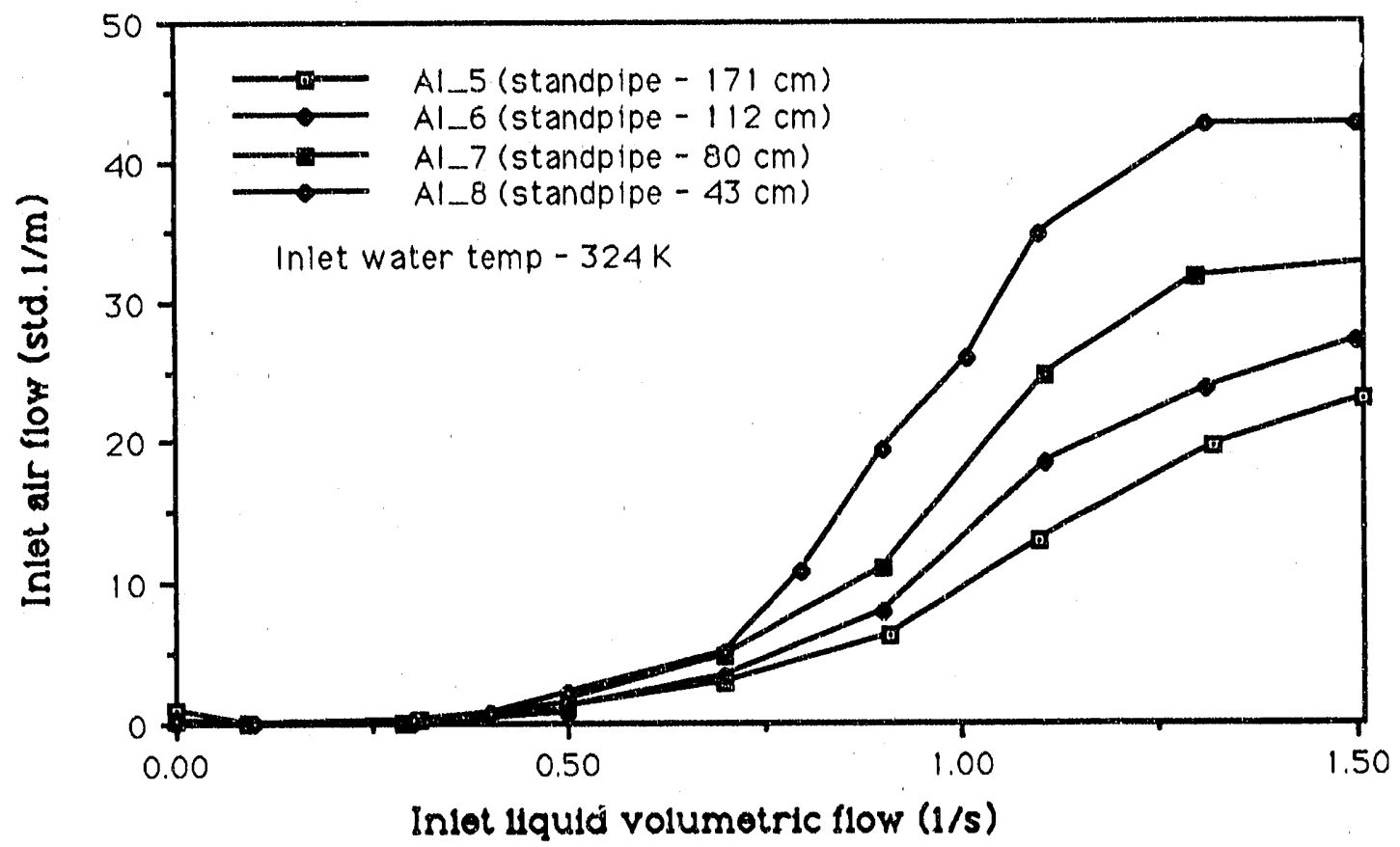

Figure G-2. Air ingress rate for $324 \mathrm{~K}$ inlet liquid temperature.

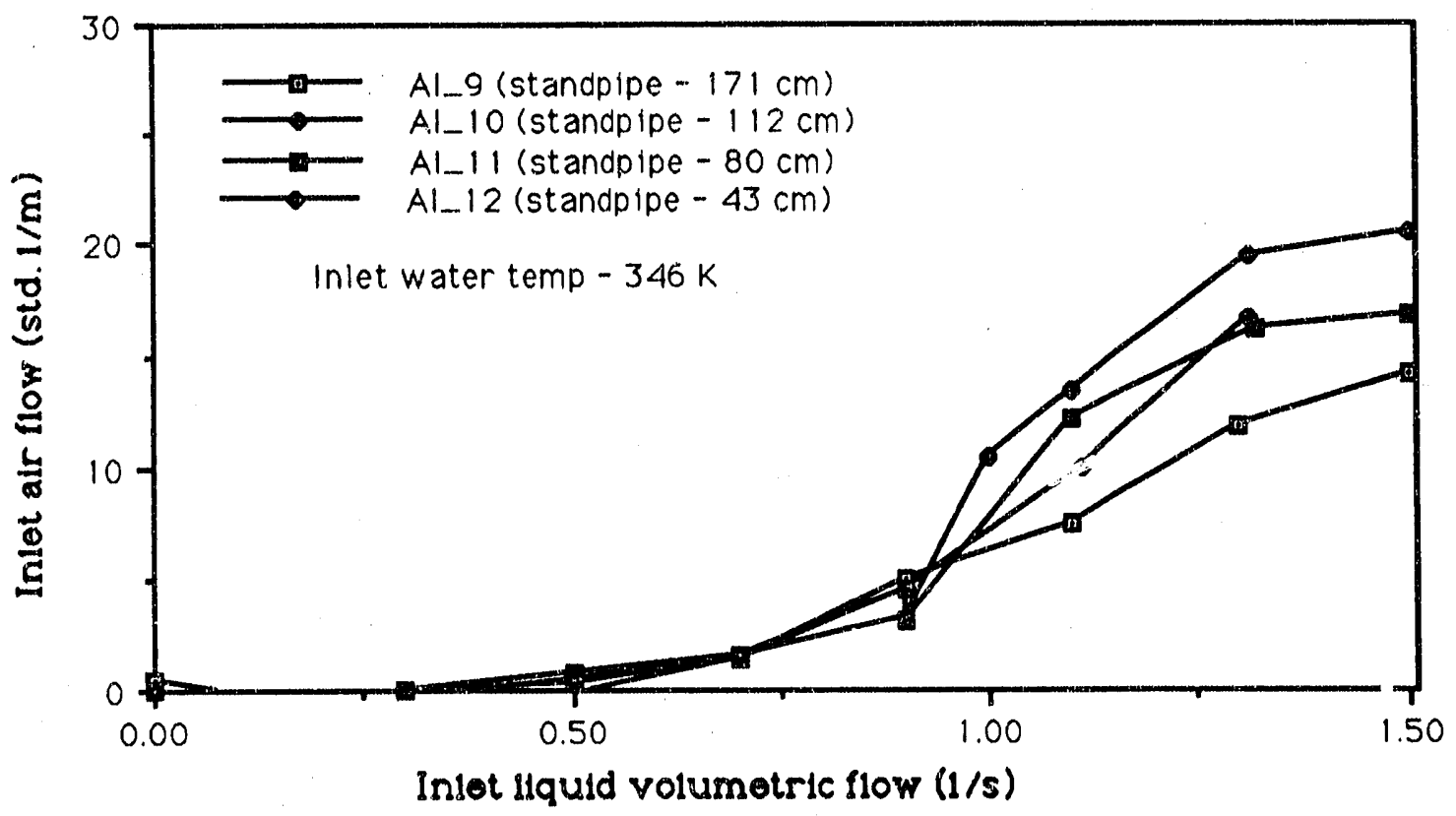

Figure G-3. Air ingress rate for $346 \mathrm{~K}$ inlet fluid temperature. 
Al tests in terms of the measured air flowrate at the test section inlet as a function of the liquid rolumetric flowrate. Each of the figures presents the data taken for a specific inlet fluid temperature and for all of the standpipe level settings.

Figures G.1, G-2, and G-3 clearly show the effects of standpipe level (back pressure) on the air ingress rate. The trend is what one would expect in that as the imposed pressure differential on the test section is decreased, the air flowrate should decrease if all other parameters remain constant. Con oidering a pressure balance on the simple schematic shown in Figure G-4, the test section flowrate is proportional to the test section and standpipe he.d difference. If $h_{1}$ is constant then as the value of $h_{2}$ increases, the driving potential for the air flow decreases. For simplicity, if we assume that all other factors are equal (interfacial drag, wall drag, viscosity effects, etc.) then the air : !owrate would be expected to decrease with increasing standpipe levels. Data shown in Figures G-1, G-2, and G-3 is consistent with this expectrtion. As shown on Figure G-2, runs at a liquid flowrate of $1.5 \mathrm{l} / \mathrm{s}$ shewed measured air flowrates of 43-, 33-, 27-, and $2.3 \mathrm{std} .1 / \mathrm{m}$ for the $43-, 80-, 112-$, and $171 \mathrm{~cm}$ standpipe levels,

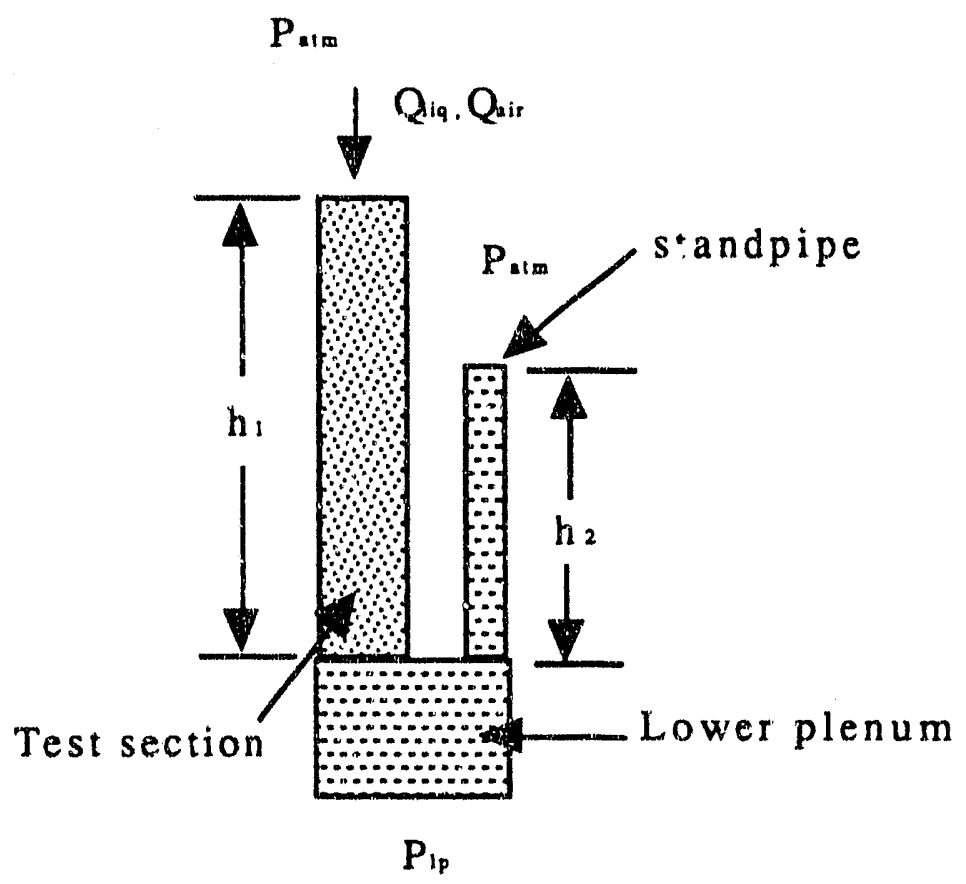

Figure G-4. Tesi section schematic for simplit. a pressure balance. 
respectively. This same trend is evident in the other figures as well. ${ }^{2}$

Inlet liquid temperature had a significant efi $c t$ on the air entrainment rate. As expected, the cooler the inlet liquid temperature, the higher the air entrainment rate. Figures G-5, G-6, G-7, and G-8 present the AI data for each standpipe setting with inlet temperature as a parameter. Data in Figure G-8 (171 cm standpipe setting) for the highest liquid flowrate (1.5 $1 / \mathrm{s}$ ) show that the air entrainment rate decreased by a factor of 2 (from about $36 \mathrm{std} .1 / \mathrm{m}$ to $15 \mathrm{std} .1 / \mathrm{m}$ ) as the inlet liquid temperature increased from $296 \mathrm{~K}$ to $346 \mathrm{~K}$. Since the liquid viscosity decreases by a factor of 2 over this range of temperature, it is likely that viscosity is a predominant factor influencing the air entrainment. As shown on the other figures, the other standpipe level settings showed the same general trends.

Tabular values for the data collected during the AI test series runs is given in Table G-2. The values listed represent time averages of

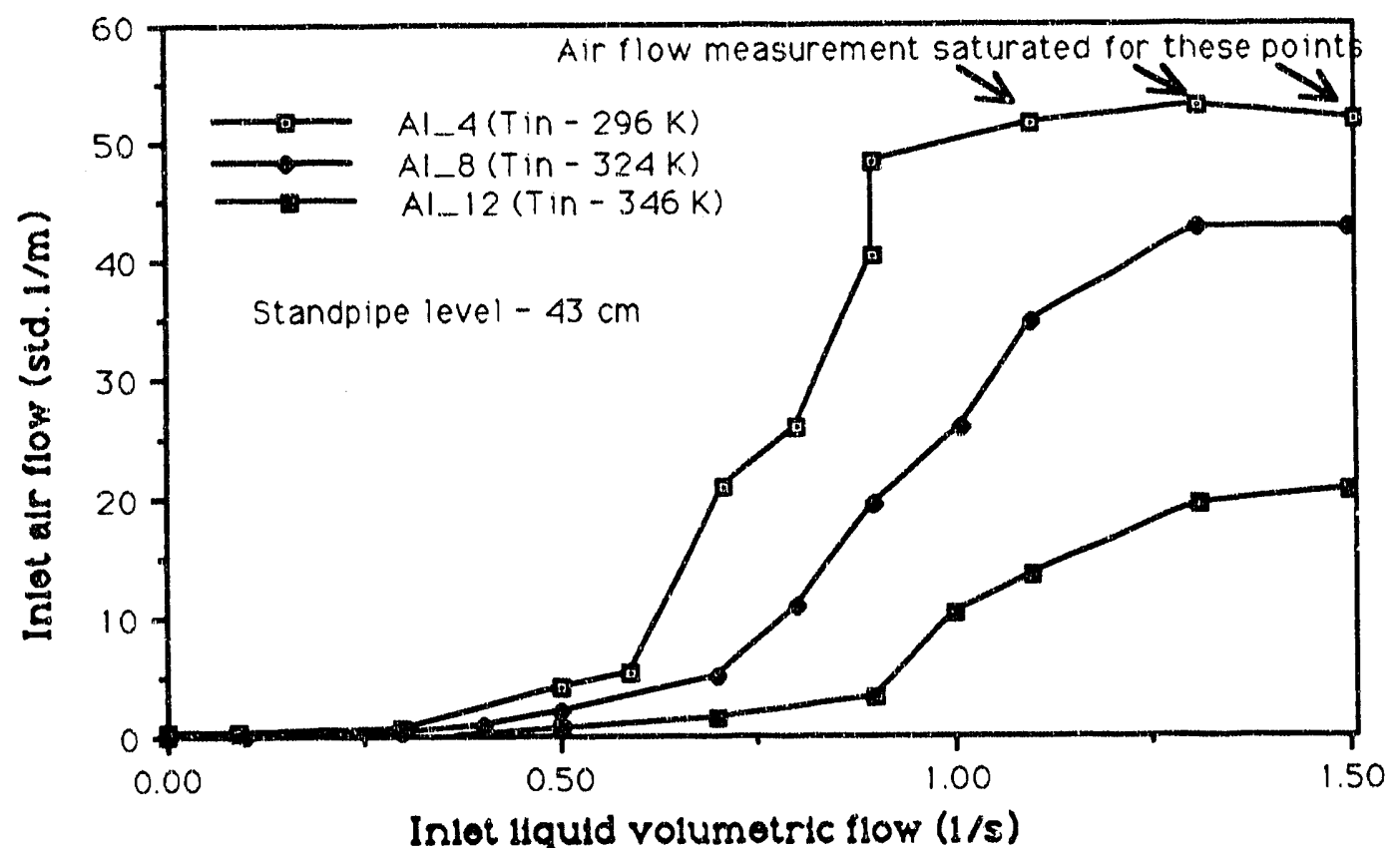

Figure G-5. Air ingress rate for $43 \mathrm{~cm}$ standpipe setting.

2. The inlet air flowrate measurement for the $296 \mathrm{~K}$ inlet water temperature case with $43 \mathrm{~cm}$ and $80 \mathrm{~cm}$ standpipe levels was near saturation (the measurement range maximum was $\sim 50 \mathrm{std} .1 / \mathrm{m}$ ). 


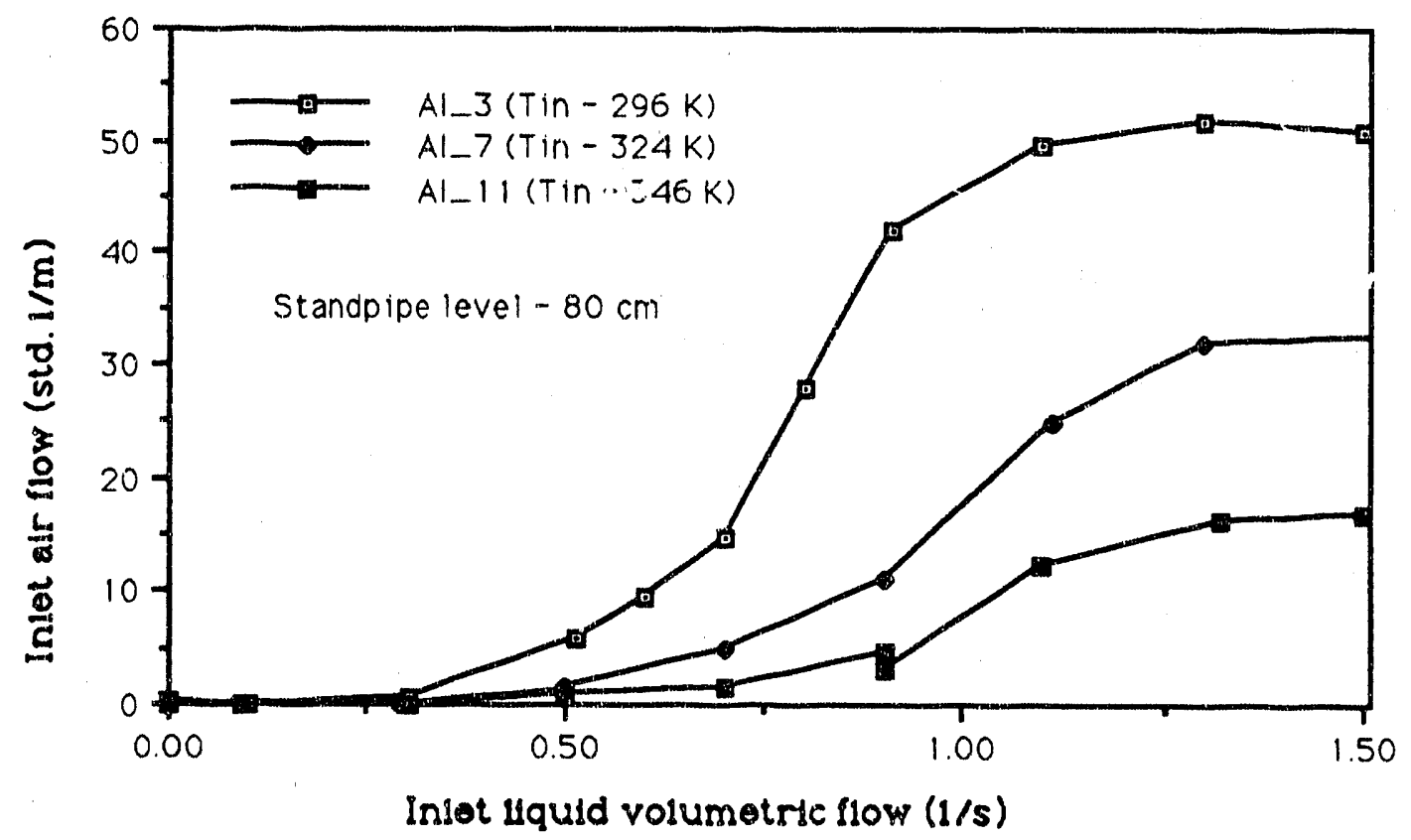

Figure G-6. Air ingress rate for $80 \mathrm{~cm}$ standpipe setting.

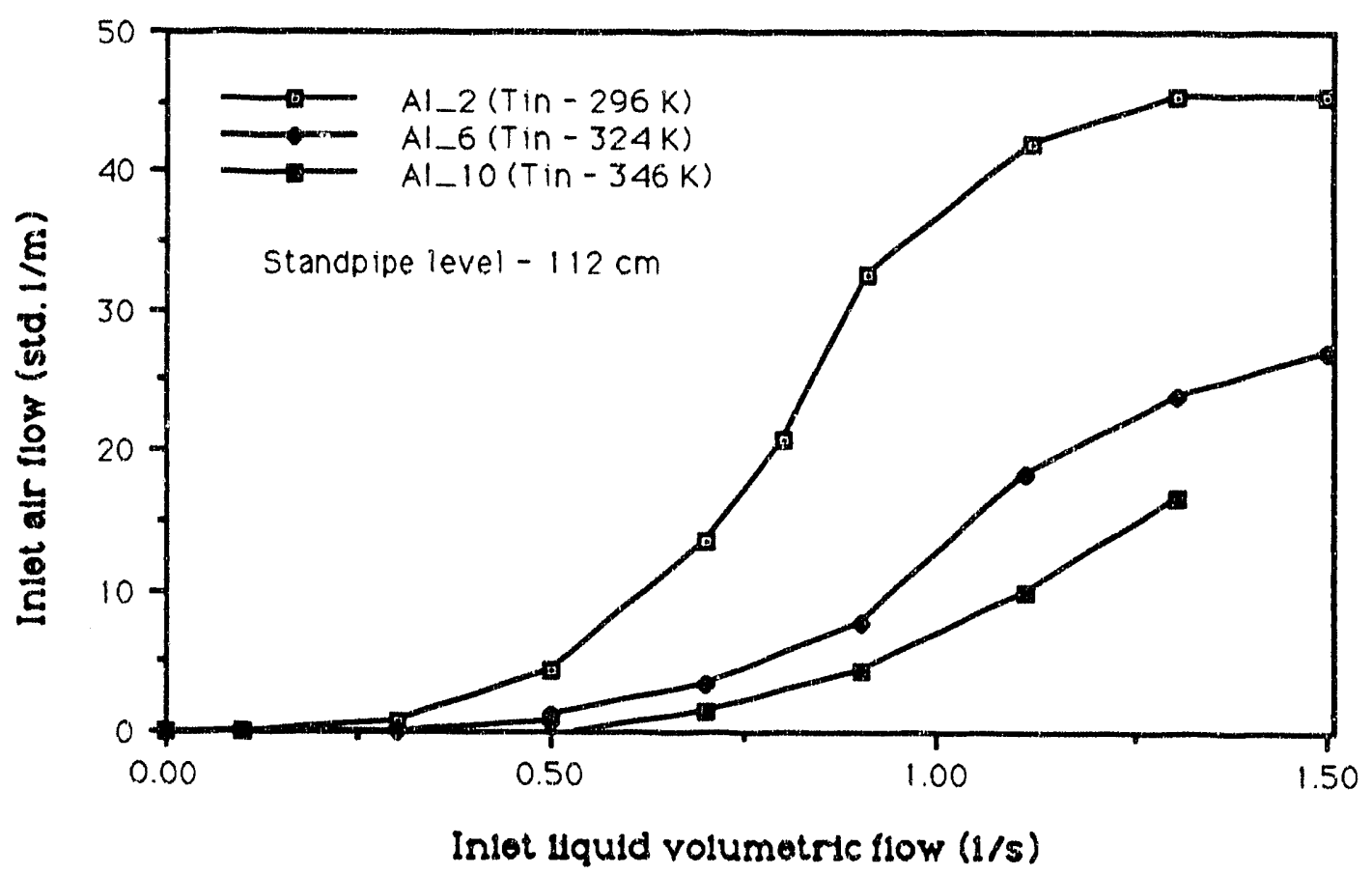

Figure G-7. Air ingress results for $112 \mathrm{~cm}$ standpipe setting. 


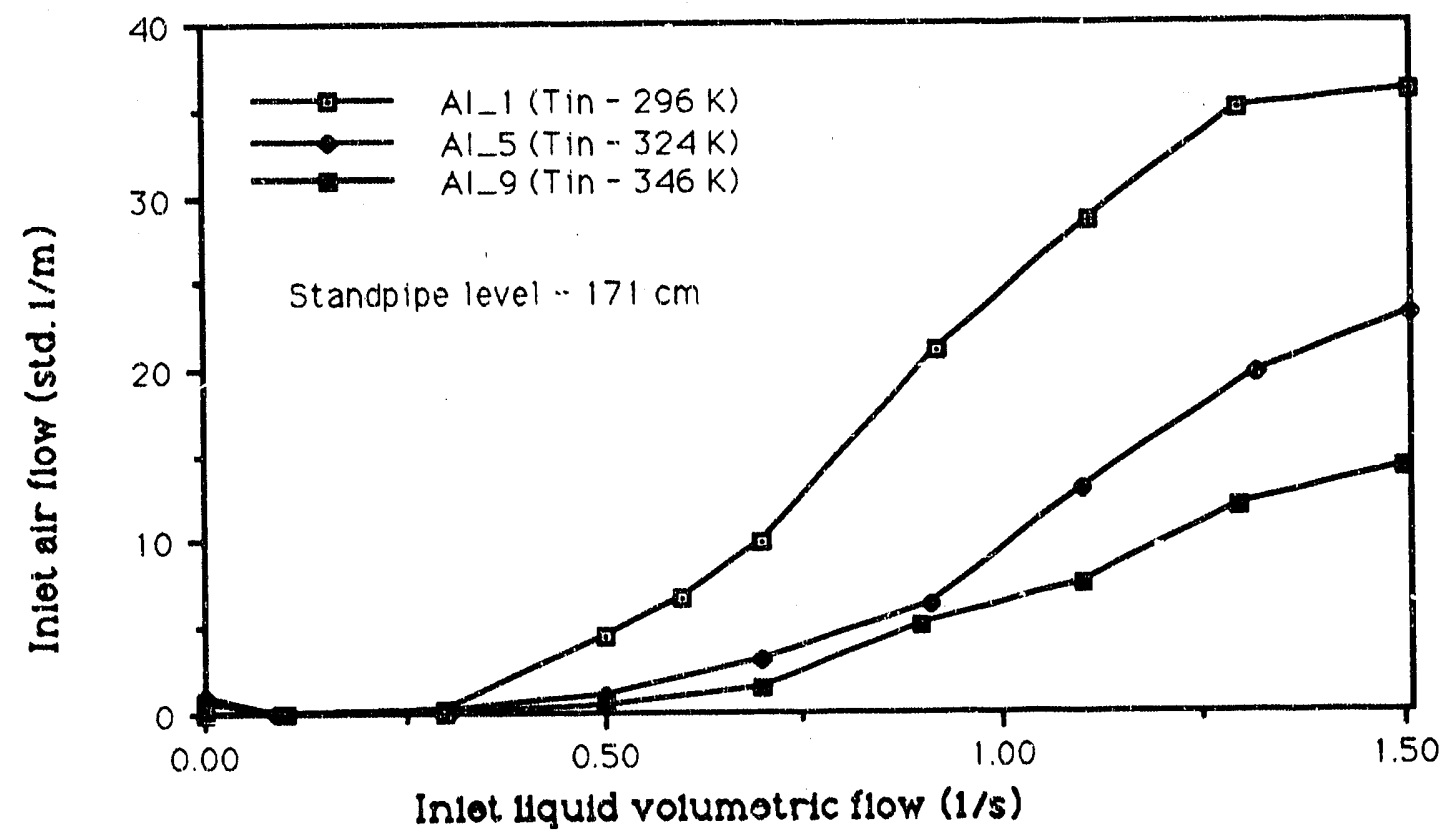

Figure G-8. Air ingress results for $171 \mathrm{~cm}$ standpipe setting.

approximately 20 data points.

\section{CONCLUSIONS}

Data was gathered in the ECS-2 facility to examine the rate at which air was entrained into the top of the test section. The data shows that the air entrainment rate is a function of the liquid fowrate, liquid inlet temperature, and back pressure imposed on the facility.

Analysis of the data indicates the following relationships:

- air entrainment rate increases with increasing liquid flowrate

- air entrainment rate decreases with increasing inlet fluid temperature

- air entrainment rate decreases as the back pressuse on the facility is increased (the standpipe height is increased). 


\begin{tabular}{|c|c|c|c|c|c|c|}
\hline \multirow[b]{2}{*}{ Test ID } & $* * * * * * * * * * *$ & Air Ingres & \multicolumn{4}{|c|}{ General Test Parameters *********** } \\
\hline & $\begin{array}{c}\text { Water } \\
\text { Inlet } \\
\text { Flowrate } \\
(1 / s)\end{array}$ & $\begin{array}{c}\text { Test Section } \\
\text { Superficial } \\
\text { Velocity } \\
(\mathrm{m} / \mathrm{s})[1 .] \\
\end{array}$ & $\begin{array}{l}\text { Water } \\
\text { Inlet } \\
\text { Temp. } \\
(\mathrm{K}) \\
\end{array}$ & $\begin{array}{c}\text { Air } \\
\text { Entrainment } \\
\quad \text { Rate } \\
\text { (std. } 1 / \mathrm{m} \text { ) }[2 .] \\
\end{array}$ & $\begin{array}{l}\text { Stand } \\
\text { Pipe } \\
\text { Height } \\
\text { (m) [3.] }\end{array}$ & $\begin{array}{c}\text { Air } \\
\text { Inlet } \\
\text { Temperature } \\
(\mathrm{K}) \\
\end{array}$ \\
\hline ECS-2AI_1 & 0.00 & 0.00 & 298.97 & -0.01 & 1.71 & 309.13 \\
\hline ECS-2AI_1 & 0.10 & 0.08 & 298.56 & 0.05 & 1.73 & 309.06 \\
\hline ECS-2AI_1 & 0.30 & 0.23 & 296.95 & 0.29 & 1.74 & 309.09 \\
\hline ECS-2AI_1 & 0.50 & 0.38 & 295.49 & 4.41 & 1.76 & 308.86 \\
\hline ECS-2AI_1 & 0.70 & 0.52 & 298.11 & 9.85 & 1.78 & 307.48 \\
\hline ECS-2AI_1 & 0.92 & 0.69 & 293.50 & 20.97 & 1.78 & 304.72 \\
\hline ECS-2AI_1 & 1.11 & 0.83 & 295.30 & 28.56 & 1.81 & 302.50 \\
\hline ECS-2AI_1 & 1.30 & 0.98 & 296.33 & 34.88 & 1.82 & 301.87 \\
\hline ECS-2AI_1 & 1.51 & 1.13 & 295.84 & 36.02 & 1.86 & 301.47 \\
\hline ECS-2AI_1 & 0.60 & 0.45 & 296.90 & 6.59 & 1.75 & 303.52 \\
\hline ECS-2AI_1 & 0.00 & 0.00 & 297.41 & 0.00 & 1.72 & 304.81 \\
\hline ECS-2AI_2 & 0.00 & 0.00 & 305.96 & 0.03 & 1.05 & 308.77 \\
\hline ECS-2AI_2 & 0.10 & 0.08 & 297.38 & 0.08 & 1.12 & 309.13 \\
\hline ECS-2AI_2 & 0.30 & 0.22 & 295.93 & 0.69 & 1.13 & 309.05 \\
\hline ECS-2AI_2 & 0.50 & 0.38 & 299.37 & 4.44 & 1.15 & 308.75 \\
\hline ECS-2AI_2 & 0.70 & 0.53 & 294.19 & 13.45 & 1.16 & 306.74 \\
\hline ECS-2AI_2 & 0.91 & 0.68 & 295.79 & 32.61 & 1.17 & 305.55 \\
\hline ECS-2AI_2 & 1.12 & 0.84 & 295.91 & 42.03 & 1.22 & 305.84 \\
\hline ECS-2AI_2 & 1.31 & 0.98 & 296.51 & 45.33 & 1.24 & 305.95 \\
\hline ECS-2AI_2 & 1.50 & 1.13 & 296.01 & 45.39 & 1.24 & 305.60 \\
\hline ECS-2AI_2 & 0.80 & 0.60 & 295.74 & 20.78 & 1.16 & 304.65 \\
\hline ECS-2AI_2 & 0.00 & 0.00 & 296.33 & 0.07 & 1.11 & 305.38 \\
\hline ECS-2AI_3 & 0.00 & 0.00 & 304.08 & 0.04 & 0.77 & 308.98 \\
\hline ECS-2AI_3 & 0.10 & 0.07 & 29.5 .82 & 0.14 & 0.81 & 309.26 \\
\hline ECS-2AI_3 & 0.30 & 0.22 & 296.87 & 0.71 & 0.83 & 329.27 \\
\hline ECS-2AI_3 & 0.51 & 0.38 & 294.86 & 5.95 & 0.84 & 308.78 \\
\hline ECS-2Al_3 & 0.70 & 0.53 & 296.47 & 14.73 & 0.86 & 307.88 \\
\hline ECS-2AI_3 & 0.91 & 0.68 & 297.50 & 41.92 & 0.88 & 306.93 \\
\hline ECS-2AI_3 & 1.10 & 0.83 & 296.17 & 49.46 & 0.96 & 306.97 \\
\hline ECS-2AI_3 & 1.30 & 0.98 & 295.77 & 51.80 & 0.89 & 306.61 \\
\hline ECS-2AI_3 & 1.50 & 1.13 & 295.17 & 50.82 & 0.94 & 306.60 \\
\hline ECS-2AI_3 & 0.80 & 0.60 & 297.56 & 27.93 & 0.86 & 306.06 \\
\hline ECS-2AI_3 & 0.60 & 0.45 & 298.15 & 9.41 & 0.85 & 305.11 \\
\hline ECS-2AI_3 & 0.00 & 0.00 & 298.17 & 0.19 & 0.80 & 305.60 \\
\hline
\end{tabular}




\begin{tabular}{|c|c|c|c|c|c|c|}
\hline \multirow[b]{3}{*}{ Test ID } & Table G-2. & \multicolumn{2}{|c|}{ Air Ingress Test } & \multirow{2}{*}{\multicolumn{3}{|c|}{ Results Summary (Cont'd) }} \\
\hline & $* * * * * * * * * * * *$ & \multicolumn{4}{|c|}{ Air Ingress General Test Parameters $* * * * * * * * * *$} & \\
\hline & $\begin{array}{c}\text { Water } \\
\text { Inlet } \\
\text { Flowrate } \\
(1 / s) \\
\end{array}$ & $\begin{array}{c}\text { Test Section } \\
\text { Superficial } \\
\text { Velocity } \\
(\mathrm{m} / \mathrm{s})[1 .] \\
\end{array}$ & $\begin{array}{l}\text { Water } \\
\text { Inlet } \\
\text { Temp. } \\
(\mathrm{K})\end{array}$ & $\begin{array}{c}\text { Air } \\
\text { Entrainment } \\
\text { Rate } \\
\text { (std. } 1 / \mathrm{m})[2 .] \\
\end{array}$ & $\begin{array}{l}\text { Stand } \\
\text { Pipe } \\
\text { Height } \\
\text { (m) [3.] }\end{array}$ & $\begin{array}{c}\text { Air } \\
\text { Inlet } \\
\text { Temperature } \\
(\mathrm{K}) \\
\end{array}$ \\
\hline ECS-2AI_4 & 0.00 & 0.00 & 295.72 & 0.07 & 0.44 & 302.23 \\
\hline ECS-2AI_4 & 0.09 & 0.07 & 299.20 & 0.22 & 0.46 & 302.58 \\
\hline ECS-2AI_4 & 0.30 & 0.22 & 297.69 & 0.65 & 0.47 & 302.65 \\
\hline ECS-2AI_4 & 0.50 & 0.38 & 294.70 & 4.21 & 0.49 & 302.63 \\
\hline ECS-2AI_4 & 0.71 & 0.53 & 296.01 & 20.78 & 0.48 & 301.63 \\
\hline ECS-2AI_4 & 0.90 & 0.68 & 295.65 & 48.23 & 0.47 & 301.85 \\
\hline ECS-2AI_4 & 1.10 & 0.83 & 296.24 & 51.36 & 0.53 & 301.76 \\
\hline ECS-2AI_4 & 1.31 & 0.98 & 295.02 & 53.07 & 0.61 & 301.57 \\
\hline ECS-2AI_4 & 1.51 & 1.13 & 294.34 & 51.71 & 0.57 & 301.91 \\
\hline ECS-2AI_4 & 0.80 & 0.60 & 297.03 & 25.77 & 0.51 & 301.99 \\
\hline ECS-2AI_4 & 0.90 & 0.68 & 295.19 & 40.17 & 0.54 & 301.87 \\
\hline ECS-2AI_4 & 0.59 & 0.45 & 297.87 & 5.41 & 0.49 & 302.69 \\
\hline ECS-2AI_4 & 0.00 & 0.00 & 297.82 & 0.22 & 0.45 & 302.98 \\
\hline ECS-2AI_5 & 0.00 & 0.00 & 322.86 & 0.18 & 1.70 & 309.90 \\
\hline ECS-2AI_5 & 0.09 & 0.07 & 325.72 & -0.01 & 1.71 & 309.87 \\
\hline ECS-2AI_5 & 0.31 & 0.23 & 324.85 & 0.22 & 1.73 & 309.70 \\
\hline ECS-2AI_5 & 0.50 & 0.37 & 324.80 & 1.11 & 1.74 & 309.83 \\
\hline ECS-2AI_5 & 0.70 & 0.53 & 324.92 & 2.93 & 1.76 & 309.56 \\
\hline ECS-2AI_5 & 0.91 & 0.68 & 323.97 & 6.30 & 1.78 & 309.48 \\
\hline ECS-2Ai_5 & 1.10 & 0.83 & 324.48 & 12.91 & 1.81 & 308.13 \\
\hline ECS-2AI_5 & 1.32 & 0.99 & 325.54 & 19.54 & 1.84 & 306.43 \\
\hline ECS-2AL_5 & 1.51 & 1.14 & 324.89 & 23.03 & 1.89 & 305.45 \\
\hline ECS-2Al_5 & 0.50 & 0.38 & 325.42 & 0.94 & 1.74 & 307.04 \\
\hline ECS-2AI_5 & 0.00 & 0.00 & 323.81 & 0.97 & 1.70 & 307.96 \\
\hline ECS-2AI_6 & 0.00 & 0.00 & 323.24 & 0.10 & 1.09 & 310.25 \\
\hline ECS-2AI_6 & 0.10 & 0.07 & 324.74 & -0.10 & 1.10 & 310.48 \\
\hline ECS-2AI_6 & 0.30 & 0.22 & 325.12 & 0.08 & 1.12 & 310.45 \\
\hline ECS-2AI_6 & 0.50 & 0.38 & 324.91 & 1.09 & 1.13 & 310.52 \\
\hline ECS-2AI_6 & 0.70 & 0.52 & 324.66 & 3.34 & 1.15 & 310.43 \\
\hline ECS-2AI_6 & 0.90 & 0.68 & 324.48 & 7.34 & 1.16 & 309.60 \\
\hline ECS-2AI_6 & 1.11 & 0.83 & 324.39 & 18.34 & 1.18 & 308.45 \\
\hline ECS-2AI_6 & 1.31 & 0.98 & 325.05 & 23.80 & 1.21 & 307.66 \\
\hline ECS-2AI_6 & 1.50 & 1.13 & 325.34 & 26.95 & 1.23 & 307.28 \\
\hline ECS-2AI_6 & 0.50 & 0.37 & 327.92 & 0.70 & 1.13 & 307.97 \\
\hline
\end{tabular}




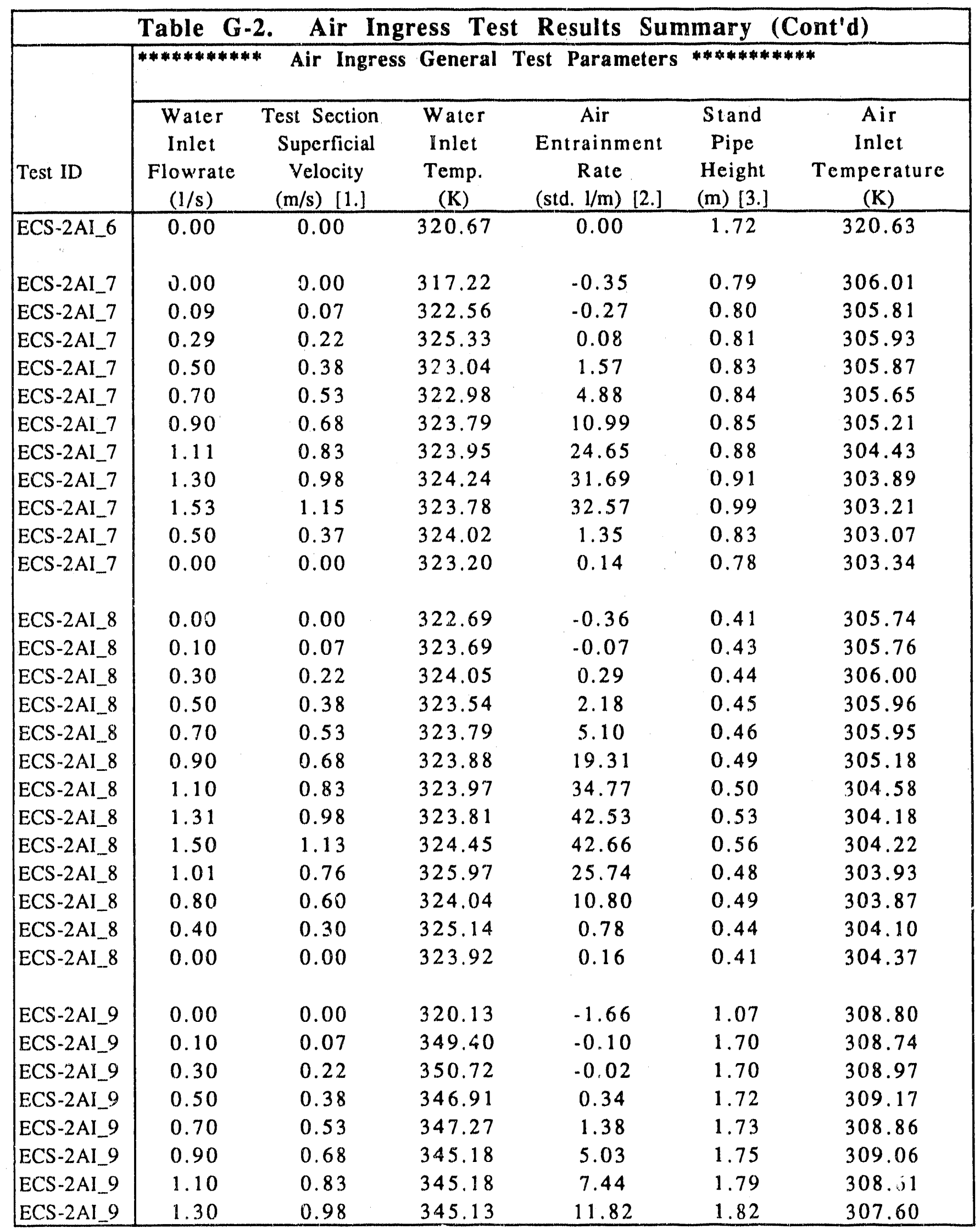




\begin{tabular}{|c|c|c|c|c|c|c|}
\hline \multirow[b]{3}{*}{ Test ID } & Table G-2. & \multicolumn{2}{|c|}{ Air Ingress Test } & \multicolumn{3}{|c|}{ Results Summary (Cont'd) } \\
\hline & \multicolumn{6}{|c|}{ *********** Air Ingress General Test Pararjeters *********** } \\
\hline & $\begin{array}{c}\text { Water } \\
\text { Inlet } \\
\text { Flowrate } \\
(1 / s) \\
\end{array}$ & $\begin{array}{c}\text { Test Section } \\
\text { Superficial } \\
\text { Velocity } \\
(\mathrm{m} / \mathrm{s})[1 .]\end{array}$ & $\begin{array}{l}\text { Water } \\
\text { Inlet } \\
\text { Temp. } \\
(\mathrm{K}) \\
\end{array}$ & $\begin{array}{c}\text { Air } \\
\text { Entrainment } \\
\text { Rate } \\
\text { (std. } 1 / \mathrm{m} \text { ) [2.] } \\
\end{array}$ & $\begin{array}{l}\text { Stand } \\
\text { Pipe } \\
\text { Height } \\
\text { (m) [3.] }\end{array}$ & $\begin{array}{c}\text { Air } \\
\text { Inlet } \\
\text { Temperature } \\
(\mathrm{K}) \\
\end{array}$ \\
\hline ECS-2AI_9 & 1.50 & 1.13 & 345.52 & 14.12 & 1.81 & 306.60 \\
\hline ECS-2AI_9 & 0.00 & 0.00 & 341.52 & 0.54 & 1.68 & 308.24 \\
\hline ECS-2AI_10 & 0.00 & 0.00 & 337.97 & -0.31 & 1.07 & 314.71 \\
\hline ECS-2AI_10 & 0.10 & 0.07 & 349.82 & -0.41 & 1.08 & 312.94 \\
\hline ECS-2AI_10 & 0.30 & 0.22 & 346.71 & -0.13 & 1.09 & 312.28 \\
\hline ECS-2AI_10 & 0.50 & 0.37 & 347.90 & -0.15 & 1.10 & 312.03 \\
\hline ECS-2AI_10 & 0.70 & 0.53 & 344.70 & 1.35 & 1.13 & 311.31 \\
\hline ECS-2AI_10 & 0.90 & 0.68 & 343.48 & 4.44 & 1.15 & 311.03 \\
\hline ECS-2AI_10 & 1.11 & 0.83 & 342.66 & 9.98 & 1.16 & 310.89 \\
\hline ECS-2AI_10 & 1.31 & 0.98 & 342.42 & 16.64 & 1.18 & 310.14 \\
\hline ECS-2AI_11 & 0.00 & 0.00 & 327.54 & -1.42 & 0.41 & 306.47 \\
\hline ECS-2AI_. 11 & 0.09 & 0.07 & 346.03 & -0.14 & 0.78 & 307.07 \\
\hline ECS-2AI_11 & 0.30 & 0.23 & 347.35 & 0.06 & 0.79 & 307.31 \\
\hline ECS-2AI_11 & 0.50 & 0.38 & 345.61 & 0.82 & 0.80 & 307.04 \\
\hline ECS-2AI_11 & 0.70 & 0.53 & 346.12 & 1.60 & 0.82 & 306.71 \\
\hline ECS-2AI_11 & 0.90 & 0.68 & 343.91 & 4.54 & 0.84 & 305.91 \\
\hline ECS-2AI_11 & 1.10 & 0.83 & 346.25 & 12.15 & 0.87 & 305.56 \\
\hline ECS-2AI_11 & 1.32 & 0.99 & 347.03 & 16.11 & 0.87 & 305.65 \\
\hline ECS-2AI_11 & 1.50 & 1.13 & 346.38 & 16.74 & 0.89 & 305.27 \\
\hline ECS-2AI_11 & 0.90 & 0.68 & 348.01 & 3.10 & 0.85 & 305.36 \\
\hline ECS-2AI_11 & 0.00 & 0.00 & 320.67 & 0.00 & 1.72 & 320.63 \\
\hline ECS-2AI_12 & 0.00 & 0.00 & 340.81 & -0.21 & 0.39 & 306.10 \\
\hline ECS-2AI_12 & 0.10 & 0.07 & 349.33 & -1.24 & 0.40 & 306.99 \\
\hline ECS-2AI_12 & 0.30 & 0.23 & 351.19 & -0.35 & 0.41 & 307.47 \\
\hline ECS-2AI_12 & 0.50 & 0.38 & 349.49 & 0.47 & 0.42 & 307.09 \\
\hline ECS-2AI_12 & 0.70 & 0.53 & 346.78 & 1.57 & 0.44 & 306.72 \\
\hline ECS-2AI_12 & 0.90 & 0.68 & 346.24 & 3.34 & 0.46 & 305.65 \\
\hline ECS-2AI_12 & 1.10 & 0.83 & 346.21 & 13.44 & 0.50 & 305.51 \\
\hline ECS-2AI_12 & 1.31 & 0.98 & 346.37 & 19.49 & 0.51 & 305.43 \\
\hline ECS-2AI__ 12 & 1.50 & 1.13 & 347.43 & 20.49 & 0.51 & 305.14 \\
\hline ECS-2AI_12 & 1.00 & 0.75 & 346.00 & 10.34 & 0.49 & 305.13 \\
\hline ECS-2AI_12 & 0.00 & 0.00 & 343.55 & 0.01 & 0.39 & 305.12 \\
\hline
\end{tabular}




\section{Table G-2. Air Ingress Test Results Summary (Cont'd)}

[1.] Superficial velocity based on test section flow area of $13.31 \mathrm{~m}^{\wedge} 2$.

[2.] Air ingress rate based on inlet air flow measurement (Q_A_IN).

[3.] Standpipe height referenced to bottom of the lower plenum.

\begin{tabular}{|lr|}
\hline Location & Elevation $(\mathrm{cm})$ \\
\hline Top of upper plenum & -182.2 \\
Bottom of upper plenum & -161.9 \\
Top of heated length & 0 \\
Bottom of heated length & 380.9 \\
Top of lower plenum & 410.2 \\
Bottom of lower plenum & 438.2 \\
\hline
\end{tabular}




\section{Appendix H}

Video System Used During the ECS-2 Thermal Excursion Tests 


\section{Appendix $H$}

\section{Video System Used During the ECS-2 Thermal Excursion Tests}

A video recording system was used on many of the thermal excursion experiments to record phenomena of interest. Figure $\mathrm{H}-1$ shows a schematic of the video equipment. Video system hardware and control software was supplied by Mark Heyer of Heyer Tech, Inc., Palo Alto, CA.

The video system consisted of three video cameras, three monitors, three video decks equipped with optical disc recorders (12" optical discs), and other associated hardware and software components. The entire system was synchronized to the data acquisition system for timing purposes. Control of the video system was accomplished using Hypercard software on a

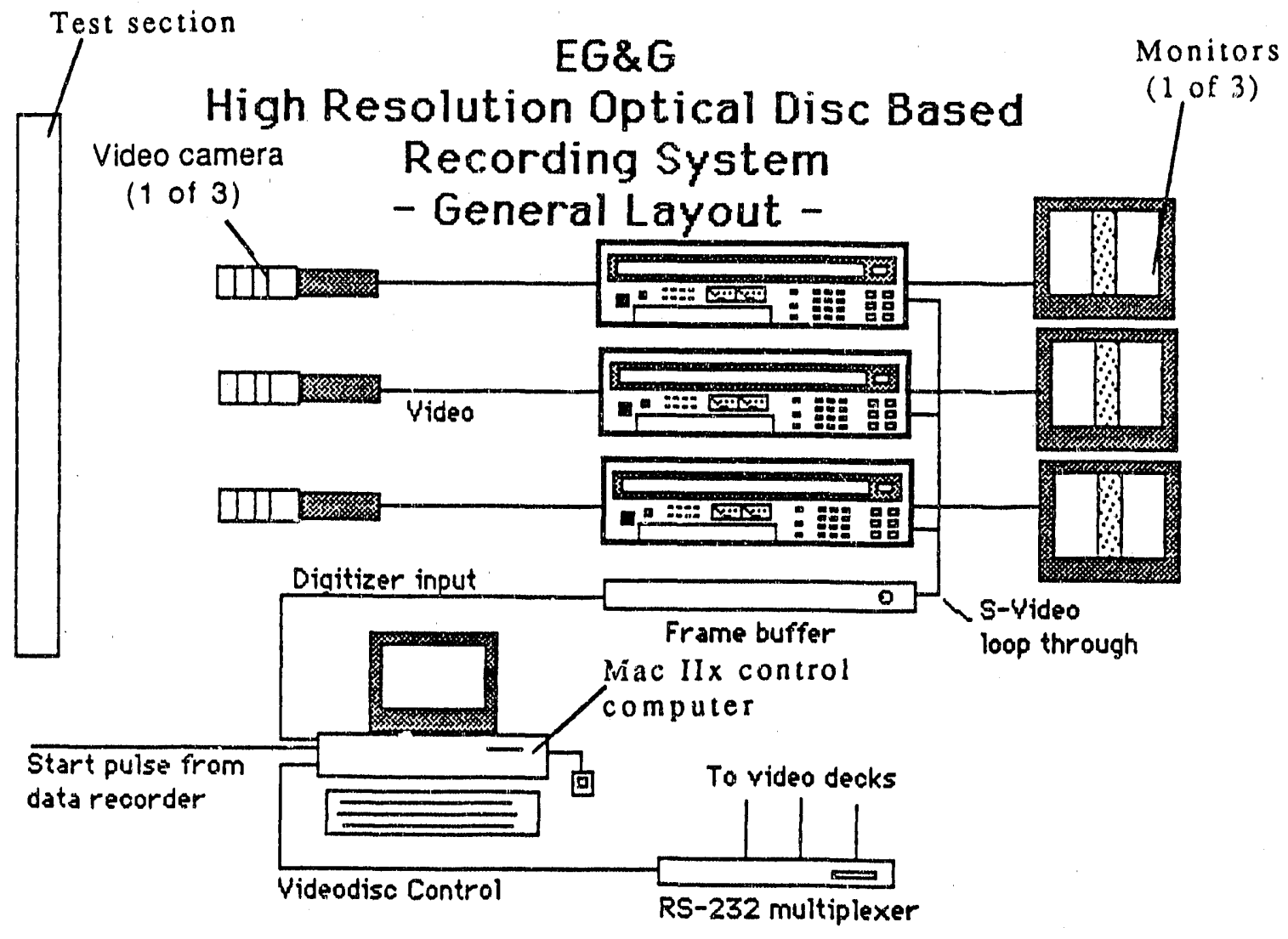

Figure H-1. Video system used on ECS-2 thermal excursion tests 
Macintosh IIx computer. Table H-1 lists the components in the video system.

The video system was capable of recording up to approximately 30 frames per second from each of the cameras. The signal was displayed on the monitors and/or written to optical disc for archival. Information regarding the archived recordings is stored in a Hypercard stack for post-test retrieval/display and analysis. At the highest recording rate, each video disc could hold approximately 30 minutes of video data.

For the ECS-2 and WSR tests, the top and middle camera were generally trained on the test section high power zone (between $200-$ and $302 \mathrm{~cm}$ ) and the bottom camera was trained on the outlet plenum. Cameras were set up to provide a $20-40 \mathrm{~cm}$ field of view. The system was used to monitor the test section on nearly all of the experiments although, due to the large volume of data generated by video, video data was noi archived for all tests nor was data archived for the whole duration of any single test.

Analysis and review of the video data is a time consuming operation. Useful and informative insights can be obtained from analysis of the video data. However, due to time constraints, video results are not presented here. 
Table H-1. Video recording system components

Compenent Manufacturer Model Number

Hardware

Camera (3)

$\mathrm{COD}$

TK -66

Monitor (3)

Sony

PVM - 122

Optical Disc Recorder (3)

Panasonic

TQ-3031F

Optical Disc

Panasonic

TQ-FH331/TQ-FH332 ${ }^{1}$

Video Distribution Amp.

Sigma Electronics

Data Broadcast Unit

Black Box

Digital Time Base Corrector FOR-A

VDA-100A

DB $8 / 25$

FA 300

Hardware/software contiol

Computer

Controller

$\mathrm{I} / \mathrm{O}$

Image capture
Apple

IoTech

National Inst.

SCION
Mac IIx

$\mathrm{Mac} /$ IEEE48 8

NB-D 10-24

Image Capture 2

1. Single-sided and double-sided discs respectively. 
Appendix I

Questionable or Failed Measurements for the ECS-2 and ECS-2c Thermal Excursion Experiments 


\section{Appendix I}

\section{Questionable or Failed Measurements for the ECS-2 and ECS-2c Thermal Excursion Experiments}

During the INEL thermal excursion experiment program, a detailed written log was maintained to document various aspects of the experiment including instrumencation/measurement problems. After review of quick look plots (data comparisons compiled immediately after the conduct of an experiment) and more thorough analyses of the experimental data, additional measurements known or suspected of being bad have been identified.

For historical documentation, the measurements known to be questionable for each thermal excursion experiment are listed in Table I-1. The table lists the experiment name, the date the experiment was conducted, and the measurements identified by "DAS Tag ID" (see Appendix B for a description of the measurement) deemed or known to be questionable. An entry of a particular measurement on a given test does not necessarily imply that the measurement was unusable for the whole experiment and does not imply that the measurement was unusable for experiments conducted chronologicaliy after that point in time. Generally, measurements problems were electrical or electronic in nature (bad connectors, problems with analog-to-digital conversion cards, broken wires, reference oven problems, etc.) and were readily corrected once identified.

The information in Table I-1 provides a quick indication of measurements that obviously experienced some problem during the excursion tests and does not constitute an extensive data quality review. Furthermore, the fact that an instrument is not listed in the table does not guarantee that the measurement performed flawlessly during the experiments. 


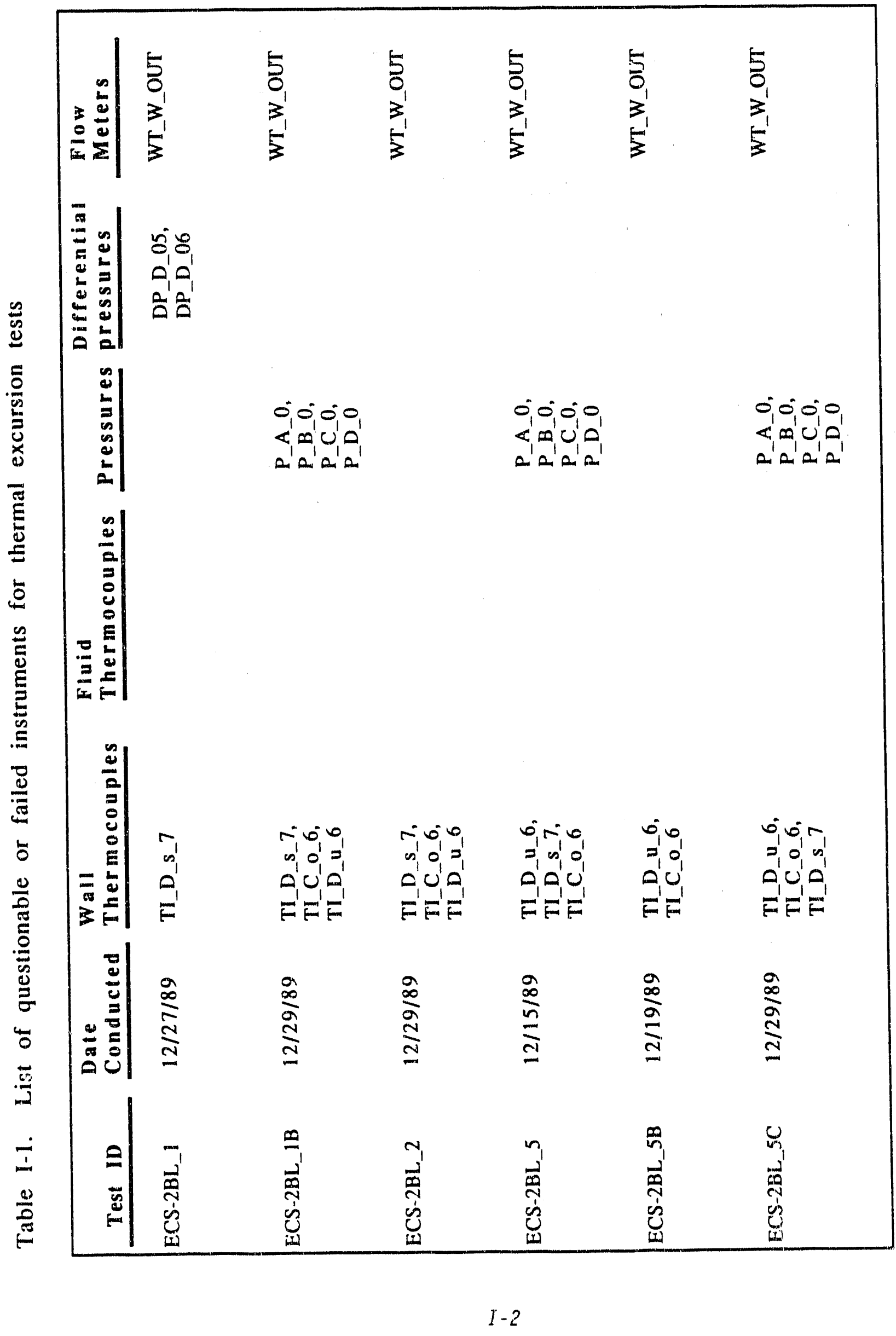




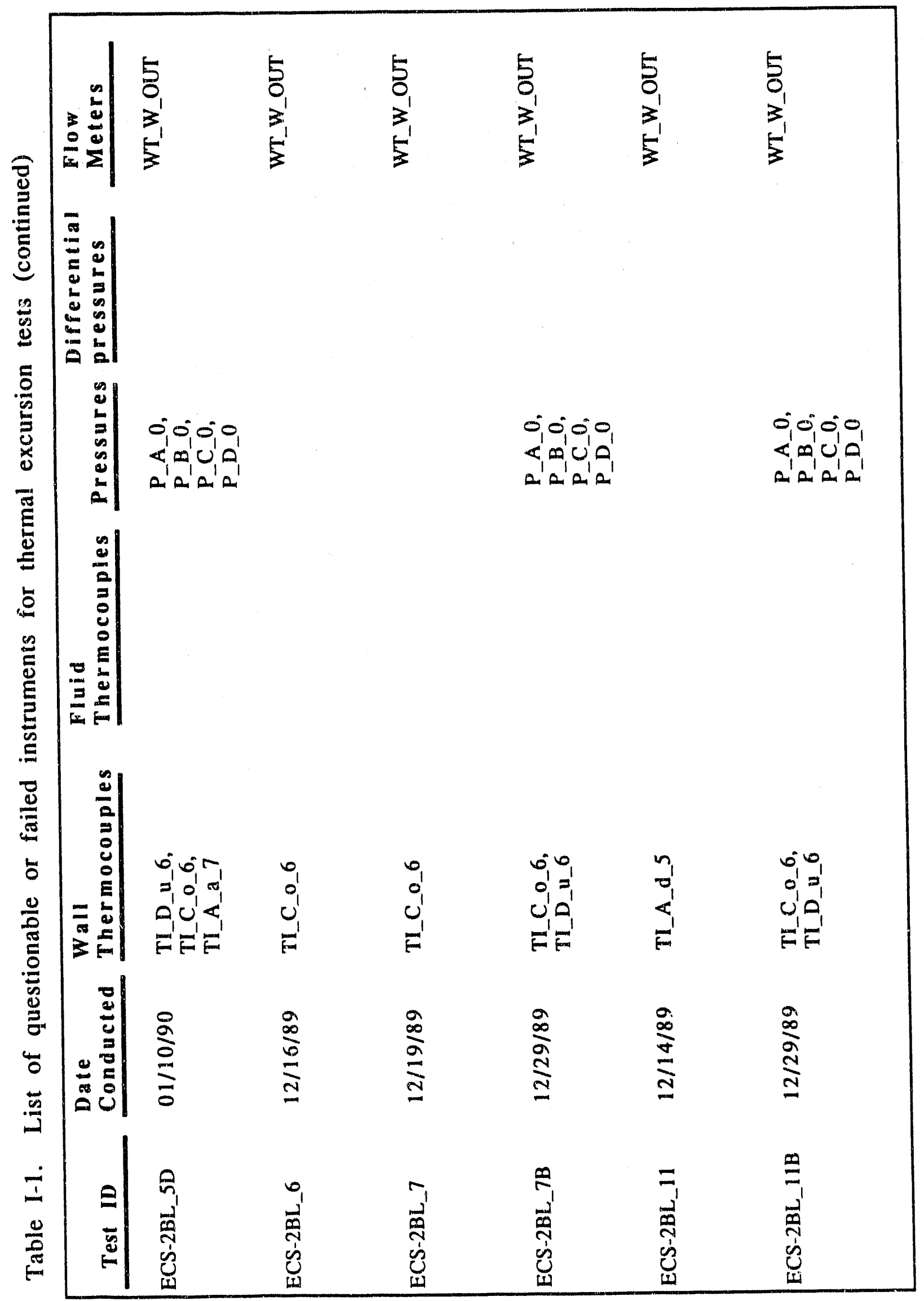




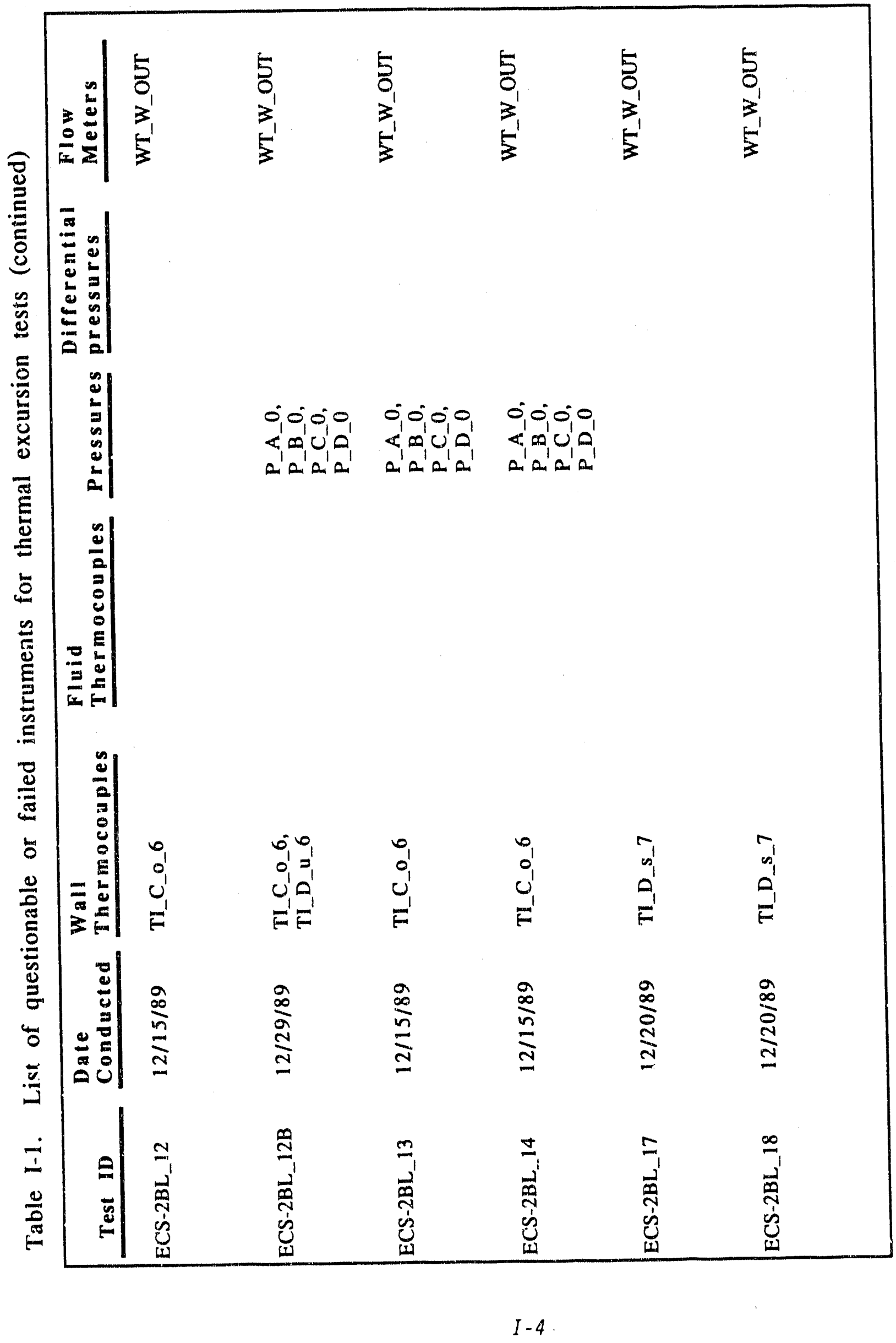




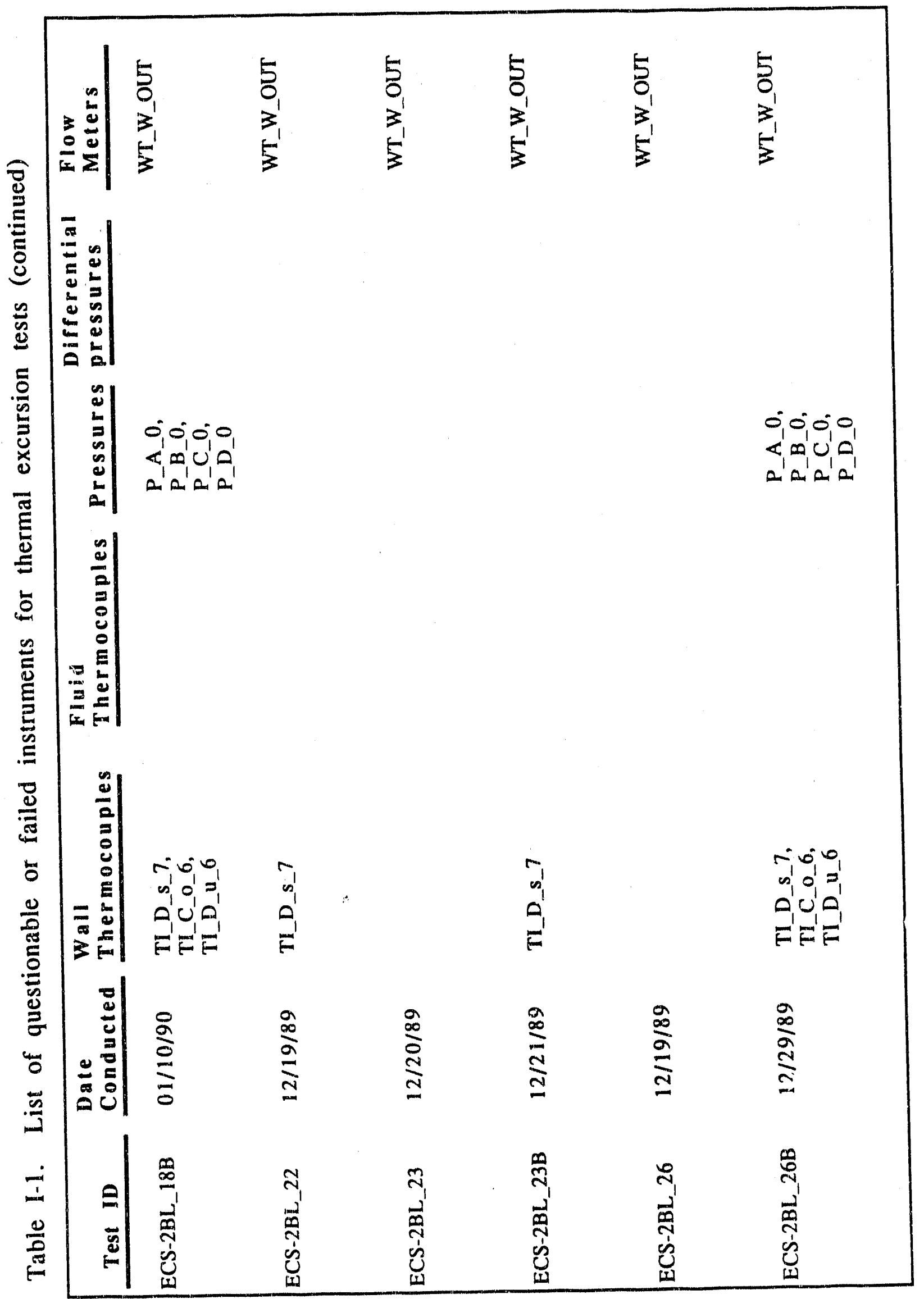




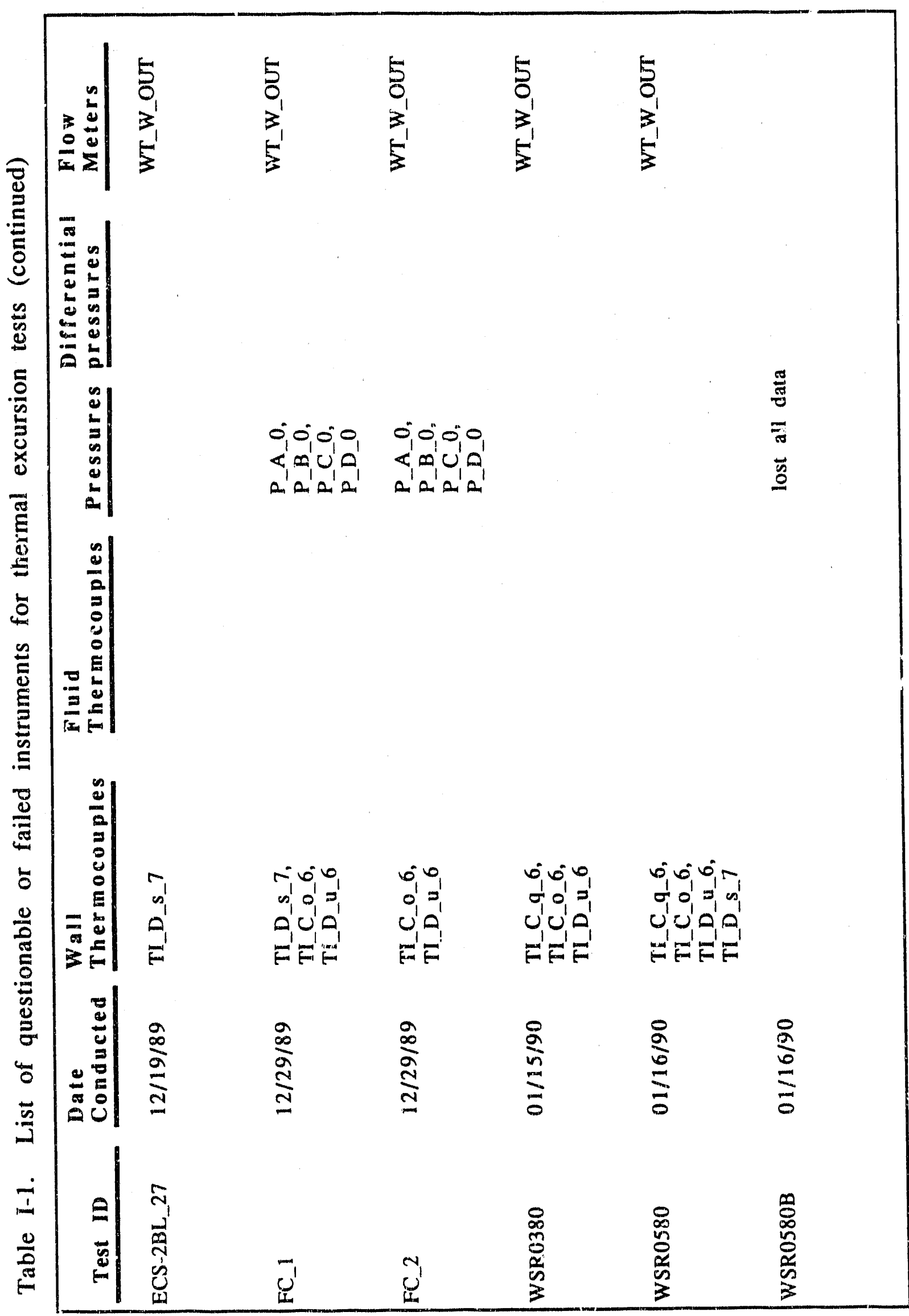




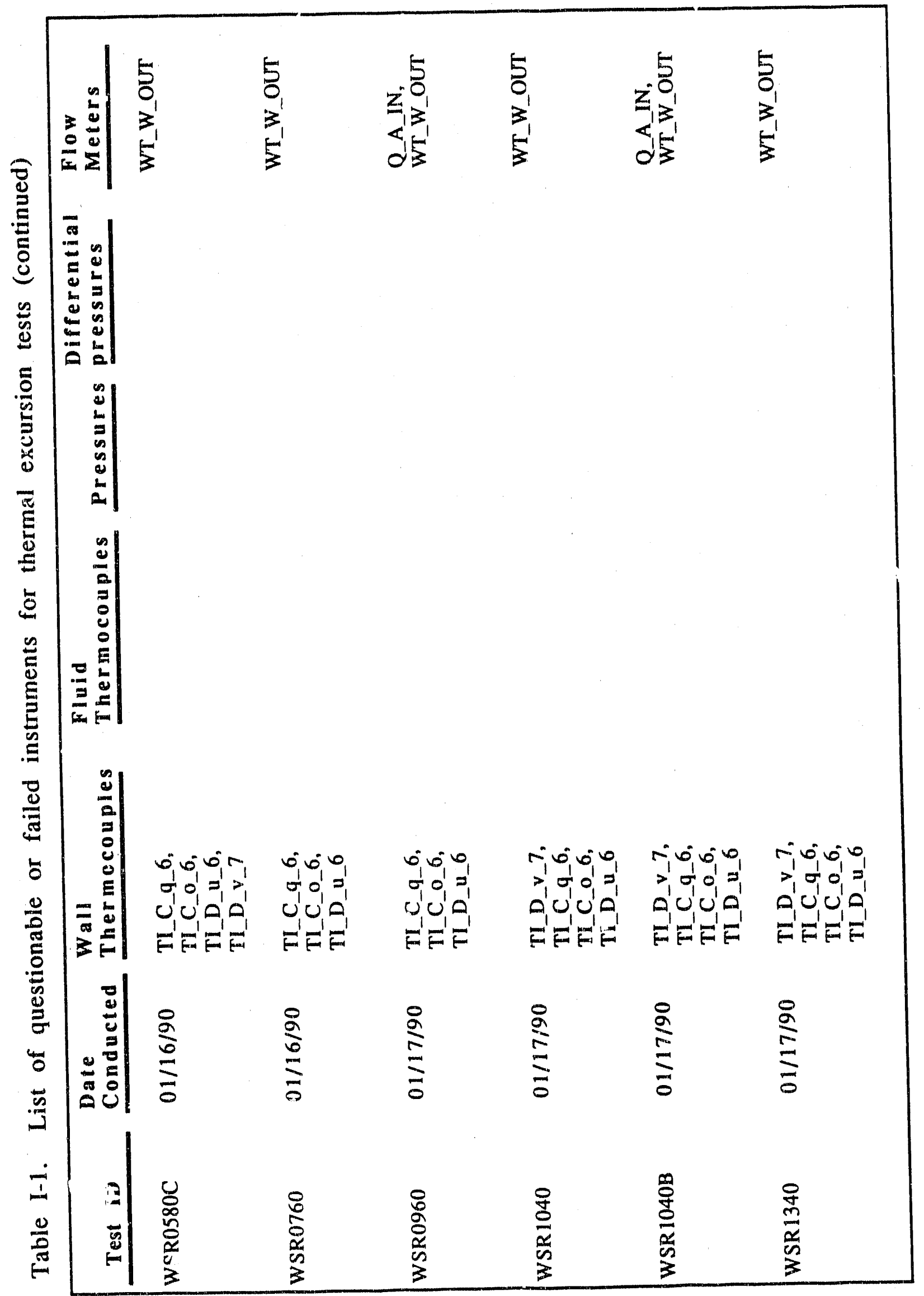




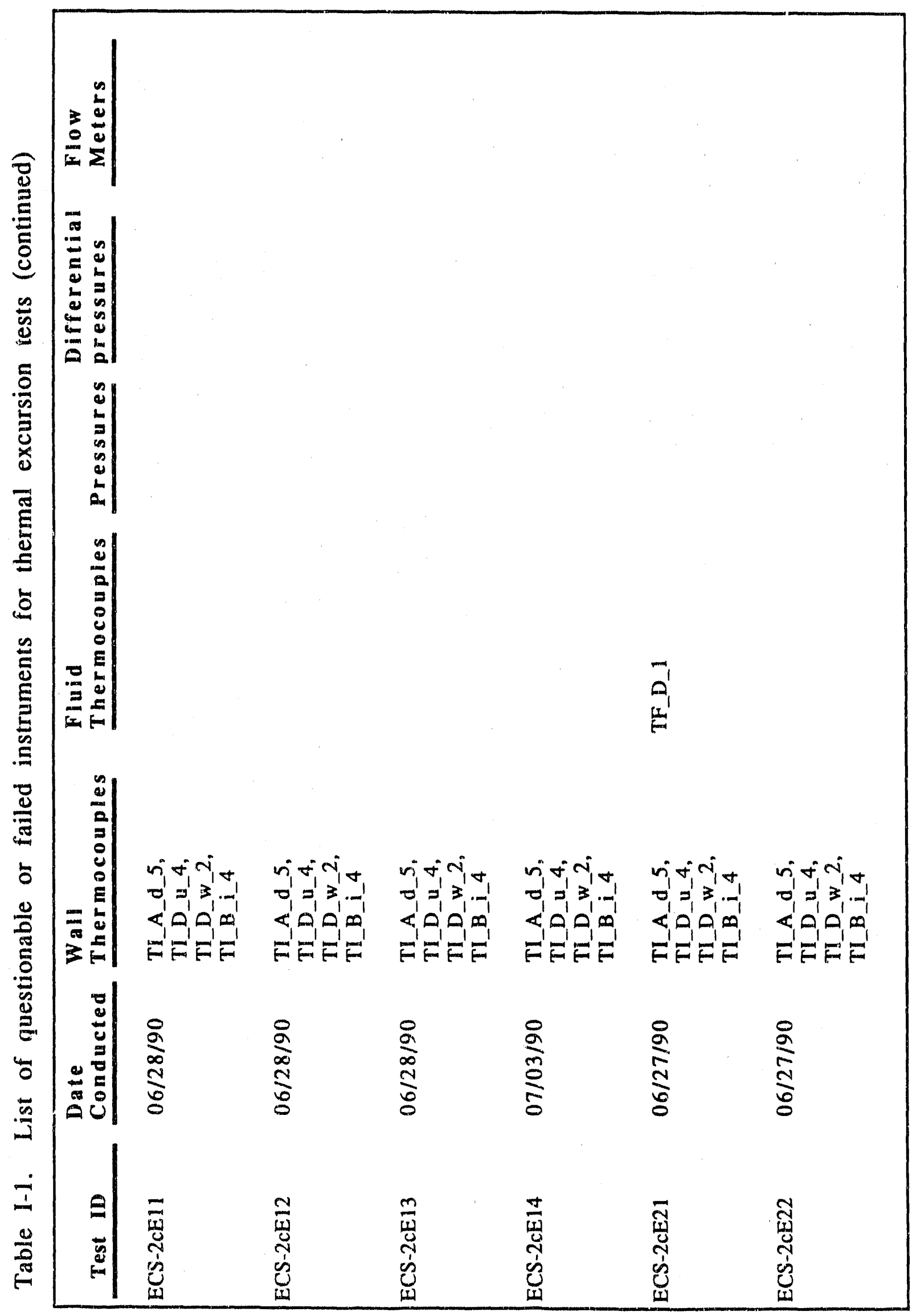




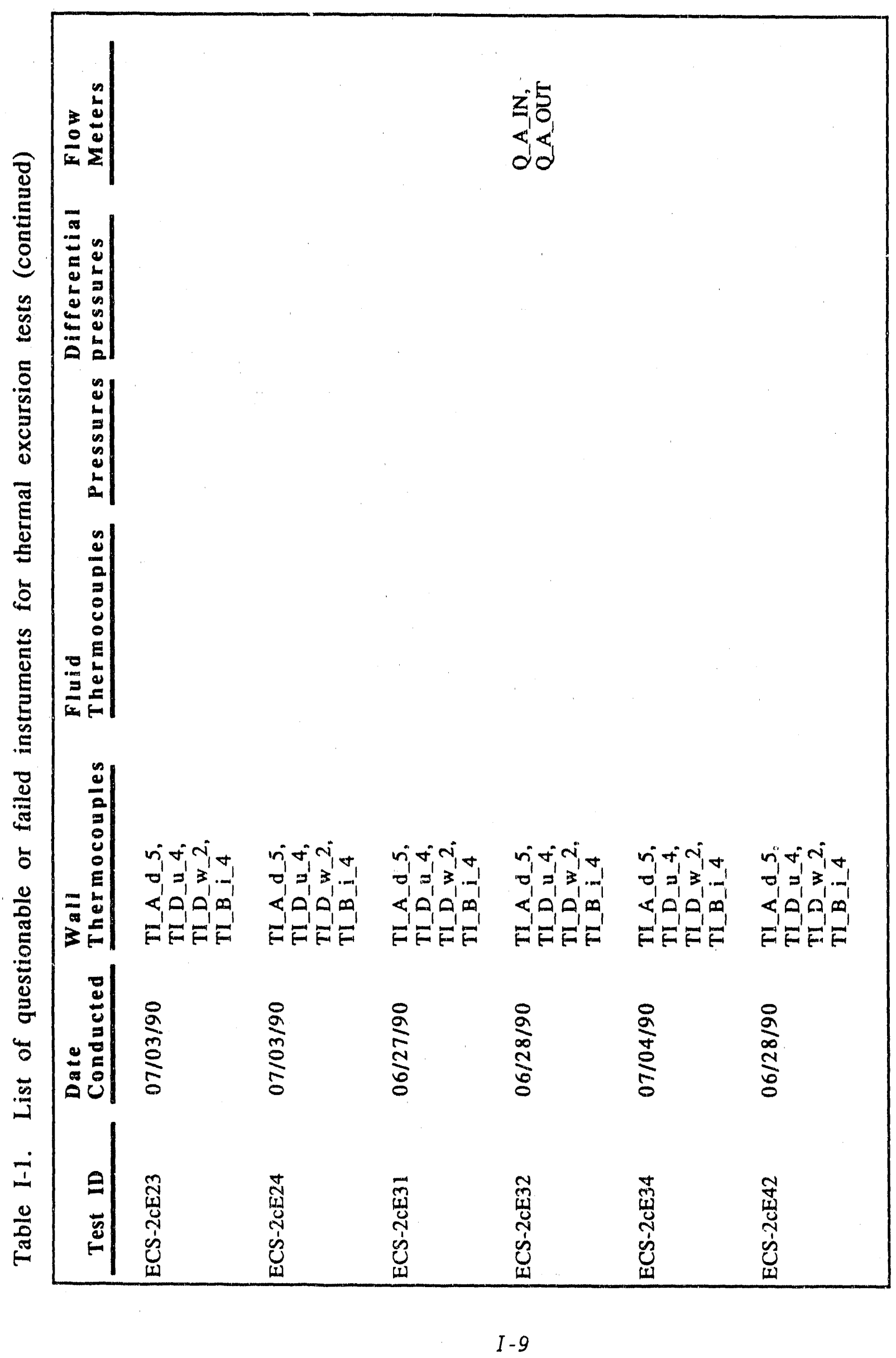




\section{Appendix $\mathbf{J}$}

Experimental Data Summary for INEL Thermal Excursion Tests (ECS-2, WSR, and ECS-2cE tests) 


\section{Appendix $\mathbf{J}$}

\section{Experimental Data Summary for INEL Thermal Excursion Tests (ECS-2, WSR, and ECS-2cE tests)}

The manner in which the INEL thermal excursion tests were conducted constituted a series of steady-state steps during which the power and flowrate were constant. Data averages during these constant power steps were calculated in order to facilitate data interpretation. Averages were necessary due to fluctuations in the data - especially as suturation conditions were achieved in the test section and/or the dryout point was approached. This appendix presents data averages calculated for each parameter recorded on the DAS for each of the thermal excursion experiments conducted. Averages computed for the power step immediately preceding the power step on which excursion occurred and for the power step on which excursion occurred are presented on the following tables. Since the time frame for averaging on each experiment was different, the starting and ending time for the computation of the averages is given in the tables. Every effort was made to ensure that averages were computed during time frames when all wall thermocouples were in a wetted state, although this was not always possible.

Note that in the attached data tables, questionable or failed measurement values are highlighted. Note also that due to the chaotic flooding processes occuring during the excursion power step, the air flow measurements may not be valid.

Attached tables contain the following information:

Table J-1 General test parameters for the ECS-2BL experiments

Table J-2 ECS-2BL test pre-excursion and excursion power step data averages

Table J-3 General test parameters for the WSR experiments

Table J-4 WSR test pre-excursion and excursion power step data averages 
Table J-5 General test parameters for the ECS-2cE experiments

Table J-6 ECS-2cE tests pre-excursion and excursion power step data averages. 


\begin{tabular}{|c|c|c|c|c|c|}
\hline \multirow[t]{2}{*}{ 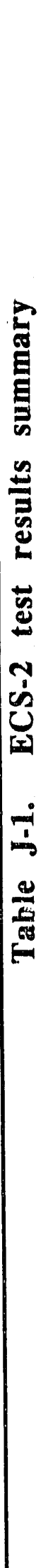 } & 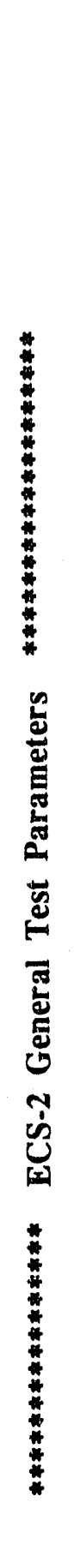 & 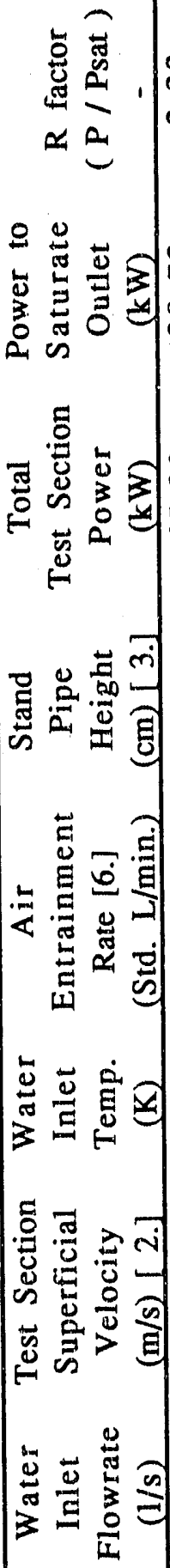 & 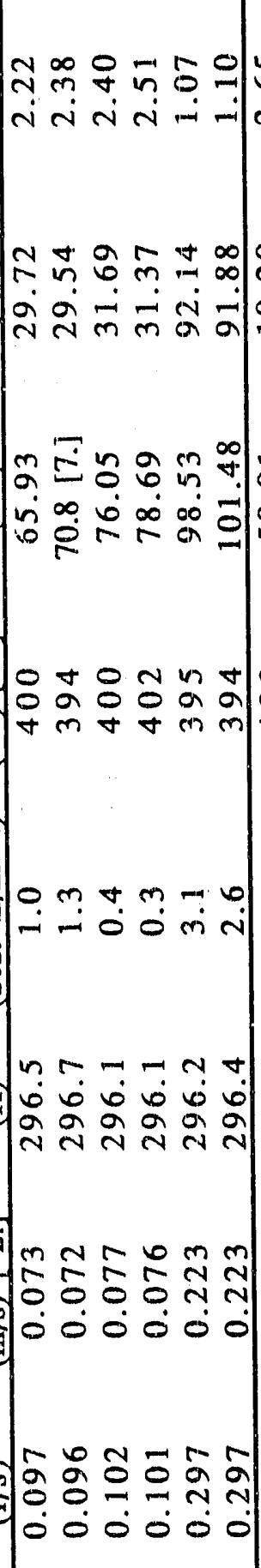 & 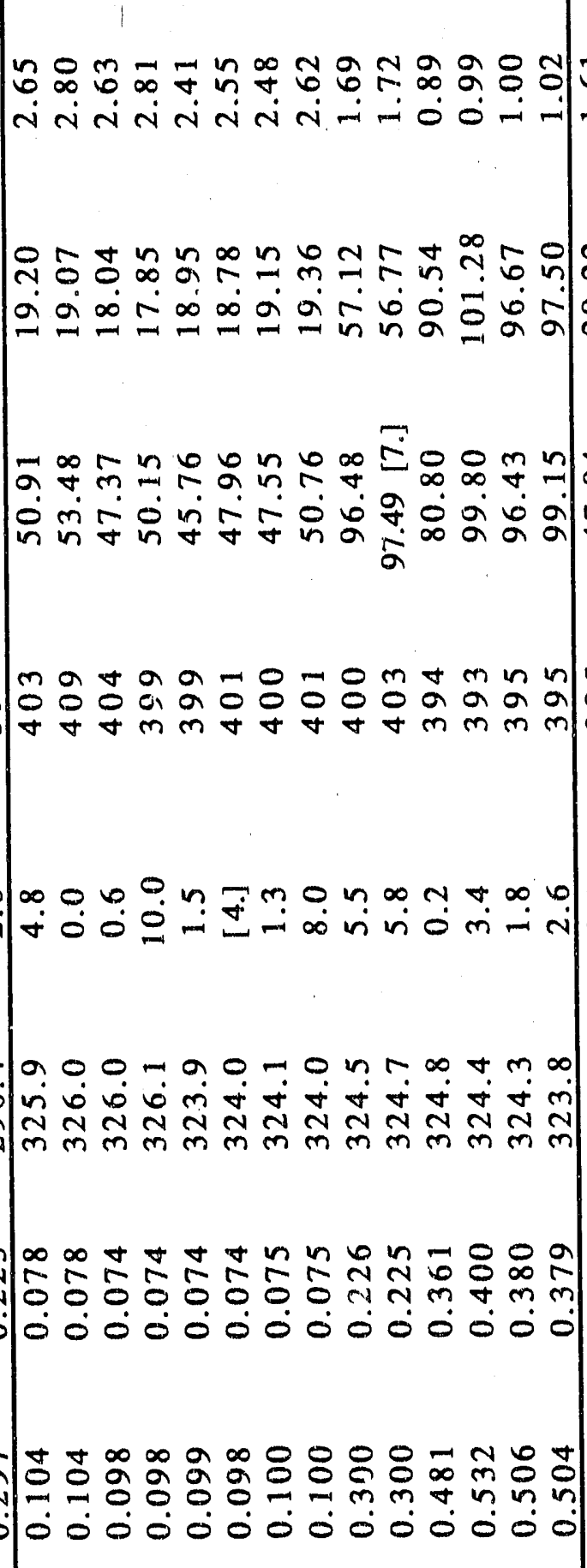 & 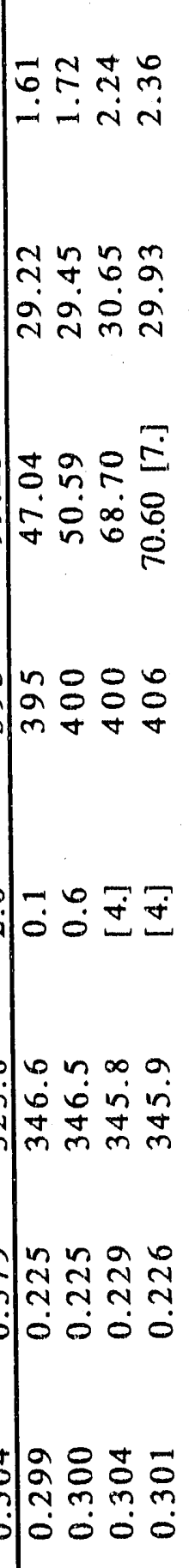 \\
\hline & & 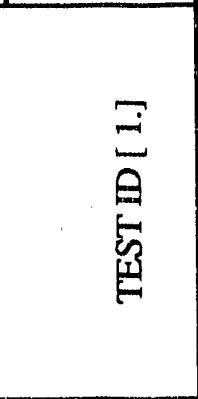 & 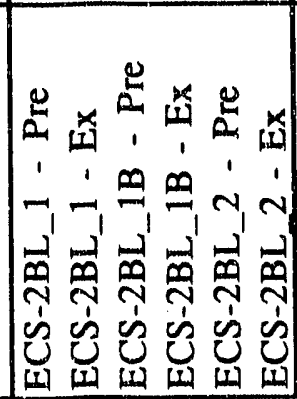 & 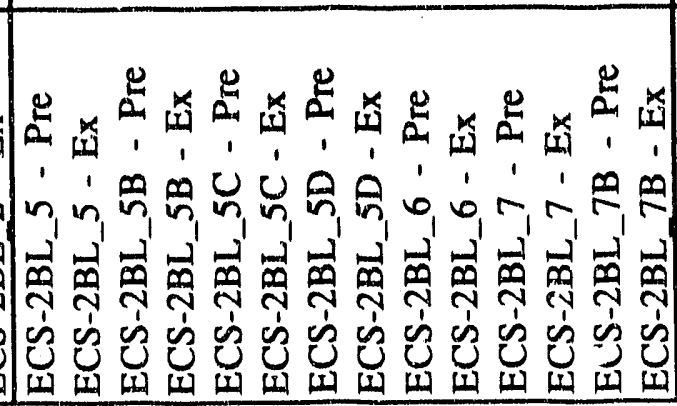 & 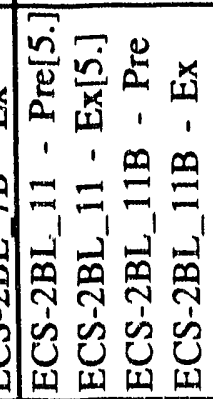 \\
\hline
\end{tabular}




\begin{tabular}{|c|c|c|c|c|c|c|}
\hline 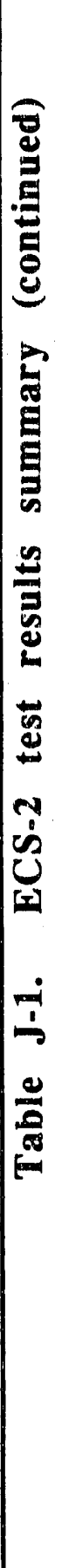 & 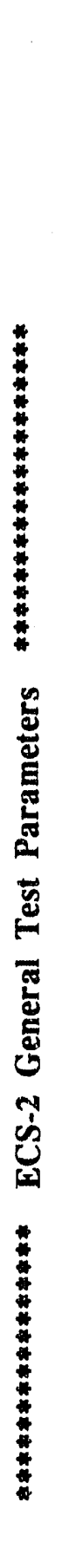 & 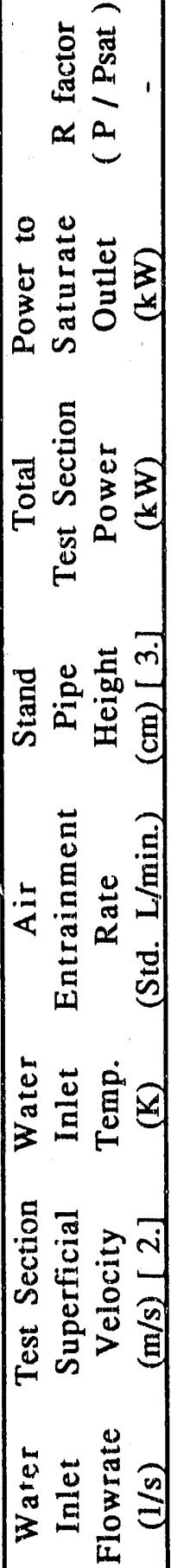 & 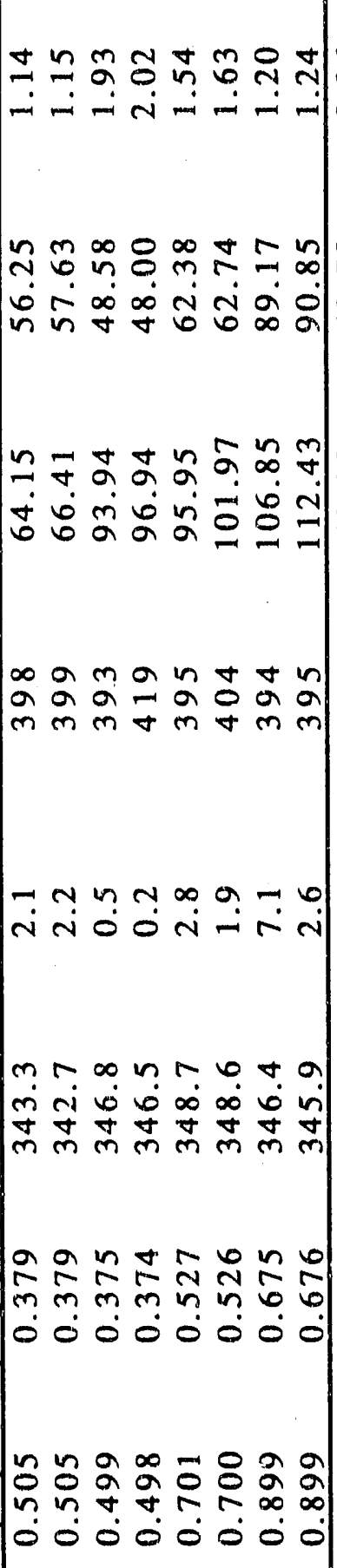 & 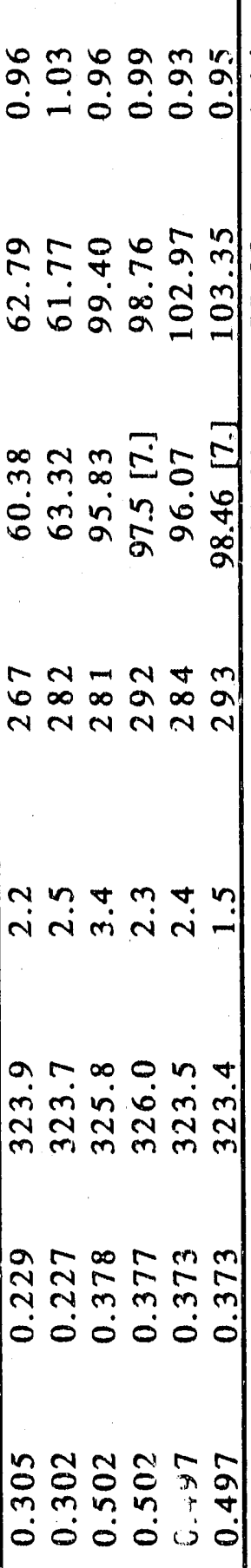 & 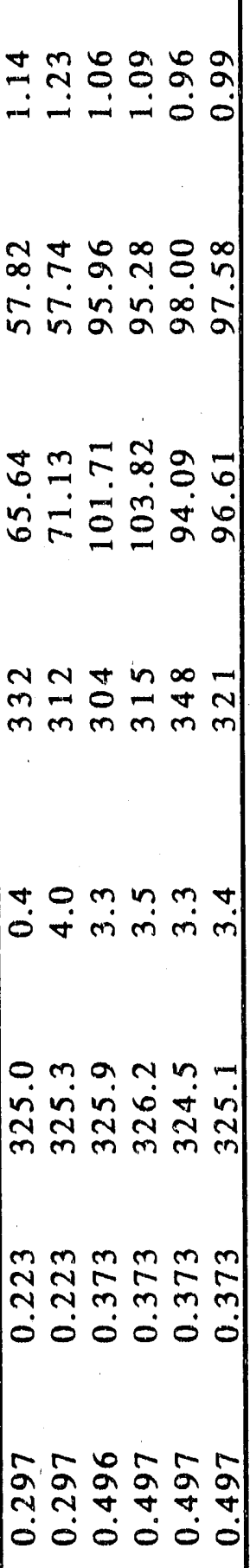 & 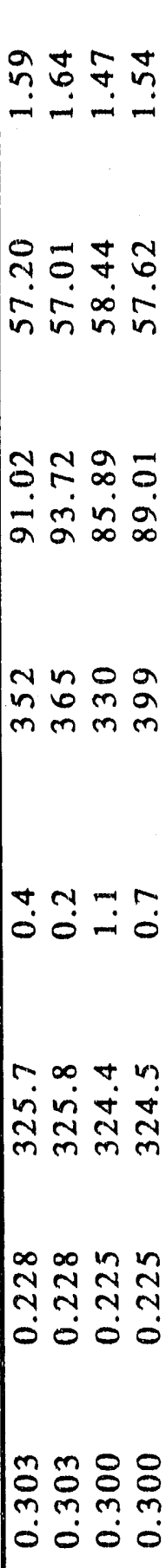 \\
\hline & & 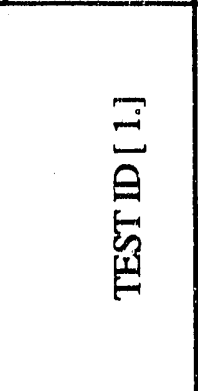 & 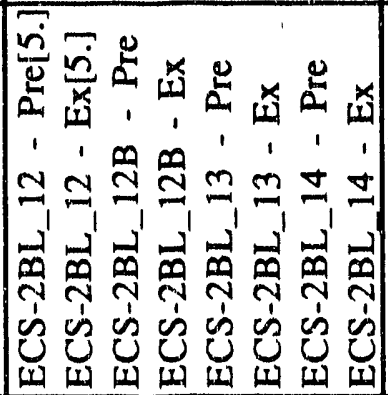 & 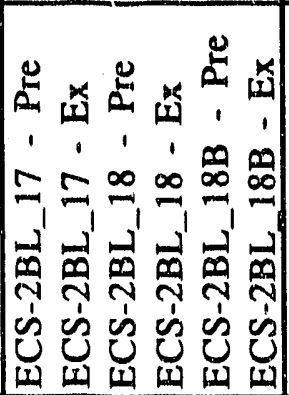 & 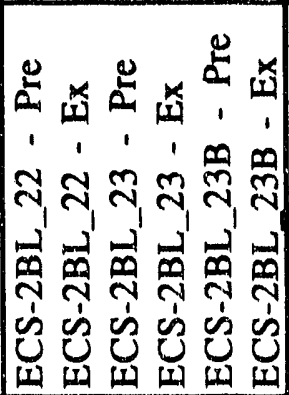 & 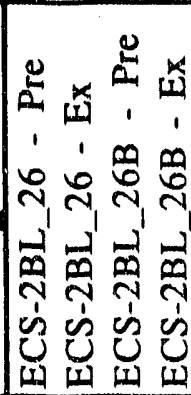 \\
\hline
\end{tabular}




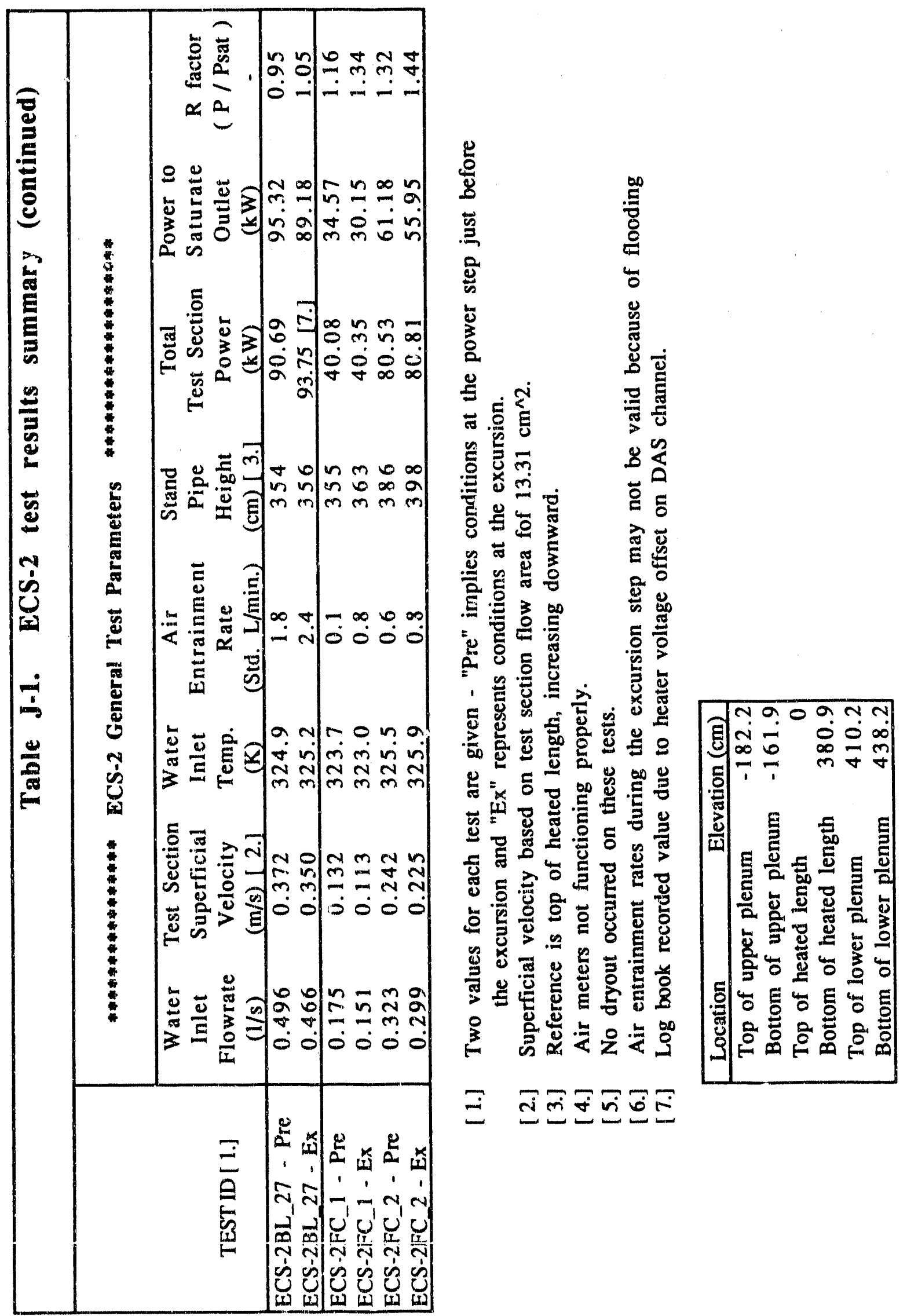




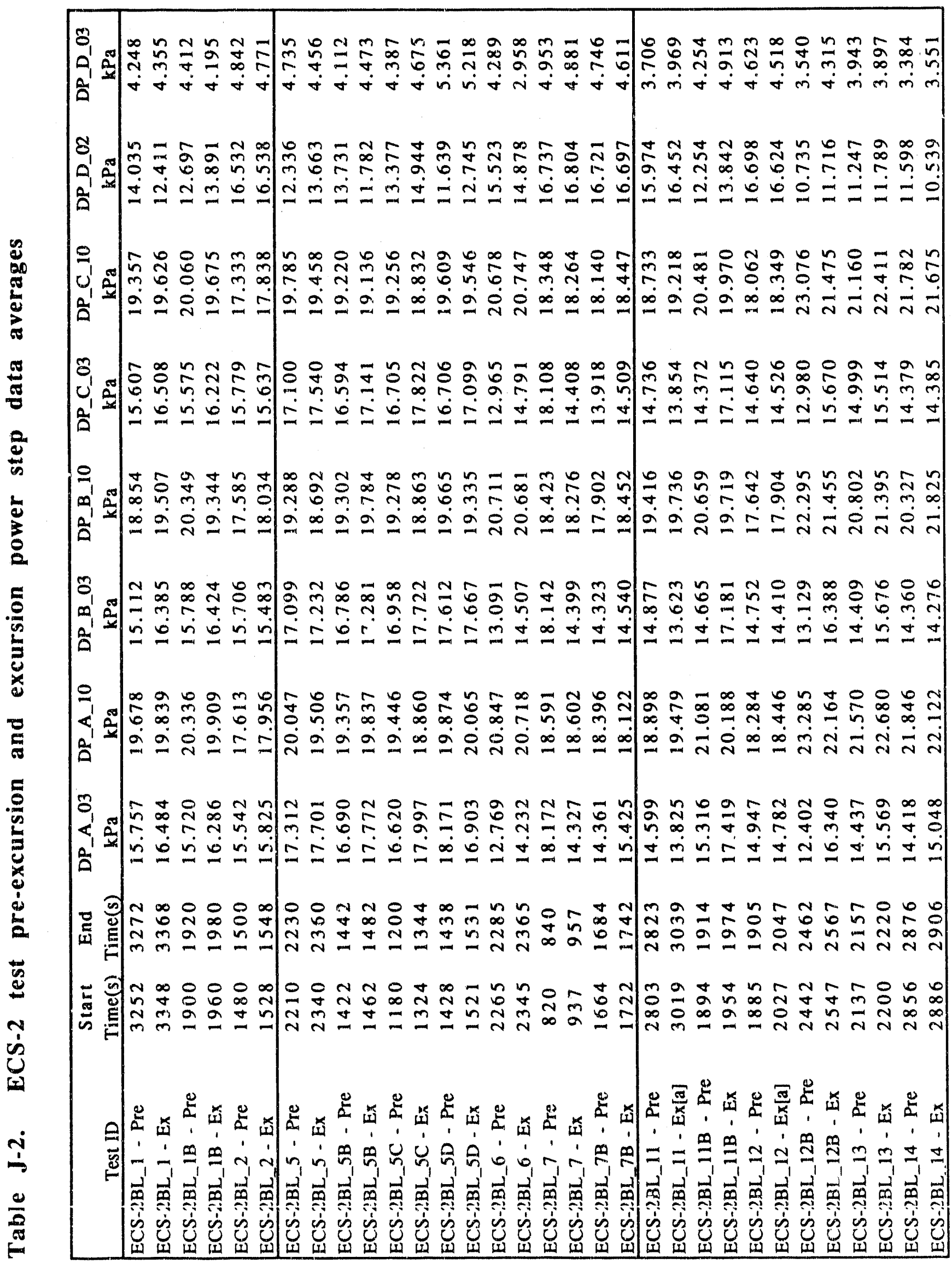




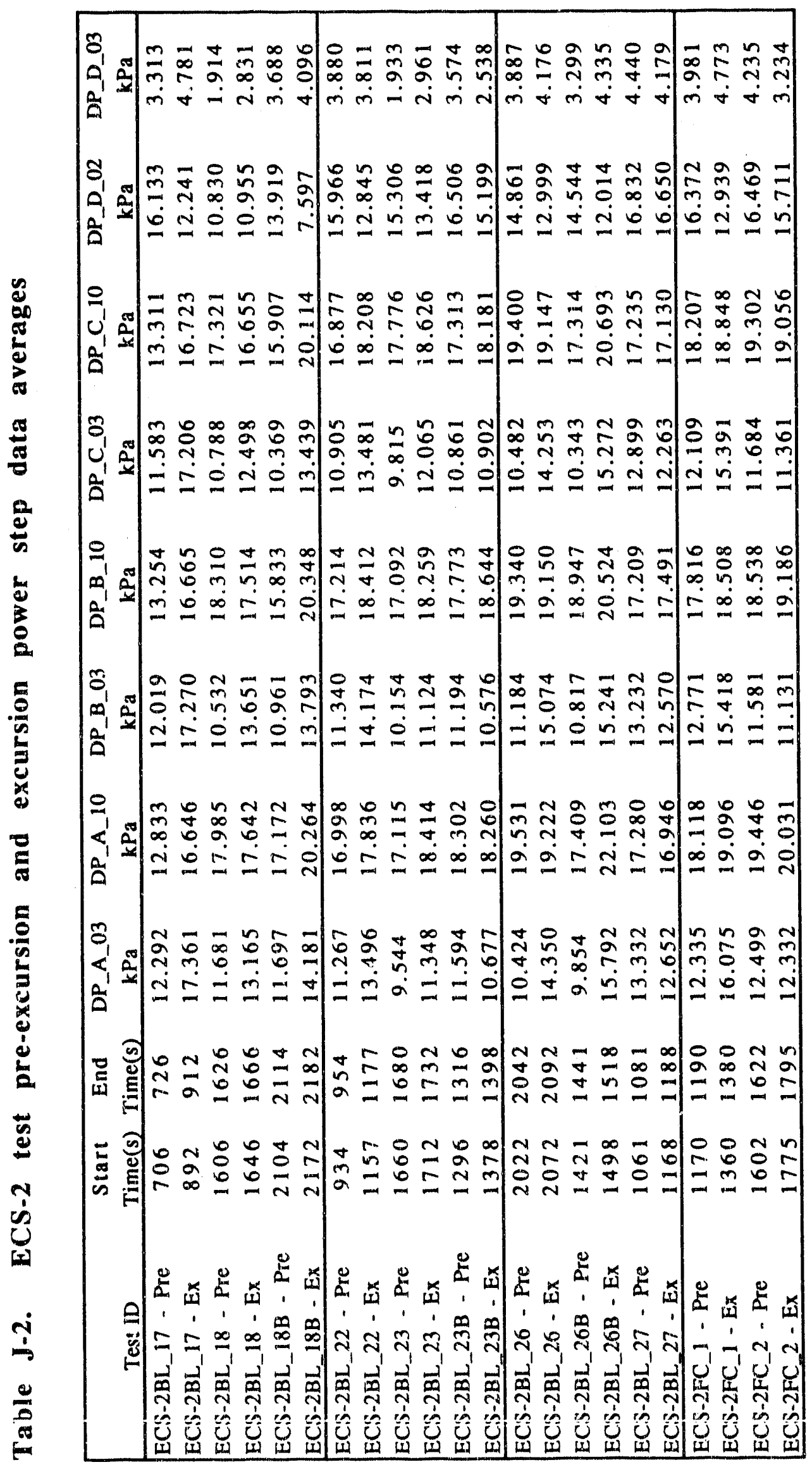




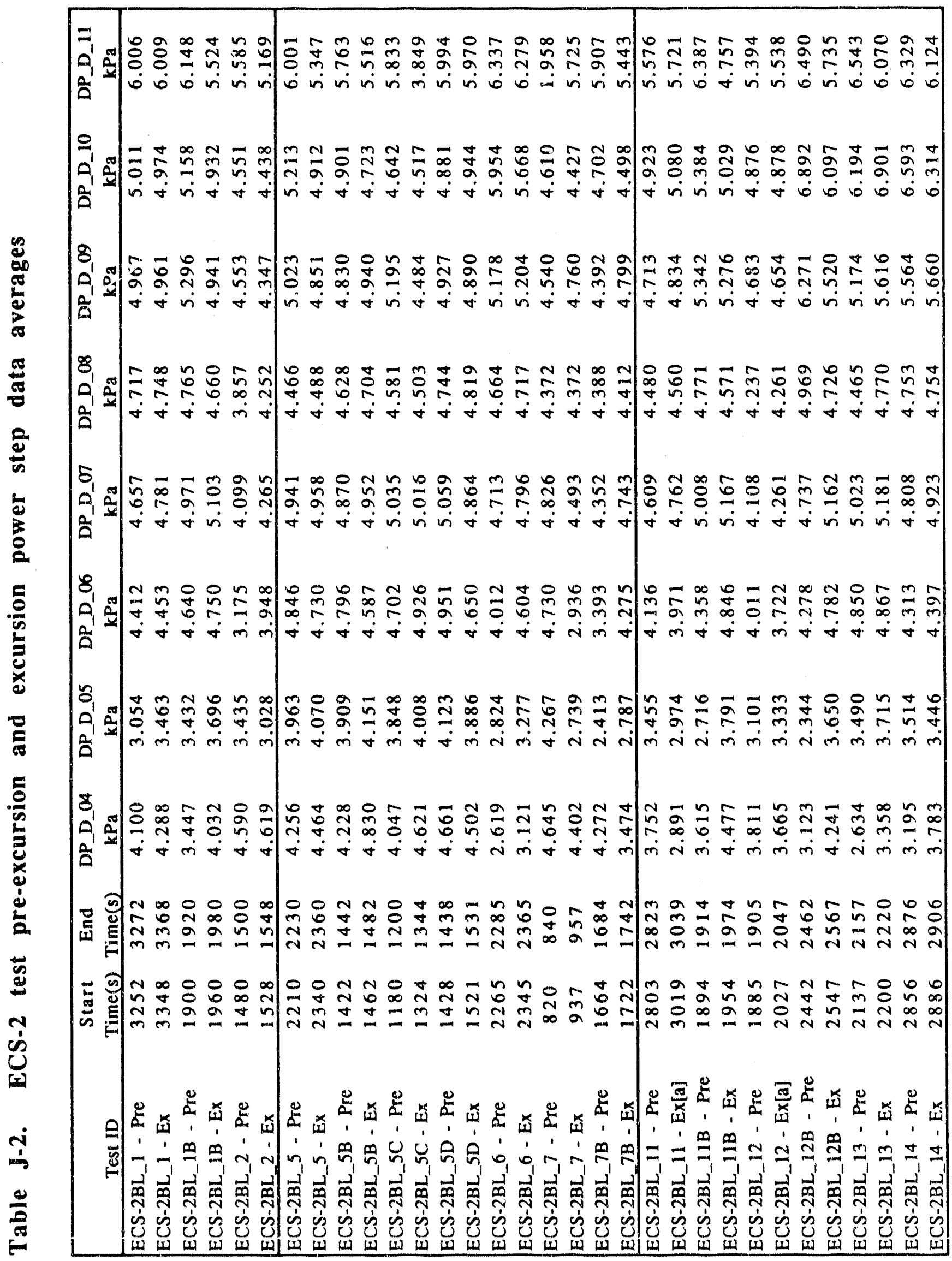




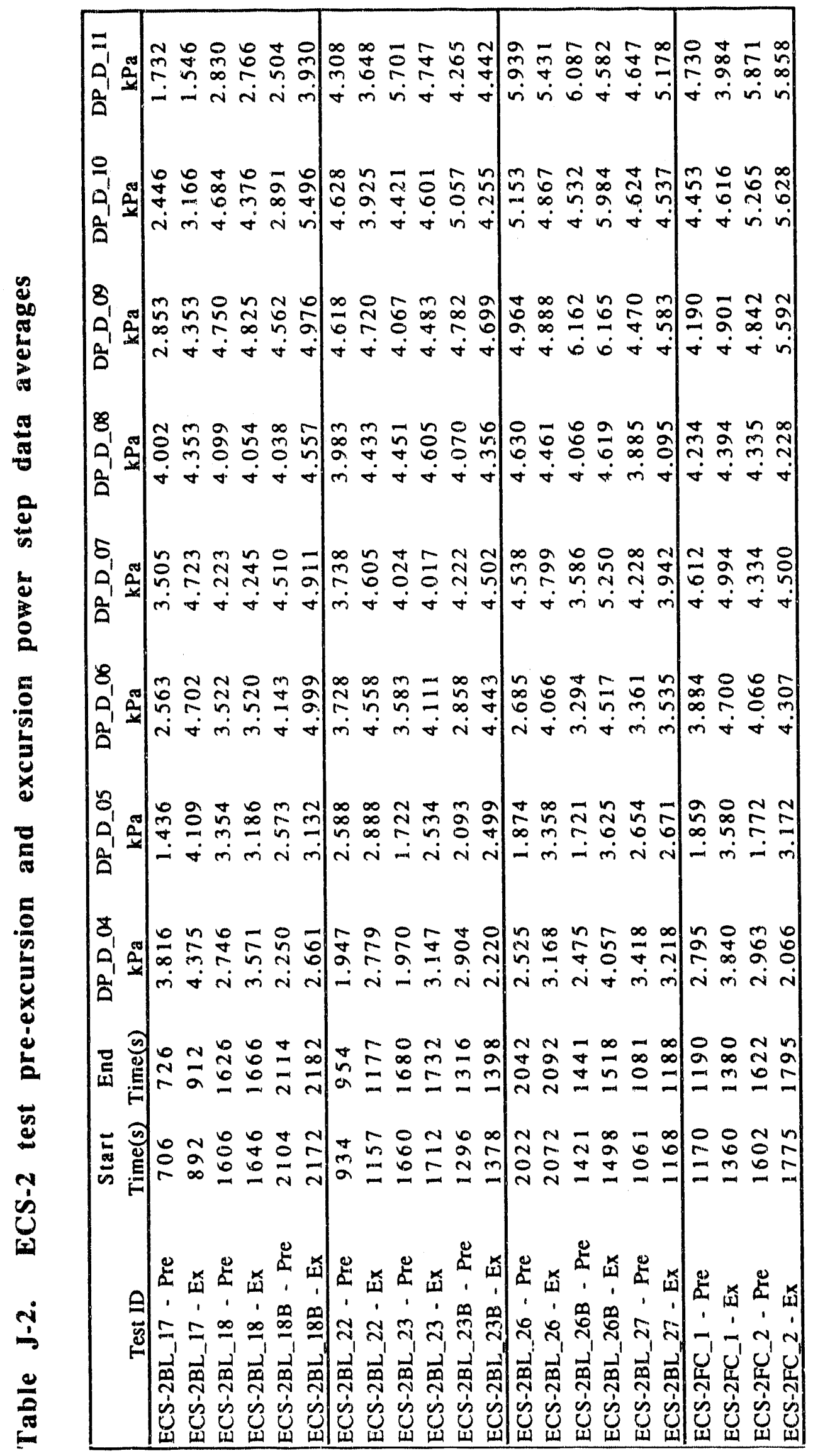




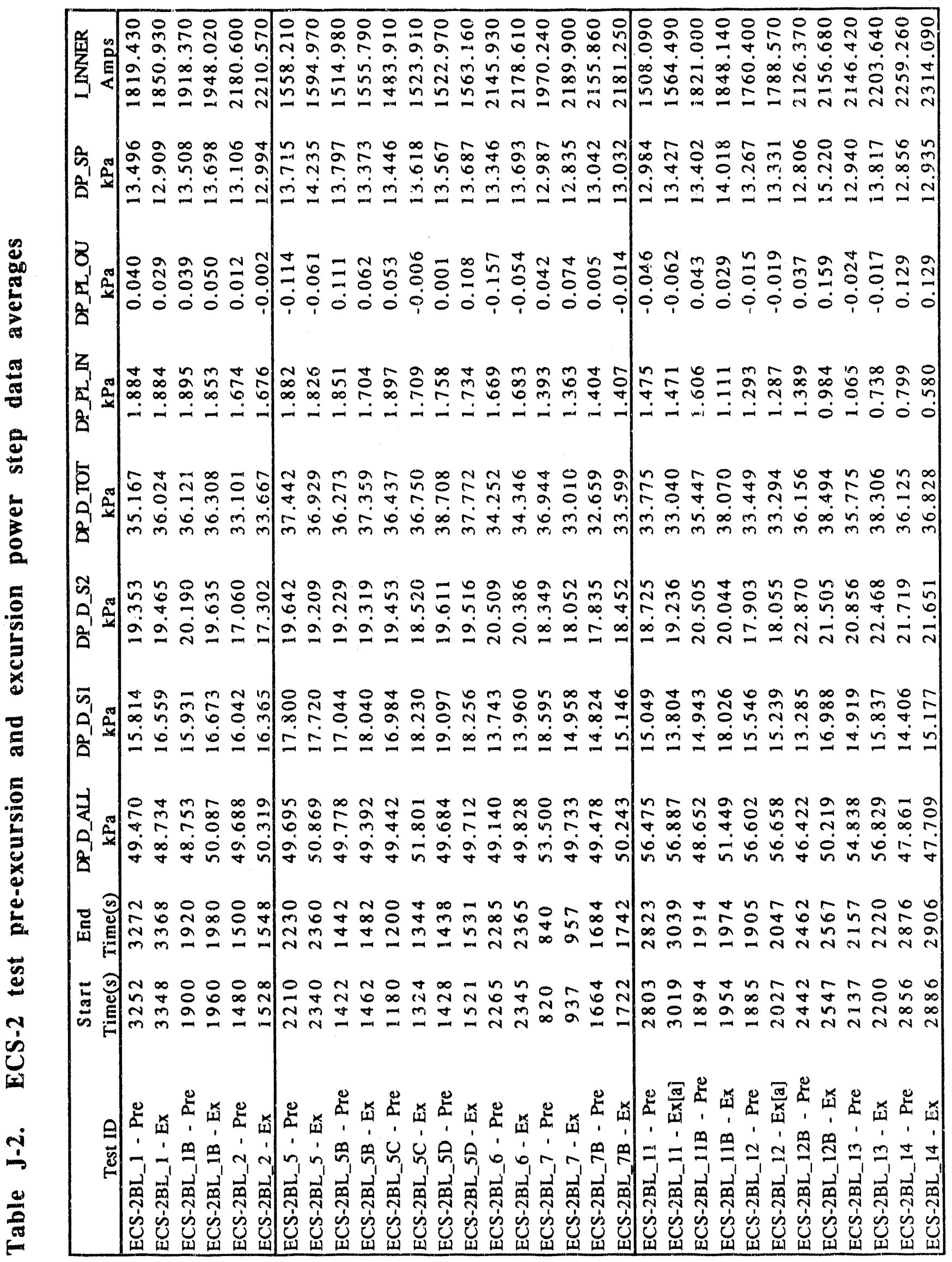




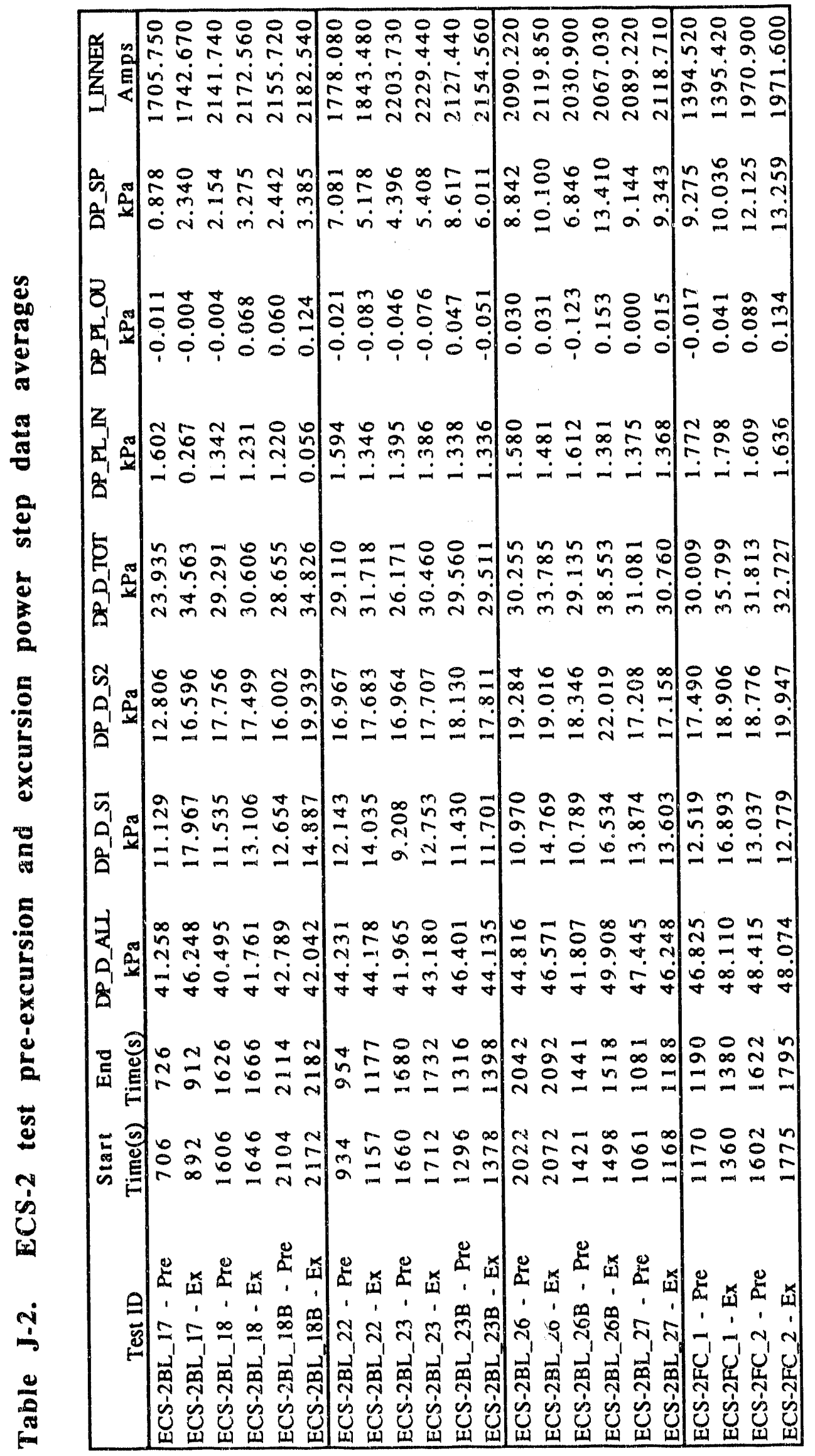




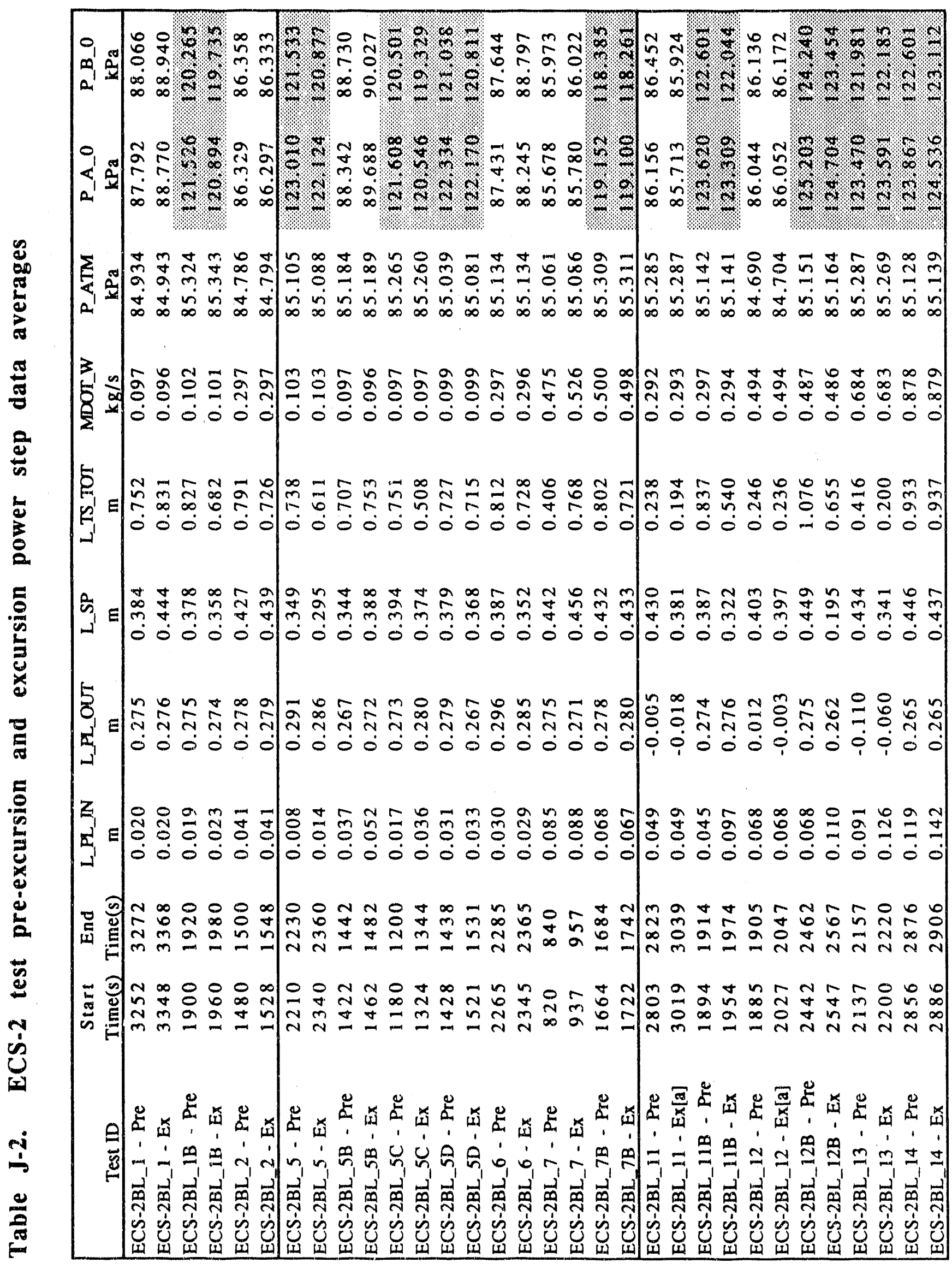




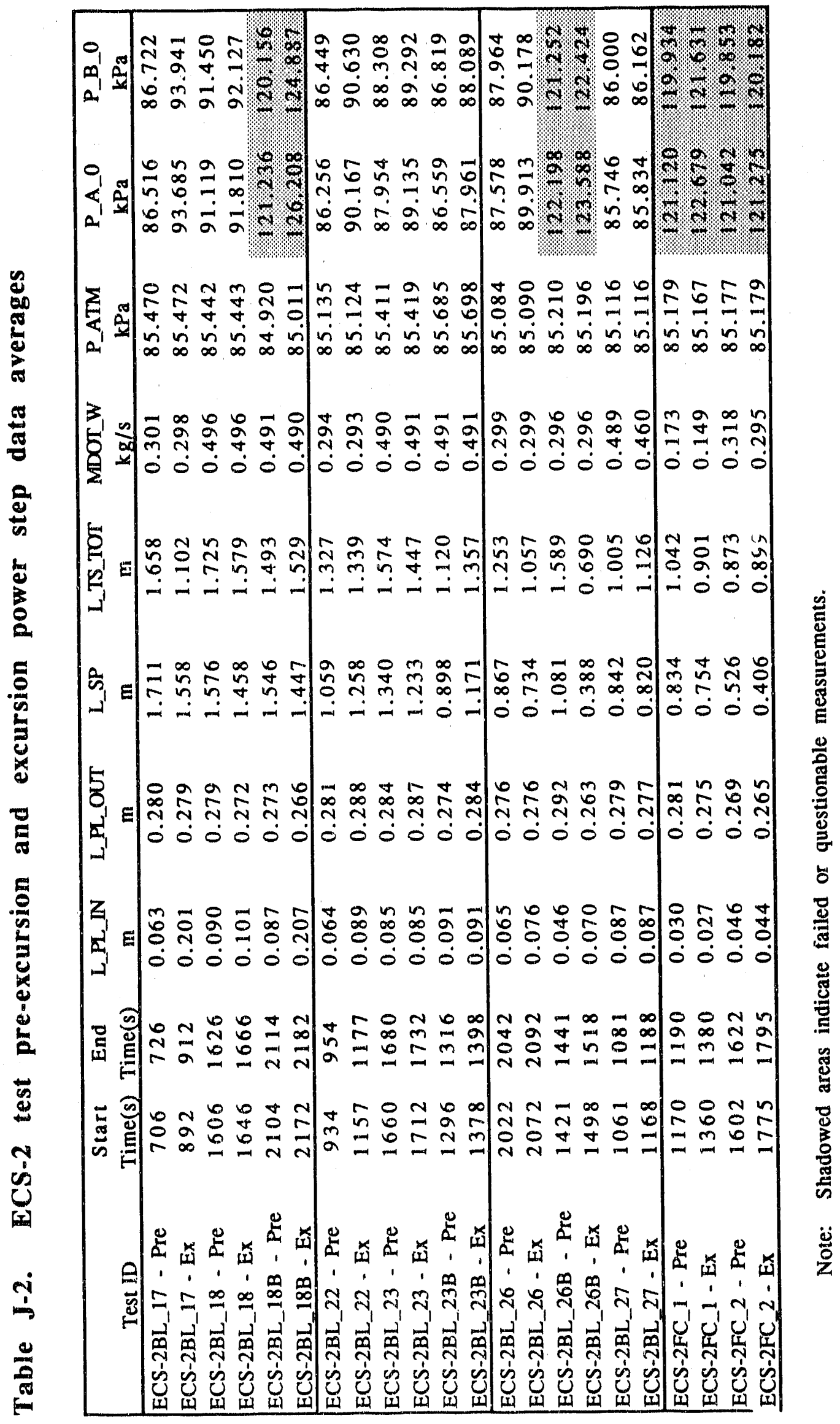




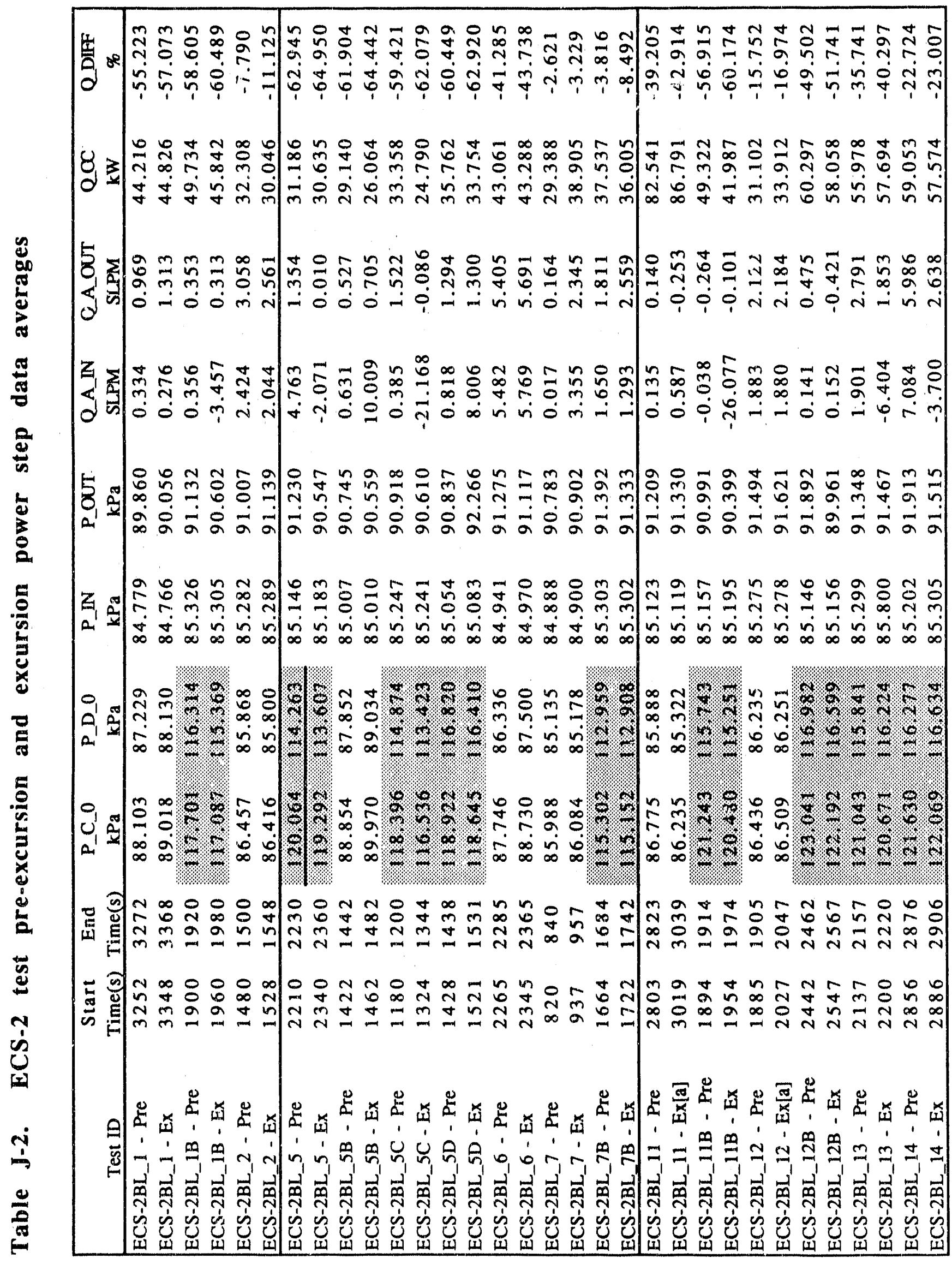




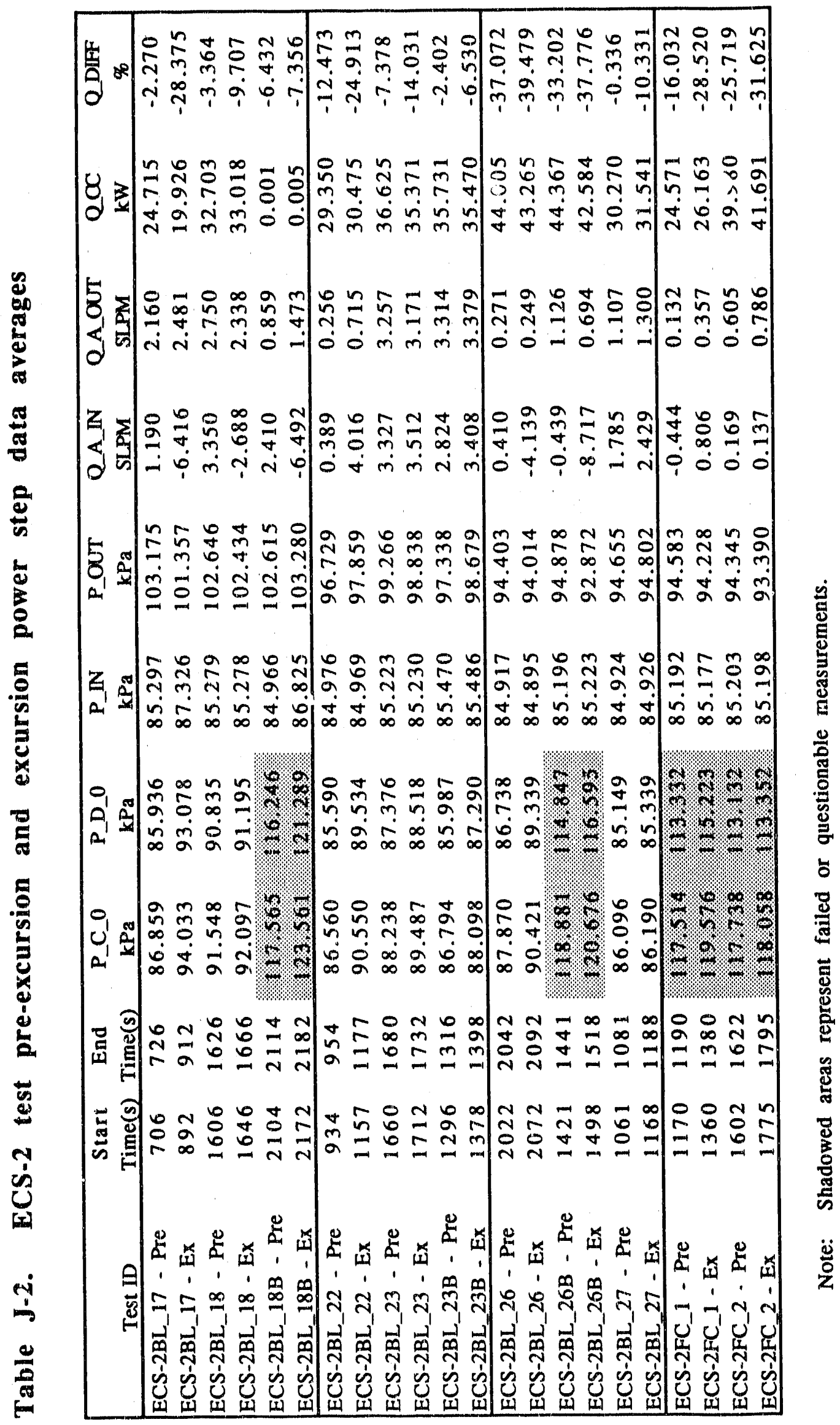




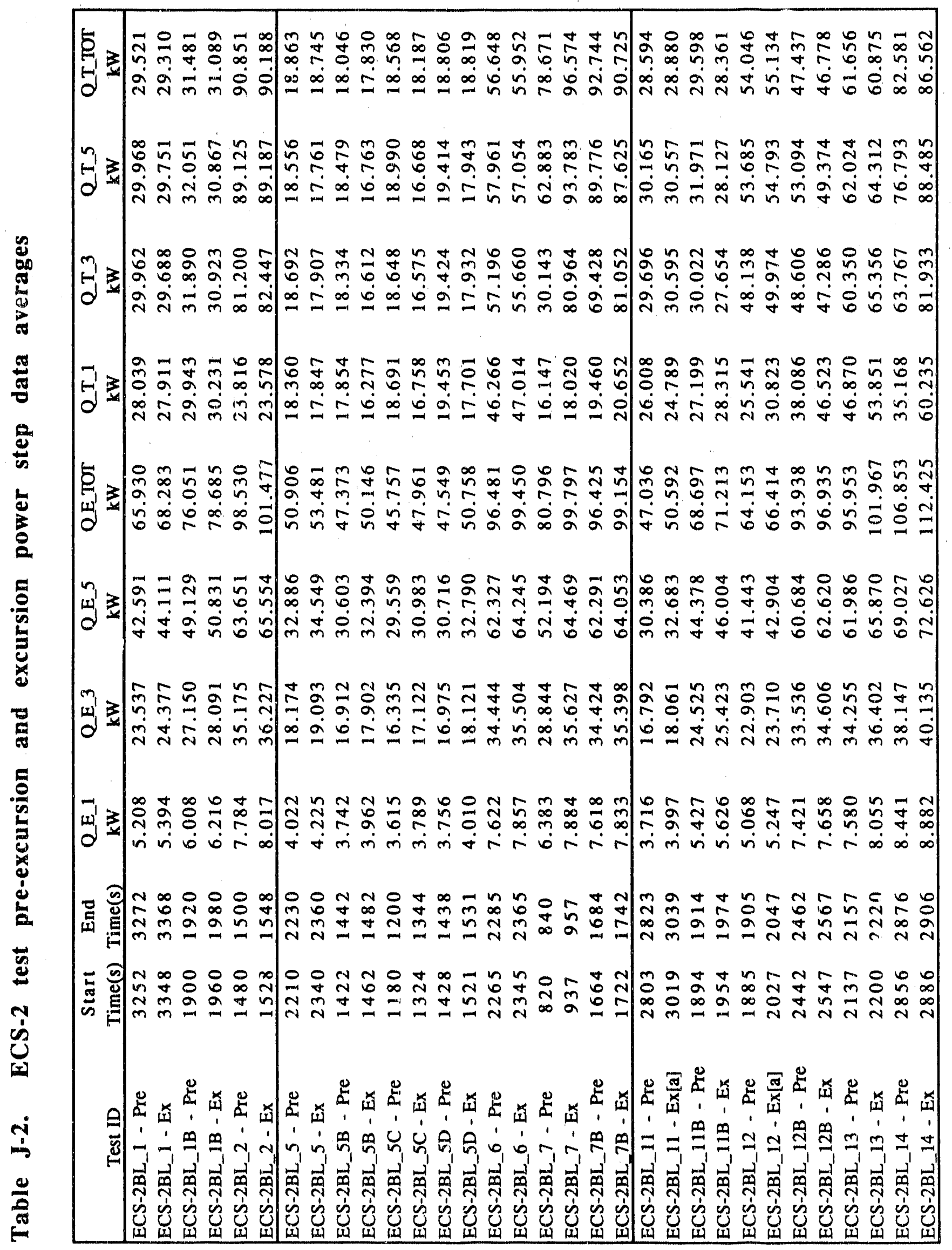




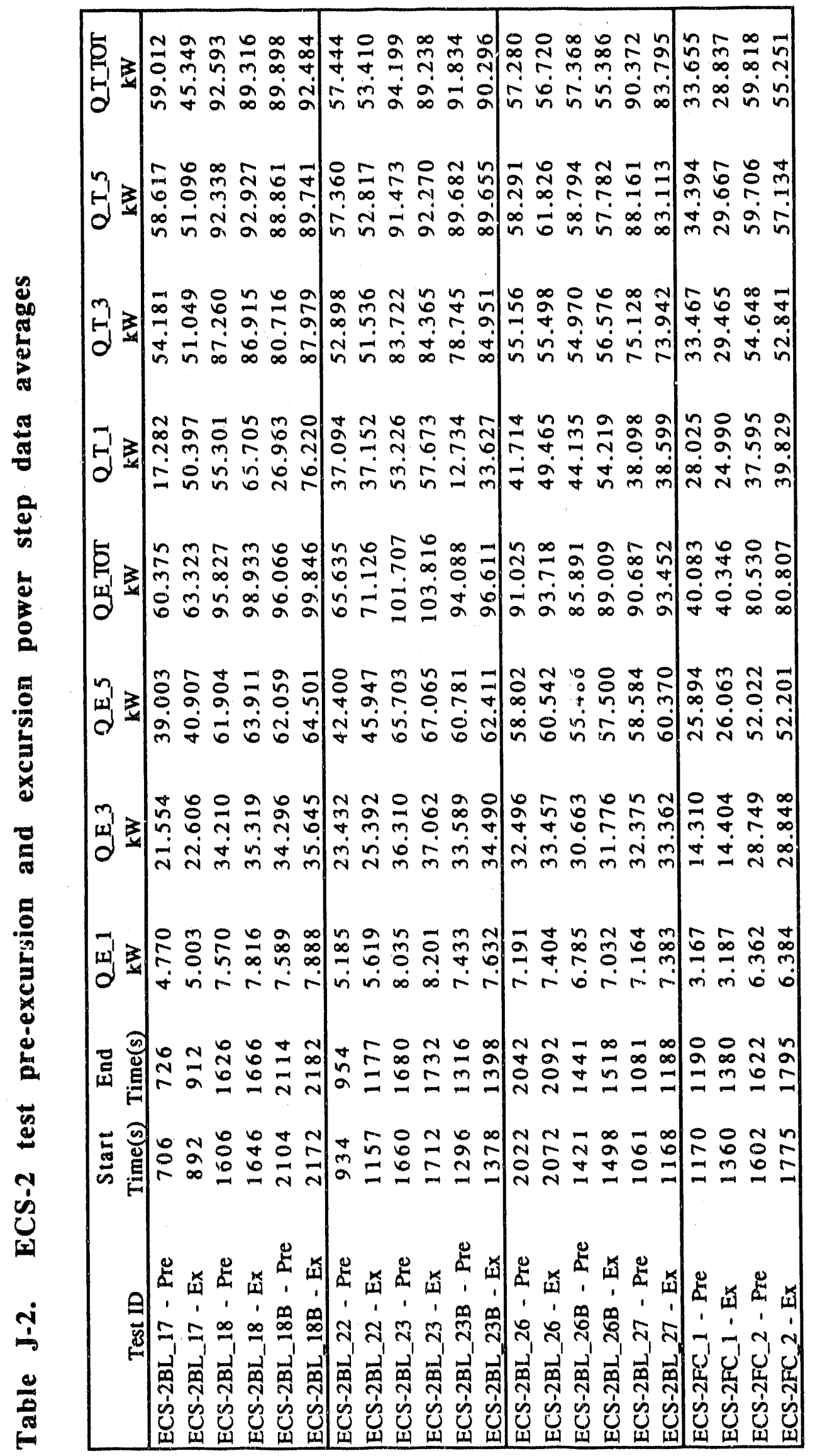




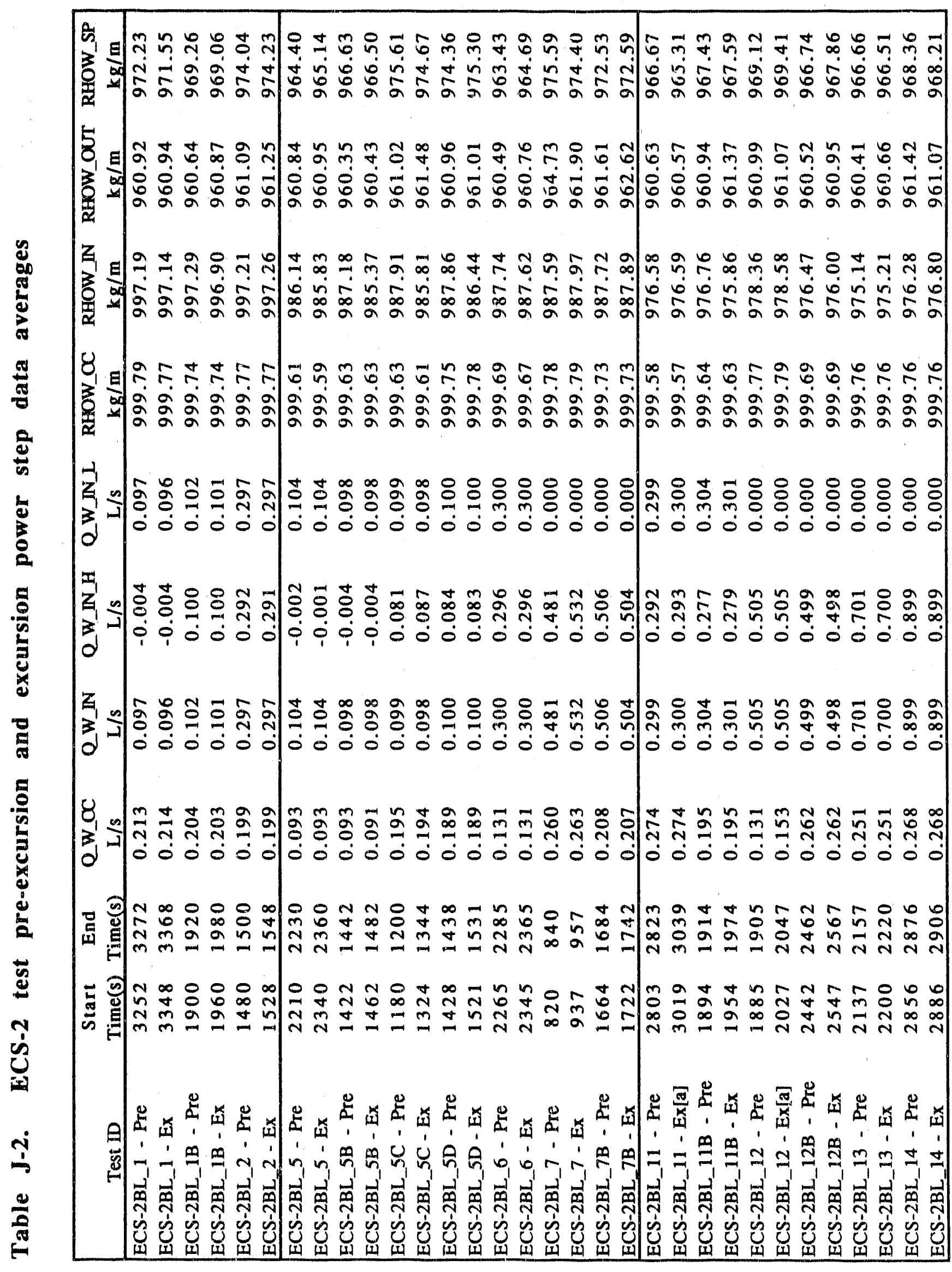




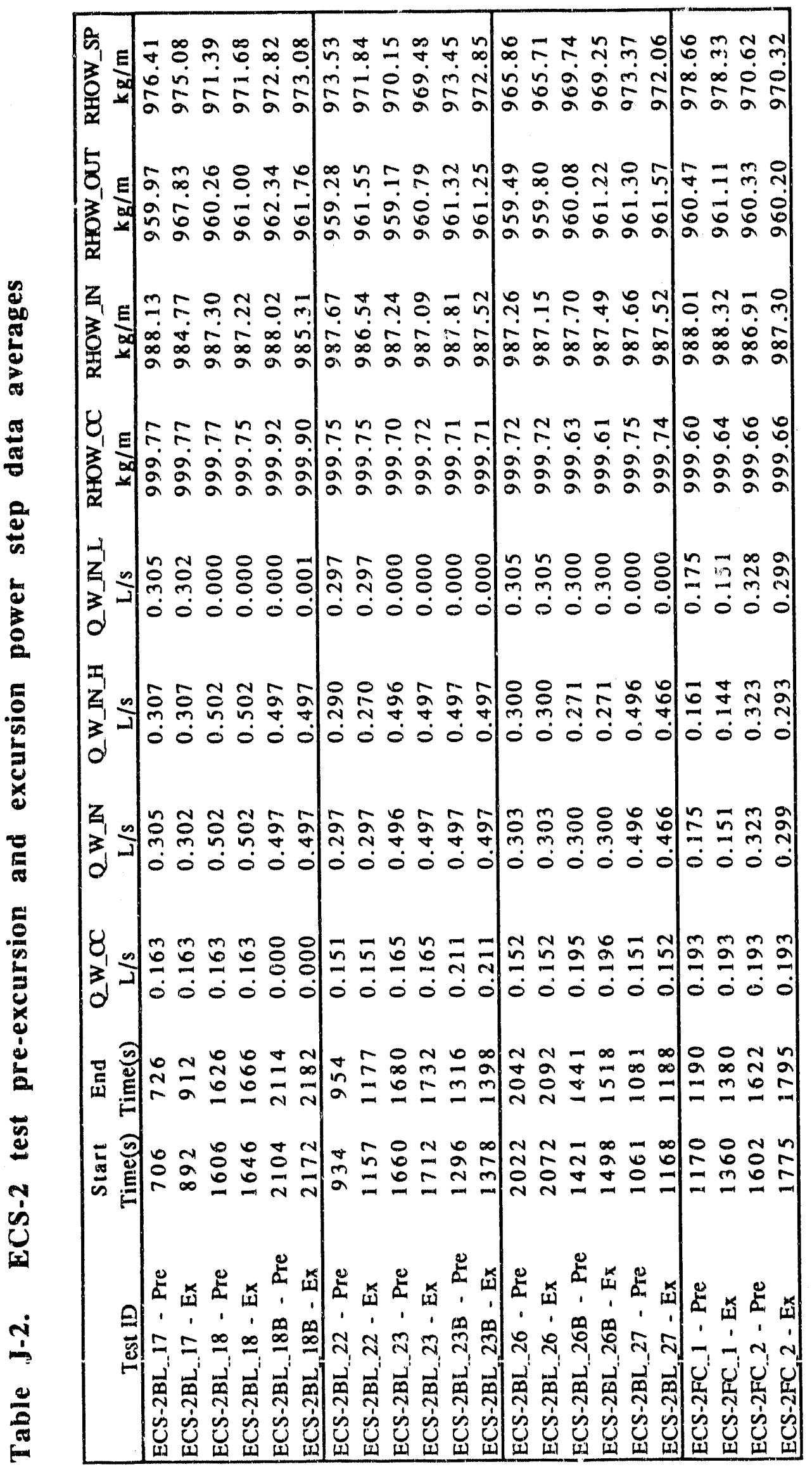




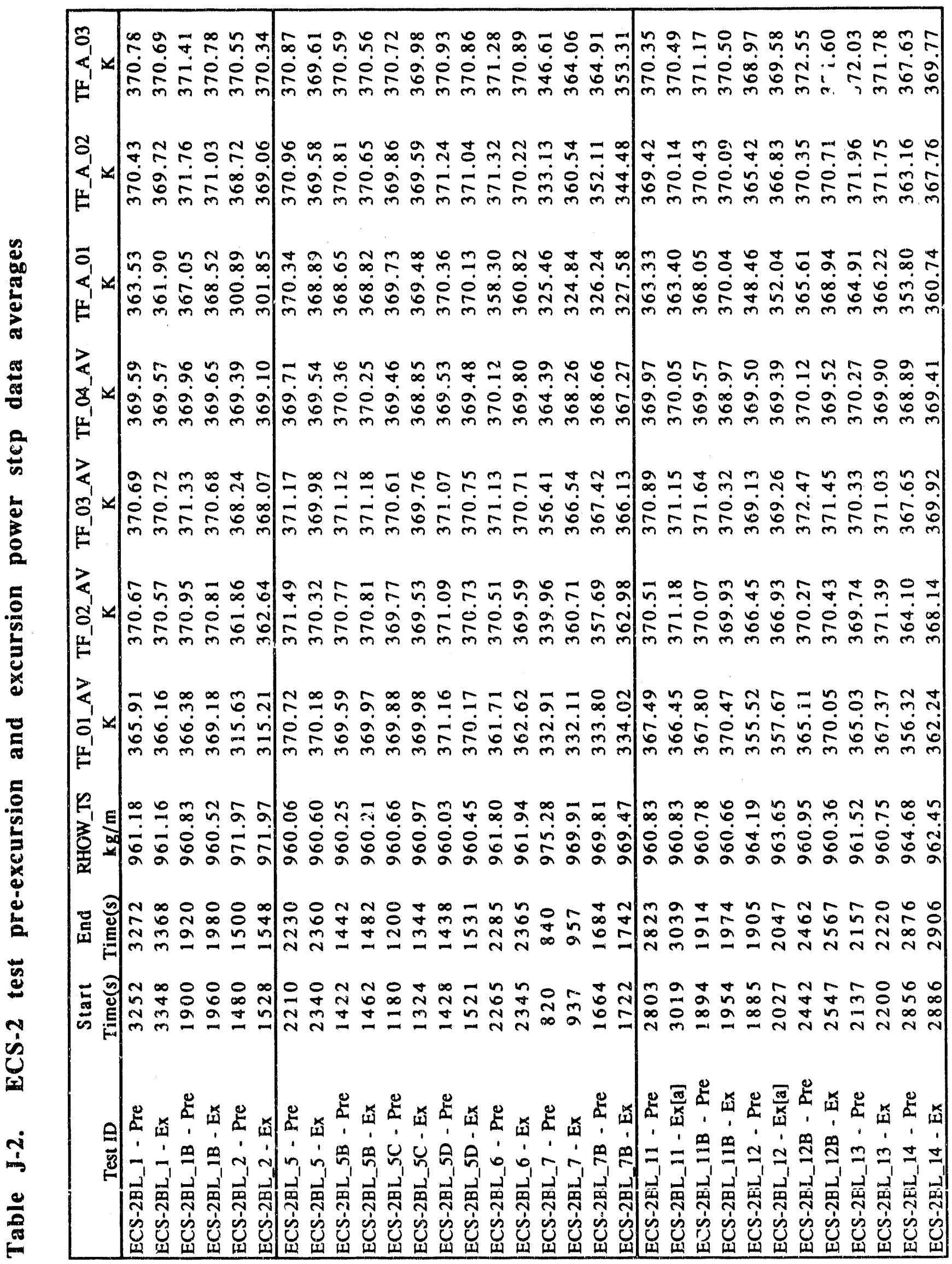




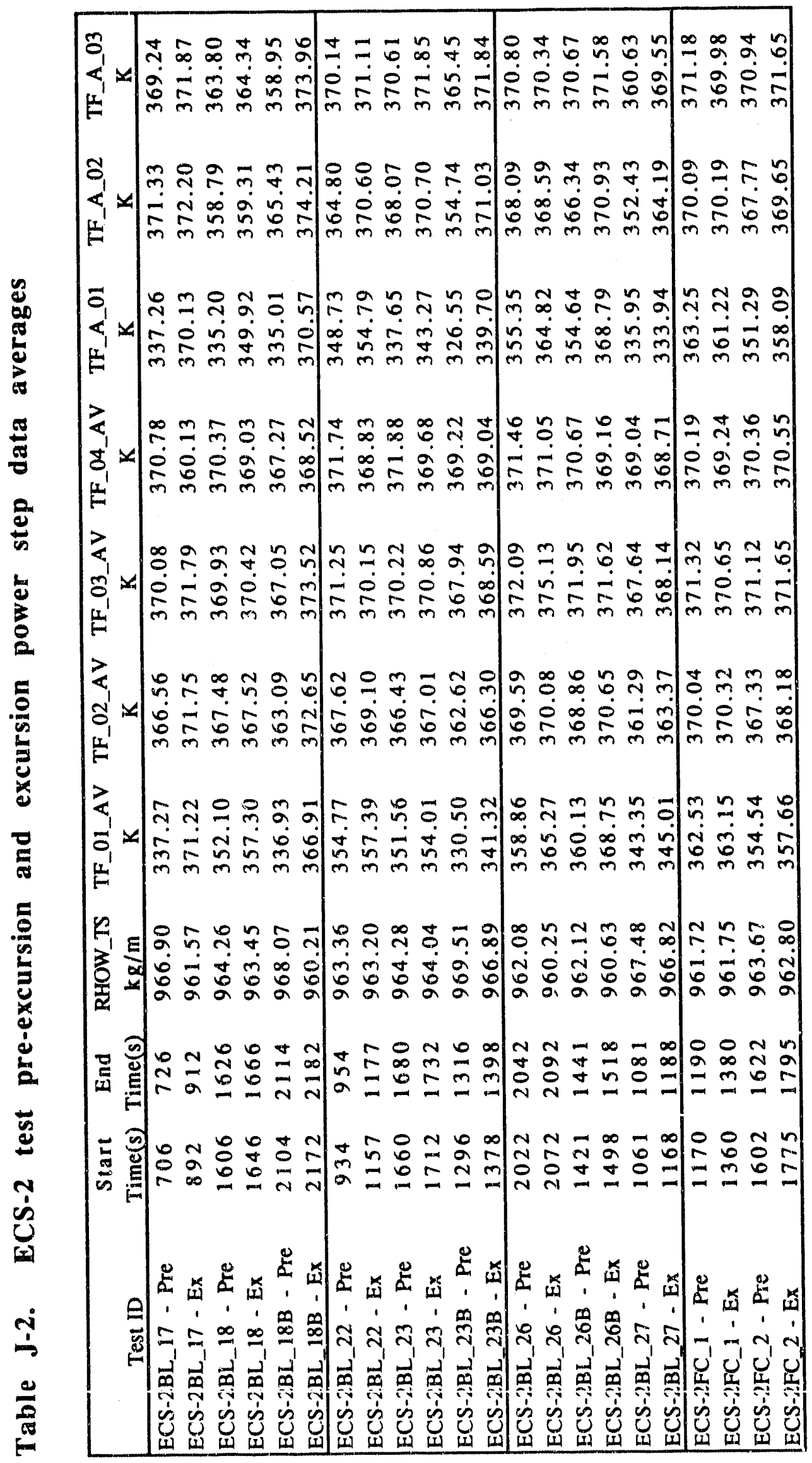




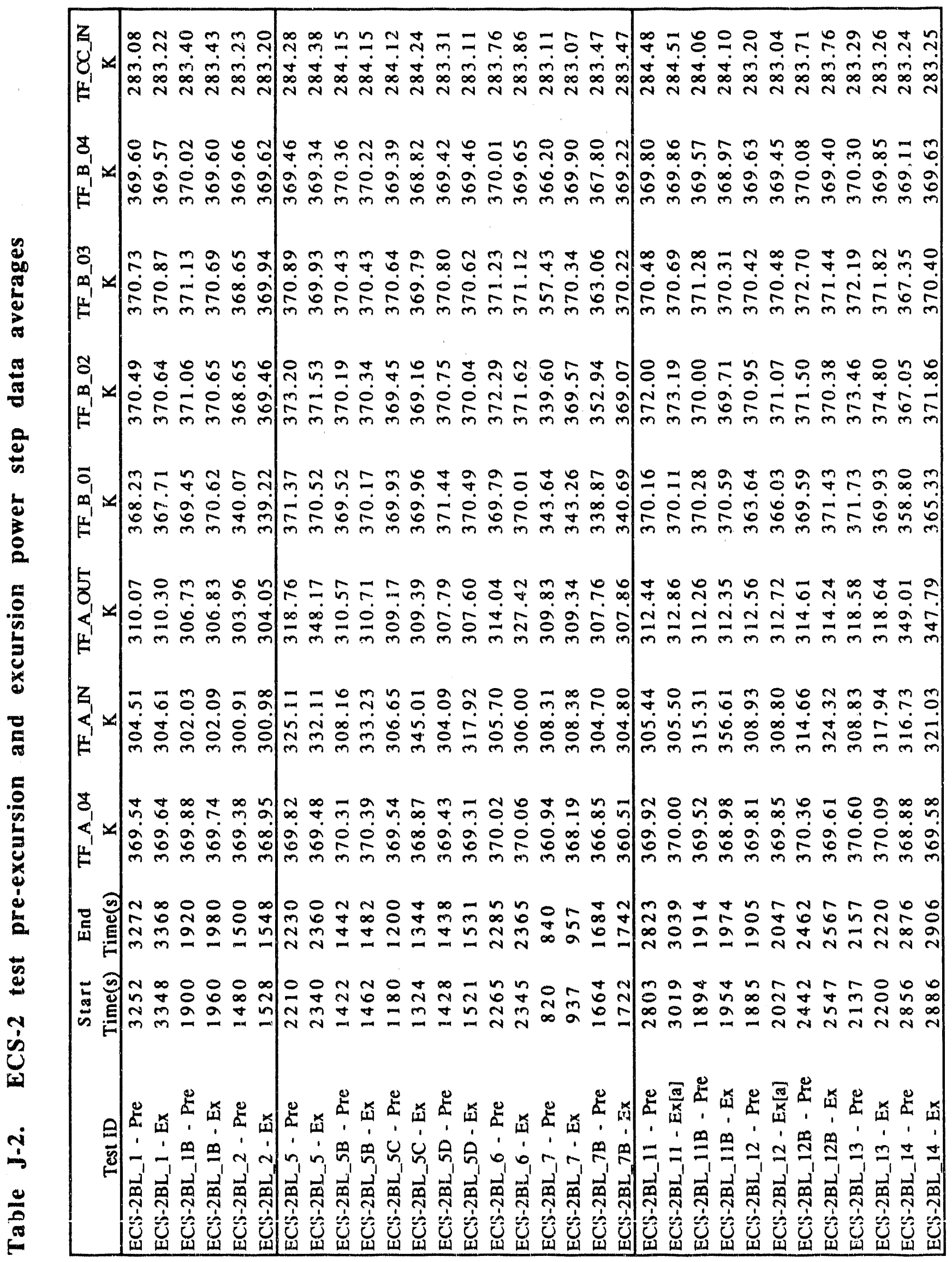




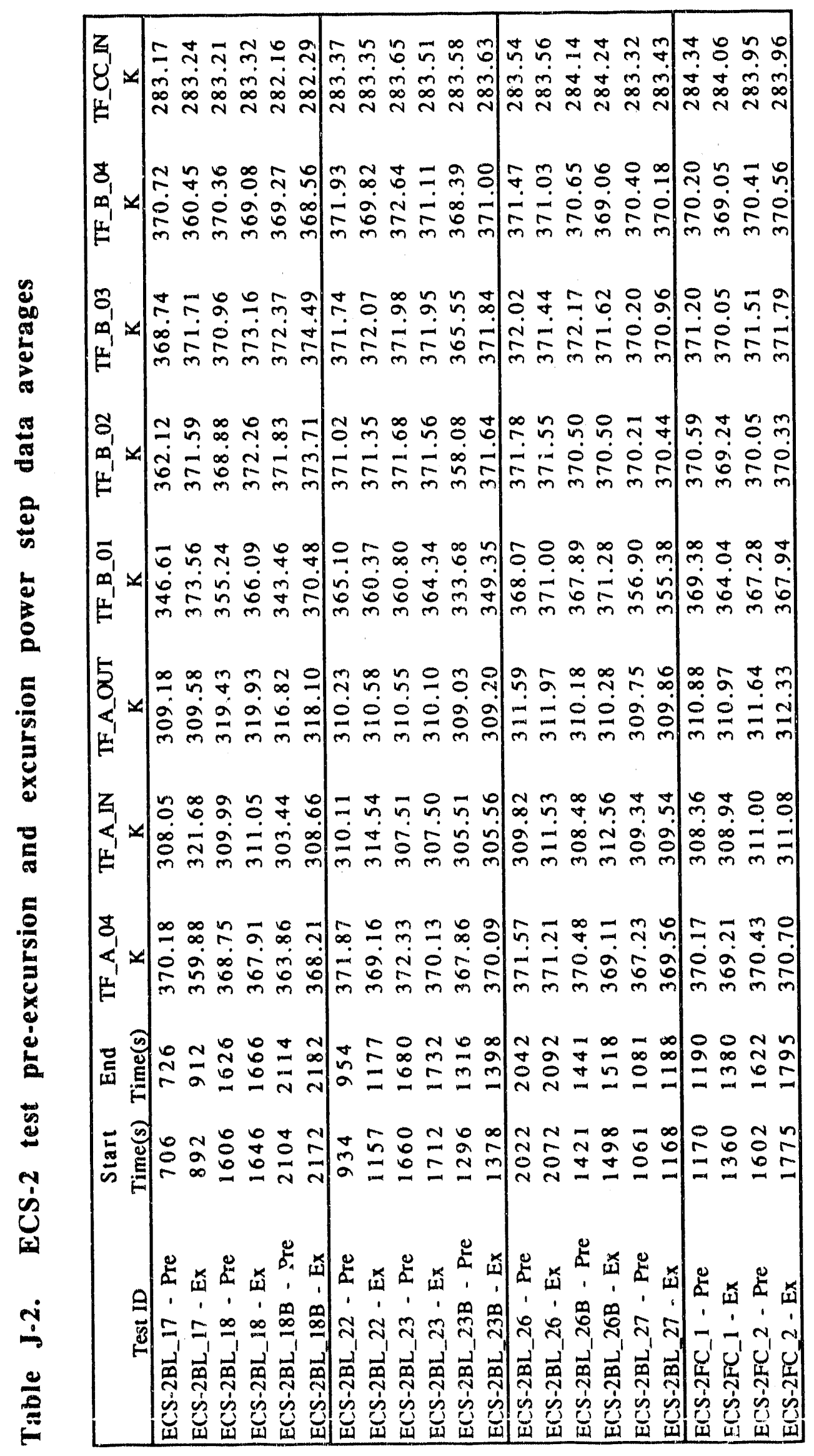




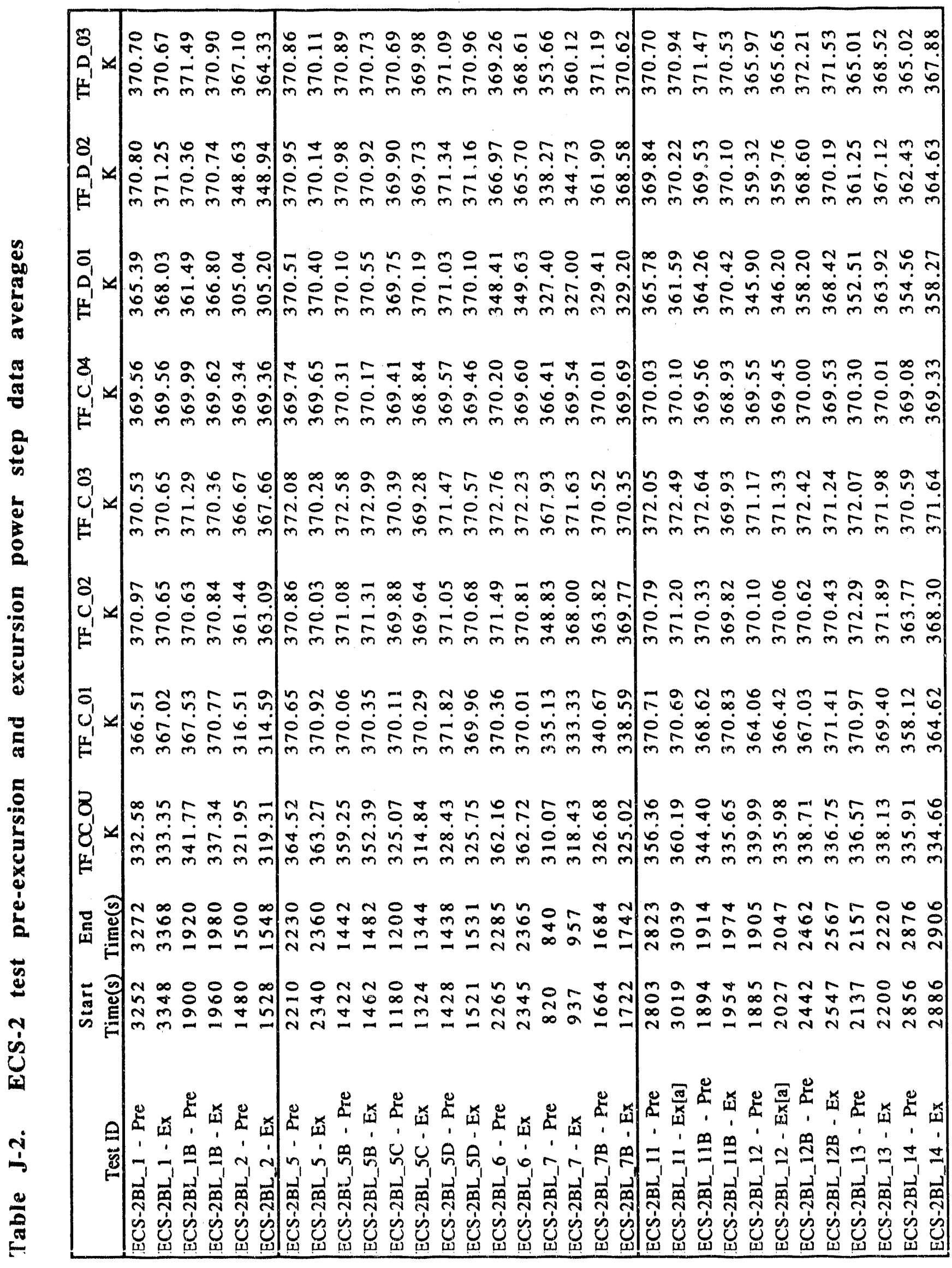




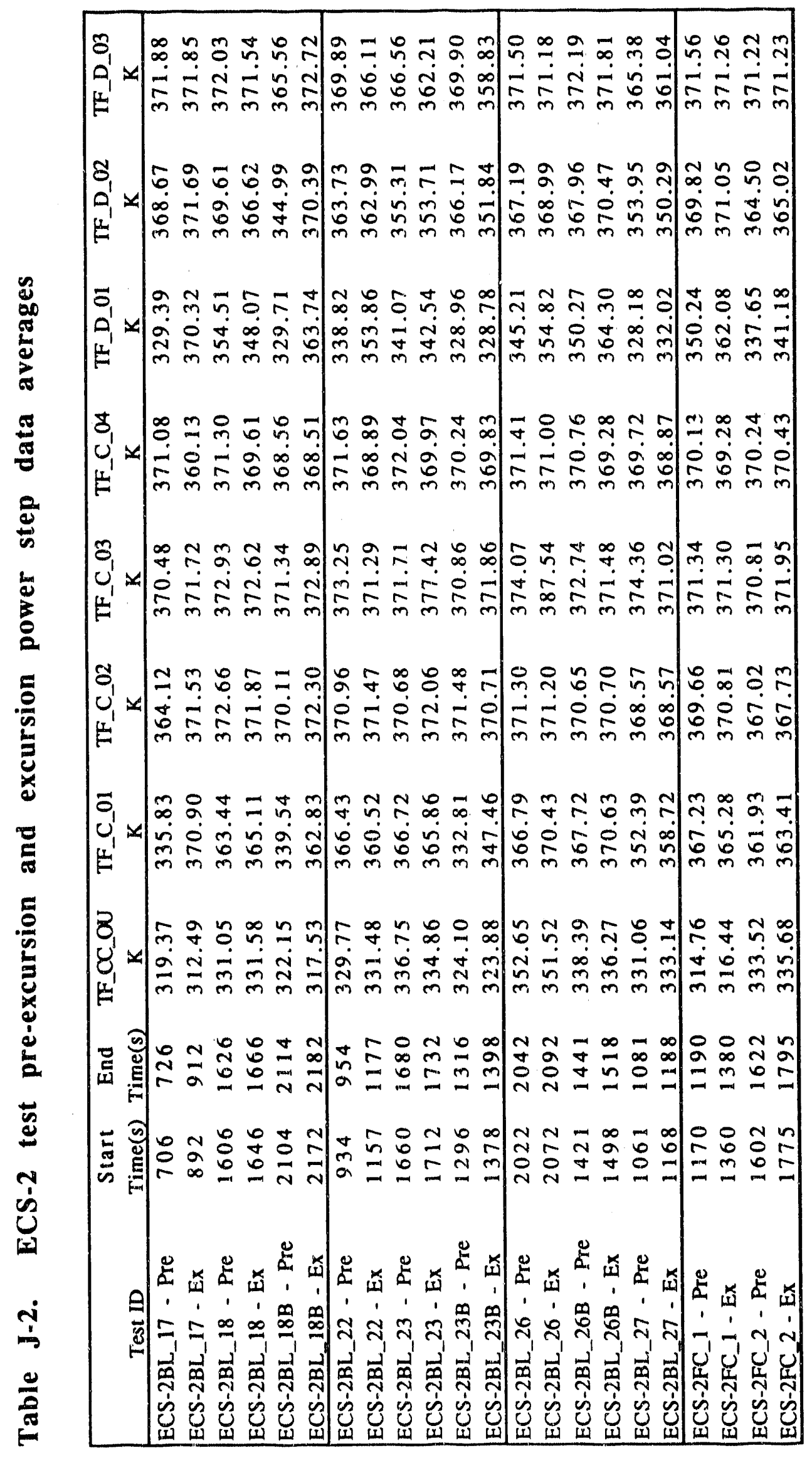




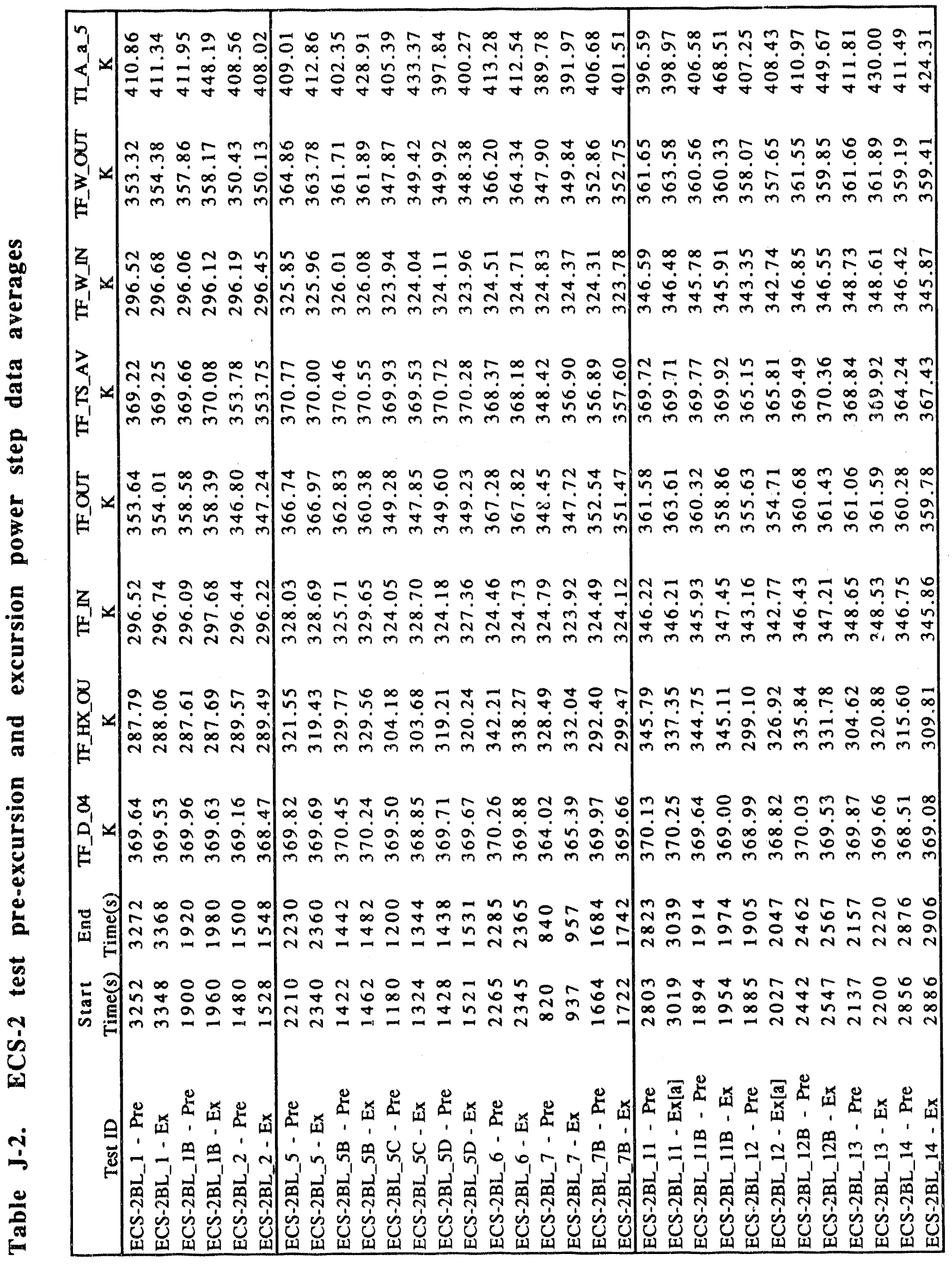




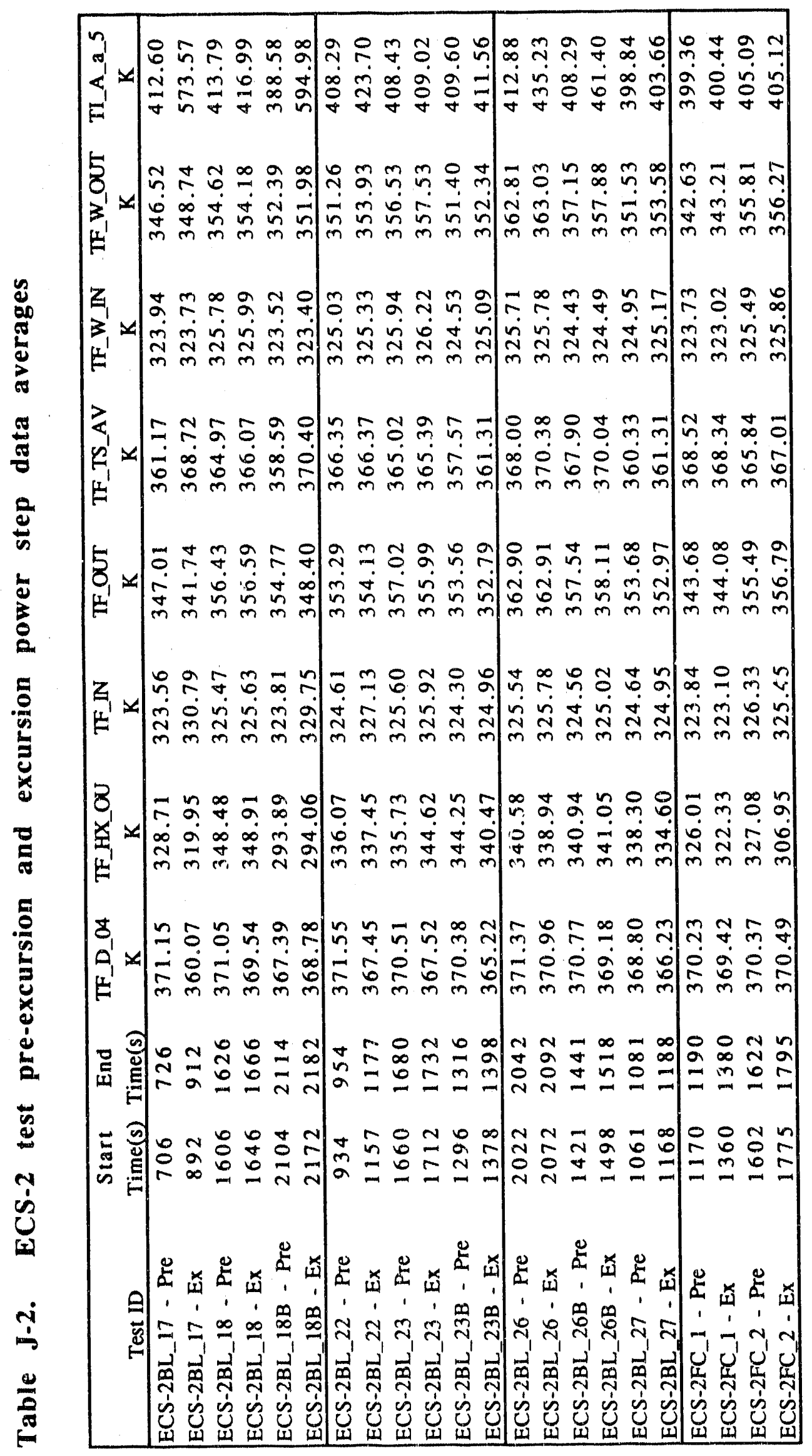




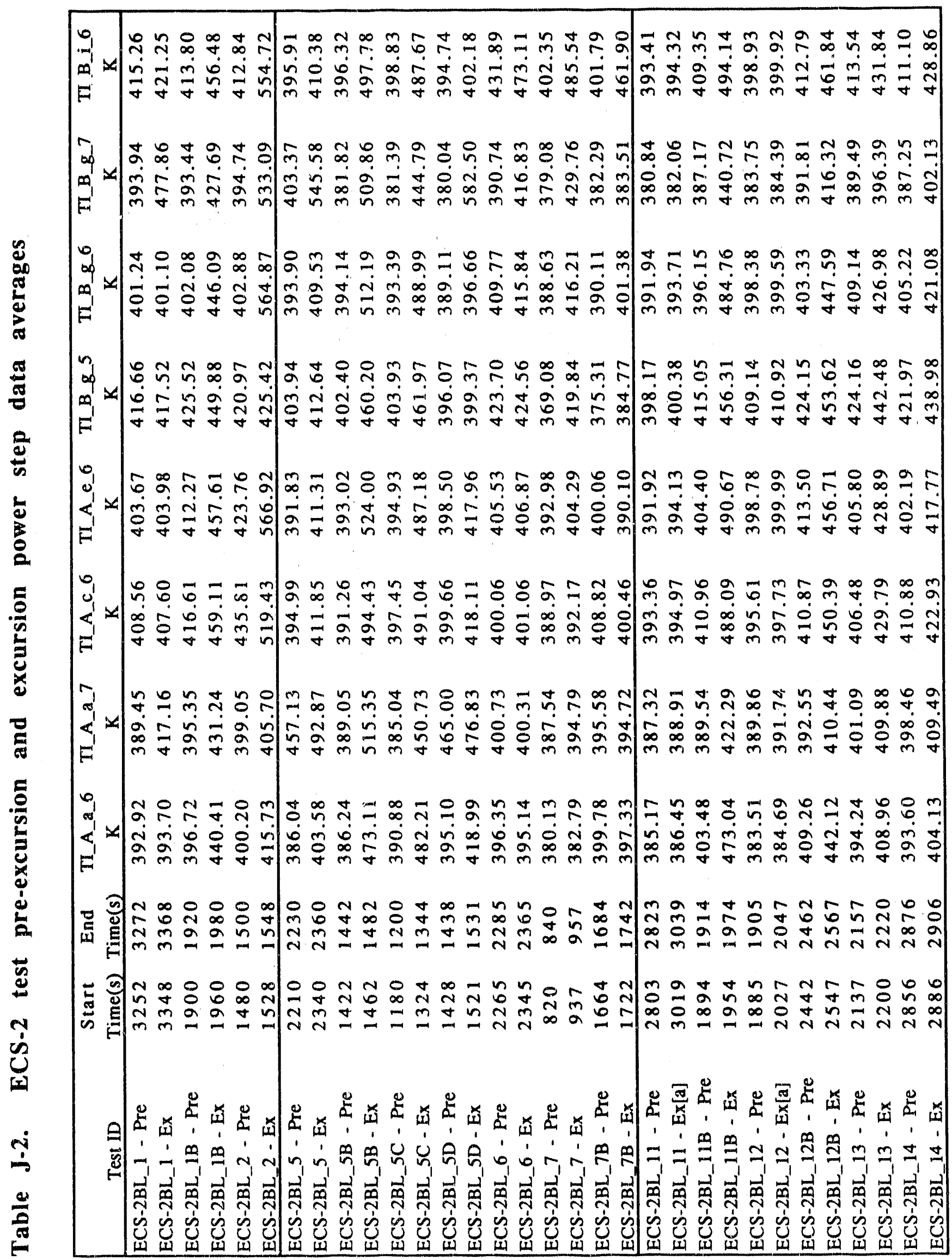




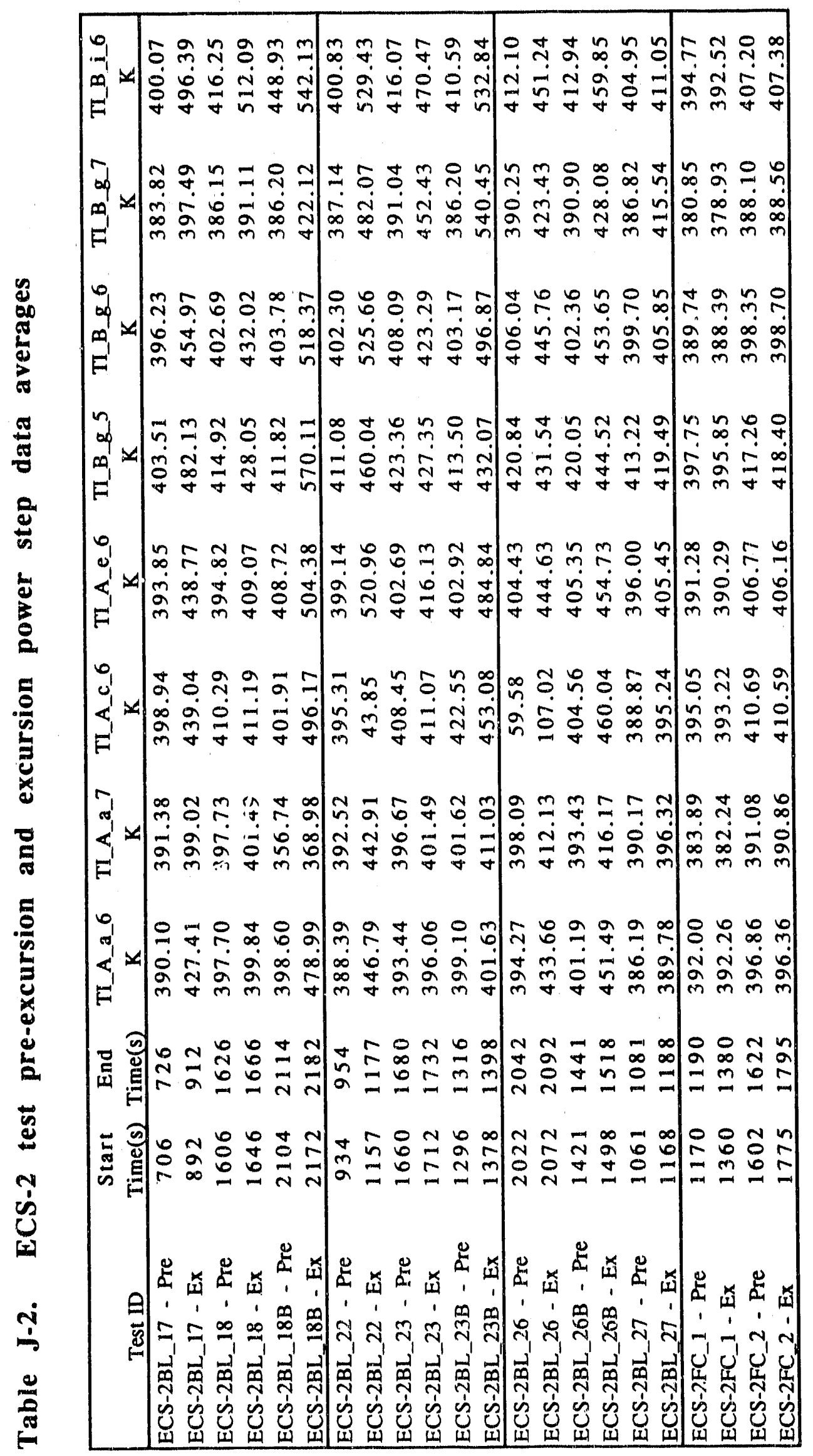




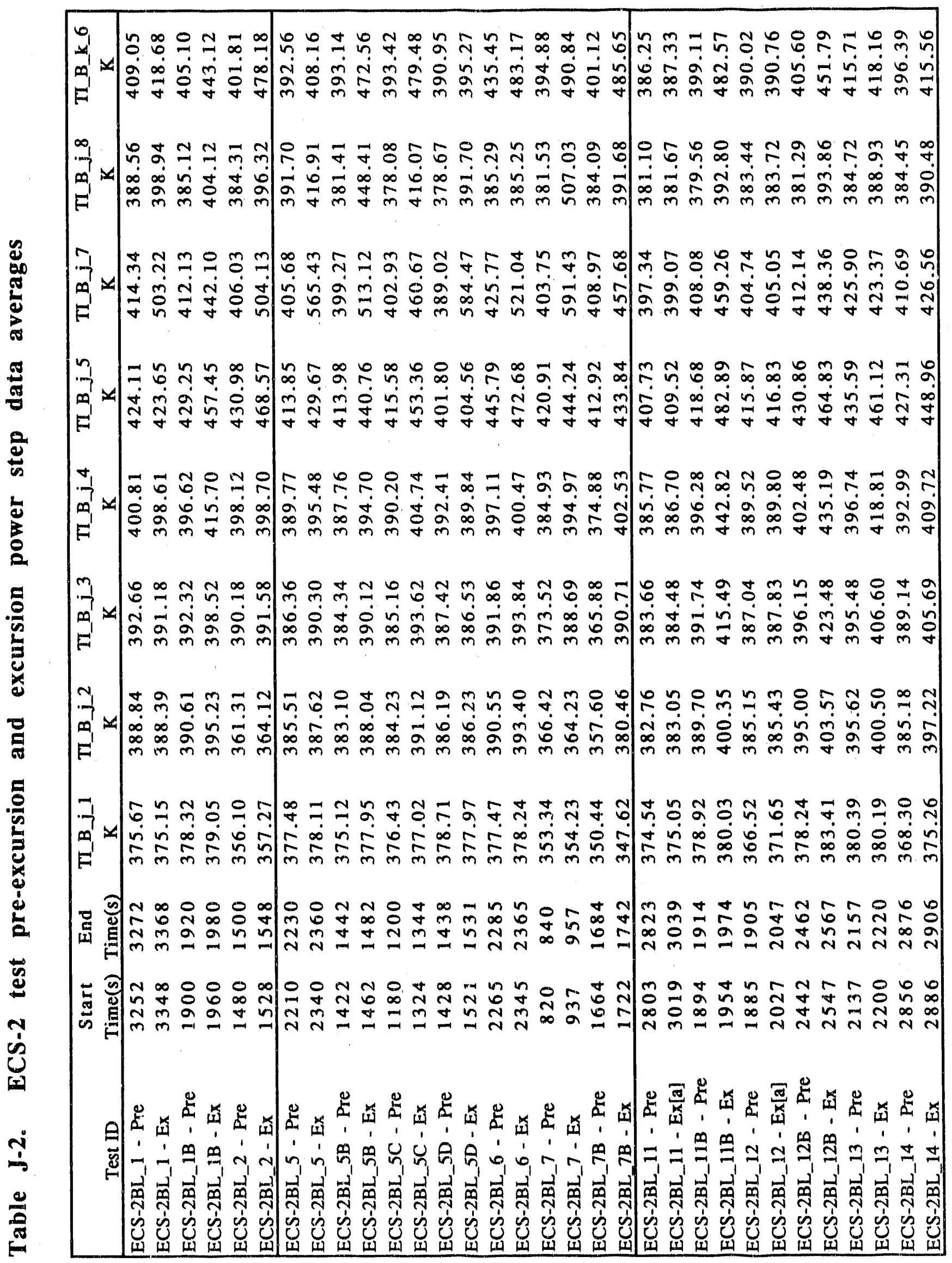




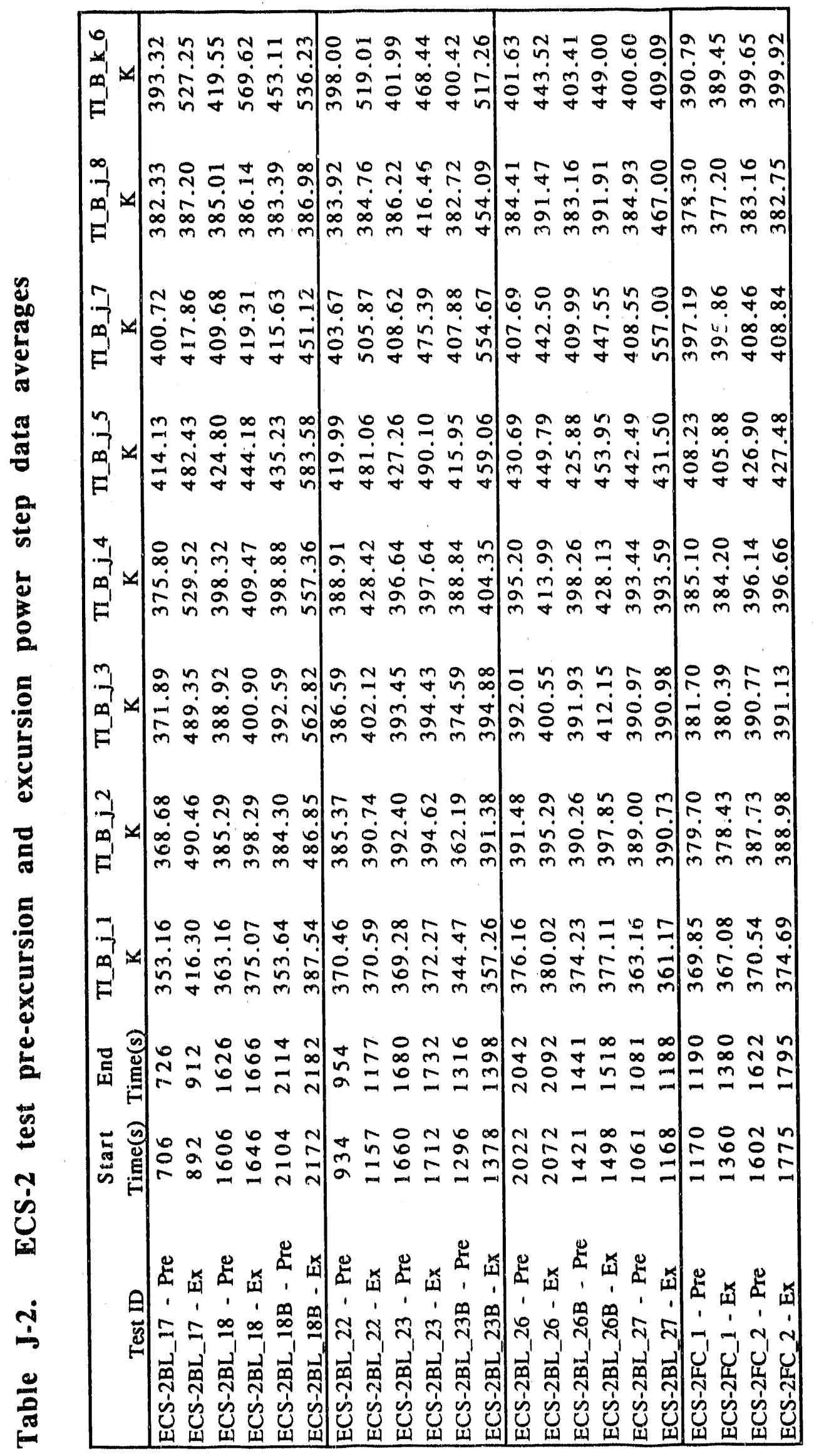




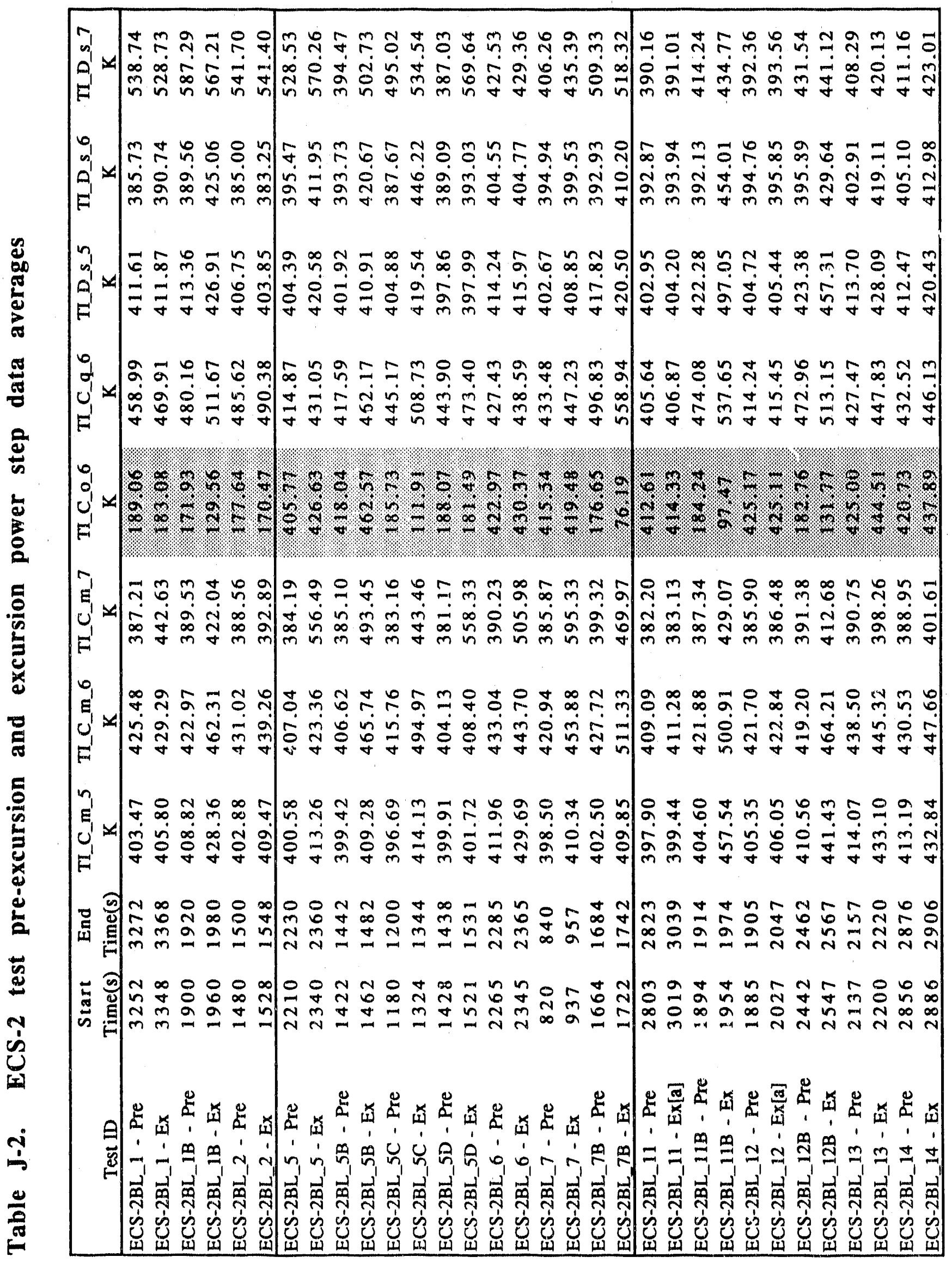




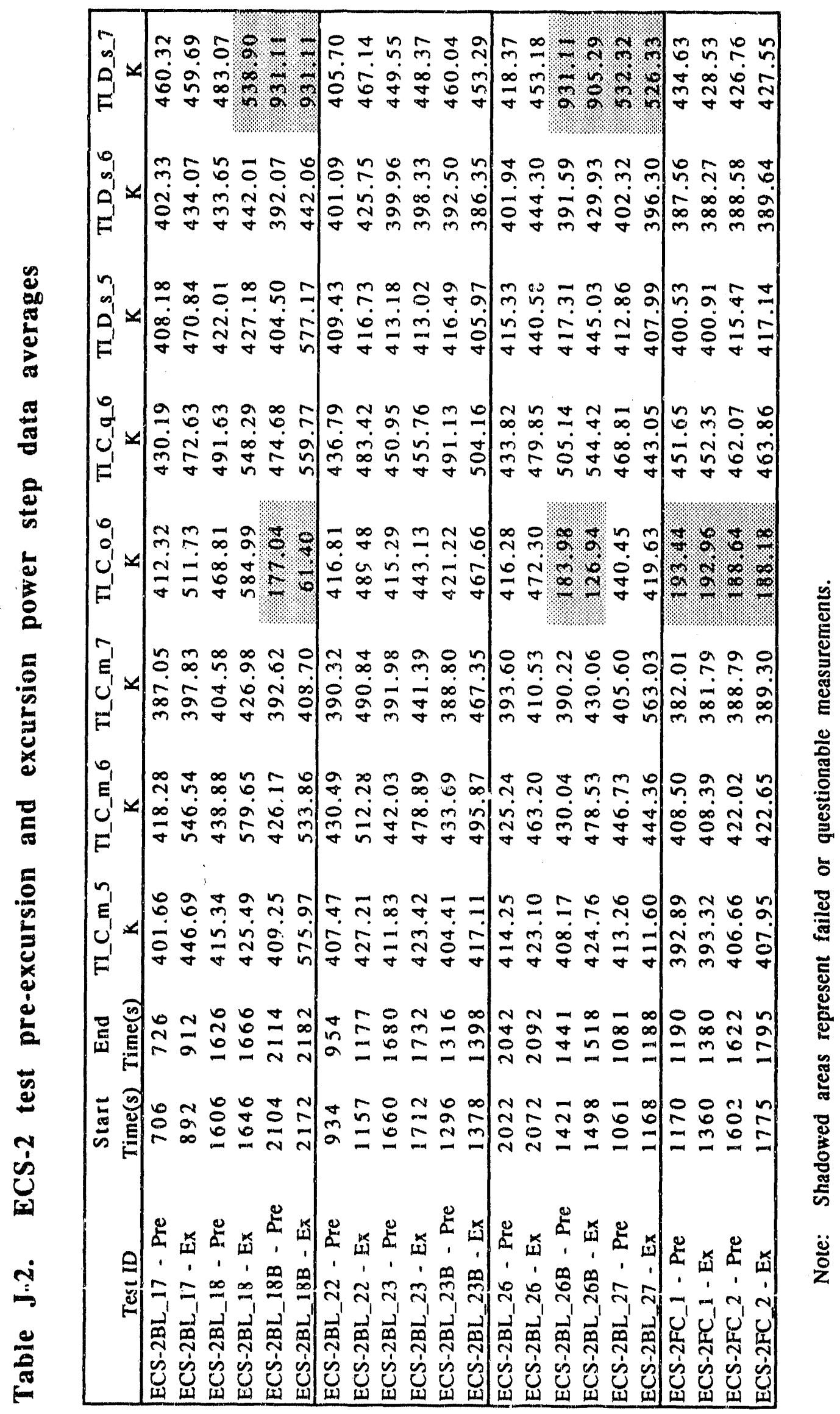




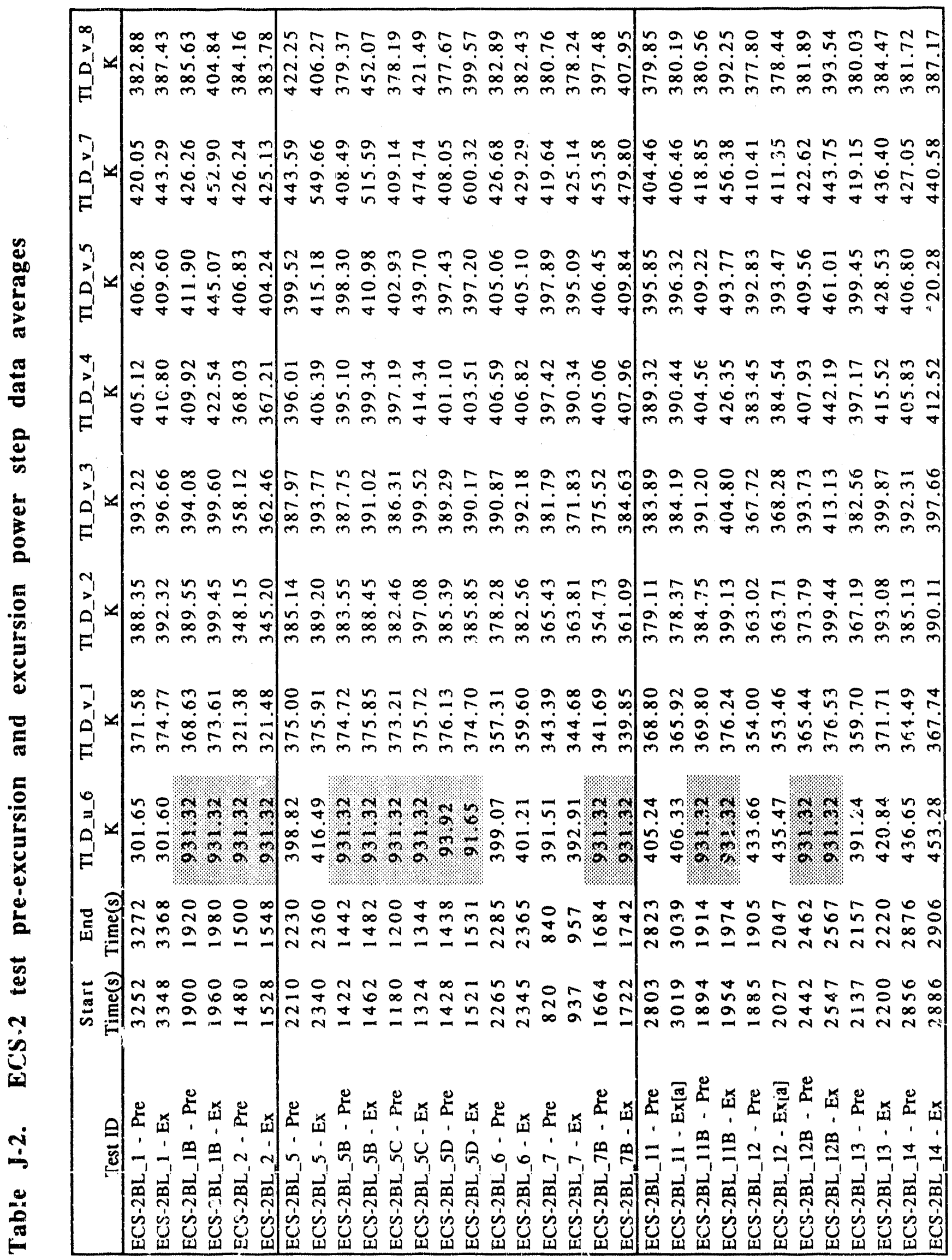




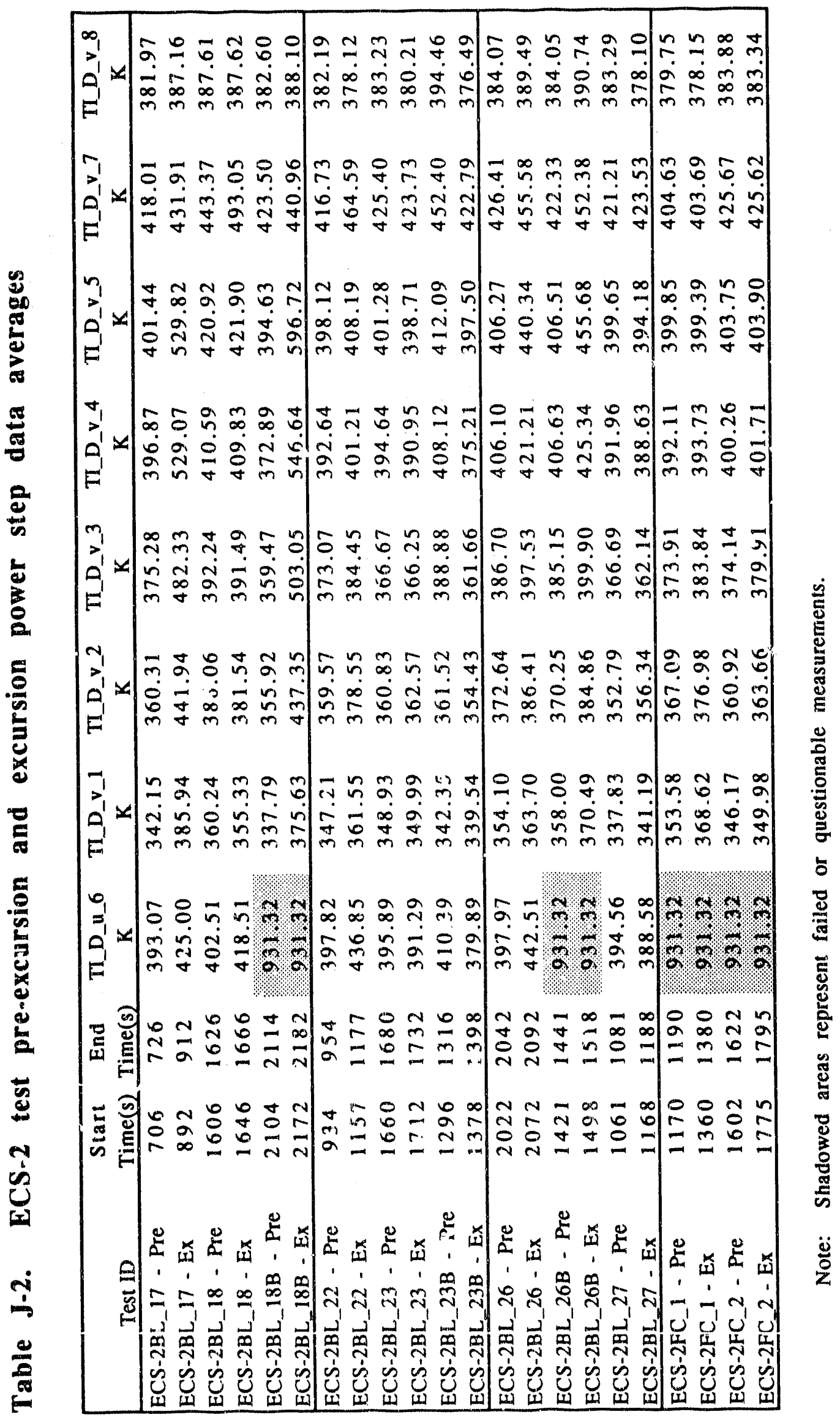


里

है

$\underset{6}{*}$

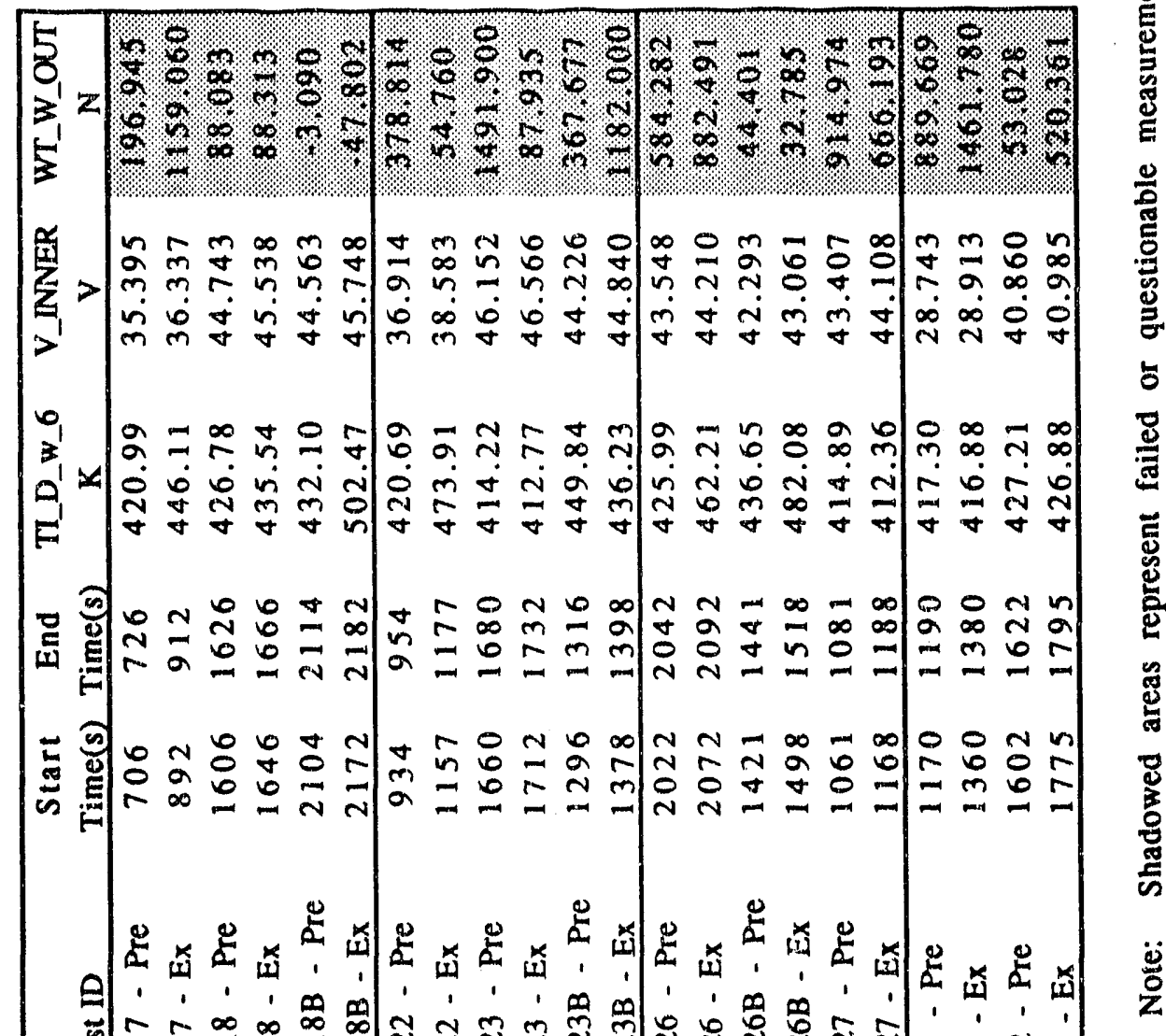

$\underset{1}{1}$

$\frac{0}{6}$

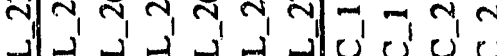

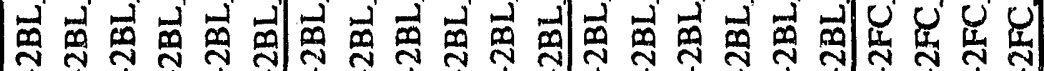

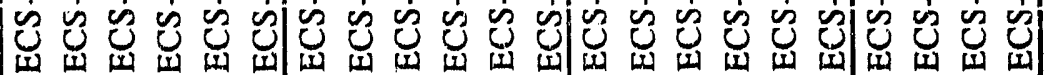




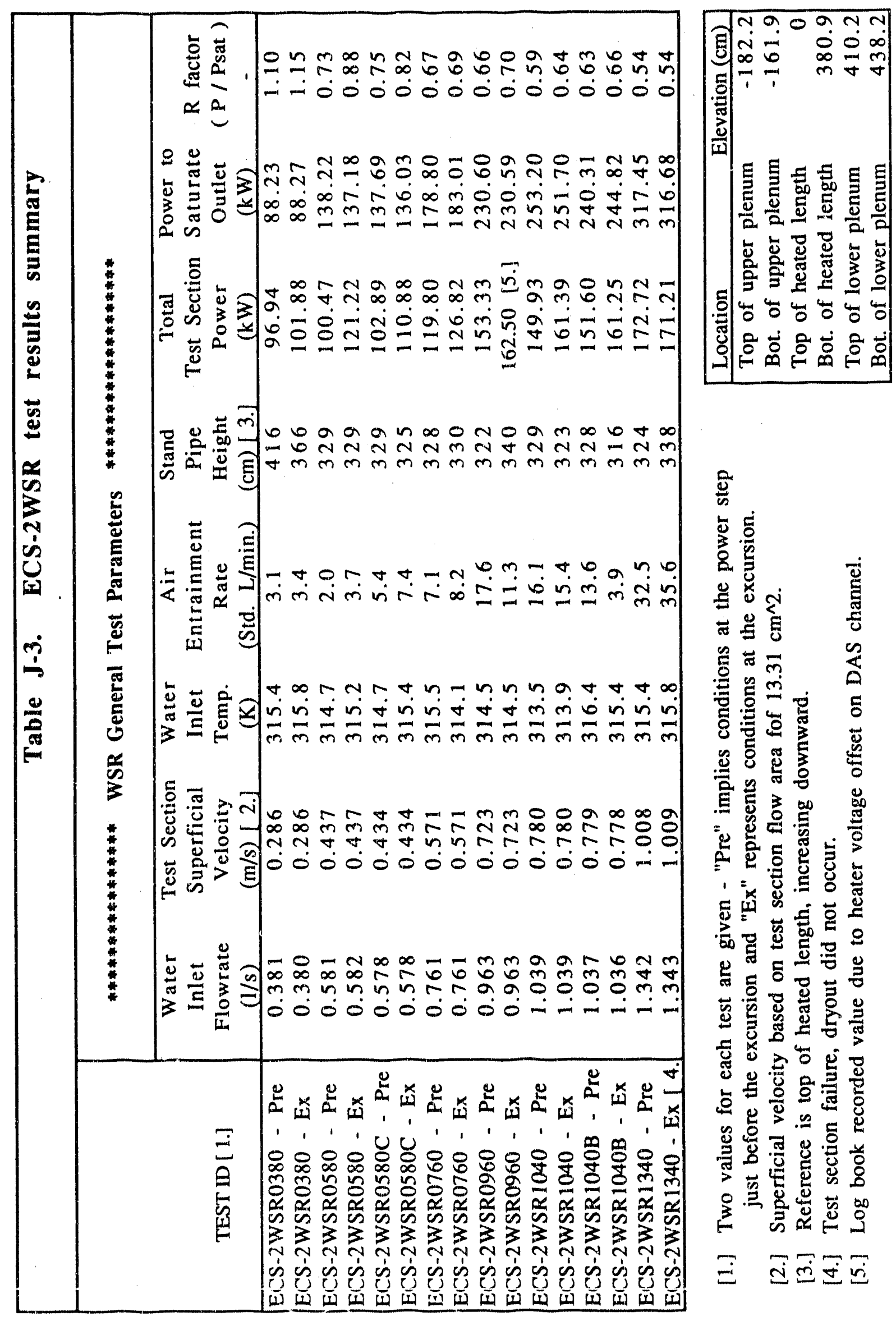




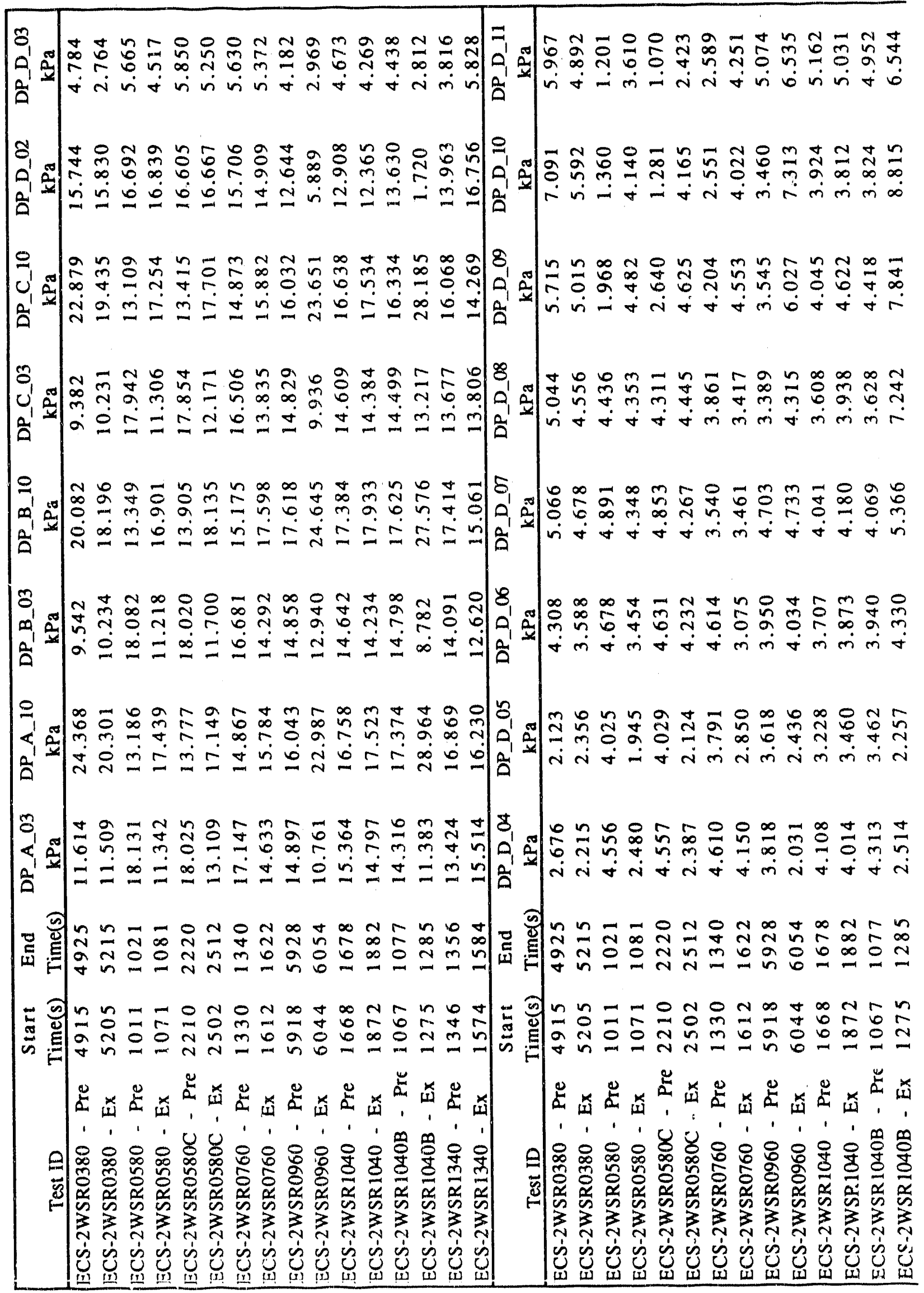




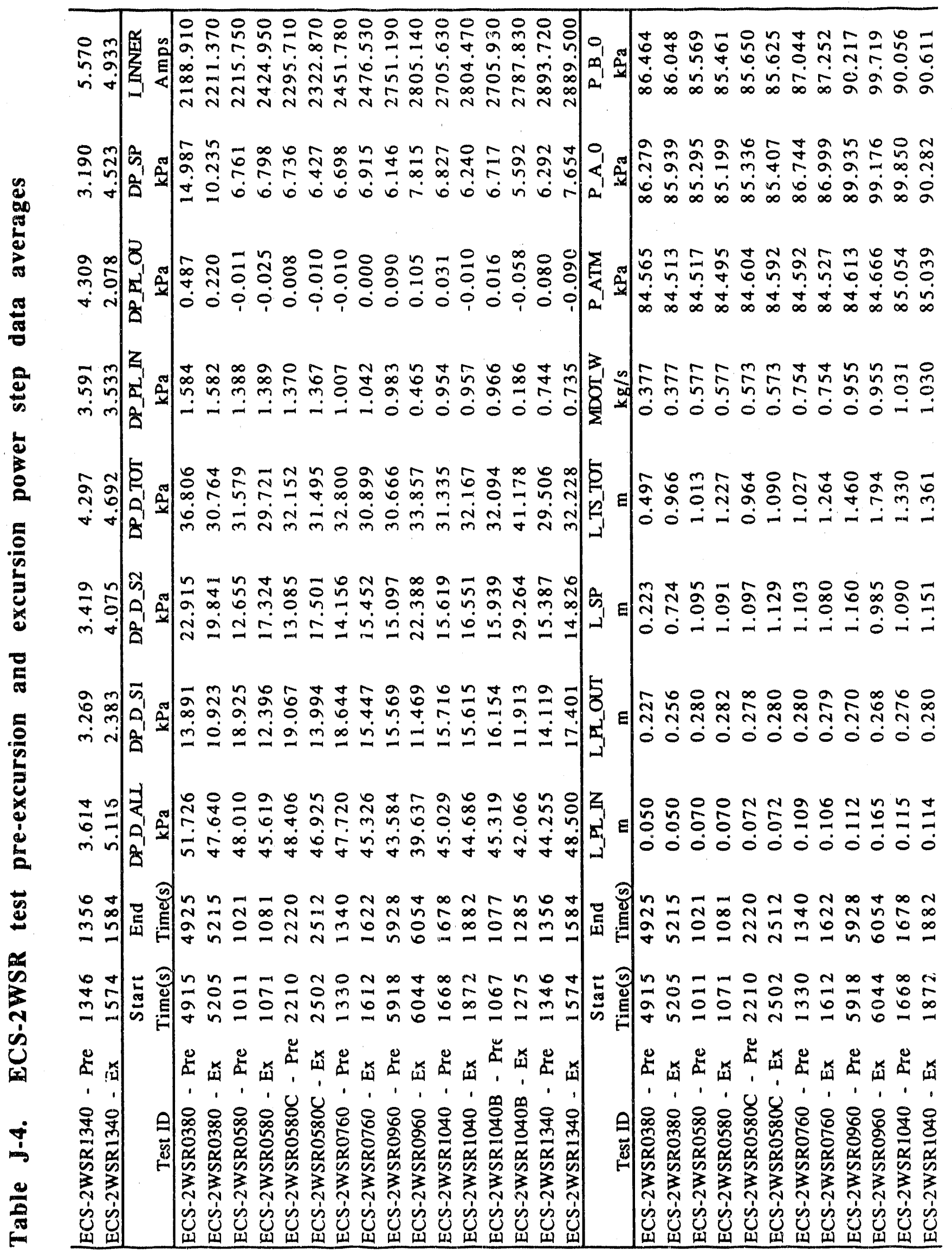




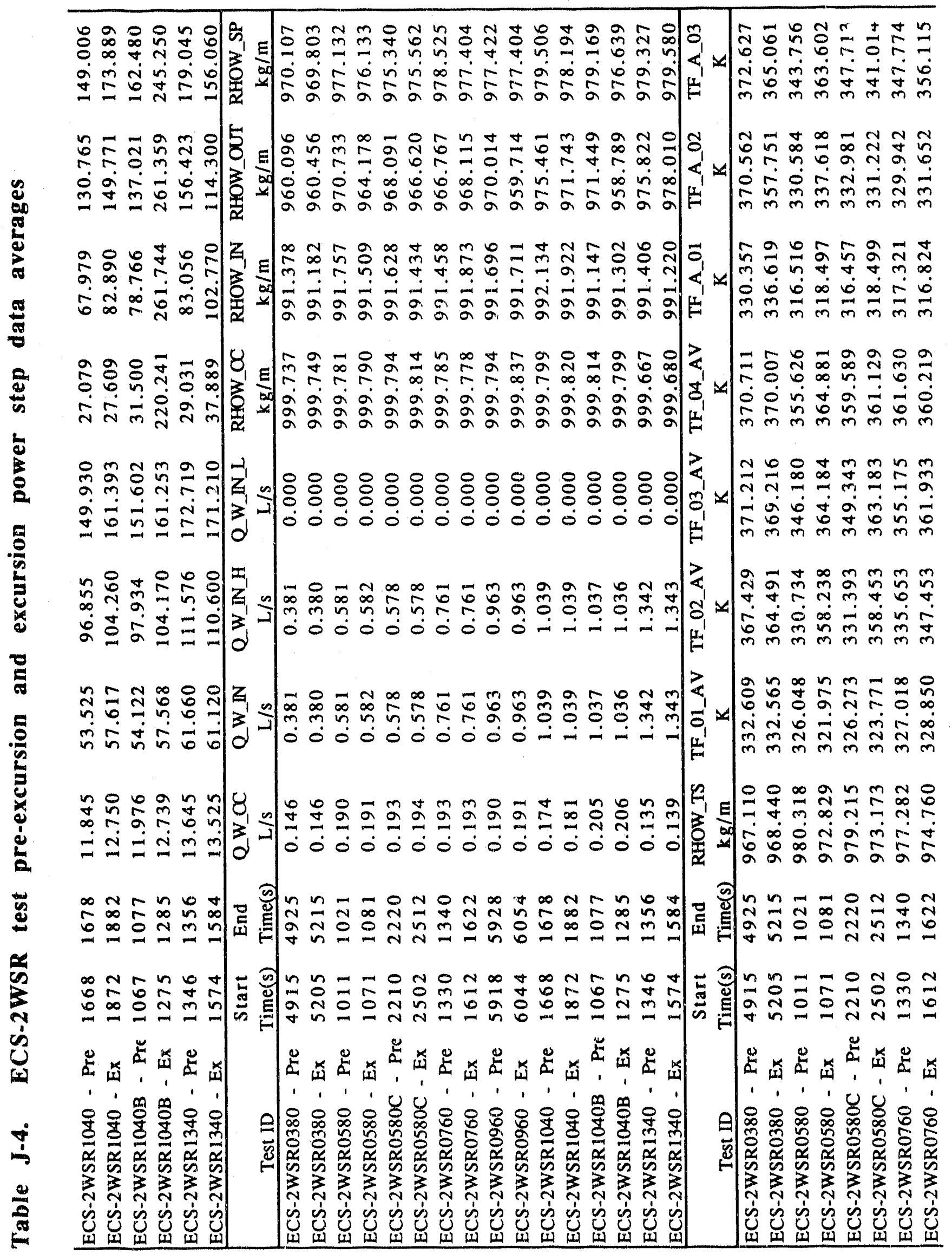




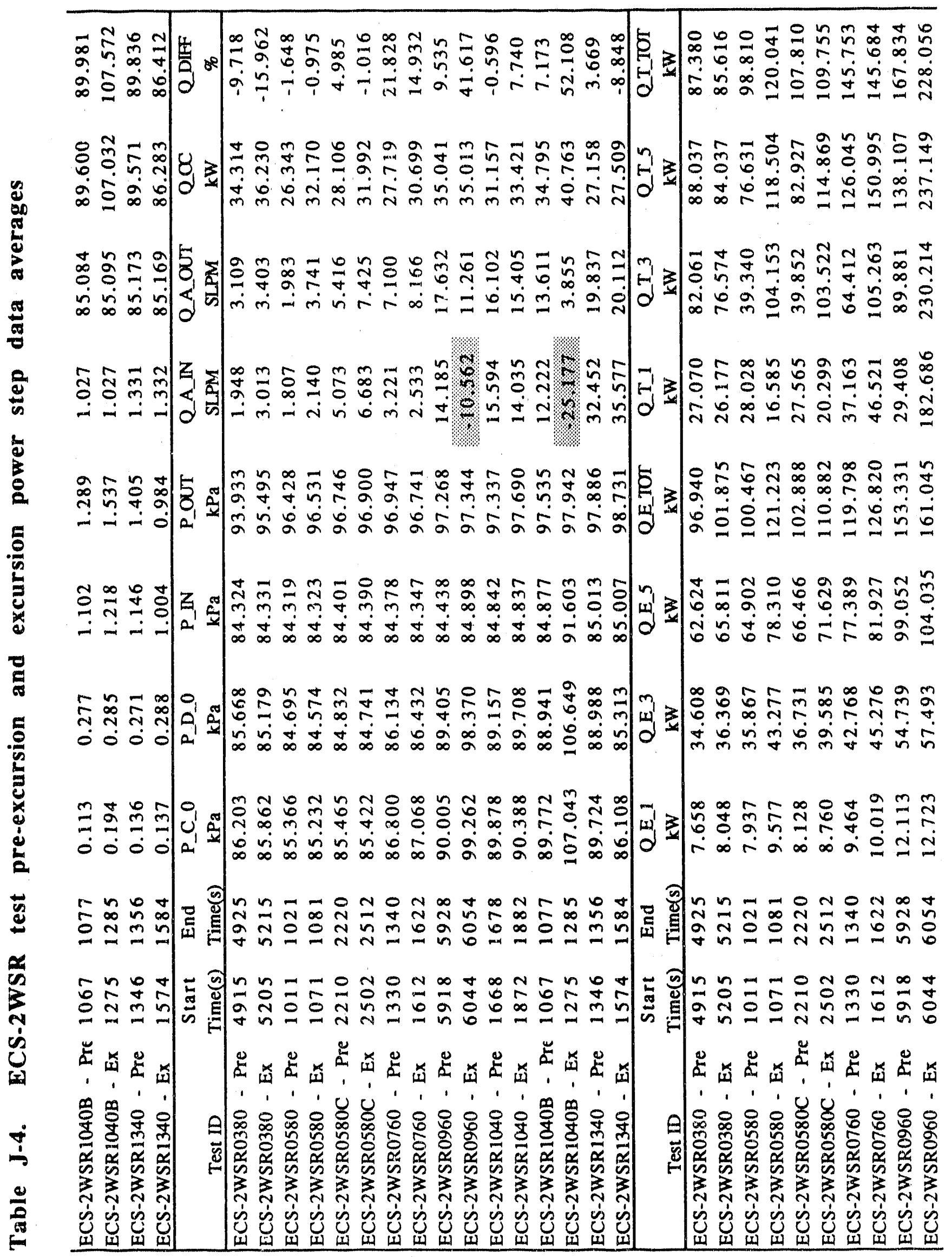




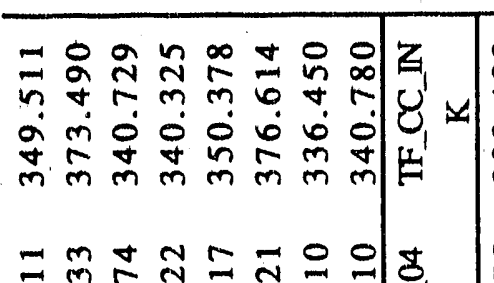

$\forall \stackrel{m}{n}$ m vim $\dot{\sim} \dot{0} \sim \dot{0}$

$m b m N m$

$m m$ en $m$ m $m$

a $n n$ 요요

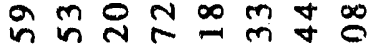
$\therefore m$ $\vec{m} \underset{m}{m} \bar{m} \vec{m}$ क $\vec{m}$ m

o $9 \operatorname{man} \infty$ o

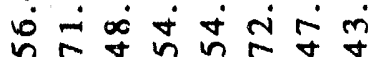

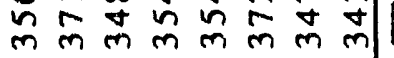

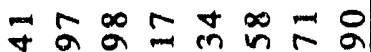
$-\infty$ b $r$ o $\forall$ y

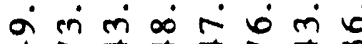
$\forall$
$m$

N $0+\infty \quad \infty \quad 0 \quad \infty$ a 0

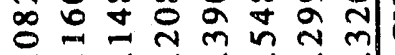
in $\dot{n} \dot{m} \dot{m} \dot{0} \dot{m}$ $m \sim n m m$ 를

:

这

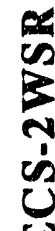

in $N=$ a 46. N) m $m$ m m m m

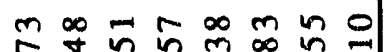

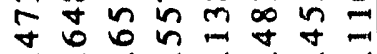

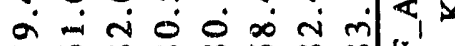

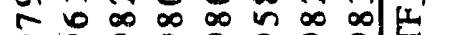

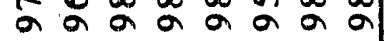

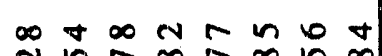

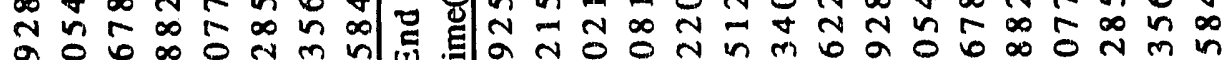

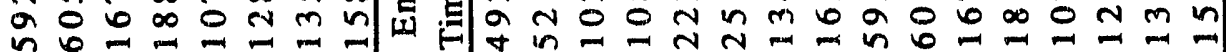

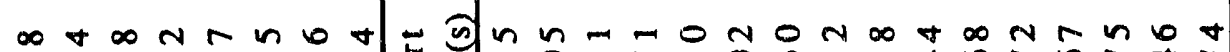

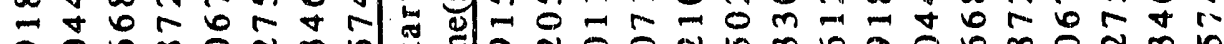

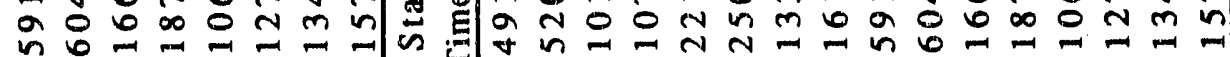

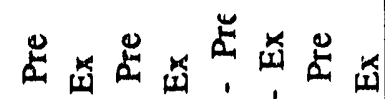

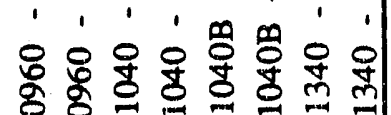

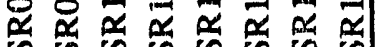

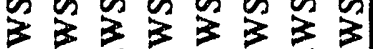

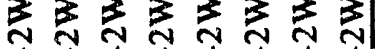

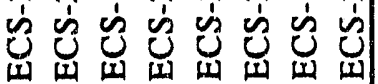

సี

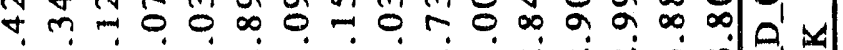

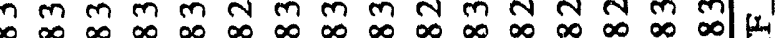

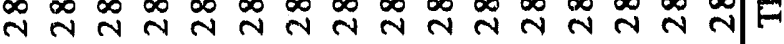

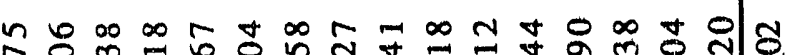

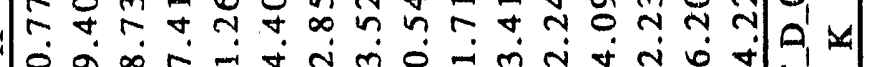

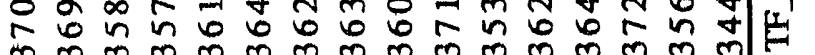

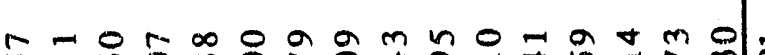

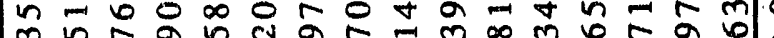

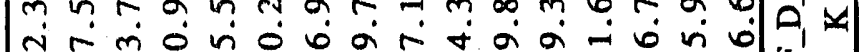

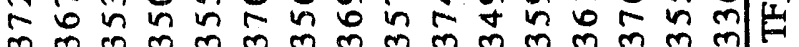

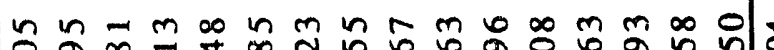
a)

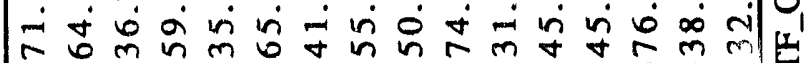

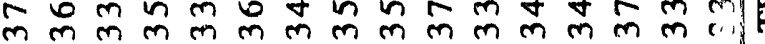

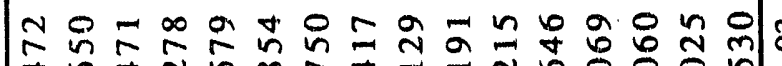
$M \mid$

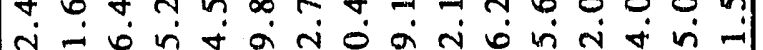

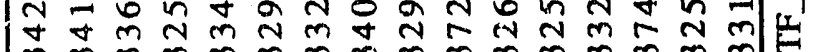
$m m n m m m m m m m m m$

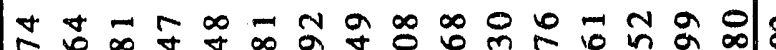

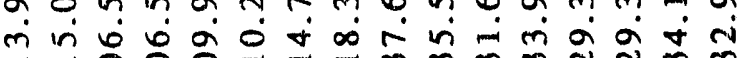

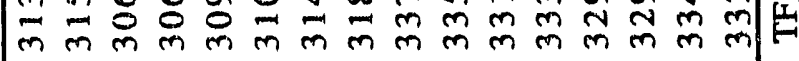

m 40

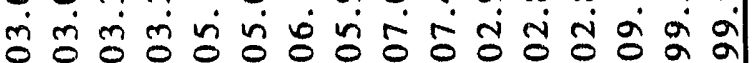
$m$ m $m$ m $m$ m $m$ m $m$ m $m$ m $m$ m $m$ i

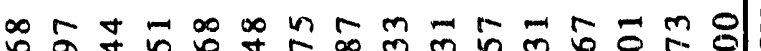

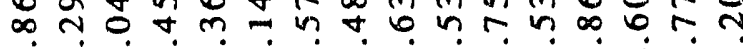

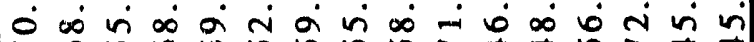

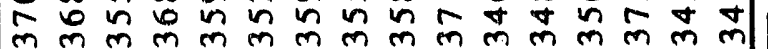
a)

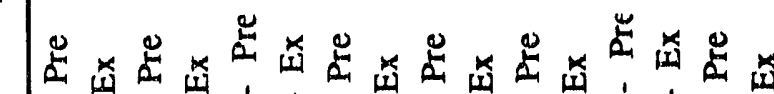

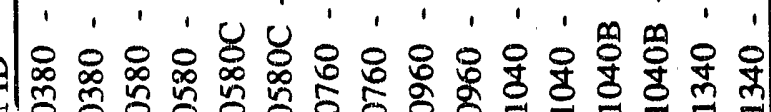

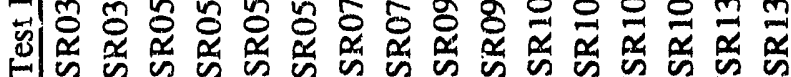

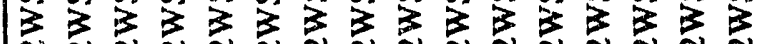
ฟ

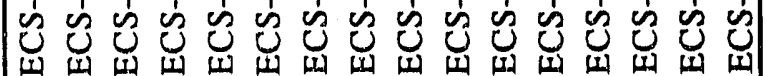

F a $\forall \because \pi+\infty$ $0 N m-\infty$ in $\hat{m} \approx m$ m $m$ m

$\pi \approx n m \pm 6$ m $0 \mathrm{~N}$.

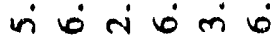
$\begin{array}{llllll}0 & 0 & N & 0 & N & 0 \\ m & m & m & m & m & m\end{array}$

$-6 \sim 6 m=$ $\stackrel{N}{\pi} \underset{\infty}{\infty} \stackrel{\infty}{\sim}$ $m$ in 6 o $r \infty$

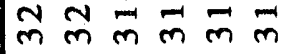

n $4 \infty-1+$

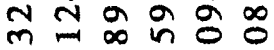
0 m $\dot{\pi} \dot{0} 0$ $\hat{m} \sim m$ m $m$

$m$ en $n \infty \pm n$

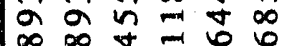

$\infty \dot{-i} \dot{\sim} \dot{0} 0$ m $m$ m $m$ m

윰휴 त $m$ b a $y$ i a m

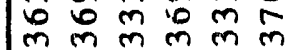

$m=0$ a $\$ m$ m $\infty$ a cy a

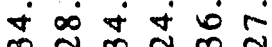
$m$ m $m$ m $m$ m

는요용 \& N N a $\sim \dot{0} \dot{\sim} \sim r$ m $\forall$ m $n$ ल

⿹ $n n-m-0 N$

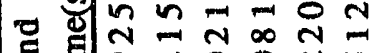
in

- ⿹勹 nn- $n-0$ n ㄷำ $0=120$ a $N 00 N$ n

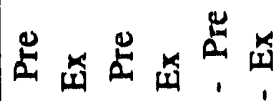

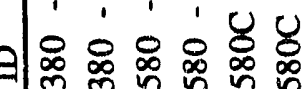
பั)

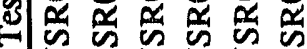

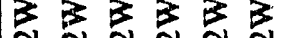
के मे iे के के 


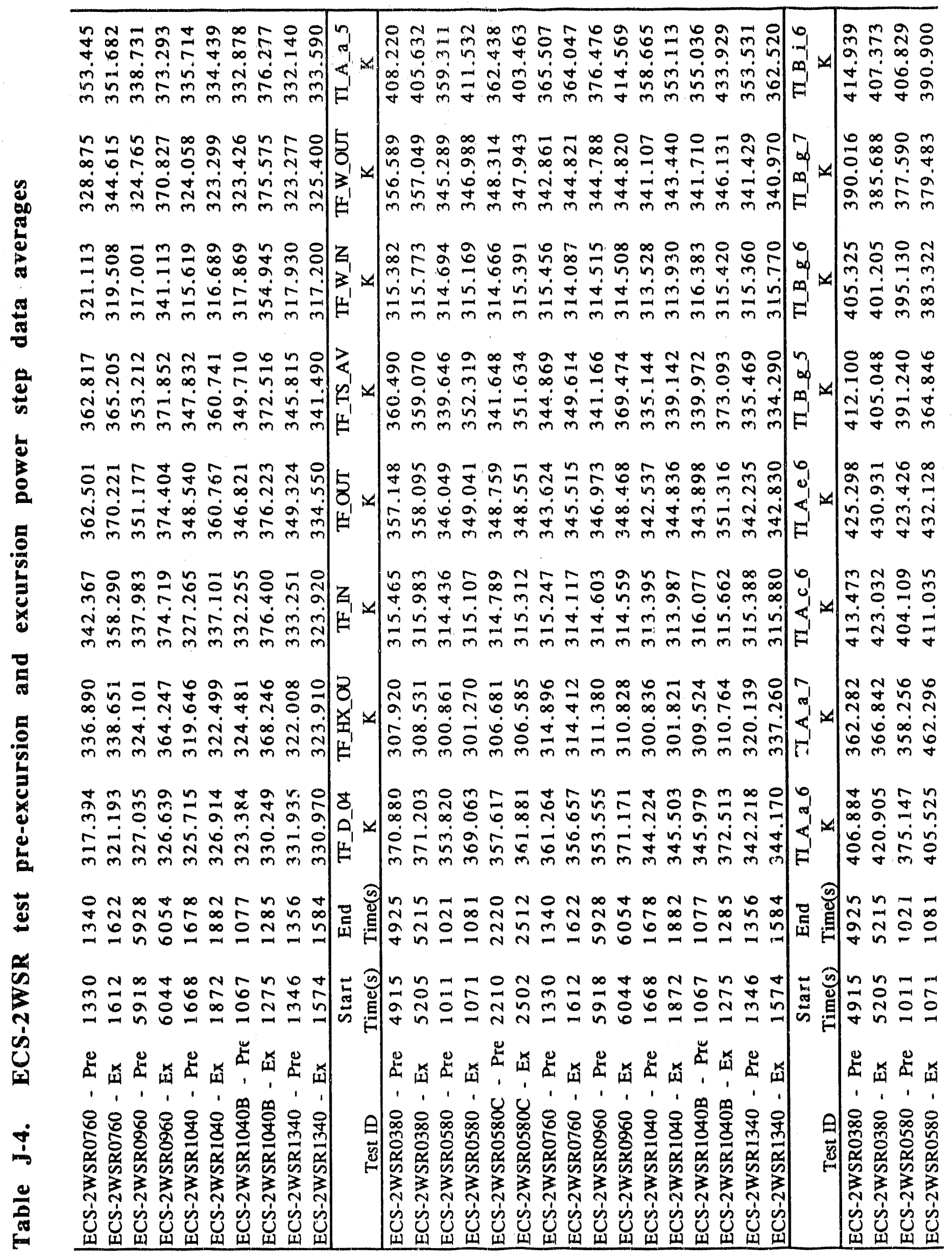


*nผ

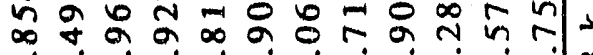

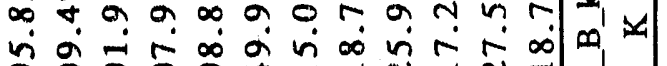
잉

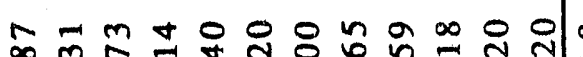

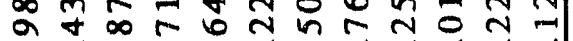

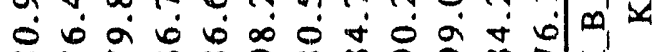

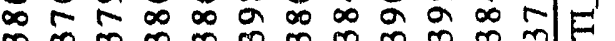

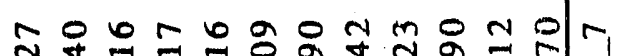
N

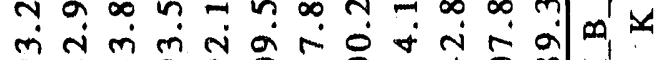

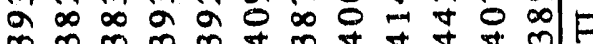

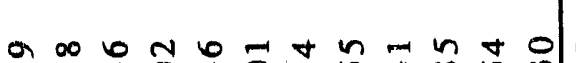

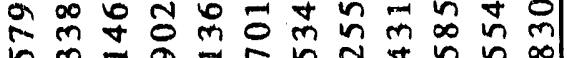
욜 m. a

m

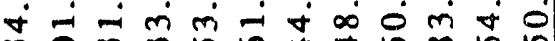
moj

Zm $m$ a

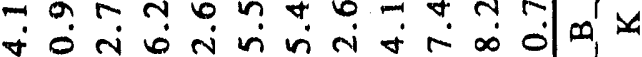

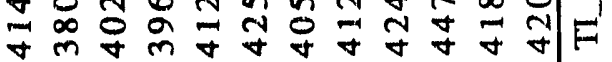

Non $00 \infty \pi+\infty \pi-0$

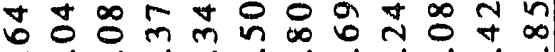

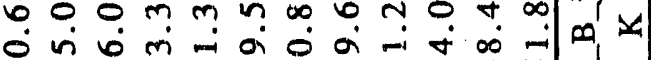

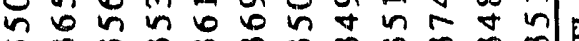
$m m m m m m m$

$\infty r a$ o n o n m $r$ a $m$

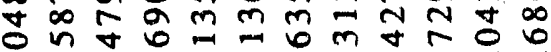

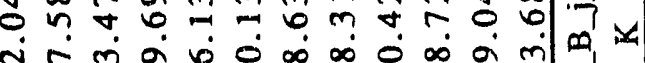

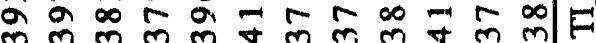

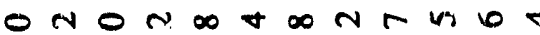

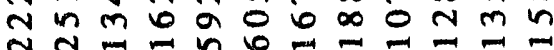

0 N

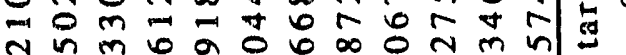

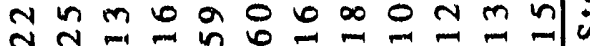

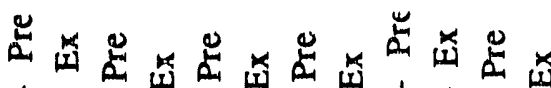

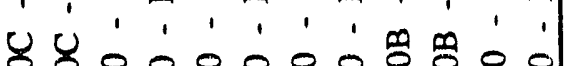

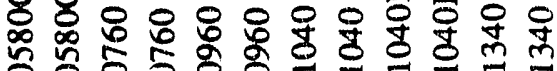

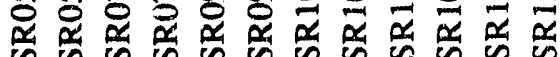

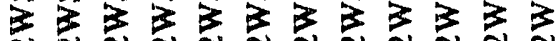
ฟ

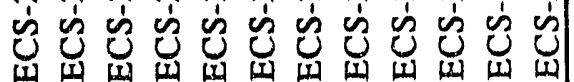

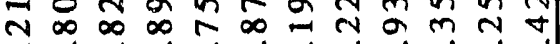

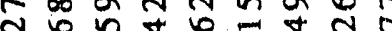
N

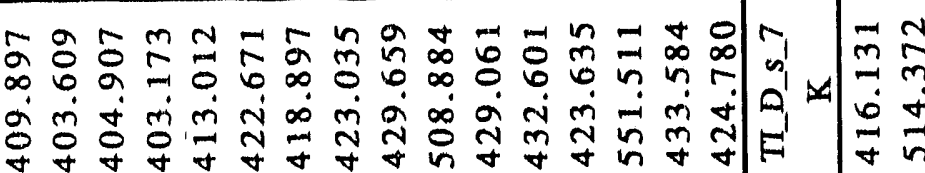

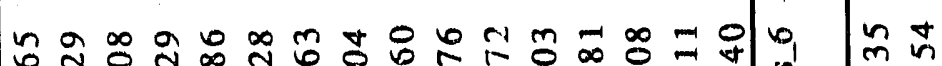

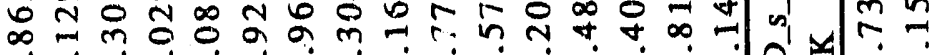

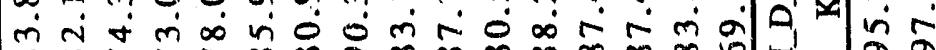

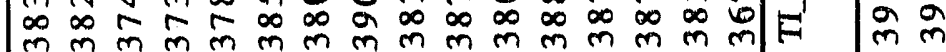

$0 \forall m \infty n \infty$ o ก

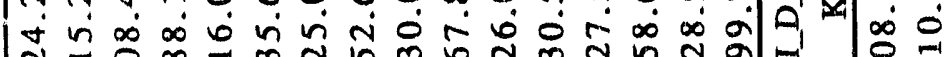

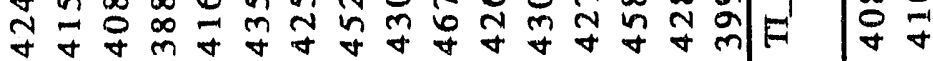
0 o 0 l $m$ n

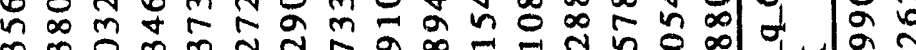

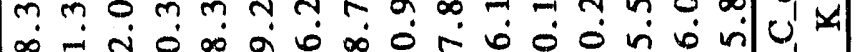

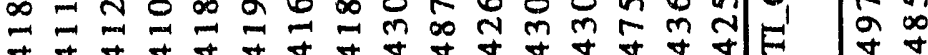

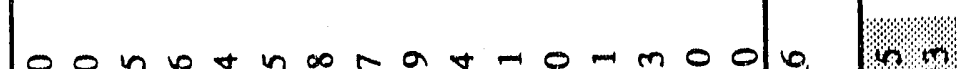

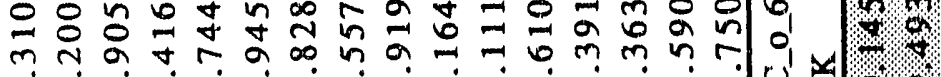

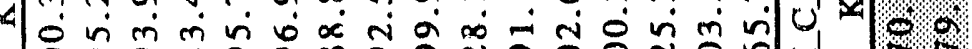

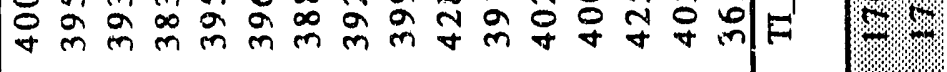

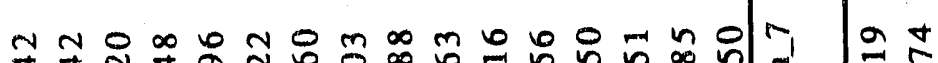
サ

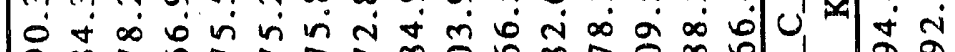

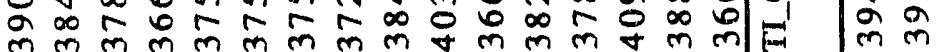

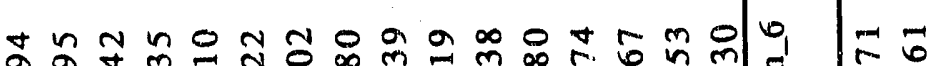

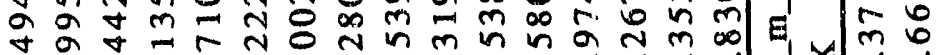

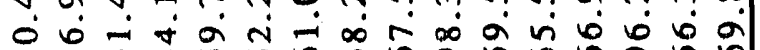

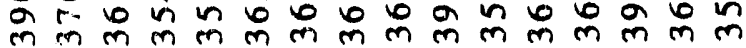
a $n-1-a m+\infty n-00-1 m \infty 0$

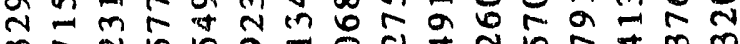

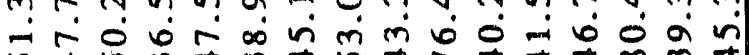

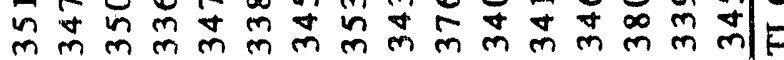

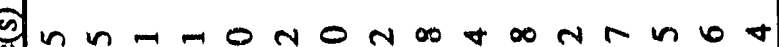

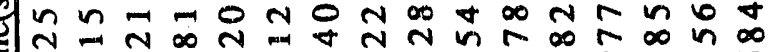

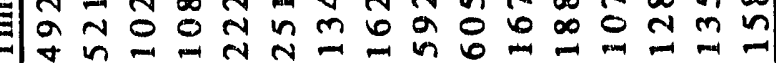

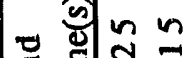

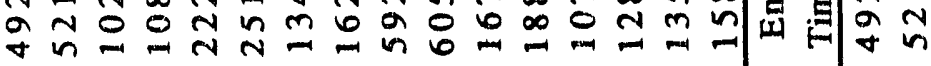

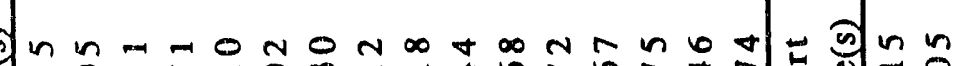

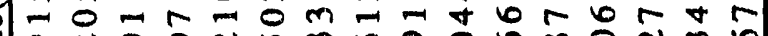
a $N$ O 0 N $n$ m 0 a 0 lo

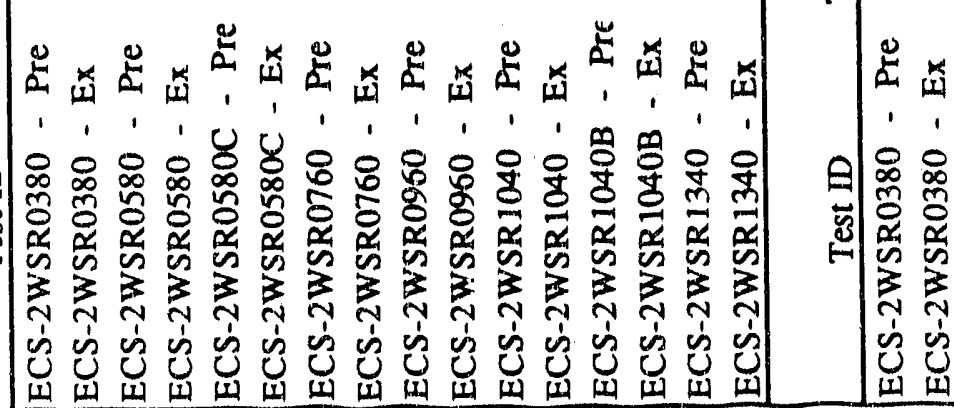
E n $\sum_{i=1}$ y $n$ 


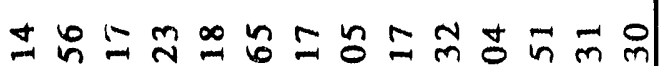

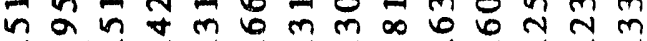

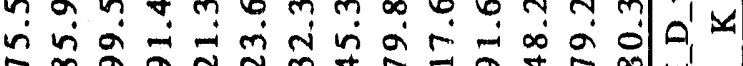

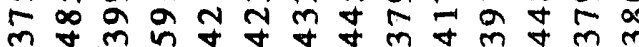

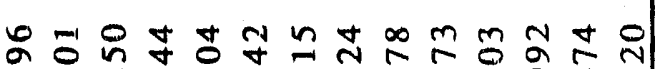
$0 \sim \infty N 0 \infty 0 \geqslant 0$ a $m 0 \quad y$ in б m $\forall$ y

$\infty \pi$ a

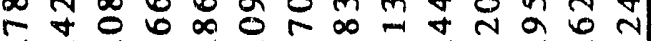

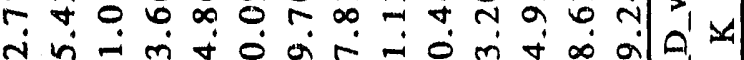
o $=\pi \cdots$

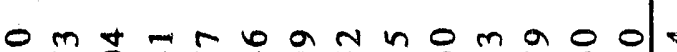
$m$ ? $\infty$ o

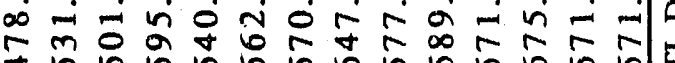

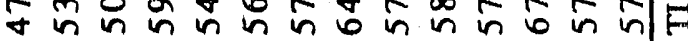

1

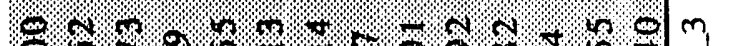

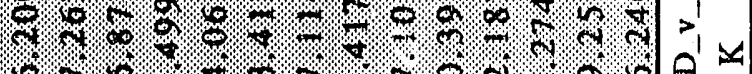

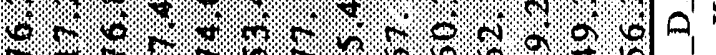

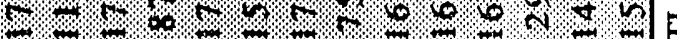

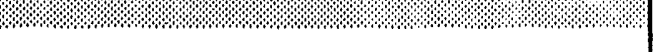

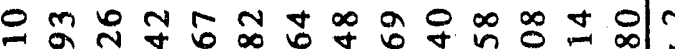
$\exists$ I 0 出

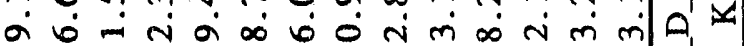

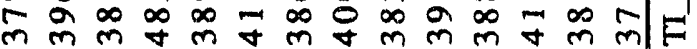

ㄱํำ

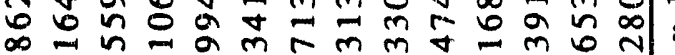

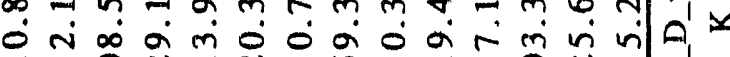

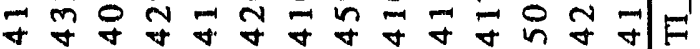

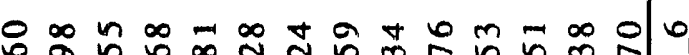

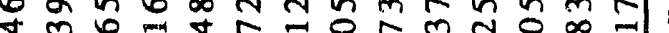

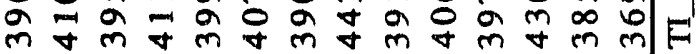

m m

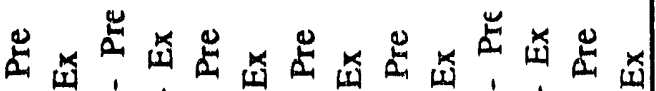

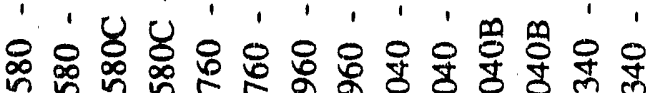

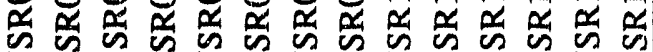

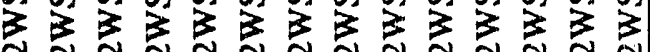
4 त

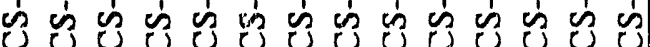

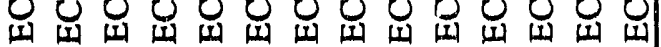

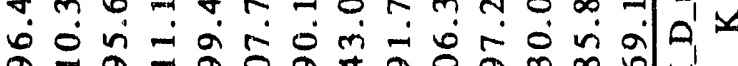

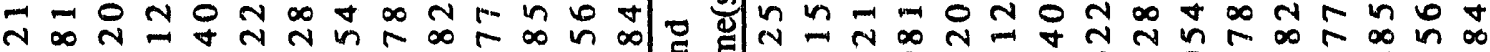

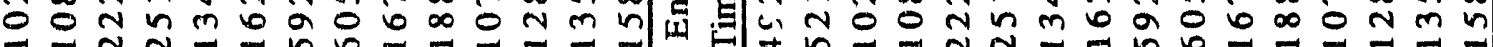

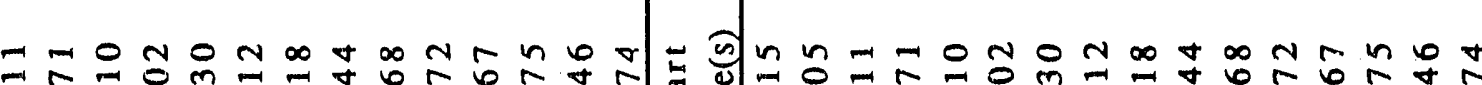

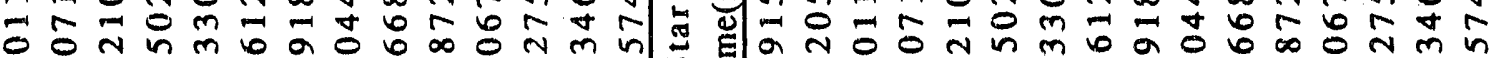

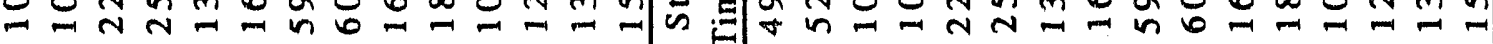
它

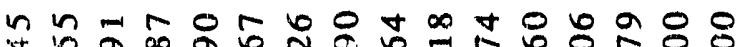

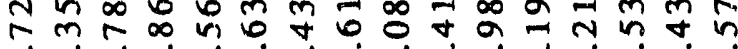

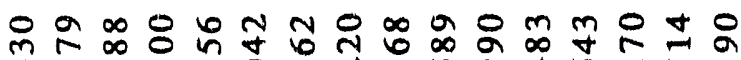
$\forall+\infty$.

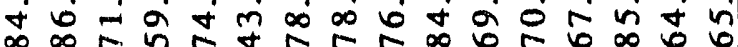

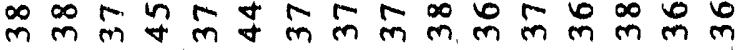
$\Rightarrow 8$ ำ lo $b$ in $r$ a a 90 .

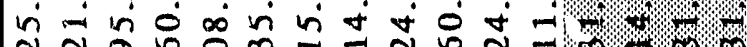

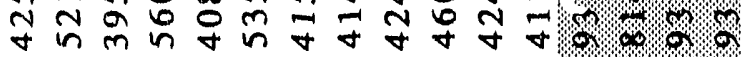

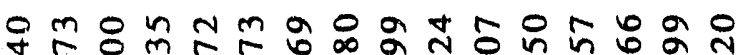
$\infty \forall \infty$ a $m$ b a $m$ n in $\infty$ b $n$ b $1-N$

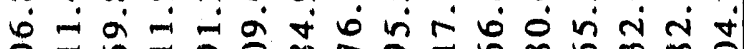

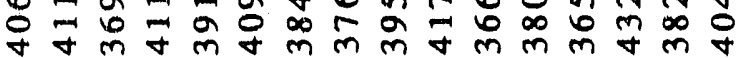

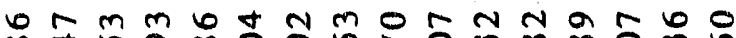
$\infty \forall n g$ 舟

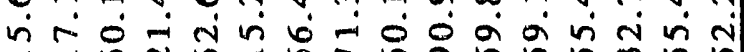

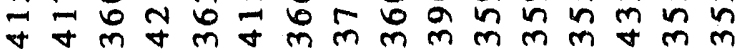

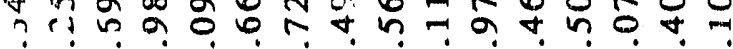

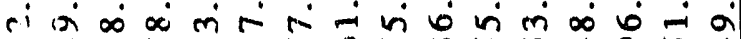

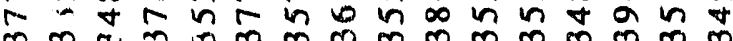

n -1 ก

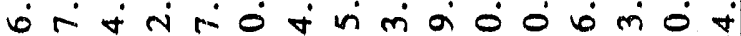

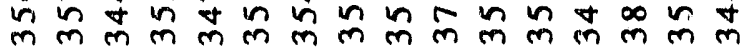

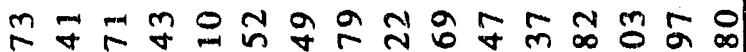

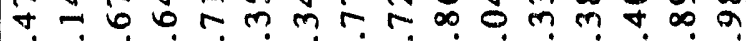

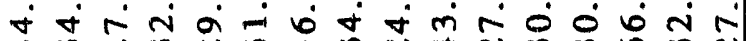

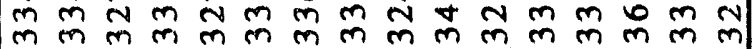
1.8.

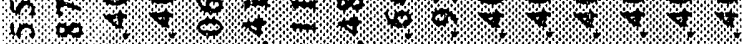

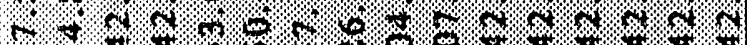

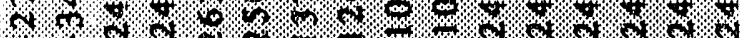

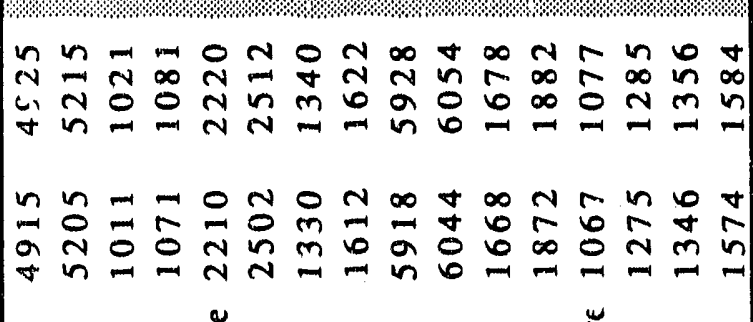

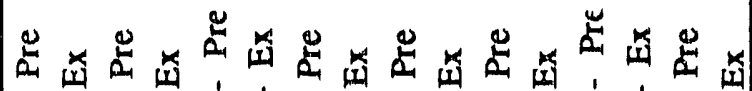

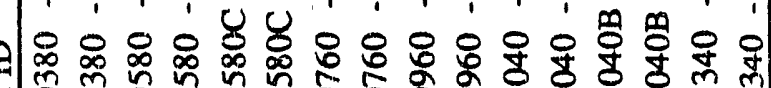
:

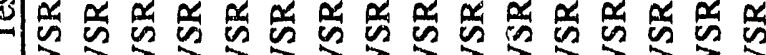

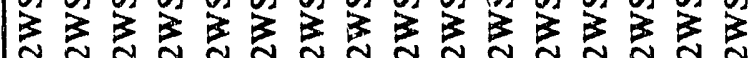

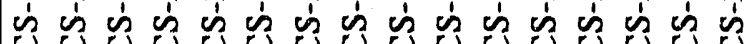

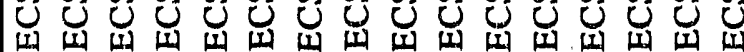


0

5
8
8

톨

를

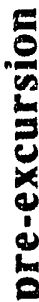

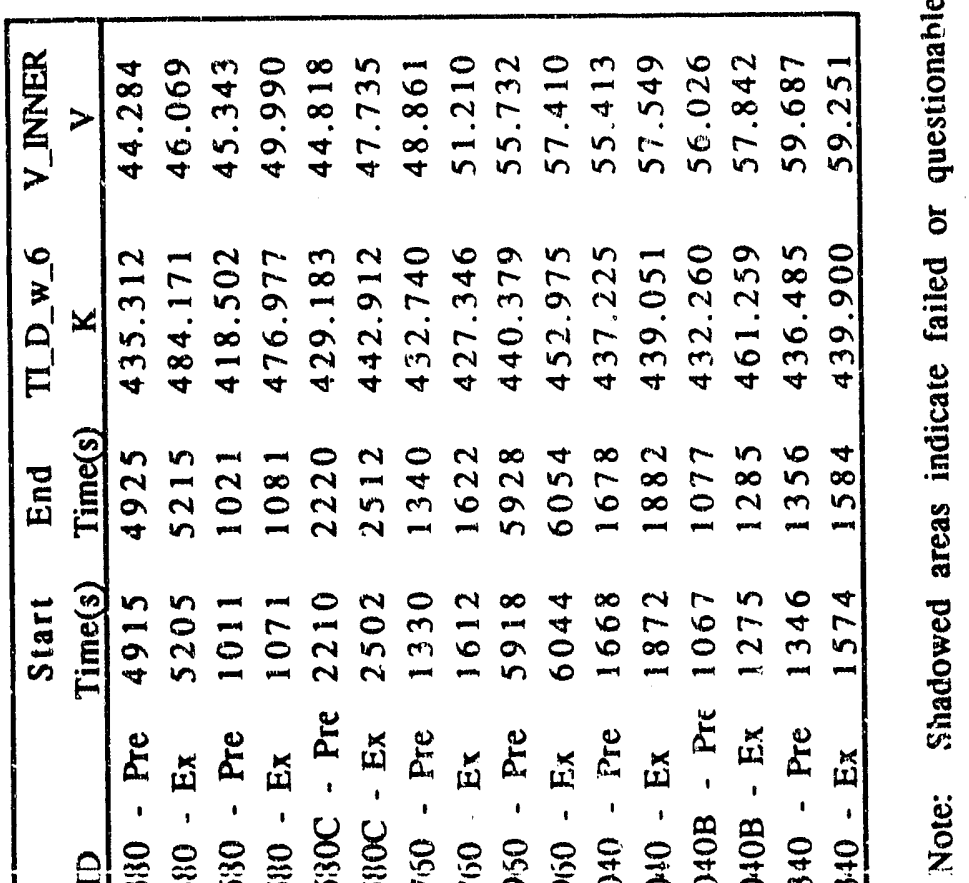

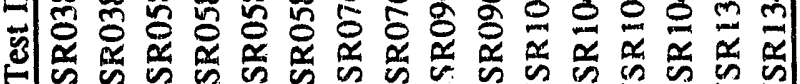

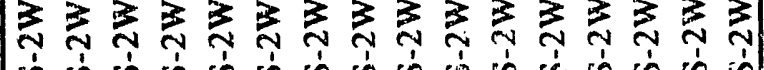

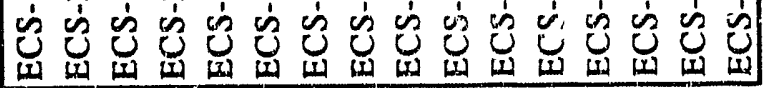




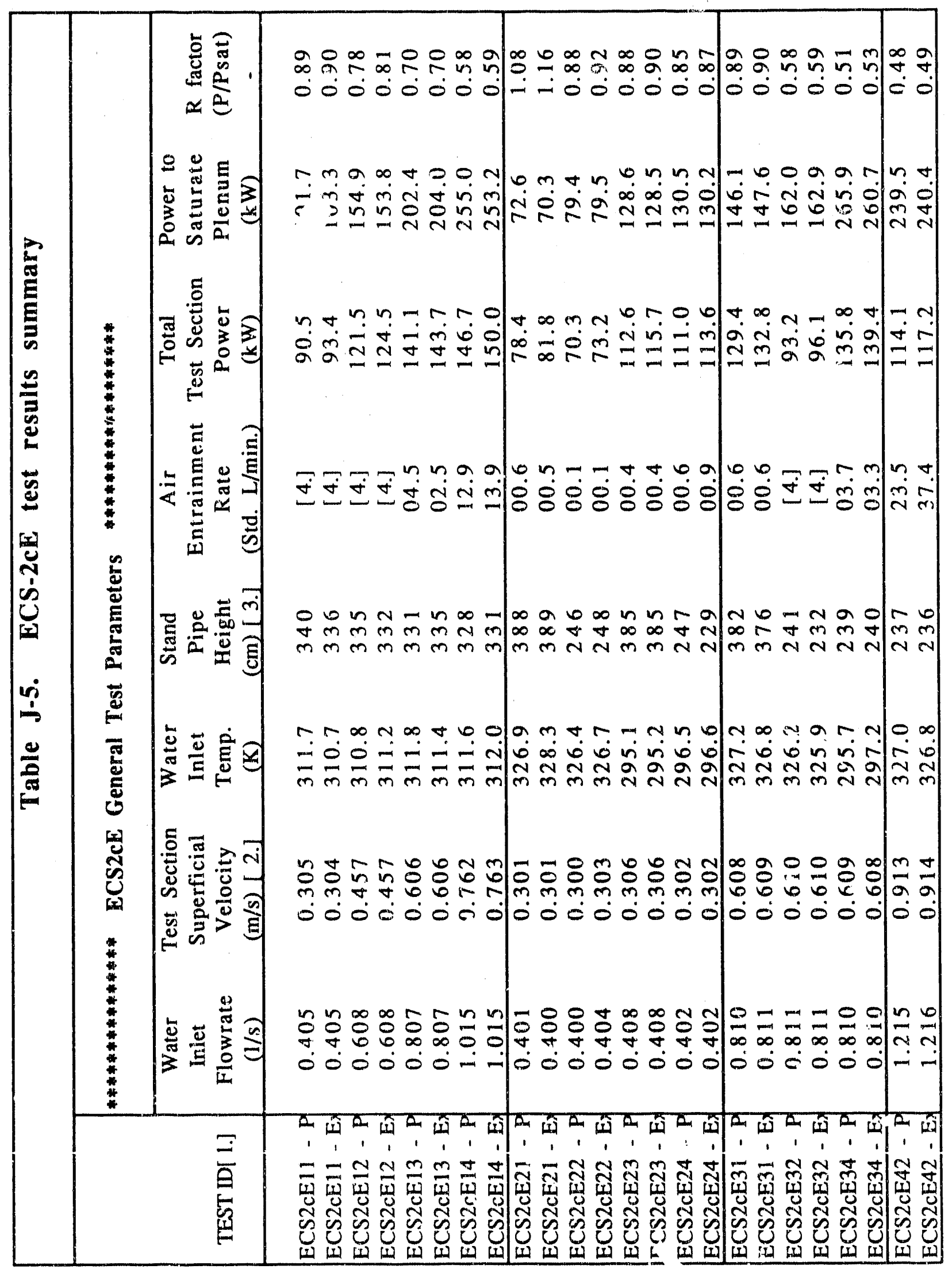




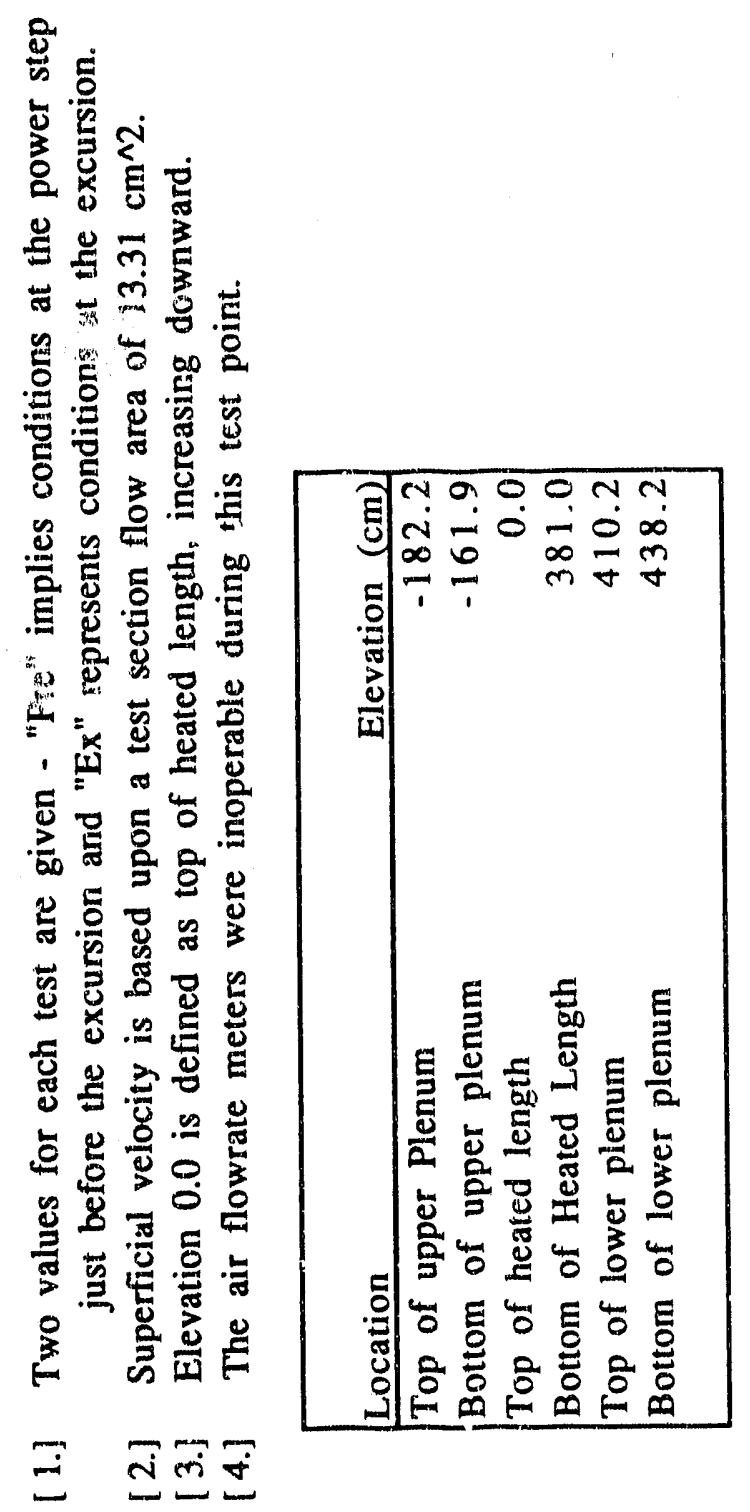




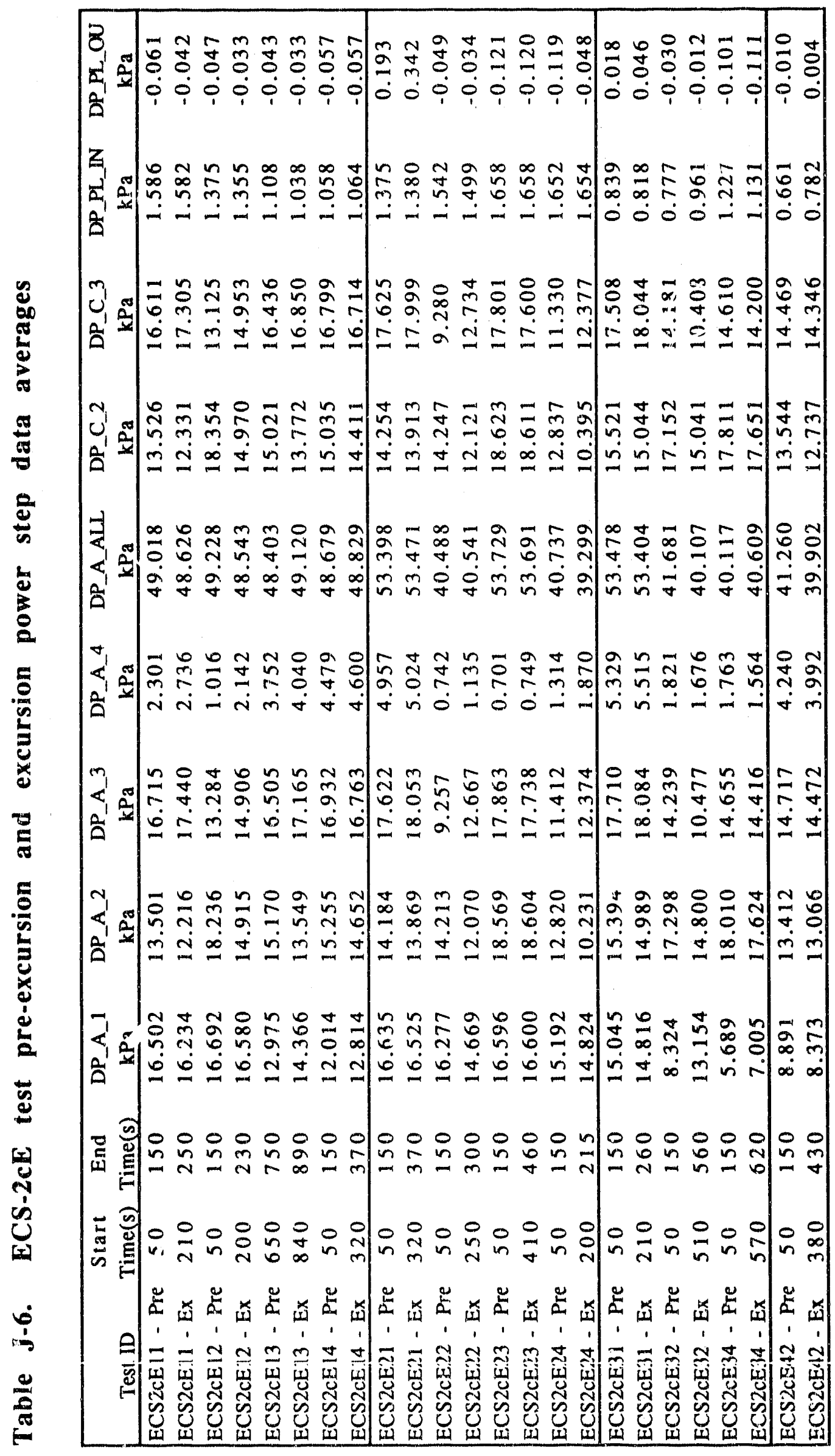




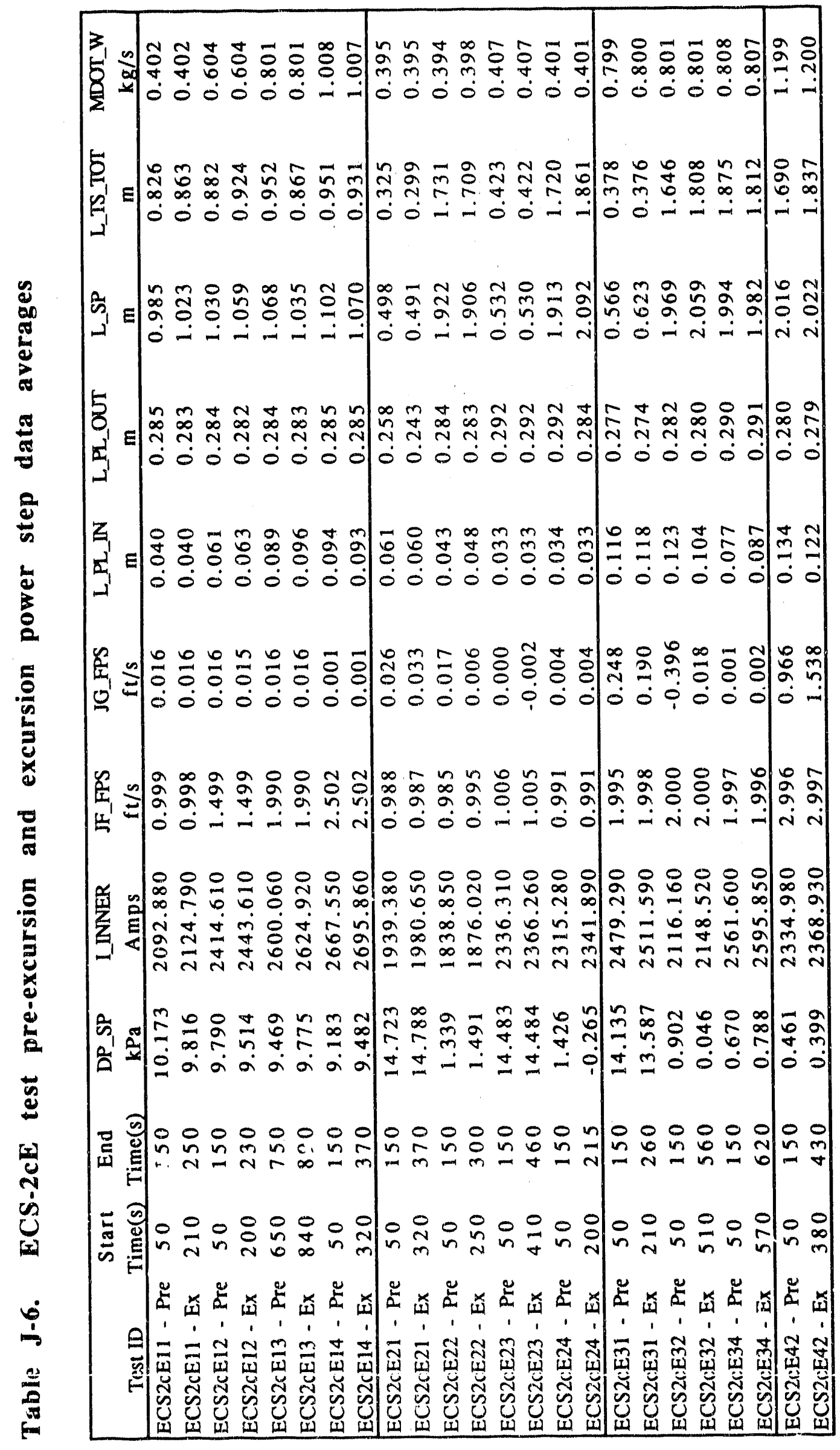




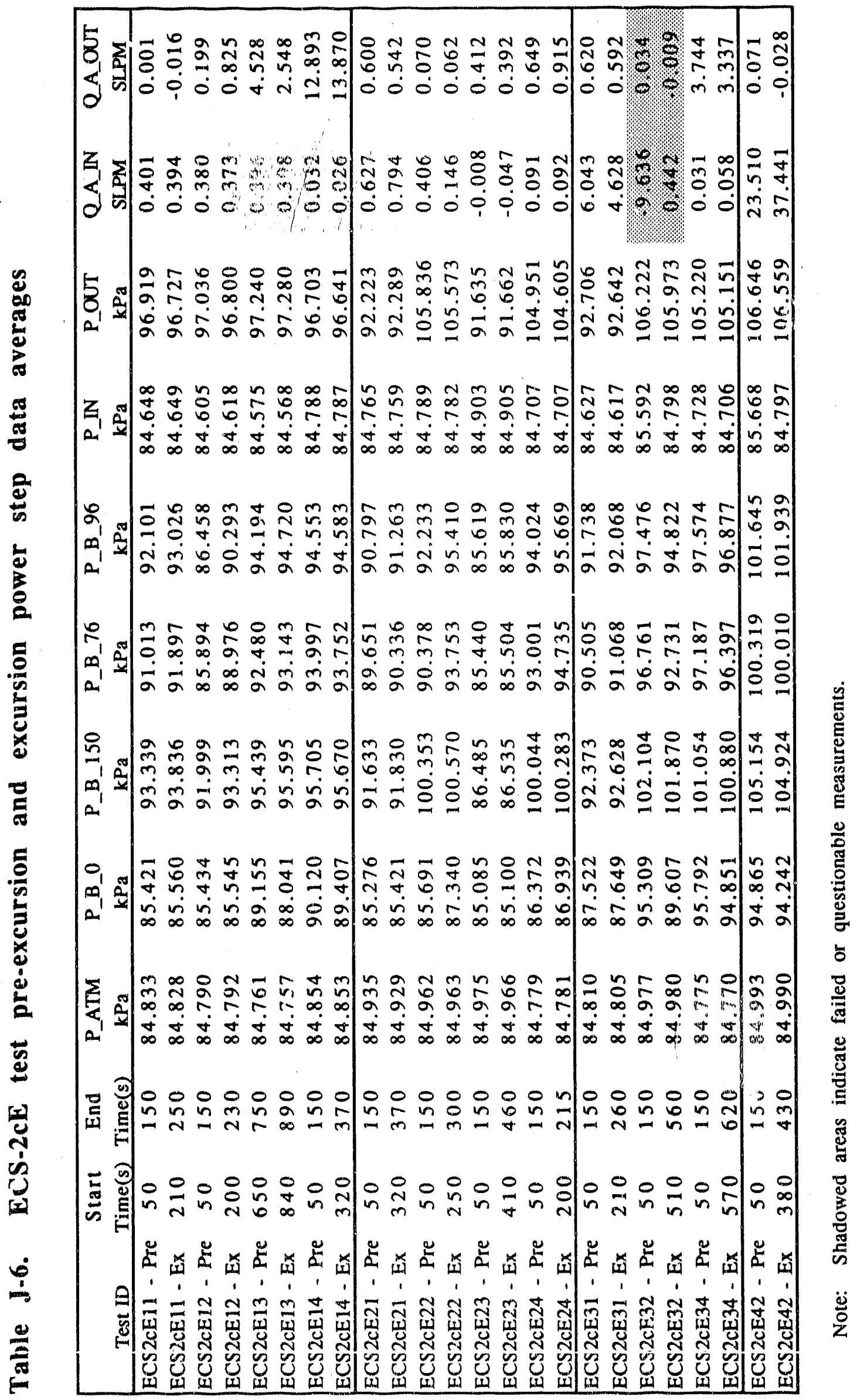




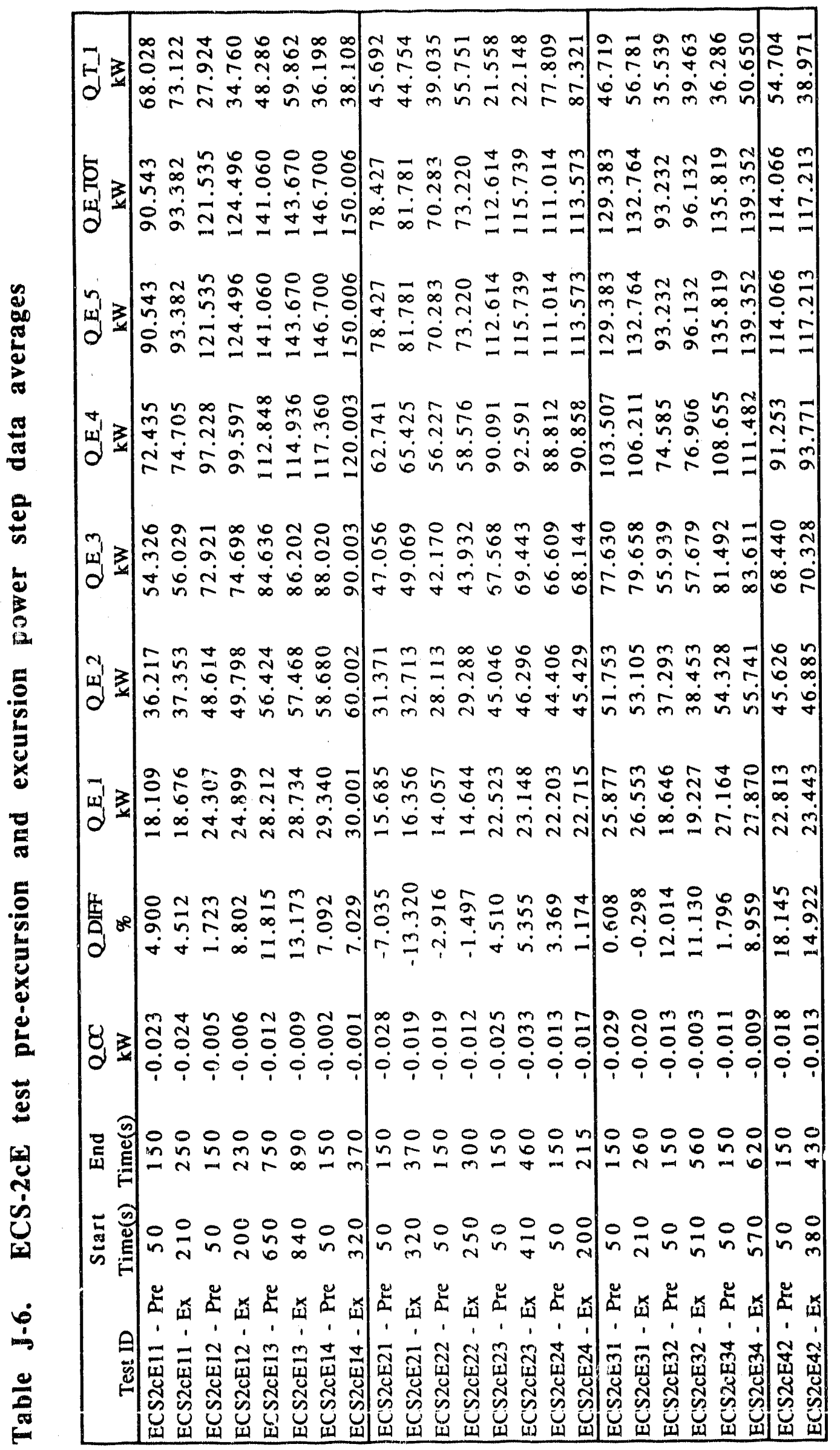




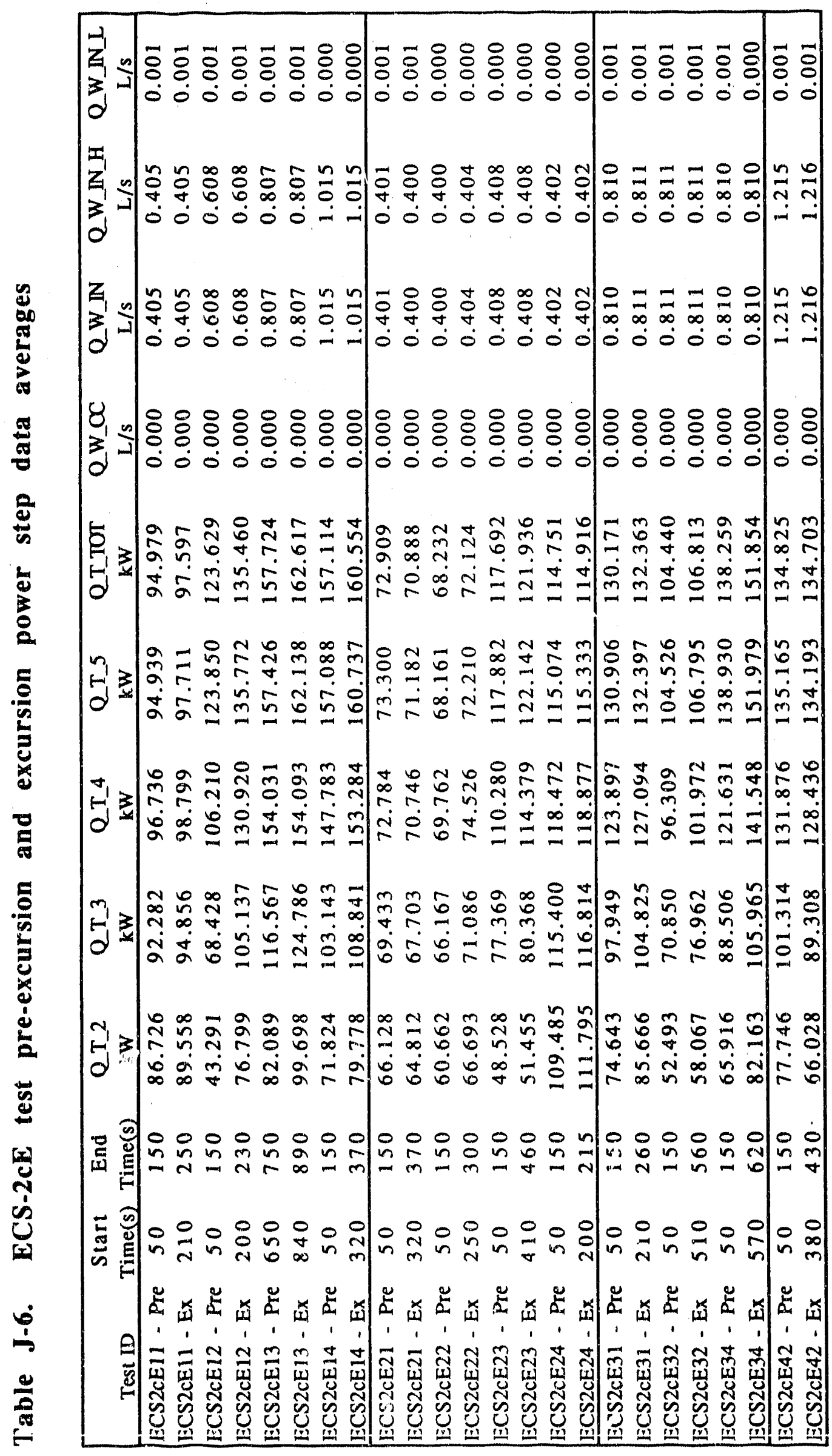




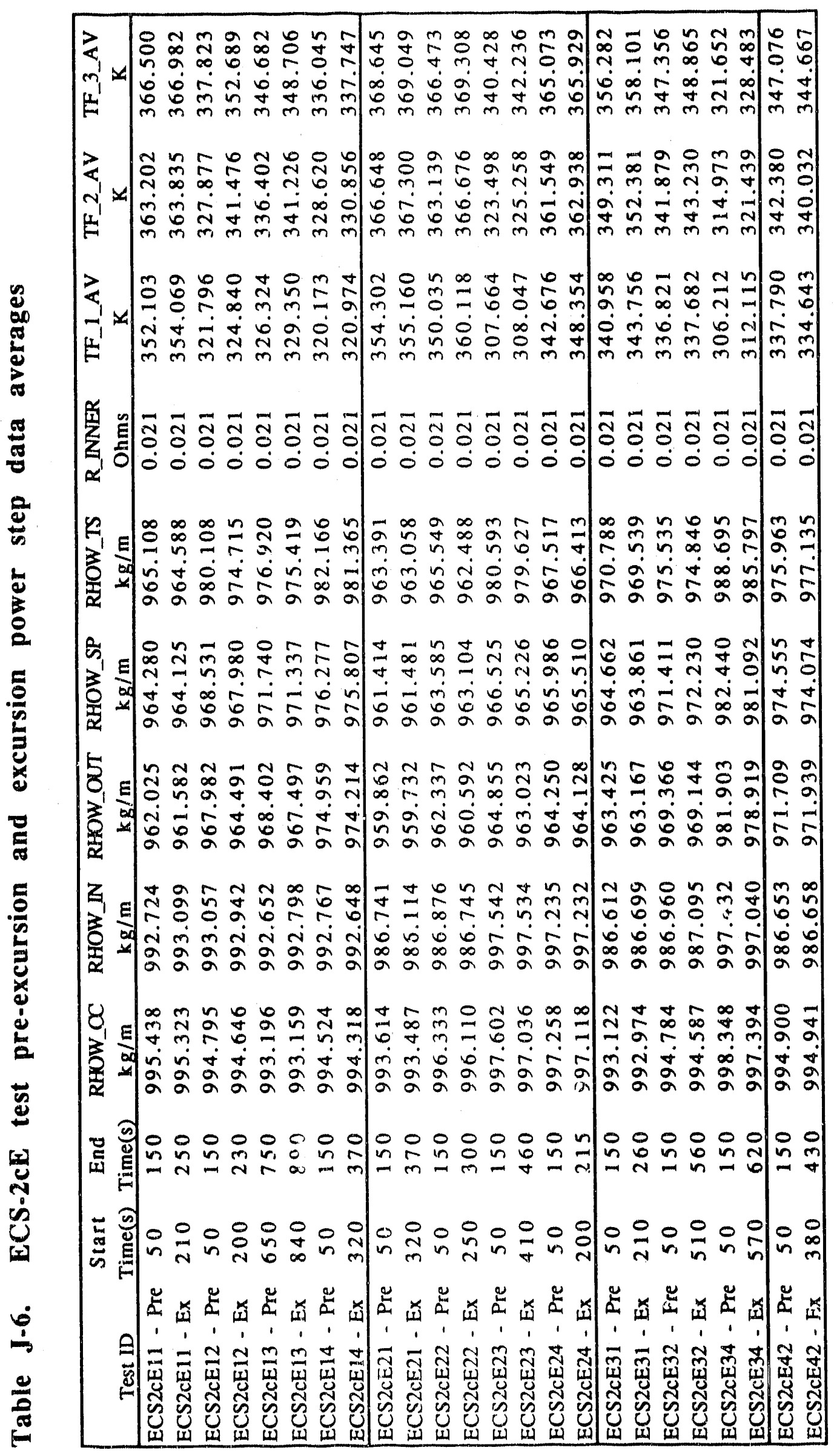




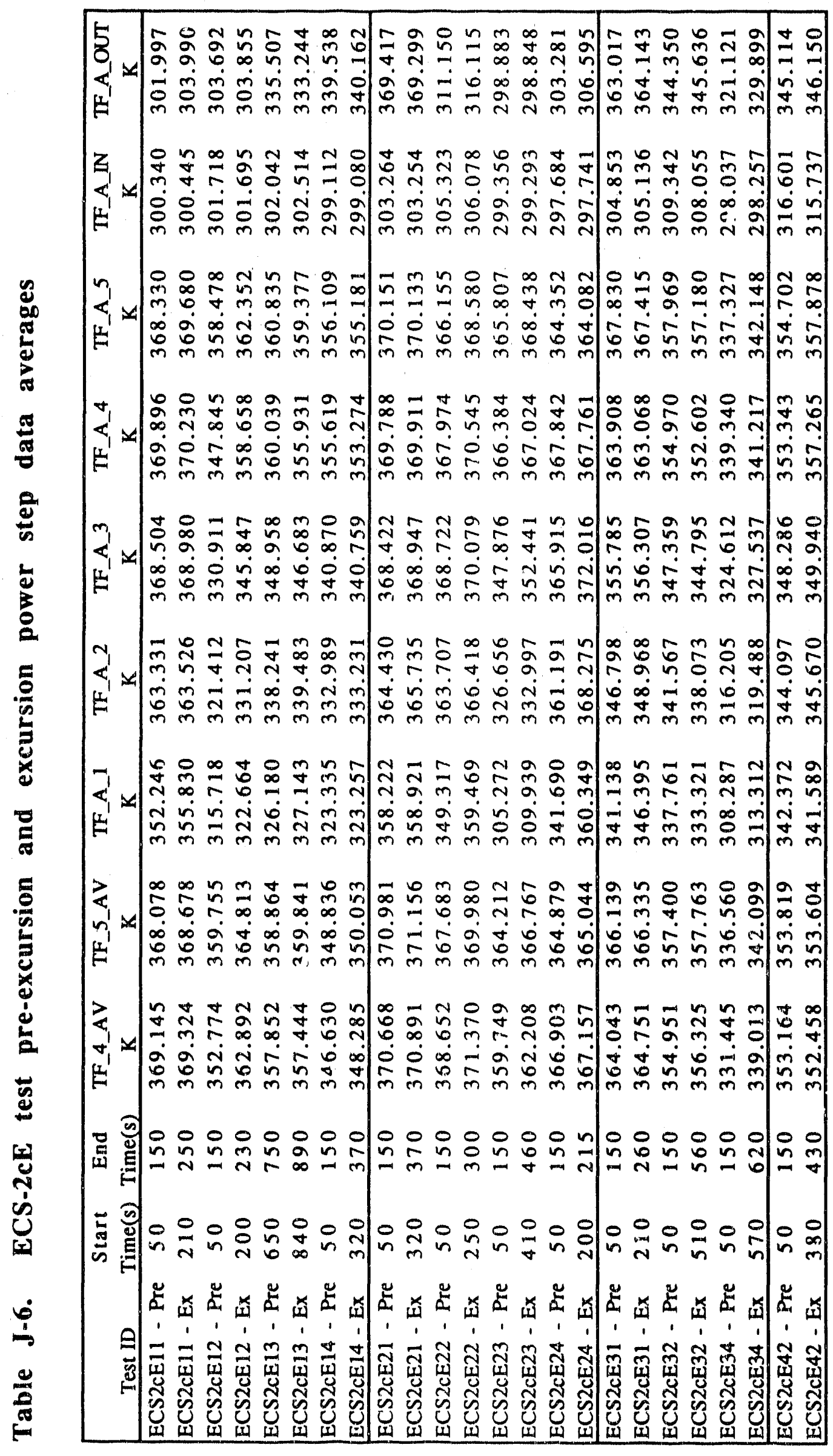




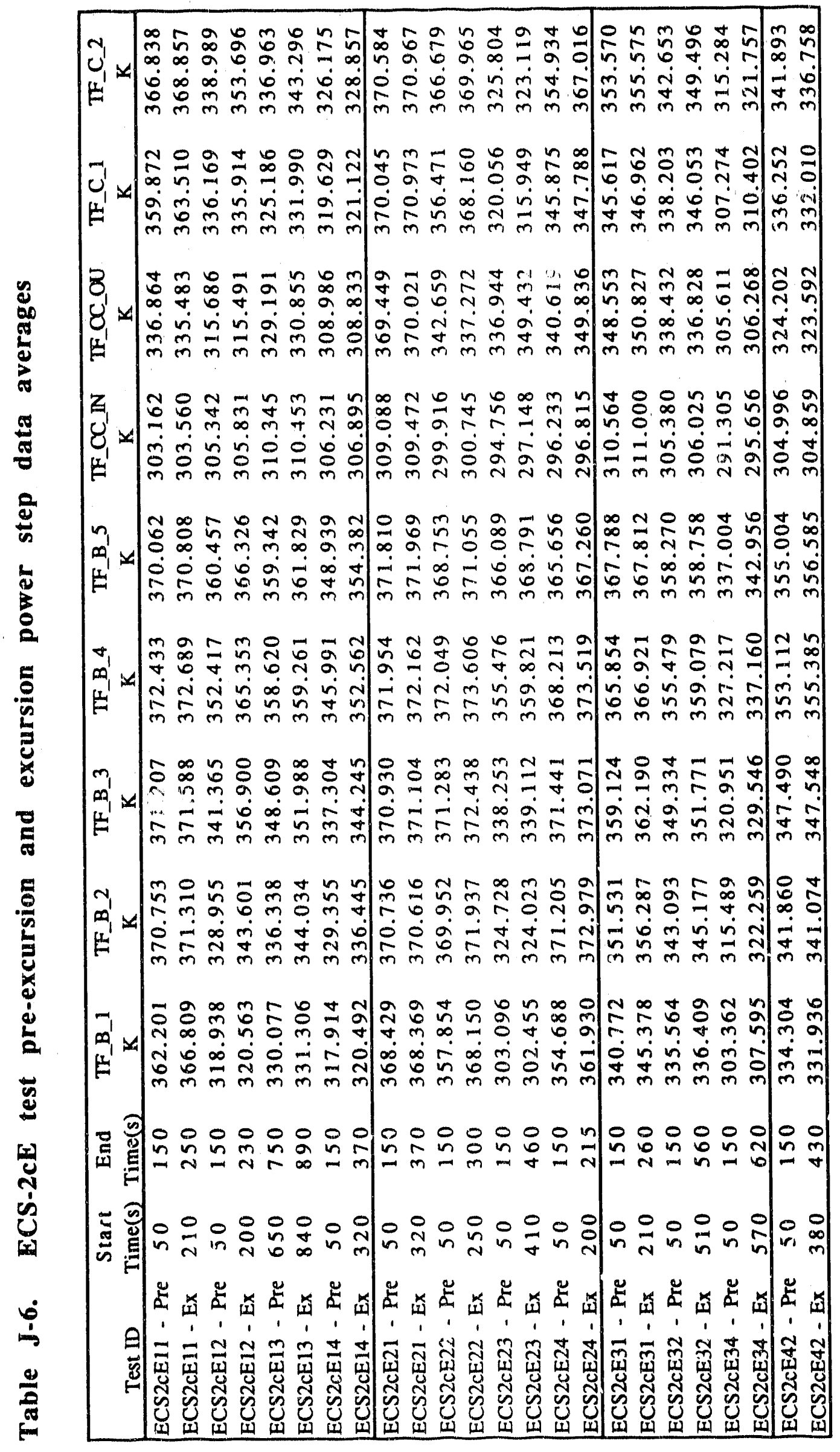




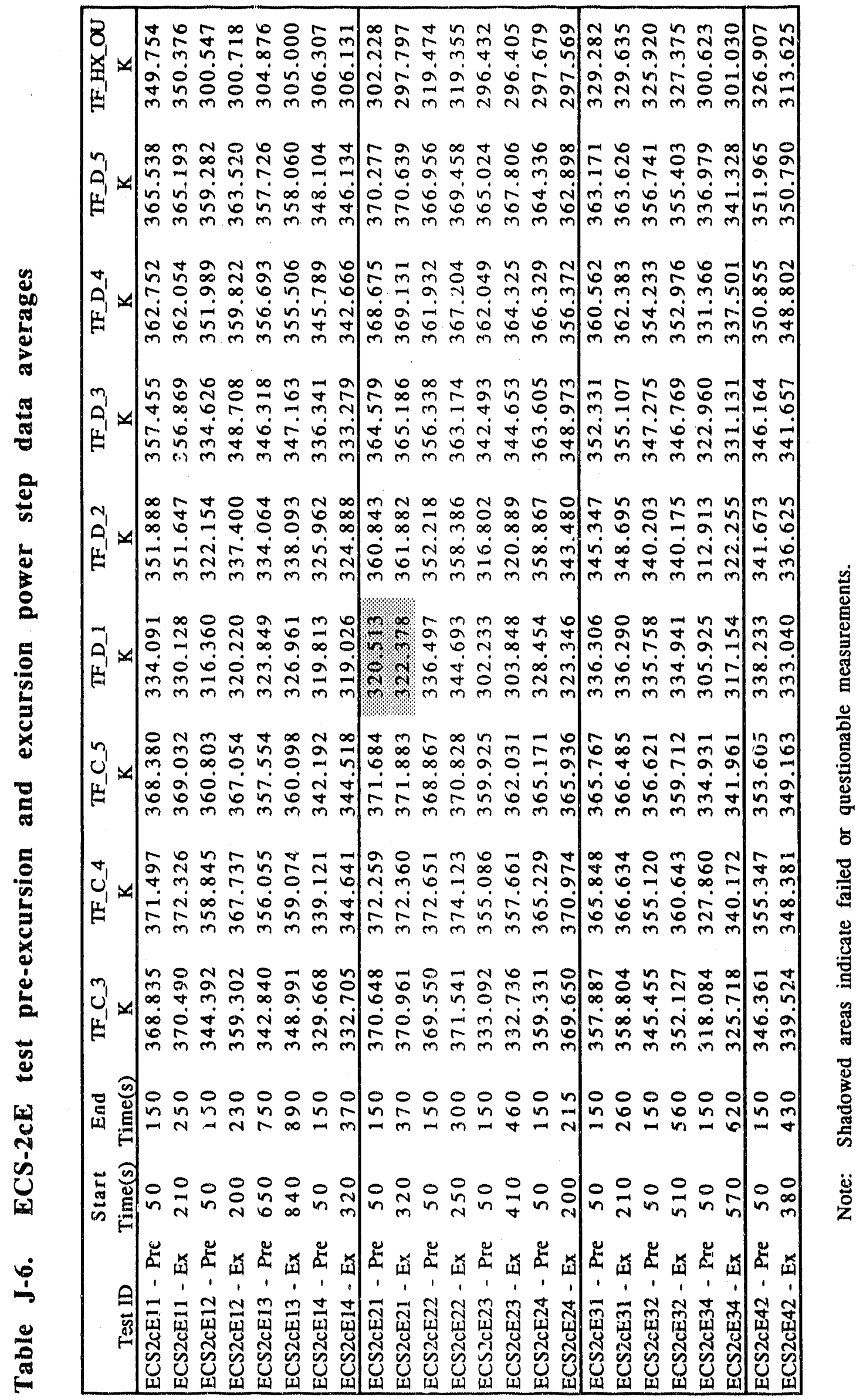




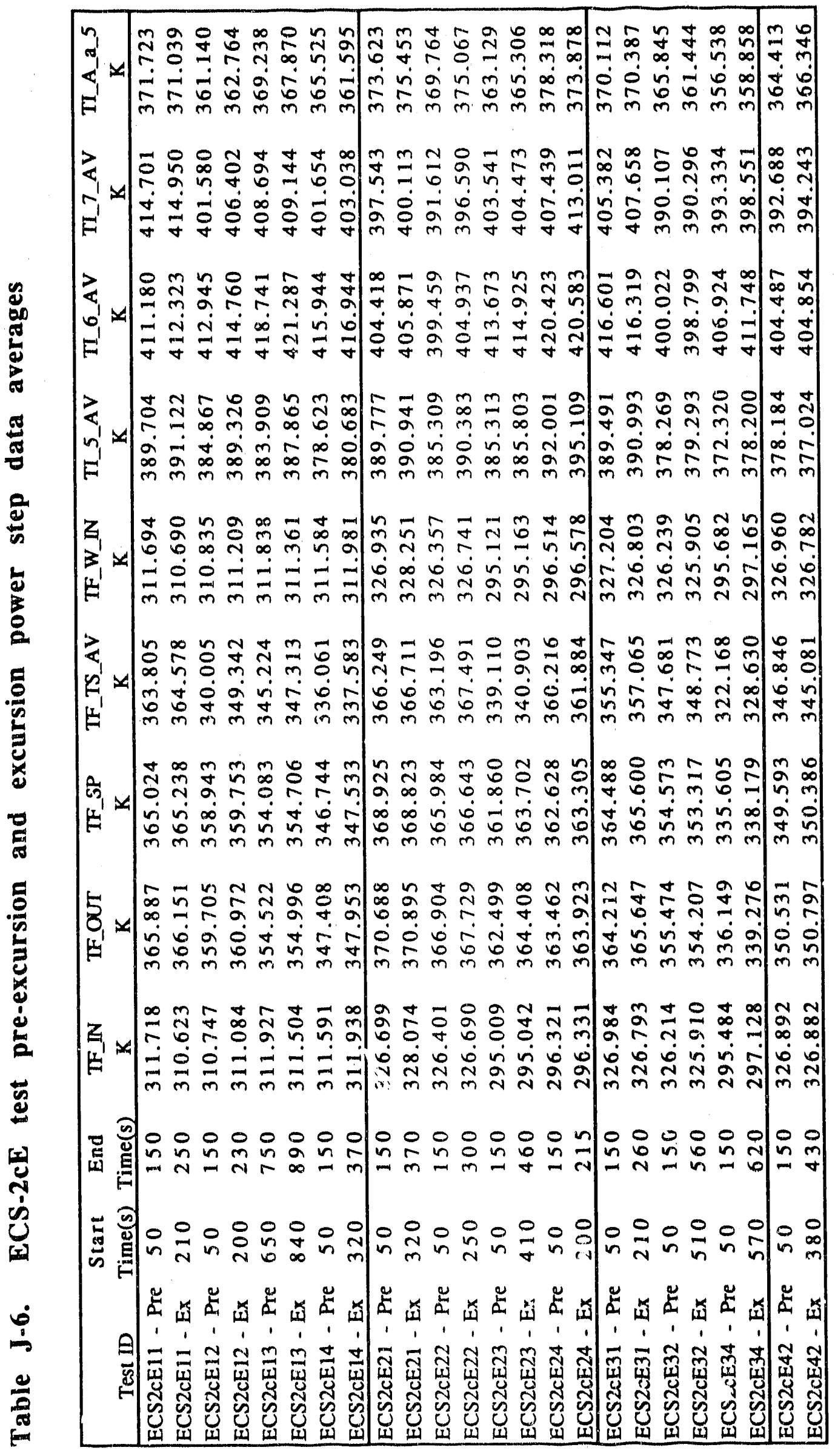




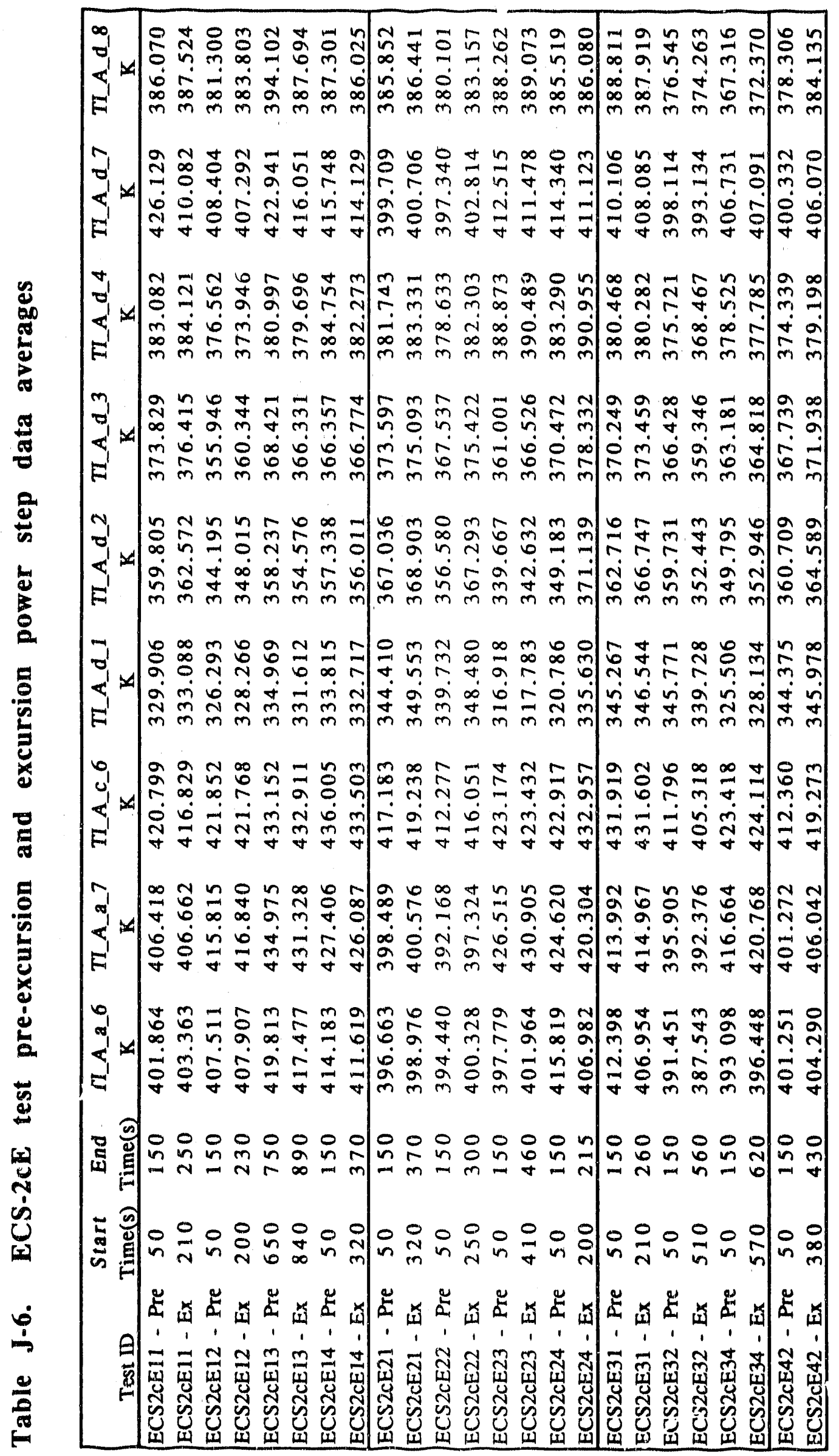




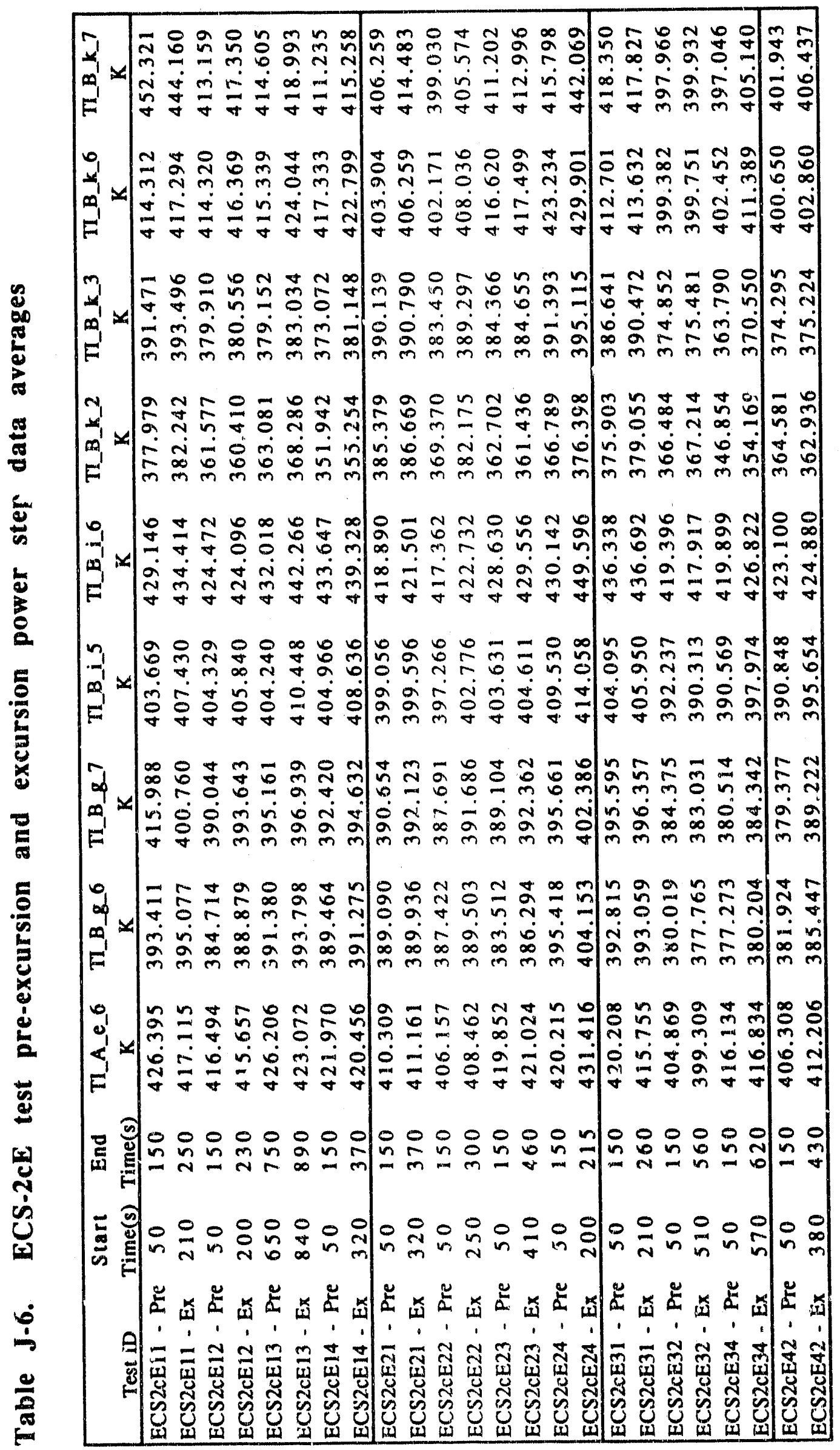




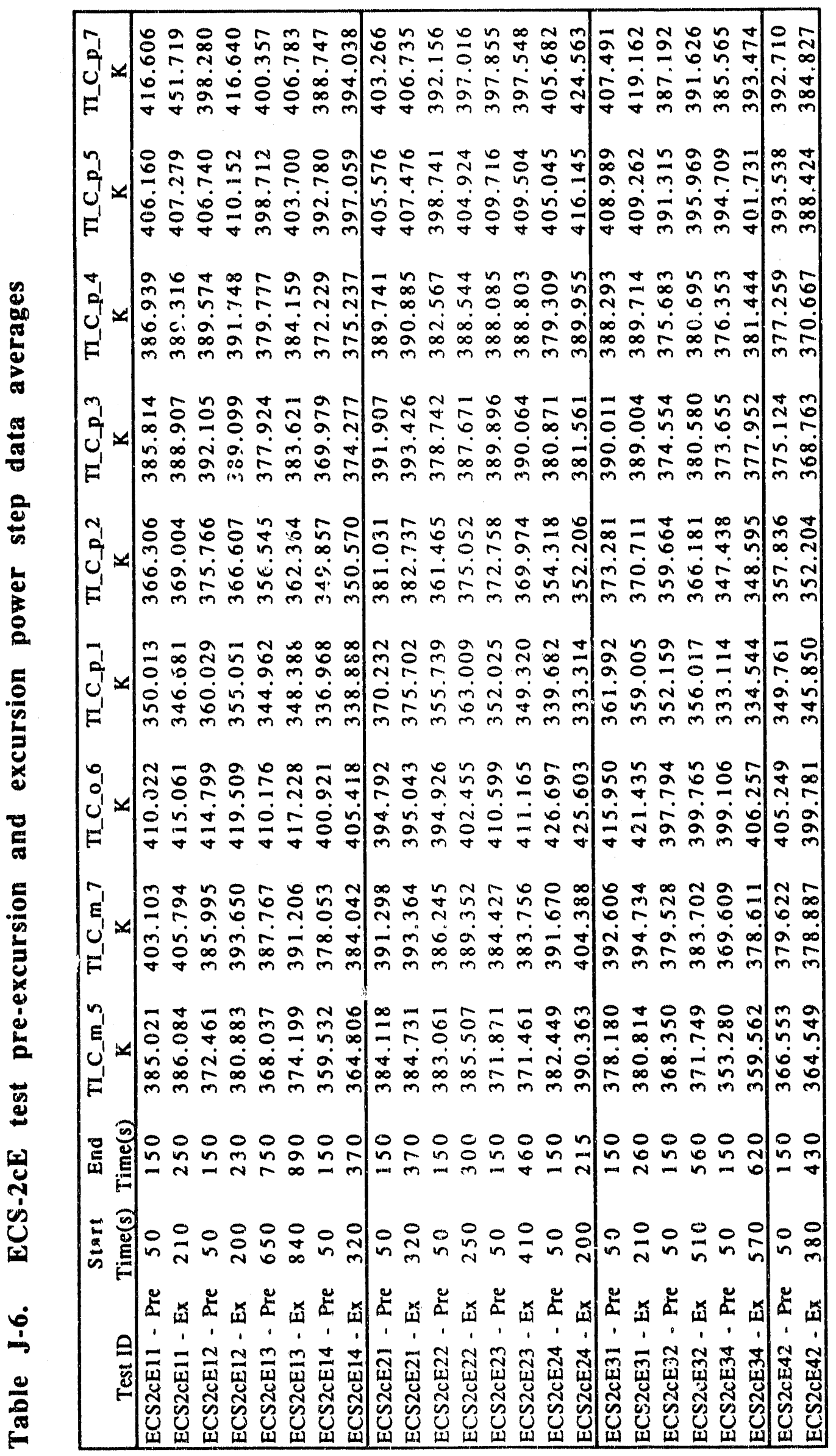




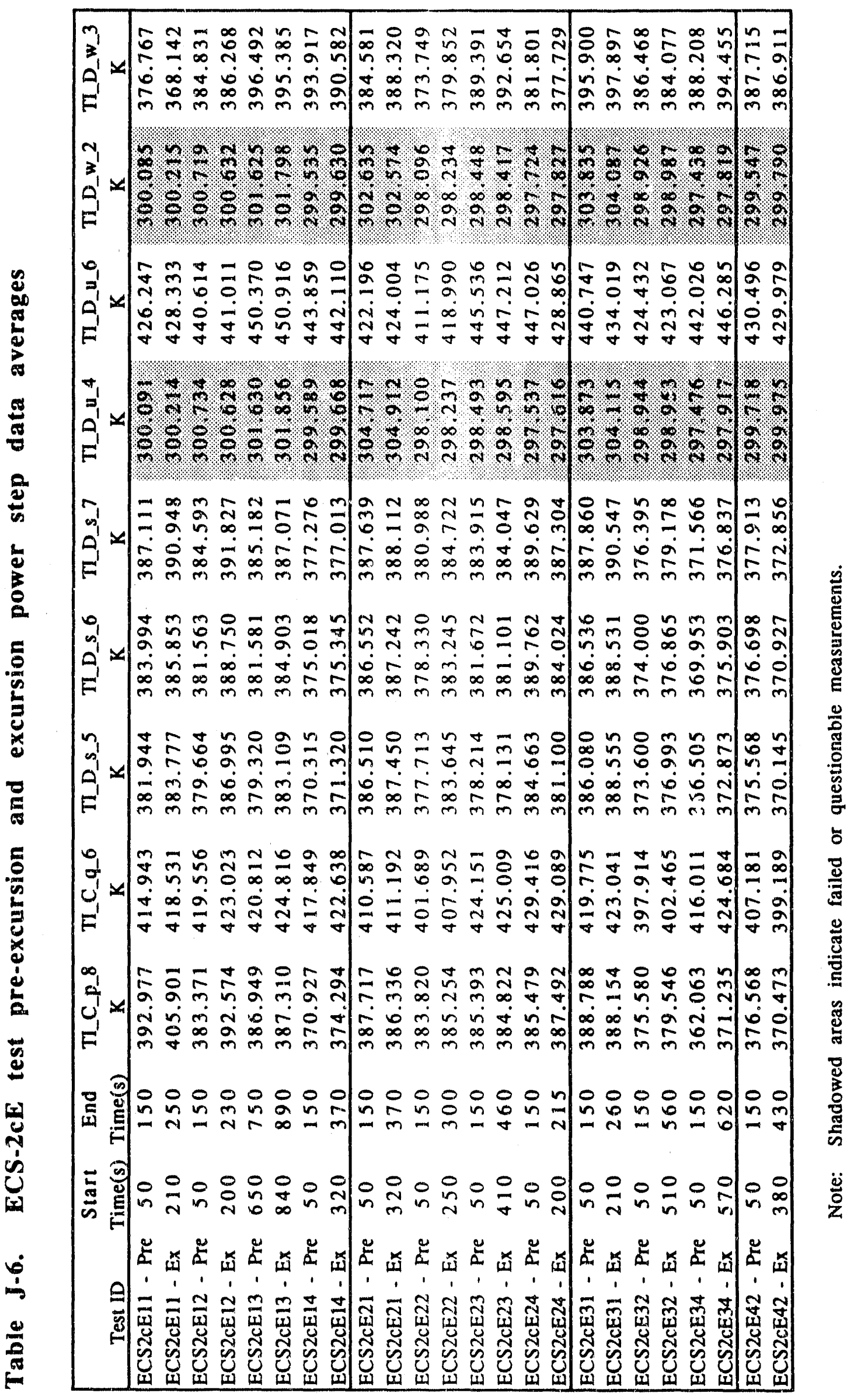




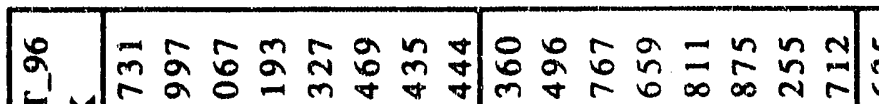

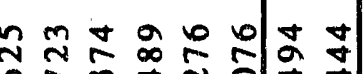
1 व.

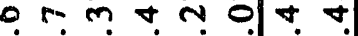

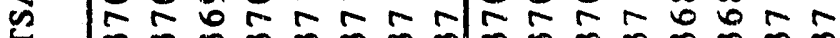

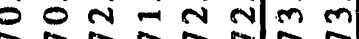
in $m$ m $m$ m $m$

$\tilde{m}$ in $\tilde{m}$ in

के

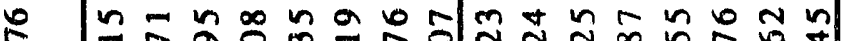

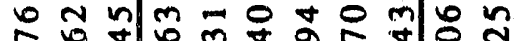

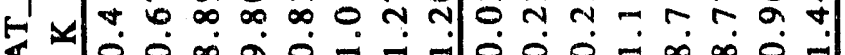

$\forall 0 \infty-a$

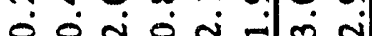

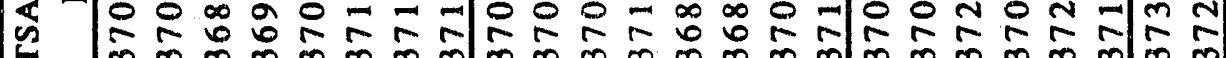

造

a

ํㅗㅇ

$\ddot{g}$

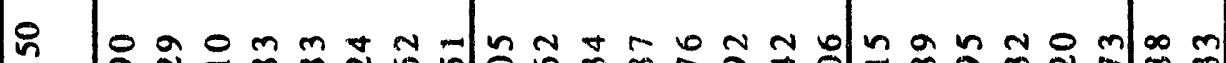

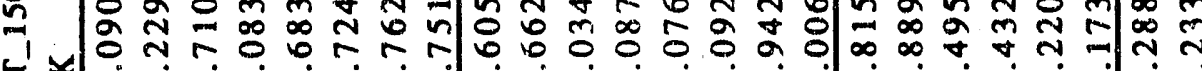

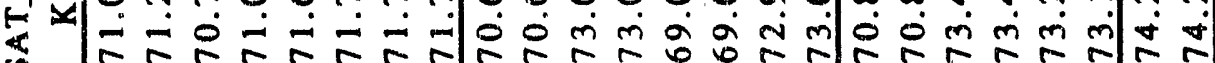

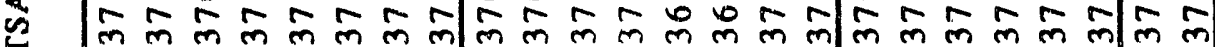

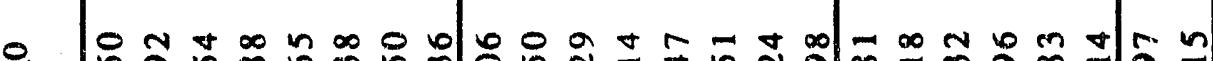

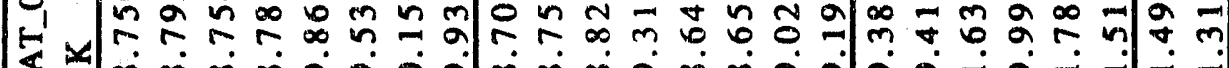

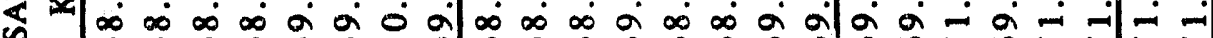

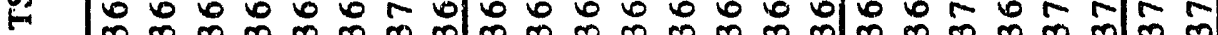

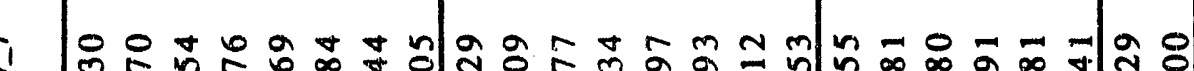

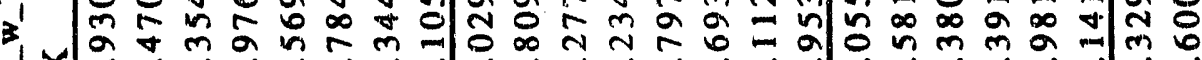

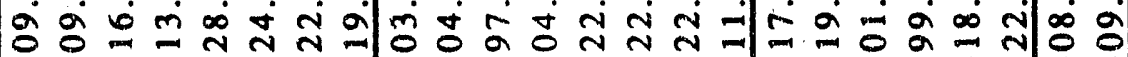
E

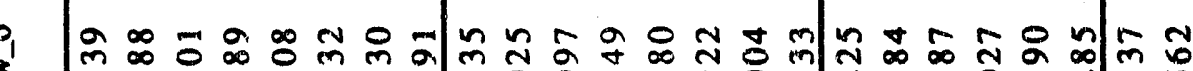

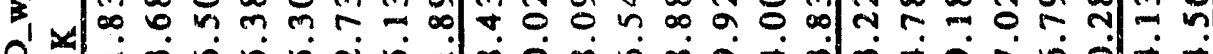

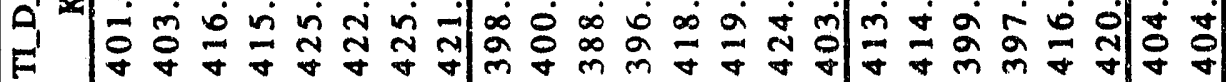
- J00 $00000000000000 n 100000000$ 핍. (19) : (x)

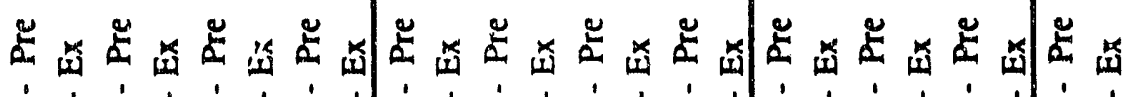

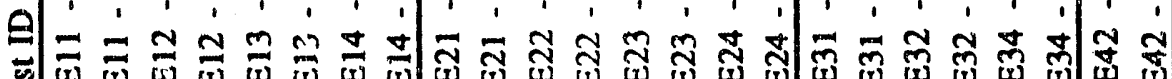




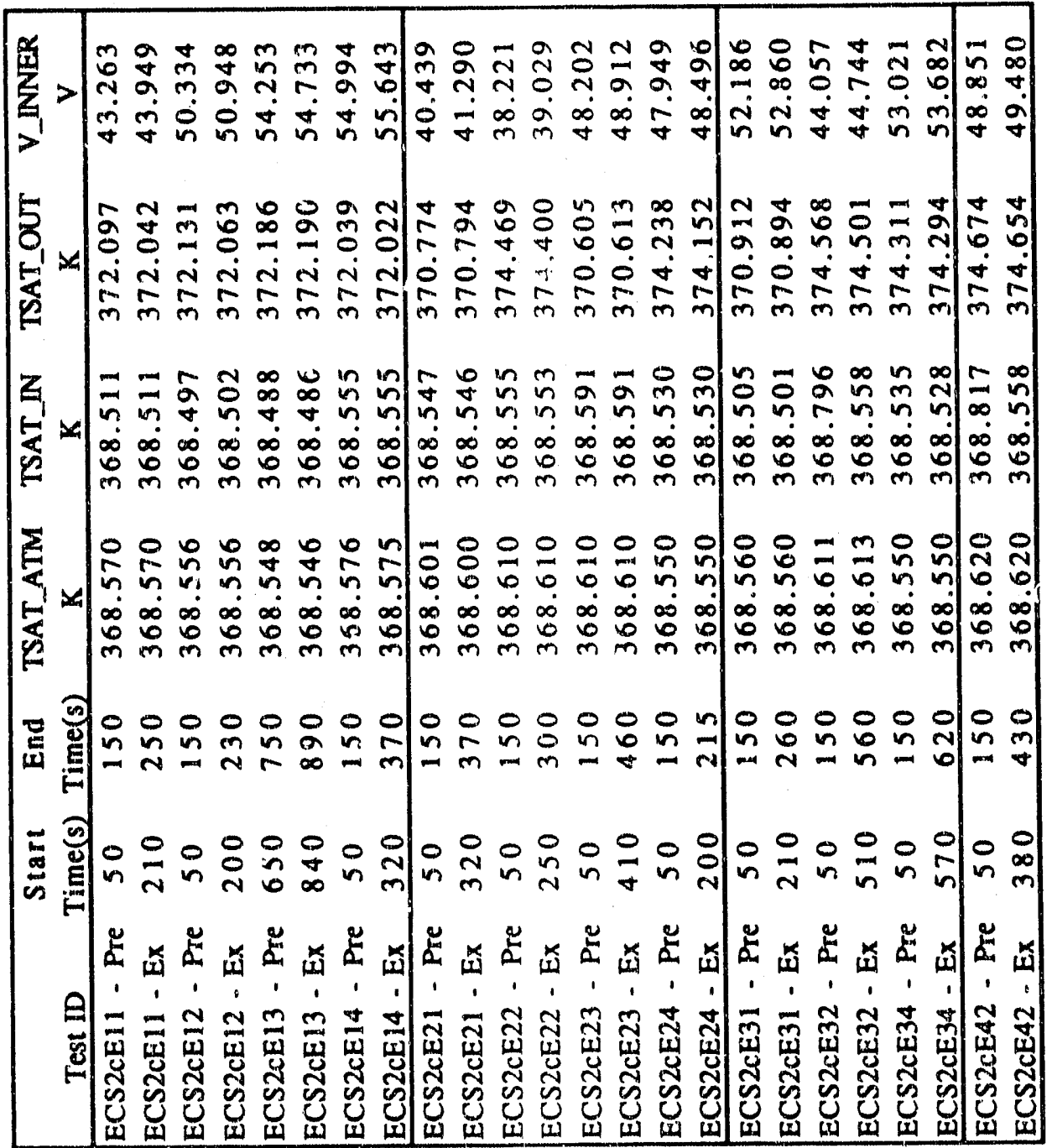



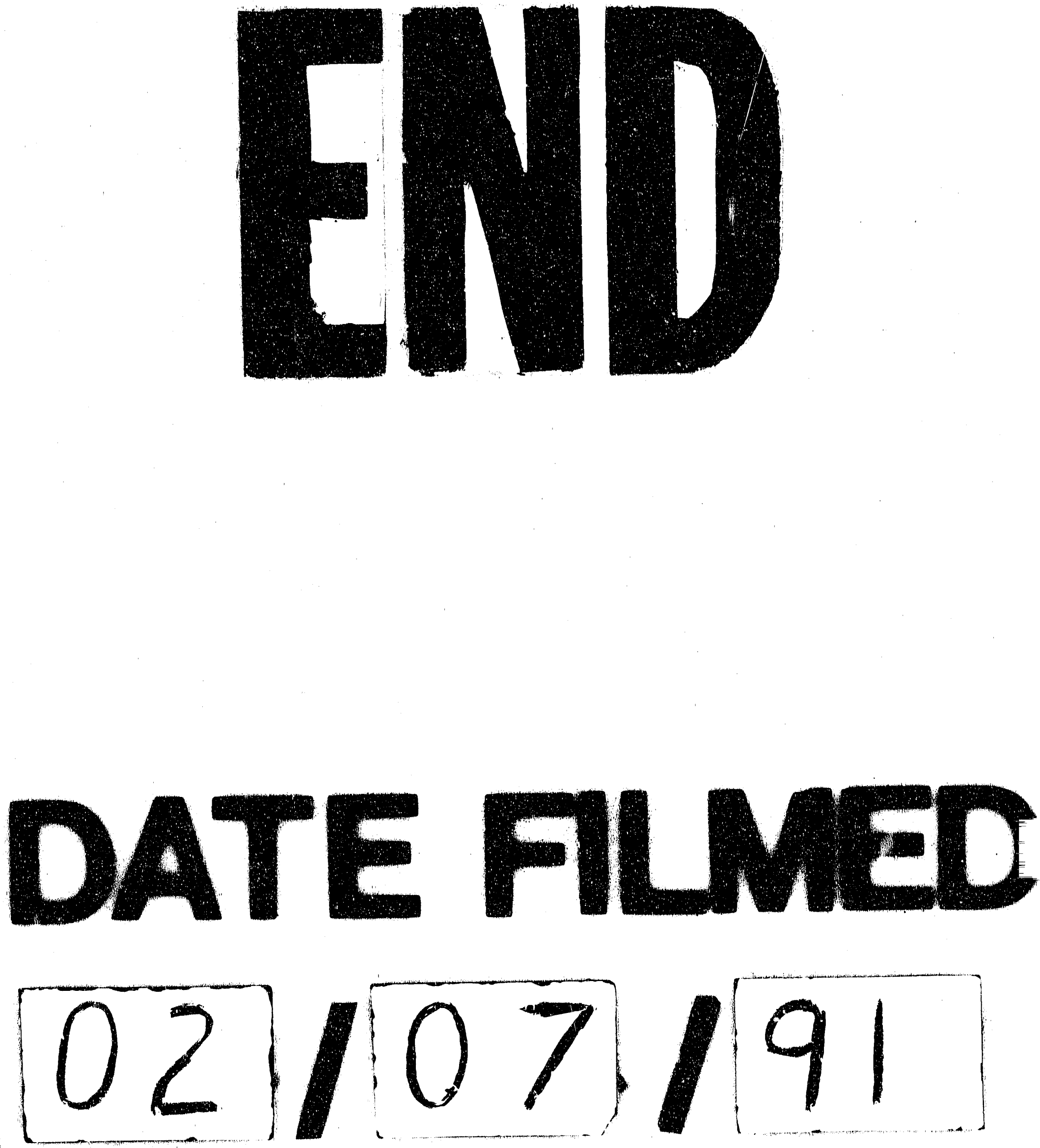
